\title{
(RE)WRITING HISTORY IN BYZANTIUM
}

A CRITICAL STUDY OF COLLECTIONS OF HISTORICAL EXCERPTS

Panagiotis Manafis

$$
\text { ok }
$$




\section{(Re)writing History in Byzantium}

Scholars have recently begun to study collections of Byzantine historical excerpts as autonomous pieces of literature. This book focuses on a series of minor collections that have received little or no scholarly attention, including the Epitome of the Seventh Century, the Excerpta Anonymi (tenth century), the Excerpta Salmasiana (eighth to eleventh centuries), and the Excerpta Planudea (thirteenth century). Three aspects of these texts are analysed in detail: their method of redaction, their literary structure, and their cultural and political function. Combining codicologi$\mathrm{cal}$, literary, and political analyses, this study contributes to a better understanding of the intertwining of knowledge and power, and suggests that these collections of historical excerpts should be seen as a Byzantine way of rewriting history.

Panagiotis Manafis is a post-doctoral research fellow at the University of Birmingham, UK. His research interests include middle Byzantine literature, with a particular focus on the manuscript transmission of texts. 
$\because$ Taylor \& Francis

Taylor \& Francis Group

http://taylorandfrancis.com 


\section{(Re)writing History in Byzantium}

A Critical Study of Collections

of Historical Excerpts

\section{Panagiotis Manafis}


First published 2020

by Routledge

2 Park Square, Milton Park, Abingdon, Oxon OX14 4RN

and by Routledge

52 Vanderbilt Avenue, New York, NY 10017

Routledge is an imprint of the Taylor \& Francis Group, an informa business

(C) 2020 Panagiotis Manafis

The right of Panagiotis Manafis to be identified as author of this work has been asserted by him in accordance with sections 77 and 78 of the Copyright, Designs and Patents Act 1988.

The Open Access version of this book, available at www.taylorfrancis.com, has been made available under a Creative Commons Attribution-Non Commercial-No Derivatives 4.0 license.

Trademark notice: Product or corporate names may be trademarks or registered trademarks, and are used only for identification and explanation without intent to infringe.

British Library Cataloguing-in-Publication Data

A catalogue record for this book is available from the British Library

Library of Congress Cataloging-in-Publication Data

Names: Manafis, Panagiotis, author.

Title: (Re)writing history in Byzantium: a critical study of collections of historical excerpts / Panagiotis Manafis.

Description: Abingdon, Oxon; New York, NY: Routledge, 2020. | Includes bibliographical references and index.

Identifiers: LCCN 2020002344 (print) | LCCN 2020002345 (ebook) |

ISBN 9780367367305 (hardback) | ISBN 9780429351020 (ebook)

Subjects: LCSH: Byzantine literature-History and criticism. |

Byzantine Empire-Historiography. | Byzantine Empire-Abstracts-History.

Classification: LCC DF505 .M36 2020 (print) | LCC DF505 (ebook) |

DDC 949.5/02072-dc23

LC record available at https://lccn.loc.gov/2020002344

LC ebook record available at https://lccn.loc.gov/2020002345

ISBN: 978-0-367-36730-5 (hbk)

ISBN: 978-0-429-35102-0 (ebk)

Typeset in Times

by Deanta Global Publishing Services, Chennai, India 
To Eleni and Ioanna 
$\because$ Taylor \& Francis

Taylor \& Francis Group

http://taylorandfrancis.com 


\section{Contents}

List of illustrations $\quad \mathrm{x}$

List of manuscripts xii

Acknowledgements xiv

Abbreviations $\quad \mathrm{xV}$

Introduction xviii

1 Greek compilation literature from Byzantium 1

1.1 Terminology 1

1.1.1 Byzantine terminology 1

1.1.2 Modern terminology 10

1.2 The culture of sylloge 12

1.2.1 Florilegia, Gnomologia, Catenae, Quaestiones et responsiones 14

1.2.2 Chronicles 17

1.2.3 Condensed 'libraries' 20

1.3 The working method of excerptors of historical texts 26

1.3.1 Selection 27

1.3.2 Editing 31

1.3.3 Composition 38

2 Excerpta Anonymi

2.1 Dating of the Parisinus suppl. gr. 607a 44

2.2 Content, structure and sources of the Excerpta Anonymi 46

2.2.1 Content 46

2.2.2 The structure of the Excerpta Anonymi 49

2.2.3 The sources of the Excerpta Anonymi 53

2.3 The working method in the Excerpta Anonymi 60

2.4 The EC and the Excerpta Anonymi 66

2.4.1 The EC 67 
viii Contents

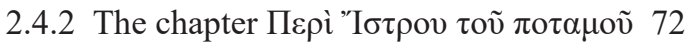

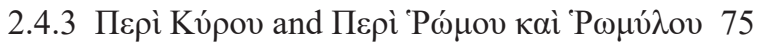

2.4.4 The passages on Roman history 77

2.4.5 The $E C$ as a depository of knowledge 81

2.4.6 Conclusion 84

2.5 Historical and cultural context 84

2.5.1 Portrayals of emperors in the Excerpta Anonymi 85

2.5.2 Comparison of the Excerpta Anonymi and the Parastaseis 86

2.5.3 The politics of ethnography and geography in the Excerpta Anonymi 96

2.6 Conclusions 108

3 Excerpta Salamasiana

3.1 Manuscript transmission 110

3.1.1 Vaticanus graecus 96110

3.1.2 Vaticanus Palatinus 93112

3.1.3 Parisinus graecus 1763113

3.2 Excerpta Salmasiana and John of Antioch 115

3.3 Structure and sources of the Excerpta Salmasiana 117

3.3.1 Excerpta Salmasiana I 117

3.3.2 Excerpta Salmasiana II 118

3.3.3 The Agathias part 135

3.4 The selective use of historical material in the Excerpta

Salmasiana 135

3.4.1 Agathias on the others 135

3.4.2 The politics of ethnography in the Agathias part of the Excerpta Salmasiana 138

3.5 Towards the methodological principles of the Excerpta

Salmasiana 140

3.6 General conclusions on the Excerpta Salmasiana 145

4 The Epitome of the Seventh Century

4.1 Manuscript transmission 148

4.1.1 Parisinus suppl. gr. 1156148

4.1.2 Oxford, Auctarium E.4.18 149

4.1.3 Parisinus graecus 1555 A 149

4.1.4 Athonensis Vatopedinus graecus 286150

4.1.5 Baroccianus gr. 142151

4.1.6 The ớnò $\varphi \omega v \tilde{\eta} \varsigma$ in Baroccianus gr. 142153

4.2 The Epitome as an excerpt collection 154 
4.3 The structure of the Epitome 159

4.4 The Epitome and the HE of Eusebius of Caesarea 161

4.4.1 The relationship between the manuscripts of the Epitome 163

4.4.2 Passages added to the selected Eusebian text 165

4.4.3 The redaction of the Eusebian part 173

4.5 General conclusions on the Epitome 180

5 Excerpta Planudea

5.1 Manuscript transmission 181

5.1.1 The codices 181

5.1.2 The relationship between the manuscripts of the $\Sigma v v \alpha \gamma \omega \gamma \dot{\eta} 185$

5.1.3 Maximus Planudes 186

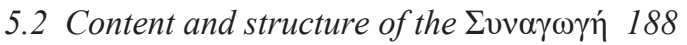

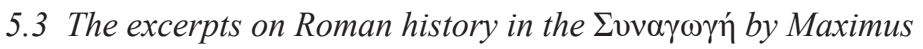
Planudes 191

5.3.1 The origins of the passages on Roman history 191

5.3.2 The source of the $\Sigma v v \alpha \gamma \omega \gamma \eta$ : an earlier corpus on Roman history? 196

5.3.3 Excerpting John of Antioch and Xiphilinus 198

5.3.4 Thematisation of history in the Excerpta Planudea 203

5.4 Conclusions 213

6 Collections of historical excerpts as a specific locus for (re)writing history

6.1 J. Signes Codoñer's classification of Byzantine historical writing 215

6.2 Literary features in Byzantine collections of historical excerpts 218

6.2.1 Language, style, function 218

6.2.2 Period covered and use of sources 221

6.2.3 Structure 224

6.3 Other collections of historical excerpts 226

6.4 Conclusion 228

Appendix I: Texts

Appendix II: Tables

Bibliography 


\section{List of illustrations}

\section{Figures}

3.1 The codex Parisinus gr. 1630 (B) and the Exc.Salm.II A 122

4.1 The relationship between the manuscripts of the Epitome 165

\section{Tables}

2.1 The contents of Parisinus suppl. gr. 607a 47

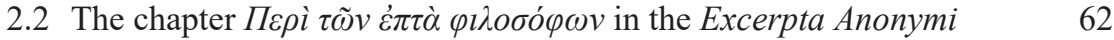

2.3 The chapter $\Pi \varepsilon \rho i े \tau \tilde{\omega} v \beta^{\prime} \sigma \tau \alpha v \rho \tilde{\omega} v \tau \tilde{\omega} v \lambda \eta \sigma \tau \tilde{\omega} v$ in the Excerpta Anonymi 64

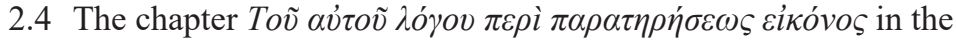
Excerpta Anonymi

2.5 The sources of the passage On the Istros river, 42, 5-44, 21

2.6 Passages on Roman history excerpted in the Excerpta Anonymi 79

2.7 Peter the Patrician's Historia in the Excerpta Salmasiana 80

3.1 Excerpts in the Exc.Salm.II $A$ that do not derive from John Malalas 119

3.2 Malalas' Chronographia in B and in the Exc.Salm.II 122

3.3 The derivation of the Exc.Salm.II 8

3.4 The Exc.Salm.II 18, B and the Suda 125

3.5 The Exc.Salm.II 32, Malalas and the Suda 126

3.6 Passages in common between Malalas, the Exc.Salm.II 1-43, Symeon Logothetes' Chronicon and Ps.-Symeon's Chronographia 128

3.7 Shared passages in the Exc.Salm.II and the Excerpta Anonymi 129

3.8 Exc.Salm.II B, 66-82 130

3.9 The Exc.Salm.II B, 66-82 and parallel passages 131

3.10 The Exc.Salm.II 66 and $67 \quad 131$

3.11 The Exc.Salm.II 68 and $69 \quad 132$

3.12 The Exc.Salm.II and the Leoquelle 133

3.13 The source texts of the Exc.Salm.II 134

3.14 The Agathias excerpt 3 of the Exc.Salm. 141

3.15 The Agathias excerpt 6 of the Exc.Salm. 142

3.16 Agathias-excerpt 15 of the Exc.Salm. 143

3.17 The Agathias excerpt 23 of the Exc.Salm. 144 
3.18 The Agathias excerpt 37 of the Exc.Salm. 144

3.19 Type of textual changes in the Agathias part 145

4.1 The headings in the manuscript transmission of the Epitome 156

4.2 The Epitome in the five extant manuscripts 159

4.3 The Epitome in G. C. Hansen's edition 162

$\begin{array}{ll}\text { 4.4 Passages added to the selected Eusebian text } & 166\end{array}$

$\begin{array}{ll}4.5 \text { The origin of } 5 \mathrm{E} & 170\end{array}$

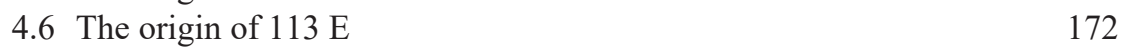

$\begin{array}{ll}4.7 \text { The redaction of the Eusebian part } & 174\end{array}$

$\begin{array}{ll}4.87 \text { E and Eusebius' } H E & 176\end{array}$

4.964 E and Eusebius' $H E \quad 178$

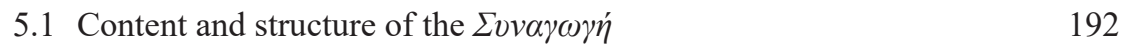

$\begin{array}{ll}\text { 5.2 The EPL and Manasses' chronicle } & 194\end{array}$

$\begin{array}{ll}5.3 \text { The EPL and Paeanius } & 195\end{array}$

5.4 Excerpts 45-328 in Laurentianus Plut. 59, 30

5.5 The EPL in the Athonensis Iviron 812, the Suda, and the EC 200

5.6 Xiphilinus' Epitome in the EPL 202

5.7 The selection of excerpts on the Roman Republic by Maximus
Planudes 


\section{List of manuscripts}

Excerpta Anonymi

Codex Parisinus suppl. graecus 607a, mid-10th c.

Excerpta Salmasiana

Codex Vaticanus graecus 96, mid-12th c.

Codex Vaticanus Palatinus 93, mid-12th c.

Codex Parisinus graecus 1763, ca 1606.

Codex Parisinus graecus 1630, 14th c.

\section{Epitome}

Codex Auctarium E.4.18, 10th c.

Codex Parisinus suppl. graecus 1156, 10/11th c.

Codex Athonensis Vatopedinus graecus 286, 13 th c.

Codex Parisinus graecus 1555a, 13/14th c.

Codex Baroccianus graecus 142, 14th c.

EC

Excerpta de virtutibus et vitiis

Codex Turonensis 980, 11th c.

Excerpta de insidiis

Codex Parisinus gr. 1666, 15th/16th c.

Codex Scorialensis $\Omega$ I ii, 16th c.

Excerpta de legationibus

Codex Scorialensis R III 14, 1574.

Codex Bruxellensis 11031-16, 16th c.

Codex Monacensis 267, 16th c.

Codex Parisinus graecus 2463, 16th c.

Codex Vaticanus graecus 1418, 16th c.

Codex Vaticanus Palatinus 413, 16th c. 
Excerpta Planudea

Codex Laurentianus Plut. 59,30, 13th/14th c.

Codex Vaticanus graecus 951, 15th c.

Codex Athonensis Iviron 812, 14th c.

Codex Neapolitanus graecus 165, 14th c.

Codex Parisinus graecus 1409, 14th/15th c.

Codex Vaticanus Palatinus 141, 14/15th c. 


\section{Acknowledgements}

This book originates in my doctoral dissertation at the Department of Ancient History in Ghent University. I would like to express my special thanks of gratitude to Prof. Dr. Peter Van Nuffelen and Prof. Dr. Marc De Groote, my research advisers, for their continuous support, immense knowledge, encouragement, and useful critiques of my research work. I would like to express my very great appreciation to Prof. Dr. Lieve Van Hoof, for her clear-sightedness and her numerous suggestions and remarks on the contents of this book. My deep gratitude also goes to Prof. Paolo Odorico (EHESS, Paris) who generously read earlier versions of chapters in this book and offered insightful comments and constructive suggestions on my research. My sincere and warm thanks go to Prof. Catherine Holmes (University College Oxford), for giving me the opportunity to spend three months in Oxford (February-May 2016) and for taking an interest in my work. I also wish to thank the Research Foundation - Flanders (FWO) which funded my research stay at Oxford (15 February-15 May 2016). I would like to thank Prof. Paul Magdalino, who read closely my last draft of the article "Political margins. Geography and history in the Excerpta Anonymi" and offered extremely helpful suggestions. I would also like to offer my special thanks to Prof. Panagiotis Sotiroudis (Thessaloniki) for his palaeographical assistance. I am particularly grateful for the assistance given by the hieromonk Palamas from the Holy Monastery of Vatopedi on Mount Athos as well as Dr. Ilaria Ciolli from the Biblioteca Apostolica Vaticana. My grateful thanks are also extended to my colleagues at the Department of Ancient History: to Dr. Maria Conterno, Dr. Emerance Delacenserie, Dr. Marianna Mazzola, Dr. Lorenzo Focanti, Dr. Matthew O'Farrell, Dr. Andy Hilkens, Dr. Raf Praet, and Dr. Maria Tomadaki. In researching and writing this book, I have benefitted greatly from the knowledge and suggestions by Prof. Hugh Houghton, the principal investigator of the CATENA and Codex Zacynthius projects, in which I had the privilege of being a member as a research fellow at the Department of Theology and Religion in the University of Birmingham (UK) from 2018 to 2020. Part of the research was undertaken as part of the CATENA project, which has received funding from the European Research Council (ERC) under the European Union's Horizon 2020 research and innovation programme (grant agreement no. 770816). I would also like to thank my parents and my friends for their encouragement. And lastly, I would like to thank my wife, for her support and patience over the past years. This volume is dedicated to her and to our daughter, Ioanna. 


\section{Abbreviations}

$\begin{array}{ll}\text { AMI } & \text { Archaeologische Mitteilungen aus Iran und Turan. Berlin: } \\ & \text { Deutsches Archäologisches Institut. } \\ \text { Ann.Univ.Tosc. } & \text { Annali delle Università Toscane. Pisa: Università Toscane. } \\ \text { BBGG } & \text { Bollettino della Badia Greca di Grottaferrata. Grottaferrata: } \\ & \text { Congregazione d'Italia dei Monaci Basiliani. } \\ \text { BHG } & \text { Bibliotheca Hagiographica Graeca, 3rd ed., ed. F Halkin, 3 } \\ & \text { vols. Brussels, 1957. } \\ & \text { Byzantine and Modern Greek Studies: University of } \\ \text { BMGS } & \text { Birmingham, Centre for Byzantine, Ottoman, and Modern } \\ & \text { Greek Studies. } \\ \text { BollClass } & \text { Bollettino dei Classici. Roma: Accademia Nazionale dei } \\ & \text { Lincei. } \\ \text { Byz } & \text { Byzantion: revue internationale des études byzantines. } \\ & \text { Leuven: Peeters. } \\ B Z & \text { Byzantinische Zeitschrift. Berlin: de Gruyter. } \\ C C S G & \text { Corpus Christianorum Series Graeca. Leuven: Brepols. } \\ C D & \text { Cassius Dio. } \\ C F H B & \text { Corpus Fontium Historiae Byzantinae. } \\ C P G & \text { Clavis Patrum Graecorum. Turnhout: Brepols } \\ C Q & \text { Classical Quarterly. Oxford: Oxford University Press. } \\ C S H B & \text { Corpus Scriptorium Historiae Byzantinae. Bonn. } \\ D A I & \text { De Administrando Imperio. } \\ D C & \text { De Cerimoniis. } \\ D O P & \text { Dumbarton Oaks Papers. Washington (D.C.): Dumbarton } \\ & \text { Oaks Research Library and Collection. } \\ D T & \text { De Thematibus. } \\ E C & \text { Excerpta Constantiniana. } \\ E p i t o m e & \text { The Epitome of the Seventh Century. } \\ E I & \text { Excerpta de Insidiis. } \\ E L & \text { Excerpta de Legationibus. } \\ E P L & \text { Excerpta Planudea. } \\ E S & \text { Excerpta de Sententiis. }\end{array}$


Eus.-Hier. Chron. Die Chronik des Hieronymus, ed. Rudolf Helm, Berlin, 1956.

EV1 Excerpta de Virtutibus et Vitiis, ed. Theodor BüttnerWobst, Berlin, 1906.

EV2 Excerpta de Virtutibus et Vitiis, ed. Antoon Gerard Roos, Berlin, 1910.

Excerpta Anonymi Excerpta Anonymi Byzantini ex Codice Parisino suppl. Gr. $607 \mathrm{~A}$.

Exc.Salm. Anecdota Graeca e codd. Manuscripts Bibliothecae regiae Parisiensis, II.

GRBS Greek, Roman and Byzantine Studies. Durham (N.C.): Duke University, Department of Classics.

HE Historia Ecclesiastica.

HT Historia Tripartita.

JMEMS Journal of Medieval and Early Modern Studies. Duke University Press.

$J O ̈ B \quad$ Jahrbuch der Österreichischen Byzantinistik. Wien: Verl. der Österreichischen Akademie der Wissenschaften.

$M G H$

Pet. Patr. Monumenta Germaniae Historica.

$P G$ Peter the Patrician.

Patrologiae cursus completus, Series graeca, ed. J.-P. Migne, 161 vols. Paris, 1857-1866.

PLRE The Prosopography of the Later Roman Empire, edd. A. H. M. Jones, J. R. Martindale, and J. Morris, 1-2. Cambridge, 1971-1980.

Ps.-Symeon Anonymi opus ineditum apud cod. Parisinum B.N. Gr. 1712, ff. 18v-272r.

PTS Patristische Texte und Studien. Berlin: de Gruyter.

REA Revue des études anciennes. Pessac: Université Michel de Montaigne, Maison de l'archéologie.

REB Revue des études byzantines. Paris: de Boccard.

Res.Publ.Litt. Res Publica Litterarum: Studies in the Classical Tradition. Roma: Salerno.

RE Paulys Realencyclopädie der classischen

Altertumswissenschaft, edd. G. Wissowa et al., Stuttgart, 1894-1963.

RhM Rheinisches Museum für Philologie. Frankfurt am Main: Sauerländer.

SO Symbolae Osloenses. Norwegian Journal of Greek and Latin Studies. Oslo: University of Oslo, Norway.

St. Class. Or. Studi Classici e Orientali. Pisa: Istituti Editoriali e Poligrafici Internazionali.

Sym. Log. Symeonis Magistri et Logothetae Chronicon I, ed. Stephanus Wahlgren (CGHB 44,1), Berlin, 2006. 
Symm Symmeikta. Athens: Institute of Historical Research.

TAPhA Transactions and Proceedings of the American Philological Association. Baltimore (Md.): Johns Hopkins University Press.

Teubner Bibliotheca Scriptorum Graecorum et Romanorum Teubneriana.

TM Travaux et Mémoires du Centre de recherche d'histoire et civilisation byzantines. Paris: de Boccard.

TU Texte und Untersuchungen zur Geschichte der altchristlichen Literatur.

ZNW Zeitschrift für die Neutestamentliche Wissenschaft und die Kunde der älteren Kirche. Berlin: de Gruyter. 


\section{Introduction}

The purpose of this book, besides bringing hitherto unstudied material to the attention of scholars, is to contribute to a better understanding of the literary phenomenon of Byzantine compilation literature and, in particular, collections of historical excerpts. The following is a working definition of a collection of historical excerpts: a text consisting of passages extracted from a single or different historical texts of the same or of different authors and put together under a principle, that is, thematically.

For a long time, such collections only received attention as sources for the works they rely on and not as works of literature in their own right. Studies of historical works produced through processes of compilation, on the other hand, have always been in dialogue with the concept of encyclopaedism. This concept was presented by the French philologist Paul Lemerle in his famous book on Byzantine written culture entitled Le Premier Humanisme Byzantin published in 1971. More than half the book was devoted to the cultural revival of the ninthtenth centuries and the book closed with a chapter on what Lemerle called encyclopaedism in the tenth century. ${ }^{1}$ Lemerle introduced the concept of encyclopaedism to demarcate the resurgence in literary production under the emperor Constantine Porphyrogenitus $^{2}$ and used the term encyclopaedia to refer to works produced under the auspices of this emperor by processes of compilation. ${ }^{3}$ According to

1 Lemerle (1971), 266-300. Earlier than in this book, Lemerle had already referred to the existence of encyclopaedias in Byzantium; cf. Lemerle (1965), 596-616.

2 Constantine was only 7 years old when his father, the emperor Leo VI, died and a number of regents were appointed in his place. From 919-944 Constantine shared the throne with Romanus I Lecapenus, a Byzantine naval commander of Armenian descent. Constantine's sole reign began in 945 and lasted until his death. On Constantine Porphyrogenitus, see Grierson and Jenkins (1962), 133-138, Lemerle (1971), 266-300; Toynbee (1973), esp. 1-25 and 575-605; Tartaglia (1982), 197-206; Wilson (1996), 140-145; Ševčenko (1992a), 167-195; Karpozilos (2002), 281-296; Németh (2018), 20-53.

3 Lemerle was not the first to speak of Byzantine encyclopaedism. Büttner-Wobst (1906b) had put forward the term historiche Encyclopädie and Alphonse Dain had already supported in 1953 that until, and mainly in the ninth century, the interest in the classical past was expressed through the transliteration of ancient texts into minuscule script and that the habit of selecting and reordering of various passages of various works in the manner of sylloge appears only in the tenth century. A phenomenon, which Dain integrated in the encyclopaedism of the tenth century; Dain (1953), 64-81. 
Lemerle, the phenomenon of encyclopaedism covers the compilation of works

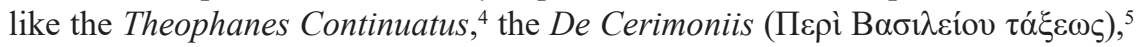

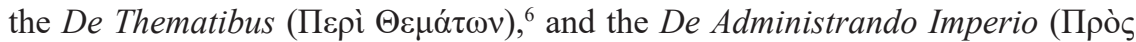

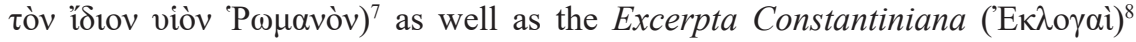

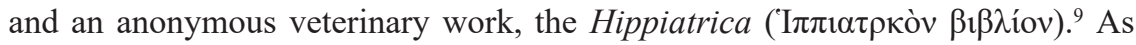

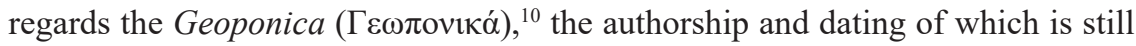
debated, Lemerle argued that the function of the work was to transmit knowledge, but he simply characterises it as a sylloge, that is a collection of passages, related to the court of Constantine Porphyrogenitus. ${ }^{11}$

Lemerle's concept has since dominated scholars' approaches to the Byzantine literary culture during the Macedonian dynasty and the term encyclopaedism continues to be employed by Byzantinists. For instance, A. P. Kazhdan, C. Hannick, J. Shephard, and M. McCormick also consider the tenth century the age of

4 The text survives in a single manuscript, Vaticanus gr. 167 (eleventh c.). On the date of the codex,

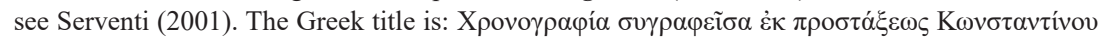

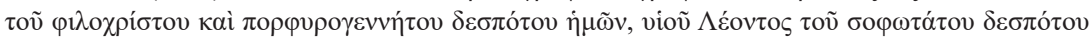

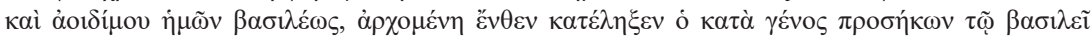

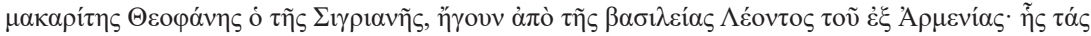

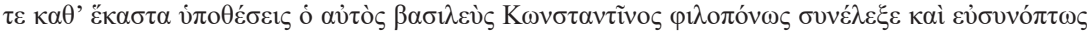

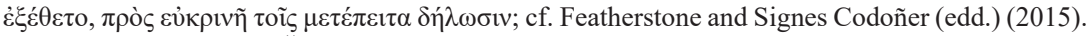
On books I-IV, see also Ševčenko (1998); Featherstone (2011), (2012); Treadgold (2013), 188196. On the so-called Vita Basilii, the fifth book of the Theophanes Continuatus, see Ševčenko (ed.) (2011); Treadgold (2013), 165-180. Book VI was probably a later addition to the original corpus of the first five books of Theopahnes Continuatus by Basil the Nothos; Featherstone (2014), 353-372. In Vaticanus gr. 167, book VI comes immediately after the Vita Basilii, but without any heading or numeration whatsoever; Németh (2018), 155. J. Signes Codoñer and I. Ševčenko showed that the first five books were composed by a team of writers working under the supervision of Constantine Porphyrogenitus; Signes Codoñer (1989), 17-28; Ševčenko (1992), 184-187; Signes Codoñer (2017), 17-21. W. Treadgold attributed the Vita Basilii to Theodore Daphnopates; Treadgold (2013), 166-180. W. Treadgold's hypothesis had been examined and refuted in Markopoulos (1985), 171-182.

5 Reiske (ed.) (1829); Vogt (ed.) (1967); Moffatt and Tall (transl.) (2012).

6 Pertusi (ed.) (1952). Treadgold (2013), 154 dates the text around the year 934. On the date of the $D T$, see also Pertusi (ed.) (1952), 43-47 and Oikonomidès (1972), 242-243. Lounges (1973), 299-305 suggests a later date.

7 Moravcsik and Jenkins (edd.) (1967). On the date of the DAI, see Bury (1906b), 522-524; Jenkins (1962), 1-8; Moravcsik and Jenkins (edd.) (1967), 32-33; Howard-Johnston (2000), 301-336.

8 de Boor (ed.) (1903-1910).

9 The Recensio B in the textual transmission of the text appears to be related with the scriptorium of Constantine Porphyrogenitus. In particular, it has been supported that the codex Phillippicus 1538 (Berlin) was made for Constantine Porphyrogenitus; McCabe (2007), 269-275. On this scrip-

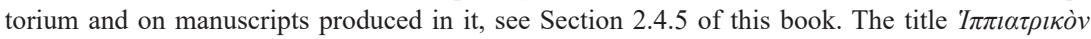
Blßiiov is transmitted in the Suda 4739 and Suda 267, as well as in the codex Emmanuel College 251 (Cambridge); cf. McCabe (2007), 1.

10 Beckh (ed.) (1895). On the Geoponica, see Koder (1993); Koutrava-Delivoria (2002), 365-380; Lefort (2008), 231-310.

11 Lemerle (1971), 266-300. 
encyclopaedism. ${ }^{12}$ Lemerle's view was challenged by Paolo Odorico, first in an article published in 1990, in which he introduced the concept of the culture of sylloge. ${ }^{13}$ The term characterises the phenomenon of selecting, recopying, synthesising, and presenting older textual material. ${ }^{14}$ P. Odorico in a series of surveys on the subject, convincingly showed that encyclopaedism is an inaccurate and misleading term to expound what were in fact collections or syllogae. ${ }^{15}$ In fact, encyclopaedia is a modern term pointing to artefacts with literary functions different from Byzantine collections. Moreover, P. Odorico showed that there was nothing innovative about the collections executed on imperial commission in the tenth century. ${ }^{16}$ They excerpt older texts employing a method similar to that applied by florilegia, gnomologia, military and historical compositions that were compiled centuries earlier than the tenth century. Nevertheless, Lemerle's term of encyclopaedism continued to make its way into scholarship. In June 2007, a conference on encyclopaedism before the Enlightenment was held at St Andrews, the proceedings of which were edited by Jason König and Greg Woolf in 2013 under the title Encyclopaedism from Antiquity to the Renaissance. The title of the book as well as the papers presented in it showed that the term Byzantine encyclopaedism continued to be elaborated amongst Byzantinists and that a number of scholars were disposed to recognise the uniqueness of collections executed during the reign of Constantine Porphyrogenitus in terms of methods and goals. ${ }^{17}$

In May 2009, a conference was held in Leuven on works consisting of excerpts and on the validity of Lemerle's concept of encyclopaedism. The proceeds of the conference are collected in a book entitled Encyclopedic Trends in Byzantium? edited by Peter Van Deun and Caroline Macé and published in 2011. Though many of the participants kept repeating the term encyclopaedism, it was during this congress that $\mathrm{P}$. Odorico established his own concept of the culture of sylloge tackling Lemerle's term. ${ }^{18}$ In the same book, though, Paul Magdalino's article acknowledges the distinctiveness of the tenth-century collections. Magdalino sees the fact that these collections were designed or commissioned by emperors as a key feature that differentiates them from earlier or later collections. ${ }^{19}$ It should

12 Hunger (1978), 244, 360-367; Kazhdan and Wharton Epstein (1985), 14-15; Kazhdan (1991), 696-697; Hannick (1986), 2031-2039; Shepard (2008), 87, 403; Karpozilos (2002), 696-697; Kazhdan and Angelidi (2006), 311-336.

13 Odorico (1990), 1-21. On Lemerle's view, see n. 1.

14 Odorico (1990).

15 The concept of culture of sylloge was further developed in: Odorico (2011a); Odorico (2014a); Odorico (2014b); Odorico (2017). See also the review of the book: Van Deun and Macé (2011) by A. Kaldellis; cf. Kaldellis, in The Medieval Review 12.10 .30 (https://scholarworks.iu.edu/journals/ index.php/tmr/article/view/17693/23811).

16 Odorico (2014a); Odorico (2014b); Odorico (2017).

17 Németh (2013), 232-258.

18 Odorico (2011a).

19 Moreover, P. Magdalino associated the designation of the imperial collections of the tenth century with the triumph of orthodoxy over iconoclasm. In his view, the Orthodox concept of law and good order $(\varepsilon \dot{\tau} \tau \alpha \xi \xi i \alpha)$ dominates collections produced under the reigns of Leo VI and Constantine 
be noted that, in line with Magdalino, in 2010 Andreas Németh devoted a large part of his dissertation on the Excerpta Constantiniana to arguing that collections during the reign of Constantine Porphyrogenitus were executed in an innovative manner, different from that of earlier collections. ${ }^{20}$

In February 2012, a workshop on textual transmissions of Byzantine texts took place in Madrid. The papers delivered at the workshop were edited by Juan Signes Codoñer and Inmaculada Pérez Martín in the book Textual Transmission in Byzantium: Between Textual Criticism and Quellenforschung, published in 2014. This time the spotlight was set on the terminology covering all sorts of compositions. A number of papers in the book dealt with the rewriting processes of collections of selections and compilation literature. Nevertheless, the different case studies presented in the book reveal that practices of excerpting have wrongly been restricted to the cultural context of the tenth century; the practice of gathering and excerpting starts much earlier than the tenth century.

Recently, scholars have tended to take collections of historical excerpts seriously as a literary phenomenon and study them as autonomous pieces of literature. ${ }^{21}$ One collection of excerpts, the so-called Excerpta Constantiniana, has received much attention in particular: ${ }^{22}$ the manuscript transmission of the $E C$ was rigorously studied by J. Irigoin and K. Schreiner, ${ }^{23}$ the numbers and names of the Constantinian collections have been treated by P. Lemerle, K. Schreiner, B. Flusin, and A. Németh, ${ }^{24}$ and the methodological and structural principles of the $E C$ have been investigated by U. Roberto, A. Németh, and D. Rafiyenko. ${ }^{25}$ But whereas the $E C$ have thus received quite some scholarly attention, other excerpt collections are still awaiting detailed study. In this book, I therefore focus on a series of minor collections that have received little or no attention at all, namely the so-called Epitome of the Seventh Century, the Excerpta Anonymi (tenth c.), the Excerpta Salmasiana (eighth-eleventh c.), and the Excerpta Planudea (thirteenth c.).

Porphyrogenitus. In terms of ideology, order seemed to have denoted the return to orthodoxy after the disastrous period of iconoclasm and the restoration of education after its decline during the previous two ages; cf. Magdalino (2011), 143-160.

20 Németh (2010), esp. 27-31 and 228-235. Németh expands on this view in a monograph published in 2018; cf. Németh (2018).

21 In addition to the papers presented at the conferences mentioned above, see also the dissertation by A. Németh (2010), Nemeth's monograph (2018) and the special issue of Byzantinoslavica 75 (2017) edited by P. Odorico.

22 The extant parts of the $E C$ were published in de Boor (1903), de Boor (1905), Büttner-Wobst (1906), Boissevain (1906), and Roos (1910).

23 Irigoin (1959), 177-181; Irigoin (1977), 237-245; Schreiner (1987), 1-29; Németh (2010), 93-178.

24 Lemerle (1971), 327-328; Schreiner (1987), 1-29; Flusin (2002), 537-559; Németh (2010), 65-92; Németh (2013), 232-258; Németh (2018), 187-211.

25 Roberto (2009), 71-84; Németh (2010), 179-245; Rafiyenko (2017), 291-324; Németh (2018), $102-115$ and 214-237. 


\section{xxii Introduction}

This book intends to offer the first systematic study of collections of historical excerpts in Byzantium, uncovering their method and function, and arguing that they constitute a historical subgenre in their own right. I treat these collections of excerpts in their entirety, that is, as cultural forms in their own right ${ }^{26}$ and as original attempts to transmit history. More particularly, I embark on a close analysis of three aspects of the aforementioned texts: a. their method of redaction, b. their literary structure, and c. their cultural and political function.

a. Working method: The book aims at specifying the working method applied in the excerpt collections and argues in favour of viewing these texts as the product of the culture of sylloge, an approach to older texts that was common in the time when the collections studied in this book were made. I set forth not only the kind of sources used, but also how excerptors integrated the excerpts from older collections into their own work so as to form entirely new texts pursuing their own aims within their own context. In particular, a) I identify three steps in the process of redacting a sylloge of historical excerpts: reading, selection, and composition, and b) I show that the texts examined in this book share compositional principles: their compilers retained the language and style of the original text, respected the original sequence of excerpts, and aimed at brevity and accuracy. The Epitome, the Excerpta Anonymi, the Excerpta Salmasiana, and the Excerpta Planudea are syllogae just like those produced in Byzantium from late antiquity onwards. They are rooted in a common approach as regards the transmission of knowledge to succeeding ages by embedding the classical texts into the new social, political, or theological context.

b. Literary structure: in a second step, I start out from linguistic data to study how the excerpted texts are transformed in the process of excerpting; changes in vocabulary, grammatical structures, and overall organisation provide the basis for understanding how the original text was adapted to a new audience. I treat the collections not as mere witnesses to the texts they excerpt, but as literary creations in their own right. By studying the overall message and structure of these new literary works, I identify possible authors and their target readers. In addition, this book seeks to consider how the pervasive use of excerpt collections impacted on the writing of history: I argue for a modified understanding of the history of Byzantine historiography by highlighting that excerpt collections reflected a common way of dealing with historical texts of the past.

c. Cultural and political function: A further goal of this book is to explore the political dimension of the works produced through processes of compilation. That is, I focus on how the past was reordered and reconstructed in collections of historical excerpts. We shall see that omissions and alterations in the course of the redaction of the excerpt collections point to political attitudes 
and the perception of the world current in the period they were compiled. Their compilers appear to serve the dominant imperial policy of the time. Therefore, placing each collection within its political and cultural framework will allow us to get a better insight into the changes selected pieces of texts underwent before their inclusion into the collection. This book seeks to show that political circumstances and cultural contexts had a strong bearing on the authors' system of selection.

Chapter 1 serves to introduce the reader to the concept of culture of sylloge. The term refers to a specific technique or method applied by Byzantine writers in a variety of disciplinary fields. The chapter explores the origins of the culture of sylloge and surveys the types of texts in which the culture of sylloge is practised. The last part of the chapter elucidates the three steps of redaction of an excerpt collection.

Chapter 2 embarks upon a close analysis of the date, content, and structure of the tenth-century Excerpta Anonymi. The study of the historical excerpts in the sylloge sheds new light on the methodological principles of the Excerpta Anonymi: it shows that the Excerpta Anonymi employed a method similar to the one applied in the EC. Similarities in content and method between the two works suggest that the compiler of the Excerpta Anonymi possibly had access to material gathered in the first place for the $E C$. Furthermore, Chapter 2 focuses on the historical and political context of the Excerpta Anonymi; omissions and alterations on the part of the compiler of the sylloge point to the concept of limited ecumenism, the foreign policy that characterised the Macedonian dynasty.

Chapter 3 looks at the so-called Excerpta Salmasiana. The historical excerpts transmitted in this text are often discussed in studies on the original text from which they were taken, and which is usually attributed to John of Antioch. Chapter 3 argues that the Excerpta Salmasiana comprise three distinct syllogae of excerpts and aims at identifying possible collections of excerpts behind the compilation of the sylloge. The study of the working method applied to the various parts of the Excerpta Salmasiana reveals the three steps of redacting an excerpt collection as seen in the EC and the Excerpta Anonymi. Furthermore, the study of the material selection from Agathias' text permits us to understand how the compiler of the sylloge imbued it with a new meaning. The passages reflect on a period in which the Empire had territorially shrunk and its civilising influence had been restricted.

Chapter 4 is devoted to the so-called Epitome of the Seventh Century. The text is an anonymous collection of historical excerpts transmitted in five manuscripts dated from the tenth to the fourteenth centuries. The sylloge was originally compiled in the seventh century, though. Chapter 4 aims to challenge the traditional view that the Epitome is a summary of a collection consisting of the complete texts of a number of ecclesiastical histories. The study of the content and structure of the Epitome shows that the initial heading of the work, as preserved in the manuscript tradition, must be the original title of the work. Accordingly, what is conventionally called Epitome is a collection of 


\section{xxiv Introduction}

historical excerpts taken from a variety of sources. The selection of excerpts from Eusebius' $H E$ in the Epitome is edited for the first time in the appendix of this book.

Chapter 5 is concerned with the $\Sigma v v \alpha \gamma \omega \gamma \eta^{\prime}$, a collection of excerpts compiled by Maximus Planudes at the end of the thirteenth century. The focus of the chapter lies in a series of excerpts on Roman history transmitted as part of the $\Sigma v v \alpha \gamma \omega \gamma \eta$. The section on Roman history in the $\Sigma v v \alpha \gamma \omega \gamma \eta \dot{\eta}$ contains excerpts from John of Antioch, Paeanius, Xiphilinus, and a lost chronicle, traces of which can be encountered in Manasses and other Byzantine texts from the middle Byzantine period. The study of the excerpts reveals that this part of the $\Sigma v v \alpha \gamma \omega \gamma \dot{\eta}$ is derived from an earlier collection of historical excerpts compiled by Maximus Planudes himself. Chapter 5 examines the arrangement of excerpts in the $\Sigma v v \alpha \gamma \omega \gamma \eta \dot{\eta}$ as well as the strategies by which Planudes redacted his sylloge. It shall become manifest that Planudes was aware of the issue of flawed contextualisation caused by the excerpting method and that he resorted to the same strategies as earlier compilers of excerpt collections. Planudes' rhetorical training becomes evident in the selective use of excerpts from his sources as well as in the political use of his collection: Planudes aimed to counsel the emperor Andronicus II (1282-1328) to pursue a military offensive policy towards the enemies of the Empire in the East and the Balkans.

The concluding Chapter 6 reflects on the implications of reading collections of historical excerpts as proper works of history. In particular, this chapter intends to show that collections of historical excerpts share a series of literary features which identify them as a specific group within historiography. Specifically, a) collections of historical excerpts share methodological principles. Yet shifting patterns of contents, such as the addition, omission, or alteration of extracts, are one of the particularly interesting features of Byzantine collections of historical excerpts. The study of their structure and the examination of certain passages in them identify several features of compilation practice. b) compilers of excerpts collections often drew on earlier syllogae. Textual borrowings amongst historical collections link them as a distinct genre and suggest that the compilers were aware of the fact that they belonged to a common tradition of historical writing. c) collections of historical excerpts represented history according to themes. The analysis of the format and function of all four excerpt collections points out that the selective use of passages and their thematic arrangement were shaped by cultural concerns, contemporary ideology, as well as personal intentions. The result to be drawn is that collections of historical excerpts merit being seen as a third way, along with histories and universal chronicles, of writing history, for they were intended to serve the role of history, that is, to preserve memory, supply posterity with moral examples, and shape political and cultural thinking.

To achieve the aforementioned goals, I build on a close analysis of the reciprocal relationship between methods of transmission and contexts. Combining codicological, literary, and political analyses, this book endeavours to contribute to a better understanding of the intertwining of knowledge and power. The contents of 
manuscripts were checked using the online Pinakes catalogue. ${ }^{27}$ Some of the collections have not been edited before, and for those that have been edited, recourse to the manuscripts was necessary. Such a codicological study is meant to provide further building blocks for future editions. I also provide partial editions of unedited texts. ${ }^{28}$ All uncredited translations are my own.

27 https://pinakes.irht.cnrs.fr.

2850 excerpts from Agathias' Historiae preserved in Vaticanus gr. 96 and Vaticanus Pal. 93 as well as 126 excerpts from Eusebius' $H E$ transmitted in four of the total five manuscripts of the so-called Epitome are edited in the appendix of the book for the first time. 
$\because$ Taylor \& Francis

Taylor \& Francis Group

http://taylorandfrancis.com 


\section{Greek compilation literature from Byzantium}

This book endeavours to show that along with the two traditional historical genres, e.g., history and chronicle, collections of historical excerpts constitute another approach to history in Byzantium. Considering collections of historical excerpts as discrete works of history throughout the Byzantine millennium, I shall first reflect on the technical terms Byzantines used to refer to these texts. I also present contemporary definitions of terms used in this book, and, in some cases, give my own definition. After discussing Byzantine and modern terminology, I shall consider the origins of the so-called culture of sylloge and show how collections of historical excerpts relate to it. This will enable us to set historical excerpt collections within the historiographical tradition. In the last part of this chapter, I shall examine the methodological principles underlying the compilation of a Byzantine collection of historical excerpts.

\subsection{Terminology}

\subsubsection{Byzantine terminology}

Byzantine writers refer to historiographical writing in a variety of ways, without making strict distinctions between different historiographical genres. Terms such as historia, syngraphe, chronikon, chronographia, ekthesis, diegesis, and biblos were often used indistinctively by Byzantine writers. The Theophanes Continuatus (Books i-iv) and the Vita Basilii, for instance, are both structured according to the lives of certain emperors. The Theophanes Continuatus is referred to as a chronographia in its preface whereas the Vita Basilii is identified as a historical diegesis (narrative). ${ }^{1}$ When referring to the chronicle by Theophanes, the DAI, a tenth-century manual on the administration of the empire, uses both terms chronikon and historia. At times, these general terms were often accompanied by other terms, such as syntomos, epitome, synopsis, and paradosis to indicate a process of sum-

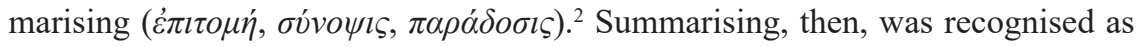

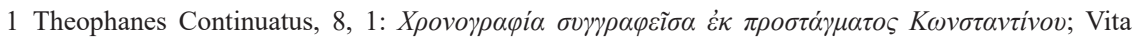

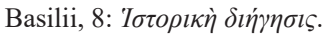

2 Magdalino (2012), 219. See also Signes Codoñer (2016), esp. 233-242 and Macrides (2016), 259. 


\section{Greek compilation literature from Byzantium}

a distinct manner of rewriting a text, and a number of historical works were writ-

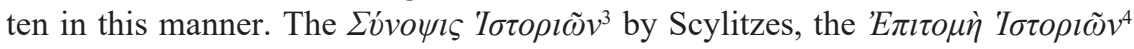

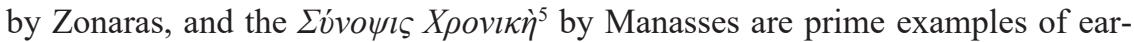
lier texts shortened and represented in a new form. ${ }^{6}$ The titles transmitted along with those texts are indicative enough of the technique applied by their authors. Theophanes Confessor, in the preface to his Chronographia refers to the Ecloga chronographica of George Syncellus as a concise chronographia. ${ }^{7}$ Yet summarising is undeniably involved in another category of rewriting, as well; namely, the aggregation of different excerpts into a single, new text. ${ }^{8}$ As will be shown in

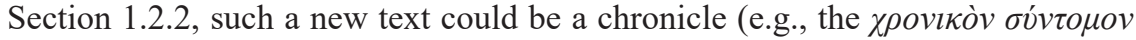

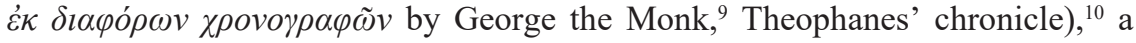

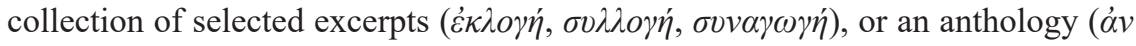
$\theta o \lambda o ́ \gamma ı \nu, \dot{\alpha} v \theta o \lambda o \gamma i ́ \alpha)$.

I would like to draw attention to a prefatory remark to the chronicle of George the Monk. In the prologue to his work, George sets out his working method:

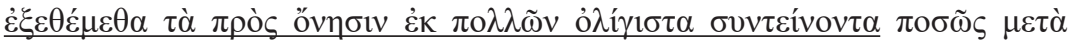

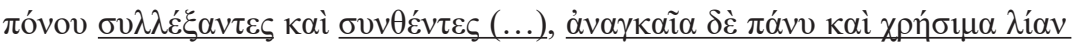

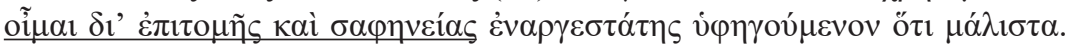

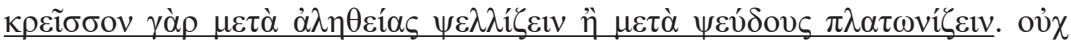

3 Scylitzes (ca 1040-1110) wrote a chronicle covering the period from the death of Nicephorus I in 811 to the accession of Isaac I Komnenos in 1057. On Skylitzes, see Thurn (ed.) (1973); Flusin (2010), xii-xxxiii.

4 Zonaras' historical writing (mid-twelfth century) ran from Creation to 1118. On Zonaras, see Banchich (2009), 1-19.

5 Manasses (ca 1130-ca 1187) wrote a chronicle in verse covering the period from Creation to 1081. On Manasses, see Reinsch (2002), 81-94; Nilsson (2006), 15-31; Jeffreys (2012); Nilsson (2014), 98-111.

6 Summaries of earlier texts already appear in late antiquity. Stephanus of Byzantium refers to such historiographical summaries; cf. Sautel (2000), 88-92. On a collection of passages from Polybius dated in the ninth century, see Moore (1965), 55-73. On a collection of passages from Diodorus of Sicily' Biblotheca Historica, see Bertrac (1993), cxxxvii-cxxxviii. See also Goukowsky (2012) on possibly the earliest summary of historiographical text, the Papyrus Hauniensis 6, dated to the second century ad.

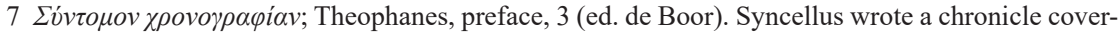
ing the period from creation to the year 284. The text has been transmitted complete. On Syncellus, see the edition of the Ecloga chronographica by Adler and Tuffin (2002). Theophanes Confessor expanded Syncellus' work up to 813. Mango (1978) and Speck (1994) suggested that Theophanes simply organised a bunch of sources assembled by George Syncellus. On Theophanes, see Mango and Scott (2006); Scott (2006), 49-65; and the papers published in Jankowiak and Montinaro (2015).

8 Signes Codoñer (2016), esp. 69-72.

9 Odorico (2010), 209-216. George the Monk composed a chronicle from Adam to the death of the emperor Theophilus (842 ad). See P. Magdalino's interpretation of George the Monk's Chronicon as an embedded florilegium in chronicle form in Magdalino (2011), esp. 158-159. On the structure of George the Monk's chronicle see de Boor (1886); Detoraki (2015), 103-130.

10 Kazhdan (1999), 219-254; Odorico (2010), 209-216. 


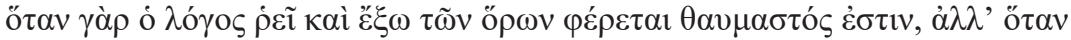

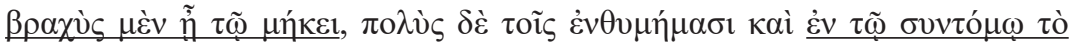

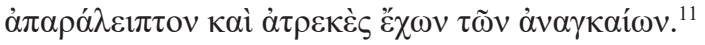

we strove to set out, for your benefit, the least of the many (accounts), having collected it and put it together with hard work (...), I believe that what should be placed first and above all is that the most essential and the very useful (should be given) abridged and in the most plain manner, for it is better to speak plainly but truly rather than to speak elegantly but falsely. The speech is not admirable when it flows outside the boundaries, but when it is short in length and rich in meaning, and when it concisely contains the complete and precise (meaning) of the most essential.

According to this statement, George the Monk collected, selected, abridged, and represented a number of passages in a new whole. The terms $\dot{\pi} \pi \imath$ n $\mu \grave{\eta}$ and $\dot{\varepsilon} v \tau \tilde{\omega}$

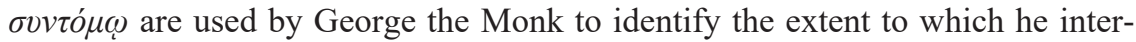
vened in the original texts, after their selection and before their arrangement in the chronicle. As we shall see in Section 1.2.2, his working method is similar to that applied to other works belonging to the culture of sylloge.

As regards the extent to which the excerptors used to intervene in the original text, the prooemium to the $E C$ provides us with important information:

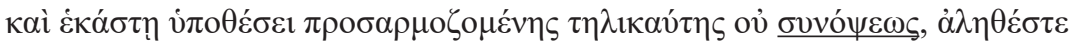

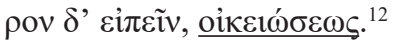

The statement implies that Constantine Porphyrogenitus made a choice between two existing manners of creating excerpt collections: summarising ( $\sigma \dot{v} v \psi_{\imath \varsigma}$ ) or

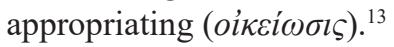

P. Odorico pointed out that compilers of these type of texts often inserted statements in the prefaces to their works that outline their working method. ${ }^{14} \mathrm{He}$ drew attention to the fact that the vocabulary in the prefaces is quite frequently identical; terms such as $\dot{\varepsilon} \kappa \lambda \sigma \gamma \dot{\eta}, \sigma v \lambda \lambda \dot{\varepsilon} \gamma \omega, \sigma v \lambda \lambda o \gamma \eta^{\prime}, \sigma v \lambda \lambda \dot{\varepsilon} \xi \alpha \sigma \theta \alpha l, \sigma v v \alpha \dot{\xi} \omega, \sigma v v \alpha \gamma \omega \gamma \eta \dot{\eta}$, and

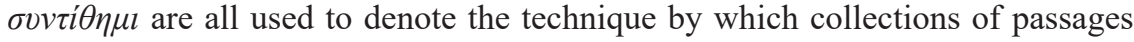
were compiled. It should also be noted that, in the Byzantine period, the term $\varepsilon \kappa \lambda o \gamma \eta \dot{~ w a s}$ used to identify both a single selected excerpt and an entire compilation of passages. The term also occurs in the plural, $\dot{\varepsilon} \kappa \lambda$ o $\alpha \dot{\text {, }}$, as in the title $\dot{\varepsilon} \kappa \lambda \circ \gamma \alpha \dot{i}$

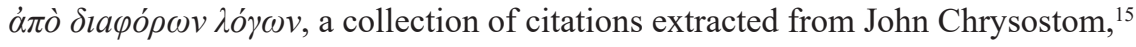

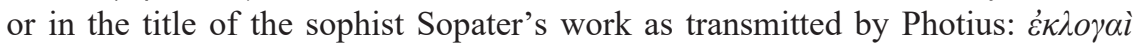

11 George the Monk, Chronicon 2, 4-13.

$12 E L$ 2. For a thorough analysis of the passage as well as for relevant bibliography, see section 1.3.

13 Németh (2010), 18-19.

14 Odorico (2011a), 89-107; Odorico (2014a), esp. 374-376 and (2017).

$15 P G$ 63, cols. 567-902. 


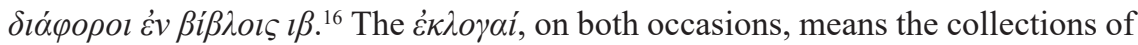
selections. ${ }^{17}$ The word $\dot{\varepsilon} \kappa \lambda o \gamma \alpha i$ (extracts) appears also in manuscripts transmitting collections of exegetical extracts on the Gospels, known as catenae. ${ }^{18}$ In extant catenae manuscripts, terms such as $\sigma v v \alpha \gamma \omega \gamma \eta \dot{~(c o l l e c t i o n) ~ a n d ~} \dot{\varepsilon} \rho \mu \eta v \varepsilon i \alpha$ (interpretation) are also often transmitted in headings preceding the collections of exegetical passages. ${ }^{19}$ Such terms pointed to the working method by which catenae were composed as well as the format in which selected texts were represented. ${ }^{20}$ It is important to note that catenists frequently intervene in the original text by omitting or altering textual material. ${ }^{21}$ Recently, K. Demoen showed that a number of epigrams preserved in manuscripts transmitting collections of excerpts on a particular subject use the same vocabulary detected by P. Odorico in the introductions to various syllogae..$^{22}$

With the exception of the $E C$, the texts under discussion in this book survive without any preface. The preface to the $E C$ calls the subject categories according to which the excerpts were classified $\dot{v} \pi \circ \theta \varepsilon \dot{\varepsilon} \sigma i \varsigma .{ }^{23}$ The Excerpta Anonymi survives without a preface or any heading. The same holds true for the Excerpta Salmasiana. The manuscript tradition of the so-called Epitome of the Seventh Century transmits the heading $\Sigma v v \alpha \gamma \omega \gamma \eta$. The same term is found in two of the manuscripts transmitting the Excerpta Planudea.

In order to understand better what the Byzantines meant by $\sigma v v \alpha \gamma \omega \gamma \eta$, one should pay attention to the common use of the words $\sigma v v \alpha \gamma \omega \gamma \dot{\eta}, \sigma v \lambda \lambda \sigma \gamma \dot{\eta}$, and $\varepsilon \kappa \lambda o \gamma \eta^{\prime}$ in their works produced through processes of compilation. Two manuscripts, Monacensis gr. 358 (ninth c.) and Athous Koutloumousiou 10 (eleventh c.), transmit a collection of comments on the Octateuch and Kingdoms under the heading $\dot{\varepsilon} \kappa \lambda o \gamma \tilde{\omega} v \dot{\varepsilon} \pi \imath \tau o \mu \grave{\eta}$ (epitome of selected passages) attributed to Procopius, the sixth-century Christian sophist and rhetorician from Gaza. ${ }^{24}$ At the beginning of the collection, Procopius states that this work is a shortened version of an

16 Bibliotheca, cod. 161.

17 Signes Codoñer (2013), 69-70, n. 28.

18 Houghton and Parker (2016), 2. On catenae, see Devreesse (1928); Wilson (1967), 244-256; Dorival (1986); Auwers and Guérard (2011).

19 Earlier single-author commentaries on the New Testament, by contrast, were described as

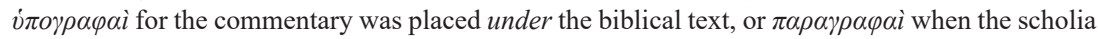
were added to the sides of the biblical text.

20 See Houghton and Parker (2016).

21 Panella discusses features of compilation practice encountered in catenae on 1 Corinthians of Paul in Panella (2016) 117-140. See also in the forthcoming Manafis (2020).

22 Demoen (2013), 89-98. On epigrams, see Lauxtermann (2003b) and Lauxtermann (2007).

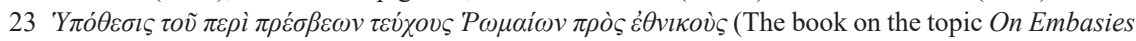
of Romans to Foreigners); ed. Németh (2018), 267. My translation. $\tilde{\omega} v \kappa \varepsilon \varphi \alpha \lambda \alpha \iota \omega \delta \tilde{\omega} v$ vं $\pi \circ \theta \dot{\varepsilon} \sigma \varepsilon \omega v$

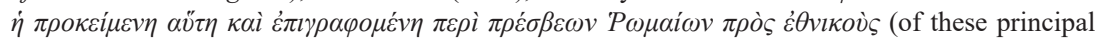
topics, the present text bearing the heading On Embasies of Romans to Foreigners); ed. Németh (2018), 268, transl. Németh (2018), 62. On the use of the term ímó $\theta \varepsilon \sigma ı \varsigma$ in Polybius 12. 25f (ES 154), see Németh (2018), 216-217.

24 PG 87(1). See the edition of the text in Metzler (2015). 
earlier catena composed by himself. Procopius also briefly explains the method by which the original catena was compiled:

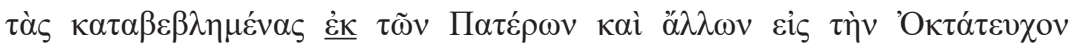

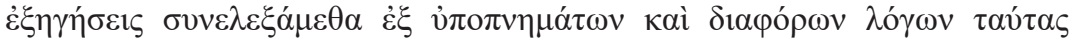

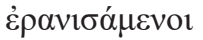

we collected explanations on the Octateuch laid down by the Fathers and others, extracting these from commentaries and various speeches. ${ }^{25}$

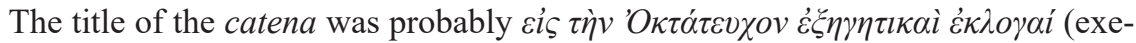
getical extracts on the Octateuch). ${ }^{26}$ Procopius composed two other epitomes of

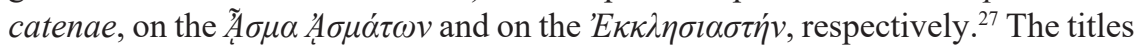
of the two works are worth mentioning:

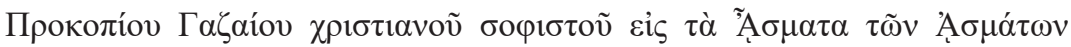

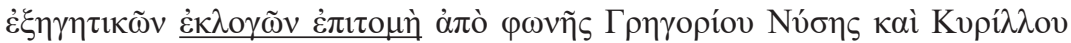

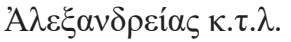

Epitome of a selection of explanations on the Song of Songs by Procopius of Gaza, the Christian sophist, according to the teaching of Gregory of Nyssa and Cyrill of Alexandria...

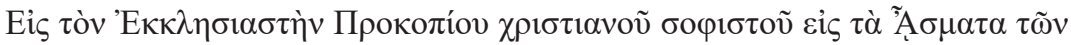

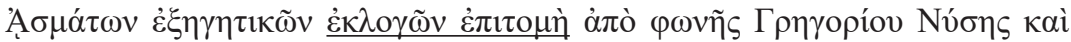
Kvpí $\lambda \lambda$ ov А $\lambda \varepsilon \xi \alpha v \delta \rho \varepsilon i ́ \alpha \varsigma \kappa . \tau . \lambda$.

Epitome of a selection of explanations on the Ecclesiastes by Procopius of Gaza, the Christian sophist, according to the teaching of Gregory of Nyssa and Cyril of Alexandria...

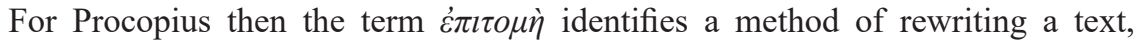
whereas the term $\dot{\varepsilon} \kappa \lambda \sigma \gamma \dot{\eta}$ refers to a collection of extracts. Indeed, Procopius' works consist of a series of comments taken from the Fathers augmented with material written by Procopius himself. The arrangement of the selected citations as well as the added text aim at clarifying parts of the Bible.

Furthermore, the so-called first Palestinian catena, the oldest catena on Psalms, dated to the second quarter of the sixth century is transmitted in the ninth-century codex Baroccianus 235 under the heading $\dot{\varepsilon} \xi \eta \gamma \eta \tau \iota \kappa \tilde{\omega} v \dot{\varepsilon} \kappa \lambda o \gamma \tilde{\omega} v$ (selections of interpretations). ${ }^{28}$ In fact, $\dot{\varepsilon} \kappa \lambda o \gamma \dot{\eta}$ and $\sigma v v \alpha \gamma \omega \gamma \grave{\eta}$ are the most frequently encountered

$25 P G 87(1)$, col. 21.2-5.

26 Dorival (2016), 72.

27 PG 87/2, col. 1545-1780. See also in Devreesse (1928); Ceulemans and Auwers (2012), 493-508.

28 The catena assumed that name from the place of its origin, namely Caesarea in Palestine. On the transmission of the Palestinian catena in Baroccianus 235, see Devreesse (1928), 1116; Richard (1957), 88. 


\section{Greek compilation literature from Byzantium}

terms in the headings of manuscripts transmitting selections of exegetical extracts. The terms were also used indiscriminately to identify the same work, as the transmission of the heading of the sylloge of exegetical passages on the Gospel according to Luke by Nicetas of Heraclea illustrates. ${ }^{29}$ The word $\sigma v v \alpha \gamma \omega \gamma \grave{\eta}$ occurs on $\mathrm{f}$. 5r of Athonensis Iviron 371 (eleventh c.) and f. 1v of Taphou 466 (twelfth c.) in

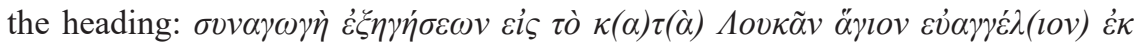

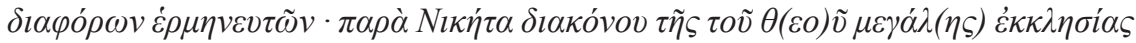
$\kappa(\alpha i) \delta \imath \delta \alpha \sigma \kappa \alpha ́ \lambda$ ov $\gamma \varepsilon \gamma o v v \tilde{\alpha} \alpha$ (composition of expositions on the holy Gospel of Luke taken from various commentators - made by Nicetas, the deacon and teacher of the Great Church of God ). ${ }^{30}$ The term $\dot{\varepsilon} \kappa \lambda \sigma \gamma \eta \dot{y}$, on the other hand, is transmitted on f. 1r of the catena in Vaticanus gr. 759 (fourteenth c.): $\dot{\alpha} \pi \dot{o} \tau \tilde{\eta} \varsigma \dot{\varepsilon} \kappa \lambda o \gamma \tilde{\eta} \varsigma N \imath \kappa \dot{\eta}(\tau \alpha)$ $\Sigma \varepsilon \rho[\rho] \tilde{\omega} v$ (from the collection of Nicetas of Serrae).

Photius in his Bibliotheca ${ }^{31}$ furnishes us with the titles, contents, and extracted passages of a considerable number of books he had studied. At some point, Photius refers to the fifth-century Lexicon of Helladius by using the term $\sigma v v \alpha \gamma \omega \gamma \eta$, but when he comes to compare it with the lexicon of Diogenianus, he uses the term $\sigma v \lambda \lambda o \gamma \dot{\eta}$ for the latter:

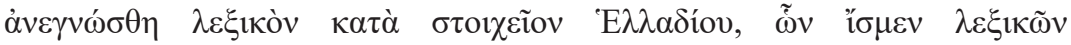

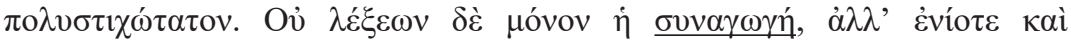

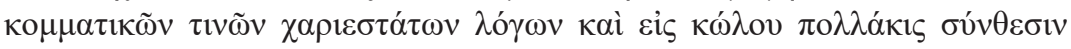

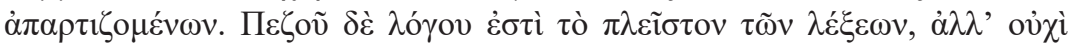

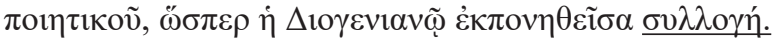

I read the Lexicon of Helladius, arranged in alphabetical order. It is the most comprehensive of the lexicons that I know, the collection consisting not only of words, but also of some most agreeable short clauses, which frequently become perfect members. The words are for the most part taken from prose writers, not from the poets, like the compilation of Diogenianus. ${ }^{32}$

Shortly afterwards, however, Photius identifies Helladius' Lexicon as both, $\sigma 0 \lambda \lambda o \gamma \dot{\eta}$ and $\sigma v v \alpha \gamma \omega \gamma \eta^{\prime}$. Specifically, in Bibliotheca, cod. 158, Photius refers to a $\sigma v v \alpha \gamma \omega \gamma \dot{\eta}$ of words and clauses compiled by Phrynichus the Arabian and he concludes that:

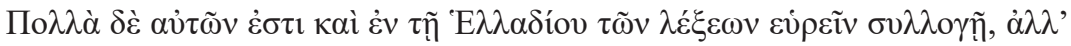

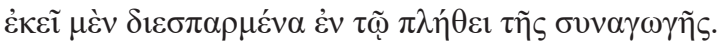

29 On Nicetas, see Sickenberger (1902); Darrouzès (1960), 179-184; Krikonis (1976), esp.17-25.

30 Passages from Iviron 371 have been published in Krikonis (1976).

31 Photius' Lexicon, another work of his, was composed through the process of compilation and

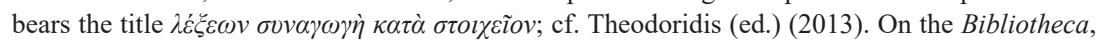
see Section 1.2.3.

32 cf. Bibliotheca, cod. 145. 
many of these are to be found in the $\sigma v \lambda \lambda \mathrm{o} \gamma \dot{\eta}$ of Helladius, but there they are dispersed throughout the $\sigma u v \alpha \gamma \omega \gamma \eta{ }^{33}$

Interestingly, Photius describes as $\sigma v v \alpha \gamma \omega \gamma \grave{\eta}$ the lexicon of Boethus as well as the content of a collection of chronicles and a list of Olympian victors:

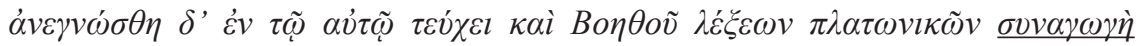

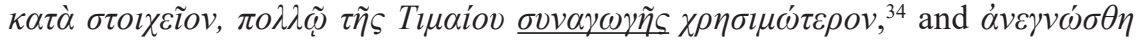

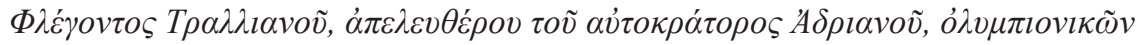

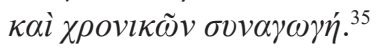

Proceeding to the Geoponica, ${ }^{36}$ a collection of agricultural lore compiled during the tenth century in Constantinople, we notice that the beginning of Book

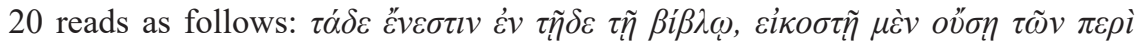

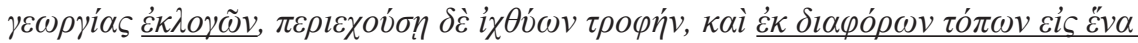

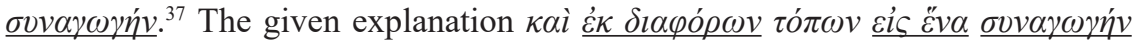
as well as the content itself of the Geoponica provide us, lucidly and aptly, with what is meant by the term $\sigma v v \alpha \gamma \omega \gamma \eta$ : that is, a collection of passages excerpted from different works and put together into a single text. In the prooemium to the Geoponica, the same principle is repeated through the use of a derivative of

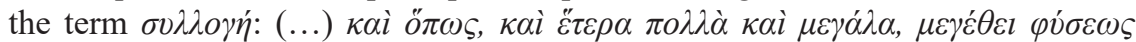

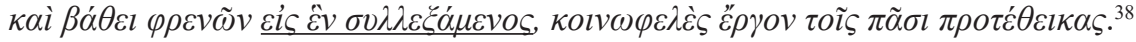
Furthermore, the beginning of Book 1 reads:

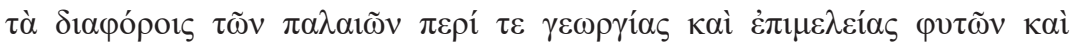

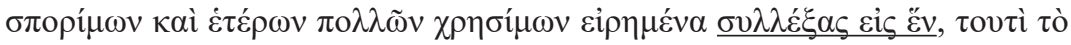

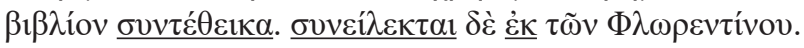

After I gathered together the various sayings of ancient people on agriculture and the care of the plants and crops and many other useful subjects in a single entity, I compiled this volume. And I extracted from the writings of Florentius. ${ }^{39}$

33 cf. Bibliotheca, cod. 158.

34 Read in the same book, the List of Platonic Words by Boethus 1 in alphabetical order. It is dedicated to a certain Melant(h)as and is far more useful than the collection of Timaeus; cf. Bibliotheca, cod. 154.

35 Read the Collection of Chronicles and List of Olympic Victors by Phlegon of Tralles, a freed man of the emperor Hadrian; cf. Bibliotheca, cod. 97.

36 Beckh (ed.) (1895); trans. Dalby (2011).

37 These (subject matters) are present in this book, which is the twentieth consisting of selections on agriculture and it contains information on the food of fishes, and (the contents) taken from various passages are put together in a unified whole); Geoponica, book 20.

38 And similar to the way, as happens with many other and great things, the magnitude of the character and depth of the mind are collected in one unity, a work of common utility has been put forward; Geoponica, prooemium.

39 Geoponica, Book 1. 


\section{Greek compilation literature from Byzantium}

In addition to this, at the beginning of each book the same sentence is repeated to describe the working method of the compiler: $\tau \dot{\alpha} \delta \varepsilon \varepsilon \varepsilon^{2} v \varepsilon \sigma \tau \imath v \dot{\varepsilon} v \tau \tilde{\eta} \delta \varepsilon \tau \tilde{\eta} \beta i \beta \lambda \omega$,

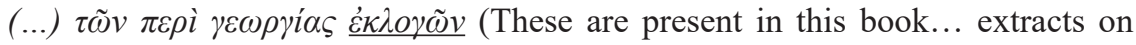
agriculture).

The Geoponica consists of passages taken from a number of earlier collections of agricultural precepts, one of which was definitely the fourth/fifth-century collection of Vindanius Anatolius of Berytus. Photius who read and commented

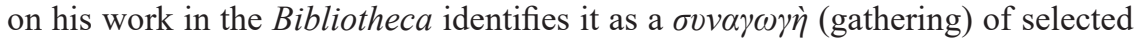
excerpts from other works:

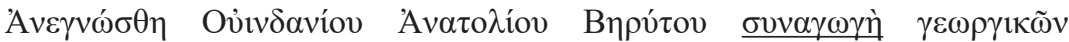

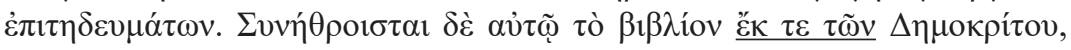

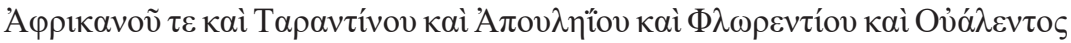

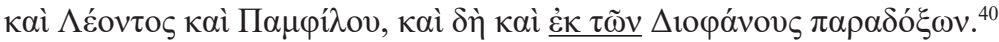

Read the collection of instructions on Agriculture by Vindanius Anatolius of Beirut. He has drawn on Democritus Africanus of Tarentum, Apuleius, Florentius, Valens, Leo, Pamphilus, and the 'Marvels' of Diophanes. ${ }^{41}$

As shown, when Photius comes to refer to Sopater's collection, which was compiled by employing a method similar to that applied to the Geoponica or the

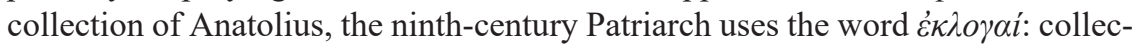
tions of selections. And Photius goes on as follows:

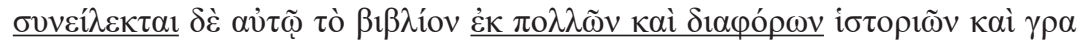
$\mu \mu \alpha ́ \tau \omega v^{42}$

he gathered his material from many different histories and other writings. ${ }^{43}$

The term ovvei $\varepsilon \varepsilon \kappa \tau \alpha l$ (third person singular of the Present Perfect tense, Passive Voice of $\sigma v \lambda \lambda \dot{\varepsilon} \gamma \omega$ ) could, here, mean the collecting of works (possibly complete works). Photius, however, goes on to explain:

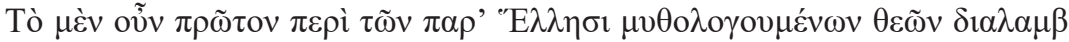

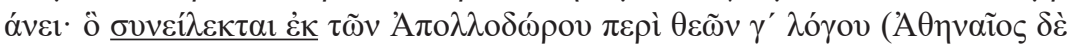

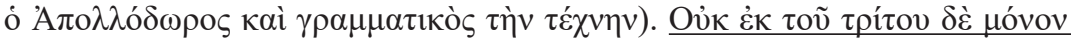

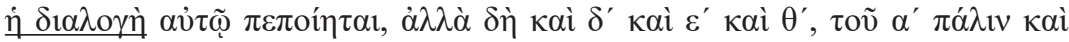

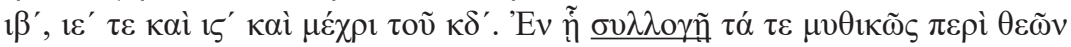
$\delta 1 \alpha \pi \varepsilon \pi \lambda \alpha \sigma \mu \varepsilon \dot{v} \alpha^{44}$

40 Bibliotheca, cod. 163.

41 Transl. Wilson (1994), 147.

42 Bibliotheca, cod. 161.

43 Transl. Wilson (1994), 143.

44 Bibliotheca, cod. 161. 
Book 1 discusses the gods of Greek mythology; it is compiled from Book 3 of Apollodorus' 'On the gods' (Apollodorus was an Athenian and a teacher of literature by profession). But the selection is not made from Book 3 only; it also draws on Books 4, 5, and 9, then 1, 12, 15, 16, and successive books up to 24 . He includes in his collection myths about the gods and material from historians. ${ }^{45}$

Photius makes it clear that Sopater had assembled a selection of passages for his own collection. The words $\delta \iota \alpha \lambda o \gamma \dot{\eta}$ and $\sigma v \lambda \lambda o \gamma \tilde{\eta}$, used by Photius in his comment on the text, point to the excerpting method used by Sopater.

My last example comes from Photius' comment on Gelasius of Cyzicus' Historia ecclesiastica. When Photius refers to Gelasius' compositional technique, he writes:

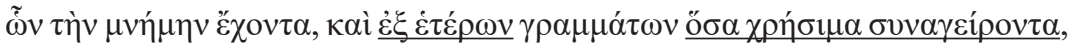

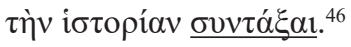

With his recollection of this, and by collecting useful information from other sources, he put together his history. ${ }^{47}$

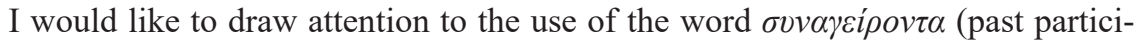
ple of the $\sigma v v \alpha \dot{\gamma}(\omega)$. The term foregrounds the creation of a structure out of the selected pieces ( $\dot{\varepsilon} \xi \dot{\varepsilon} \tau \dot{\varepsilon} \rho \omega v)$.

From the above, it becomes evident that terms, such as $\sigma v \lambda \lambda \sigma \gamma \dot{\eta}, \dot{\varepsilon} \kappa \lambda \sigma \gamma \eta^{\prime}$, and $\sigma v v \alpha \gamma \omega \gamma \eta \dot{ }$ were often used by compilers indiscriminately. It is also apparent that the term epitome should be reserved for the summary process, since it represents a category of rewriting a text rather than a conflation of different texts into a single entity. The term synagoge, by contrast, embraces both the technique by which the excerpts were selected and the composition of a text from the selected pieces.

A further term reflecting the activity of those compiling an excerpt collection is $\varepsilon \rho \alpha{ }^{\prime} \zeta \omega$. In the early third century, the term occurs in the Refutatio omnium haeresium, a Christian polemical work attributed to Hippolytus of Rome: $\underline{\varepsilon} \kappa \pi \alpha \sigma \tilde{\omega} v$

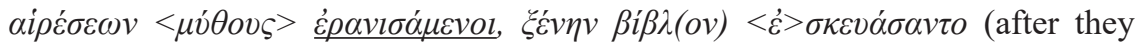
extracted $<$ myths $>$ from all heretical writings, they composed a strange book). ${ }^{48}$ As seen, in the sixth century, Procopius of Gaza uses the term in the prooemium to his commentary on Genesis.

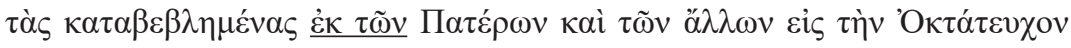

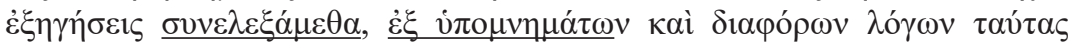

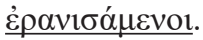

45 Transl. Wilson (1994), 143.

46 Bibliotheca, cod. 88.

47 Transl. Wilson (1994), 95.

48 Refutatio omnium haeresium 10.29.2. 
we collected explanations on the Octateuch laid down by the Fathers and others, extracting these from commentaries and various speeches. ${ }^{49}$

The term appears to point to the cut and paste technique employed in these works. The codex Bruxellensis 11301-11316 preserving the EL1 possibly transmits the name of a member of the team working under the supervision of Constantine Porphyrogenitus:

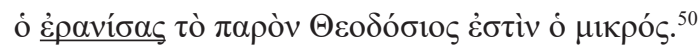

Theodosius the Younger is the collector for the present (collection).

The phrase was copied in the margin of $\mathrm{f} .2 \mathrm{r}$ in a different hand from that of the rest of the codex and it is not certain whether the sentence was also found in the archetype of the EL1. ${ }^{51}$ Even if we accept that Theodosius the Younger was on the team of Constantine Porphyrogenitus, the sort of task assigned to the Ép $\alpha v i \sigma \alpha \varsigma$ is not clear. ${ }^{52} \mathrm{He}$ could be either the person who collected and excerpted the texts of the EL1 or the person who put a series of selected passages in order. It is equally possible that Theodosius was responsible for both the selection and the arrangement of the excerpts. The same

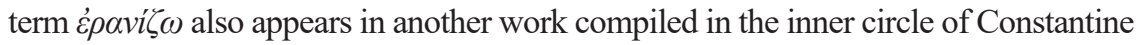
Porphyrogenitus, the $D C$. When the compiler describes his method, he adds:

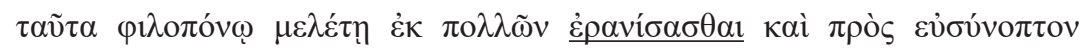

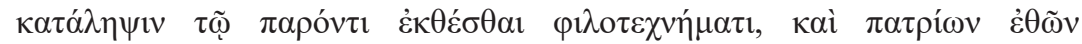

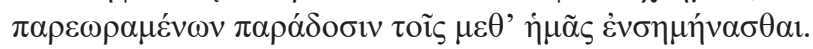

to collect with unremitting effort from many sources those things and to set them out in the present arrangement and to record for those who come after us, in the form of an easily comprehended account, the tradition of our ancestral customs which have been neglected. ${ }^{53}$

In this case, the term seems to point to the selection of the passages being included in the $D C$.

\subsubsection{Modern terminology}

Before I proceed to discussing the origins of the culture of sylloge, I briefly give my own definitions of a number of terms used in the book. I consider

$49 P G 87(1)$, col. 21.2-5.

50 See Büttner-Wobst (1906), 100; Schreiner (1987), 25.

51 Németh (2010), 140 doubts the authenticity of the sentence. A. Németh shares Moore's hypothesis, namely, that the name Theodosius belongs to a member of Andreas Darmarios' scriptorium, where Bruxellensis 11301-16 was copied; Moore (1965), 165.

52 Lemerle (1971), 285.

53 Trans. Moffatt (2012), 4. 
this essential because scholars have not yet arrived at a consensus about a number of terms concerning compilation literature. As a result, terms such as compilation, collection, selection, anthology, corpus, miscellany, collectanea, anthology, and florilegium are frequently used to refer to the same category of texts, without any distinction whatsoever - a fact that prevents us from understanding the structure, the function, and the working methods of certain type of texts.

To begin with, in this book the term compilation is used as an umbrella term covering works produced by assembling material collected from earlier sources. All the terms that follow, then, are subspecies of compilation. A first subspecies is an excerpt collection, for which I have already given a working definition: a whole comprising passages excerpted from single or different historical texts of the same or different authors and put together under a principle, that is, thematically. Such excerpt collections were intended for specific audiences: they could be used for teaching at schools, to expose moral examples as well as to narrate historical or theological events. The Greek term for collection is $\sigma v \lambda \lambda o \gamma \dot{\eta}$ (sylloge). Accordingly, in what follows, an excerpt collection on a particular subject shall also be mentioned as a sylloge of excerpts. It is worth citing here that florilegia are syllogae of citations drawn from the Scriptures and the writings of the Church Fathers. ${ }^{54}$ Catenae are syllogae of passages extracted from early Christian authors commenting on the Bible. In this book collections consisting of complete texts are designated as anthologies. It follows that such receptacles could house smallformat genres, such as epigrams, poems, and letters. The Anthologia Palatina, ${ }^{55}$ for instance, is an anthology of epigrams; it has come down to us through a manuscript dated to the second half of the tenth century. ${ }^{56}$ The same codex preserves also an anthology of Anacreontic poems. ${ }^{57}$ Anthologies comprising letters of fictitious or authentic authors appear in the ninth and tenth centuries, as well. ${ }^{58}$ In fact, since these anthologies consist of selected complete texts, they are not syllogae of

54 On florilegia see Ehrhard (1901), 394-415; Richard (1962), 475-511; Alexakis (1996), 6-42; Brubaker and Haldon (2001).

55 On the Anthologia Palatina see C. Preisendanz (ed.) (1911); Wolters (1883), 97-119, Lauxtermann (2007), 194-208; Maltomini (2011), 109-124. According to Al. Cameron and Lauxtermann, it is highly likely that the Palatine Anthology was compiled during Constantine Porphyrogenitus' sole reign (945-959); Al. Cameron (1993), 98-99, 115-116; Lauxtermann (2003b), 83-86. R. Auberton had proposed a much later date for the Anthologia Palatina, namely the period 10501070; Auberton (1968), 32-82. M.L. Agati suggested a date at the end of the tenth century; cf. Agati (1984), 43-59. N. G. Wilson dates it between 930 and 950; cf. Wilson (1996), 138. Beckby (1957-1958), 70 proposed a date around the year 980.

56 Palatinus gr. 23 is now deposited at Heidelberg. Part of Palatinus gr. 23 is kept in the Bibliothèque Nationale de France at Paris, labelled as Parisinus suppl. gr. 384; Beckby (1957-1958), 68-90; Al. Cameron (1993); Lauxtermannn (2003b), 83-114; Magdalino (1997), 169-170.

57 West (1993); Al. Cameron (1993).

58 On letters written in the tenth century, see Darrouzes (1960); Németh (2018), 205. On collections of epistles of fictitious authors, see in Malherbe (1977), 6-34; Hinz (2001), 129-141. 


\section{Greek compilation literature from Byzantium}

excerpts. Where anthologies consist of a series of complete texts by one and the same author, I use the term corpus. ${ }^{59}$

There is a significant number of Byzantine codices in which the inserted passages are not related to each other as they were not copied under a principle, that is, thematically or alphabetically. These manuscripts are called miscellanies. Miscellanies are thus receptacles containing pieces of texts of various genres and on assorted subject matters written by a single or different authors. This book does not study miscellanies, for they are not, in the absence of an ordering principle, syllogae of excerpts. ${ }^{60}$

As far as the content of a sylloge is concerned, I use the terms excerpt or extract to describe a piece of text extracted from an earlier work. In a collection/sylloge such excerpts are likely to vary in length but not in subject matter: their arrangement creates a new unity. On the other hand, by collectanea I mean the passages extracted from heterogeneous sources and on a variety of subjects. These extracted pieces of texts put together constitute a miscellany. I use the term source text to describe an earlier work from which excerpts or extracts and collectanea were drawn from. The term excerptor is used to denote the person who excerpts or collects excerpts or collectanea. I call the Byzantine scholar who reworks and synthesises the selected excerpts in a new entity a compiler. It is important to note that the excerptor and the compiler could or could not be, but often were, the same person. Finally, in this book, terms such as epitome (epitomise) and synopsis (synopsise) are reserved for the summary process, that is, a category of rewriting a text rather than an accumulation and a representation of different texts into a single entity.

\subsection{The culture of sylloge}

The concept of the so-called culture of sylloge has been introduced to describe the working method by which a series of works, from late antiquity onwards, was executed: the deconstruction of carefully selected older texts and their reconstruction in a new receptacle, that is, in a different format and context. ${ }^{61}$ It should be noted that every age of Greek literature cared about preserving texts considered essential to be preserved at the time. The Hellenistic scholars conceived it as their duty to be the critics, the coordinators, and the epitomisers of classical Greek literature. ${ }^{62}$ Thus, the Alexandrians determined the classical canon producing editions by engaging in copying and pasting. During the Hellenistic period, the Alexandrians gave us also the commentaries. ${ }^{63}$ Such treatises flourished in the Roman world. In later centuries, this practice and phenomenon found its expres-

59 Nyström (2009), 45 calls corpus an authors'total production.

60 On miscellanies, see Crisci (2004), 109-144; Maniaci (2004), 75-108; Ronconi (2004), 145-182; Ronconi (2007); Nyström (2009), 45-48.

61 This is the definition given of the culture of sylloge by P. Odorico; Odorico (2017), esp. 24-27.

62 Jenkins (1963), 97.

63 Kaldellis (2012), 71-85. 
sion through compilations of excerpts, which meant intervention in the original narrative sequence of a work, omission of what they did not consider essential to the narrative structure, and production of excerpts from previous entire works. There is an assortment of works compiled in late antiquity employing this method: a series of passages are thematically extracted from earlier texts and put together into a single receptacle. Florilegia, for instance, produced as a result of the theological controversies from the fifth century onwards, are entirely based on the aforementioned working method. ${ }^{64}$ In fact, the origins of such practices can be traced through profane collections of texts, which were compiled much earlier than the first florilegia. Miscellaneous collections of the second and third centuries

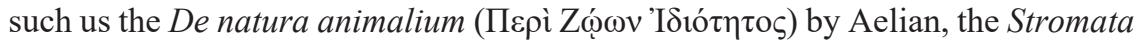

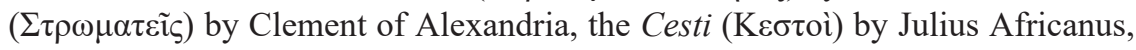
and the Noctes Atticae in Latin by Aulus Gellius also bear a striking resemblance with regard to the concept of compilation literature to later excerpt collections. The miscellaneous collections exhibit a lack of rigid structure, though ${ }^{65}$ In the early Byzantine period, when Christians began to create their own collections, they relied on anthologies of the Hellenistic age in terms of method and content. Thus, a new form of engagement with the preserving of knowledge emerged. ${ }^{66}$ The culture of sylloge is both the heir to those earlier traditions, but also espouses a new vision as regards the transmission of knowledge to succeeding ages. This came about as a result of the new social, political, and theological context in which compilation literature was produced.

From the above, it becomes evident that what should concern us is not the sort of sources the excerpt collections are made up from. Attention should instead be drawn to the structure and the function of the collections. For instance, collections of historical excerpts as well as certain Byzantine chronicles were constructed on the basis of the same technique. The format through which the excerpts were transmitted in these two sorts of texts is different, though. The collections have never, so far, been seen as independent pieces of literature and as attempts to transmit history. On the one hand the anonymity under which such collections have been handed down to us and, on the other hand, the fact that scholars long considered them lack originality have obscured their significance as texts in their own right. It is this dismissive view of excerpt collections that this book aims at

64 Some scholars are disposed to emphasise the influence of florilegia on the production of excerpt collections: P. Magdalino considers what P. Odorico names culture of sylloge as a literary phenomenon rooted in the florilegic tradition and translates the concept as the florilegic habit; cf. Magdalino (2011), 143-156. About the significant role of doctrinal controversies in compiling florilegia, see Richard (1951), 721-748. For the florilegia concerning church councils, see Alexakis (1996), 6-42 and 116-132.

65 On Aelian, see Hercher (ed.) (1864-1866). On the cultural and literary function of Aelian's work, see Kindstrand (1998), 2962-2996. On Clement, see Méhat (1966). On Julius Africanus' Cesti, see Wallraff, Scardino, Mecella, and Guignard (edd.) (2012). On Aulus Gellius, see M. Hertz (ed.) (1853).

66 For an excellent review of the ancient anthologies and their impact on the florilegia of the early Byzantine period, see Chadwick (2006), 1-10. 
tackling. In what follows, I put forward the types of works in which the culture of sylloge is to be found: Florilegia, Gnomologia, Catenae, Quaestiones et responsiones, Menologia (1.2.1), chronicles (1.2.2), and condensed 'libraries' (1.2.3).

\subsubsection{Florilegia, Gnomologia, Catenae, Quaestiones et responsiones}

The fifth century witnessed the emergence of a new way of classifying and organising biblical interpretations, the so-called catena, that is a collection of comments on the Bible taken from early Christian writers. Catenae reflected the Byzantine interest in puzzling and understanding the deeper meanings of the Biblical texts. Yet, throughout the middle and late Byzantine periods, they were employed in debates on theological and canonical maters. In fact, in the sixth and seventh centuries, we see a large part of the literary activity focused on authenticity when seeking the true gnosis according to Orthodox teaching. The polemical literature of that period, including catenae, homilies, and collections of Patristic citations, was created in response to the historical circumstances and formed as efforts towards systematising knowledge.$^{67}$ In this framework, gnomologia such as the Apophthegmata Patrum, ${ }^{68}$ John Stobaeus' Anthologium, ${ }^{69}$ Ps.-Dionysius the Areopagite's works, ${ }^{70}$ the catenae by Procopius of Gaza, ${ }^{71}$ Victor of Antioch, ${ }^{72}$ and Titus of Bostra, ${ }^{73}$ Antiochus' Pandecta scripturae sacra ${ }^{74}$ and Ps.-John of

67 The topic has been elucidated by A. Cameron; cf. Cameron (1991), 298-299; Cameron (1996), 250-276. On the dogmatical controversies of the period, see Hovorun (2008), esp. 14-15, 59, 71, and 88-89. In particular, the religious rivalries and dogmatical disputes of the seventh century were depicted in the arguments of the Councils of 681 and 690 ad, the canons of the Councils of 691-692 (which are not florilegia but illustrate theological controversies of the age (cf. Nedungatt and Featherstone (1995), 45-185), the letters concerning the Monothelite controversy, the homilies written by three seventh-century Palestinian intellectuals, namely by John Moschus, Sophronius of Jerusalem, and Maximus the Confessor, Sophronius' Christmas Sermon of 634 and his Greek anacreontics, and the writings of John of Damascus (see n. 75). On the three Palestinian intellectuals and their role in the contemporary theological disputes, see Booth (2013). On Sophronius' sermons and anacreontics, see Usener (ed.) (1886), 500-516; Gigante (ed.) (1957).

68 The Apophthegmata Patrum, a collection of sayings of the Desert Fathers, was arranged alphabetically but also according to 21 themes; see Guy (1962), 119.

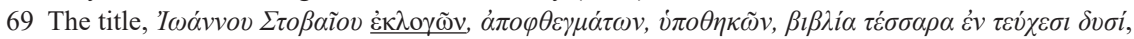
is indicative of the method used by Stobaeus; cf. Bibliotheca, cod. 167. On Stobaeus, see also Meineke (ed.) (1855-1857); Wachsmuth (1882), 55-79; Hense (1916), 2549-2586; Luria (1929), 81-104 and 225-248; Hose (2005), 93-99. On gnomologia in general, see Odorico (2004), 61-96; Morgan (2013) 108-128.

70 Heil and Ritter (edd.) (2012).

71 On the catenae by Procopius of Gaza, see Wilson (1967), 252-256. On catenae in general, see Dorival (1986); Auwers and Guérard (2011). A parallel development in Latin tradition in the fifth and sixth centuries can be seen in the collection of passages taken from Augustine; Houghton (2016), 59.

72 This is considered to be the oldest catena on Mark; Lamb (2012).

73 This catena is made up of passages most likely taken from Titus of Bostra's commentary on the Gospel according to Luke; Sickenberger (1901).

74 In the sixth century, Eustathius, the abbot of the monastery of Attaline, after the Persian attack on 
Damascus' Sacra parallela ${ }^{75}$ as well as the question-and-answer collections of Ps.-Caesarius ${ }^{76}$ and Maximus the Confessor ${ }^{77}$ make up fine examples of the gnosis as it was understood during these centuries. All of them created collections from selected passages of Patristic texts, sayings from the Gospels and the New Testament and texts from Biblical or Jewish Wisdom literature, classified by subject matter or arranged in alphabetical order. These collections continued to be adapted and used in subsequent years as rhetorical tools. ${ }^{78}$

This sort of activity continued during the eighth and ninth centuries. The eighthcentury Doctrina Patrum represents citations from 93 ecclesiastical writers organised under thematic headings. ${ }^{79}$ The Quaestiones et responsiones by Anastasius of Sinai is made up of a series of citations extracted from their original context and reorganised in chapters in a new text, the so-called Soterios. ${ }^{80}$ The outbreak of iconoclasm at about 726 and the need to defend icons, support the Orthodox dogma, and refute iconoclasm reinforced the search for works of the Fathers and the creation of collections of citations. The efforts were initially made under the auspices of the iconophile Patriarch Tarasius which set the basis for a trend that was to dominate the next centuries, namely, that of collecting related texts and creating collections of excerpts. The following Councils of 754, 787, and 815 and the second phase of iconoclasm, which broke out in 815 and lasted until 842, intensified the production of florilegia. ${ }^{81}$ To give but one example, the florilegium of the Iconoclast Council of 815 was compiled by employing a method similar to that of gnomologia and collections of theological questions of the fifth, sixth, and seven centuries presented above. ${ }^{82}$ The function of such florilegia coincided with

Ancyra which compelled the monks of the monastery to flee, asked his friend Antiochus to compile a patristic anthology, the so-called the Pandecta scripturae sacra; cf. $P G 89$, coll. 1421 . The anthology was later used by John of Damascus, who organised its material in alphabetical order in his work called Sacra parallela. This title was introduced by M. Lequien in his edition of the text in 1712; Lequien (ed.) (1712). The text in $P G$ 95, coll. 1040-1588 and $P G$ 96, coll. 9-441 is that edited by Lequien. The collection was used widely in the tenth century. On the Sacra parallela, see Ehrhard (1901), 394-415; Richard (1962), esp. 476-480; Odorico (1990), 9-12.

75 On the iconophile treatises of John of Damascus, see Kotter (ed.) (1975); Louth (2002). On Ps.John of Damascus' Sacra parallela, see Ehrhard (1901), 394-415; Odorico (1990), 9-12. The De fide orthodoxa by John of Damascus makes up a repository of Orthodox knowledge; cf. Magdalino, (2013a), 219-231.

76 Riedinger (1969); Riedinger, (ed.) (1989); for this work as a sample of the culture of sylloge, see Papadogiannakis (2011), 29-41. On this type of literature in general, see Rey (2004), 165-180.

77 On Maximus the Confessor, see Louth (1996); Booth (2013).

78 Hock and O'Neil (2002).

79 F. Diekamp ascribes the work to the period between the years 685 and 726; cf. Diekamp and Chrysos (1981), lxxix-1xxx and xlv-lxvi.

80 See the critical edition of the 103 Quaestiones et responsiones ascribed to Anastasius of Sinai by Richard and Munitiz (edd.) (2006). On the so-called Soterios, see De Groote (2015), 63-78.

81 On florilegia used in Church Councils, see above n. 64. On the period, see Mango (1977), 105177. The Amphilochia by Photius, a collection of questions and answers based to a large extent on patristic texts, can be seen in the context of the aftermath of the iconoclastic debate after the restoration of the icons in 843; cf. Laourdas and Westerink (1986-1998).

82 Alexander (1953), 35-66. 
that of collections of questions-and-answers; namely, to accumulate and preserve various aspects of the true dogma as well as vindicate and authenticate doctrines and council decisions. In addition, the approach to older texts is the same, albeit the structure in which citations are represented was different.

In the tenth century, a number of works that were similarly religious in scope, share compositional methodologies and have much in common with earlier collections in terms of content: ${ }^{83}$ the Vita sancti Andreae Sali, ${ }^{84}$ the Synaxarion Ecclesiae Constantinopolitanae, ${ }^{85}$ Theodorus Daphnophates' ${ }^{86}$ and Symeon Metaphrastes' collections of speeches. ${ }^{87}$ All of them are composed on the basis of selections. What differentiates one from another is their format and their function. Daphnophates' and Symeon Metaphrastes' speeches are formed by a series of interconnected citations extracted from John Chrysostom and Basil of Caesarea, respectively ${ }^{88}$ The collections aimed, primarily, at preserving and defending the true gnosis. The eleventh-century Theophylact, archbishop of Ohrid, and Nicetas, bishop of Heraclea, as well as a twelfth-century monk in Constantinople, Euthymius Zigabenus, composed catenae on the New Testament, the text of which became quite popular as shown by the large number of the extant copied manuscripts ${ }^{89}$ It goes without saying that the addition, omission, or alteration of patristic comments are one of the particularly interesting features of Greek New Testament catenae. In fact, very little is known about how different catenae on the various books of the New Testament are related to each other and what distinctive contribution was made by each compiler. Given the vast number of textual witnesses to catenae on the New Testament, it is difficult at this stage of research to arrive at tenable conclusions regarding the issue of whether later catenists tended to abbreviate earlier catenae..$^{90}$ The latter has recently been supported by W. Lamb with regard to the Catena on Mark..$^{91}$ The study of the structure of the earliest catena on Luke, that is, the text transmitted in the eight-century Codex Zacynthius,

83 Upon the prominent role of Christianity in the Byzantine society around those years, see Dragon (2003); Magdalino and Nelson (2010), 1-38.

84 Rydén (1995).

85 The author of the Synaxarion was the deacon and bibliothecarius Evaristus; Sauget (1969), 32. On the relation with the imperial court, see Flusin (2001), 41-47. A. Papadopulos-Kerameus was the first to associate the Synaxarion with the court of Constantine Porphyrogenitus; Ševčenko (1992), 188. On the other hand, H. Delehaye attributes the patronage of the Synaxarion to Leo VI; Delehaye, (ed.) (1902), LVI. On the Synaxarion, see also Rapp (1995), 31-44; Mango (1999), $79-87$.

$86 P G$ 63, coll. 56; cf. Odorico (2011a), 100.

87 PG 32, coll. 1115-1382; $P G$ 34, coll. 821-968.

88 Odorico (2011a), 99-100. On John Chrysostom, see Odorico (2003), 290-291. On the citations taken from Basil of Caesarea, see Rudberg (1964), 100-119 and Kindstrand (1985), 91-111.

89 Theophylact's catenae are printed in $P G$ 123-126. On Nicetas, see Sickenberger (1902). Zigabenus' catena is printed in $P G 129$ and in Kalogeras (1887).

90 A new catalogue of Greek New Testament catenae manuscripts is currently being compiled by Dr. George Parpulov within the framework of the CATENA project at the University of Birmingham, UK. At present, an initial spreadsheet of the catalogue has been released by Parpulov at http:// epapers.bham.ac.uk/3086.

91 Lamb (2012), 64. 
and the examination of certain passages in it, identify several features of compilation practice..$^{92}$ As shown below, the rewriting of the text is involved in all formats through which gatherings of selected texts are given. The extent of adaptation of selected excerpts varied amongst syllogae even of the same sort of texts. The different degrees of changes in terms of language and style as well as the distinct extent of insertions or omissions were contingent on or determined by the educational level of the compiler, his aims, and his target audience. The texts which were gathered and put together in the Synaxarion have been subject to similar linguistic and stylistic alterations. ${ }^{93}$ The entire assemblage is, however, formulated according to the compositional pattern which is perceptible in earlier catenae, gnomologies, or questions-and-answers: a series of selections taken from their original contexts and assembled in a single container, according to a particular ordering principle.

In the twelfth-century Comnenian era, Patristic extracts and passages from earlier florilegia were put together to form theological collections defending

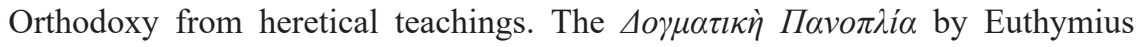

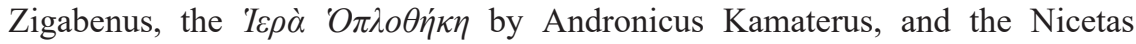
Choniates' $\triangle о \gamma \mu \alpha \tau \iota \kappa \eta े ~ П \alpha v o \pi \lambda i \alpha$ concern contemporary theological debates and appear to have been compiled by learned men seeking political recognition by mirroring the Emperor as the saviour of the true dogma.${ }^{94}$ The same period witnessed the appearance of collections of gnomic statements intending to offer admonitions to members of the imperial family. ${ }^{95}$ The assemblage of passages was determined by the compilers' political and literary aspirations. ${ }^{96}$ There is nothing innovative about the working method applied in these texts. In all these works, passages have been extracted thematically and arranged in the form of a florilegium.

\subsubsection{Chronicles}

A number of chronicles are constructed likewise on the basis of the same technique: passages from different works were singled out and put together to produce a homogeneous text. Thus, certain chronicles were actually syllogae formulated and articulated in a form other than that of florilegia, catenae, and collections of theological questions. Recently, P. Odorico showed that the text found in the codex Parisinus gr. 1336, conventionally called the Commentary on the Hexaemeron, is a universal chronicle designed as a typical product of the culture

92 See the forthcoming Manafis (2020). On the Codex Zacynthius, see also Parker and Birdsall (2004).

93 See n. 85.

94 On Zigabenus' text (ca 1110), see Migne (1865); The initial part of Kamaterus' collection (ca 1174) has been edited in Bucossi (2014); On Choniates' collection (first quarter of the thirteenth century), see the partial edition of Van Dieten (1970). On the political function of these collections during the Comnenian period, see Agapitos, (2020).

95 On these texts, see Agapitos (2020), 13-14.

96 Agapitos (2020). 
of sylloge: a series of citations taken from different works and put together to form a new text. ${ }^{97}$ The method of the anonymous compiler of the chronicle is similar to that of George the Monk. During the second period of iconoclasm, George the Monk compiled his own history, ${ }^{98}$ which is, to a considerable extent, a collection of excerpts mainly taken from patristic texts and put together to form a homogeneous text. The reworking of the excerpts before their insertion into the chronicle is not consistent throughout the whole. The chronicle was intended to provide knowledge for Orthodox readers. ${ }^{99}$ This purpose outweighs the chronological goals of George the Monk's historical narrative. His extracting method is the same as the one applied by florilegia, catenae, question-and-answer works, and collections of speeches. Thus, in George's chronicle nothing was written by George himself.

Theophanes, at the beginning of the ninth century, pursues a similar method in compiling his own chronicle. In the prooemium to his work, Theophanes makes clear his methodological approach to his sources; his chronicle is actually a compilation of selected pieces and nothing is written by the compiler himself.

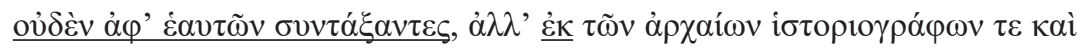

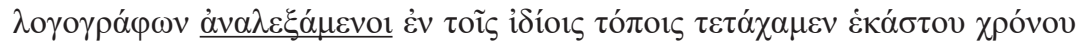

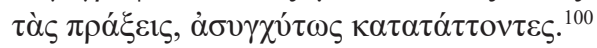

I did not set down anything of my own composition, but have made a selection from the ancient historians and prose writers and have consigned to their proper places the events of every year. ${ }^{101}$

In addition, Symeon Logothetes' chronicle as well as the so-called chronicle of Ps.-Symeon appear to include antiquarian material in a similar manner. ${ }^{102}$ The title transmitted along with Symeon's chronicle is representative of the technique followed by the historian: a series of passages selected and extracted from different chronicles were arranged in a way to form a new chronicle.

97 The text is mistakenly attributed to Eustathius of Antioch; cf. Odorico (2014a). According to P. Odorico, the chronicle includes extracts from Eusebius' Chronicon, Basil of Caesarea's Homiliae in hexaemeron, Athanasius of Alexandria, the Physiologus, Achilles Tatius, Origen, and Flavius Josephus; cf. Odorico (2017).

98 As regards the dating of George the Monk's chronicle, see Afinogenov (1999), 437-447; Afinogenov (2004), 237-246.

99 See n. 9. See also Odorico (2010), 209-2016; Odorico (2011a), 100-101; Odorico (2014a), 380.

100 cf. Theophanes, Chronographia 4, 13-15.

101 Engl. trans. Mango, Scott, and Greatrex (2006), 1-2. P. Odorico interpreted also another passage

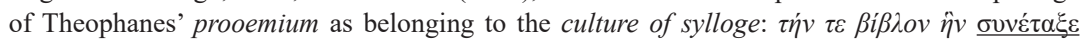

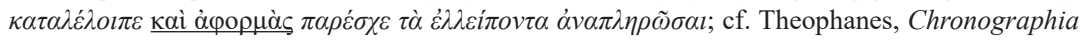
4, 1-2; Odorico (2010), 209-216.

102 On Symeon Logothetes, see Markopoulos (1978); Kazhdan (2006), 167-168; Wahlgren (2006); Treadgold (2013), 211-212. See also n. 206 in Chapter 2. 


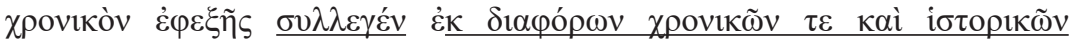
$\dot{\alpha} \rho \chi 0 ́ \mu \varepsilon v o v \dot{\alpha} \pi$ ò A $\delta \alpha \dot{\alpha} \mu{ }^{103}$

a chronicle made of selections from various chronicles and histories put in order beginning from Adam.

Theophanes and Ps.-Symeon's texts were extensively excerpted by George Cedrenus in the eleventh century. ${ }^{104}$ Cedrenus, like Theophanes and Scylitzes, in the preface to his chronicle outlines the method in using his sources.

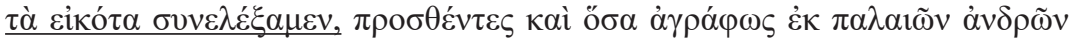

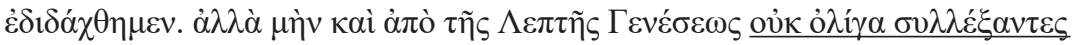

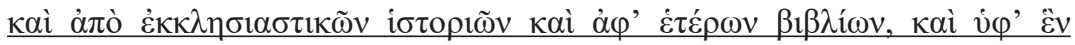

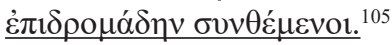

we collected the most reasonable (accounts), and we supplemented them with unwritten (accounts) that we were taught by the old men, we did not collected, however, less from the Lesser Genesis as well as from written ecclesiastical accounts and other books, and we put them together quite quickly.

It turns out that the steps he follows in composing his chronicle correspond to those recorded in the prooemium to the $E C$ : Cedrenus assembled a series of diverse works (chronicles and theological writings), he read them carefully and made a selection of the passages he had interest in. Then, he put the selected pieces in chronological order and augmented them with oral sources. Throughout Cedrenus's work we encounter a considerable number of entries irrelevant to the general narrative having been inserted with the word öt $t .{ }^{106} \mathrm{It}$ is interesting that in contemporary compilations as well in the $E C$ a century earlier and other works attributed to Constantine Porphyrogenitus or other excerpt collections of the same age, such as, the Excerpta Anonymi we detect a similar introductory ö $\tau l$ for entries. The preface also reveals the aim of the arrangement of the excerpts: to facilitate the accessibility to older texts and to refresh the memory of the reader. ${ }^{107}$

103 cf. Symeon Logothetes, Chronicon, 5. On the original title of the work, see Wahlgren (ed.) (2006), esp. 95*-96* and $111 *-114 *$.

104 Bekker (ed.) (1838-1839).

105 cf. Cedrenus, Compendium historiarum, 6. On Scylitzes' preface, see Flusin (2010), xii-xxxiii.

106 cf. Bekker (ed.) I, 12, 15-17, 20-23, 26-28, 321-323, 325-327, 330-333, 563-567; cf. Tartaglia (2007), 239-255; Magdalino (2011), 158-159.

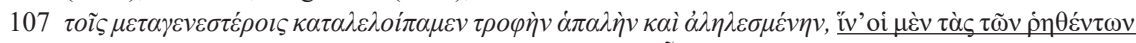

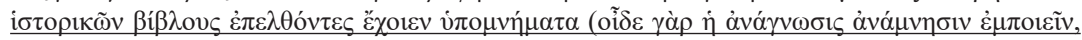

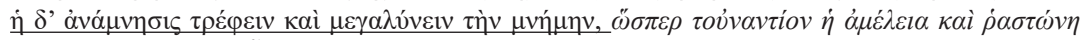

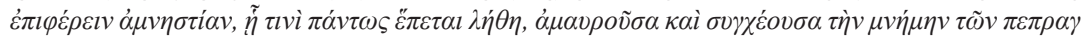

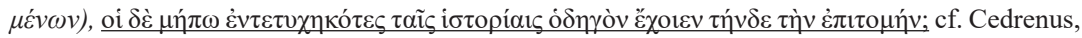
Compendium historiarum, 6. 
Strikingly, the same practical functions are explicitly highlighted in Stobaeus' Anthologium, the Doctrina Patrum, and the EC. ${ }^{108}$

The examples mentioned above reflect syllogae of excerpts presented in the form of a chronicle. Besides the different format of the receptacle, its excerpting and compiling method is the one already seen in the theological writings from the fifth century onwards. Undeniably, the function of a chronicle diverges from that of a florilegium, gnomologium, or catena. Nevertheless, the vocabulary that occurs in the prooemia to these chronicles is congruous with that encountered in the titles and prefaces to religious-in-scope works. The common use of terms in the titles and prefaces points to the same working method behind the composition of these works.

\subsubsection{Condensed 'libraries'}

There is a category of works in which it is impossible to identify all the sources used and, accordingly, the extent to which the sources were re-edited and adapted. Moreover, they are not syllogae of excerpts in the strict sense of the term: a series of citations or longer excerpts put together to form a new entity. P. Odorico considers these texts collectively as bibliothèques miniatures. ${ }^{109}$ These works either represent a series of complete works reworked stylistically or linguistically or they consist of a sequence of summaries of earlier texts. The intervention on the part of the compiler is either more extended or difficult to evaluate. Condensed libraries cannot be deemed encyclopaedias either. Moreover, their practical and political functions run counter to the aim which encyclopaedias serve, namely, the circulation of knowledge. Yet the arrangement of the selected sources in condensed libraries differ from the way seen in florilegia, catenae, collections of theological questions, and certain chronicles. Despite their deviations, we should not prevent ourselves from categorising them within the umbrella term compilation literature. Symeon Metaphrastes' Menologion, for instance, consists of complete texts, which underwent much change in terms of style and language in the course of their transmission. ${ }^{110}$ The very last fact led P. Odorico to be sceptical as to whether Symeon's Menologion is to be viewed in the context of the culture of sylloge. ${ }^{111}$ Yet though its author's working method is similar to that of the collections belonging to the culture of sylloge, the Menologion cannot be considered

108 Odorico (2014a), 375-376.

109 Odorico (2017).

110 Symeon was not without precedent. The first menologia can be traced back to the late eighth and early ninth century when Theodore the Studite compiled a collection of panegyrics on feasts of saints and the future Patriarch Methodius who had compiled a hagiographical collection; cf. Rapp (1995), 32-34. It is likely that Basil the Nothos stands behind the production of the Menologion by Symeon Metaphrastes; cf. Høgel (2002), esp. 70. Moreover, the Menologion by Symeon Metaphrastes provided the basis for subsequent collections of the lives of saints, the so-called Menologia. Concerning the process of redacting of these collections, see Høgel (2002), 88-110.

111 See P. Odorico's scepticism on the nature of these compilations in Odorico (2017). 
as a proper sylloge, on the grounds that it comprises complete texts. As far as the practical function of the Menologion is concerned, it was intended to serve liturgical needs of everyday worship in monasteries and churches.

The kind of texts the condensed libraries preserve varies. In the early sixth century, during a period of religious and dogmatic turmoil, we know that the bishop of Gangra encouraged Theodorus Anagnosta to compile a compilation consisting of the three histories of Socrates (379-440), Sozomen (380-440), and Theodoret of Cyrrhus (393-466). ${ }^{112}$ A conspicuous number of military and legal compilations were executed under the reigns of Basil I (r. 867-886) and Leo VI (r. 886-912). The cultural revival of late antiquity initiated by these two emperors is known as the Macedonian Renaissance. ${ }^{113}$ These compilations inspired the imperial compilation literature during the reign of Constantine Porphyrogenitus. ${ }^{114}$ The legal compilation known as Procheiros Nomos was accomplished during the reign of Basil I. ${ }^{115}$ The Procheiros Nomos consists of 40 titles and was largely dependent on the Justinianic Code as well as on the Ekloge, the selection of laws made under Leo III, the Isaurian. ${ }^{116}$ Leo VI's the Tactika,${ }^{117}$ a treatise on the tactics of war, as well as his two legal compilations, the Basilica ${ }^{118}$ and the Book of the Prefect ${ }^{119}$ should be seen in the context of the compilation literature, as well. They are all compiled of passages taken from earlier works on military matters and imperial law, respectively.

Anthologies and lexica of the middle Byzantine period should be seen in the framework of the condensed libraries, as well. I have already referred to the Palatine Anthologia and the anthologia of Anacreontic poems preserved in Palatinus gr. 23 (Heidelberg). ${ }^{120}$ The Palatine Anthologia also includes a series of excerpts on oracles taken from Herodotus' historical work; the collection of oracles appears to have been produced employing a method identical to the one used in the EC. ${ }^{121}$ The Anthologia Barberiana is another collection of epigrams and

112 Taking into consideration that this was the age in which florilegia flourished, we perceive the essential role of florilegia in the establishment of the culture of sylloge. On the history by Theodorus Anagnosta, see Hansen (ed.) (1995).

113 Lemerle (1971); Treadgold (1984), 75-98; Wilson (1996), 79-147.

114 It has been supported that Basil I and Leo VI relied on the legal projects of Theodosius II (r. 408450) and Justinian (r. 527-565) in terms of ideology, content, and method; Magdalino (1997), 175-176; Magdalino (2011); Németh (2018), 26-28, 171. For a different perspective, see Holmes (2010), 55-80 and Markopoulos (2006), 277-297. On the link between the legal activity of Leo VI and the historiographical projects of Constantine Porphyrogenitus in terms of the ideology of order, law, and dogma, see Pieler (1989), 79-86; Magdalino (1997), 169-182.

115 Zachariä von Lingenthal (ed.) (1837). On the Procheiros, see also Signes Codoñer and Santos (2007), esp. 182-270.

116 Burgmann (ed.) (1988); Schminck (1986), 17-54.

117 Dennis (ed.) (2010); PG 107, coll. 669-1116; Dain and Foucault (1967), 353-363; Haldon (2014).

118 Scheltema and Van Der Wal (edd.) (1955-1988). See also the preface to the Eisagoge in Signes Codoñer and Santos (edd.) 2007.

119 Koder (ed.) (1991).

120 See n. 55 and n. 56.

121 Németh (2018), 202-204. 


\section{Greek compilation literature from Byzantium}

Anacreontic poems compiled shortly after 919. ${ }^{122}$ Palatinus gr. 398 (Heidelberg) from the ninth century and Ambrosianus B 4 sup. dated to the tenth century transmit collections of letters by historical figures. ${ }^{123}$ A significant number of anthologies of historiographical speeches appeared in Byzantium. It would suffice here to refer to the anthology of speeches by John Stobeaus made in the fifth century and to a tenth-century collection on military speeches included in Ambrosianus B 119 sup., ff. 141r-161r, a personal manuscript of Basil the Nothos. ${ }^{124}$ As far as lexica are concerned, the Haimodein Lexicon is basically a collection of entries on rare words. ${ }^{125}$ Passages of the entries were extracted from late antique historians (Procopius, Agathias, Menander, and Theophylact Simocatta). ${ }^{126}$ The method of the culture of sylloge is evident. The compiler of the lexicon retained the basic structure of the selected pieces. The originality of the new entity lies in the sequencing of the passages assumed in the Haimodein Lexicon. The socalled Suda is a lexicographical treatise of the end of the tenth century. ${ }^{127}$ The Suda consists of entries on rare words or terms, on geographical and ethnographical notices, as well as on names of important figures. The entries, arranged in alphabetical order, appear to have been extensively drawn from the $E C$, from late

122 The collection is transmitted in a single manuscript, Vaticanus Barb. gr. 310; Lauxtermann (2003a), 123-128.

123 On Palatinus gr. 398, see Musso (1976), 1-10; Marcotte (2007), esp. 168-169. On Ambrosianus B 4 sup., see Martini and Bassi (1906), 92-94; Laourdas (1951), 370-372.

124 See the recently published book on such anthologies compiled from antiquity to early modern times by Iglesias-Zoido and Pineda (2017). On Stobaeus' anthology, see Hense (ed.) (18941912); Hense (1916). On Ambrosianus B 119 sup., see Mazzucchi (1978); Eramo (2017); Németh (2018), 42-44, 206-209. On the possibility that the excerptor of Ambrosianus B 119 sup. relied on draft copies made in the course of the redaction of the $E C$, see Müller (1882), 26-27; Németh (2010), 175-177; Németh (2018), 207-209.

125 Dyck (ed.) (1995). Dyck dates the lexicon between Photius' Lexicon and 994; cf. Dyck (ed.) (1995), 862-864. A. Németh suggested that the Haimodein Lexicon made use of word lists compiled by the excerptors of the Constantinian collections during the preparation of draft copies of the $E C$; cf. Németh (2010), 33-35.

126 Procopius of Caesarea was the author of four historical texts: the De Bellis consisted of eight books. Books I-II are concerned with the wars against the Persians. Books III-IV deal with the wars against the Vandals, and books V-VIII deal with the wars against the Goths. Book VIII updated the narrative until 553; the Historia Arcana written shortly after Theodora's death; the De aedificiis; and an ecclesiastical history traces of which are found in De Bellis, 8.25.13 and in Historia Arcana, 11.33. Agathias of Myrina's Historiae are dated to the second half of the sixth century. Agathias also wrote series of epigrams, the so-called Cycle and Daphniaka. An epigram identifies Agathias as curator civitatis in Smyrna (Cameron 1970, 2). Menander Protector served as a military officer at the court of the emperor Maurice who reigned from 582 to $602 \mathrm{ad}$. Menander wrote a historical account running from 558 to 582. Theophylact wrote about the wars under the reign of Maurice in eight books. His work survives in only one manuscript, Vaticanus gr. 977. On Procopius in general, see Rubin (1954); Cameron (1996b); Kaldellis (2004); Greatrex (2014). See also the bibliography provided in Section 2.5.2. On Agathias' life and works, see Cameron (1970); Kaldellis (1999); Kaldellis (2003); Schulte (2006); Treadgold (2007), 279-290. On Menander, see Treadgold (2007), 293-299. On Theophylact, see Treadgold (2007), 329-340.

127 Adler (ed.) (1928-1938). See also Lemerle (1971), 297-299; Theodoridis (1993), 184-195; Katsaros (2002); Németh (2010), 35-38. 
antique historians, from the Onomatologos by Hesychius of Miletus, and from various philosophical and grammatical treatises. ${ }^{128}$ According to A. Németh, the Suda was compiled concurrently with the execution of the final deluxe copies of the $E C$. Németh thinks that the compilers of the Suda had access to the final deluxe copies of the $E C$ deposited in the imperial library. The Suda drew directly on the body text of the thematic volumes of the $E C$ as well as on the marginal indices added during the redaction process of the $E C{ }^{129}$

Entries in the Bibliotheca ${ }^{130}$ and the Amphilochia ${ }^{131}$ by Photius (810-891) summarise to a large extent the collected texts. This is why scholars are not disposed to treat Photius' works as wholes made up of collections of selections. ${ }^{132}$ Yet amongst these works, there are big differences. If we look at, say, the Bibliotheca of Photius and the $E C$, we find a very different literary format of a collection of passages: whereas Photius provides summaries of the ancient works he had read, the excerptors working on the $E C$ under the auspices of Constantine Porphyrogenitus preserve the original wording of the texts. The intended audience and the literary structure adopted by the author were the key factors determining such a choice. As shown above, the method of summarising can be well implicated in the creation of collections of selections. Although Photius' works such as his Lexicon, ${ }^{133}$ the Bibliotheca and the Amphilochia are not syllogae in the strict sense of the term, they reflect, to a large extent, the same approach to older texts: the method of collecting, selecting, extracting, and representing of textual pieces. In the Bibliotheca, the treatment of the original texts is not consistent throughout the entire work: the Bibliotheca consists of 280 codices, that is, entries of books that Photius had read and studied; some codices transmit excerpts of the books, while some others contain condensations or summaries of ancient and late antique authors. ${ }^{134}$ In a similar manner, the reworking of the selected pieces is unsteady throughout the Amphilochia. Photius excerpted long passages from a variety of writers; excerpts from John Chrysostom, Polychronius, Germanus of Constantinople, John of Damascus, and Theodoret have passed with

128 On the textual relation between the Suda and the EC, see de Boor (1914-1919), Adler (1931), esp. 701-706; Schreiner (1987); Prandi (1999); Roberto (ed.) (2005b), Ixxxix-ci. A. Németh conjectures the existence of lists of words made during the preparation of the $C E$, which lexica such as the Suda and the Haimodein Lexicon drew on; cf. Németh (2010), 36-38 and 217ff. On the source texts used by the Suda, see Zecchini (1999), 75-88; Adler (1928), xxi-xxii.

129 Németh (2018), esp. 240-249.

130 On the Bibliotheca, see in the edition by Henry and Schamp (edd.) (1959-1991). On the date of the Bibliotheca, see Markopoulos (1987); Kazhdan and Angelidi (2006). On the secular and Christian works read and summarised or excerpted by Photius, see Treadgold (1983), 37-51.

131 Westerink (1986-1998).

132 See Németh (2010), 23-26 and Németh (2018), 178-179.

133 Theodoridis (ed.) (2013). On Photius' literary efforts in general, see Hägg (1975); Treadgold (1983); Hussey (1986); Louth (2006), 206-223.

134 Unlike codices 1-233, the part including codices 234-280 contains more extracted passages than summaries. This led Treadgold to argue that the second part was a later addition to the work; Treadgold (1983), 37-51. 
minor changes, whereas excerpts from Athanasius, Basil, Gregory of Nazianzus, Ps.-Dionysius the Areopagite, and Maximus the Confessor have been subject to greater changes. The fact that the selection of historians in the Bibliotheca coincides to a great extent with that in the $E C$ has led scholars to assume a close relationship between the two projects. ${ }^{135}$ It should be noted that Photius' aims of compiling his Bibliotheca coincide with those of Stobaeus and Constantine Porphyrogenitus when executing the Anthologium and the $E C$, respectively: Photius, like Stobaeus, aimed to help his brother get acquainted with a variety of works, and, like Constantine Porphyrogenitus, intended to accumulate a large number of texts and facilitate those willing to read through them.

Constantine Porphyrogenitus' $D T$ and $D A I$ are manuals on the internal and external policies of the Empire. ${ }^{136}$ His $D C$ is a compilation on imperial ceremonies, ordinations, and festivities. ${ }^{137}$ They are all constructed on the basis of passages extracted from earlier works. ${ }^{138}$ The mentality, that shaped their formation is the same as apparent in other products of the culture of sylloge: the accumulation of a selection of texts, their deconstruction, and representation in a new format. It is quite likely that these compositions were continuously updated, revised, and supplemented with new material until the 960s and under the supervision of Basil the Nothos. ${ }^{139}$ As far as the function of these compilations is concerned, it is determined by the political ideology of the Macedonian dynasty.

135 Markopoulos (2006), 288-289; Treadgold (2013), 161 n.34.

136 On the possible textual relation between the $C E$ and other works compiled on Constantine Porphyrogenitus' commission, see Ševčenko (1992a), 191; Pratsch (1994), esp. 60-71; Németh (2018), 121-144. The DT survives in Vaticanus gr. 1065, ff. 7v-21r (twelfth c.) and Parisinus gr. 854, ff.

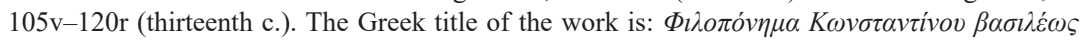

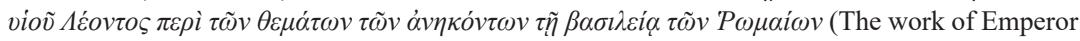
Constantine, the son of Leo on the provinces which belong to the empire of the Romans); Pertusi (ed.) (1952), 48-49; trans. Németh (2018), 125. The DAI, composed in 952, survives in a sin-

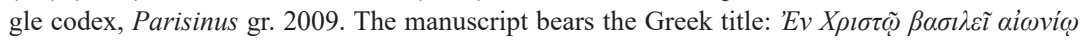

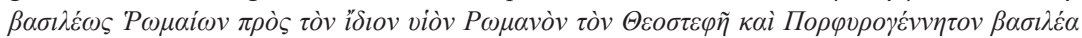
(In Christ the eternal Emperor of the Romans to his son Romanus the Emperor crowned of God born in the Purple); Moravcsik and Jenkins (edd.) (1967), 44-45. On the DAI, see HowardJohnston (2000), 231-236; Magdalino (2013b), 23-42; Németh (2018), 130-137. On Parisinus gr. 2009, see Moravcsik and Jenkins (edd.) (1967), 15-21; Mondrain (2002).

137 The $D C$ consisted of two books and survives in a single manuscript, Lipsiensis Rep. I. 17 (end of the tenth century). On the codex, see Featherstone (2002), 457-479. On the manuscript tradition of the $D C$, see Featherstone (2004), 113-121. On Basil the Nothos, the bastard son of Romanus I Lecapenus, as the final redactor of the $D C$, see Featherstone (2011), 109-116; Featherstone (2013), 353-372.

138 See now the analysis made by Németh (2018), 122-141. Németh shows that their compiler's conceptual approach and his working method are identical to the $E C$. On the working method, see also Sode (2011), 161-176 and Pratsch (1994), 13-136. The DAI includes material taken from archival documents as well as excerpts from Theophanes' Chronographia and Stephanus Byzantius's Ethnica and the $D C$ comprises excerpts from the archives and Peter the Patrician's history; cf. Treadgold (2013), 156. On the proposition that part of the DAI had been compiled under Leo VI, see Howard-Johnston (2000), 304-329.

139 Németh (2018), 36-46; Holmes (2010), 69-72. 
It is noteworthy, that these compilations are all conveyors of Constantine's geographical outlook on the Empire and serve to propagate the emperor's political aims. $^{140}$

As we have seen, barriers in defining what is meant by compilation literature are removed when studying the phenomenon of excerpting, synthesising, and re-editing older material as part of Byzantine written culture, in particular, that of the culture of sylloge. Such a reading would presuppose for scholars to focus primarily on the compositional and organisational structure of collections and on their function within the Byzantine literary, social, and political framework, since the key feature of compilation literature is the variety of forms and literary genres within which it can be encountered. ${ }^{141}$ The works mentioned above expressed and at the same time determined a fashion in terms of literary production during the whole Byzantine period; the chief concern of a writer was to collect writings corresponding to a particular subject matter and to extract information perceived as essential to be preserved. Compilation literature gained a significant importance in the tenth century and especially during Constantine Porphyrogenitus' reign. In fact, what is discernible throughout Constantine Porphyrogenitus' literary efforts is his prominent desire to direct and authorise the historiographical writings as well as the compilation literature of his age. The theme has been treated by P. Magdalino, who compares the three historical writings undertaken under the emperor's auspices. P. Magdalino, however, maintains that these works have unique and distinctive features setting them apart from other compilations. ${ }^{142}$ Yet C. Holmes sees the military compilations produced under Constantine's reign as an effort on the part of the emperor to gain political legitimacy and enhance his political authority. ${ }^{143}$ The aims of such an endeavour on the part of the emperor can be traced in the imperial ideology of the entire Macedonian dynasty, adopted by Constantine Porphyrogenitus and his predecessors to legitimise their rulership. ${ }^{144}$ Basil I, the founder of the Macedonian dynasty was of Armenian descent and a peasant by his birth. He usurped the throne after murdering first Bardas, the emperor's Caesar and soon afterwards the emperor himself, Michael III. On the other hand, Constantine Porphyrogenitus considered the revival of knowledge, arts, and sciences as vital to the growth of Byzantium and also as part and parcel of his imperial duties to strengthen the administration of the state. ${ }^{145}$ In the next chapter, I shall set out the steps according to which the original texts were employed by the compilers before they were embedded into the collections.

140 See especially Magdalino (2013b); Magdalino (2013c), and Section 2.5.2 of this book.

141 See also Holmes (2010), 55-80.

142 Magdalino (2013c), esp. 201-205.

143 Holmes (2010), 55-80.

144 For the political history of the age, see Treadgold (1997), esp. 453-455. On the ideology of the Macedonian dynasty, see also Markopoulos (1994), 159-166 and Markopoulos (2006), 286-292.

145 cf. Theophanes Continuatus, ed. Bekker (1838), 445-446. 


\subsection{The working method of excerptors of historical texts}

This section scrutinises the methodological principles underlying the compilation process of a sylloge of historical excerpts. In the following pages, I examine how an excerpt collection was redacted. In particular, I shall set out the steps according to which the original texts were employed by the compilers before they were embedded into the collections. In studying the working process followed in collections of historical excerpts I shall rely a) on the prooemium of the $E C$ as well as the content of the collections that are studied in this book, and b) on external sources providing information on the creation of similar Byzantine literary works.

The prooemium of the $E C$ reveals to a considerable extent the method and criteria used for this enterprise. The prooemium was appended to the beginning of the EL (codex Scorialensis B.I.4) and EV (codex Turonensis 980) but it preceded each book of the $E C .{ }^{146}$ An iambic poem dedicated to Constantine Porphyrogenitus came immediately after the prooemium in the codex Turonensis 980 transmitting the $E V{ }^{147}$ The folio transmitting the prooemium, the table of contents, and the poem in Turonensis 980 is now lost. The proem and the prooemium are known to us through transcriptions from the seventeenth century. ${ }^{148}$ The other excerpt collections scrutinised in this book are not accompanied by any such prooemium. Nevertheless, their compilers, occasionally, break the concatenation of excerpts by inserting in the collection material of their own. The new insertions are bridging passages introduced in order to enhance the narrative sequence of the excerpts. Upon careful examination, the augmented texts shed light on the excerpting method and selection criteria of the excerpt collections. In what follows, I examine the extent to which information furnished by the prooemium of the $E C$ could help us get a better understanding of the structure and method of the four collections of excerpts examined in this book.

Secondly, external information derived from contemporary works shall help us to determine the various steps of the working process and to explore whether or not this working method corresponds to a pattern of compilation of excerpts before, during, or after the reign of the Macedonian dynasty. It is worth comparing the prooemium of the EC to the encomium on Symeon Metaphrastes written by Michael Psellos and referred to the working method of Symeon, probably concerning a theological work of Symeon commissioned by an emperor,

146 On the prooemium, see Lemerle (1971), 281-282; Flusin (2002), 538-549; Odorico (2017); Németh (2018), 60-71. For a French translation of the prooemium, see Lemerle (1965), 605; Odorico (2017). For an English translation of the prooemium, see Németh (2018), 61-62.

147 A. Németh provides an edition of the iambic poem dedicated to Constantine Porphyrogenitus in the codex Turonensis 980; cf. Németh (2018), 268-269.

148 Henri de Valois (1634), 2-7 edited them based heavily on the edition of EL by Hoeschel (1603) and the edition of Polybius by Casaubon (1634). The poem as it was found in Turonensis 980 was copied also by C. Salmasius in a manuscript (Parisinus gr. 2550, f. 120r) in 1631/32; cf. BüttnerWobst (1905), 756-757. The Scorialensis B.I.4 (EL) had been deposited in the Escorial Library and it was destroyed in a fire in 1671. From this manuscript there is a significant number of copies made in the sixteenth century. On the codex, see below n. 109 in chapter 2. 
presumably by Constantine Porphyrogenitus. ${ }^{149}$ Finally, Photius' judgement on John Stobaeus' Anthologium ${ }^{150}$ written some centuries earlier and the preface to John Damascenus' Sacra parallela ${ }^{151}$ provide significant information on the creation of excerpt collections. The external sources chosen represent compositions each of which relies on texts of different literary genres. This book advances the hypothesis that such texts were the product of a common approach to older texts in Byzantium. They are all rooted in a late antique approach as regards the transmission of knowledge to succeeding ages by embedding the classical texts into the new social, political, or theological context.

Three steps and procedures may be identified in the process of redacting a sylloge of historical excerpts: (1) The text in question was read through to the end before being chosen for the collection. Long or brief passages were selected from a certain text and then copied word by word. (2) The passage was then rephrased, amended, and shortened. These altered versions of the passages were then copied and assembled in a new codex. (3) A new narrative was composed.

\subsubsection{Selection}

Certain passages were selected and extracted from their original environment. The selected passages were drawn from their original context and copied word by word before being edited and adopted into the collection. The procedure also emerged from the prooemium of the EC and Psellos' encomium of Symeon Metaphrastes. Both texts yield significant information on the working method of the excerptors and reveal aspects of a seemingly common pattern of compilation of excerpts during the Macedonian dynasty. After presenting the motives and purposes of the collection, the prooemium goes on to discuss the working process:

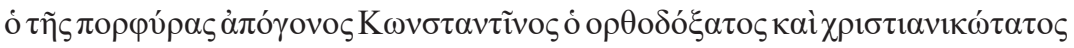

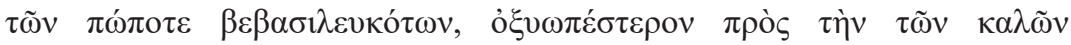

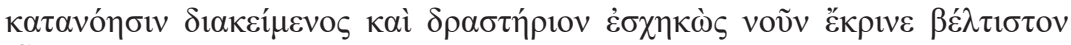

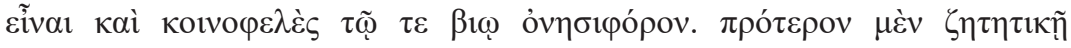

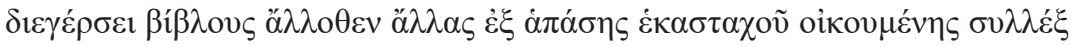

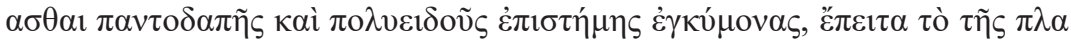

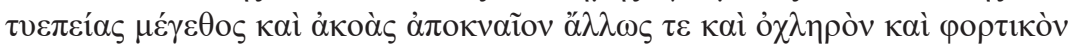

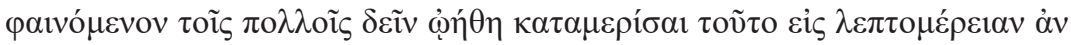

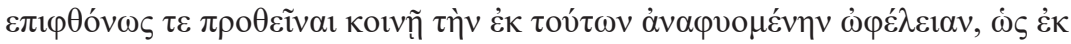

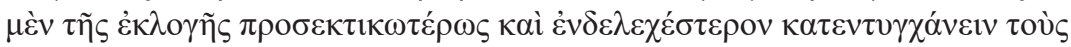

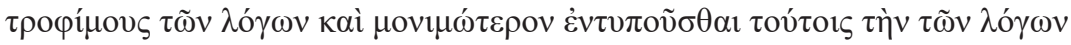

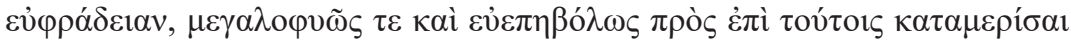

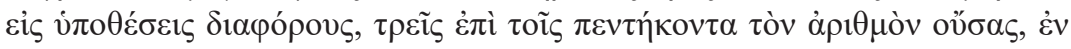

149 Kurtz and Drexl (ed.) (1936), 94-107; Fischer (ed.) (1994), 269-288.

150 Bibliotheca, cod. 167.

151 On the Sacra Parallela, see n. 75. 


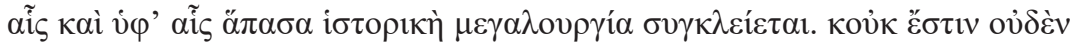

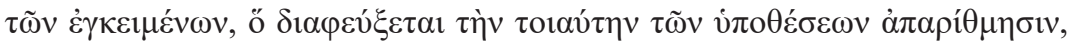

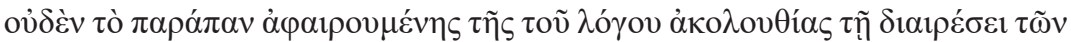

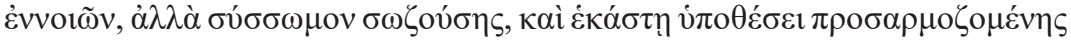

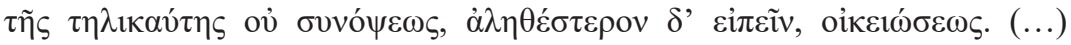

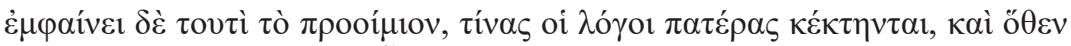

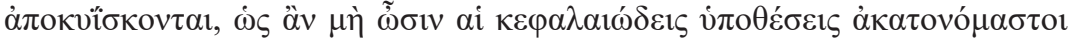

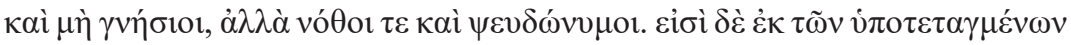

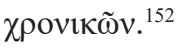

So it is that Constantine, born in the purple, that most orthodox and most Christian of emperors up to the present time, fitted to the task by extremely keen discernment regarding what is good and possessing an enterprising intellect, judged that the best thing, the most conducive to the common good and useful for governing conduct is - in the first place - to collect by means of diligent research all manner of books from all over the known world, books teeming with every kind and variety of knowledge. Next, he thought it necessary to divide and distribute their great quantity and extent, which weigh heavily on the understanding and seem too many to be irksome and burdensome, into small sections. Hence, the profit of this fertile material could $<$ he thought $>$ be made available unstintingly to common use, so that, by the virtue of selection, they might find more carefully and persistently the nourishment of texts, while the beauty of the texts could be more permanently impressed upon them. In addition, $<$ his intention was $>$ to distribute [the material] in an ingenious and careful manner into principal topics, fifty-three in number, in and through which all the great achievements of history might be grouped together. Nothing contained in the texts will escape this distribution into topics; $<$ since $>$ by the division of the content this procedure omits nothing of the continuous narration, but rather preserves it in a corpus and establishes the correspondence with each topic, it is not a summary but, to speak more properly, an appropriation. (...) this proem states from which author each of the texts was conceived and whose labour brought them forth, so that principal topics may not be, as if were, anonymous and illegitimate, indeed like bastard children bearing a stranger's name. ${ }^{153}$

Throughout the prooemium we detect the importance of the selection ( $\dot{\varepsilon} \kappa \lambda$ 윌) described above as the basic procedure in the redaction. The selection was determined by the aims of the collection. Accordingly, compilation literature is to be found in a variety of disciplinary fields and there have been historiographical and military collections, florilegia, collections of patristic quotations, philosophical collections and the so-called chreiai and gnomai that were collections of anecdotes

152 EL, 1-2; Németh (2010), 184-186; Németh (2018), 267-268.

153 Németh (2018), 61-62. A French translation of the prooemium is provided in Lemerle (1971), 281-282. 
(see Section 1.2). The identification of the different authorities assembled into a single text appear to be significant for the compilers. ${ }^{154}$ The end of the prooemium to the $E C$ is revealing:

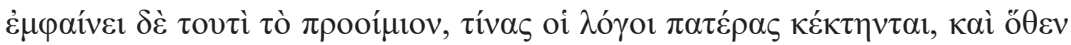

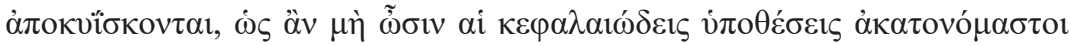

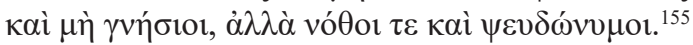

As we shall see, the Excerpta Anonymi indicate the source of the passages (see Section 2.2.2), the series of excerpts in the Excerpta Salmasiana is transmitted

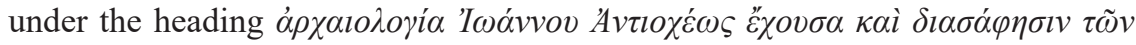
$\mu v \theta \varepsilon v o \mu \varepsilon ́ v \omega v$ (see Section 3.2), and the so-called Epitome transmits its material under headings indicating the author from which the passages were taken (see Section 4.2). The first part of the Epitome contains excerpts from the ten books of Eusebius' $H E$. At the beginning of each book the same sentence is repeated to

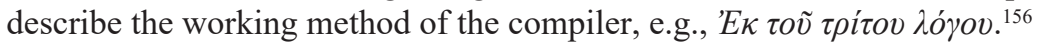

The selection of the texts that were appropriate for the purposes of a collection was also guided by the need to facilitate the reader interested in a specific topic

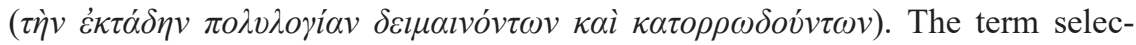
tion is repeated twice in the prooemium ( $\sigma 0 \lambda \lambda \dot{\varepsilon} \xi \alpha \sigma \theta \alpha l$, $\dot{\varepsilon} \kappa \lambda \sigma \gamma \tilde{\eta} \varsigma)$. The excerptors of the $E C$ were first commissioned to select historical texts concerning the 53 subjects of the collection, before proceeding to create excerpts from them. Each excerptor was requested to split up the entire work of an author into short excerpts according to certain subject matters. The division of the original text required the careful selection of relevant passages. That procedure was followed by the

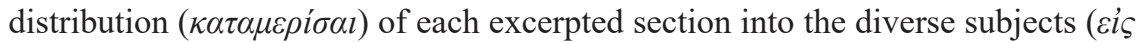

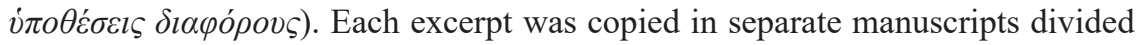
thematically.

According to A. Németh, the excerptors of the $E C$ have first created copies of the complete works of the historians to be excerpted. ${ }^{157}$ It should be noted that the fragmented nature of the $E C$ prevents us from drawing definite conclusions on the matter. I am leaning toward arguing in favour of P. Odorico's argument, which supports that it was only the selected passages on a certain topic that were copied verbatim. ${ }^{158}$ We shall see that the structure itself of the selected pieces in the syllogae examined in the various chapters of this book verifies that the compiler read

154 It is noteworthy that the majority of florilegia and catenae identify the author of the excerpted passages too. To give but one example, see the catena on Luke transmitted in the so-called Codex Zacynthius dated to 700; Manafis (2020). See also the forthcoming edition of the catena text in Houghton, Manafis, and Myshrall (edd.), (2020). The same occurs in the earliest recension of the Hippiatrica; cf. McCabe (2007), esp. 262-269.

155 EL, 2; Németh (2018), 268.

156 See Appendix I: Text IV.

157 Németh (2010), 242-245; Németh (2018), esp. 59-70.

158 Odorico (2017), 23-42. 
and employed selected texts, having first copied them word by word. The compiler would read the relevant passage through to the end annotating it thoroughly. This procedure permitted him to combine disparate details and go on to the next step later, which was to edit the original text. That allowed him also to rearrange the material when he thought that the meaning was not clear enough or when he wanted to give a new meaning to a certain text passage.

The other external source providing information on the working methods of Byzantine text composition is the encomium of Symeon Metaphrastes written by Michael Psellos. At the end of his encomium, Psellos discusses the composition of Symeon's Menologion:

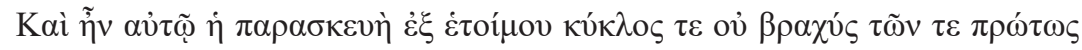

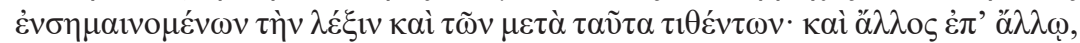

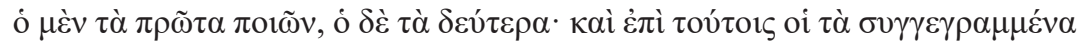

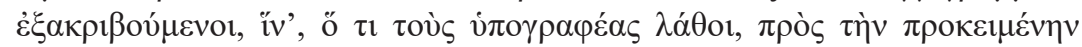

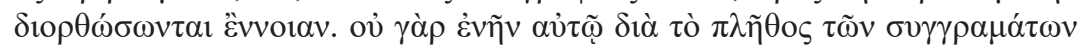

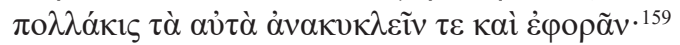

And he (Symeon Metaphrastes) had a preparation at hand and not too small group (of assistants); those who first selected the passage and those who, after this, wrote it (the passage) down. One man after the other, one doing the first task, the other the second one; and in addition to these people, (there were) others that revised the passages written down, so as to make corrections of mistakes that had escaped the notice of the amanuenses, according to their intended meaning. ${ }^{160}$

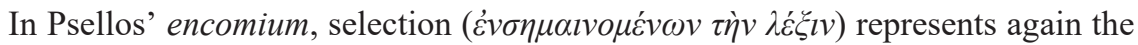
second step in the redaction. Psellos refers to a group of redactors who worked together under supervision. ${ }^{161}$ Some members of this group selected the passages to be extracted and some others, the copyists, wrote them down ( $\tau \alpha \tilde{v} \tau \alpha \tau \imath \theta \varepsilon \dot{v} \tau \omega v)$. In the end, other members of the group verified or revised the work of the amanuenses ( $\tau \dot{\alpha} \sigma v \gamma \gamma \varepsilon \gamma \rho \alpha \mu \mu \dot{v} v \alpha \dot{\varepsilon} \xi \alpha \kappa \rho \imath \beta o v ́ \mu \varepsilon v o l)$.

C. Høgel, in discussing the same passage in his book on Symeon Metaphrastes,

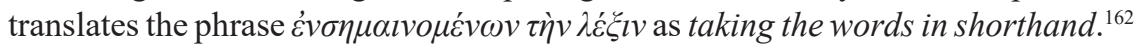

159 Michaelis Pselli, 105, 19-26.

160 See also the English translation by Høgel (2002), 93. P. Odorico offers an Italian translation of the passage in Odorico (1990), 10. See also the French translation of the passage by Flusin and Paramelle (1984), 22-23.

161 The working process manifested through the prooemium of the $E C$ and the nature itself of the enterprise (including works of at least twenty-six historiographers divided thematically) presupposed the collaboration of a great number of employees. Psellos, as it has already been noticed, in his encomium refers to Symeon Metaphrastes' enterprise, a tenth-century collection of saints' lives.

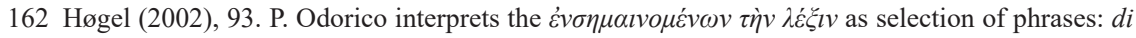
coloro che segnalavano dapprimma l'espressione; cf. Odorico (1990), 10. 
In his view, Psellos states at this point that the original text was taken down in shorthand before being copied into normal script. This preposition leads him to surmise that the original text was rephrased and reformulated orally before being dictated by Symeon or someone else to the copyists. ${ }^{163}$ First, I would like to point

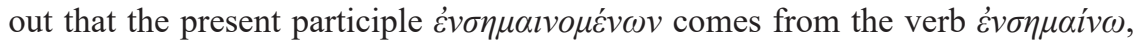
which means report, signal, give sign of, intimate, or impress. ${ }^{164}$ Therefore, the meaning of the term alludes to the activity of selection rather than to that of forming shorthand. C. Høgel is likely to have ended up translating it differently because of the word $\tau \grave{\eta} v \lambda \varepsilon^{\varepsilon} \xi l v$ that follows the participle. The term $\lambda \dot{\varepsilon} \xi l \varsigma$ means a single word or phrase and C. Høgel translated that way. However, $\lambda \dot{\varepsilon} \xi l \varsigma$ can also mean the text of an author ${ }^{165}$ and the phrase $\dot{\varepsilon} v \sigma \eta \mu \alpha l v o \mu \varepsilon \dot{v} \omega \omega v \tau \grave{\eta} v \lambda \dot{\varepsilon} \xi l v$ in Psellos' text corresponds to the selection of the passages to be extracted. Nevertheless, Høgel's assertion of the oral reformulation as the most important part in the working process of the Menologion is not baseless, especially when we turn our attention to the kind of differences detected between Symeon's version of saints' lives and their old ones. ${ }^{166}$ Psellos, however, does not verify Høgel's assumption at this point and I shall return to this in what follows when discussing the second step of the redaction.

\subsubsection{Editing}

During the second step of redaction, the text was employed, modified, or shortened for the purpose of copying. It should be noted that evidence in the extant copies of the $E C$ suggest that the procedure relied on the annotations made during the previous step: editorial comments or symbols in the margins pointing to the classification of passages in the 53 collections of the $E C$ have passed on to the final copies of the work. Quite often a shortened version of each of the selected passages was created and copied. The editing of the material was based on certain general criteria as well as on individual ones.

Concerning the issues of similarities in the sequencing and the transferal of details, we detect that collections of historical excerpts remain faithful to the original texts and at several points they copy the source texts word by word. Such an approach is in line with a statement found in the prooemium of the $E C$ :

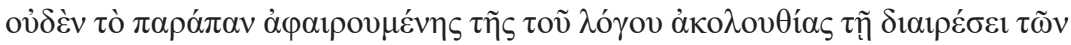

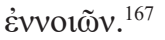

163 Høgel (2002), 94-96.

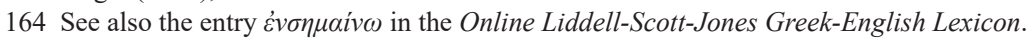

165 Asp.in EN122.27, Arr.Epict.3.21.7, Dam.Pr.165, 169; cf. The Online Liddell-Scott-Jones GreekEnglish Lexicon, http://stephanus.tlg.uci.edu/lsj/\#eid=64422\&context=lsj\&action=from-search.

166 Høgel (2002).

167 EL, 2; Németh (2018), 268. 


\section{Greek compilation literature from Byzantium}

The prooemium of the $E C$ enables us to identify the principles which a compiler adheres to when editing a certain text:

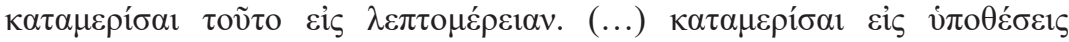

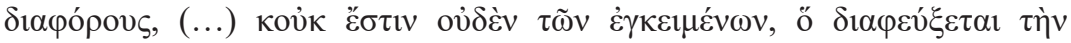

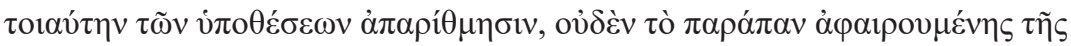

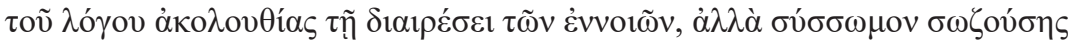

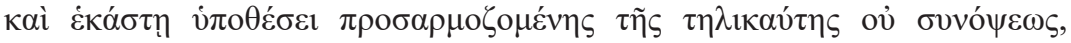

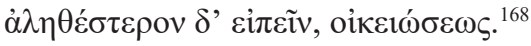

The text supplies us with a fuller picture about the requirements which compilers insisted on. The prooemium repeats the necessity of precision and narrative

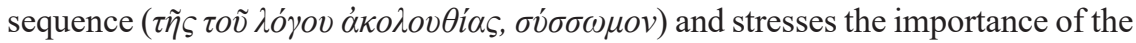
compositional and organisational structure of a collection as the term $\kappa \alpha \tau \alpha \mu \varepsilon \rho i \sigma \alpha l$ is frequently used throughout the prooemium.

In a passage from the Excerpta Anonymi, the compiler himself reveals significant information about his own criteria synthesising his material. The passage is

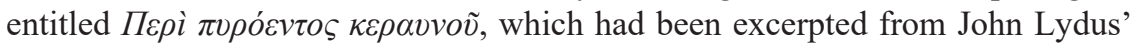
De Ostentis. The compiler of the Excerpta Anonymi intervenes three times adding personal comments: he inserts a personal statement at the beginning of the excerpt, a linking phrase in the middle of the excerpt, and a second personal statement at the end of it. All of the interventions were integrated into the original passage in order to justify the compiler's decision to insert a certain excerpt precisely at a specific point into the collection. The three statements are the following:

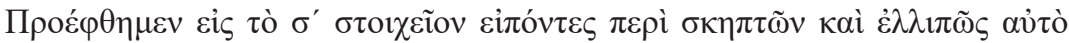

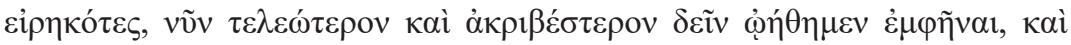

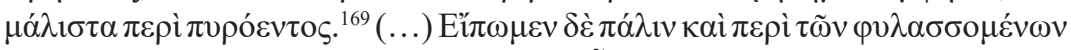

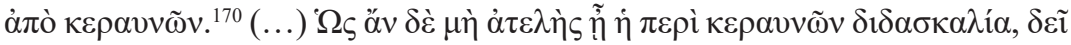

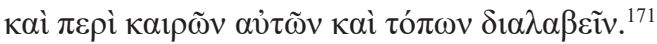

We anticipated the eighteenth element by speaking of thunderbolts and as we have spoken of them inadequately, we considered it necessary for them (the thunderbolts) to be presented entirely and more precisely, and above all (to speak of) the fiery ones. (...) We spoke in turn of what avoids thunderbolts (...) So that the elucidation of thunderbolts will not be incomplete, the seasons and the places (concerning thunderbolts) need to be treated.

It is noticeable that the chapter begins with the author's statement that the previous chapter, entitled $\Pi \varepsilon \rho i \sigma \kappa \eta \pi \tau \tilde{\omega} v$, had opened a new section in the collection 


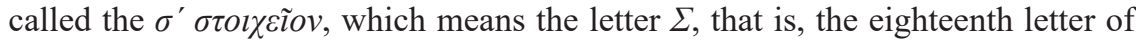

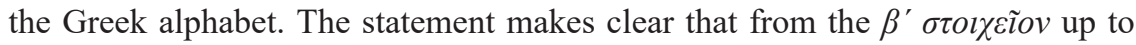
that point there had also been another fifteen $\sigma \tau o l \chi \varepsilon i \tilde{\alpha}$. From this, it can be inferred that the compiler had first divided the collection thematically and then decided to synthesise and present the material by arranging it in alphabetical order; a methodological approach which corresponds to the one evident throughout the prooemium of the $E C$ : the excerptors working under Constantine's supervision had to

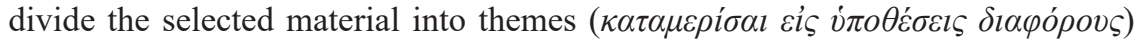

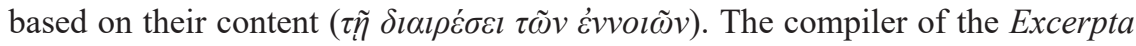
Anonymi professes that in order to make things clearer, despite his narrative having reached the eighteenth section - which the letter $\sigma^{\prime}$ implies - he needed to include a chapter, even if this did not follow the intended alphabetical order. The compiler's statement, at this point, also contains a phrase which reveals his strive

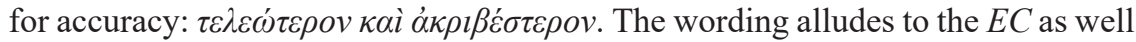
as to Symeon Metaphrastes' claims in the prefaces to the Vita Sancti Symeonis Stylitae and the Vita Sancti Sampsonis Xenodochi. ${ }^{172}$

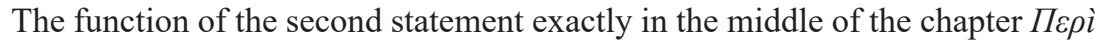

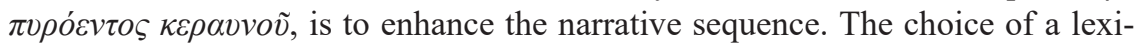
cal verb $(\varepsilon i \pi \omega \mu \varepsilon v)$ turns the compiler into an author and the first-person plural, instead of the first person singular one, gives a sense of immediacy to the text.

In the last paragraph of the same chapter, the compiler stresses, once again, the importance of clarifying what he is writing down ( $\Omega_{\varsigma} \ddot{\alpha} v \delta \dot{\varepsilon} \mu \grave{\eta} \dot{\alpha} \tau \varepsilon \lambda \dot{\eta} \varsigma \tilde{\eta} \dot{\eta} \pi \varepsilon \rho \grave{i}$ $\kappa \varepsilon \rho \alpha v v \tilde{\omega} v \underline{\delta l \delta \alpha \sigma \kappa \alpha \lambda i \alpha})$. The word $\delta i \delta \alpha \sigma \kappa \alpha \lambda i \alpha$ ascertains his aim of creating a collection for practical as well as didactical purposes. It is worth noting that when the prooemium of the $E C$ explains the motives of the project, it refers to practical and didactical aims:

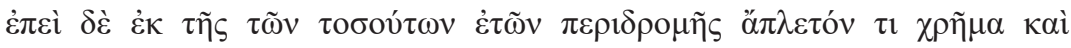

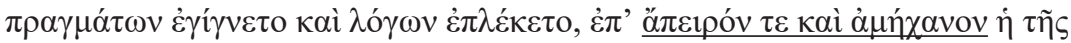

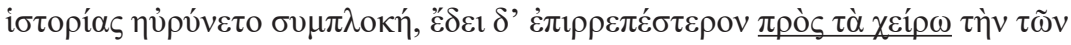

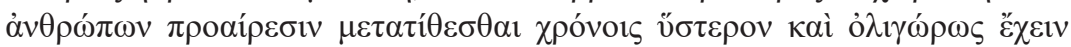

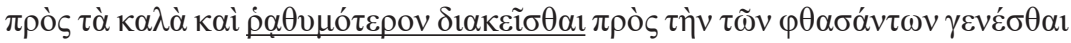

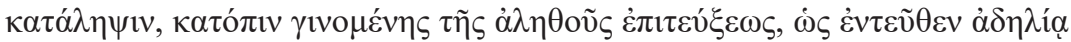

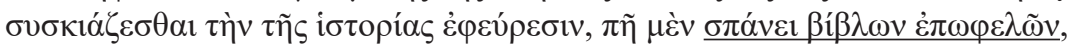

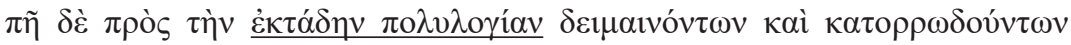

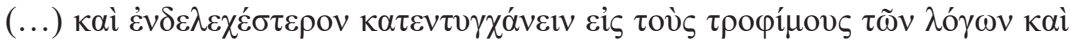

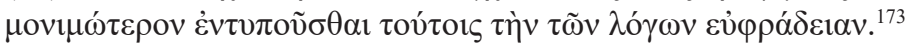

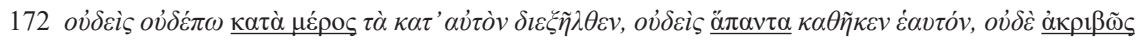

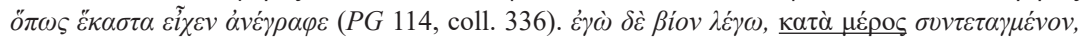

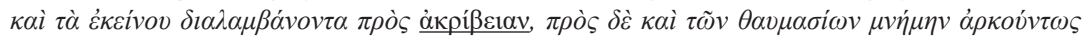

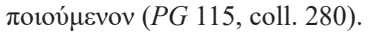

$173 E L, 1-2$. Németh (2018), 267-268. 
According to the prooemium, people at that time were prone to making the wrong choices ( $\pi \rho \grave{\varsigma} \varsigma \tau \grave{\alpha} \chi \varepsilon \dot{\varepsilon} \rho \omega)$ because they were unable to learn the lessons of the past

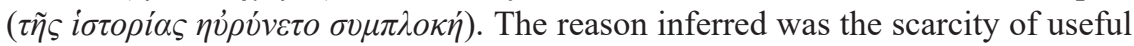

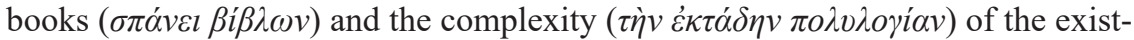
ing ones. Consequently, the creation of a collection of the most important historiographical works could alleviate the problem of the lack of books and would facilitate readers' access to them. The content of the collection could also provide the readers with historical exempla and help them to cope with similar cases in the future. ${ }^{174}$ The last sentence of the aforementioned passage recalls Photius' comment on the didactical usefulness of Stobaeus' Anthologium in his Bibliotheca. ${ }^{175}$

A similar attitude can be also detected in another chapter in the Excerpta Anonymi indicated only by the letter $\gamma$ :

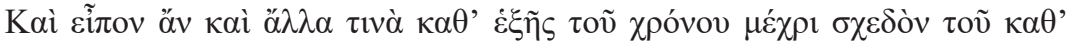

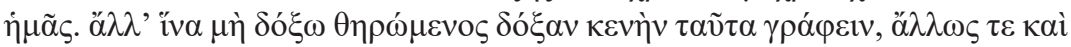

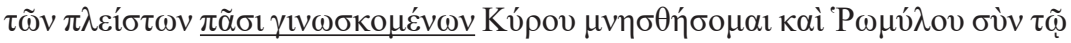

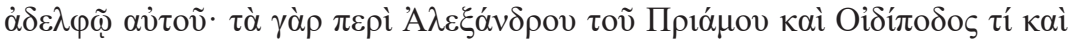

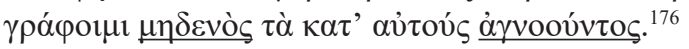

I could say even more of such things, one after another, up to our time, but in order not to be considered that I write about these things seeking vainglorious reputation, and because most of these things are known to all, I will mention Cyrus as well as Romulus and his brother. However, wherefore to write about Alexander, the son of Priam and about Oedipus, since everyone is acquainted with their stories.

The entire paragraph constitutes an addition by the compiler himself. He states that he could say even more about the subject matter he deals with (occult science and astrologers predicting the future) but he will not do so as he does not want to be deemed arrogant and all knowing ( $\theta \eta \rho \omega ́ \mu \varepsilon v o \varsigma \delta o ́ \xi \alpha v \kappa \varepsilon v \eta \dot{v})$. Besides that, most of the incidents concerning predictions of death and occult science are well known $(\pi \tilde{\alpha} \sigma l \gamma l v \omega \sigma \kappa o \mu \varepsilon \dot{v} \omega v)$. Next, he informs his reader of his intention to narrate a

174 It has to be pointed out that in the De administrando imperio, Constantine VII addressing his son, emphasises a similar aim for this work: 'for it is worthwhile, my dearest son, that a record of these things also should not escape you, in order that, should the same things come about on similar occasions, you may by foreknowledge find a ready remedy'; cf. DAI, 46.166-169.

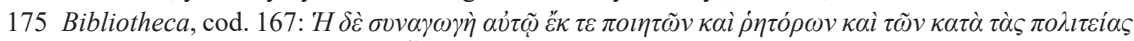

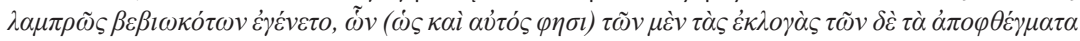

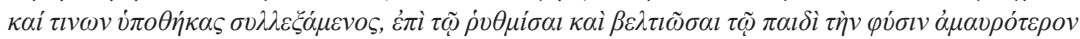

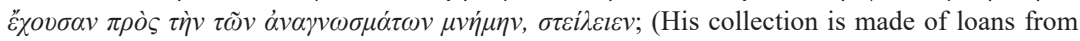
poets, speakers and the famous politicians. He joined together, he says, in some cases a selection of pieces, in others some sentences and elsewhere some precepts of life to discipline and improve in his son, in communicating to him, a naturally slight gift for memorising readings); transl. Freese (1920), cod. 167. On the passage, see Odorico (1990), 15-16.

176 Excerpta Anonymi, 32, 28-33. 
story related to Cyrus and a story concerning Romulus and Remus while leaving out excerpts on Alexander the son of Priam and on Oedipus. The reason he gives for his choice is that all people were acquainted with the last two ( $\mu \eta \delta \varepsilon v \grave{s} \tau \tau \dot{\alpha} \kappa \alpha \tau$,

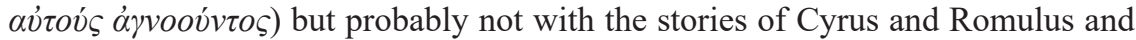
Remus. Consequently, the passage highlights yet again the practical requirements in excerpting and the Excerpta Anonymi compiler here stresses the practical and didactic aims of his collection. What emerges here is the usefulness of a text in facilitating the accumulation of knowledge. Similar preoccupations are explicitly claimed in other works produced by processes of compilation. ${ }^{177}$ In Byzantine compilations, what matters is the selection of relevant passages to be represented and in particular in the case of the Excerpta Anonymi, it is the arrangement of material in alphabetical order which facilitates the reader interested in geography and occult science. ${ }^{178}$

As P. Lemerle first noticed, the prooemium of the Geoponica, ${ }^{179}$ a twentyvolume collection of agricultural lore compiled during the tenth century on the commission of Constantine Porphyrogenitus, bears a resemblance to the $E C$ when referring to the practical use of the collection: ${ }^{180}$

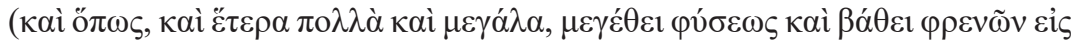

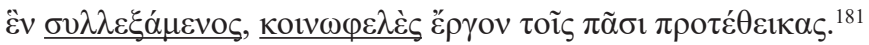

and similar to the way, as happens with many other and great things, the magnitude of the character and the depth of the mind are collected in one unity, a work of common utility has been put forward.

The term $\dot{\omega} \varphi c^{\prime} \varepsilon \varepsilon l \alpha$ is also encountered in the preface to the Tactika of Leo VI written some decades earlier:

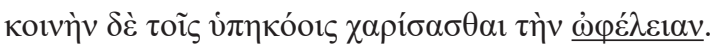

to graciously bestow a common benefit upon our subjects. ${ }^{182}$

In the preface to Sacra parallela, a sylloge of patristic quotations, John of Damascus refers to the motives of his work:

177 The matter has repeatedly been treated by P. Odorico in several articles. Similar didactical claims

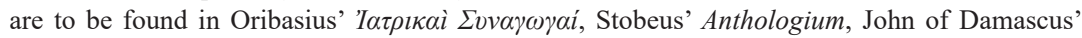
Sacra Parallela, and Doctrina Patrum de Incarnatione; cf. Odorico (1990); Odorico (2017). See also McCabe (2007), 62. The same holds true for a number of military manuals compiled through processes of compilation, such as the tenth-century Parangelmata Poliorcetica; Sullivan (2000).

178 On the function of Byzantine literature, see Cavallo and Odorico (2006). On the practical function of texts produced by processes of compilation, see Odorico (2017).

179 Beckh (ed.) (1895).

180 Lemerle (1971), 289.

181 Geoponica, 2.

182 Dennis (ed.) (2010), 6. 


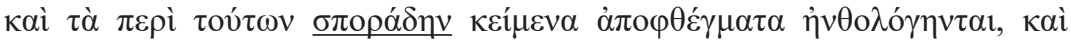

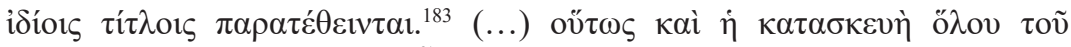

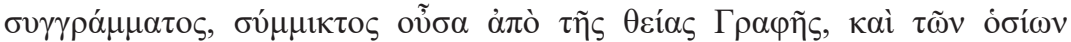

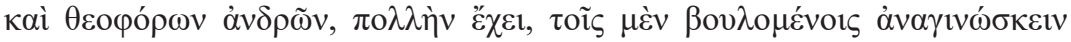

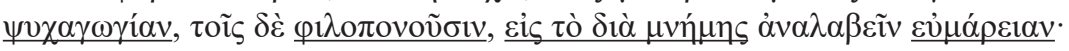

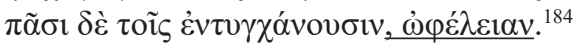

and the scattered sayings about them have been collected and supplied with their own titles (...) thus, the compilation of the whole book, consisted of passages from the Holy Scriptures and the works of saints as well as those inspired by God, on the one hand offers pleasure to those who desire to read, and, on the other, facilitation by learning through memory to those who love the study (of the Fathers).

The word $\sigma \pi \circ \rho \alpha \dot{\alpha} \eta v$ alludes to the scarcity of books described in the prooemium of the EC. According to John of Damascus, the Sacra parallela is a collection of texts which was meant to facilitate ( $\varepsilon \dot{v} \mu \alpha \dot{\alpha} \rho \varepsilon \alpha v)$ the study of the Fathers of the

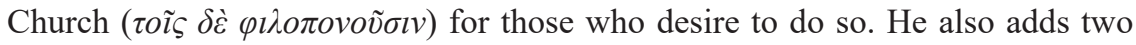
more purposes for his enterprise: pleasure ( $\psi v \chi \alpha \gamma \omega \gamma i \alpha v)$ and teaching through memory ( $\delta i \grave{\alpha} \mu v \eta \dot{\eta} \mu \eta \varsigma \dot{\alpha} v \alpha \lambda \alpha \beta \varepsilon \tilde{\varepsilon} v)$. The passage above also bears a striking resemblance to a remark made by Photius in the Bibliotheca about John Stobaeus' Anthologium. There Photius' judgement yields significant information as to the requirements John Stobaeus intended to meet by creating his Anthologium: ${ }^{185}$

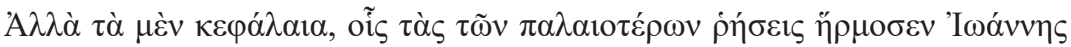

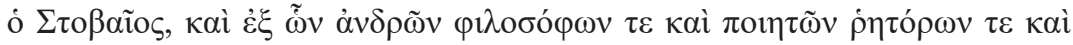

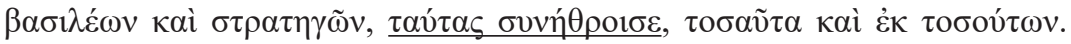

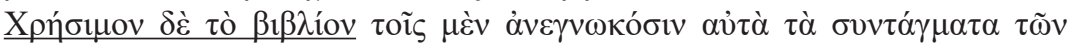

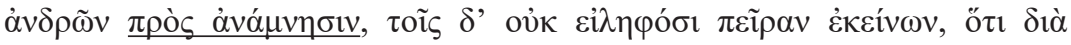

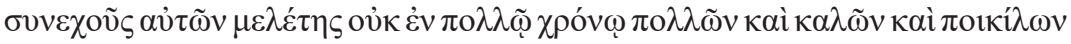

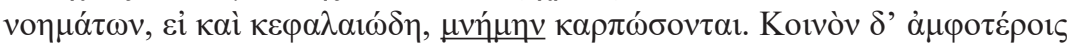

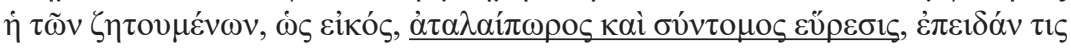

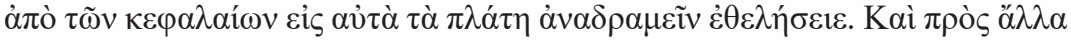

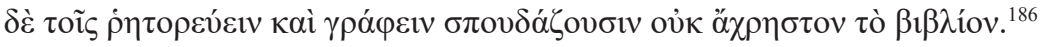

But such is thus the number of the chapters in which John Stobaeus classified the words of earlier authors and the number of writers, philosophers, poets, orators, kings, and generals from which he borrowed to make his collection. This book is of obvious utility to those who read the works of these

183 Lequien (ed.) 1712, 279; $P G$ 95, coll. 1041.

184 Lequien (ed.) 1712, 279; $P G$ 95, coll. 1044.

185 Photius when giving a summary of the fourth-century collection of historical writings by Sopater,

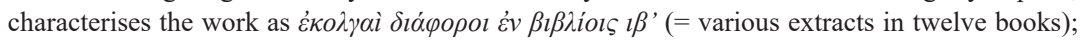
cf. Bibliotheca, cod. 161.

186 Bibliotheca, cod. 167. 
writers; it will help their memory and will be useful to those who have not approached them yet because, thanks to a constant exercise, they will be able in a little time to acquire a summary knowledge of many beautiful and varied thoughts. Both categories will have the advantage, naturally, of being able to find without pain or waste of time what is sought if one wants to pass from these chapters to complete works. Moreover, for those who want to speak and write, this book is not without utility. ${ }^{187}$

It is noteworthy that Photius in commenting on the usefulness of the anthology

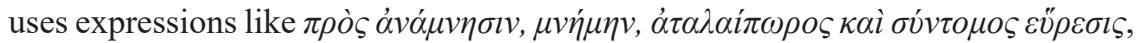
which are terms very close in meaning to those that occurred in the Sacra parallela. According to Photius, John Stobaeus' Anthologium is well worth consulting $(\chi \rho \dot{\sigma} \sigma l \mu o v \delta \dot{\varepsilon} \tau \dot{o} \beta \imath \beta \lambda i ́ v)$ because its structure allows the reader - as in the case of the EC and the Sacra parallela - to go through the content easily and quickly

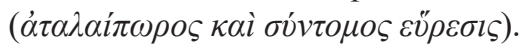

Intentions and desires to simplify complex material and make it more acceptable and pleasant are also found in the preface to the manual of siege craft Parangelmata poliorcetica. ${ }^{188}$ The preface stresses the need for clarity ( $\sigma \alpha \varphi \dot{\varsigma} \varsigma$,

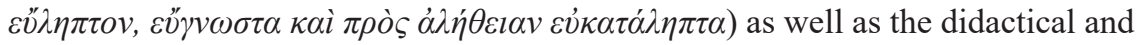
practical importance of the present manual. Accuracy in terminology, common

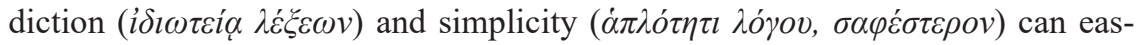
ily teach anyone ( $\tau \tilde{\omega} v \tau v \chi o ́ v \tau \omega v)$ how to carpenter and construct siege engines

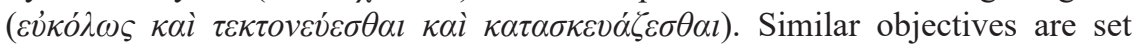
in the introduction to the Tactika of Leo $\mathrm{VI}^{189}$ and in the prefaces to the $D C^{190}$ and the DAI of Constantine Porphyrogenitus. ${ }^{191}$ It should be pointed out that excerpt collections such as the EC, the Excerpta Anonymi, the military treatises, the Geoponica and the Hippiatrica ${ }^{192}$ were all based on late antique texts. Their practical purposes could be disputed by the fact that their sources were very old

187 Transl. Freese (1920), cod. 167.

188 The work is preserved along with another compilation, namely the Geodesia, in the eleventhcentury codex Vaticanus gr. 1605. Both works are derivatives of a tenth-century compilation on the subject matter of sieges. On the two manuals, see Sullivan (2000).

189 Dennis (ed.) (2010), 6.

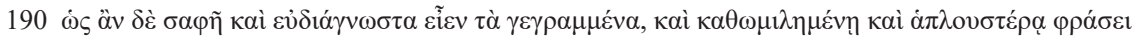

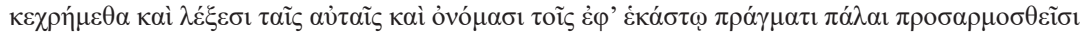

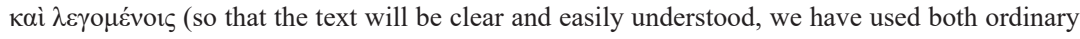
and quite simple language and the same words and names applied and used for each thing from of old); cf. $D C$, proem., 5 .

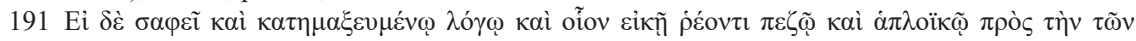

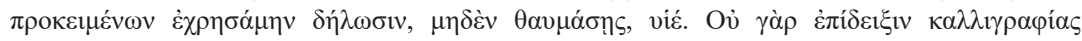

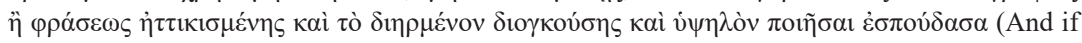
in setting out my subject I have followed the plain and beaten track of speech and, so to say, idly running and simple prose, do not wonder at that, my son. For I have not been studious to make a display of fine writing or of an Atticizing style, swollen with the sublime and lofty; cf. DAI, 1.8-12; Moravcsik and Jenkins (edd.) (1967), 49.

192 A tenth-century veterinary collection. See n. 9 in the Introduction. 
and out of date. ${ }^{193}$ In addition, these collections relied on texts very often quite blurred and difficult in linguistic terms. In the preface to the Geodesia, the compiler claims that:

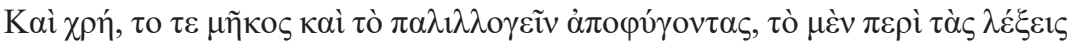

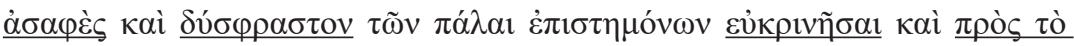

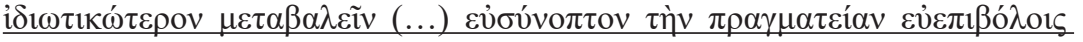

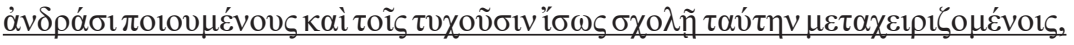

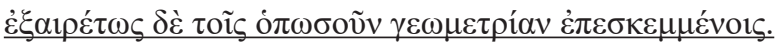

and it is necessary to avoid length and repetition, to render distinct what is unclear and difficult in the diction of knowledgeable men of former times, and to translate it into a more familiar style (...) making the treatise easy to survey for shrewd men and those who happen to take it by chance in hand as time permits, but especially for those who in any way have studied geometry. ${ }^{194}$

Compilers, in some cases endeavour to update their classical and late antique material by adding explanations or simplifying vocabulary. One should wonder, however, whether compilations like the Hippiatrica and Geoponica could really practically be used by horse-doctors or agriculturists of the tenth century as both works lack innovations in horse medicine and agriculture, respectively, which had taken place after late antiquity. Nevertheless, collections, even if antiquarian in terms of content, were still considered useful mainly for teaching at schools. ${ }^{195}$

\subsubsection{Composition}

In the foregoing, I have shown how the excerpts were employed, rephrased, and shortened following certain criteria. Accordingly, the compiler of an excerpt collection would aim at accuracy, brevity, retaining the narrative sequence, and fulfilling practical and didactical purposes. It is however apparent that such goals set restrictions for the compilers on rephrasing the text to any large extent. I am going to discuss this matter beginning from what is evidenced in the prooemium of the $E C$, which furnishes us with significant information:

193 There are cases in which compilers themselves doubt the contemporary relevance of the material they include in their collections. Nicephoros Ouranos in his Tactica and the author of the De velitatione are two prime examples of compilers expressing doubts on the practical usefulness of the knowledge they transmit; cf. Holmes, (2010), 61-62. P. Lemerle considers the Geoponica as a work which represents a late antique manual supplemented with a tenth-century preface; $\mathrm{cf}$. Lemerle (1971), 289.

194 Sullivan (2000), 116-117.

195 On that, see in McCabe (2007), 299-301. 


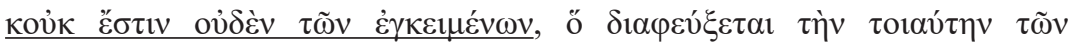

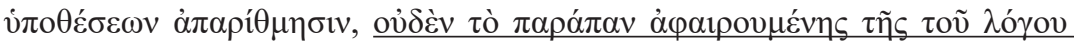

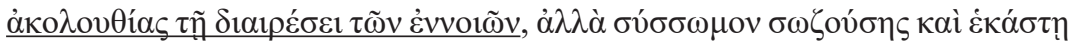

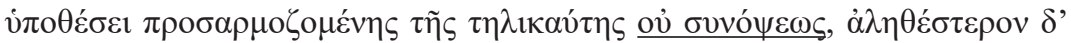

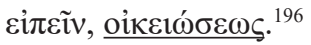

The statement means that the excerptors do not summarise but retain the exact structural form of the original text. It also implies that Constantine Porphyrogenitus made a choice between two confirmed manners of making collections of pas-

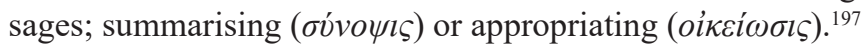

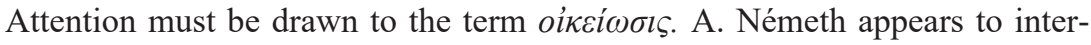
pret the term oikci $\omega \sigma l \varsigma$ as the exact copy of the entire historical work that is to be excerpted at a later stage of the redacting procedure. ${ }^{198}$ In that way, according to Németh, the fifty-three collections covered entire works without losing text in the process of classification. ${ }^{199} \mathrm{P}$. Odorico, by contrast, assigns to the $\dot{\varepsilon} \gamma \kappa \varepsilon \nu \mu \varepsilon v \omega v$, preceded the term in question, the meaning of selected pieces of text, arguing thus that it is only selected passages that were incorporated, without any textual intervention, into draft manuscripts before the official copies of the fifty-three subject categories are executed. ${ }^{200} \mathrm{P}$. Odorico's argument seems to be more tenable based on the content and format of the extant collections of the $E C$ as well as other Byzantine collections. As I have already argued, the integration of the original extracted passages initially into the collection is made manifest in Psellos' comments as well as in the way Symeon composes his Menologion and the Excerpta

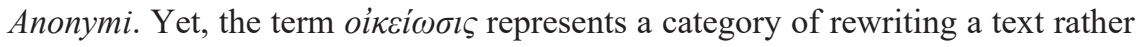
than a conflation of different texts into a single entity; the excerptors working under the auspices of Constantine Porphyrogenitus preserve the original structure of the extracted pieces. Accordingly, ov́voyı should be reserved for the summary process, another category of rewriting, too. Interestingly, the author of the prooe-

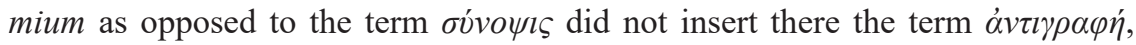
which would make the difference clearer. Instead he inserts a word that derives from the verb oikєló $\omega-\tilde{\omega}$ that means adapt, make something to fit, make something suitable for. When discussing the theory and practice of producing a collection of thematically connected passages in tenth-century Byzantium, Németh introduces the term 'appropriation'. The term sometimes refers to the classification of the excerpted passages into fifty-three subject categories ${ }^{201}$ and at other times to the textual adaptation of selected passages to fit the needs of contemporary readers. ${ }^{202}$

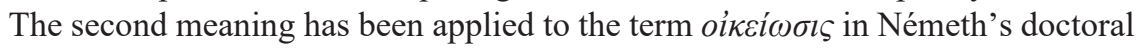

196 EL, 2; Németh (2018), 268.

197 See Németh (2010); Németh (2017), 259-261.

198 Németh (2010), 186 and 228-234.

199 Németh (2018), esp. 59-60 and 68-70. (59, 60, 68-70).

200 Odorico (2017).

201 Németh (2018), 55, 68, 115.

202 Németh (2018), 66, 121. 
dissertation. ${ }^{203}$ Németh argues that extracts from earlier historians have been copied verbatim into the collections. His assertion runs counter to the examples presented in his book, though: the extracted passages from Procopius discussed in his study show that the original text underwent textual modifications (omissions and additions) before its inclusion in the EC. ${ }^{204}$ The term oikeíwols does not strictly exclude any intervention in the text whatsoever, it ensures however the original narrative sequence. ${ }^{205}$ The term oiksi $\omega \sigma l \varsigma$, on the one hand, allows the excerptors to correct the original material according to the specific circumstances and preoccupations under which these were originally composed and on the other to adapt them, through the process of editing, to the sociopolitical context of the tenth century. In the $E C$ the term oiksi $\omega \sigma l \varsigma$ permits the distribution of the excerpts according to precise themes without any major modifications in the content and such an approach allows for the omission of passages but does not permit the summarising of what an excerptor may regard as irrelevant for each thematic section. ${ }^{206}$

Psellos aptly describes Symeon's approach to the original texts at another point in his encomium:

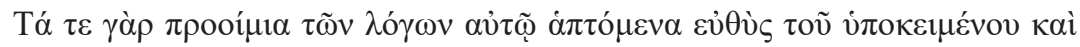

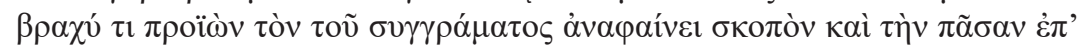

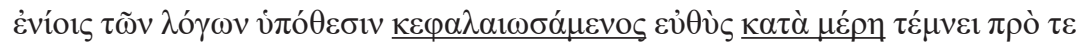

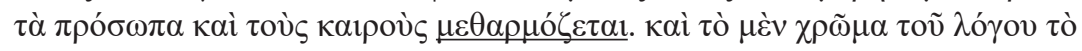

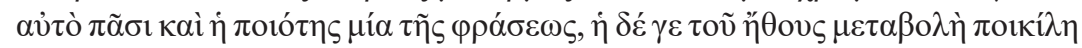

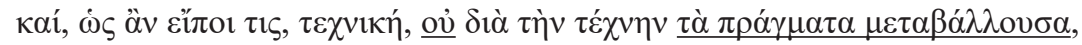

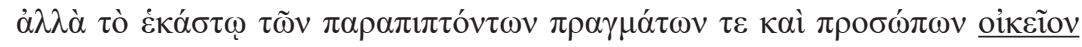
$\delta 1 \varepsilon \rho \mu \eta v \varepsilon v ́ 0 v \sigma \alpha .^{207}$

He relates the beginning of the passages directly to the subject and, moving on slowly, discloses the aim of the composition, and by shortening the entire subject of some passages, he, concurrently, divides (the passages) into

203 Németh (2010), 259-261.

204 Németh (2018), 77-83.

205 The excerptors when wanting to mark the division of excerpts, add the conjunction $\delta \tau^{\prime} \iota$ at the beginning of each text. They also add names and chronological data or short statements in order to rationalise the narrative; Roberto (2009), 79. C. de Boor accentuates an occasion where an excerptor had added three words at the beginning of an excerpted passage of Procopius', which intended to connect this passage with the previous one; cf. de Boor (1912), 388.

206 The excerptors in general do not abridge the original text. However, there are exceptions. For instance, excerpts from John of Antioch and John Malalas that have been epitomised; Roberto (2009), 81-82. For Malalas, see Thurn (ed.) 2000; Flusin (2002), 539-546. Al. Cameron has also noticed a case in which the excerptors of the $E C$ have summarised an epigram transmitted in variants in Diodorus of Sicily' Bibliotheca historica and George the Monk's Chronicon by relying on the text as it is found in the Palatine Anthology; Cameron Al. (1993), 293-297. On the use of the Palatine Anthology by the excerptors of the EC, see Cameron Al. (1993), 294-295; Pratsch (1994), 84-87; Németh (2018), 201-204. On the use of Diodorus of Sicily in the $C E$, see Irigoin (1977), 241-242; Goukowsky (2006), x-xii; Cohen-Skalli (2012), lxv.

207 Kurtz and Drexl (ed.) (1936), 103, 19-29; Fisher, 282, 276-283, 285. 
sections and adapts them to the persons and to the circumstances. The colour of language remains the same throughout the passages, and the quality of style is one and the same. The diction, instead, changes in various ways - as one might say - skillfully, the events do not undergo any change through the method, but each feature is interpreted so as to be adaptable to each of the events and to each of the persons in question.

Psellos states that Symeon shortens the old text ( $\kappa \varepsilon \varphi \alpha \lambda \alpha \iota \omega \sigma \alpha ́ \mu \varepsilon v o \varsigma)$ by dividing the original material into small parts ( $\kappa \alpha \tau \grave{\alpha} \mu \varepsilon \dot{\varepsilon} \rho \eta \tau \dot{\varepsilon} \mu v \varepsilon l)$ and by making changes in the text $(\mu \varepsilon \theta \alpha \rho \mu o ́ \zeta \varepsilon \tau \alpha l)$ relevant to the character of each saint and related to the circumstances of the saints' time. Nevertheless, Symeon does not distort the

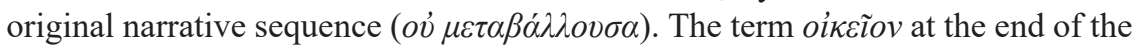
passage recalls the prooemium of the EC. Psellos explains that Symeon's interventions and modifications in the text stem from the necessity to make the new composition fit the personal traits of each saint and the incidents related to him. We shall see in the following chapters that a similar approach to older texts is detectable throughout the so-called Epitome, the Excerpta Anonymi, the Excerpta Salmasiana, and the Excerpta Planudea: the authors of the collections intervene in the original text but they do not epitomise it. They relied methodologically on already determined principles by following the procedures described above.

The four syllogae of excerpts scrutinised in separate chapters in this book were products of a common approach to older texts and of traditional excerpting techniques. The four collections under discussion excerpt historical texts employing a method that is congruent with the one applied to the $E C$. This argument runs counter to A. Németh 's proposition that the excerpting method of the $E C$ was innovative compared to previous excerpting techniques. ${ }^{208}$ In my view, omissions or insertions of passages and rearrangement of sentences within a single excerpt reflect the same pattern of reworking earlier texts and disclose ideological tendencies and priorities. For the main feature of a sylloge is the accumulation of selected knowledge. The selection of material as well as the degree of omissions and additions are determined by the scope and the goal of each of them and by the extent to which they aim to excercise censorship. ${ }^{209}$

Accordingly, no distinction should be made between collections commissioned by emperors and syllogae compiled by scholars or literate men working independently and not under imperial patronage. The former are linked to the reorganisation of the imperial library, when all sorts of books were accumulated in Constantinople under the reign of Leo V (813-820) and their texts were transliterated into minuscule script. ${ }^{210}$ The Byzantine cultural Renaissances of ninth

208 Németh (2010), 17-63; Németh (2018), esp. 54-60 and 77-87.

209 See also Odorico (2017). The same holds true for the various types of catenae on certain books of the New Testament.

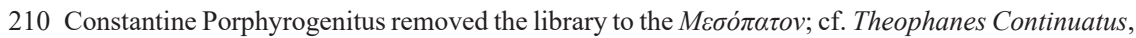
206, 80. Monks from monasteries in Constantinople and around the capital had begun copying manuscripts systematically shortly after the Empress Irene took power in 780 and the iconophile Tarasius was appointed Patriarch of Constantinople; cf. Treadgold (1984), 80-81. 
and tenth centuries were in close connection with the increasing concentration of education and schooling and of the accumulation of books in one hand. The former emerged as part of the necessity of well-educated men to enter the imperial bureaucracy. The latter stems from the central interest in ancient and late antique literature at that period, which, in turn, derives from two chief reasons: the intensive desire to unite pagan and Christian culture and the efforts made by the first emperors of the Macedonian dynasty to legitimise its authority on the basis of affinities with the glorious classical past. ${ }^{211}$ The compilation efforts by scholars are mirrored through the activities of creating florilegia, syllogae, anthologiae, as well as anonymous manuscripts of text fragments selected to some extent according to a steady principle. Nevertheless, these scholars were writing under the pressure of the dominating imperial policy, even if they have not been commissioned directly to serve it. An author belonging to the contemporary bureaucratical or intellectual milieu is likely to have absorbed what the dominant ideology expressed at that time so that his work was a product of certain social, political, and religious circumstances. ${ }^{212}$ Formation of opinion and strengthening of identity may have been amongst the scopes of collections of historical excerpts. ${ }^{213}$ On the other hand, such collections were likely to express the preoccupations of individual scholars, especially through periods of anxiety and apprehension. ${ }^{214}$ From this perspective it is no coincidence that a common desire amongst well-educated Byzantine writers was to preserve material of the past, material that was perceived as part of a common inheritance.

211 On the classical influences in the literature of the tenth century, see Jenkins (1954), esp. 21. On the union of the pagan and Christian culture, which was marked by St Basil's celebrated Advice to young Christians on what use to make of the Classics, see Jenkins (1963), 40; cf. PG 31, coll. 564-589. The topic of the efforts made by the first emperors of the Macedonian dynasty to legitimise their authority has been treated by Markopoulos (1994), 159-170; Holmes (2010), 62-69; Magdalino (2013c), 187-209.

212 This seems to hold true for historical narratives throughout the Byzantine ages. Histories written in the ninth century, namely those of George the Monk and the Ecclesiastical History of Nicetas the Paphlagonian, had not been commissioned by any imperial authority, whereas other historical narratives, namely the Regum libri quattuor of Genesius, the first part of Theophanes Continuatus, and the Vita Basilii were composed under the auspices of Constantine Porphyrogenitus, an emperor whose intention was to direct the composition of historical works in order to impose his imperial authority. On Niketas' history, which is now lost, see Paschalides (2004), 161-173; Karpozilos (2002), 213-249. On the history of Genesius, see Lesmüller-Werner and Thurn (edd.) (1978); Kaldellis (1998); Karpozilos (2002), 315-330; Kazhdan and Angelidi (2006), 144-152; Markopoulos (1986), (2009); Treadgold (2013), 180-188. On knowledge and authority under Constantine Porphyrogenitus, see Holmes (2010), esp. 62-69; Magdalino (2013c), 187-209.

213 On the role of historiography in the context of identity formation, see Debié (2009), 93-114 and Wood (2010). Both scholars are concerned with Syriac texts, though. The matter merits further investigation.

214 The Empire passed many of such periods from the sixth century on. I only refer to the overthrow of the tyrant Phocas at the beginning of the seventh century, the Sassanian invasion under Chosroes II, the devastation of cities in the Near East, including Jerusalem, the siege of Constantinople by the Avars and the Persians in 626 AD. See in general Treadgold (1997). 


\section{Excerpta Anonymi}

The Excerpta Anonymi are an anonymous sylloge of excerpts dated to the second half of the tenth century. The sylloge comprises excerpts from anonymous patriographic texts, a considerable number of passages taken from late antique historians, and passages on geometry. The excerpts are arranged in alphabetical order. Thematically, the excerpted passages deal with prophecies and oracular powers hidden in statues and dreams as well as with geography and ethnography.

In the following pages, I 1) date the unique codex of the Excerpta Anonymi to the mid-tenth century, 2) consider the contents, sources, and the structure of the Excerpta Anonymi, 3) reflect on the compositional method of the collection, 4) examine the relationship between the Exerpta Anonymi and the $C E$, and 5) put forward the historical and cultural context within the Excerpta Anonymi were compiled. Specifically, contrary to previous scholarly views that the selection of material in the Excerpta Anonymi either was made at random $^{1}$ or represents the genre of lexica, ${ }^{2}$ I shall show that 1 ) the anonymous compiler of the sylloge made a conscious selection of passages, 2) the working method in the Excerpta Anonymi is identical to the one applied to the $E C$ as well as to earlier collections of historical excerpts, and 3) that the selection of material was motivated by contemporary ideology. The dating to the mid-tenth century of the unique codex of the Excerpta Anonymi enables us to contextualise the collection and to identify its political dimension. I argue, in particular, that the selection of texts in the Excerpta Anonymi served the so-called restricted ecumenism that characterised the foreign policy of the Macedonian dynasty.

1 Cameron and Herrin (1984), 5.

2 Németh (2010), 33. 


\subsection{Dating of the Parisinus suppl. gr. 607a}

The Excerpta Anonymi were published from the unique codex Parisinus suppl. gr. 607a by M. Treu in $1880 .{ }^{3}$ The Parisinus suppl. gr. 607a consists of $84+2$ folia measuring $190 \times 128 \mathrm{~mm}$. Folia 85 and 86 were left blank. The text occupies an area of $125 \times 66 \mathrm{~mm}$ and there are twenty lines of text per page. The ruling pattern is Leroy 20D1. The codex is made of ten-and-a-half quaternions and the folios are numbered 1 to 84 by a later hand.

Scholars have held different opinions regarding the date of Parisinus suppl. gr. 607a. P. Goukowsky and P. Odorico place the codex to the years around $950 .{ }^{4}$ A. Németh, by contrast, dates Parisinus suppl. gr. 607a to the late ninth or early tenth centuries. ${ }^{5}$ I have doubts about the validity of his proposition, since there seems to be no compelling argument for it. On the contrary, codicological and palaeographic features of the manuscript suggest a dating to the second half of the tenth century. Primarily, the shape of breathings, the manner of writing on ruled lines and the frequent use of uncial letters speak of a date in the second half of the tenth century. ${ }^{6}$ In addition, Parisinus suppl. gr. 607a shares a significant number of palaeographic characteristics with a group of manuscripts written in a minuscule script already well established in the second half of the tenth century, namely the Vaticanus gr. 1613, ${ }^{7}$ Athonensis Dionysiou $70,{ }^{8}$ and Vaticanus Urb. gr. $20 .^{9}$

The script of the original text can be characterised as bouleté $e^{10}$ with features of the later pearlscript. ${ }^{11}$ In fact, the codex represents an early stage of the pearlscript. The letters stand vertical on the ruled lines and they are shaped with clarity and regularity. Although the handwriting approaches the pearlscript, some elements essential to the canon, as determined by Hunger, are still missing. ${ }^{12}$ The roundness of the omicron $(o)$ and alpha $(\alpha)$ is not unitary throughout Parisinus suppl. gr. 607a. When it occurs at the end of the line, the alpha $(\alpha)$ loses its roundness and it is executed in a narrow shape.

3 Treu (1880). On Parisinus suppl. gr. 607a, see also Omont (1888b), 283; Agati (1992), 299-300. On the Excerpta Anonymi, see also Preger (1901), X; Preger (1907), XXI-XXIV; Cameron and Herrin (1984), 4-8; Goukowsky (1995), 63-70; Amerio (1999), 35-42; Odorico (2014b), 755-784.

4 Goukowsky (1995), 63; Odorico (2017). H. A. Omont dates the codex to the tenth century; Omont (1888b), 283.

5 Németh (2010), 33.

6 My special thanks go to Prof. Panagiotis Sotiroudis (Thessaloniki) for his palaeographical assistance. In his opinion, the codex was written at the end of the tenth century.

7 The codex dates to the reign of Basil II. It was written between the years 979 and 989; cf. Follieri (1969), 33-35 and fig. 20.

8 K. Lake and S. Lake (1934-1939), 154-155, fig. 28a.

9 The codex dates to the year 992; cf. Follieri (1969), 36-37 and fig. 22.

10 About bouletée, see Irigoin (1977), 191-199; Agati (1992).

11 Pearlscript was the writing style derived from the minuscule bouletée, the writing style of the first half and middle of the tenth century. The Pearlscript was succeeded by the liturgical minuscule emerging in the eleventh century. On pearlscript, see Hunger (1954), 22-32.

12 Hunger (1954). 
Amongst the main features of the so-called pearlscript observed in Parisinus suppl. gr. 607a are the following: a) the uncial form of $v$ in Parisinus suppl. gr. $607 \mathrm{a}$ is a standard feature of the late pearlscript of the very-late-tenth and the early-eleventh centuries; b) in Parisinus suppl. gr. 607a the ligature epsilon-iota is common, whereas in the earlier bouleté and the later liturgical minuscule the ligature is often replaced by the two letters written separately; c) the uncial form of the letters beta and epsilon in Parisinus suppl. gr. 607a is a feature of the pearlscript in general; $\left.{ }^{13} \mathrm{~d}\right)$ there is also no open form of omega $(\omega)$. The letter $\omega$ as it occurs in the Parisinus suppl. gr. 607a is common in pearlscript; e) the presence of uncial nu $(v)$; f) the iota $(l)$ is the same size as the rest of the letters; g) there are more connections between the letters (in comparison, for instance, to the liturgical minuscule script of the eleventh century) $;{ }^{14} \mathrm{~g}$ ) there is no ligature tau-omicron with omicron formed in a loop from the right part of the horizontal stroke of the tau (this ligature is common in the minuscule script of the eleventh century).

As noted, Parisinus suppl. gr. 607a also exhibits palaeographic features that occurred in manuscripts written in bouletée. Accordingly, the letter lambda $(\lambda)$ is not the same height as the rest of the letters and the letter $\eta$ is identical to the ones in a number of manuscripts in bouletée. For instance, the lambda exceeds the average height in Athens, Ethniki Bibliothiki $2641^{15}$ dated in 913/914, Baroccianus $134{ }^{16}$ dated in $947 / 948$, and in Auctarium E.2.12, ${ }^{17}$ which dates to the year 953, the time when bouletée reaches its culmination. The letter $\eta$ is identical in Jerusalem, Timiou Stavrou $55^{18}$ dated in 927 and in Parisinus gr. 139 (midtenth c.). ${ }^{19}$

Parisinus suppl. gr. 607a bears some characteristics of later script as well. Such features are the frequent use of uncials and the form of the letter rho $(\rho)$. The rho $(\rho)$ is not connected to the following alpha $(\alpha)$ or omicron $(o)$. The letter rho occurs in that form in a number of manuscripts in bouletée, as well as in liturgical minuscule. $^{20}$

13 In the liturgical minuscule the letters epsilon, zeta, theta, kappa, lambda, phi, and omega are also enlarged.

14 Liturgical minuscule is more static and almost upright, there are not many connections between letters, many letters are enlarged, and the strokes of the letters are reduced.

15 Irigoin (1977), 196.

16 Barbour (1981), 6, fig. 19.

17 Irigoin (1977), 197; Barbour (1981), 6 and fig. 21.

18 Irigoin (1977), 197.

19 Irigoin (1977), 194. In manuscripts in liturgical minuscule the strokes of the letter $\eta$ are reduced; see, for instance, the Athens, Ethniki Bibliothiki 179; cf. Marava-Chatzinicolaou and Toufexi-Paschou (1978), pls. 143-150; Ethniki Bibliothiki 63; cf. Marava-Chatzinicolaou and Toufexi-Paschou (1978), pls. 155-158; Ethniki Bibliothiki 174; cf. Marava-Chatzinicolaou and Toufexi-Paschou (1978), pls. 183-186; Ethniki Bibliothiki 2645; cf. Marava-Chatzinicolaou and Toufexi-Paschou (1978), pls. 314-322.

20 For instance in the codex Arch. S. Petri B 58; cf. Canart (1966), pl. II; and in the codex Dumbarton Oaks MS 1, 3, 4; cf. Kavrus-Hoffmann (1966), 289-312. 
The handwriting of the author of Parisinus suppl. gr. 607a is quite even and controlled, betraying a professional scribe. The medium is the usual dark brown Byzantine ink. Headings and initials are in uncials but in the same ink. It is impossible to identify a specific scriptorium but an external source helps us determine the origin of the manuscript, namely Constantinople. We know that the Patria II of the Patria of Constantinople possibly used the Excerpta Anonymi themselves and certainly a common source. ${ }^{21}$ This suggests that Parisinus suppl. gr. 607a originated in the same place as the Patria. ${ }^{22}$

\subsection{Content, structure and sources of the Excerpta Anonymi}

\subsubsection{Content}

The content of Parisinus suppl. gr. 607a can thematically be divided as follows: 1)

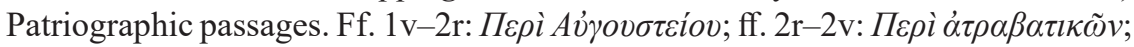

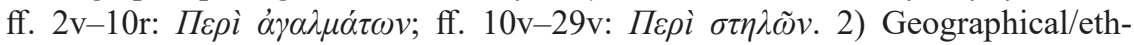

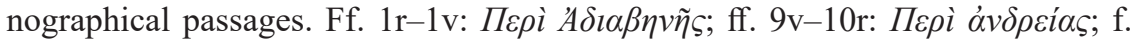

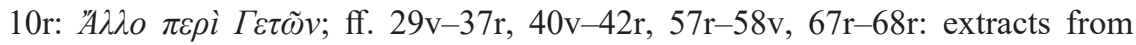

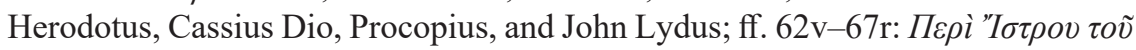

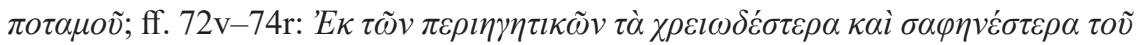

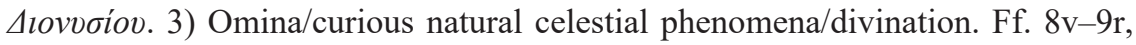
31r-62v: extracts from scholia on Homer, Cassius Dio, Procopius, Appian, and John Lydus. 4) Astronomic/geometric passages. ff. 75v-83r: excerpts from Leon the Mechanic's $\Pi \tilde{\omega} \varsigma \delta \varepsilon \tilde{l} i \sigma \tau \grave{\alpha} v \sigma \varphi \alpha \tilde{\imath} \rho \alpha \nu$ and $\Delta l \alpha i \rho \varepsilon \sigma \iota \varsigma \tau \tilde{\eta} \varsigma \sigma \varphi \alpha \tilde{\rho} \rho \alpha \varsigma$; ff. 83r-84v: Theon of Alexandria's Scholia.

As can be seen in Table 2.1, in spite of the fourfold content of the Excerpta Anonymi, the structure of the collection is alphabetical. As shall be shown in the following section, the alphabetical order often breaks, though. Brief connecting passages were inserted by the compiler to explain his decision to include passages that do not follow the alphabetical arrangement.

21 The Patria of Constantinople is a corpus of texts relating to the antiquities of Constantinople, dated to 995. That the Excerpta Anonymi were composed earlier than the Patria of Constantinople can also be supported by the fact that the Suda, the lexicon of the late-tenth century, also drew on the Excerpta Anonymi; cf. Preger (1901), X. On the Patria II, see Preger (1907), 151-209. For the manuscript tradition of the Patria, see Preger (1907), III-XXV; Berger (1988). See also Berger (2013).

22 It seems likely that the Patria II of the Patria of Constantinople were made in two stages drawing on the codex (codices) that the Excerpta Anonymi also drew on. The possibility that Parisinus suppl. gr. 607a was also in the possession of the compiler of the Patria II can by no means be excluded. On the complex manuscript transmission of the Patria II and their textual relationship with the Excerpta Anonymi, see Section 2.5.1. 
Table 2.1 The contents of Parisinus suppl. gr. 607a

\begin{tabular}{|c|c|c|c|}
\hline Paris. supp. gr. $607 a$ & $\sigma \tau o \imath \chi \varepsilon i ̃ o v$ & Theme & Source \\
\hline 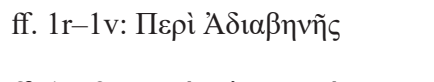 & A & $\begin{array}{l}\text { Geography/ } \\
\text { superstition }\end{array}$ & $C D 68,27$ \\
\hline 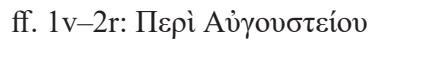 & A & Statuary & $\begin{array}{l}\text { John Lydus, De } \\
\quad \text { Mensibus } 163,3 \mathrm{~W}\end{array}$ \\
\hline 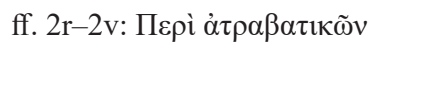 & $\mathrm{A}$ & Roman ritual & $\begin{array}{l}\text { John Lydus, De } \\
\text { Magistratibus 21, } \\
18 \mathrm{~W}\end{array}$ \\
\hline 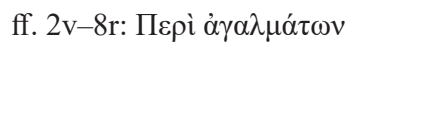 & $\mathrm{A}$ & $\begin{array}{l}\text { Statuary/ } \\
\text { mythology/ } \\
\text { hidden powers }\end{array}$ & Unidentified \\
\hline 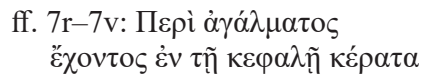 & A & $\begin{array}{l}\text { Statuary/ } \\
\text { mythology }\end{array}$ & Appian, Syriaca, 11 \\
\hline 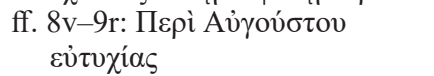 & A & Prophecy & $\begin{array}{l}\text { Appian, Bellum civile, } \\
2\end{array}$ \\
\hline 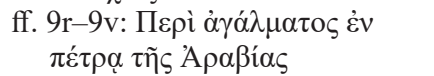 & A & Statuary & Appian \\
\hline ff. $9 \mathrm{v}-10 \mathrm{r}: \Pi \varepsilon \rho i \grave{\alpha} v \delta \rho \varepsilon i ́ \alpha \varsigma$ & $\mathrm{A}$ & $\begin{array}{l}\text { Ethnography/ } \\
\text { mythology }\end{array}$ & Unidentified \\
\hline 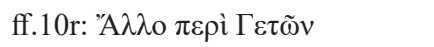 & A & Ethnography & Unidentified \\
\hline 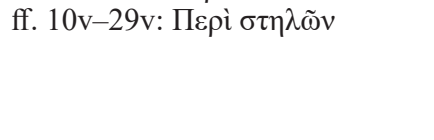 & A & $\begin{array}{l}\text { Statuary/hidden } \\
\text { powers/ } \\
\text { prophecy/ } \\
\text { omina }\end{array}$ & Parastaseis \\
\hline 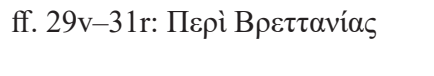 & $\mathrm{B}$ & $\begin{array}{l}\text { Geography/ } \\
\text { ethnography }\end{array}$ & $C D 76,12$ and 13,3 \\
\hline 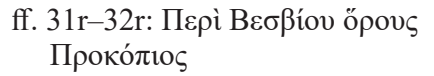 & $\mathrm{B}$ & $\begin{array}{l}\text { Geography/ } \\
\text { superstition }\end{array}$ & $\begin{array}{l}\text { Procopius, De bellis } \\
\quad 6,4,22\end{array}$ \\
\hline 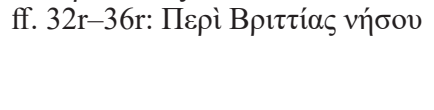 & $\mathrm{B}$ & $\begin{array}{l}\text { Geography/ } \\
\text { ethnography/ } \\
\text { superstition }\end{array}$ & $\begin{array}{l}\text { Procopius, De bellis } \\
\quad 8,20\end{array}$ \\
\hline 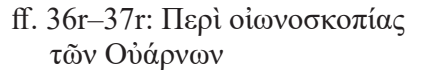 & & $\begin{array}{l}\text { Ethnography/ } \\
\text { omina }\end{array}$ & $\begin{array}{l}\text { Procopius, De bellis } 8 \text {, } \\
\quad 20,11-20\end{array}$ \\
\hline 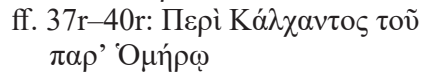 & & Omina & $\begin{array}{l}\text { Scholia in Iliadem 2, } \\
\quad 299-329\end{array}$ \\
\hline 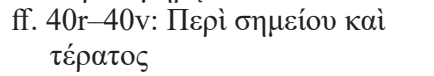 & & Omina & Scholia on Homer \\
\hline 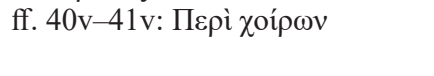 & & $\begin{array}{l}\text { Ethnography/ } \\
\text { omina }\end{array}$ & $\begin{array}{l}\text { Procopius, De bellis } 5 \text {, } \\
\quad 9,1-6\end{array}$ \\
\hline 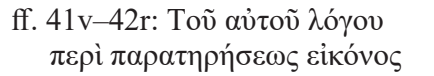 & & $\begin{array}{l}\text { Ethnography/ } \\
\text { omina }\end{array}$ & $\begin{array}{l}\text { Procopius, De bellis } \\
\text { 5.9.22-27 }\end{array}$ \\
\hline 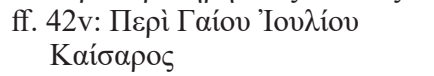 & & $\begin{array}{l}\text { Omina/prophetic } \\
\text { dream }\end{array}$ & $C D 44,18,2-3$ \\
\hline 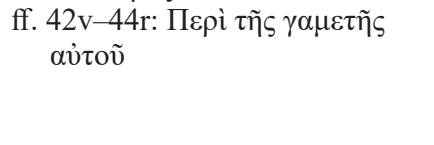 & & $\begin{array}{l}\text { Omina/prophetic } \\
\text { dream }\end{array}$ & $\begin{array}{c}C D 44,17,1 ; 37,52, \\
2 ; 45,1,3 ; 45,1, \\
3-5 ; 45,2,1 ; 45, \\
2,2\end{array}$ \\
\hline
\end{tabular}

(Continued) 
Table 2.1 Continued

\begin{tabular}{|c|c|c|c|}
\hline Paris. supp. gr. $607 a$ & $\sigma \tau o \imath \chi \varepsilon \bar{\imath} o v$ & Theme & Source \\
\hline 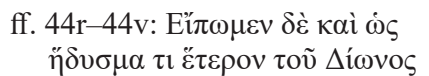 & & Omina & $C D 47,48,4-49,2$ \\
\hline 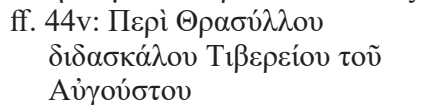 & & Omina & $C D 55,11,1-2$ \\
\hline ff. $44 \mathrm{v}-45 \mathrm{r}:{ }^{\prime} \mathrm{A} \lambda \lambda \mathrm{o} \beta$ & & Omina & $C D 55,11,3$ \\
\hline 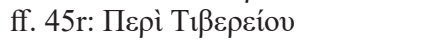 & & Omina & Unidentified \\
\hline ff. $45 \mathrm{r}:{ }^{\prime} \mathrm{A} \lambda \lambda \mathrm{o} \beta$ & & Omina & Pet.Patr. (ES 14) \\
\hline ff. $45 \mathrm{r}-45 \mathrm{v}$ : 'A $A \lambda \mathrm{o} \gamma$ & & Omina & Unidentified \\
\hline 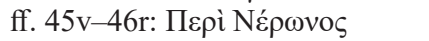 & & Omina & Pet.Patr. (ES 89) \\
\hline ff. 46r-46v: untitled & & Omina & $C D 67,16,2-3$ \\
\hline ff. $46 \mathrm{v}-47 \mathrm{r}: \beta^{\prime}$ & & Omina & $C D 67,16,3$ \\
\hline ff. $47 \mathrm{r}-47 \mathrm{v}: \gamma^{\prime}$ & & Omina & $C D 67,18,1-2$ \\
\hline 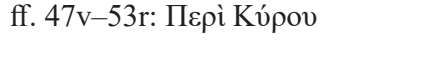 & & $\begin{array}{l}\text { Omina/prophetic } \\
\text { dream }\end{array}$ & $\begin{array}{l}\text { Herodotus, Historiae } \\
\quad 1,96-130\end{array}$ \\
\hline 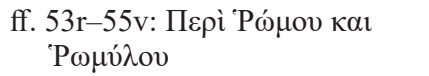 & & Mythology & Appian \\
\hline 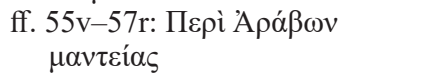 & & Omina & Appian \\
\hline 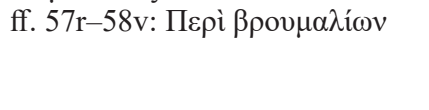 & $\mathrm{B}$ & $\begin{array}{l}\text { Ethnography/ } \\
\text { Roman ritual }\end{array}$ & $\begin{array}{l}\text { John Lydus, De } \\
\text { Mensibus } 173, \\
\text { 18-174 W. }\end{array}$ \\
\hline 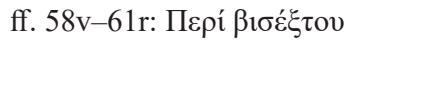 & $\mathrm{B}$ & Roman ritual & $\begin{array}{l}\text { John Lydus, De } \\
\text { Mensibus 43, } \\
\text { 17-49, 24 W. }\end{array}$ \\
\hline 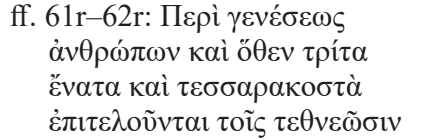 & $\Gamma$ & Superstition & $\begin{array}{r}\text { John Lydus, De } \\
\text { Mensibus } 84, \\
21-86,11 \mathrm{~W} .\end{array}$ \\
\hline 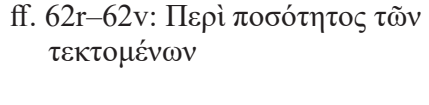 & & Superstition & $\begin{array}{l}\text { John Lydus, De } \\
\text { Mensibus 136, } \\
\text { 23-137 W. }\end{array}$ \\
\hline 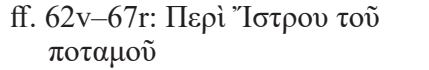 & & Geography & $\begin{array}{l}\text { An earlier excerpt } \\
\text { collection }\end{array}$ \\
\hline 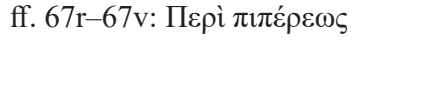 & & $\begin{array}{l}\text { Geography/ } \\
\text { ethnography }\end{array}$ & $\begin{array}{l}\text { John Lydus, De } \\
\text { Mensibus 77, 9-78, } \\
4 \text { W. }\end{array}$ \\
\hline 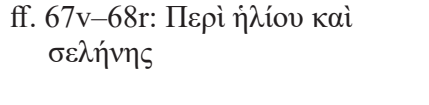 & & $\begin{array}{l}\text { Geography/ } \\
\text { astronomy }\end{array}$ & $\begin{array}{l}\text { John Lydus, De } \\
\text { Mensibus 53, 6-55, } \\
4 \text { W. }\end{array}$ \\
\hline 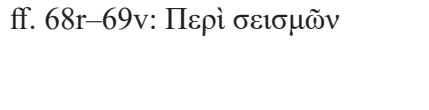 & $\Sigma$ & $\begin{array}{l}\text { Meteorological } \\
\text { phenomena/ } \\
\text { divination }\end{array}$ & $\begin{array}{r}\text { John Lydus, De } \\
\text { Ostentis } 107, \\
7-110,10 \mathrm{~W} .\end{array}$ \\
\hline 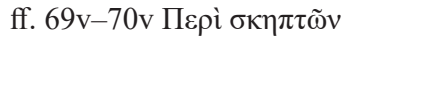 & $\Sigma$ & $\begin{array}{l}\text { Meteorological } \\
\text { phenomena/ } \\
\text { divination }\end{array}$ & $\begin{array}{l}\text { John Lydus, De } \\
\text { Ostentis } 181 \mathrm{~W} .\end{array}$ \\
\hline 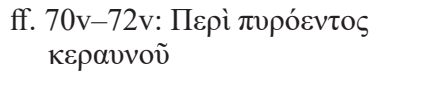 & & $\begin{array}{l}\text { Meteorological } \\
\text { phenomena/ } \\
\text { divination }\end{array}$ & $\begin{array}{l}\text { John Lydus, De } \\
\text { Ostentis } 97-100 \text {, } \\
4 \mathrm{~W} \text {. }\end{array}$ \\
\hline
\end{tabular}

(Continued) 
Table 2.1 Continued

\begin{tabular}{|c|c|c|c|}
\hline Paris. supp. gr. $607 a$ & 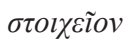 & Theme & Source \\
\hline 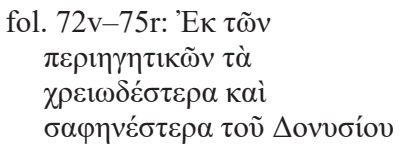 & & Geography & $\begin{array}{l}\text { Dionisius periegetam } \\
\quad(G G M, \mathrm{II}, 457 \mathrm{~b})\end{array}$ \\
\hline 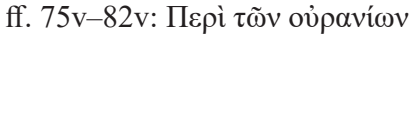 & & $\begin{array}{l}\text { Geometry/ } \\
\text { astronomy }\end{array}$ & $\begin{array}{l}\text { Leon the mechanic, } \\
\Pi \tilde{\omega} \varsigma \delta \varepsilon \tilde{\imath} i \sigma \tau \dot{\alpha} v \\
\sigma \varphi \alpha \tilde{\iota} \rho \alpha v, 264-265 \\
\text { Buchle }\end{array}$ \\
\hline 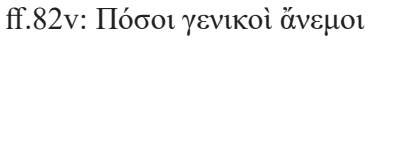 & & $\begin{array}{l}\text { Meteorological } \\
\text { phenomena/ } \\
\text { mythology }\end{array}$ & 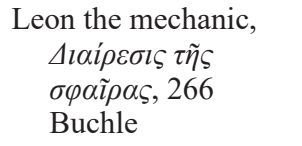 \\
\hline 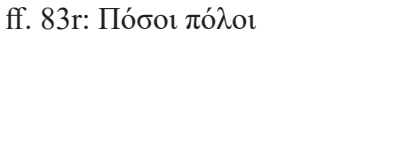 & & $\begin{array}{l}\text { Geometry/ } \\
\text { astronomy }\end{array}$ & 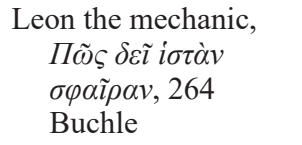 \\
\hline ff. $83 \mathrm{v}$ : 'А & & Etymology & $\begin{array}{l}\text { Scholia in Aratum, 44, } \\
\text { 5-7 Martin }\end{array}$ \\
\hline 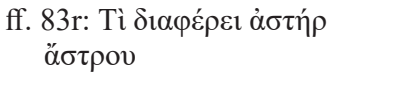 & & Astronomy & $\begin{array}{l}\text { Arati Solensis } \\
\text { phaenomena } \\
18 \text { Buchle }\end{array}$ \\
\hline 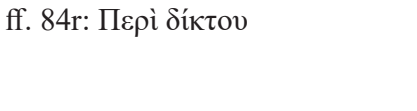 & & Magical herb & $\begin{array}{l}\text { Arati Solensis } \\
\text { phaenomena } \\
20 \text { Buchle }\end{array}$ \\
\hline 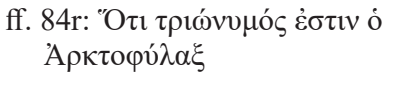 & & Astronomy & $\begin{array}{l}\text { Arati Solensis } \\
\text { phaenomena } \\
32 \text { Buchle }\end{array}$ \\
\hline 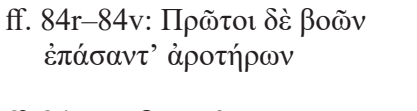 & & $\begin{array}{l}\text { Mythology/ } \\
\text { superstition }\end{array}$ & $\begin{array}{l}\text { Arati Solensis } \\
\text { phaenomena, } \\
39 \text { Buchle }\end{array}$ \\
\hline 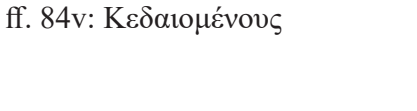 & & Etymology & $\begin{array}{l}\text { Arati Solensis } \\
\text { phaenomena } \\
\text { 46 Buchle }\end{array}$ \\
\hline
\end{tabular}

\subsubsection{The structure of the Excerpta Anonymi}

As suggested by the title of the first and single edition, the Excerpta Anonymi should be seen in the context of the culture of sylloge. The selection of material according to certain themes, its alphabetical arrangement, and the homogeneity of the narrative structure throughout the Excerpta Anonymi indicate that their author intended to produce a coherent collection of excerpts. Let us look at how this plays out in the various parts of the Excerpta Anonymi.

The compiler's tendency to present his material in alphabetical order begin-

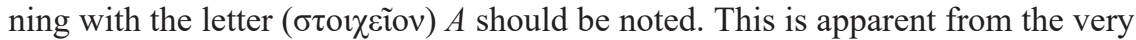
beginning of the collection as it has been handed down to us. Accordingly, the compiler organises his material under individual headings. The first three chapters 


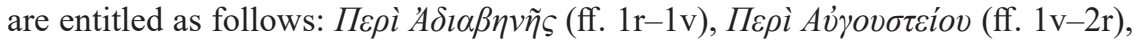

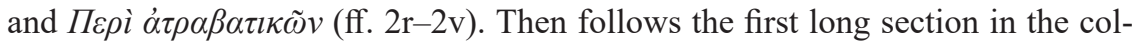

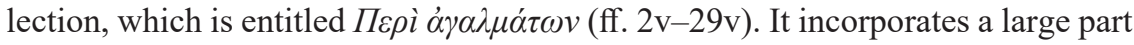
of the Parastaseis, which is marked by the indication $\Pi \varepsilon \rho i \sigma \tau \eta \lambda \tilde{\omega} v$. It is noteworthy, however, that the words $\not \dot{\alpha} \gamma \alpha \lambda \mu \alpha$ and $\sigma \tau \eta^{\prime} \lambda \eta$ have the same meaning so that the

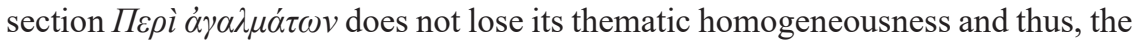
author does not break the alphabetical order of the collection. The first part of the Excerpta Anonymi ends with the indication $\tau \dot{\lambda} \lambda o \varsigma \tau \tilde{\omega} v \sigma \tau \eta \lambda \tilde{\omega} v$ written in enlarged minuscule letters on f. $29 \mathrm{v}$ and followed by a line of five crosses the same size as the letters. In terms of content, the focus in the first part is on prophecies, omens, and hidden powers.

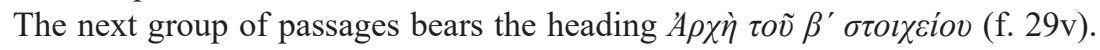
Indeed, it starts with passages concerning items beginning with that letter, but soon enters into a long digression on omina and prophecies, which breaks the alphabetical order. At the end, the author does return to the alphabetical order, and even starts with a new letter, $\Gamma$. This part is actually revelatory with regard to the working methods of the compiler and hints at the tension between the desire to respect the alphabetical order and the wish to have some form of thematic coherence. Let us look at this part in more detail.

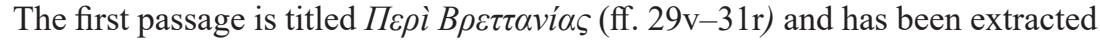

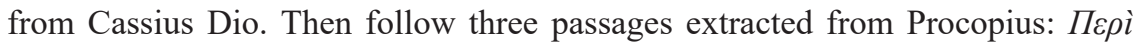

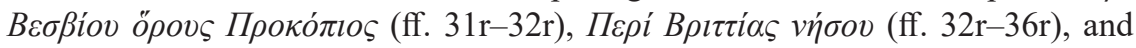

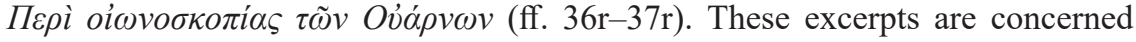
with geography and ethnography. The passage from Cassius Dio and the last two, taken from Procopius, deal with the Island of Brittia and, therefore, have a thematic correspondence. The passages also comply with the author's intention to have an

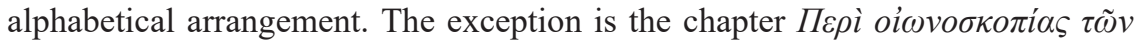

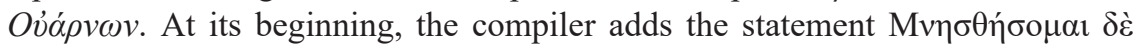

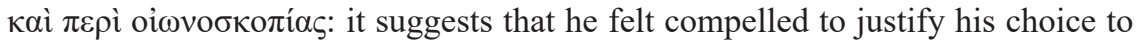
include a title at this point, because the excerpt interrupts the alphabetical arrangement. We can understand, however, why he wished to include this excerpt at this very point in his collection: it provides additional information concerning the Island of Brittia. Moreover, the interest in the omens and prophecies of the Varni harks back to the first part of the compilation.

In the first part of the collection the compiler does not mention his sources. However, from the second part onwards, he names the sources he draws on. In the first chapter, taken from Cassius Dio, the author's name is mentioned in the second line of the chapter. In the case of the second extract, Procopius is mentioned

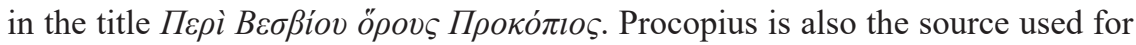

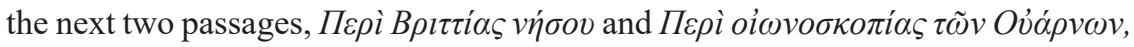
but his name is not repeated, as these two excerpts derive from the same author. This system of identification is followed throughout the entire second part of the Excerpta Anonymi. Indeed, after the chapter on the Varni, the following title,

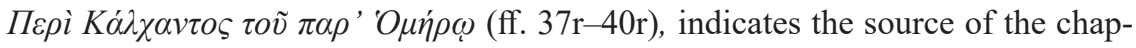

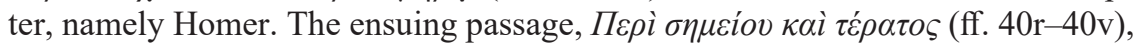


belongs to the same tradition, namely that of scholia on Homer and when the com-

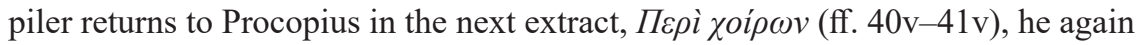
mentions his source. At this point, he once again, links the passage to the previous

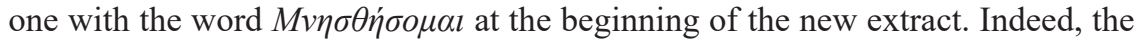

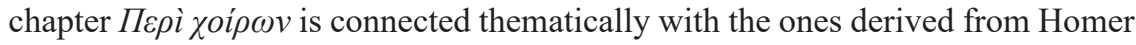
as well as with the chapter on the Varni, as it deals with a Jewish oracle. The pas-

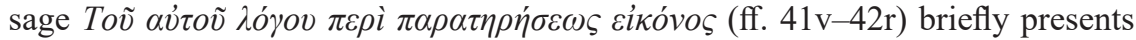
another oracle, which is linked to the Goths.

It should be clear by now that after the initial alphabetical order with excerpts on Brittain and Brittia, the compiler has added excerpts on oracles and prophecies without respecting the alphabetical order. Brief connecting phrases serve the purpose of maintaining coherence and narrative sequence. The chapter following

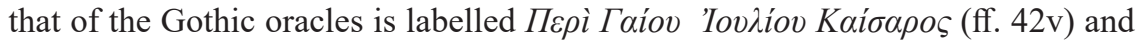

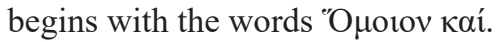

The interest in dreams, oracles, and omens continues in the following chapters (see Table 2.1). Shortly before returning to the alphabetical order, the compiler introduces an auctorial remark in the chapter simply labelled as $\gamma$. He reveals the practical and didactical aims of his enterprise. He says that he could write more

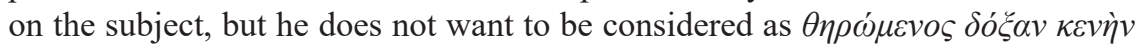
$\tau \alpha \tilde{v} \tau \alpha \gamma \rho \alpha \dot{\alpha} \varphi \varepsilon l v$, viz. as one who 'writes about these things seeking vain reputation', and he adds that most of the facts he presents are known to all.

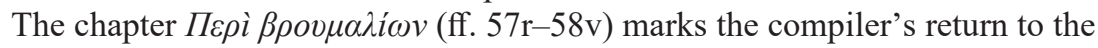
letter $B$ and subsequently to the alphabetical order. It is an excerpt from the $D e$

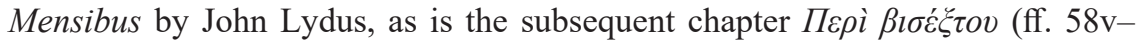
61r). The compiler of the Excerpta Anonymi has considerably shortened the original text.

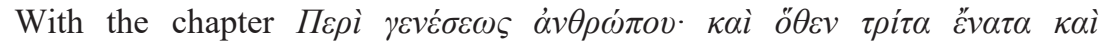

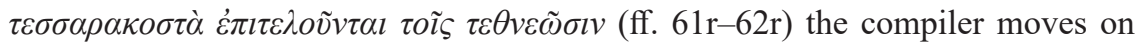
to the letter $\Gamma$. The alphabetical arrangement of the material, however, is dis-

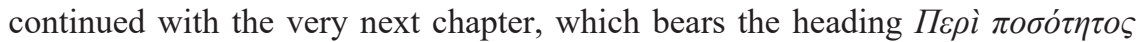
$\tau \tilde{\omega} v \tau \imath \kappa \tau o \mu \varepsilon ́ v \omega v($ ff. $62 \mathrm{r}-62 \mathrm{v}$ ). The compiler inserts a brief introduction of two sentences at the beginning of the new passage, explaining his decision to interrupt the alphabetical order again and link the new chapter to the previous one: 'E $\pi \varepsilon 1 \delta$ ’

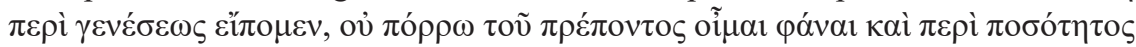
$\tau \tilde{\omega} \nu \tau 1 \kappa \tau o \mu \varepsilon ́ v \omega v$ (Since we talk about births, I believe it would be appropriate to say someting about the number of newborns). This time our author does not add

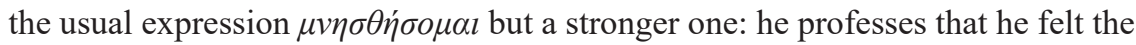
necessity to deliver more information on the particular subject he is concerned with at this point of the collection.

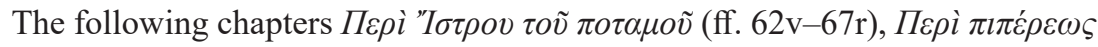

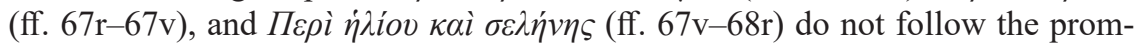
ised alphabetical order either. They are all, however, concerned with geography.

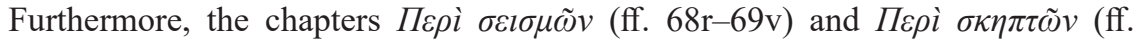

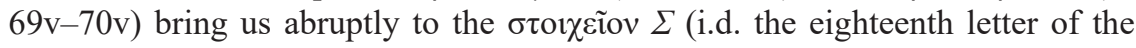

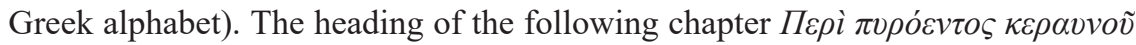




\section{Excerpta Anonymi}

(ff. 70v-72v) does not correspond to the letter $\Sigma$ but the passage has been included

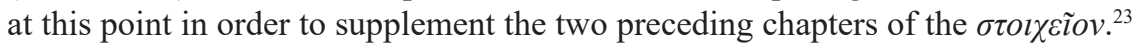
If the disorder at the end of Part 2 suggests anything, it is that the chapters, $\Pi \varepsilon \rho i$

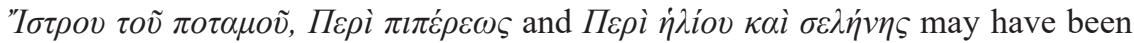
parts of a $\sigma \tau o l \chi \varepsilon \tilde{I} o v$ other than $\Gamma$, presumably whichever up to the $\Sigma$. If this is the case, it can be argued that the Excerpta Anonymi are incomplete and the missing

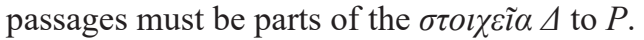

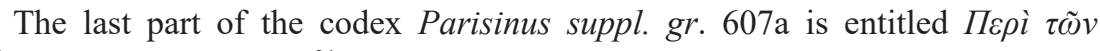
ovjpavíwv (ff. $75 \mathrm{v}-84 \mathrm{v}$ ). ${ }^{24}$ Our compiler has relied on commentaries by Theon of Alexandria ${ }^{25}$ and Leon the Mechanic upon the poem of Aratus Phaenomena, ${ }^{26}$ written probably in the middle of the third century BC. ${ }^{27}$

To conclude, the material selection was made according to certain precise themes, that of statues inhabited by demonic powers, portents, miracles, and curious dreams, curious nations and regions, and curious natural celestial phenomena. The abridged form of numerous passages copied from the Parastaseis Anonymoi Chronikai, several chronographers, historians, and scholia on Aratus' poem and the compositional and organisational format of the collection implies the compiler's striving to structure and provide knowledge upon certain themes. The selection criteria were determined by the collection's practical and educational aims. In Section 2.5 it shall be shown that the political and social context must have influenced the rationale of the selection of excerpts from various works. The omission of certain phrases, passages, or whole paragraphs reflect the compiler's intent to serve politico-cultural aims as well as practical and didactical ones, as shall be shown.

On two occasions, quotations from Homer in Parisinus suppl. gr. 607a are identified by the use of the so-called diple, that is, a symbol shaped like an arrowhead which is placed in the margin next to the Homeric text. ${ }^{28}$ It should be said that this philological sign was developed in the Hellenistic period in Alexandria to identify verses of particular interest in the text of Homer. Such symbols are quite frequently encountered in New Testament manuscripts, too; they usually indicate citations from the Septuagint. ${ }^{29}$ The diple is also used to indicate the biblical

23 In the last paragraph of the same chapter, the compiler repeats, once again, that he considers it

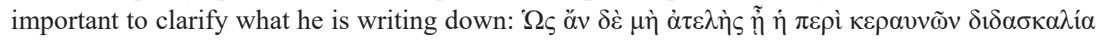
(f. 72r). The word $\delta \imath \delta \alpha \sigma \kappa \alpha \lambda i \alpha$ justifies the assumption that he aimed at creating a collection of such fragments for practical and didactical purposes.

24 The series of excerpts was first published by E. Maass under the title Isagora bis excerpta; cf. Maass (1898), 317-322. J. Martin included the excerpts in his edition of scholia on Aratus; cf. Martin (ed.) (1974), 23-31.

25 The scholia have been generally attributed to Theon of Alexandria.

26 Buchle (ed.) (1793).

27 On Aratus' life, see Kidd (1997), 3-5.

28 The verses from Homer are found on ff. 40r and 79v in Parisinus suppl. gr. 607a.

29 Houghton and Parker (2016), 5; Schmid and Sigismund (2010), 75-152. 
verses in a considerable number of catenae manuscripts, that is, collections of exegetical excerpts. ${ }^{30}$

\subsubsection{The sources of the Excerpta Anonymi}

In what follows I discuss the sources the anonymous compiler of the Excerpta Anonymi drew from.

\subsubsection{Parastaseis Syntomoi Chronikai}

The text conventionally known as Parastaseis Syntomoi Chronikai was used extensively by the Excerpta Anonymi in the section corresponding to letter A. The Parastaseis belong to the class of texts labelled as Patria, works concerned with buildings and monuments of Constantinople. ${ }^{31}$ The Parastaseis are preserved only in one eleventh-century manuscript, the Parisinus gr. 1336. Th. Preger published the text from this manuscript in $1898 .^{32}$ This edition was later incorporated (with a number of corrections) in his edition of Scriptores Originum Constantinopolitanarum. ${ }^{33}$ Preger's edition was republished together with a translation in English and a commentary on the content of the Parastaseis Syntomoi Chronikai by A. Cameron and J. Herrin. ${ }^{34}$ Excerpts from the text are preserved in the Suda, in the Excerpta Anonymi, and in the Patria II. ${ }^{35}$ Contrary to the traditional view, P. Odorico proposes that the Parastaseis are composed of two or more separate texts put together in a codex only in the late-ninth or early-tenth century. ${ }^{36}$ According to him, the first part (ch. 1-26) bears the title Parastaseis syntomoi chronikai, but its original structure and dating are uncertain. ${ }^{37}$ The second part (ch. 27-89) is a sylloge (thereafter Syl) comprising excerpts from other collections on statuary, one of which was a collection by a certain Theodore the Lector. ${ }^{38}$ They were both parts of a dossier that was a collection of other works or historical notes gathered for serving a future historical composition. The text in Parisinus gr. 1336, an exact copy of the dossier in P. Odorico's view, covers

30 To give but a few examples, diple occurs regularly in the catena text transmitted in Parisinus gr. 702, ff. 208r-252r (tenth c.); Ioannu 58 (Patmos), ff. 291r-366v (twelfth c.); Vatopedinus 530, ff. $1 \mathrm{r}-585 \mathrm{v}$ (thirteenth c.).

31 G. Dagron viewed the Parastaseis as a genuine production of the patriographic genre. See Dagron (1984), 31; the same in Berger (1988), 40.

32 Preger (1898).

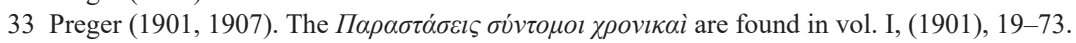

34 Cameron and Herrin (1984) (Henceforth Parastaseis).

35 Preger (1907), 151-209. On the Patria, see also Berger (1988) and Berger (2013).

36 Odorico (2013), 373-389; Odorico (2014), 755-784.

37 It is also likely that the title Parastaseis Syntomoi Chronikai has never been the original title of the chapters 1-26. The term parastaseis (only found in the Parisinus gr. 1336) could refer to the exposition of material rather than to the presentation of monuments; cf. Odorico (2011c), 33-47.

38 On the sylloge, see Odorico (2014), 762-773 (Henceforth $S y l$ ). 


\section{Excerpta Anonymi}

the ff. 111-134. ${ }^{39}$ If P. Odorico is right, the Excerpta Anonymi may have used one of the constitutive parts of the text modern scholars call Parastaseis and not the compilation as we have it today.

The Excerpta Anonymi have used and copied the Parastaseis and the Syl as a single and unitary text without taking into consideration the obvious separation between the two aforementioned works in Parisinus $g r .1336 .{ }^{40}$ For the sake of convenience, in this study, I treat the Parastaseis and the Syl that comes next in Parisinus gr. 1336 as a single but incomplete text and under the heading Parastaseis. $^{41}$

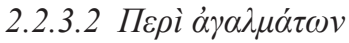

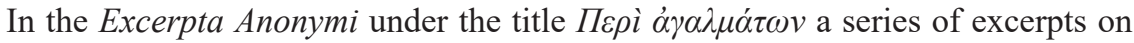
the description and allegorical interpretation of ancient Greek and Roman sculptures are transmitted. The series constitutes the first long section in the Excerpta Anonymi and it comes immediately after the first three chapters corresponding

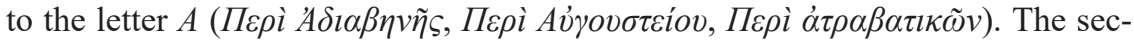

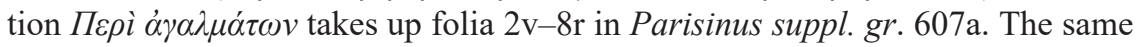
series of sculptures was also copied in the Patria II. The Patria II either copied the Excerpta Anonymi directly or from a codex which the Excerpta Anonymi also come from. ${ }^{42}$ In addition to the Patria II, the excerpts on sculptures have been handed down through the codex Vaticanus $g r .468$ (V), dated to the fourteenth century. ${ }^{43}$ Folio $80 \mathrm{v}$ in $\mathrm{V}$ transmits a passage on a number of statues of gods. The description of each sculpture in $\mathrm{V}$ is preceded by a title which, with one exception, corresponds to the one recorded in the Excerpta Anonymi and the Patria $I I{ }^{44}$ The ultimate part of the passage in $\mathrm{V}$ deviates in terms of subject matter:

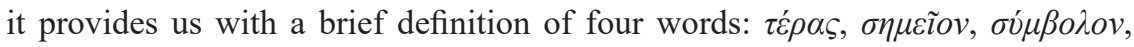

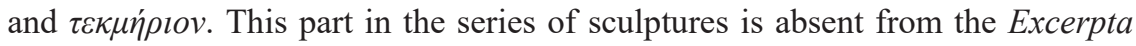
Anonymi and the Patria II. Interestingly, the Excerpta Anonymi 28, 4-9 excerpts a

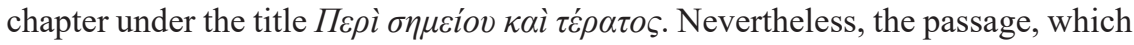
also renders an explanation for the two terms of the title, differs thoroughly with that in V. Accordingly, the following hypotheses have been put forward: 1) M. L. Amerio holds the view that both the Excerpta Anonymi and V, drew on lexica

39 On the content of the manuscript, see Omont (1888b), 16; Odorico (2014b), 778-781.

40 See Appendix II: Table I.

41 The chapter numbering is that of the Parastaseis by A. Cameron and J. Herrin, with the footnote that Chapters 1-26 and Chapters 27-89 constitute parts of two different works.

42 The series of sculptures is found in the Patria II, Chapters 2-14. On the textual relationship between the Excerpta Anonymi and the Patria II, see in Section 5.1.2.

43 See Appendix II: Table II. The $V$ transmits nine out of the fifteen excerpts in the Excerpta Anonymi and the Patria II. On the codicological characteristics and contents of the codex Vaticanus, see Turyn (1952), 152-164; Christodoulou (1977), 37-38; Mioni (1985), 255-257. Christodoulou dates the codex to the thirteenth century. A date at the end of the thirteenth century was also suggested by A. Colonna; see Colonna (1991), 205.

44 See Appendix II: Table II. 
containing such definitions of terms; ${ }^{45}$ 2) A. Berger maintained that the series of

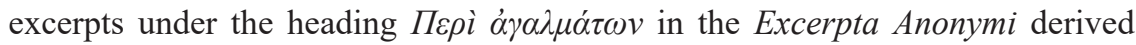
from an archetype $X$ from which John Lydus' passages on sculptures also come. ${ }^{46}$ A. Berger's view seems to be more tenable, given the textual similarities between the Excerpta Anonymi and John Lydus' De mensibus (see Appendix II: Table II).

\subsubsection{Herodotus}

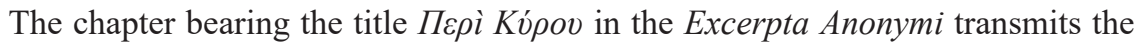
Herodotean (ca. 485-425 BC) story of Cyrus's early life. The excerpt is thematically connected with the Appian passages in the Excerpta Anonymi. As shall be shown in Section 2.4.3, evidence on the margins of the codex Parisinus suppl. gr. 607a may suggest that the Herodotean story as well as the Appian excerpts had initially been copied together in an earlier excerpt collection, from which they were in turn excerpted by the compiler of the Excerpta Amonymi. It is worth mentioning that the earliest extant copies of Herodotus are Laurentianus Plut. 70.3 and Vaticanus gr. 2369 both dated to the tenth century. ${ }^{47}$ The text copied in the Excerpta Anonymi derives from a manuscript close in dating to these copies.

\subsubsection{Appian of Alexandria}

Five passages in the Excerpta Anonymi can safely be attributed to Appian (mid-

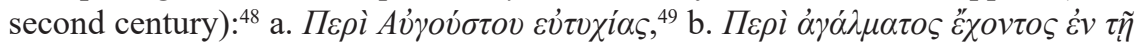

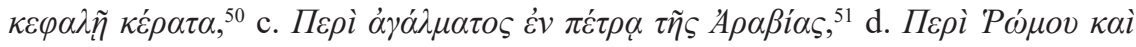

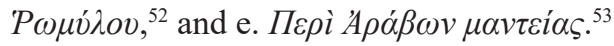

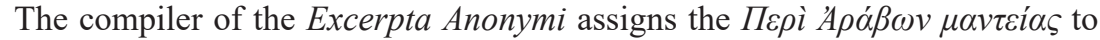

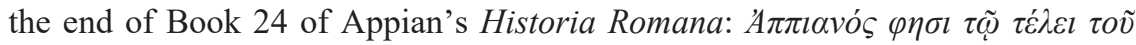
$\kappa \delta^{\prime} \beta$ l $\beta \lambda i$ iov (Appian says at the of Book 24). Photius, who lists the books of the

45 Amerio (2007), 13.

46 Berger (1988), 68.

47 On the codices, see: Bandini (1961), II, col. 657-658 and Cantore (2013), 195-202.

48 Appian's Historia Romana (second century) survives incomplete. The work originally comprised twenty-four books. Part of the text was excerpted in the EC. See Viereck and Roos (1939), xvii-xx and Németh (2018), 7.

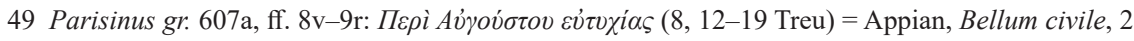
(Book 14), 57, 236 = Patria II, 81. The passage is not congruent with Plutarch, Caesar 38, 1-5, Plutarch, Moralia 319b, and Cassius Dio 41, 46, 2-3; cf. Amerio (1999), 36.

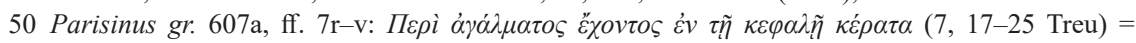
Appian, Syriaca (Book 11), 57, 293-294 = Patria II, 14.

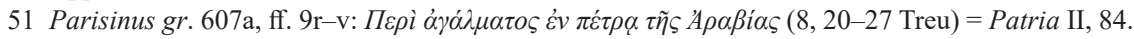

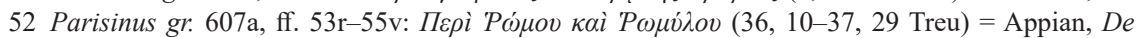
regibus, 16, b, 4-17, a, 8 Bekker = Book 1 = Appian, Historia Romana fr. 1a e 1 (edd. Viereck and Roos).

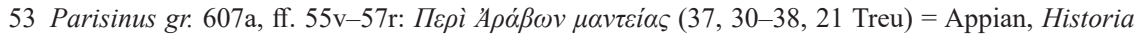
Romana fr. 19 (edd. Viereck and Roos, 534-535). 


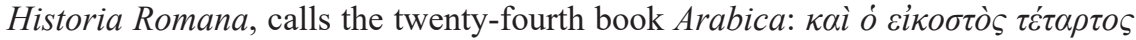

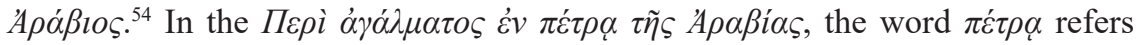
to the city of Petra. Appian refers to the city of Petra again in the excerpt $\Pi \varepsilon \rho i$ A $\rho \alpha \beta \omega \nu \mu \alpha \nu \tau \varepsilon i \alpha \varsigma$, a fact that led P. Goukowsky to attributing the excerpt $\Pi \varepsilon \rho i$

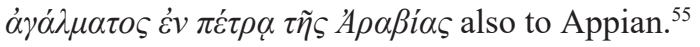

The first three Appian excerpts (a, b, c) are found in the first part of the Excerpta Anonymi, that is, the patriographic one. The last two (d, e) are transmitted separately in the collection, after a series of excerpts from Cassius Dio and Procopius. M. L. Amerio was the first to detect a different source for these two Appian

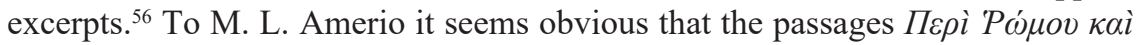

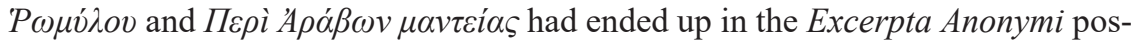
sibly via an excerpt collection. Nevertheless, she associates the inclusion of the Appian passages in the Excerpta Anonymi with the revived interest in Appian in the age of Photius, that is, in the mid-ninth century. ${ }^{57}$ As shown in Sections

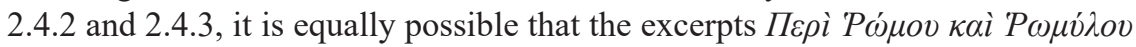

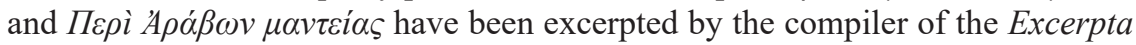
Anonymi through a draft copy produced during the redaction of the $E C$.

\subsubsection{Cassius Dio}

A considerable number of excerpts in the Excerpta Anonymi are from Cassius Dio (ca. 155-235 AD) tradition. ${ }^{58}$ Some of the passages are nominally ascribed to Cassius Dio by the compiler of the Excerpta Anonymi themselves. Passages from Cassius Dio tradition were included in the Excerpta Anonymi through an earlier collection of excerpts, now lost. ${ }^{59}$ Dio's excerpts in the Excerpta Anonymi are

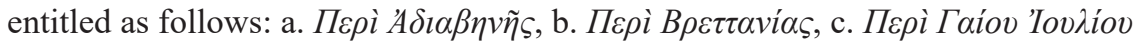

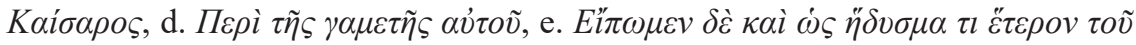
$\Delta i \omega v o \varsigma$, f. an untitled passage on the emperor Domitian, g. $\beta^{\prime}$, and h. $\gamma^{\prime}$.

\subsubsection{Procopius}

Procopius' (ca. 500-565 AD) De bellis ${ }^{60}$ has been excerpted by the Excerpta

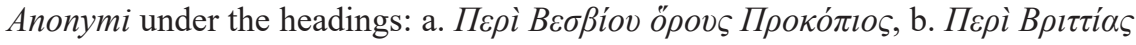

\footnotetext{
54 Bibliotheca, cod. 57.

55 Goukowsky (1995), 63-70.

56 Amerio (1999), 40.

57 Amerio (1999), 40-41.

58 Cassius Dio's Historiae Romanae comprised eighty books and run from Aeneas to 229 AD. Only a portion of it survives in direct transmission. The rest has been transmitted in the epitomes of John Zonaras and John Xiphilinus as well as in fragments. A significant number of extracts was included in the EC. On the Epitome by Zonaras, see Banchich (2009), 8-11. On the Epitome by Xiphilinus, see Mallan (2013). On the relationship between the Historiae Romanae and the EC, see Boissevain (1895), vi-xxi; Mazzuchi (1979); Molin (2004).

59 On the use of Cassius Dio in the Excerpta Anonymi, see Section 2.4.4.

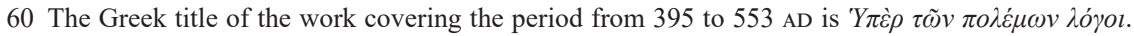




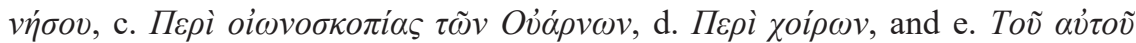

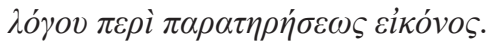

\subsubsection{John Lydus}

The Excerpta Anonymi contain passages from the three antiquarian treatises by John Lydus (ca. 490-561 AD), namely the De Mensibus (On the months), the De Magistratibus Rei Publicae Romanorum (On the Magistracies of the Roman State), and the De Ostentis (On signs in the heavens): ${ }^{61}$ specifically, 1. the De

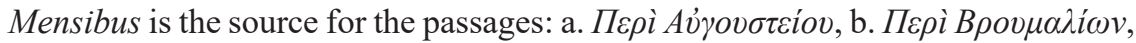

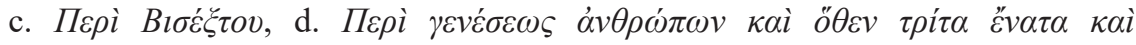

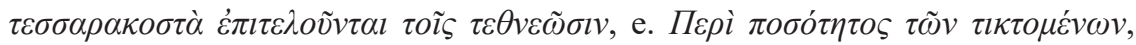

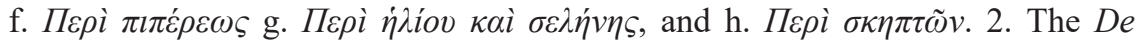

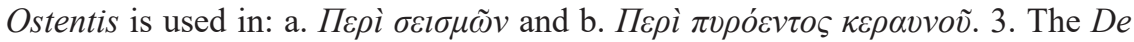

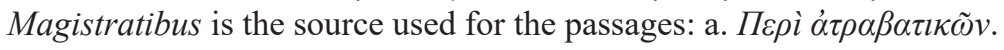

\subsubsection{Peter the Patrician}

Excerpts from Peter the Patrician's (500-565 AD) Historia were embedded in the Excerpta Anonymi through the same collection of excerpts as the passages from Cassius Dio. ${ }^{62}$ Peter the Patrician's text has been transmitted under the following

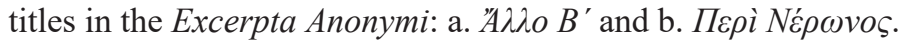

\subsubsection{Scholia on Homer}

Two chapters in the Excerpta Anonymi go back to the tradition of scholia on Homer. The complex issue of the authorship and the transmission of such scholia prevents us from drawing any conclusion as to the exact source used by the compiler of the Excerpta Anonymi. The first of the two passages is nominally

There is a vast bibliography on Procopius. See now in Greatrex (2014a) and Greatrex (2019). On Procopius' historical work, also see Section 2.5.

61 The De Mensibus, which possibly comprised four books on ancient myths and Greco-Roman history, survives in fragments through the works of George Cedrenus and John of Antioch. The De Magistratibus, preserved partially, is an important witness to the bureaucratic system of Rome from Aeneas to $541 \mathrm{AD}$. The De Ostentis, handed down complete, concerns interpretations of heavenly signs. On John Lydus’ works, see Maas (1992); Kaldellis (2005); Bandy (2013).

62 See Section 2.4.4. Peter the Patrician's historical account covered the period from Octavian to Constantius II. Part of his work has been ascribed to an Anonymus Post Dionem; see in Banchich (2015). Peter the Patrician also composed a collection of descriptions of imperial ceremonies, $O n$ ceremony, transmitted in fragments only. Fragments of this work are contained in the DC 1.84-95, in John of Lydia's De magistratibus 2.25 and in the Suda $\pi$ 1406; cf. Sode (2004); Laniado (1997); Sode (2011). A collection of documents about the treaty of 561/562 with Persia attributed to Peter the Patrician was probably part of his On ceremony; see Antonopoulos (1990), 217-221. On Peter the Patrician, in general, see Treadgold (2007), 264-270; Sode (2011); Bleckmann (2015), esp. 106-111; Roberto (2016), 51-67. 
assigned to a scholium on Homer by the Excerpta Anonymi themselves. The title

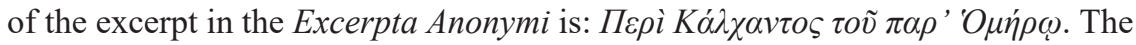

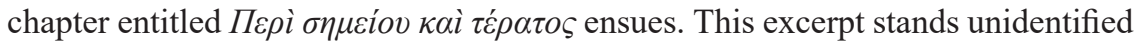
in the edition by M. Treu. Both chapters show the acquaintance of the compiler of the Excerpta Anonymi with the ancient tradition of scholia on Homer. ${ }^{63}$ In

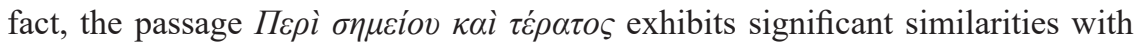
a passage in the twelfth-century collection of scholia on Homer by Eustathius of

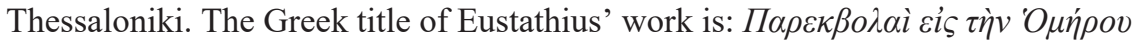

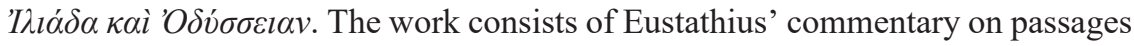
of the Homeric poems as well as extracts from earlier commentators. Eustathius' sources are difficult to identify since most of the works he used are now lost. ${ }^{64}$

\subsubsection{Scholia in Dionysium Periegetam}

Passages on geography and the derivation of place names have been extracted from the Scholia in Dionysium Periegetam. ${ }^{65}$ The whole series of passages taken

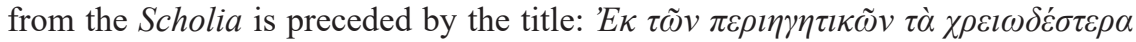

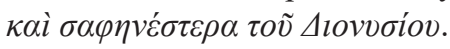

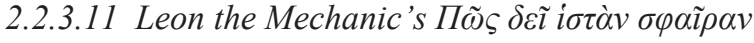

On f. $75 \mathrm{v}$ a line made up of five crosses the size of letters marks the beginning of the last part of the Excerpta Anonymi. ${ }^{66}$ The concatenation of excerpts on astronomy

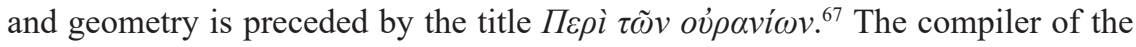
Excerpta Anonymi relied on Leon the Mechanic's and Theon of Alexandria's commentaries on Aratus Solensis' poem called Phaenomena. ${ }^{68}$ Leon the Mechanic was a mathematician and philosopher of the sixth century. The Excerpta Anonymi used his works entitled $\Pi \tilde{\omega} \varsigma \delta \varepsilon \tilde{\imath} i \sigma \tau \hat{\alpha} \nu \sigma \varphi \alpha \tilde{\imath} \rho \alpha \nu^{69}$ and $\Delta \imath \alpha i \rho \varepsilon \sigma \iota \varsigma \tau \tilde{\eta} \varsigma \sigma \varphi \alpha \tilde{\imath} \rho \alpha \varsigma .{ }^{70}$ Both Leon's treatises are based extensively on Aratus Solensis' poem and on the commentary on it by Theon of Alexandria. The latter is likely to have been the editor of a text, which became the standard edition in subsequent antiquity. ${ }^{71}$ The last part of the Excerpta Anonymi excerpts scholia by Theon of Alexandria on separate verses of Aratus' Phaenomena. In particular, the scholia concern verses 27, 33, 91, 132, and 159 of the Phaenomena. The compiler of the Excerpta Anonymi excerpts Leon's and Theon's texts in brief chapters and simplifies the selected

63 On this, also see Amerio (2007), 12-13.

64 Van der Valk (1971-1987).

65 Müller (ed.) (1861), 457b.

66 The text on ff. $73 \mathrm{v}-83 \mathrm{v}$ was published in Martin (1974), 23-31.

67 Excerpta Anonymi 50, 7-56, 19.

68 Aratus's writings are dated to the mid-third century. On Aratus' life, see Kidd (1997), 3-5.

69 Buhle (ed.) (1793), 257-264.

70 Buhle (ed.) (1793), 266.

71 Kidd (1997), 49. 
passages. Each short passage bears a brief heading. One could say that this part was created in order to be used for didactic purposes in schooling.

The author of the Excerpta Anonymi reveals his admiration for the Roman past, which he primarily interprets as pagan. The diversity of the sources (patriographic texts, geographical texts, historical and geometrical works) implies an erudite man who was acquainted with the works mentioned above and knew precisely where to look for passages apposite to the subject matter of the collection. Addition, omission, or alteration of extracts, are one of the particularly interesting features of the Excerpta Anonymi. As I shall show in Section 2.5, inaccuracies and obscurity of expression in some source texts but also political motives and ideology led the compiler to intervene and re-edit the excerpted passages.

When studying the Appian excerpts in the Excerpta Anonymi, P. Goukowsky arrived at the conclusion that the anonymous compiler of the Excerpta Anonymi a) was a monk who wrote in a monastic environment where b) he had at hand the complete text of Appian as well as the entire works of Herodotus, Dio Cassius, Procopius, and John Lydus. ${ }^{72}$ P. Goukowsky's first argument is not tenable. On the contrary, his proposition is not in accordance with the selection of material on the part of the Excerpta Anonymi compiler, who excised almost every religious reference in the original texts and who expressed covert admiration for pagan elements of the past. ${ }^{73}$ Regarding the second argument made by P. Goukowsky, the analysis of certain passages shows that it is highly likely that, in addition to any other historical sources - possibly complete historical works - the compiler also relied on pre-existing excerpt collections. As it will be shown (see Sections 2.4.2 and 2.4.3), for the chapter "On the River Istros," "74 the compiler drew on a collection of geographical material, whereas for the chapters "On Cyrus" "75 and "On Remus and Romulus"76 he drew on a collection of occult science. Similarly, passages on Roman history in the Excerpta Anonymi derive from a collection on dreams and occult science comprising excerpts from Cassius Dio and Peter the Patrician. $^{77}$

As shown, Parisinus suppl. gr. 607a is an incomplete codex dated to the reign of Constantine Porphyrogenitus. Yet the possibility that Parisinus is a copy of an earlier, probably damaged, manuscript cannot be excluded. There is sufficient evidence supporting the argument that beside the codex unicus of the Excerpta Anonymi, the collection itself is also from the mid-tenth century. Such a dating is supported by the following: a) internal evidence in the Excerpta Anonymi hints at a specific contemporary ideology, namely that of the restricted ecumenism advocated by the emperor Constantine Porphyrogenitus (see Section 2.5.2.2); b)

72 Goykowsky (1995), 69-70. For a different view, see Amerio (1999), 35-42.

73 On the elimination of religious references in Parisinus suppl. gr. 607a and its compiler's literary interests, see the analysis in Section 2.5.1.

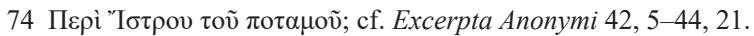

75 Пврі̀ Kúpov; cf. Excerpta Anonymi 33, 1-36, 9.

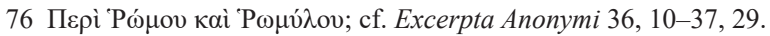

77 The chapters are thoroughly studied below in Sections 2.4.4 and 2.4.5. 
as shall be shown (see Section 2.4), the Excerpta Anonymi must have drawn on material gathered in the first place for the $E C$. The $E C$, a collection of historical excerpts on Constantine's commission, began to be compiled before Constantine's sole rulership (945-959 AD) and were completed a few decades after the death of the emperor; ${ }^{78}$ c) Macedonian emperors' efforts towards systematising knowledge become apparent in the production of manuscripts of shared themes. ${ }^{79}$ The Excerpta Anonymi are a collection of quotations on subject matters evident in other contemporary works. Accordingly, the Excerpta Anonymi put an emphasis on the prophetic meaning, dangers, and hidden powers of pagan statues as well as geographical and ethnographical interest (see Sections 2.4.2-2.4.6); and d) the Excerpta Anonymi exhibit significant similarities with the Exc.Salm.II with regard to the selective use of passages in the section on Roman history. The common selective use of passages testifies to the use of a common source, that is, an excerpt collection of passages from Cassius Dio and Peter the Patrician (see Section 3.3.2.4). It is quite likely that the compilers of the Excerpta Anonymi and the Excerpta Salmasiana, respectively, belonged to a contemporary intellectual milieu and made use of a common source. Scholarship has suggested that the Excerpta Salmasiana were compiled between the eighth and the eleventh centuries. Internal evidence, however, supports the dating of the Excerpta Salmasiana to the tenth century (see Section 3.1). The second part of the Exc. Salm.II is concerned with the personal traits, life, and deeds of certain emperors. Historical writing where the narration was focused on a certain emperor's life became fashionable from the tenth century onwards (see Section 3.3.2). In particular, this new direction of Byzantine historiography became popular under the reign of Constantine Porphyrogenitus and features in historical writings produced at his request. ${ }^{80}$ Yet a dating of the Excerpta Salmasiana to the mid-tenth century explains textual omissions and adaptations detected in the part of the Excerpta Salmasiana transmitting the Agathias excerpts (see Section 3.4).

\subsection{The working method in the Excerpta Anonymi}

As shown, the Excerpta Anonymi make up a unity of thematically connected excerpts extracted from a number of different works and acts as a new and autonomous piece of literature. The new entity can be read by itself and gets its own transmission. Its originality is reflected on the concatenation of the excerpts, that is, in the changed content and in the selected format through which a selected branch of knowledge is represented. ${ }^{81}$ The detailed analysis of single excerpts included in the Excerpta Anonymi can yield interesting results with regards to the working method of its author. The comparison of the original texts as preserved

78 Németh (2018), 94-101.

79 Németh (2018), 44-45.

80 Németh (2018), 145-164.

81 See also Odorico (2011a), 100. 
in earlier manuscripts and the Excerpta Anonymi, and the analysis of the resulting differences, omissions, and additions shall help us to understand how the sources have been employed as well as the procedure they have undergone. In particular, the content and arrangement of excerpts in the Excerpta Anonymi point to the three procedures of redacting an excerpt collection on precise themes discussed in Chapter 1: a. reading of the whole source text and selection of passages, b. rewriting of the source text, and c. composition of a new unity. The selection of excerpts was based on general criteria such as accuracy, clarity, brevity, and respect for the original narration. The examination of the three steps of redacting the collection shows that the excerptor a) respected the vocabulary and structure of the original text and b) followed certain strategies in order to cope with the lack of context that arose when a passage was extracted from a whole unit. I categorise these strategies as follows: a) additions or omissions of text, b) rearrangement of words, and c) repetition of words or phrases.

a) Selection

As noted in Chapter 1, the first procedure consisted in reading the source text and selecting passages according to certain themes. Interestingly, the author of the Excerpta Anonymi seems to rely on a considerable number of texts. The sources of the Excerpta Anonymi were discussed in the previous section. The anonymous text conventionally known as Parastaseis Syntomoi Chronikai takes up two-thirds of the part of the codex Parisinus suppl. gr. 607a corresponding to letter $A .{ }^{82}$ The rest are excerpts from Cassius Dio and John Lydus. What follows under the part of the Parisinus corresponding to letter B are excerpts from Herodotus, Cassius Dio, Appian, Procopius, and John Lydus. As shown in Section 2.4, the compiler of the Excerpta Anonymi did not necessarily draw on the entire works of the aforementioned late antique historians. Passages excerpted from Herodotus, Cassius Dio, and John Lydus appear to have been taken from pre-existing excerpt collections. The last part of the Excerpta Anonymi relies on passages on geometry and astronomy.

b) Rewriting

As shown in Chapter 1, the integration of the original text initially into the collection is made manifest in Psellos' comments, in the way Symeon composes his Menologion and throughout the EC. It is also corroborated

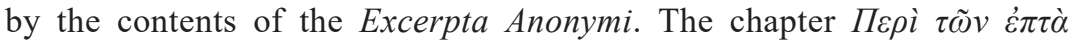
$\varphi \imath \lambda o \sigma o ́ \varphi \omega v$ in the Excerpta Anonymi (Table 2.2) shows that the second step, which was the editing and rephrasing of the excerpts, presupposed a step in which each selected text was copied in its entirety. ${ }^{83}$ In the chapter seven philosophers encounter the emperor Theodosius II (405-450) at the Hippodrome:

82 On the Parastaseis, see Section 2.2.3.1.

83 Excerpta Anonymi, 17, 31-18, 24. 


\section{Excerpta Anonymi}

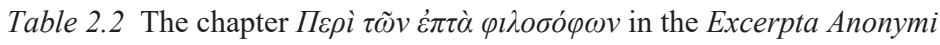

Parastaseis, Chapter 64

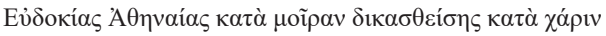

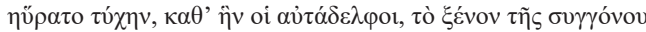

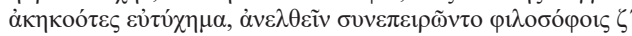

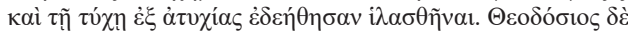

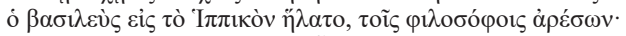

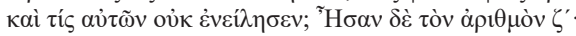

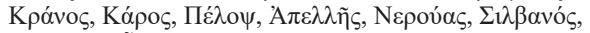

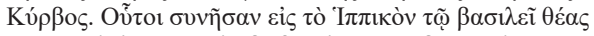

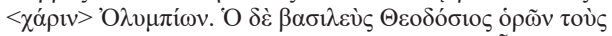

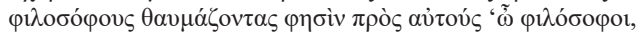

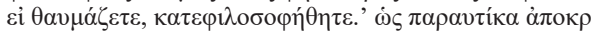

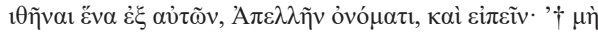

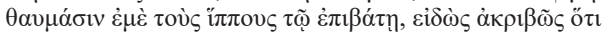

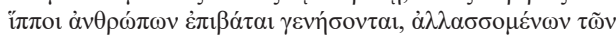

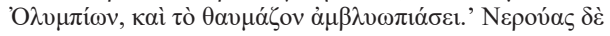

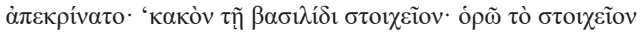

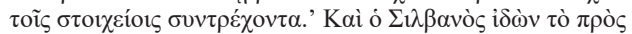

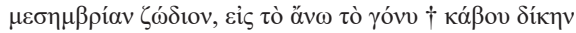

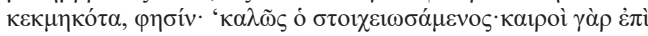

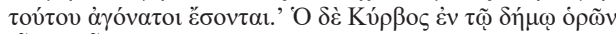

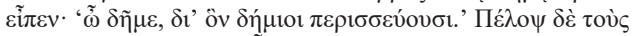

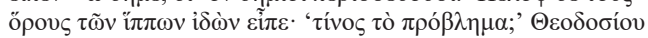

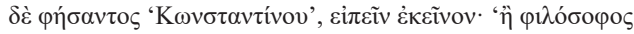

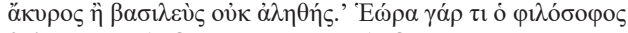

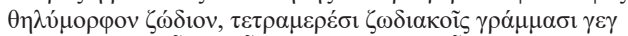

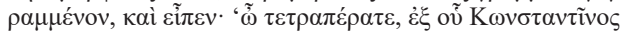

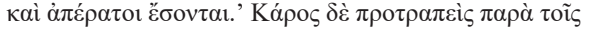

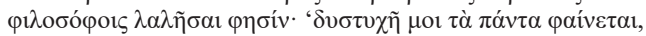

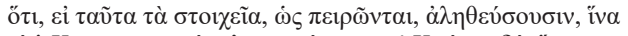

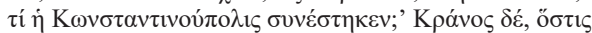

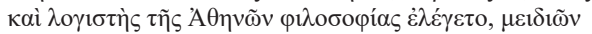

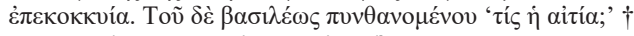

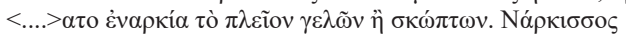

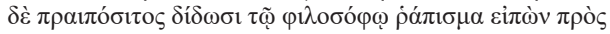

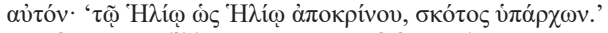

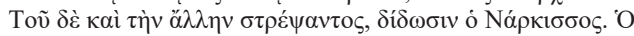

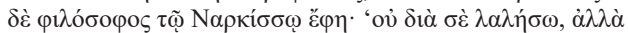

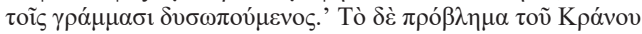

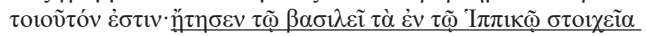

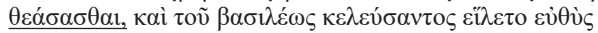

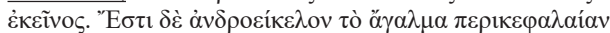

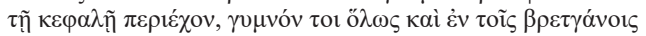

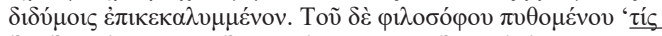

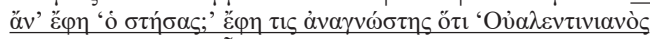

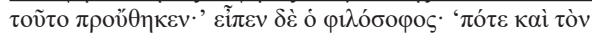

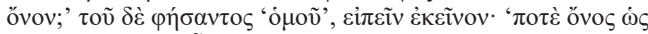

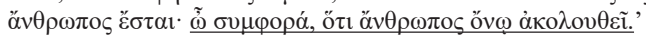

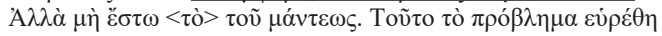

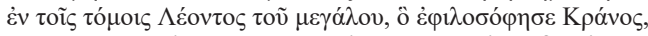

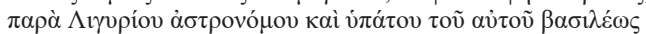
$\Lambda$ ćovtos.
Excerpta Anonymi 17, 31-18, 24

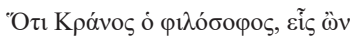

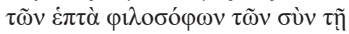

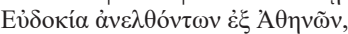

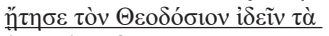
غ่v $\tau \tilde{\omega}$ i $\pi \pi 0 \delta \rho o \mu i ́ \omega \sigma \tau o \imath \chi \varepsilon \tilde{\alpha} \alpha$.

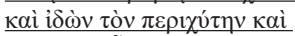

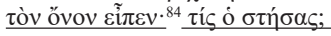

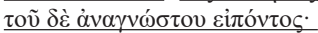

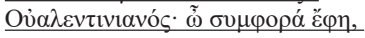

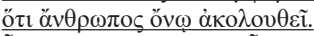

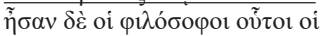

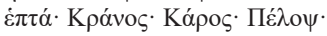

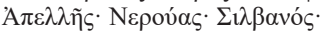

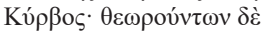

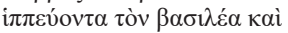

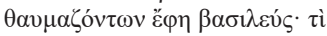
$\theta \alpha v \mu \alpha ́ \zeta \varepsilon \tau \varepsilon ; \alpha \dot{\alpha} \pi \varepsilon \kappa \rho i ́ \theta \eta \delta \dot{~} \mathrm{~A} \pi \varepsilon \lambda \lambda \tilde{\eta} \zeta$.

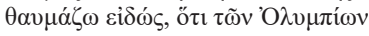

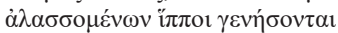

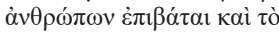

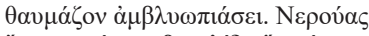

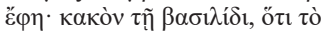

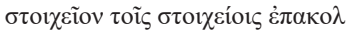

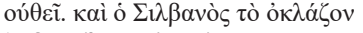

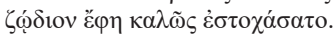

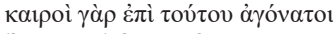

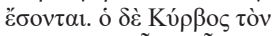
$\delta \tilde{\eta} \mu \mathrm{ov}$ i $\delta \grave{v} v \varepsilon \tilde{\tilde{i}} \pi \varepsilon v \cdot \tilde{\omega} \delta \tilde{\eta} \mu \mathrm{s}$,

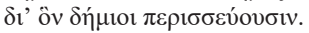

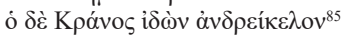
$\gamma v \mu v o ́ v, \pi \varepsilon \rho \iota \kappa \varepsilon \varphi \alpha \lambda \alpha i_{\alpha v^{86}}$

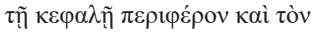

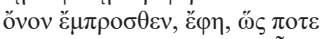

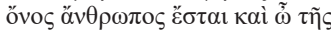

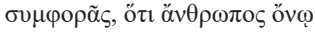

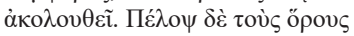

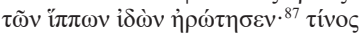

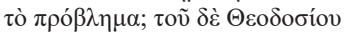

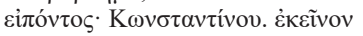

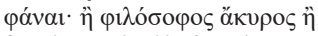

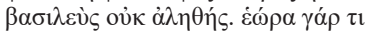

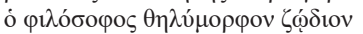

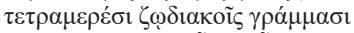

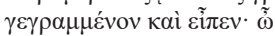

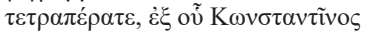

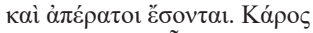

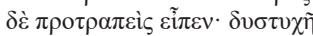

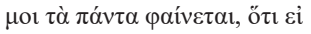

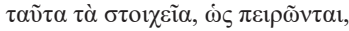

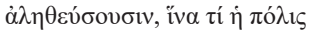

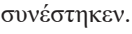

84 عĩ $\varepsilon \varepsilon$ ed. Treu (1880), 18.

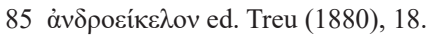

$86 \pi \varepsilon \rho \iota \kappa i ̄ \varphi \alpha ́ \lambda \varepsilon ı \alpha \nu$ ed. Treu (1880), 18.

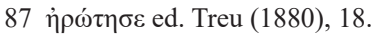


The chapter represents the story of Eudokia and the encounter of her husband, the emperor Theodosius II, with the seven brothers of Eudokia and the ensuing confrontation between them regarding the meaning of the statues. In the Parastaseis, Kranos is the one who takes on the central role, as he is the leader of the Athenian philosophers (

To begin with, the text transmitted in the Parastaseis seems to have been corrupted and, therefore, poses difficulties in interpretation. In some cases, we can only just assume the meaning of a word or a sentence. Such difficulties might have led the Excerpta Anonymi compiler not only to rearrange (as we shall see) the information from the Parastaseis but also to make textual additions to the original text. Therefore, structural differentiation in the Excerpta Anonymi text can justifiably be attributed to the compiler's efforts to simplify the original passage. ${ }^{88}$

Further, it is interesting to note how some details and separate information on Eudokia and her seven brothers have been brought together in the very first phrase in the Excerpta Anonymi. The first sentence in the Excerpta Anonymi stressing the name of Kranos and his own encounter with Theodosius at the Hippodrome, is an addition by the compiler himself based on the specific interest of Kranos in the Parastaseis, which emerged later on in the text however. I would like to draw attention to the underlined passages. The Excerpta Anonymi text begins with a reference to Kranos, which was produced by compiling material found at the end of the original text. A similar reference to Kranos is made again during the description of the question-and-answer confrontation between the philosophers and the emperor Theodosius:

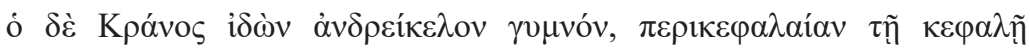

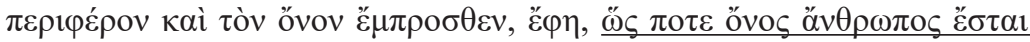

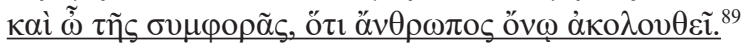

The seven philosophers speak in turn and the second reference has been removed from the end and inserted at the point between the interpretations given by Kyrvos and Pelops, respectively. Thus, the Parisinus compiler decided to end his text with the philosophers' predictions as to the fate of Constantinople. The reason for this could be the fact that the Parisinus compiler intended to shift the focus from the confrontation surrounding the relevant passage in the Parastaseis, by deleting the heated exchange between Kranos and Theodosius. In the Parastaseis when Theodosius meets the philosophers at the Hippodrome, it says: $\tilde{\omega} \varphi \imath \lambda \hat{\sigma} \sigma o \varphi o l$, $\varepsilon \dot{i} \theta \alpha v \mu \alpha \dot{\zeta} \varepsilon \tau \varepsilon, \kappa \alpha \tau \varepsilon \varphi \imath \lambda o \sigma o \varphi \eta \dot{\theta} \theta \eta \tau \varepsilon$, which is a comment indicative enough of the confrontation that was taken place there and leads to the exchange between Theodosius and Kranos later on. Interestingly, the Parisinus excises the word $\kappa \alpha \tau \varepsilon \varphi \imath \lambda o \sigma o \varphi \eta \dot{\eta} \eta \tau \varepsilon$ and replaces it by the question: $\tau i$

88 The difficult original text as well as the compiler's tendency towards clarity and accuracy and his preference for brevity seem to stand behind such a choice.

89 Excerpta Anonymi 18, 13-16. 
$\theta \alpha v \mu \alpha \dot{\zeta} \varepsilon \tau \varepsilon$;. In this way, he can also delete the emperor's exchange with Kranos and at the same time maintain the narrative kernel as well as conceal the conflict between a Christian emperor and a pagan philosopher.

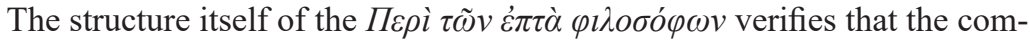
piler of the Excerpta Anonymi read and employed selected texts having first copied them word by word. The compiler would read the relevant passage through to the end annotating it thoroughly. This procedure permitted him to combine disparate details and edit the original text. That allowed him also to rearrange the material when he thought that the meaning was not clear enough or when he wanted to give a new meaning to a certain text passage.

c) Composition

As shown in Chapter 1, the prooemium of the EC as well as Psellos' encomium of Symeon Metaphrastes reveals that, when editing extracted passages, the compiler of a collection relied on certain criteria, such as accuracy and brevity. We notice that the compiler of the Excerpta Anonymi relied methodologically on the same principles by following the procedures detected in the $E C$ and Psellos' encomium. The compiler of the Excerpta Anonymi intervenes in the original text but he does not epitomise it. Two samples from the Excerpta Anonymi may suffice to reveal this. The first one is a passage drawn from the Parastaseis and placed in the first part of the collection (Table 2.3). The passage in the Excerpta Anonymi is entitled $\Pi \varepsilon \rho i \tau \tilde{\omega} v \beta^{\prime} \sigma \tau \alpha v \rho \tilde{\omega} v \tau \tilde{\omega} v \lambda \eta \sigma \tau \tilde{\omega} v$ and it is a prime example of the extent to which the compiler abridges older texts.

Interestingly, the new text is formed once we unify the underlined passages of the Parastaseis' text. It is also apparent that parts from the Parastaseis were copied word by word. One word, the one that is in bold, $\kappa \varepsilon \chi \omega \sigma \mu \varepsilon \dot{v} o r,{ }^{90}$ was removed from the middle of the Parastaseis to the beginning of the

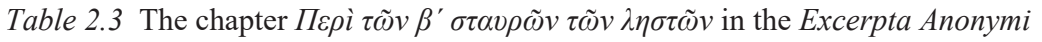

\begin{tabular}{|c|c|}
\hline Parastaseis, Chapter 23 & Excerpta Anonymi 11, 8-12 \\
\hline 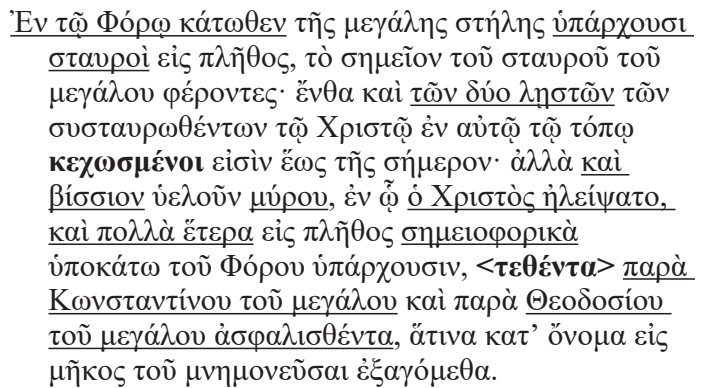 & 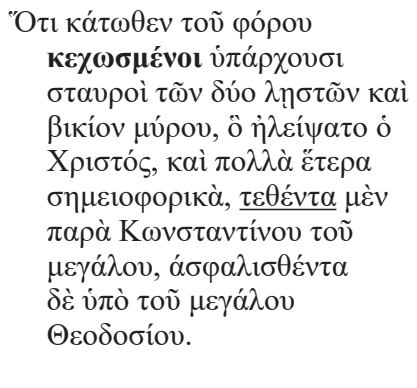 \\
\hline
\end{tabular}

90 The word reflects the attitude of Byzantines towards statues and monuments in Constantinople. Most of the monuments described in the Parastaseis do not even exist when the respective passages are written. But these monuments still exist below the surface of the city attesting to the esoteric dimension of it; cf. Odorico (2011b), 38-41. 
Excerpta Anonymi. Once more it becomes clear that the compiler of the Excerpta Anonymi had first copied the whole passage and read it through to the end before annotating, making alterations, and finally copying it. In that way, he was able to rearrange words, to add an extra word in the text when this was necessary or to delete some others. Accordingly, the word $\tau \varepsilon \theta \varepsilon \dot{\varepsilon} \tau \alpha$ was added in the Excerpta Anonymi to make the meaning of the last part of the passage clearer. The Excerpta Anonymi compiler also omits words and entire phrases without changing the meaning of the passage.

The second passage has been extracted from Procopius' De bellis and is placed in the second part of the Excerpta Anonymi (Table 2.4). The pas-

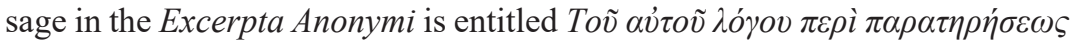
cíóvos. ${ }^{91}$

The Excerpta Anonymi author follows the source text closely and he remains faithful to the selected passages of the source text as regards events and narrative sequence. Particular attention should be given to the fact that most words of Procopius' text are reused by the Excerpta Anonymi in the same grammatical form. The passage was first copied word by word and

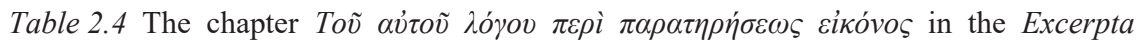
Anonymi

\begin{tabular}{|c|c|}
\hline Procopius, De bellis & Excerpta Anonymi 29, 1-13 \\
\hline 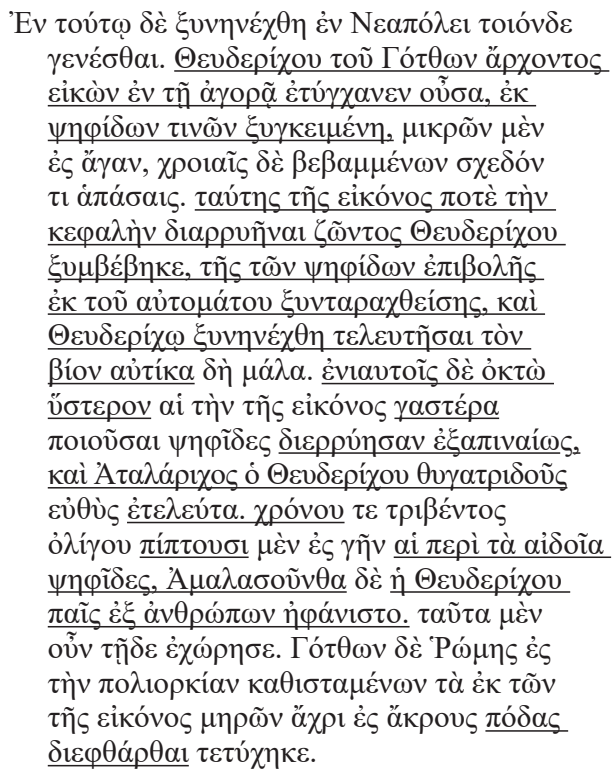 & 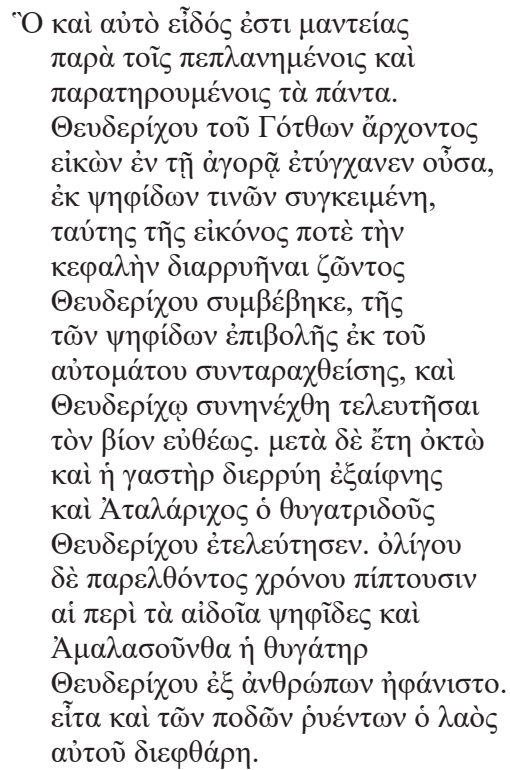 \\
\hline
\end{tabular}


it was read through to the end before being edited. Likewise in the chapter $\Pi \varepsilon \rho i \tau_{\tilde{\omega}} v \beta^{\prime} \sigma \tau \alpha v \rho \tilde{\omega} v \tau \tilde{\omega} v \lambda \eta \sigma \tau \tilde{\omega} v$, our compiler abridges, to some extent, his source by omitting less necessary material. He does not summarise and he does not wish to deviate from the meaning of the original text. The original text was supplemented with information by the compiler himself: it is the introductory statement in bold at the beginning of the Excerpta Anonymi passage. The importance of the frequent use of such brief introductions by the Excerpta Anonymi compiler has already been pointed out. In that way, our compiler makes the narrative sequence of the collection more coherent, comments on or justifies his own criteria of selection of certain texts, and attempts to make his enterprise consistent and comprehensible. The excerptors working under the auspices of Constantine Porphyrogenitus also, often, add a short introduction to selected source texts by combining words found elsewhere in the original text. To give but one example, when excerpting Polybius IV.29-30, the excerptors augmented the story with a few phrases taken from the end of the original text. ${ }^{92}$ In the following chapters, we shall see that the strategy was also used in the Excerpta Salmasiana, Epitome of the Seventh Century, and Excerpta Planudea. It turns out that their compilers were conscious of the flawed contextualisation arisen from excerpting a passage from its original context. Their compiler's conceptual approach, textual practice, and methods coincide with those detected in the $E C$.

\subsection{The EC and the Excerpta Anonymi ${ }^{93}$}

It has become clear by now that the Excerpta Anonymi and the EC were the products of a common approach to older texts in Byzantium. They are a typical product of the culture of sylloge. ${ }^{94}$ Their compilers construct a new narrative on the basis of a series of excerpts and the new whole warrants the transmission of knowledge through a new form, namely that of an excerpt collection. In what follows, I focus on the possibility of a textual relation between the tenth-century Excerpta Anonymi and the $E C$. The hypothesis is advanced that the anonymous compiler of the Excerpta Anonymi relied on earlier collections of excerpts and must have drawn on draft copies produced during the redaction of the Constantinian collections. A. Németh has proved in his dissertation that draft copies were, indeed, written before the final copies of the $E C{ }^{95}$ The existence of drafts for the $E C$

92 EL, 29; on the use of Polybius' Histories in the EC, see Moore (1965), 166-167.

93 The section originates in my article "The Excerpta Anonymi and the Constantinian Excerpts" published in Byzantinoslavica 75 (2017), 250-264. The book is edited by P. Odorico and includes contributions dedicated to the Excerpta Constantiniana.

94 Odorico (1990), 1-21; (2011a), 89-107; see also n. 15 in the Introduction.

95 The examination of the excerpting method in the $E C$ corroborates the existence of intermediary steps, that is draft copies, before the final copies of the $E C$ are executed cf. Németh (2010), 93-1771. See also Featherstone (2013), 353-372. 
raises the possibility that scholars, not necessarily involved in the $E C$ project, could have access to these copies. One should ask whether texts of these drafts could have been used in works other than those of the fifty-three subject-volumes of the $E C$. The latter could lead us to the intriguing hypothesis that the Excerpta Anonymi relied on material also used in the Constantinian project.

Interestingly, there is a group of works that could support the use of the $E C$, directly or indirectly, in the first as well as in the second half of the tenth century. The idea that other imperial treatises also used material, gathered in the first place for the $E C$ was first advanced by I. Ševčenko, who argued for the direct use of the Excerpta de legationibus from the DT, DAI, and Theophanes Continuatus in the case of the story of Soldan's capture by Louis II and his escape. ${ }^{96}$ A. Németh puts emphasis on the close relationship between the $E C$ and the $D C$ in terms of structure and content. ${ }^{97} \mathrm{~J}$. Signes Codoñer advances the hypothesis that the author of the Theophanes Continuatus was also involved in the project of the $E C .^{98} \mathrm{In}$ addition to these works, a collection of excerpts on sieges (codex Parisinus suppl. gr. 607), ${ }^{99}$ the Excerpta Anonymi, and the historical work by Leo the Deacon provide further evidence for the use of the $E C .{ }^{100}$ Significantly, Leo the Deacon's passage on the source of the river Istros bears a striking resemblance to a pas-

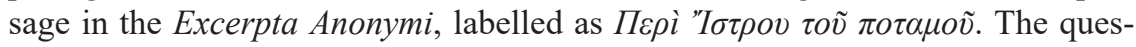
tion to be raised is whether Leo the Deacon and the anonymous compiler of the Excerpta Anonymi have used a common source and if they do so, what this source was. Could this common text be one or more excerpts drawn from one of the Constantinian collections?

\subsubsection{The $\mathrm{EC}$}

The $E C$ is a collection of historical excerpts accomplished under the auspices of the emperor Constantine Porphyrogenitus. The project started before the sole reign of Constantine Porphyrogenitus (945-959), ${ }^{101}$ lasted with certainty for decades, but we are not able to know when precisely it was completed. ${ }^{102}$ The analysis

96 cf. Ševčenko (1992a), 191 n.60. The same in Pratsch (1994), 70-71. See Signes Codoñer (2017), esp. 26-38 and Németh (2018), 121-144.

97 Németh (2018), 137-144.

98 Signes Codoñer (2017), 39. The same in Németh (2018), esp. 148-156

99 The excerpts on sieges seem to have been copied in the Parisinus suppl. gr. 607 earlier than the extant copies of the $E C$ are executed. Similarities in content and excerpting method point to the use of Constantinian collections at an early stage of their redaction; cf. Németh (2010), 147-172; Németh (2018), 115-120 and 191-193.

100 On Leo the Deacon, see Panagiotakes (1965); Markopoulos (2000); Talbot and Sullivan (2005).

101 In Theophanes Continuatus, it is attested to that Constantine established a library in the Camilas palace accumulating books from all over the known world in order to accomplish the major project of the so-called EC; cf. Theophanes Continuatus, 206, 80-82. Constantine shared the throne with Romanos Lekapenus from 920 until 945.

102 According to A. Németh, Basil the Nothos stands behind the final production of the deluxe copies of the EC completed in the early years of Basil II (958-1025); Németh (2010), 1; Németh (2018), 
of the content in the $E C$ betrays attempts made by the emperor to impose imperial authority on the selection of knowledge of the past. ${ }^{103}$ As mentioned already, the format of the $E C$ and their manner of systematising historical works show affinities with other collections of historical excerpts. ${ }^{104}$

The $E C$ as they have survived transmit excerpts from twenty-six historiographers from the fifth century $\mathrm{BC}$ to the ninth century $\mathrm{AD} .{ }^{105}$ The excerpts have been singled out and grouped in fifty-three collections which, in the preface to the work, are called $\dot{v} \pi o \theta \varepsilon \dot{\varepsilon} \sigma \varepsilon l \varsigma .{ }^{106}$ Each of the five $\dot{v} \pi \circ \theta \dot{\varepsilon} \sigma \varepsilon l \varsigma$ that have come down to us corresponds thematically to a subject. Two collections have fully survived and the rest have been transmitted partially: the Excerpta de virtutibus et vitiis have survived in a tenth-century parchment codex, the Peirescianus (Turonensis 980). ${ }^{107}$ The Excerpta de sententiis have been handed down in a palimpsest manu-

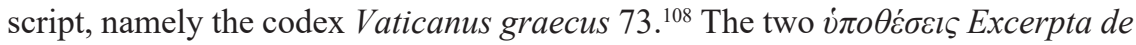
legationibus have been partially transmitted through different manuscripts. Both collections were contained in a codex, the Scorialensis B.I.4, deposited in the Escorial Library, which, unfortunately, was destroyed in a fire in $1671 .{ }^{109}$ Finally, the $\dot{v} \pi \dot{\theta} \theta \varepsilon \sigma \varsigma$ Excerpta de insidiis is partially preserved in two different manuscripts from the sixteenth century, namely the codices Parisinus gr. 1666 and Scorialensis $\Omega$. I.11. $^{110}$

37. Treadgold, by contrast, believes that the EC were completed not long before 959; Treadgold, (2013), 157.

103 Németh (2010).

104 See n. 94.

105 The $E C$ transmit a passage taken from a second-century novelist named Iamblichus. It is the only fragment from a work of fiction included in the $E C$; Németh (2018), 7. For a complete list of the authors, see Lemerle (1971), 285-287; Flusin (2002), 546-550 and 558.Th. Büttner-Wobst suggested that there were twenty-eight excerpted authors. He includes Marcellinus, the author of A Life of Thucydides, whose excerpts are found in the Excerpta de virtutibus et vitiis and the anonymous continuator of Cassius Dio, whose excerpts are found in the Excerpta de sententiis; cf. Büttner-Wobst (1906), 88-120, esp. 96. See also the discussion about the authors included in Photius' Bibliotheca but not in the EC in Treadgold (2013), 160-162. On Constantine Porphyrogenitus' selection of authors to be excerpted in the EC, see Németh (2010), 38-50; Kaldellis (2012), 71-85; Németh (2018), esp. 171-184.

106 Németh (2018), 71-77 attempts to explain the choice of number fifty-three via Christian numerology, mathematics, and ideology.

107 On this manuscript, see $E V 1$, viii-xlii. A. Németh, based on parallels in decoration between the codex Turonensis 980 and later manuscripts, suggested that the codex was made after Constantine Porphyrogenitus' death; Németh (2010), 97. P. Sotiroudis dates the codex Peirescianus to the eleventh century; cf. Sotiroudis (1989), 165-171.

108 On the codex Vaticanus graecus 73, see Mercati and De Cavalieri (1923), 67-78; Németh (2010), 127-134; Németh (2015), 281-330.

109 All copies from the lost codex we possess were made by Andreas Darmarios and his collaborators; Graux (1880), 93-97; de Boor (1902), 146-150. On the distinction between the two collections of Excerpta de legationibus, see Flusin (2002) and Carolla (2008), 129-170.

110 EI, xviii-xx. On Scorialensis $\Omega$.I.11, see Sotiroudis (1989), 174-178 and Carolla (2016), 241243. Parisinus gr. 1666 contains only excerpts from Diodorus of Sicily and John of Antioch. On the textual transmission of Diodorus of Sicily's Bibliotheca via the EC, see n. 206 in Chapter 1. 
Relying on the notes in the margins of the five surviving collections, scholars have suggested titles for the missing $v \pi o \theta \varepsilon \dot{\sigma \varepsilon l \varsigma}$ of the $E C .{ }^{111}$ In addition to the aforementioned cross-references, Németh argues that the topics of the thematic collections of the $E C$ can be identified on the basis of the priorities of interest in other court treatises compiled on the mid-tenth century under the supervision of Constantine VII and Basil Lecapenus. ${ }^{112}$ Despite this, he accepts that the cross-references transmitted in the margins of the extant copies of the $E C$ are the most reliable source for the titles. ${ }^{113}$ In the prooemium to the $E C$ the first $v \pi o ́ \theta \varepsilon \sigma \iota \varsigma$ is called

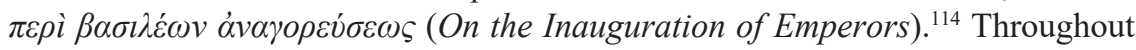
the $E C$ and other works attributed to Constantine Porphyrogenitus, we detect a particular interest in matters concerning the imperial court. Concerns about imperial hierarchy and the succession of emperors are also manifest in a number of titles transmitted in the EC as well as in the De cerimoniis. ${ }^{115}$ Suggested titles such as $\pi \varepsilon \rho \grave{i} \delta \imath \alpha \delta o \chi \tilde{\eta} \varsigma \beta \alpha \sigma l \lambda \varepsilon \dot{\varepsilon} \omega v$ (On the Succession of Sovereigns), ${ }^{116} \pi \varepsilon \rho \grave{i} \gamma \alpha \dot{\mu} \mu \omega v($ On

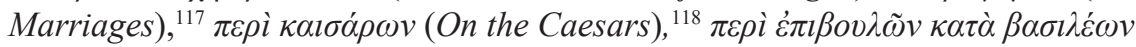

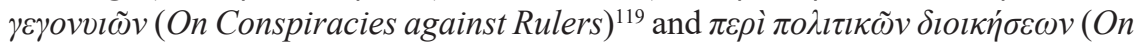
Political Affairs $)^{120}$ are linked to Constantine's interest in the imperial court as well as in politics. A. Németh has also suggested that such titles reflect Constantine's insecurity about his legitimacy. ${ }^{121} \mathrm{~K}$. Schreiner augments the list conjecturing

111 In this respect, the codex Vaticanus gr. 977 containing Theophylact Simocatta's Historiae and its continuation by the patriarch Nicephorus is of particular importance: the codex was used and marked by Constantine Porphyrogenitus' collaborators; cf. Schreiner (1987), 1-30. On numbers and names of the collections, see Wäschke (1882); Büttner-Wobst (1906b), 105-119; Lemerle (1971), 327-328; Schreiner (1987), 13-23; Flusin (2002), 553-555; Németh (2010), 65-69.

112 Németh (2018), 187-211.

113 Németh (2018), 186.

114 The title also occurs as a cross-reference in Turonensis 980, f. 39r; Németh (2018), 187.

115 See Németh (2018), 188. The table of contents of the De cerimoniis records the existence of a chapter on imperial succession; it is Chapter 42, which in the index of Book II is entitled:

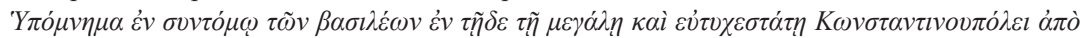

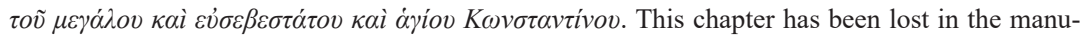
script tradition of the De cerimoniis. As, however, C. Mango and I. Ševčenko have argued the chapter is preserved in a palimpsest codex in Istanbul, the codex Chalcensis S. Trinitatis (125) 133; cf. Mango and Ševčenko (1962), 61-63.

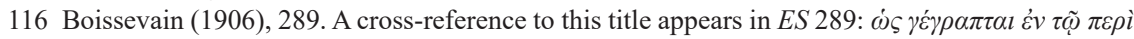
$\delta \iota \alpha \delta o \chi \tilde{\eta} \varsigma \beta \alpha \sigma \iota \lambda \dot{\varepsilon} \omega v ;$ Németh (2018), 188.

117 A cross-reference to the title occurs in EV1, 298; Büttner-Wobst (1906b), 116-117.

118 The cross-reference is found in the EI 75; Büttner-Wobst (1906b), 117.

119 This title is transmitted as a cross-reference in the EI. A similar title, probably referring to the

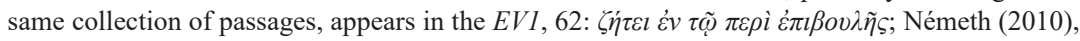
81 ; Németh (2018), 189.

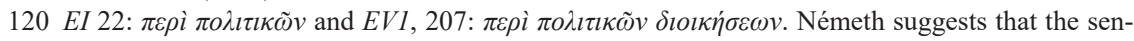

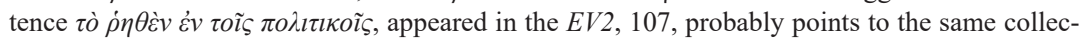
tion; Németh (2018), 194.

121 Németh (2017), 257. Holmes (2010), 55-80 shows that Constantine Porphyrogenitus exploited military compilation literature in order to gain political legitimacy and enhance his political authority. The Patriarch Nicholas I Mysticus (901-907 and 912-925) denied recognizing Con- 
the existence of collections on festivals and the deaths of the emperors. ${ }^{122}$ The

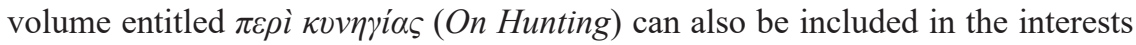
of Constantine Porphyrogenitus' inner circle. ${ }^{123}$ Constantine's interest in military affairs, specifically in war and diplomacy, is mirrored through the $\dot{v} \pi \circ \theta \varepsilon \dot{\sigma \varepsilon l \varsigma}$ bearing the proposed titles $\pi \varepsilon \rho \grave{i} \sigma \tau \rho \alpha \tau \eta \eta \mu \alpha \dot{\tau} \omega v$ (On the Command of the Army), ${ }^{124}$

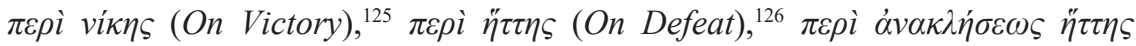
(On the Transformation of Defeat into Victory), ${ }^{127} \pi \varepsilon \rho \grave{\imath} \sigma \nu \mu \beta о \lambda \tilde{\eta} \varsigma \pi 0 \lambda \varepsilon \dot{\mu} \omega \nu$ (On

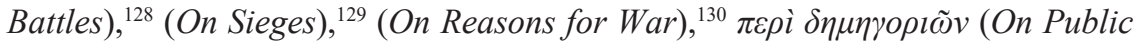
Speeches), ${ }^{131} \pi \varepsilon \rho i$ i $\pi \rho \varepsilon \sigma \beta \varepsilon \omega v$ (On Embassies by the Romans to the Barbarians and On Embassies by the Barbarians to the Romans). ${ }^{132}$ Constantine's interest in wartime virtues becomes manifest in the volume On Virtue and Vice. ${ }^{133}$ Constantine Porphyrogenitus was also interested in geography and ethnography. Apart from the ethnographical digressions embedded in two other works attributed to him, the $D A I$ and the $D T$, he appears to have included collections entitled as $\pi \varepsilon \rho \dot{\imath} \dot{\varepsilon} \theta \tilde{\omega} v(O n$ Customs) ${ }_{1}^{134} \pi \varepsilon \rho \dot{\imath} \varepsilon \dot{\theta} \theta \tilde{\omega} v$ (On Nations), ${ }^{135}$ and $\pi \varepsilon \rho i$ oik $\sigma \mu \tilde{\omega} v$ (On the Settlements). ${ }^{136}$

Scholars have also suggested titles for collections consisting of ekphraseis of

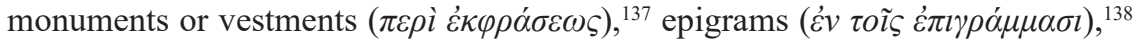
letters $(\pi \varepsilon \rho \grave{\imath} \varepsilon \dot{\pi} \pi \sigma \tau \sigma \lambda \tilde{\omega} v),{ }^{139}$ gnomic statements $(\pi \varepsilon \rho \grave{\imath} \gamma \nu \omega \mu \tilde{\omega} v),{ }^{140}$ and mythol-

stantine Porphyrogenitus as a legitimate heir to the throne because he was the son of the emperor Leo VI and his fourth wife, Zoe Karbonopsina; on the controversies regarding the validity of Leo VI 's marriage, see Oikonomides (1976a), 161-172 and (1976b). See also n. 2 in the Introduction.

122 Schreiner (1987), 21-23.

123 ELg 27. See also in Németh (2010), 83; Németh (2018), 197.

124 ELg 14; ELg 379; EI 33; EV1, 335; EV2, 116; EV2, 123; ES 93.19.

125 ELg 390.

126 ES 210.

127 EV1, 9.

128 EI 207. According to Németh, the title $\pi \varepsilon \rho \grave{\imath} \sigma \nu \mu \beta o \lambda \tilde{\eta} \varsigma$ transmitted in $E V 1,99$ refers to a separate thematic collection. He translates the $\pi \varepsilon \rho i ̀ ~ \sigma v \mu \beta o \lambda \tilde{\eta} \varsigma$ into On Combats; Németh (2018), 191.

129 The title is not transmitted in a cross-reference; Schreiner (1987), 21-23.

130 The title is not transmitted in a cross-reference; Schreiner (1987), 2-23.

131 ELr 484; EV1, 63; EV2, 153; ES 412; EI 4; EI 30; EI 48; EI 215; EI 222.

132 ELg 1-2, 4, 6, 7, 19, 65, 8, 81, 90, 121, 255, 270, 221, 229, 302, 364, 375, 380, 387, 390, 396, 410, 435-442, 477, 489, 513-568, 575, 591.

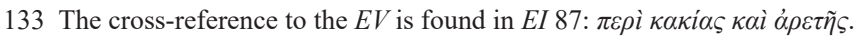

134 ELr 26.

135 EVI, 84.

$136 \mathrm{EV} 1,36$.

137 EV1, 123, 23-24: غ́v $\tau \tilde{\omega} \pi \varepsilon \rho \grave{~} \varepsilon ́ \kappa \varphi \rho \alpha ́ \sigma \varepsilon \omega \varsigma$; see also in Büttner-Wobst (1906b), 111; Németh (2010), 91. Németh (2018), 196 makes reference to a hypothetical collection of the marvels of Constantinople. As we have seen such passages were also included in the Excerpta Anonymi that drew on the Parastaseis.

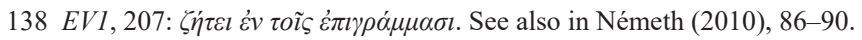

139 ELg 451.

$140 E V 1,212$ and EV1, 254 transmit the title: $\pi \varepsilon \rho \grave{i} \gamma v \omega \mu \tilde{\omega} v$. The ES 222 transmits the title $\pi \varepsilon \rho \grave{l}$ $\gamma \nu \omega \mu \iota \kappa \tilde{\omega} \nu \dot{\alpha} \pi о \sigma \tau о \mu \imath \sigma \mu \dot{\alpha} \tau \omega \nu$. Németh (2018), 209-210 supports that the latter variant should be taken as an authoritative title. 


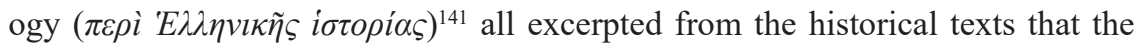
excerptors of the $E C$ had at their disposal. The titles of two other volumes reconstructed on the basis of the marginalia are $\pi \varepsilon \rho \dot{\imath} \dot{\alpha} v \delta \rho \alpha \gamma \alpha \theta \eta \mu \alpha \dot{\tau} \omega v$ (On Courageous

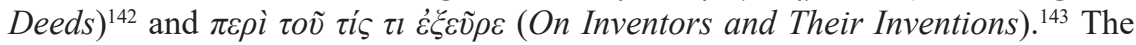
former probably contained excerpts on peculiar events and the latter on various innovative ideas and their inventors.

Constantine's interest in theology is reflected in the title $\pi \varepsilon \rho \grave{i} \varepsilon \kappa \kappa \lambda \eta \sigma \iota \alpha \sigma \tau \iota \kappa \tilde{\omega} v$ (On Ecclesiastical Affairs) of the EC. ${ }^{144}$ The content of the collection bearing the title $\pi \varepsilon \rho i{ }^{2} \pi \alpha \rho \alpha \delta \dot{\xi} \omega \nu$ (On Miraculous Events) ${ }^{145}$ is difficult to determine with accuracy. It is likely that this collection included passages on Christian miracles as well as on portents in non-Christian contexts. It is noteworthy that the Excerpta de Legationibus gentium ad Romanos transmit four excerpts drawn from the Historia Ecclesiastica by Socrates. ${ }^{146}$ The possibility that other ecclesiastical historians were excerpted in the EC cannot be ruled out. ${ }^{147}$ Constantine's interest in theology and hagiography is also expressed through works published on his initiative or under his reign: homilies on the translations of the relics of St John Chrysostom, ${ }^{148}$ Gregory Referendarios' homily on the translation of the Mandylion, ${ }^{149}$ Theodore Daphnopates' oration on the translation of the arm of

141 Büttner-Wobst (1906a), 100 argued that this collection would have included passages on Pagan

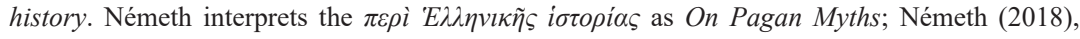

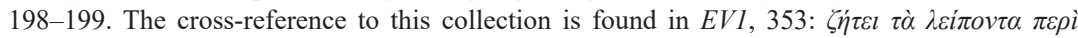

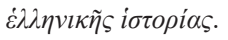

142 EI 33; EI 222; EV1, 338; EV1, 354.

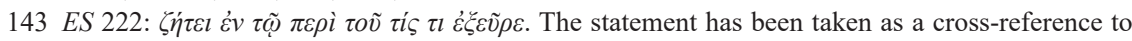
the lost book On Inventors and Their Inventions in Schreiner (1987), 21 and Flusin (2002), 555. The same in Treadgold (2013), 159 who translates the statement as On Who Discovered What. Recently, Németh unburied de Boor's proposition that the statement may point to the existence of a now lost index book assisting the scribes of the final books of the $E C$ to arrange the excerpted passages by topic. Accordingly, Németh renders the statement as On Who Found What; de Boor (1884a), 140-144; Németh (2018), 107-108.

144 EV1, 145.

145 EV1, 40-41; EV2, 172.

146 ELg 387-390.

147 Flusin (2002), 540.

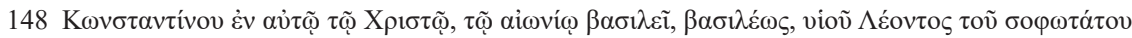

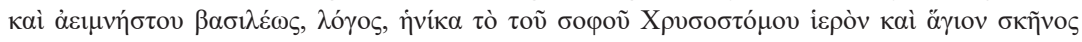

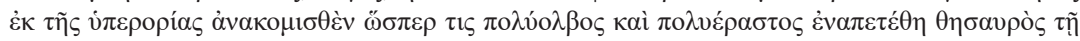

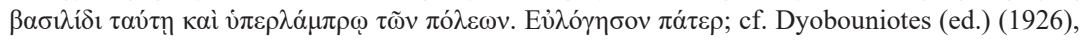
303-319. P. Lemerle rejected K. Dyobouniotes' identification of Constantine Porphyrogenitus as the actual author of the homily; cf. Lemerle (1971), 271.

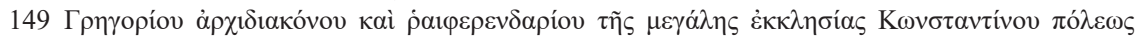

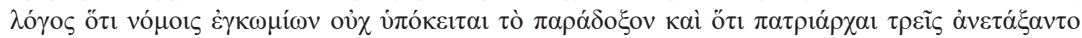

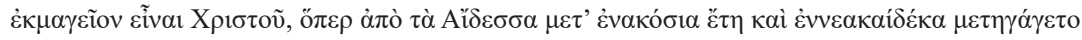

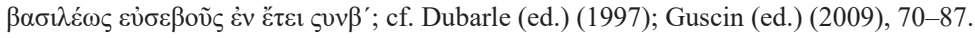




\section{Excerpta Anonymi}

St John Prodromos, ${ }^{150}$ the chains of St Peter, ${ }^{151}$ the translation of the relics of the Image of Edessa, ${ }^{152}$ a panegyric on the translation of the relics of St Gregory of Nazianzus, ${ }^{153}$ and the Synaxarion Ecclesiae Constantinopolitanae. ${ }^{154}$

In the following, I suggest that, for the chapter "On the River Istros", ${ }^{155}$ the compiler of the Excerpta Anonymi drew on a collection of geographical material, whereas for the chapters "On Cyrus"156 and "On Remus and Romulus"157 he drew on a Constantinian collection of occult science. Similarly, passages on Roman history in the Excerpta Anonymi derive from a collection on dreams and occult science. In what follows, I shall undertake a close analysis of the source

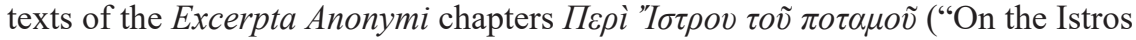

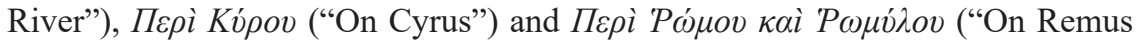
and Romulus").

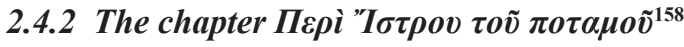

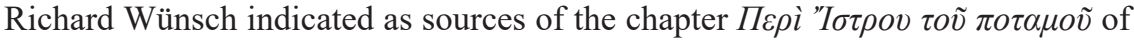
the Excerpta Anonymi passages from the De Mensibus and the De magistratibus populi romani libri tres, both composed by John Lydus. ${ }^{159}$ Yet John Lydus was not the source for the excerptor. With only very few exceptions, the passages of the De Mensibus and the De Magistratibus do not bear any textual similarities

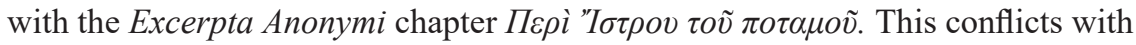
the fact that the Excerpta Anonymi normally remain faithful to the original text and, in many cases, copy their sources word by word. In fact, more than half of the

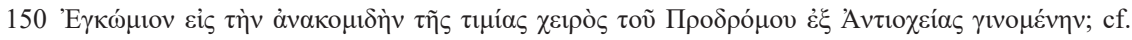
Latyshev (ed.) (1910), 15-38.

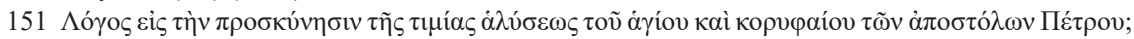
cf. Batareikh (ed.) (1908), 978-1005. E. Batareikh (1908), 974-975 attributes the homily to John Chrysostom. In P. Lemerle's view the homily was written on Constantine Porphyrogenitus' initiative; cf. Lemerle (1971), 272.

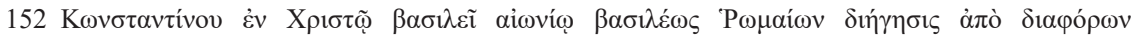

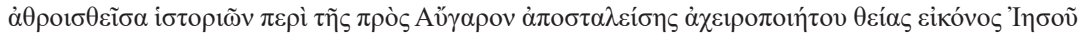

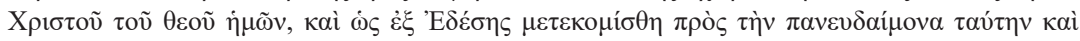

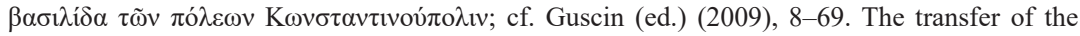
Mandylion, which bore the image of Christ's face, from Edessa to Constantinople was seen by Constantine Porphyrogenitus as an omen signifying his ascent to the throne. The text was incorporated in the Menologion; see Dobschütz (1901), 166-170; Høgel (2002), 63; Németh (2018), 32.

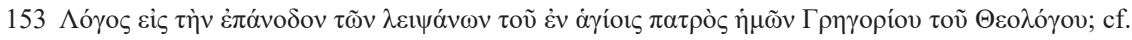
Flusin (ed.) (1999), 40-79.

154 Flusin (2001) 41-47.

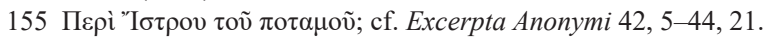

156 Пврі Kúpov; cf. Excerpta Anonymi 33, 1-36, 9.

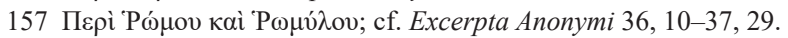

158 On the River Istros.

159 Wünsch (ed.) (1898), x-xx. On the De mensibus, see Bandy (2013). On the De magistratibus, see Bandy (1983). See also n.63. 


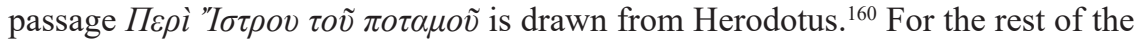
chapter the source used by the compiler needs further investigation.

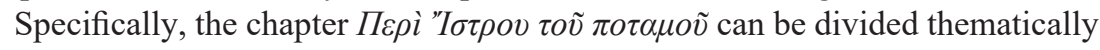
into four consecutive parts, which refer to the four rivers of Paradise: Istros (42, 5-43, 14), Nile (43, 14-26), Tigris and Euphrates (43, 27-44, 9) and again Nile $(44,10-21)$. Let us attempt to pin down the source text for each one of the four parts. The part on the river Istros $(42,5-43,14)$ is composed from three separate texts (see Table 2.5): Herodotus' History, ${ }^{161}$ John Lydus' De magistratibus, ${ }^{162}$ and Ps.-Caesarius' Quaestiones et responsiones. ${ }^{163}$ In particular, Herodotus appears to be the source text for the Excerpta Anonymi 42, 5-43, 2, the De magistratibus is the source for the Excerpta Anonymi 43, 3-11, and Ps.-Caesarius for the Excerpta Anonymi 43, 11-14. The material on the rivers Tigris and Euphrates (43, 27-44, 9) has been taken from the Paraphrases in Dionysium Periegetam. ${ }^{164}$ Finally, the two passages on the Nile (Excerpta Anonymi 43,14-26 and 44, 10-21) are taken from Diodorus Sicily's Bibliotheca historica ${ }^{165}$ and John Lydus' De Mensibus, respectively. ${ }^{166}$

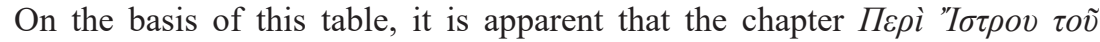

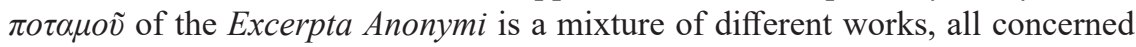
with the four aforementioned rivers, though. Impressively, the works combined in the chapter are of different literary genres; the text is made up of excerpts from two historical works (Herodotus, Diodorus of Sicily), a geographical treatise (Dionysius Periegetes), two antiquarian texts (John Lydus), and an ecclesiastical work (Ps.-Caesarius).

Table 2.5 The sources of the passage On the Istros river, 42, 5-44, 21

\begin{tabular}{ll}
\hline Theme & Source \\
\hline Istros 42, 5-43, & Herodotus, History 4, 48-50 \\
Istros 43, 3-11 & John Lydus, De magistratibus populi Romani, 3, 32 \\
Istros 43, 11-14 & $\begin{array}{l}\text { Ps.-Caesarius, Quaestiones et responsiones, ch. 67 } \\
\text { and 163 } \\
\text { Nile 43, 14-26 }\end{array}$ \\
$\begin{array}{l}\text { Tigris and Euphrates 43, 27-44, } 9 \\
\text { Nile 44, 10-21 }\end{array}$ & $\begin{array}{l}\text { Paraphrases in Dionysium Periegetam 977-1000 } \\
\text { John Lydus, De Mensibus, 4, 107 }\end{array}$ \\
\hline
\end{tabular}

160 M. Treu indicates Herodotus along with a passage from John Lydus' De Mensibus as the only sources of the chapter "On the Istros River"; cf. Treu (1880), 58.

161 Herodotus, 4, 48-50.

162 De magistratibus populi Romani, 3, 32.

163 Quaestiones et responsiones, Chapters 67 and 163.

164 Paraphrases in Dionysium Periegetam, 977-1000.

165 Bibliotheca historica 1, 37, 9.

166 De Mensibus, 4, 107. 


\section{Excerpta Anonymi}

Interestingly, such an approach towards source texts on the part of the Excerpta Anonymi is unique: in all the other chapters of the Excerpta Anonymi, the texts excerpted are clearly distinguished from each other and occasionally identified by the compiler himself. The exceptional situation in the chapter on the River Istros therefore makes it unlikely that the compiler of the Excerpta Anonymi was

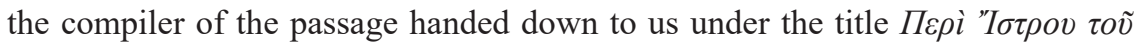
$\pi о \tau \alpha \mu о \tilde{v}$. This hypothesis is corroborated when examining the collection in its entirety. The Excerpta Anonymi transmit a sylloge of excerpts just like those produced in Byzantium from the fifth century onwards. Excerpt collections appear to conform to a number of structural principles: the compiler of a sylloge excerpts pre-existent texts and edits them while respecting their general structure. Furthermore, the selection of excerpts in the Excerpta Anonymi was based on general criteria such as accuracy, clarity, brevity and yet faithfulness to the original narration. The compiler of the Excerpta Anonymi creates a new narrative on

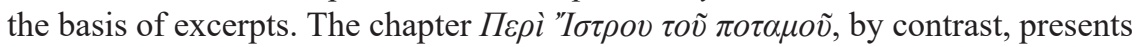
itself as a single excerpt but is in fact a brief compilation within a collection of excerpts. Throughout the Parisinus suppl. gr. 607a, with the exception of the

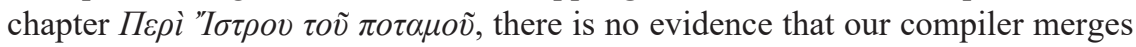
separate source texts to create a single excerpt. The conclusion must be that the compiler of the Excerpta Anonymi has excerpted the passage on the four rivers of Paradise as a single entity from another manuscript. What was, however, the nature of that manuscript? Was it a different excerpt collection, miscellaneous writings, a depository of notes intended for the private use of the compiler, or a manuscript representing an intermediate stage to a final work? The composite nature of the passage, a conflation of different works on the same subject, could favour the latter argument. The hypothesis is further strengthened by the exist-

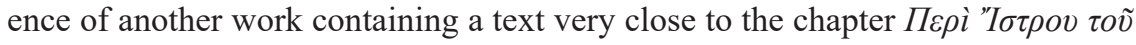

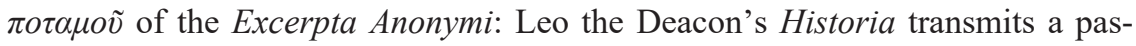
sage similar to that of the collection; the only divergence is that Leo the Deacon records that the Istros resurfaces in the Celtic Mountains, whereas in the Excerpta Anonymi the river reemerges in the Apennine Mountains. ${ }^{167}$

Leo the Deacon was born ca. 950 in western Anatolia and came to Constantinople in his youth to receive his secondary education. He was ordained a deacon around 970 and joined the palace clergy in 976 during the reign of Basil II. Several passages in his Historia manifest his classical education. ${ }^{168}$ As a member of the palace clergy he is likely to have had access to the imperial scriptorium and to the draft copies of the $E C$. $^{169}$

167 Leo the Deacon's work survives in the Parisinus gr. 1712, ff. 272r-322r (fourteenth c.). On Parisinus gr. 1712, see Snipe (1991), 543-548. Németh (2018), 159 mentions that a flyleaf containing Leo the Deacon's erased text was recently discovered in Vaticanus gr. 1307, f. i (thirteenth c.).

168 Talbot and Sullivan (2005), 9-10.

169 The same has also been supported by A. Németh; cf. Németh (2010), 99; Németh (2018), 158161. On the existence of the imperial scriptorium, see Irigoin (1959), 177-181. 
In his Historia, Leo the Deacon draws on a significant number of earlier historians, such as Herodotus, Thucydides, Diodorus of Sicily, Dionysius of Halicarnassus, Procopius, and Agathias. ${ }^{170}$ It is noteworthy that all of these historians had also been excerpted and used in the $E C .{ }^{171}$ In addition, Leo the Deacon's Historia contains a considerable number of speeches and digressions reflecting topics of the fifty-three Constantinian hypotheses: the origin of the Mysians, the customs of the Rus, and the accounts on the Hole Tile, and on the source of the river Istros. ${ }^{172}$ As mentioned above, Leo's passage on the source of the river Istros bears a striking resemblance to the passage in the Excerpta Anonymi, labelled as

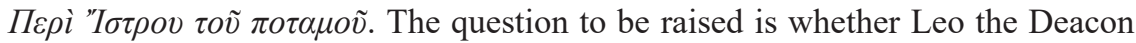
and the anonymous compiler of the Excerpta Anonymi used a common source and if they did so what was this source. Could this source be one or more excerpts drawn from one of the Constantinian collections?

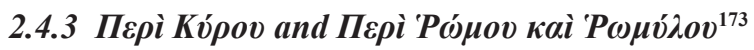

The other two chapters, under discussion, are "On Cyrus" and "On Remus and Romulus". In the Excerpta Anonymi 32, 28-33, the anonymous compiler interrupts the sequence of excerpts to insert a statement of his own. Apparently, he intends to inform the reader about the content of the forthcoming chapters:

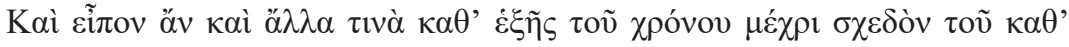

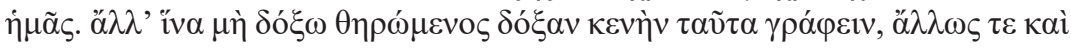

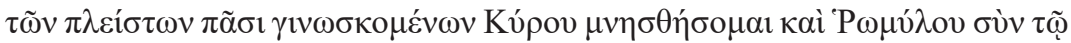

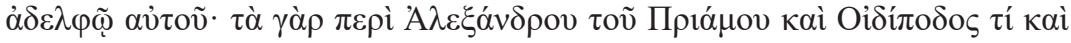

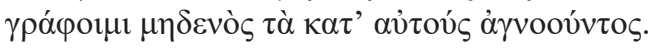

I could say even more of such things, one after another, up to our time, but in order not to be considered that I write about these things seeking vainglorious reputation, and because most of these things are known to all, I will mention Cyrus as well as Romulus and his brother. However, wherefore to write about Alexander, the son of Priam and about Oedipus, since everyone is acquainted with their stories?

If we take the statement at face value, we could say that the compiler had all four stories at hand, but that he selected only two, because they were less well known to the public. Moreover, the Excerpta Anonymi compiler names four characters,

170 Talbot and Sullivan (2005), 16-19. On the textual transmission of the work, see Panagiotakes (1965), 42-129.

171 On the use of Thucydides' Historiae in the EC, see irigoin (1977), 242-244. On Diodorus, see n. 206 in Chapter 1. On Dionysius, see Sautel (2000), 90-91; Parmentier-Morin (2002), 461-476; Pittia (2002); Fromentin (2010). On Procopius, see n. 60 in this chapter. On Agathias, see Treadgold (2007), 279-290 and n. 50 in Chapter 3.

172 Talbot and Sullivan (2005), 16.

173 On Cyrus and On Remus and Romulus. 
who all share a number of characteristics: first, they are stories about a son of a king, exposed to death but miraculously spared to accomplish great achievements later on, and second, dreams play a crucial role in all four narratives. The compiler prefers to recount only two of them, namely the story of Cyrus and the story of Remus and Romulus. At least two of these stories were known to the compilers of the $E C$ : unlike the stories of Cyrus and Remus and Romulus, the story of Oedipus and of Alexander are included in the $E C$. The former is found in a short excerpt in the $E I$ under the name of Nicolaus of Damascus. ${ }^{174}$ The story of Alexander is presented briefly in the $E V 1$ where the excerptors used John of Antioch. ${ }^{175}$ This renders it likely that the four stories had been excerpted and put together by the Constantinian excerptors in a now lost collection about dreams.

We can note in passing that it is likely that the $E C$ also knew the two other stories. In the $E V 1$, the excerptors included two passages concerning Remus and Romulus, under the name of Nicolaus of Damascus. ${ }^{176}$ The excerpts were inserted immediately after excerpts narrating Cyrus' conquest of Lydia. ${ }^{177}$ The coincidence in content and sequence with the Excerpta Anonymi is striking. The chapter Пврі Kúpov in the Excerpta Anonymi records the Herodotean story of Cyrus's early life. Herodotus was also excerpted in the $E V 2 .{ }^{178}$ One of the excerpts juxtaposed in the $E V 2$ was extracted from the story of Cyrus' early life, which is also included in the Excerpta Anonymi. ${ }^{179}$ In particular, in the EV 2, we encounter the story of Harpagus, whom Astyages tricked into eating his own son. After the meal, Astyages' servants brought Harpagus the head, the arms, and the legs so that he would realise that he had eaten his own son. The previous part of the story is missing. It might or might not have been excerpted in one of the other fifty-three hypotheses.

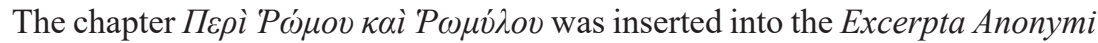
after the material on Cyrus and precedes a passage excerpted from Appian, namely

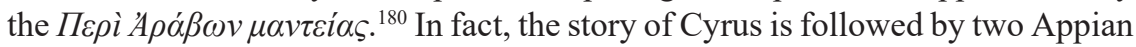
excerpts, which are also thematically connected: they both narrate oracles that

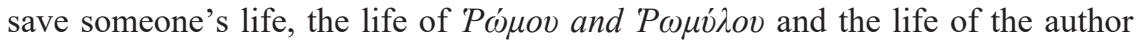
himself, respectively. With regard to the correlation between the $\Pi \varepsilon \rho \grave{~ K u ́ \rho o v ~ a n d ~}$ the two Appian excerpts, I have two points to make. First, on the left margin on f. 47v in the codex Parisinus suppl. gr. 607a there is a number precisely in front

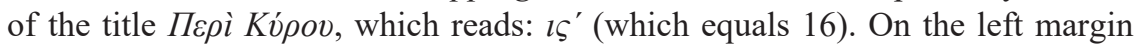

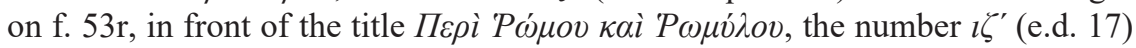

174 EI 7. On the relationship between Nicolaus of Damascus and the $E C$, see Parmentier-Marin and Barone (2011), xi-lxi.

175 EV 1, 166-167.

176 EV 1, 349-353.

177 Though the excerpts were extracted from Dionysius of Halicarnassus, they were mistakenly inserted into text passages of Nicolaus of Damascus.

178 EV 2, 1-30.

179 Excerpta Anonymi 33, 1-36, 9.

180 Excerpta Anonymi 37, 30-38, 21. 
occurs, ${ }^{181}$ and finally, on the left margin on f. 55v, in front of the title of the last Appian excerpt, we encounter the number $i \eta^{\prime}$ (e.d. 18). The numeration implies an order. However, what does this order refer to? An order according to what? I suggest that the numeration at this point in the Excerpta Anonymi reflects the order by which the three excerpts had been copied in the manuscript which our compiler relied on. Given the fact that the three excerpts are thematically connected, this manuscript most probably was a dossier comprising material on omens and dreams, perhaps a depository of texts for later use. The fact that in the EV 2 two different passages, on Cyrus and Remus and Romulus respectively, had been copied in a sequence similar to that in the Excerpta Anonymi may be a coincidence. If we bear in mind, however, the way the Constantinian excerptors employed the complete narratives they had at hand, it seems probable that there was at least a draft manuscript containing, in sequence, material taken from the Herodotean version of Cyrus' early life and the Appian version of the founders of Rome. ${ }^{182}$

\subsubsection{The passages on Roman history}

The Excerpta Anonymi 29, 14-32, 27 transmit a series of excerpts derived from the Cassius Dio tradition; some excerpts show similarities with Dio's direct tradition and some others exhibit textual congruence with Xiphilinus' epitome of Dio. ${ }^{183}$ Interestingly, the concatenation of Dio excerpts in the Excerpta Anonymi is interrupted by four consecutive passages, which $\mathrm{M}$. Treu either mistakenly assigns also to Cassius Dio or leaves unidentified. ${ }^{184}$ Two of the passages, namely the

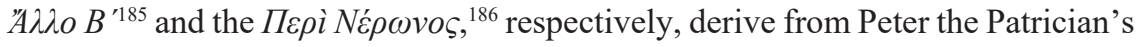
Historia preserved in the ES of the EC. ${ }^{187}$

181 M. Treu here mistakenly indicates $\iota \varsigma^{\prime}$ in the apparatus criticus instead of $\iota \zeta^{\prime}$; cf. Excerpta Anonymi 36, 10.

182 The Excerpta Anonymi contain three further excerpts from Appian in the first part of the col-

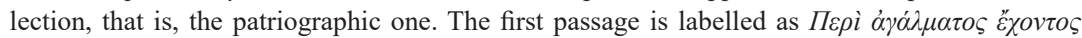
$\dot{\varepsilon} v \tau \tilde{\eta} \kappa \varepsilon \varphi \alpha \lambda \tilde{\eta} \kappa \varepsilon \dot{\varepsilon} \rho \tau \alpha$ and was taken from Appian's book on the Syrian war (Syrian War 11, 57,

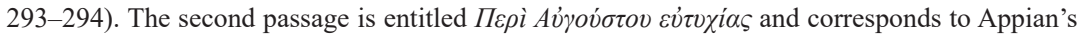

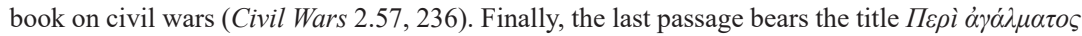
$\dot{\varepsilon} v \pi \dot{\varepsilon} \tau \rho \alpha \tau \tilde{\eta} \varsigma$ A $\rho \alpha \beta i \alpha \varsigma$. The text has been copied also in the Patria II (Patria II, 84). The word $\pi \varepsilon \dot{\varepsilon} \rho \alpha$ refers to the city of Petra. Appian refers to the city of Petra again in the excerpt $\Pi \varepsilon \rho i$

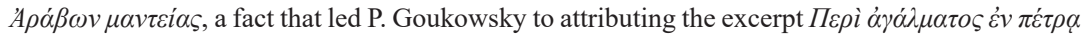

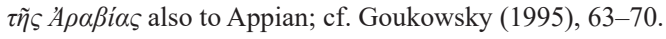

183 My thanks go to Dr. Dariya Rafiyenko for much helpful discussion on the matter: much attention is needed in dealing with U. P. Boissevain's edition of Cassius Dio. For U. P. Boissevain relied on Dio's direct tradition only when this is possible. In many cases, he combines Dio's sources in order to form a Dio text that is as reliable as possible. See, for instance, $C D 59,25,5 \mathrm{~b}-7$ and $63,7,2$.

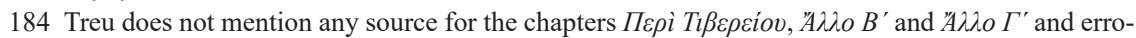
neously ascribes the chapter $\Pi \varepsilon \rho \grave{~} N{ }^{\prime} \rho \omega v o \varsigma$ to Cassius Dio; cf. Treu (1880), 58.

185 Excerpta Anonymi 31, 14-17.

186 Excerpta Anonymi 31, 24-30.

187 ES, 243, 11-13, and ES, 253, 23-27. 
The " $A \lambda \lambda o$ B (Excerpta Anonymi 31, 14-17) is decidedly close to ES 14 of the $E C$. Stress should be laid on the fact that the Excerpta Anonymi as well as the ES

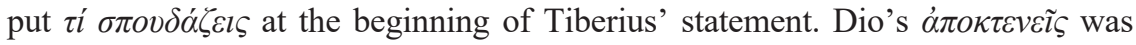

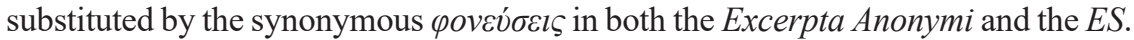

In addition, the Excerpta Anonymi exhibit significant similarities with another excerpt collection, namely, the Exc.Salm.II ${ }^{188}$ with regard to the selective use of passages in the section on Roman history. Both excerptors have chosen to excerpt and include the same passages from the Cassius Dio tradition. ${ }^{189}$ The wording is virtually identical. Accordingly, the excerptors appear to share an interest in occult science as well as in dreams predicting the future. They both incorporate texts dealing with emperors who mistakenly underrated the abilities of astrologers to foresee the future. The common selective use of passages testifies to the use of a common source, that is, an excerpt collection comprising certain excerpts from the Cassius Dio tradition. ${ }^{190}$ The collection must have been on dreams and occult science.

I would like to draw attention to Exc.Salm.II 54. As Table 2.6 shows, the excerpt is impressively identical to a passage from Peter the Patrician's Historia, preserved in the ES 89 of the EC. The respective passage in the Excerpta Anonymi is, like-

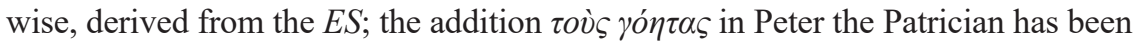
transmitted in both, the Exc.Salm.II and the Excerpta Anonymi. The same holds

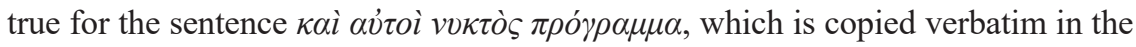
Exc.Salm.II 54 and the Excerpta Anonymi 31, 24-30. Cassius Dio, by contrast, says

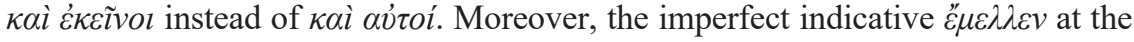
end of the Exc.Salm.II 54 is only found in Peter the Patrician's text. Furthermore, that Dio's text was first abridged and used by Peter becomes manifest in the inclu-

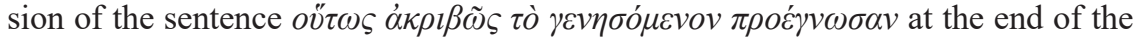
ES 89. The Exc.Salm.II 54 do not excerpt the phrase.

188 The Excerpta Salmasiana are a sylloge of historical excerpts named after the French humanist Claude Saumaise, who copied them around the year 1606 from a mid-twelfth century codex in Heidelberg. The compiler of the sylloge remains anonymous but in all likelihood, he collected and put the excerpts together between the eighthth and the eleventh-twelfth centuries. The Excerpta Salmasiana, in the form they have been handed down to us, represent a compilation of two distinct collections of excerpts. Each of the two collections is based on a different historiographical tradition. The first part, the Exc.Salm.I is transmitted under the name of John of Antioch. As far as the Exc.Salm.II are concerned, the arrangement of the selected excerpts reveals the activity of an excerptor who attempted to expand on the Exc.Salm.I by composing a sylloge running from the Deluge to the fifth century. The Excerpta Salmasiana are studied in Chapter 3.

189 Exc.Salm.II 44 = Excerpta Anonymi 29, 19-21 and 25-27 =CD 44, 17, 1 and 37, 52, 2, Exc. Salm.II 45 = Excerpta Anonymi 29, 28-30, $10=$ CD 45, 1, 3-45, 2, 2, Exc.Salm.II $54=$ Excerpta Anonymi 31, 24-30 = Pet.Patr. $($ ES 89) = CD 65, 1, 4, Exc.Salm.II $56=$ Excerpta Anonymi 32, 1-9 = CD 67, 16, 2-3 Exc.Salm.II 57 = Excerpta Anonymi 32, 11-21 = CD 67, 18, 1-2.

190 It is noteworthy that Exc.Salm.II 53, 54, and 59 correspond to Peter the Patrician, ES 59, 89, and 112 , respectively. 
Table 2.6 Passages on Roman history excerpted in the Excerpta Anonymi

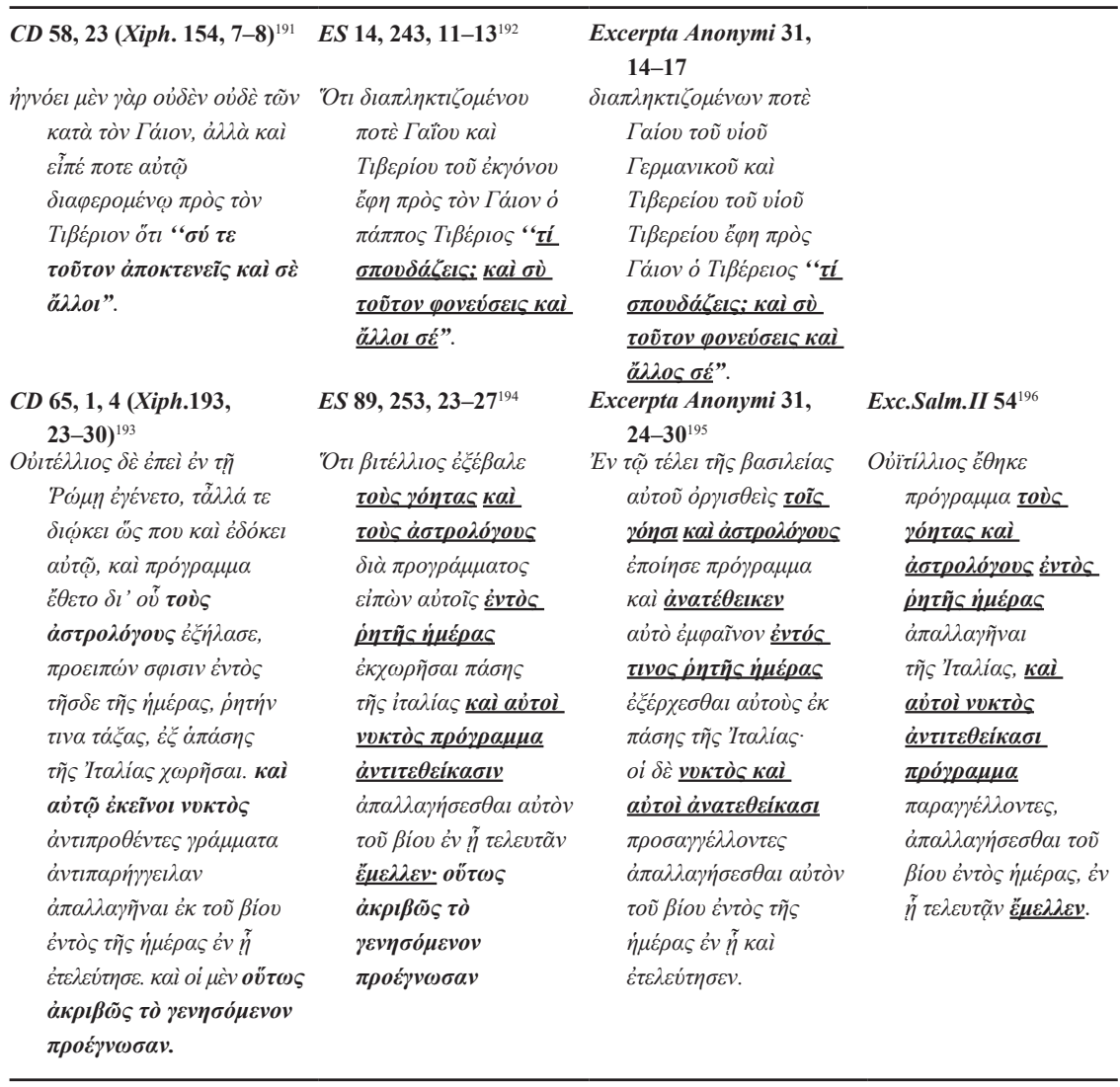

191 Transl. Banchich (2015), 31: Once when Gaius, the son of Germanicus, and Tiberius, the son of Tiberius were sparring, Tiberius said to Gaius, "Why hurry? You will kill him and another you".

192 Transl. Banchich (2015), 31: Once when Gaius and Tiberius, his [Tiberius] descendant, were sparring, Tiberius the grandfather said to Gaius, 'Why hurry? You will slay him and others you'.

193 Transl. Banchich (2015), 72: When Vitellius was in Rome, he was, I suppose, managing other matters as seemed right to him, and he issued an edict through which he expelled the astrologers, having told them to leave from all Italy within this day, having posted the specified one. And they, when they had issued a counter notice at night, in turn ordered him to depart from life on the day in which he died. And thus, on the one hand, they accurately prognosticated what was going to occur.

194 Transl. Banchich (2015), 72: Vitellius expelled the sorcerers and the astrologers through the edict, having told them to depart all of Italy on the specified day. And they, during the night, set up a counter edict stating that he was going to depart from life on the day in which he died. And thus, they accurately prognosticated what was going to occur.

195 At the end of his rule, irritated by the sorcerers and the astrologers, he edicted on what specified day they were to leave from all Italy. They, on the other hand, during the night, countered by announcing that he was going to depart from life on the very day he died.

196 Vitellius issued an edict to send the astrologers and the sorcerers away from Italy on a specified day. And they, during the night, countered by announcing that he was going to depart from life on the very day he died. 
Strikingly, Excerpt 54 is not the only passage in the Excerpta Salmasiana to derive from Peter the Patrician. Exc.Salm.II 59 is blatantly identical to ES 112 of the EC. The Exc.Salm.II 59 preserves Peter's order ( $\tau \grave{\eta} v \dot{\alpha} \rho \chi \dot{\eta} v \tau \tilde{\omega} v \delta o \rho v \varphi o ́ \rho \omega v$

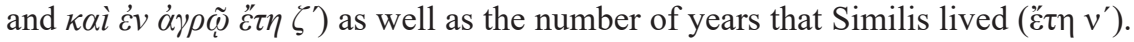
Cassius Dio, on the other hand, records only that Similis had a life of many years ("̌̃ $\eta \tau o ́ \sigma \alpha$ ), without giving the exact number.

Finally, Exc.Salm.II 53 corresponds to ES 59 of the EC. The passage transmits an oracle foretelling that the last of Aeneas' sons would kill his mother and govern. ${ }^{197}$ Table 2.7 exhibits the Excerpta Salmasiana passages assigned to Peter the Patrician.

Table 2.7 Peter the Patrician's Historia in the Excerpta Salmasiana

\begin{tabular}{|c|c|c|}
\hline $\begin{array}{c}C D \text { 62, 18, } 4 \text { (Xiph. } \\
169,2-6)\end{array}$ & Pet.Patr. (ES 59) & Exc.Salm.II 53 \\
\hline 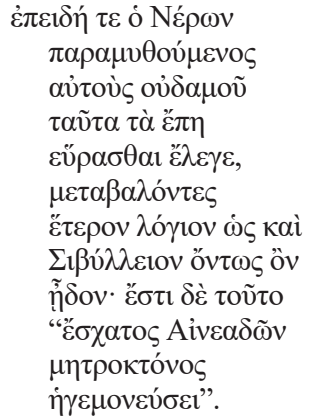 & 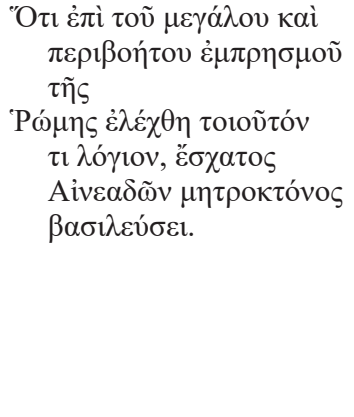 & 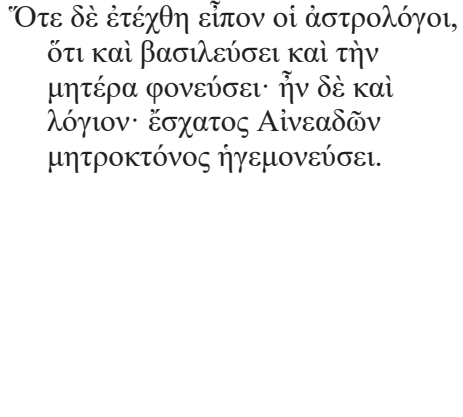 \\
\hline $\begin{array}{c}\text { CD 69, 19, } 2 \text { (Xiph. } \\
253,19-23+ \\
\text { EVetV) }\end{array}$ & Pet.Patr. (ES 112) & Exc.Salm.II 59 \\
\hline 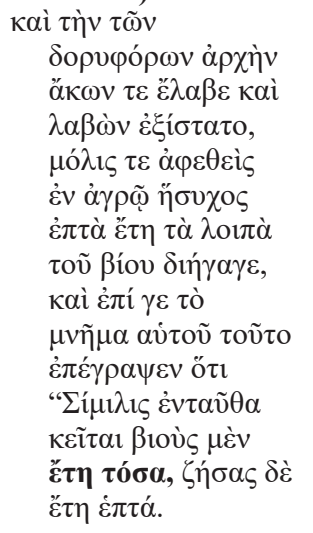 & 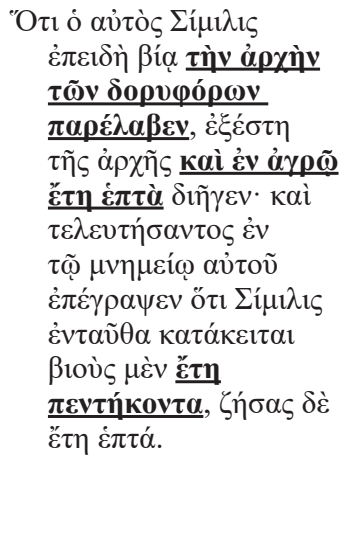 & 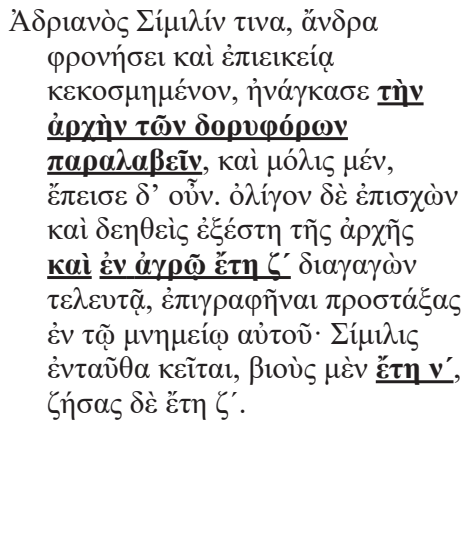 \\
\hline
\end{tabular}


If I am right in postulating a common source between the Exc.Salm.II and the Excerpta Anonymi, this source could be 1) a collection of excerpts on dreams and occult science; the excerpts are taken from Cassius Dio and Peter the Patrician's works and 2) Peter the Patrician's Historia.

The latter possibility is tempting, if very difficult to prove given the paucity of evidence for Peter's texts. The $E S$ and $E L$ of the $E C$ are the unique sources for the sixth-century author from Thessaloniki. ${ }^{198}$ The extant fragments from his history show a strong adherence to Dio's text. ${ }^{199}$ This seems to be the only piece of evidence we possess with respect to his literary preference. The unidentified passages in the Excerpta Anonymi are congruent with the historical interests of Peter's and could easily plug gaps in his narrative as it was handed down in the $E C$. Nevertheless, both arguments are not sufficient to positively ascribe the whole section on Roman history in the Excerpta Anonymi to Peter the Patrician.

\subsubsection{The EC as a depository of knowledge}

As noted, I. Ševčenko was the first to argue that other treatises compiled in the palace also used material gathered in the first place for the $E C .^{200}$ In fact, geographical interest dominates the $D T$ and the $D A I$. The DT made use of historians excerpted also in the $E C{ }^{201}$ The same holds true for the DAI. In addition, the codex Laurentianus Plut. 55,4, which was a product of the imperial scriptorium, contains geographical information, too. ${ }^{202}$

Interestingly, there is also a group of histories that were certainly produced under the direction of Constantine Porphyrogenitus (944-959) and Basil the Nothos (that is under Nicephorus Phocas' reign, 963-969) through processes of compilation. This bunch of texts comprises Genesius' Regum Libri Quattuor, ${ }^{203}$

The oracle has also been transmitted as a later scribal addition to Symeon Logothetes' Chronicon; cf. Symeon Logothetes, Chronicon, 85.

198 The grammatical treatise $\Pi \varepsilon \rho i \grave{\Sigma} \Sigma v v \tau \dot{\alpha} \xi \varepsilon \omega \varsigma$ transmits two brief quotations from Peter's Historia; cf. Bekker (ed.) (1814), 130 and 149.

199 Bleckmann (2015), 103-116; Roberto (2016), 51-67.

200 See n. 96.

201 See, for instance, passages taken from Nicolaus of Damascus and Polybius; Németh (2018), 128.

202 Dain and Foucault (1967), 362. The codex Laurentanus Plut. 55.4 is a collection of Leo VI's military treatises assembled by Constantine Porphyrogenitus. On the codex, see Mazzucchi (1978), 276-316, Rance (2007), 733-736; Breccia (2011), 139-140. See the similar remarks made in Németh (2018) esp. Chapter 5.

203 The history by Genesius covers more briefly the same period as the first part of the Theophanes Continuatus (813-867) and similarly to Theophanes Continuatus is addressed to Constantine Porphyrogenitus. The work survives in a single manuscript, Lipsiensis gr. 16 (eleventh c.), ff. $248 \mathrm{r}-285 \mathrm{v}$. The narrative contains geographical notices and quotations from Homer (like the Excerpta Anonymi); cf. Lesmüller-Werner and Thurn (edd.) (1978), esp. xxi-xxvi.; Kaldellis (1998). Genesius completed his historical work before 961; Markopoulos (2009), 141. Genesius tends to explain place named with myths; Markopoulos (2009), 144 n.44. 


\section{Excerpta Anonymi}

the Theophanes Continuatus, ${ }^{204}$ Ps.-Symeon's Chronographia, ${ }^{205}$ and the two versions of Symeon Logothetes' Chronicon. ${ }^{206}$ These works, produced in imperial circles, show affinities in methodology, content, and sources. Accordingly, they quite often correlate with each other in terms of common references to the past, mythological figures, exaggerated accounts, and geographical allusions. ${ }^{207}$ The phenomenon implies the existence of a shared written tradition ${ }^{208}$ as well as a common repository of relevant references, that is a collection of historical-geographical material. J. Signes Codoñer holds the same view when arguing that a common source should be considered to be an anonymous collection of historical excerpts. ${ }^{209}$ When exploring the sources of the historical-geographical digressions encountered in the official histories throughout the tenth century, we arrive at two significant conclusions: 1) these original texts were also excerpted in the $E C$ and 2) the sources were used in works which were compiled decades after Constantine Porphyrogenitus' death. The latter point may suggest that material employed in the Constantinian imperial scriptorium continued to be used and elaborated for years inside and out of it.

204 See n. 4 in the Introduction. The text has been handed down to us in a single manuscript, the codex Vaticanus gr. 167 and comprises six books or three distinct parts: Part 1 (four books on the reigns of Leo V, Michael II, Theophilus, and Michael III, respectively), Part 2 (a book entitled Vita Basilii), and Part 3 (a book on the reigns of Leo VI, Alexander, Constantine VII, Romanos I, Constantine VII, and Romanos II). The third part may consist of two separate parts given the distinct political orientation of each of them. On the title of the Vita Basilii, see Ševčenko (2011), 3-55.

205 The text is transmitted in the codex Parisinus gr. 1712 (fourteenth c.), ff. 18v-272r and remains unedited except for the folios 235r-272r edited first by F. Combefis, in Combefis (ed.) (1685), 401-498. This edition was reprinted by I. Bekker in Bekker (1838), 603-760. Beside Bekker's edition, a few passages (ff. 83r-88v) were published in Halkin (1959-1960), 7-27 and some others (ff. 200v-235r) in Browning (1965), 406-410. On the Parisinus gr. 1712, see Markopoulos (1978), 30-37 and Wahlgren (ed.) (2006), 46 and 87-89.

206 The first version of Symeon's chronicle was edited by S. Wahlgren; cf. Wahlgren (ed.) (2006). The second version remains poorly edited. Passages of parts of manuscripts preserved the second edition and were published in Bekker (1838), 353-481; Istrin (1922), 3-65; Markopoulos (1979), 91-100; Featherstone (1998), 420-433. On the manuscript tradition of the first and second version of the chronicle, see Wahlgren (ed.) (2006), 27-49. On the dating of the two versions, see also Markopoulos (1979), 83-119 and Treadgold (2013), 203-217. The identification of the Symeon Logothetes with Symeon Metaphrastes was disputed in Høgel (2002), 61-88 and Wahlgren (ed.) (2006), 3-8.

207 A. Markopoulos seems to be certain that Genesius' history and Theophanes Continuatus used common sources; cf. Markopoulos (2009), 137-150. Treadgold (2013), 180-181, Featherstone and Signes Codoñer (2015), 10-13 and Signes Codoñer (2017), 19 share A. Markopoulos' view. W. Treadgold sees the lost Secret History of Nicetas the Paphlagonian as the common source shared by Genesius and Theophanes Continuatus; cf. Treadgold, 180-196. Treadgold's view does not seem to be tenable though; see Ljubarskij (1987), 12-27 and n. 212 in Chapter 1. I. Ševčenko argued that the author of the Regum Libri Quattuor was a member of the literary circle of Constantine Porphyrogenitus; cf. Ševčenko (1992a), 171.

208 A. Diller first observed that the idea of historical embellishment is parallel to the revival of antique pagan themes in contemporary Byzantine plastic arts; cf. Diller (1950), 245, esp. n. 11.

209 Signes Codoñer (1993-1994), 319-341; Featherstone and Signes Codoñer (2015), 10-13. On the existence of such a source, see also Magdalino (2013c), esp. 200-206. 
Specifically, the aforementioned histories transmit geographical allusions that originally occurred in Homer, Strabo, Stephanus Byzantius, Dionysius of Halicarnassus' Antiquitates Romanae, Nonnus' Dionysiaca, Scholia on Apollonius Rhodius, Scholia on Dionysius Periegetes, Arian's Bithyniaca, John Malalas' Chronographia, and Hesychius' Patria. ${ }^{210}$ As noted, in addition to the imperial treatises manifesting the Constantine Porphyrogenitus' interest in geography and ethnography, Laurentianus Plut. 55.4, a codex assigned to the imperial scriptorium of the same period, displays the same preference for geographical and ethnographical passages. ${ }^{211}$ As far as the Excerpta Anonymi are concerned, the excerpt collection contains geographical references that occur likewise in some of the histories, namely the Excerpta Anonymi 49, 1-4 on Tarsus occur in Genesius $^{212}$ and the Excerpta Anonymi 49, 17-18 on the origins of the name of the Medes bears significant resemblance to a passage in Ps.-Symeon. ${ }^{213}$

I would also like to draw attention to two chapters embedded into the first part of the Excerpta Anonymi. The first part is mainly made up of passages on Constantinopolitan statuary. The thematic sequence is contaminated by two apparently irrelevant ethnographic digressions of two peoples, namely the Norici ${ }^{214}$ and the Getae. ${ }^{215}$ The first chapter is a mythical account of how the Norici adopted their ethnic name: a divinely sent boar was ravaging the land, until a man managed to catch it. Then the Norici shouted 'one man', which in their own language means berounous and that way the city was named Berounion. The account, not found elsewhere in Greek literature, ${ }^{216}$ bears marked resemblance to a similar

210 For a detailed analysis of the common use of these allusions in the four official histories of the tenth century, see Diller (1950), 246-252. On the use of the geographical lexicon by Stephanus of Byzantium in works produced under the auspices of Constantine Porphyrogenitus, see Diller (1938) and Nawotka (1994), 323-324.

211 On the association of Laurentianus Plut. 55.4 to the imperial scriptorium, see Irigoin (1959), 177-181 and Irigoin (1977), 298-299. Other manuscripts assigned to this scriptorium are the two codices of the EC (Turonensis 980 and Vaticanus gr. 73), a personal manuscript of Basil the Nothos, the codex Ambrosianus B 119 sup., and the manuscript bearing the text of the $D C$, Lipsiensis Rep. I.17. On Ambrosianus B 119 sup., see Mazzucchi (1978); Németh (2018), 42-44.

212 Genesius, Regum Libri Quattuor 47, 6-10. The geographic notice on Tarsus is originally derived from Stephanus Byzantius; cf. Meineke (ed.) (1849), 605.6-13.

213 The passage, originally found in Stephanus Byzantius, has passed similarly changed in terms of structure to both the Excerpta Anonymi and Ps.-Symeon; cf. Theophanes Continuatus, 706.16. The Excerpta Anonymi claim that the Medes' name comes directly from Medea. Ps.-Symeon, instead, gives Medos as eponymous ancestor of the Medes. Herodotus claims that the name came directly from Medea herself, when she came to their land after leaving Athens; cf. Herodotus, Historiae 7.62.1. There are various traditions on the parentage of Medos: he was a son of Medea either by Aigeus (Ps.-Apollodorus, Bibliotheca 1.9.28), an Asian king (Diodorus, Bibliotheca historica 4.55.7), or Jason (Strabo, Geographica 11.13.10).

214 Excerpta Anonymi 8, 28-29, 9. On the passage as a source of information on Virunum, see Dobesch (1997), 107-128; Nollé (2001), 79 n. 238; Hofeneder (2010) 123-135.

215 Excerpta Anonymi 9, 10-13.

216 The only parallel is an entry in the Suda, which draws on the Excerpta Anonymi; cf. s.v. Bᄁpoúviov [158 T 1]). 
digression about the naming of Italy in Genesius: ${ }^{217}$ some people, when crossing Italy, met a cow and shouted 'Italian, Italian', which in their dialect meant cow. The account is also unique in Greek literature. Both accounts seem to derive from a common tradition. (Dionysius of Halicarnassus, Antiquitates Romanae 1.35 and Apollodorus, Bibliotheca 1.8.2-3).

\subsubsection{Conclusion}

The $E C$ appear to have been used in treatises produced within court circles as well as in non-imperial works. The latter were written by persons associated with the palace or the imperial library. The anonymous compiler of the Excerpta Anonymi must have drawn on draft copies produced during the redaction of the Constantinian collections.

As the analysis of the chapter "On the River Istros" has shown, the passage must have been excerpted from an earlier dossier, presumably a collection of notes on geography. The chapters "On Cyrus" and "On Remus and Romulus" reflect the selection and arrangement of similar material in the $E C$. The passages on Roman history in the Excerpta Anonymi derive from a collection of excerpts on dreams, which could have been produced during the redaction of the Constantinian collections. This strongly suggests that amongst now lost Constantinian collections of excerpts, there probably existed collections of geography, dreams, and portents. In the surviving Constantinian collections we detect excisions of passages on geography that can be explained by Constantine's intention to include them in another thematic collection. To cite but one example: when excerpting Procopius for the $E L$, the excerptors leave out the description of Beroea. ${ }^{218}$ The omissions in the $E C$ cover a subject usually mentioned with the phrase $\zeta \dot{\eta} \tau \varepsilon \nu \dot{\varepsilon} v \tau \tilde{\omega} \pi \varepsilon \rho \grave{\text { (Look }}$ for it in the) plus the name of the collection, which appears in the surviving manuscripts when a passage in the main narrative is missing. Concerning geographical materials, the cross-references reveal the existence of three relevant, but now lost,

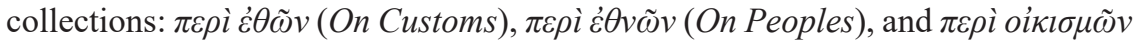
(On Settlements). The possibility of yet more collections on the subject cannot be excluded.

\subsection{Historical and cultural context}

In this section, I explore the extent to which ideology, contemporary attitudes and preoccupations influence the transmission of knowledge to the succeeding ages. Accordingly, what follows is an attempt to contextualise the Excerpta Anonymi. Certain preoccupations in the Excerpta Anonymi confirm that they belong to a time when the transformative power and civilising influence of the Empire had been restricted. The implications of the new circumstances are reflected on the

217 Genesius, Regum Libri Quattuor 82, 50-55.

218 EL 6 (2.7.2). 
selection of excerpts as well as omissions and distortions of passages on the part of the compiler of the Excerpta Anonymi. It should also be stressed that the Excerpta Anonymi share concerns evident in other contemporary works, namely an emphasis on the prophetic meaning, dangers, and hidden powers of pagan statues as well as geographical and ethnographical interest. I shall begin by examining the attitude of the Excerpta Anonymi towards Roman emperors through a comparison with the Parastaseis and the Patria II. Then I elucidate the compiler's attitude towards ethnographic material of earlier centuries.

\subsubsection{Portrayals of emperors in the Excerpta Anonymi ${ }^{219}$}

This section argues that, in the portrayals of emperors in the Excerpta Anonymi, we can detect the impact of the propaganda of the Macedonian dynasty: the conception constantinienne ${ }^{220}$ and the notion of restricted ecumenism. ${ }^{221}$ Constantine Porphyrogenitus was considered the New Constantine ${ }^{222}$ who attempted systematically to erode Justinian's reputation by distorting the emperor's military ambitions and policies of reforming and restoring the Roman state, as the age of Justinian I was a time of territorial expansion. It shall be shown how the Excerpta Anonymi use material from an earlier collection of excerpts, the conventionally called Parastaseis Syntomoi Chronikai, and how this compares to the use Patria of Constantinople made of the same work. In particular, it will become evident that the compiler of the Excerpta Anonymi holds a negative attitude towards Justinian I and that he does not include theological judgements or comments. I shall start by comparing the Excerpta Anonymi and the Parastaseis regarding emperors. As mentioned, these works relied on a shared source or the Excerpta Anonymi used the Parastaseis.

219 Section 2.5 .1 originates in my article "History through an excerpt collection. The case of the Excerpta Anonymi and the Patria of Constantinople" that was submitted for the book edited by E. Amato, P. De Cicco, B. Lançon, and T. Moreau, Les historiens fragmentaires de langue grecque à l'époque impériale et tardive to be published by Presses Universitaires de Rennes.

220 The term was coined by Hélène Ahrweiler; cf. Ahrweiler (1975), 48. Leo VI's desire was to compare his father, Basil I, with the king David and compared himself with the king Solomon; Markopoulos (1994), esp. 161-164; Shepard (2003), 341-345; Magdalino (2013c), 187-209. Basil I, the founder of the dynasty, came to be descended from Constantine the Great, the founder of Constantinople. The Vita Basilii, a work commissioned by Basil's grandson, Constantine Porphyrogenitus, introduced his genealogical links with Constantine the Great on the side of his mother and with the Arsacids, the Parthian dynasty, on his father's side. According to the Vita Basilii, Basil I and consequently his descendants are also descended from Alexander the Great; cf. Vita Basilii, 3, 23-27 ed. Ševčenko; Markopoulos (2006), 286-292.

221 The concept of limited ecumenism, as a specific theory about Byzantine foreign policy in this period, was first advanced by T. Lounges; cf. Lounges (1981), 49-85; Lounges (1990). For a reappraisal of his theory, see Magdalino (2013b), 23-42. Certain preoccupations in the Excerpta Anonymi seem to reflect the tenth-century restricted ecumenism. On the matter, see Section 2.5.2.

222 Markopoulos (1994), 162-166. 


\subsubsection{Comparison of the Excerpta Anonymi and the Parastaseis}

a) Julian

In the Parastaseis, contemporary worries about idolatry are discernible throughout references to the emperor Julian the Apostate (361-363), the persecutor of Christians. The Parastaseis calls Julian $\theta \varepsilon o \sigma \tau v \gamma \eta \varsigma^{2},{ }^{223}$ which means hated by God, an epithet with theological weight that has been omitted by the compiler of the Excerpta Anonymi. ${ }^{224}$ Parastaseis Chapters 46-49, which again refer unfavourably to Julian, have also been omitted in the Excerpta Anonymi; in Chapter 46 Theodosius the Great, full of anger, breaks a statue of Julian's and forbids coins with his image, ${ }^{225}$ in Chapter 47 Julian is accused of leading a lot of people to idolatry; ${ }^{226}$ Chapter 48 reports the destruction of a statue depicting Jesus and the burning of a monk upon the orders of Julian; ; $^{27}$ and in Chapter 49 Julian encourages people in idolatry. ${ }^{228}$ Chapter 70 of the

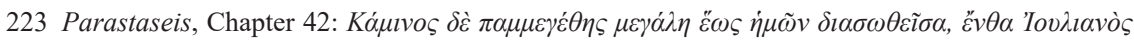

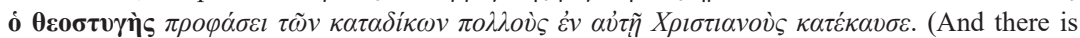
an enormous great furnace, preserved until the present day, where Julian, hated by God, burned many Christians on the pretext of their being criminals).

224 A little further on in the same chapter, where the Parastaseis call the emperor Phocas d́vá $\xi_{l o \varsigma}$, which means unworthy in theological terms, the Excerpta Anonymi and the Patria once more omit the theological epithet assigned to an emperor; cf. Parastaseis, Chapter 42; Excerpta Anonymi 15, 29.

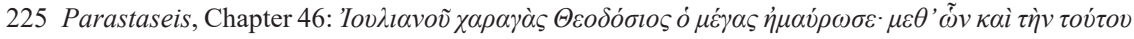

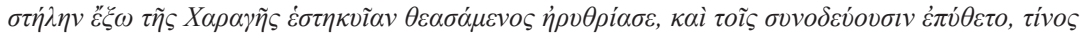

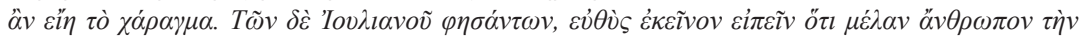

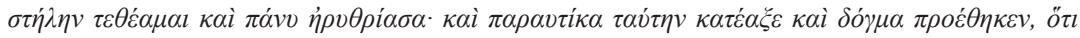

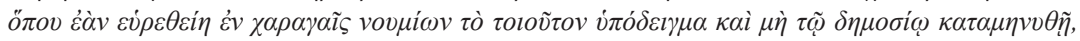

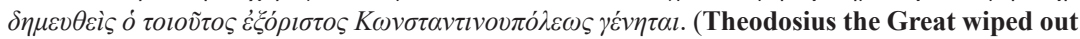
the coinage of Julian. In addition, when he saw his statue standing outside the Mint, he turned red and asked his companions whose likeness it was. When they replied that it was Julian's he said at once: 'I have seen a black man represented in a statue and I grew very red', and at once he broke it and issued a decree saying that whenever that same man's likeness was seen on coins and the Treasury was not notified, he who was responsible should suffer confiscation and be banished from Constantinople).

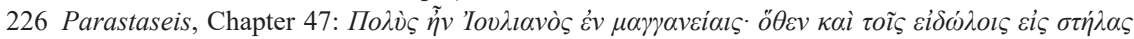

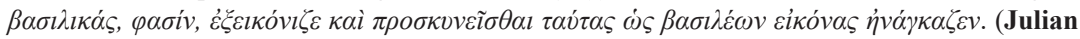
was deeply involved in sorcery; thus he fashioned eidola into the semblance of imperial statues, it is said, and forced everyone to do obeisance to them as if to images of emperors).

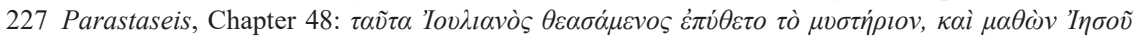

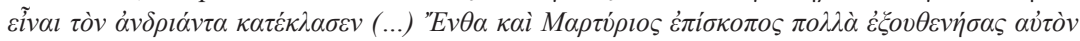

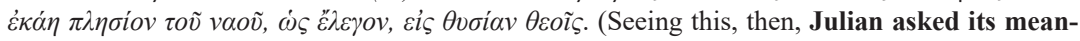
ing and when he heard that the statue was of Jesus, he broke it (...) And there the bishop Martyrius, who strongly opposed the emperor, was burned near the temple, they say, as a sacrifice to the gods).

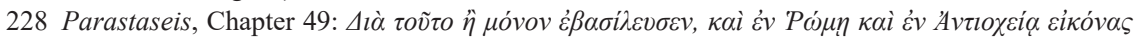

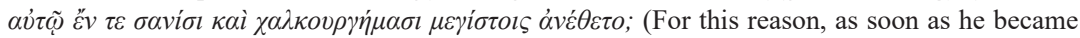
emperor, he set up images to him, in Rome and Antioch, in the form of panels and large bronze statues). 
Parastaseis is devoted to the so-called Philadelphion, ${ }^{229}$ but at the end of the passage, the Parastaseis report that Julian ejected his wife from the throne because she was a Christian. Although the Excerpta Anonymi have included that chapter, its compiler has excised the reference on Julian. ${ }^{230}$ If we bear in mind that Julian at that time embodied the enemy of Christianity, ${ }^{231}$ such suppressions on the part of the compiler of the Excerpta Anonymi betray his admiration for the Roman past, which he primarily interprets as pagan.

b) Verina

Chapter 29 of the Parastaseis refers to two statues of Verina, the wife of Leo the Great (457-474 AD). It is noteworthy that the Excerpta Anonymi, 12, 24-32. have left out the last sentence of the excerpted passage, according to which Verina was very orthodox, omitting, once more, a religious designation. ${ }^{232}$

c) Anastasius

The Excerpta Anonymi excerpt Chapter 25 from the Parastaseis, ${ }^{233}$ where the emperor Anastasius (491-512 AD) is associated with the restoration of the church of Saint Menas. ${ }^{234}$ Such a choice contrasts, as shown below, with their silence concerning Justinian's building activities. It is noteworthy that some centuries earlier, Procopius, John Lydus, and Hesychius made favourable references to Anastasius that have been considered as implicit disapproval of Justinian's policies. ${ }^{235}$

d) Justinian I

Chapter 1 of the Parastaseis refers to the rebuilding of the St Mocius church and Chapter 2 reports the restoration of the St Agathonikos church both under Justinian's reign (527-565 AD). ${ }^{236}$ In addition, the unnamed emperor of

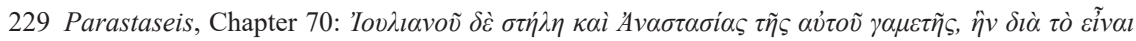
$X \rho \imath \sigma \tau \iota \alpha \nu \grave{\eta} v \dot{\varepsilon} \xi \dot{\varepsilon} \beta \alpha \lambda \varepsilon \tau \tilde{\eta} \varsigma \beta \alpha \sigma \imath \lambda \varepsilon i \alpha \varsigma$. (There was a statue of Julian and Anastasia his wife, whom he ejected from the throne because she was a Christian). On the Philadelphion, see Cameron and Herrin (1984), 265-266.

230 Excerpta Anonymi 19, 5-9.

231 The Patriarch Germanus condemned Julian in his letters addressed to two Anatolian bishops; cf. $P G$ 98, col. 164 B, 165 C-D, 168 D-188 B.

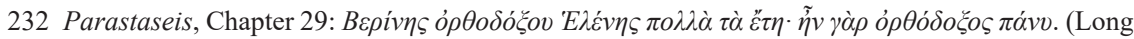
life to Verina the orthodox Helena'. For she was very orthodox).

233 The Parastaseis contain three chapters referring to the emperor Anastasius I (491-518 AD). The Excerpta Anonymi excerpts only one of these.

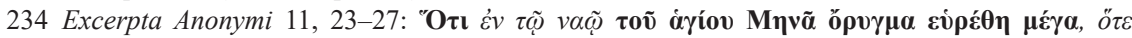

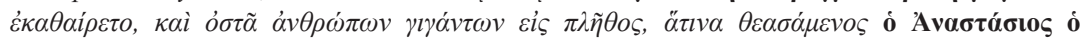

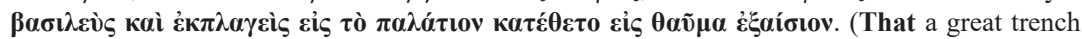
was found in the Church of St Menas when the church was being cleaned, and a lot of bones of giant men, which the Emperor Anastasius saw and marvelled at and deposited them in the palace as an extraordinary wonder).

235 Kaldellis (2005), 394.

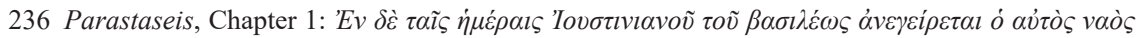
$\kappa \alpha \grave{i} \ddot{i} \sigma \tau \alpha \tau \alpha l \ddot{\varepsilon} \omega \varsigma \dot{\eta} \mu \tilde{\omega} v^{*}$ (But in the days of the Emperor Justinian the same church was rebuilt

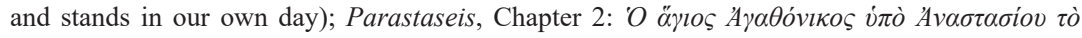


Chapter 4, associated with a wonder that happened when a statue was suddenly removed, could easily be Justinian I. ${ }^{237}$ None of the aforementioned chapters are included in the Excerpta Anonymi.

The Parastaseis Chapter 61 makes a reference to the statue of Justinian erected to commemorate his victory over the Persians. ${ }^{238}$ Although the author of the Excerpta Anonymi excerpted Chapter 61, he chose to omit the reference to Justinian's statue. In addition, Chapter 68 of the Parastaseis, which refers to another statue of Justinian, set up in the Augusteum, has been entirely eliminated. ${ }^{239}$ Finally, Chapter 81 of the Parastaseis, which transmits information about a statue in the Zeuxippus, erroneously assigned to Justinian I instead of Justin II, has also been excised in the Excerpta Anonymi. ${ }^{240}$

Only two chapters containing information on Justinian have been included in the Excerpta Anonymi. The first one is the Parastaseis Chapter 11 referring to the rebuilding of the Hagia Sophia and presenting Justinian in a favourable way. ${ }^{241}$

In contrast to the Parastaseis, the Excerpta Anonymi describe the fact with brevity and limit it to one sentence only. It is also interesting that the name of the emperor is not accompanied by any typical epithet ${ }^{242}$ and that the compiler of the Excerpta Anonymi adds an extra word to the text, which is an

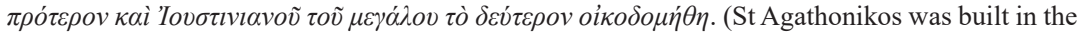
first place by Anastasius and a second time by Justinian the great).

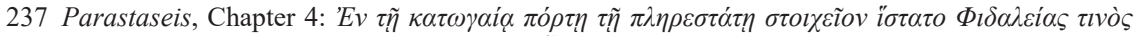

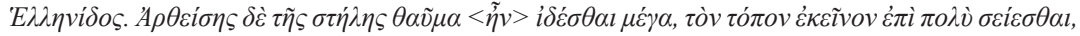

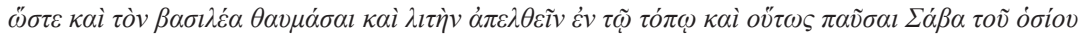

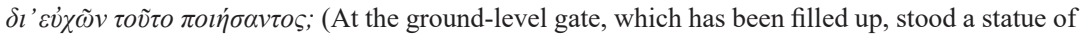
a certain pagan, Fidalia. When the statue was removed, a great wonder was to be seen, namely that the place shook for a long time, so that even the emperor marvelled and sent a procession to the place and only stopped it in this way. St Sabas achieved this by his prayers).

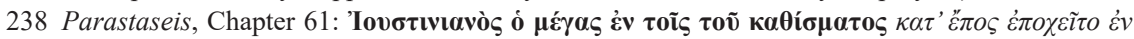

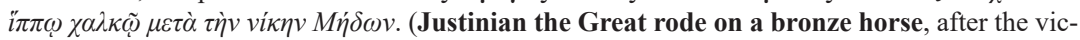
tory over the Medes). On that statue, see Cameron (1977), esp. 42-48.

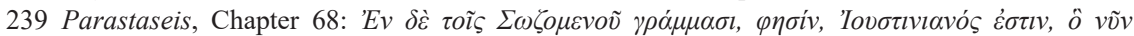

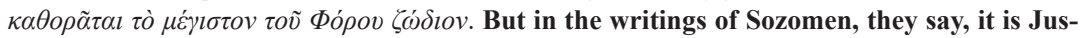
tinian who is seen there today.

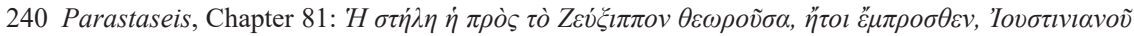

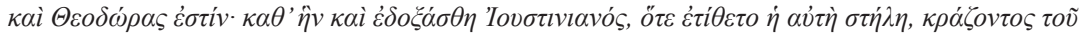

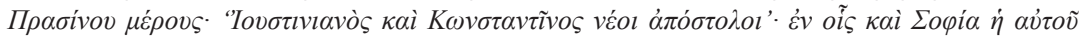

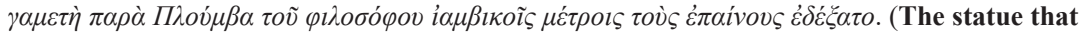
faces the Zeuxippus, that is in front of it, is of Justinian and Theodora. When it was erected Justinian was showered with praise, the Greens chanting: 'Justinian and Constantine the new apostles'. Also there was Sophia his wife, who received praise through iambic verses of the philosopher Plumbas).

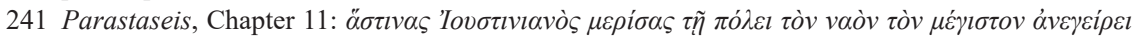

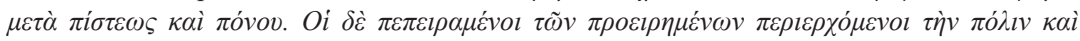

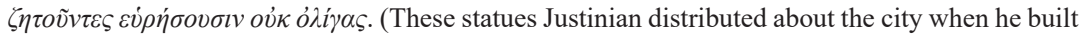
the Great Church with faith and effort. Those who know the foregoing find a good number of them if they go around the city and look for them).

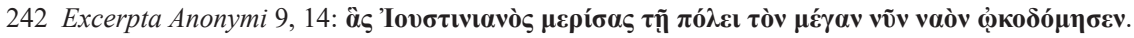
(Justinian distributed (these statues) about the city when he built the present Great Church). 
adverb of time, $v \tilde{v} v$, in order to emphasise that the Hagia Sophia was greater at the time of the completion of the Excerpta Anonymi.

e) Philippicus and Justinian II

The Parastaseis appear to be favourable to the emperor Philippicus (711$713 \mathrm{AD}$ ). This emperor had usurped the throne by deposing Justinian II (685$695,705-711 \mathrm{ad})$, to whom the Parastaseis is hostile, calling him $\ddot{\alpha} \theta \varepsilon o \varsigma$ (= godless), ${ }^{243}$ whereas the Excerpta Anonymi name him $\tau \dot{v} \rho \alpha v v o \varsigma$ (= tyrant) twice. ${ }^{24}$ Justinian II was a very unpopular emperor known for his despotic tendencies. The compiler of the Excerpta Anonymi follows the unfavourable attitude of the Parastaseis towards Justinian II but he has replaced the religious epithet $\ddot{\alpha} \theta \varepsilon o \varsigma$ (= ungodly) with a secular one, that is $\tau \dot{v} \rho \alpha v v o \varsigma$ (=tyrant).

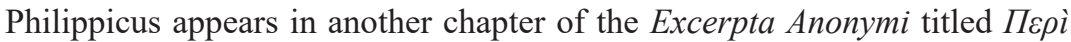
$\tau \tilde{\omega} v \mathcal{\varepsilon} v \tau \tilde{\omega} \kappa v v \eta \gamma i \omega \sigma \tau \eta \lambda \tilde{\omega} v,{ }^{245}$ namely in the description of Philippicus' order for a statue to be buried when a certain philosopher, called John, informs him that the statue involved malevolent power. It is noticeable that the Parastaseis add that the philosopher John had found the malevolent power of the statue by divine providence, a statement which reinforces Philippicus' decision to bury it. ${ }^{246}$ This quotation has been omitted from the same extract in the Excerpta Anonymi. Strikingly, the compiler has chosen, once again, to throw out a theological comment.

The last reference to Philippicus in the Excerpta Anonymi is made in the chapter $\Pi \varepsilon \rho i \tau \tilde{\eta} \varsigma \dot{\varepsilon} v \tau \tilde{\omega} Z \varepsilon v \xi \xi i \pi \pi \omega{ }^{247}$ Philippicus is called $\pi \rho \alpha \dot{o} O \varsigma$, which means the most gentle, alluding to the Parastaseis Chapter 82, in which Philippicus is also praised for being gentle and the picture painted by himself was admired by artists for its realism. ${ }^{248}$ The Excerpta Anonymi do not praise Philippicus extensively (they just call him gentle), in contrast to the Parastaseis. In my view, what could lead the compiler of the Excerpta Anonymi to adopt, to some extent, the favourable attitude of the Parastaseis towards Philippicus is the fact that Philippicus took the throne by murdering the tyrant Justinian II.

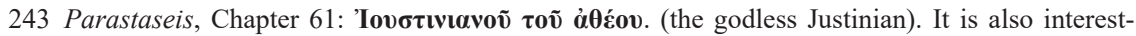
ing that Philippicus was the first emperor to be hostile to the cult of images. He belonged to the Monothelite party. In the Parastaseis Chapter 37 Justinian II is identified as tyrant, as well: $\tau \dot{\eta} v$

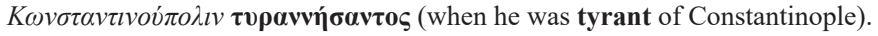

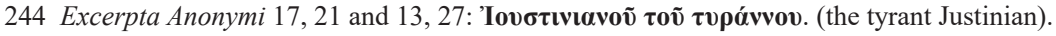

245 Excerpta Anonymi 12, 7-23.

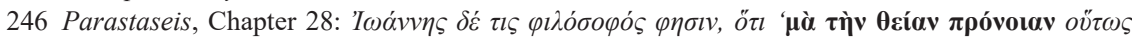

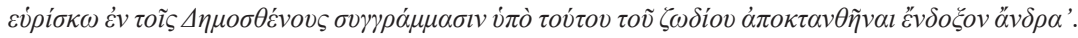
A certain John, a philosopher, said 'By divine providence, I find it so in the writings of Demosthenes, that a man of rank would be killed by the statue'.

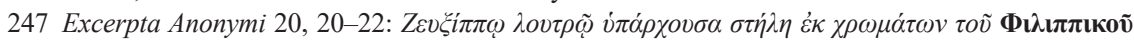

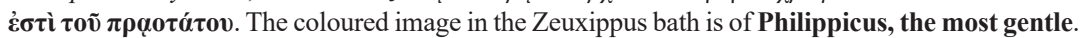

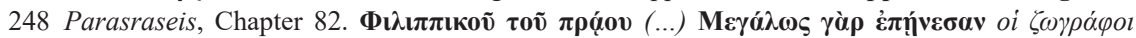

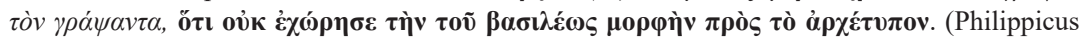
the gentle (...) Painters greatly praised the artist, because he did not depart from the emperor's appearance with regard to the archetype). 
The latter was the last member of Justinian's royal dynasty and the Excerpta Anonymi, as we have seen, contain a considerable number of cases in which we detect efforts made by the compiler to undermine the image of the emperor Justinian I. From this perspective, the hostility of Excerpta Anonymi to Justinian II could be interpreted as an indirect disapproval of Justinian I.

\section{f) Leo III}

The first iconoclast emperor, Leo III (717-741 AD), is recorded three times in the Parastaseis under the name Leo the Isaurian or Conon. ${ }^{249}$ The passages may have been written at the beginning of the eighth century, so it is not surprising that it includes references to emperors in relation to iconoclasm. References to iconoclast emperors were largely suppressed in later works. Indeed, throughout the Excerpta Anonymi there are no references to the ungodly emperor Leo III. Leo III is called Conon in the Parastaseis Chapters 1 and $72 . .^{250}$ Interestingly, Chapter 1 belongs to the part of the Parastaseis concerned with Arianism, namely the chapters 1 to 10, which the Excerpta Anonymi compiler has entirely excised. It is likely that the Excerpta Anonymi have intentionally excluded the part of the Parastaseis dealing with Arianism for two reasons: first, the part contains information that belongs to ecclesiastical history, a topic that is of no interest to the Excerpta Anonymi ${ }^{251} \mathrm{sec}-$ ondly and more intriguingly, the Chapters 1 to 10 supply us with information about the building activities of Justinian I (527-565 ad). It may be that these chapters were an important motive for the exclusion of the aforementioned chapters by the compiler of the Excerpta Anonymi, in connection with the political issues dominating during the tenth century and as an expression of the Macedonian dynasty's propaganda. ${ }^{252}$

249 Parastaseis, Chapters 1, 5d, 72. The Parastaseis Chapter 5d is supplied from the Patria. The entry characterises Leo III as $\dot{\alpha} \lambda o ́ \gamma l \sigma \tau o \varsigma$ (irrational). In iconophile context, the term $\dot{\alpha} \lambda \dot{\gamma} \gamma \imath \sigma \tau o \varsigma$ was used to criticise iconoclasts. Under this perspective, the term, probably an addition from the Patria, fits well the iconophile stance of the latter; cf. Cameron and Herrin (1984), 177-178. The earlier attestation of the epithet Conon is found in the Adversus Constantinum Caballicum ( $P G$ 95, col. 336c). A. Berger dates the latter not before 802; cf. Berger (1988), 43.

250 The Parastaseis Chapter 5, even, naming Leo Isaurian, reports that many statues were destroyed by Leo III. On the two epithets in relation to Leo III, see Cameron and Herrin, 168-169.

251 It is noteworthy that the Parastaseis contain references to Arianism, linking the heresy of Arius with iconoclasm following thus the tendency of using Arianism in the iconoclastic polemic of the eighth century; cf. Parastaseis, Chapters 1, 7, 8, 10, and 39. The Excerpta Anonymi are more circumspect in writing about emperors, heresies, and doctrines. The Excerpta Anonymi refers

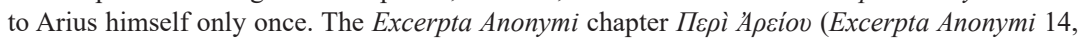
25-31), corresponding to the Parastaseis Chapter 39, informs us that Arius met his death in the Forum and Theodosius represented him on a slab of marble, in order that passers-by could urinate and spit on it. However, it has to be pointed out that, whereas the author of that passage in the Parastaseis uses the wording $\mu \iota \alpha \rho o v$ in order to describe Arius' death, the author of the Excerpta Anonymi has changed it to al゙ $\chi \imath \sigma \tau o v$. I have already mentioned that in many cases the Excerpta Anonymi eliminates Christian terms in favour of secular ones.

252 On this, see Section 2.5.2.2. 
g) Constantine $\mathrm{V}$

The tendency of the Excerpta Anonymi to avoid references to iconoclast emperors is better reflected on the case of Constantine V (741-745 AD), Leo III's son. Two chapters from the Parastaseis contain references to events that could be dated to the time of Constantine V. ${ }^{253}$ The two chapters have not been included in the Excerpta Anonymi, an exclusion that fits the inclination of the Excerpta Anonymi to avoid, as we have seen, religious matters.

\subsubsection{Comparison of the Excerpta Anonymi and the Patria II}

Having analysed how the Excerpta Anonymi adapted its source text, I shall study how the Excerpta Anonymi themselves were adapted in the Patria II. Before discussing the attitude towards the aforementioned emperors in the Patria II, some remarks on the Patria of Constantinople are required. The text has been transmitted through a rich manuscript tradition analysed in detail by Preger. ${ }^{254}$ The Patria of Constantinople comprise four books originally produced at different periods of time but put together in an anthology around 989/990. The Patria I

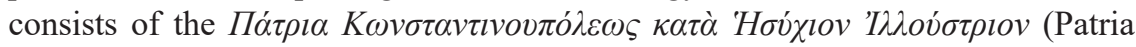
of Constantinople by Hesychius of Miletus), which is the only surviving fragment of Hesychius' Chronicle and a revised version or paraphrase of Hesychius's short final chapters, written in the sixth century. ${ }^{255}$ The Patria II, under the head-

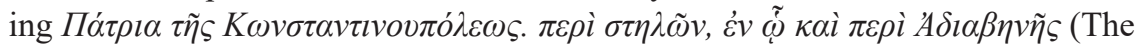
Patria of Constantinople, on statues, together with a chapter on Adiabene), have

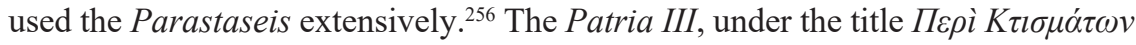
(On Buildings), is a compilation of 215 notices on foundations and buildings in

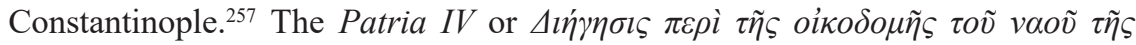

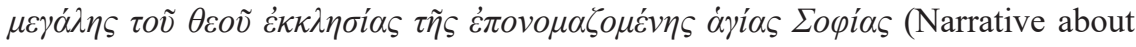
the Construction of the Temple of the Great Church of God the so-called Hagia Sophia) is an account of the construction of the Hagia Sophia most likely composed in the middle of the ninth century. ${ }^{258}$

This chapter is only concerned with the Patria $I I{ }^{259}$ The complex manuscript transmission of the Patria II does not permit definite conclusions as to the textual relationship of the former with the Parastaseis and the Excerpta Anonymi. The first editor of the Patria II as well as Cameron and Herrin are inclined to support the view that the Patria II had extensively relied on the first part of the

253 Parastaseis, Chapter 15 and Parastaseis, Chapter 63.

254 Preger (1907), iii-xxv; Preger (1895).

255 Preger (1901), 1-18 and Preger (1907), 135-150.

256 Preger (1907), 151-209; henceforth, Patria II.

257 Preger (1907), 214-283.

258 Preger (1901), 74-108, and Preger (1907), 284-289.

259 The English translation of the passages is that of the edition of the Patria of Constantinople by Berger (2013). 


\section{Excerpta Anonymi}

Excerpta Anonymi ${ }^{260}$ It has long been supported that the Excerpta Anonymi and the Patria II had used a common model, a manuscript which was derived from the same codex that Parisinus gr. $1336^{261}$ comes from. ${ }^{262}$ In fact, entries of the Parastaseis occur in the Patria II in the same abbreviated form as in the Excerpta Anonymi, with the same omissions. The Patria II, however, includes entries from the Parastaseis excised in the Excerpta Anonymi and in some cases supplement entries taken from the Excerpta Anonymi with material possibly drawn from another copy of the Parastaseis.

In particular, the Excerpta Anonymi do not include Parastaseis Chapters 1-10, 13-15, and 17. The Patria II, instead, incorporate the complete Chapters 1-20 of the Parastaseis at the end of the text. When looking at entries, such as the Parastaseis Chapters 42, 61, and 70, we detect that the Patria II supplement the passages with material not found elsewhere, i.e., neither in the Parastaseis nor in the Excerpta Anonymi. In addition, The Patria II entries 35-37, 45, 46a, 54-65, 72, 101, 103 are absent from both the Parastaseis and the Excerpta Anonymi. Finally, the Patria contain some references twice. ${ }^{263}$ It may be argued that the compiler of the Patria II had at hand not only the text of the Excerpta Anonymi but also a more extensive text of the Parastaseis. ${ }^{264}$ Nevertheless, this view is challenged by P. Odorico who argues that the Parastaseis is not a unitary work but that it was collected by a compiler in preparation of a chronicle. ${ }^{265}$ It seems more likely that the Patria II were indeed made in two stages drawing on the codex (codices) which the Excerpta Anonymi also drew on. Finally, the possibility that the Excerpta Anonymi were also in the possession of the compiler of the Patria II can by no means be excluded. ${ }^{266}$

When compared with the Excerpta Anonymi, the Patria II is characterised by an iconophile tone, albeit a less intense one than the one detectable in the other three books of the Patria of Constantinople. In the Patria II iconophile implications are conveyed through unfavourable references to iconoclast emperors, which had been excluded from the Excerpra Anonymi. In the Patria II Chapter 90, the iconoclast emperor Leo III is called $\dot{\alpha} \lambda \hat{\gamma} \gamma \imath \sigma \tau o \varsigma$ (irrational). Leo is also debased

260 Preger (1901), X; see also Cameron and Herrin (1984), 5-6.

261 The codex preserving the Parastaseis. On Parisinus gr. 1336, see Section 2.2.3.1.

262 P. Odorico also appears to hold the same view when supporting that the codex Parisinus gr. 1336 is nearer to the dossier used both by the Parisinus suppl. gr. 607a and the Patria II; cf. Odorico (2014b), 755-784. In Berger's view, the Patria II are divided into two parts: a. The Patria II 1-85 copied from the codex X, that is, a now lost codex from which the Excerpta Anonymi also derive, and b. the Patria II 86-110 copied from another manuscript containing the Parastaseis; cf. Berger (1988), 48-49 and 64-70.

263 Parastaseis, Chapters 16, 18, 20 = Patria II 16, 18, 19 = Patria II 102, 104, 105.

264 Cameron and Herrin (1984), 6-8. See also Berger (1988), 49 and 66, who disagrees with A. Cameron and J. Herrin.

265 On P. Odorico's view, see Odorico (2014b), 755-784.

266 The transmission of the Parastaseis, Chapters 42, 61, 70 is particularly interesting in this connection. 
in the Patria II Chapter 68, which calls him Conon. ${ }^{267}$ As regards Constantine V, Leo III's son, the Patria II includes the Parastaseis Chapter 15 concerning him, though the chapter has been excised in the Excerpta Anonymi. ${ }^{268}$ It is also

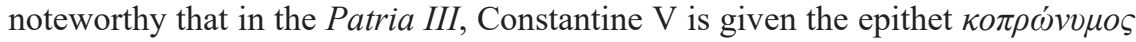
(dung-named). ${ }^{269}$

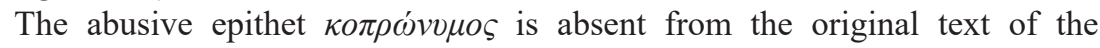
Parastaseis as well as from the Excerpta Anonymi. ${ }^{270}$ Nevertheless, the aforementioned references do not constitute theological comments on the part of the copyist of the Patria II. The textual framework in which they are used is not theological either. The epithets seem to have been copied as common characterisations ascribed to certain iconoclast emperors. The Patria II was not intended to deliver any ideological message in support of orthodoxy, for in the late tenth century its triumph was undeniable. Like the Excerpta Anonymi, the Patria II omits theological comments of the Parastaseis. The case of the emperor Julian in the Patria II is indicative. There, the references to this emperor are left out. In particular, Chapter 53 of the Patria, which contains a text close to that of the Excerpta Anonymi, omits the epithet $\theta \varepsilon o \sigma \tau v \gamma \eta$ ' which occurred in the Parastaseis, as shown above. ${ }^{271}$ Interestingly, neither the Excerpta Anonymi nor the Patria have included Chapters 46-49 of the Parastaseis, where Julian is portrayed unfavourably. Finally, the theological comment on Julian in the Parastaseis Chapter 70 is also excised in the Patria Chapter 48 (concerning the Philadelphion) and in the Excerpta Anonymi. ${ }^{272}$

The tendency in Patria II to follow the Excerpta Anonymi in avoiding religious references emerges once more in the Chapters 24, 25, 56, and 77. Accordingly,

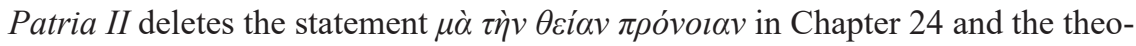
logical comment at the end of Chapter 25 according to which Verina was a truly orthodox Christian. Both passages preserve a text copied from the Excerpta Anonymi. The Patria II supplements the Chapter 25 with the additional information that the church of St Barbara was close to the Artotyrianos ${ }^{273}$ as well as the

267 On the term, see above n. 249.

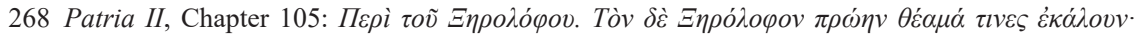

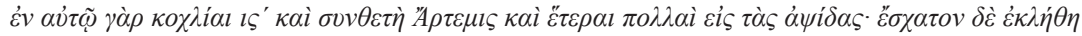

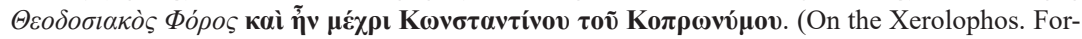
merly, some people called the Xerolophos a spectacle. For in it were sixteen spiral columns, and a composite statue of Artemis, and many others on the arches. Finally, it was called the Forum of Theodosius, an appellation which lasted until the reign of Constantine Kopronymos).

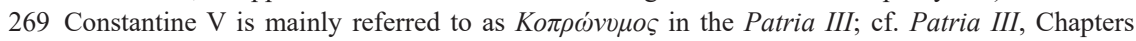
9, 68, and 149. The Patria III also portray Constantine V in an unfavourable way in Patria III, Chapters 68 and 134.

270 Parastaseis, Chapter 20; Excerpta Anonymi 11, 1-7.

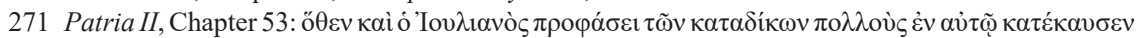

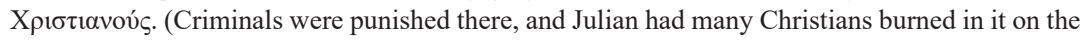
pretext of them being convicted criminals).

272 See above n. 230.

273 On Artotyrianos, see Jannin (1964), 37 and 100. 
epithet Makelles accompanying the name of the emperor Leo I. ${ }^{274}$ The Patria Chapter 53 deletes the epithet $\dot{\alpha} v a ́ \xi \xi o \varsigma$, which means unworthy, applied to the emperor Phocas in the Parastaseis. ${ }^{275}$ Finally, in Chapter 77, the Patria replaces the religious epithet $\ddot{\alpha} \theta \varepsilon o \varsigma$ (ungodly) with the secular epithet $\tau \dot{v} \rho \alpha v v o \varsigma$ (tyrant), to characterise Justinian II, obviously copying the Excerpta Anonymi. ${ }^{276}$

Proceeding to the case of Justinian I, we can now ask if the Patria II adopts the tenor of the Excerpta Anonymi in depicting this emperor.

The Patria II includes the Parastaseis chapters 1, 2, and 4 on Justinian I. ${ }^{277}$ As shown above, these chapters were excised in the Excerpta Anonymi. It is noteworthy that in Chapter 110 of the Patria II Justinian is referred to as $\tau o \tilde{v} \mu \varepsilon \gamma \alpha \dot{\lambda} o v$ (the great) whereas in the Parastaseis the appellation was $\tau o \tilde{v} \beta \alpha \sigma \lambda \dot{\varepsilon} \omega \varsigma .{ }^{278}$ Chapters 86 and 107 of the Patria II are copied almost verbatim from the Parastaseis Chapters 4 and 2, respectively, referring to Justinian in a favourable way. ${ }^{279}$ In addition, the Patria II Chapter 96 draws directly on Chapter 11 of the Parastaseis, which praises Justinian I, even though this very Chapter 11 had been included in the Excerpta Anonymi. ${ }^{280}$ Entry 40 of the Patria II concerning the cistern of the Basilica reads as follows:

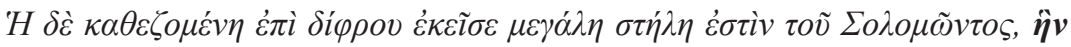

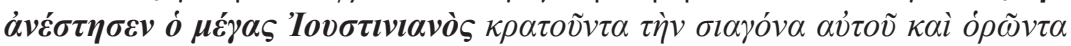

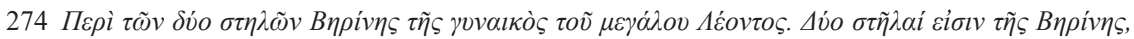

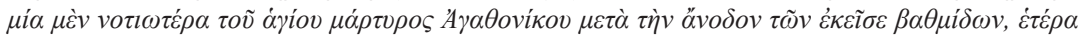

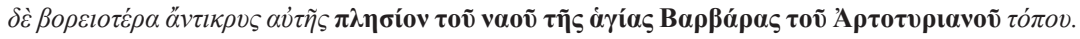

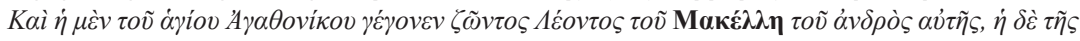

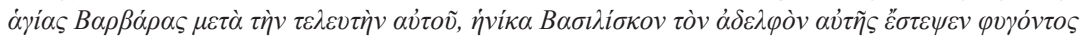

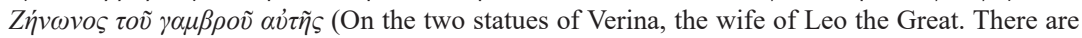
two statues of Verina, one to the south of $<$ the church of $>$ the holy martyr Agathonikos above the steps, and the other more to the north opposite her, near the church of Saint Barbara of the Artotyrianos Topos. The statue of Saint Agathonikos was erected during the lifetime of Leo Makelles, her husband; the one at Saint Barbara after his death, when she crowned her brother Basiliskos after the flight of her son-in-law Zeno); cf. Patria II, Chapter 25.

275 See n. 224.

276 See above; see also n. 244. The Patria add that the statue in question was the Scylla, part of a bronze group including the ship of Odysseus. The reference is not included in the Parastaseis. The Excerpta Anonymi do not transmit it either; cf. Patria II, Chapter 77; Parastaseis, Chapter 61. On the bronze group of Scylla, see Säflund (1972).

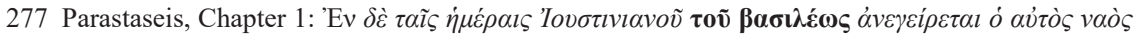

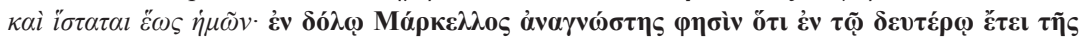

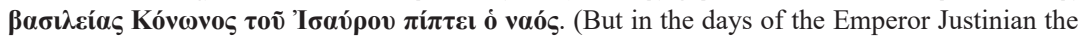
same church was rebuilt and stands in our own day. Marcellus the Lector falsely states that the church collapsed in the second year of Conon the Isaurian).

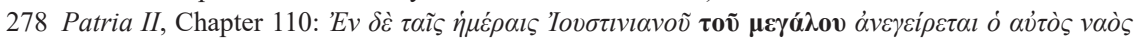

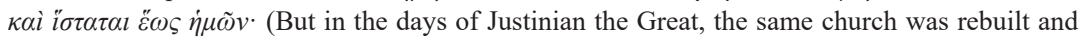
stands to our own day). Interestingly, at this point, the Patria II delete the reference in the Parastaseis to Conon the Isaurian.

279 The Parastaseis Chapter 2 refers to the restoration of St Agathonikos under Justinian's reign and Chapter 4 refers to a miracle associated presumably with Justinian; see n. 236 and n. 237.

280 The Excerpta Anonymi describe briefly the rebuilding of the Hagia Sophia; see above. 


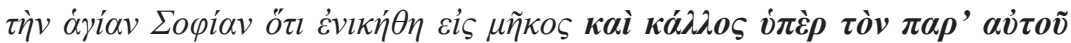

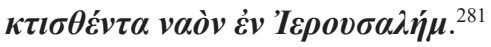

The entry clearly emphasises the magnificence of the Hagia Sophia built by Justinian I but it is noteworthy that the Parastaseis and the Excerpta Anonymi do not transmit the above laudatory image of this emperor. ${ }^{282}$

The late-tenth-century Patria II, unlike the Excerpta Anonymi, does not yield significant evidence that its compiler intended to undermine the image of the emperor Justinian. In fact, it seems to be in line with the Patria IV, which supplies us with a laudatory image of Justinian. ${ }^{283}$ Nevertheless, the Patria II is silent with regard to Justinian's successful military policies or his achievements in the field of jurisdiction. The Patria II, as a genuine product of the patriographic genre, is exclusively concerned with the Constantinopolitan monuments and statuary. The entries on Justinian are favourably inclined like the ones dedicated to works ascribed to other emperors.

In conclusion, both texts, the Excerpta Anonymi and the Patria II, exhibit a special interest in ancient monuments and statues and discuss disparate and obscure facts associated with them. Their attitude towards emperors is conditioned by the aim for which each work was designed and the message their author desired to convey. Accordingly, the Excerpta Anonymi is a composition made for practical as well as didactical purposes. The portrayal of emperors in the Excerpta Anonymi is influenced by the political ideology current at the time of their composition. The selection, as well as the omissions and the insertions in the Excerpta Anonymi should be seen as influenced by the propaganda of the Macedonian dynasty. Aligned with this, the compiler of the Excerpta Anonymi undermines the images of Justinian I, Justinian II, and other members of their royal dynasty.

This contrasts with the portrayals of emperors in the Patria II. The author of the Patria II does not seem to have held particularly strong views on emperors of the past. For the Patria of Constantinople is an exposition of the Constantinopolitan statuary and monuments intended to emphasise not only the eminence of the city but also the link with the magnitude of Rome. The Patria II follows the Excerpta Anonymi, however, in avoiding religious references. The epithets accompanying emperors' names in the Patria II do not constitute theological comments on the part of the author but they have been copied as conventional characterisations ascribed to certain iconoclast emperors. The absence of theological judgements or comments and the selection of the material presented in the Excerpta Anonymi conform to their compiler's interests in the pagan statuary, the magic powers the statues conveyed, and portents and predictions that relied on occult science.

281 Patria II, Chapter 40: The great statue, which Justinian the Great erected, sitting on the chariot is Solomon holding his cheek and looking at Hagia Sophia, as he was awed by its size and beauty, which is greater than that of the temple he built in Jerusalem.

282 Parastaseis, Chapter 74; Excerpta Anonymi 19, 26-29.

283 Justinian is credited with the construction of the Hagia Sophia and other buildings in the Patria $I V$; cf. Preger (1901), Chapters, 2, 8-10, 12-18, 21-26, and 29. 
Throughout the collection, the entries reflect antiquarian interest on the part of the compiler in historical figures, in Roman history, in geographical and in astronomical subjects.

\subsubsection{The politics of ethnography and geography in the Excerpta Anonymi ${ }^{284}$}

In the following, I aim to evaluate the perception of late antique ethnographic accounts in the tenth-century Excerpta Anonymi. I shall demonstrate that a scholar's attitude towards ethnographic material of preceding centuries is influenced by the cultural and political context of his age. I will examine the function of the ethnographic passages in Procopius and in the late antique ethnographical tradition, and then discuss the function they assume in the different cultural and political context of the tenth century.

To begin with, Chapter 20 of book VIII of Procopius' De bellis, which deals with the island of Brittia and the nations living on it, has been preserved in the codex Parisinus suppl. gr. 607a. ${ }^{285}$ Six excerpts have been selected, copied, rearranged, and synthesised by the anonymous author of the Parisinus in two separate chapters entitled "On the Island of Brittia" and "About the Sorcery of the Varni". ${ }^{286}$

It has long been recognised that the geographic and ethnographic descriptions of Procopius were published during the reign of Justinian I, at a time of territorial expansion and ideological transformation. ${ }^{287}$ They serve as vehicles of criticism of his own society by reflecting on how the Romans viewed themselves in relation to other peoples. ${ }^{288}$ The Excerpta Anonymi, instead, bear witness to a period in which the transformative power and civilising influence of the Byzantine Empire had been restricted. As will be shown, the compiler of the Excerpta Anonymi did not seek to change traditional perceptions of the other; he did not intend to make the reader reflect on dominant beliefs of those societies, but highlight the cultural differences in order to reinforce the geographical and political frontiers already in place.

\subsubsection{Ethnography and Geography}

Ethnography focuses on accounts of foreign peoples, their way of life, physical features, social structure, military organisation, religion and beliefs, sexual habits, laws and institutions, and geography. Ethnography and geography often appear in short or extensive digressions embedded in historical texts or other literary

284 Section 2.5 .2 originates in my article "Geography and history in the Excerpta Anonymi" published in Byzantion, 87 (2017), 233-257.

285 The oldest codex containing the De Bellis is the fourteenth-century Vaticanus gr. 152.

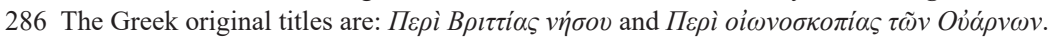

287 See in general Cesa (1982), 189-215; Cameron (1993b); Maas (2007), 67-84.

288 Kaldellis (2013), 11-25. 
genres such as epics or imperial panegyrics. ${ }^{289}$ In most cases, such ethnographical or geographical digressions retain their identity and predominant function within the narrative sequence. Very often, the digression is not an integral part of the main narration, so that it can be isolated and function separately from its original context.

Anthony Kaldellis distinguishes two subcategories of late antique ethnography. In the first one, ethnography is a description of a land with its people, incorporated into a historical text written from a distant point of view. In the second one, it is an account of foreign peoples written in the first person by an ambassador who has travelled to a foreign land. ${ }^{290}$

It could be argued with a fair degree of certainty that ethnography, for both classical and late antique literature, was mostly used to stress or even to confirm the cultural distinction between Romans and barbarians. Romans who wrote ethnographic accounts wanted to describe and emphasise the distance between the uncivilised barbarians and their own society. Roman rule characterised and reassured the civilised society. Thus, Romans considered as 'barbarians' peoples that had not yet been subjugated to Roman rule. ${ }^{291}$ This distinction could easily justify Roman imperialism as Rome believed in the transformative power of Roman law and society and in the civilising mission of transforming barbarians into civilised people. ${ }^{292}$ Therefore, Romans following classical models in their writings highlighted the well-established contrast between them and barbarians and so did authors of ethnographies from the fifth century onwards. ${ }^{293}$ The historians of the fifth and sixth centuries were aware of the power of the Roman Empire. Even the loss of western lands in the fifth century was considered a temporary event, and indeed, Justinian soon reconquered North Africa, Italy, and a part of Spain. Foreign peoples were regarded as culturally, politically, and militarily inferior seeking recognition from Constantinople. ${ }^{294}$ Accordingly, Roman ethnography and geography expressed contemporary attitudes, preoccupations, and politics. ${ }^{295}$

289 Kaldellis (2013), 2.

290 Kaldellis (2013), 1-2.

291 Maas (2003), 153.

292 Maas (2003), 157.

293 See for instance: Priscus of Panium's account of the ambassador to Attila; cf. Blockley (1983), fr. 11.2.407-547. Priscus composed a history covering the period from ca. $430 \mathrm{AD}$ to $476 \mathrm{AD}$ in eight books. He was a member of an embassy sent by the emperor Theodosius II to the court of Atttila the Hun. Thus, Priscus was able to give a vivid and trustworthy account of the ethnography of the Huns. On Priscus, see Treadgold (2007), 96-103 and Carolla (2008); Procopius' description of the Huns and Moors; cf. Procopius, De bellis 1.3.2-7, and 4.11.5-13; and Agathias' passages on the Franks; cf. Agathias, Historiae I.2.

294 Two prime examples are two passages in Procopius' De bellis; cf. Procopius, De bellis 8.20.10 and 7.33.4.

295 See how political reasons affected Agathias' positive description of the Franks; Agathias, Historiae I.2, I.7.1-3, II.1.6-7, II.23.8-9, II.25.3, III.5.1. See also Cameron (1965), 1203-1216; Cameron (1968), 95-140. On Agathias' ethnography, see Chapter 3. 
Procopius was very interested in geography and gives us extensive descriptions of lands, mountains and rivers, and their inhabitants. ${ }^{296} \mathrm{He}$ begins the narrations of the Vandal and Gothic wars with extensive accounts of the geography of the Mediterranean and of Europe ${ }^{297} \mathrm{He}$ also introduces a major digression on the geography of Italy, ${ }^{298}$ on the ancestry of the Heruls, ${ }^{299}$ on the land of Thule and the ancestral customs of its inhabitants, on the Caucasian mountains and its peoples. ${ }^{300}$ Procopius used geographical mixed with historical and ethnographic material in his excursuses. ${ }^{301}$

Procopius' ethnographic digressions can be understood as reflecting his age and the self-perception of late Roman society in relation to other peoples. ${ }^{302}$ In line with one of the traditional functions of ethnography, Procopius intended to reflect on aspects of the customs, the social structure, the social justice and injustice of his own time through representations of the way of life of foreign peoples. Accordingly, barbarian features were occasionally idealised in order to reveal the immorality of the decadent Romans. ${ }^{303}$ At the same time, we must not forget that Procopius employed geography in the service of imperial history and his narratives in the De bellis reflected the emperor's military ambitions and policies of reforming and restoring the Roman state, as the age of Justinian I was a time of territorial expansion and ideological transformation. ${ }^{304}$

Noticeable is the decline of ethnography in the Middle Byzantine period, from the seventh century up to the thirteenth century, although the Byzantine scholars who wrote historical texts in those centuries were familiar with the previous tradition and had sufficient material to draw from as well as the know-how. Unlike their predecessors, middle Byzantine authors do not write contemporary ethnography, and middle Byzantine ambassadors are not open to recounting what they saw on their journeys. ${ }^{305}$ One of the reasons for this is that historiog-

296 Procopius, in his accounts of the Persian, Vandal, and Gothic wars, introduced information about foreign peoples, their land, and their customs having drawn from classical models. Herodotus' account of the Scythians had probably become the main source on which subsequent narrations of Huns, Chazars, Avars, and Turks were based.

297 Procopius, De bellis 3.1.4-19 and 5.12.

298 Procopius, De bellis 5.15.

299 Procopius, De bellis 6.14-15.

300 Procopius, De bellis 8.3.1-2.

301 Cesa (1982), 289-409; Revanoglou (2005). On Procopius in general, see Rubin (1954); Cameron (1996b); Kaldellis (2004).

302 Kaldellis (2013).

303 For a similar attitude in earlier historians, see Ammianus' ethnographic digression on the Persians; cf. Ammianus Marcellinus, 23.6. Priscus' account on the embassy to Attila; cf. Blockley (1983), fr. 11.2.407-547.

304 Maas (2007), 69. Av. Cameron also traces the sixth-century belief that Justinian would restore the magnificence of Roman antiquity in Procopius' De aedificiis; cf. Cameron (1996b), 112. On the De aedificiis in general, see Whitby (2000), 45-57. In the early years of Justinian's reign belong also the geographical treatises by Stephanus Byzantius and Hierocles; cf. Meineke (ed.) (1849); Billerbeck (ed.) (2006-2016); Honigmann (ed.) (1939).

305 On the matter and the reasons for the decline in ethnography in the middle Byzantine period see Mango (1988-1989), 360-372 and Kaldellis (2013), 71-77. 
raphy, the primary genre in which ethnographic and geographical accounts were embodied, ${ }^{306}$ from the eighth century onwards focused chiefly on Constantinople and the imperial court. ${ }^{307}$ Another chief reason for the decline of ethnography can be traced back to the Islamic conquests and the establishment of the Lombards in Italy and the Slavs and Bulgars on the Balkans, which seems to have provoked a significant decline in historiography as well. ${ }^{308}$ Consequently, from the seventh century onwards, historians were uncertain about the dominant position of the Roman Empire, whose territory had been continuously shrinking. They were, therefore, reluctant to apply similar interpretative strategies to ethnic differences as Procopius or Agathias had previously done. The historians preferred to write about nations that were not a big threat for the Empire or peoples that were subjects to the Romans. ${ }^{309}$

Despite the fact that after the seventh century ethnographical accounts were reduced markedly, ethnography did not disappear completely. In the middle Byzantine period, short ethnographical and geographical passages are to be found in texts, though not in histories or chronicles in the classical sense. Theophanes is a prime example of a middle period chronicler who avoids including descriptions of peoples in his work. ${ }^{310}$ Contrary to Theophanes' text, the Tactika by Leo VI, ${ }^{311}$ a military treatise, Photius' Bibliotheca, ${ }^{312}$ the DAI, a manual of domestic and

306 In the fifth century, ethnographic accounts appear also in the ecclesiastical history of Philostorgius and in Palladius' work De gentibus Indiae et Bragmanibus. In the sixth century, ethnography appears in the hagiographical work of Ps.-Neilos of Ankyra called Narrationes and in Topographia Christiana by Cosmas Indicopleustes. In the middle Byzantine period ethnography is almost absent from Christian literature. Nevertheless, ethnography is traced in the Vita Barlaam et Joasaph, the Vita Sancti Macarii Romani, and the Vita Andreae Apostoli; cf. Kaldellis (2013), 64-67.

307 C. Mango first argued that Byzantine writers and the Byzantine public ceased to be interested in lands that had broken away from Constantinople under the Arab conquest in the seventh century; cf. Mango (1988-1989), 360-372.

308 Whitby (1992), 66-74; Haldon (1990), 425-435. It has been claimed to be due to the weakness of historians to interpret the failures of the Empire: the well-established faith in the superiority of Orthodoxy over 'the infidel peoples' was difficult to overcome. Defeat in religious war made it difficult for the Byzantines even to discuss their enemies and impossible to understand their motivation; cf. Kaldellis (2013), 71-77.

309 This is apparent amongst the historians of late antiquity. We encounter, however, such an attitude amongst the historians of the middle Byzantine period as well. See, for instance, Psellos' ethnographic account on the Pechenegs; cf. Chronographia 7.67-69.

310 Mango, Scott, and Greatrex (edd.) (2006).

311 Dennis (ed.) (2010). Ethnography can be found in military treatises such as the Tactika by Leo VI. It should be stressed that the rhetoric of the Christian empire, which originated in the age of Justinian, is apparent in Leo's Tactika. Thus, the Bulgars differ from the Hungarians because the first are Christians (Tactika 18.59), the Franks and the Lombards are Christians and therefore somewhat friendlier towards the Empire (Tactika 18.74) whereas the Saracens were always presented as enemies of the Romans because they were not Christians (Tactika 18.105).

312 Henry and Schamp (edd.) (1959-1991). 
foreign policy by Constantine Porphyrogenitus, ${ }^{313}$ and the Vita Basilii, ${ }^{314}$ a historical biography, abound with ethnographic and geographical material. In addition to this, ethnographic passages were excerpted from classical and late antique writers and incorporated into collections of historical excerpts, such as the Excerpta Anonymi and the Excerpta Salmasiana. ${ }^{315}$ It becomes manifest, therefore, that after the seventh century we only encounter short ethnographies or ethnographical excerpts inserted in a variety of literary structures. The issue to be investigated is what literary and political purposes the selection, extraction, and representation of ethnographic or geographical excerpts serve in the subsequent centuries of Byzantine history.

Certain passages in the Excerpta Anonymi show evidence of how a tenthcentury compiler imposed a new meaning onto the excerpts of Procopius, thus shedding more light on the history of ethnography in the subsequent centuries of Byzantine history. Ethnography did not disappear completely, but its meaning changed profoundly, under the influence of the changed political circumstances of the tenth century.

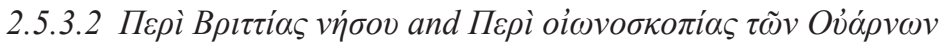

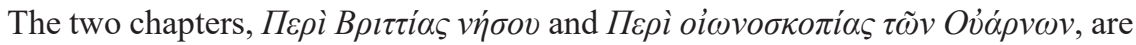
part of the historical part of the Excerpta Anonymi. As has already been noted, the text of the two chapters has been excerpted from the eighth book of Procopius' De bellis. It is clear that an ethnographic and geographic interest dominates this book published two years after Procopius had finished the first seven books of the De bellis. ${ }^{316}$

\section{Excerpt $1^{317}$}

The excerpt begins abruptly with the description of the geographical position of

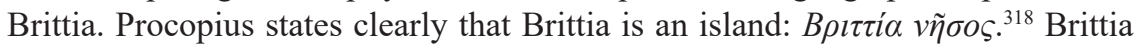
is only about two hundred stades from the continent, approximately opposite the mouth of the Rhine. ${ }^{319}$ Then, Procopius distinguishes Brittia from Brettania and Thule; Brittia is situated between them. ${ }^{320}$ The former is situated in the West and

313 Moravesik and Jenkins (edd.) (1967).

314 Ševčenko (ed.) (2011). On the text, see also Karpozilos (2002), 345-366; Kazhdan (2006), 137144.

315 On the ethnographical passages embedded in the Excerpta Salmasiana, see Chapter 3.

316 On the date of publication of Book VIII, see Greatrex (1994) and Greatrex (2014a), 97.

317 See Appendix I: Text I.

318 Excerpta Anonymi 23, 12. Procopius repeatedly mentions in this chapter that B $\rho \imath \tau i \alpha$ is an island; cf. Procopius, De bellis, 8.20.1, 4, 6, 7, 10.

319 Excerpta Anonymi 23, 14-15.

320 Excerpta Anonymi 23, 17. Procopius had already mentioned earlier that Brettania is larger than even Sicily; cf. Procopius, De bellis 6.6.28. 
the latter in the East. ${ }^{321}$ Procopius mentions that Brittia is inhabited by three peoples and that each of them has a king of its own. The three nations are the Angles, the Frisians, and the Britons. They dwell in a land belonging to the Franks. ${ }^{322}$

As can be observed in Appendix I: Text I, the first passage excerpted from Procopius halts at the point where Procopius gives us a brief description of a Frankish embassy at Justinian's court in Constantinople, ${ }^{323}$ in Paragraph 10. In Procopius' text, the Franks ${ }^{324}$ had invited some of the Angles who had settled on their land, to accompany them to Constantinople. The reason behind this obviously was, as Procopius states, to show that Brittia was ruled by the king of the Franks. ${ }^{325}$ What is of major importance there is that the Franks sent an embassy to Constantinople to secure Justinian's recognition of their claim to rule the land where the immigrants had settled. ${ }^{326}$ It is worth noting that in the De bellis 7.33.4 Procopius also tells us that the Franks did not consider their possession of Gaul secure until the emperor had put the seal of his approval upon their title. ${ }^{327}$

The passage on the Frankish embassy is absent in the Excerpta Anonymi. A closer look at the collection suggests that the suppression is possibly linked to the compiler's attitude towards Justinian throughout the Excerpta Anonymi. I showed already that omissions and modifications in the passages excerpted from

321 J. B. Bury supported the opinion that Brittia in Procopius' text means Britain; cf. Bury (1907), 79-88. A. R. Burn also believes that Brittia as well as Brettania represent Britain; cf. Burn (1955), 258. The argument that Brittia and Britain is one and the same island is reinforced by a comment that occurs later in the same chapter, viz. that on this island of Brittia men in ancient times had built a long wall, cutting off a large portion of it; cf. Excerpta Anonymi 24, 2-4. Jordanes, however, refers to British horses; cf. Jordanes, Getica II.15. Bury went further arguing that Procopius by Brittia meant Britain, but that he did not realise that the land he described was indeed Britain; cf. Bury (1907), 83. Thompson agrees that Brittia represents Britain but he believes that by Brettania Procopius meant Armorica, the province that nowadays is called Brittany; cf. Thompson (1980), 499; cf. Bury (1906a), n. 168, 157. Av. Cameron judges positively Thompson's proposition; cf. Av. Cameron (1996b), 215. The view that Brittia and Brettania are two different islands was supported by J. O. Ward, too; cf. Ward (1968), 465.

322 That this migration took place in the first half of the sixth century can be argued with certainty and Procopius' account of the immigration of people from Brittia to the Continent conforms with the situation presented by his contemporary Gildas; cf. Stenton (1967), 5-8 and Stevenson (1899), 32-46. Procopius' account also bears resemblance to an account written by a monk of Fulda shortly before the year 865; cf. Langebec, (ed.) (1773), 38-49 and Pertz (ed.) (1829), 673-681.

323 This Frankish embassy was set up in ca. 550; cf. Procopius, De bellis 8.20.10.

324 The term Franks (in Greek $\Phi \rho \alpha ́ \gamma \gamma o l$ ) is not classical but is an ethnonym that emerged in late antiquity. The use of that name was not a form of classicism; cf. Kaldellis (2013), 112 and 115.

325 Procopius, De bellis 8.20.9-10.

326 Thompson argues that Procopius in writing this passage had in mind the move to Britanny started in the fifth century. According to Thompson, by Britania Procopius means Brittany; cf. Thompson (1980), 499-503.

327 The matter of Roman power over Brittia during Justinian's reign has been treated by J. O. Ward; cf. Ward (1968), 460-471. It is likely that Justinian claimed a theoretical title over the island of Brittia. In the third book of the De bellis (cf. Procopius, De bellis 3.2.38), Procopius states that the Roman rule over Britain ended after 409. Roman rule is unlikely to have come to such an abrupt end; cf. Av. Cameron (1996b), 213. This topic has been treated by many scholars; cf. Thompson (1980), 409-503; Thompson (1982); Johnson (1980); Welsby (1982); Wood (1984), 1-25. 
the Parastaseis occur intentionally and not without a goal. When reading the Parastaseis it turns out that the building activity of Justinian I figures rarely in the Excerpta Anonymi and is largely pruned away.

This we have to understand against the political background of the tenth century and as an expression of the Macedonian dynastic propaganda. Certain preoccupations in the Excerpta Anonymi confirm that they belong to the context of the tenth-century 'restricted ecumenism', as expressed in the treatises that appeared under the auspices of Constantine Porphyrogenitus. The concept of 'limited ecumenism', as a specific theory about Byzantine foreign policy in this period, was first advanced by T. Lounges. ${ }^{328}$ His theory, long neglected, was recently unburied and reappraised by $\mathrm{P}$. Magdalino. ${ }^{329}$

Indeed, Constantine Porphyrogenitus only occasionally refers to Justinian I in the $D T^{330}$ and Justinian I is markedly ignored in the $D A I$. Moreover, in the $E C$, an enterprise also undertaken under Constantine Porphyrogenitus' auspices, excerptors have intervened in the excerpts from the chronicle of Theophanes, distorting what the emperor had considered irrelevant to his purpose and presenting Justinian I unfavourably. ${ }^{331}$ The geographical perspective outlined by Constantine Porphyrogenitus in his $D A I$ is also determined by the prospects and expectations of possible imperial administration and rule in formerly imperial territories that were still considered to be within the grasp of the Empire. ${ }^{332}$ But this Empire was smaller than the one Justinian I had conquered. The DAI Chapters 26-28, centred on the history of Italy and the Lombard invasions, seem to have been constructed to justify the Venetian, Lombard, and Frankish settlements on former imperial territories. Their content distorts the origins of the division of Italy into Frankish and Byzantine rule by providing 'information' with no basis in reality. ${ }^{333}$ The chapters appear to propagate the division of the West according to the political agenda of Constantine Porphyrogenitus. ${ }^{334}$ In the tenth century, the Macedonian dynasty had already accepted the division of the Empire, and Italy was considered definitely lost. Consequently, Constantine Porphyrogenitus intended to erode the memory of Justinian I by omitting or distorting the reconquest of Italy for the Byzantine Empire under the reign of this emperor. ${ }^{335}$

Seen from this perspective, the Excerpta Anonymi belong to a time when the transformative power and civilising influence of the Empire had already been

328 Lounges (1981), 49-85 and Lounges (1990).

329 Magdalino (2013b), 23-42.

$330 D T, 61,62,63,65,70,76$.

331 Lounges (1981), 55.

332 Magdalino (2013b), 23-42.

333 In Chapter 27, Constantine Porphyrogenitus places the Lombard invasion in the eighth century, rather than in the sixth; cf. $D A I, 27$.

334 See also Von Falkenhausen (1989), 25-38. Chapters 29-36 are an attempt to make allowances for the settlement of the Croats and the Serbs in Dalmatia and the Balkans; cf. Magdalino (2013b), 23-42.

335 Lounges (1990). 
restricted. Accordingly, the omission of the reference to the Frankish embassy should be placed within this historico-political context. The compiler wanted to avoid reminding Byzantine readers of the late-tenth century of a period in which the possession of Gaul by the Franks was not guaranteed until the emperor had put the seal of his approval upon their title. ${ }^{336}$

\section{Excerpts 2 and $3^{337}$}

The second excerpt from Procopius reports that the people who live closer to the Franks are the Varni. Only the river Rhine separates the Varni from the Franks, whereas the Britons are settled in another land, called 'Iov $\beta \varepsilon \rho v i \alpha$.

First, it is worth noting that the compiler is concise regarding that passage and greatly simplifies the original text. Let us have a look at the original context of the passage: after speaking about the geographical position of Brittia and the nations settled on it, Procopius goes on to narrate a curious story about the king of the Varni. ${ }^{338}$ This king, called Hermegisclus, predicted his own death on the basis of a portent he had suddenly seen: a bird that was croaking loudly, which Hermegisclus interpreted as a sign of his own death after forty days. Accordingly, the king, in a speech addressed to his people, warned them to take only Frankish women as spouses and not from the people of the Britons, because the former were their real neighbours. Similarly, the king compels his son to abandon his future wife because she belongs to the people of the Angli. The girl then decides to take revenge by waging war on the people of the Varni. ${ }^{339}$

The Procopian passage 8.20.18 is part of the speech of Hermegisclus. It is apparent, therefore, that the compiler of the Excerpta Anonymi has singled out a reference to the neighbours of the Varni and incorporated it as an independent piece of information into his text. Excerpt 3 is a short excerpt from the account on Hermegisclus, too. The Excerpta Anonymi author again cuts out an isolated piece from its genuine context, referring to the mores of the Angli. It is obvious that the author of the codex preferred to represent that story in an independent chapter,

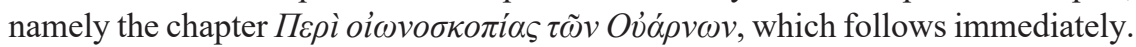

Up to this point, the compiler has spoken about the geographical position of Brittia, has informed us on the nations settled on it and he now tells us something about the customs of one of the island's peoples. We never learn from the Excerpta Anonymi about the romantic story of a couple in Brittia. The author of the Excerpta Anonymi has also chosen to omit the conduct of the king of the Varni. The passage contains only three sentences reflecting the virtue amongst the Varni.

336 Procopius again refers to this; cf. Procopius, De bellis 7.33.4.

337 See in the Appendix I: Text I.

338 This account is the subject of the following chapter (Excerpt 6 in this book) in the anonymous

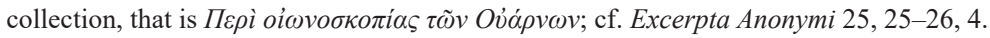

339 Procopius, De bellis 8.20.11-25. 
It must also be stressed that the author of the Excerpta Anonymi has excluded the wording $\beta \alpha \dot{\alpha} \rho \beta \alpha \rho o l$ (= barbarians) from his text. He never uses this characterisation to refer to peoples who settled in the West. For Procopius and surely for the Romans of the sixth century the foreign peoples who are presented through these digressions were first of all barbarians. What we detect throughout these six excerpts is an ethnographic account, the main goal of which is not to underline the superiority of the Romans over a foreign people. ${ }^{340}$ Interestingly, the excerpts comply with Constantine Porphyrogenitus' high regard for the Franks, which is evident especially in his $D A I .^{341}$ It should also be noted that, in this line, the Excerpta Anonymi compiler supplies better information on the West than Procopius did, by mentioning Hibernia ${ }^{342}$ and by identifying the Germans with the Franks. ${ }^{343}$ It could also be argued that the Excerpta Anonymi compiler did not attempt to distinguish Brittia's nations from the Romans on the basis of their distinctive manners of living. Consequently, there is no reference to the social structure of these peoples, their religious beliefs, or their way of life. The fact that each of the three nations has its own king denotes merely that they are three distinct peoples who live in different parts of Brittia.

\section{Excerpt $4^{344}$}

Excerpt 4 is a very brief description of the Britons and the Varni's battle gear on the battlefield: peoples on Brittia have never seen horses. I suggest that at this point the compiler of the Excerpta Anonymi introduces a mini-military ethnography. He, once again, isolates a couple of sentences from an entire episode in order to offer what he considered most important to serve his purpose of thematic homogeneity throughout the compilation. The two sentences were excerpted from Procopius' account of the Angles' attack on the Varni, under the leadership of the woman whom the son of Hermegisclus had decided not to marry. ${ }^{345}$ The ethnographic digression of Excerpt 4 has been placed between the moral comment upon the Angli (Excerpt 3) and the tale of the dead souls that are ferried to Brittia (Excerpt 5). I believe that such a digression could be seen as an ethnographic addition to the previous brief representation of the people of Brittia and serves to introduce us to the fantastic and exaggerated account that follows. If the author

340 Leon VI in his Tactika includes a very brief description about Franks. It is likely that it was less urgent for the Empire of his time. Franks were Christian and generally friendly to the Empire; cf. Tactika, 18.74-92.

341 See, for instance, the DAI, 13.110-121.

342 I am indebted to Prof. Paul Magdalino for this remark. The only reference to Hibernia that I

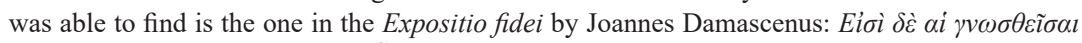

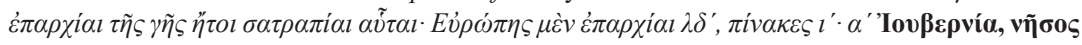
Врєтаиıкиं; cf. Expositio fidei, 24b.1-2.

343 This piece of information is possibly taken from Procopius, De bellis 3.3.1. Agathias also identifies the Franks with the Germans; cf. Agathias, Historiae I.2.

344 See Appendix I: Text I.

345 Procopius, De bellis 8.20.26-31. 
had stopped his narrative with the morality of Angli, the following tale would have been presented abruptly and without any ostensible reason.

\section{Excerpt $5^{346}$}

Excerpt 5 contains a story about the souls of the dead that are ferried to the island of Brittia by fishermen inhabiting the land of the Franks. It is likely that Procopius had heard that story from the Anglian members of the Frankish embassy at Constantinople. ${ }^{347}$ Procopius also states clearly that the story of the transfer of these souls was well known in Byzantium. ${ }^{348}$ It was a story recounted by men who had taken part in the transportation of the souls ${ }^{349}$ and was common knowledge amongst the Byzantines, so that Procopius claims he feels obliged to include it into his historical narrative. ${ }^{350}$ He adds a story, however, which he himself does not even believe to be true: he states that he will record a story that belongs to the sphere of mythology. ${ }^{351}$

The same story was included in our anonymous collection. The question is what was the rationale for the selection of that passage. I suggest we have to think about the role the socio-political context played in the selection and the presentation of the present story. I propose that the incorporation of this kind of material is very much in line with the tenth-century Constantinopolitan political agenda: the notion of restricted ecumenism. Accordingly, the Excerpta Anonymi author consciously attempts to restrict himself and all the Byzantines in an area located in one part of the continent, whereas in another one, far away from Constantinople, a fictitious and frightening event takes place: fishermen conveying dead souls. In addition, we do not detect any covert comment upon any previous presence of Byzantines in Britain. The story is set in a distant place, distinguishing a civilised and erudite people on the one hand and an exotic and peculiar place and community on the other. The compiler of the Excerpta Anonymi represents Brittia as a fabulous place. The differentiation could thus justify why such a story would only take place distant from Constantinople and accordingly the description of Brittia and its peoples excludes in the Excerpta Anonymi the possibility of political inclusion and cultural transformation. The civilising mission of the Empire depicted in Justinian's missionary activity ${ }^{352}$ and testified to in Procopius' writings is totally missing. . $^{353}$

\section{See Appendix I: Text I.}

347 Burn (1955), 259. F. M. Stenton argues that Procopius' narration shows a knowledge of Germanic customs, which could only have been acquired from a barbarian informant; cf. Stenton (1967), 5.

348 Procopius, De bellis 8.20.47.

349 Procopius, De bellis 8.20.47.

350 Procopius, De bellis 8.20.47.

351 Procopius, De bellis 8.20.47.

352 On the subject, see Beck (1967), 649-674; Av. Cameron (1996b), 120-125; Ševčenko (19881989), 7-27; Greatrex (2005), 477-509.

353 See Procopius' account of the Tzani's conversion; cf. Procopius, De bellis 1.15.18-25. Procopius' account of Heruls' conversion; cf. Procopius, De bellis, 6.14.33-34. See also Procopius' account of Tzani in De aedificiis, a work devoted to the building activity of Justinian; cf. Procopius, De aedificiis 3.6.1-14. 
The compiler's attempt to reinforce the distinction between Byzantines and peoples in Brittia is also evident in the passage on Brittia excerpted from Cassius Dio. ${ }^{354}$ The description of Cassius Dio reveals a place impassable and inhospitable rather than a place worthy of being part of the Roman Empire: ö $\rho \eta \ddot{\alpha} \gamma \rho \imath \alpha \kappa \alpha i$

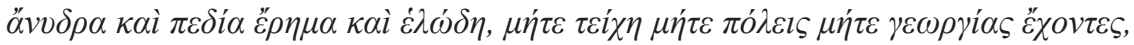

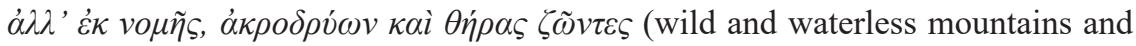
desolate and swampy plains, and they have no enclosures, nor towns nor tilled fields, but they live on their flocks, wild game, and certain fruits). ${ }^{355}$ The ethnographic description that follows reports mostly on the military equipment of the Kalydonians. The text puts an emphasis on their primitive poverty and their

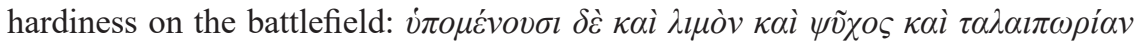

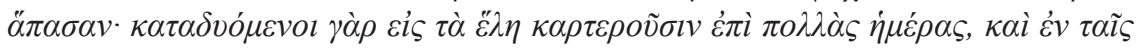

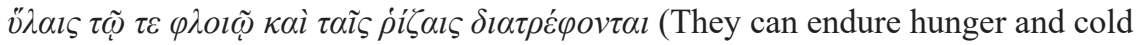
and any kind of hardship; for they plunge into swamps and exist there for many days, and in the forests they support themselves upon bark and roots). ${ }^{356}$ The passage does not contain any reference, direct or indirect, to the importance of the foreign peoples' adoption of civilised life. In the Excerpta Anonymi ethnographic passages peoples become identifiers of the lands and the possibility of cultural transformation is totally lacking. It is worth mentioning that similar preoccupations are evident in the Synaxarium Ecclesiae Constantinopolitanae, a collection of hagiographies, the compilation of which is associated with the tenth-century imperial court, too. ${ }^{357}$ According to the vita of Aristoboulos, the Apostle was

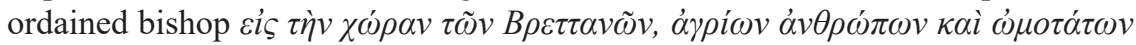
(in the land of Britons', who were wild and savage people) ${ }^{358}$ and according to the

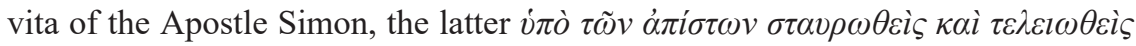

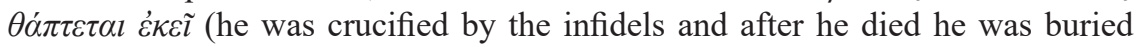
there). ${ }^{359}$

\section{Excerpt $6^{360}$}

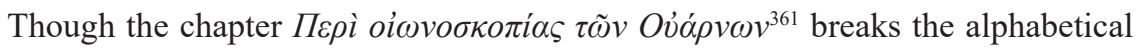
order, it was embedded at this point in the Excerpta Anonymi because the chapter

354 Excerpta Anonymi 21, 26-22, 19. A paraphrased version of the passage is found in the margins of f. $24 \mathrm{v}$ in the fifteenth-century codex Athos, Iviron 175 which contains the chronicle by Michael Glycas. See Constantinides (2008), 15-23 with the marginal note edited on pp. 20-21. The chronicle of Michael Glycas is edited in Bekker (ed.) (1836). On Michael Glycas, see Hunger (1978), 422-426; Mavromati-Katsougiannopoulou (1984). On Iviron 175, see Constantinides (2008), 17-18.

$355 C D$ 77.12.1.

$356 C D 77.12 .4$.

357 On the relation with the imperial court, see n. 85 in Chapter 1.

358 Synaxarium ecclesiae Constantinopolitanae, cols. 539.3-540.11.

359 Synaxarium ecclesiae Constantinopolitanae, cols. 671.11-30 and 781.27-32.

360 See Appendix I: Text I.

361 Excerpta Anonymi 25, 25-26, 4. 
refers to Brittia and its inhabitants (the nation of Varni). In addition, the chapter

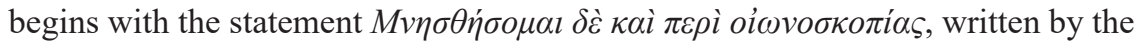
compiler and denotes that he felt the necessity to justify his choice to include a title that does not follow the previous alphabetical arrangement. It is possible that the author considered the passage so important that he needed to insert it at that point of his compilation: the chapter on the one hand provides additional information concerning the island of Brittia, and, on the other, links a nation of Brittia, namely that of the Varni, to the tradition of omens and prophecies. The introduc-

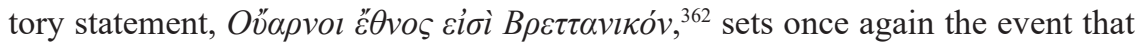
follows in a distant place, in Britain.

The central point in Procopius' narration is the figure of Hermegisclus and his crucial decision to repudiate the wife chosen by his son, which leads to the war against the Angli later on. By contrast, the central point in the Excerpta Anonymi is the portent that Hermegisclus interpreted as an omen of his own death after forty days. Our compiler omits almost the entire story of Hermegisclus and only keeps the reference to the portent that made the king change the decision concerning his son's wedding. In the Excerpta Anonymi, the central point is the prediction of Hermegisclus' death. It is obvious that the author of the Excerpta Anonymi desired to include passages that matched, in terms of subject matter, the ones of the first part of the compilation, which concern prophecies, omens, and hidden powers. ${ }^{363}$

I have argued that Roman geographic descriptions reflect contemporary attitudes and the perception of the world current in the period they are composed. In the Excerpta Anonymi as well as in Procopius' ethnographical accounts, foreign lands and their people are set apart from civilisation by their isolation. Barbarian lands are inhospitable and impassable and cut their inhabitants off from contact with the Roman Empire. The people inhabiting these distant places have peculiar habits and beliefs. However, Procopius' geographic digressions come from the age of Justinian I, which was a time of territorial expansion and ideological transformation. His ethnographic accounts express a belief in the civilising influence of the Empire and in the transformative power of Roman imperialism by integrating foreign people into Roman institutions or into a Christian community. In Procopius' De bellis we encounter geographical accounts which reveal how the Romans helped these inferior nations on the way to civilisation. Such integrating efforts depicted primarily the superiority of the Romans over these peoples.

In the Excerpta Anonymi, instead, these ideas are missing. They rather use the difference in the civilisation level to reinforce already established geographical and political frontiers. In the foregoing pages I have suggested that this changed perception has parallels in other sources as well, in particular the Constantinian treatises. I would suggest that the author of the Excerpta Anonymi was writing 
under the pressure of the dominant imperial policy, even if he has not been commissioned directly to serve it. It has to be stressed that an author belonging to the contemporary bureaucratical or intellectual milieu is likely to absorb the dominant ideology expressed at that time. Even if he is not a tool of propaganda, he is likely to be influenced by it. In fact, indirectly the codex depicts the contemporary political situation and contains information that seems to be anachronistic. However, the Excerpta Anonymi update the information about the past by placing it in a tenth-century context, thereby revealing the author's efforts to preserve certain texts by making them fit into a new time frame. As noted, the compiler of the Excerpta Anonymi collects and rearranges material that corresponds to meticulously selected themes, such as the otherness of non-Byzantines and the belief in portents. Finally, the Excerpta Anonymi reflect the choices and interests of its compiler, while, at the same time, betraying what kind of texts attracted particular attention in his own age. ${ }^{364}$

\subsection{Conclusions}

In this section, I would like to repeat the main arguments I have made in this chapter: 1) Paleographic, textual, and contextual evidence suggest that the Excerpta Anonymi date to the second half of the tenth century. 2) The sylloge comprises excerpts taken from a variety of sources; patriographic, geographic, geometric, and historical treatises. A certain number of excerpts had been excerpted in the Excerpta Anonymi through earlier collections of excerpts. Structurally, the passages were selected thematically and arranged alphabetically. The author of the Excerpta Anonymi, at times, breaks the alphabetical sequence of excerpts and inserts passages that clarify the content of earlier passages and enhance the thematic homogeneousness of the sylloge. 3) I also elucidated the working method applied in the Excerpta Anonymi and I identified the three procedures followed by a compiler, namely a) reading and selection, b) editing, and c) synthesis. 4) The $E C$ and the Excerpta Anonymi share significant similarities in terms of content, format, and methodology. I suggested that, for the chapter "On the River Istros", the Excerpta Anonymi drew on a collection of geographical material, whereas for the chapters "On Cyrus" and "On Remus and Romulus" they drew on a Constantinian collection of occult science. Similarly, some passages on Roman history in the Excerpta Anonymi derive from a collection on dreams and occult science. And 5) The tenth-century socio-political context played a significant role in the selection and in the re-editing of excerpts. In particular, I suggest that a) the excerptor of the Excerpta Anonymi debases Justinian, and b) that Roman geographic and

364 The Parisinus interest in history matches a cultural revival that had started at the end of the eight century and was lively during the tenth century. I. Ševčenko has pointed out that the Ecloga chronographica of George Syncellus, the Chronographia brevis of Patriarch Nicephorus and the Parastaseis Syntomoi Chronikai constitute the beginning of Byzantine interest in the past; cf. Ševčenko, (1992b) 279-293. See also Markopoulos (2006), 283-286. On Syncellus, see Adler and Tuffin (2002). 
ethnographic descriptions in the Excerpta Anonymi reflect contemporary attitudes and the current perception of the world in the period they were composed in. It has also been shown that the purification of the text from religious references should be seen under the influence of the intellectual and cultural tendencies of the tenth century. 


\section{Excerpta Salamasiana}

The Excerpta Salmasiana are an anonymous sylloge of historical excerpts named after the French humanist Claude Saumaise, who copied them around the year 1606 from a mid-twelfth-century codex in Heidelberg. ${ }^{1}$ The sylloge was probably put together between the eighth and the eleventh-twelfth centuries. This chapter argues that the Excerpta Salmasiana comprise three distinct syllogae of excerpts: 1) the Exc.Salm.I, which consists of excerpts taken from a single historical work, namely John of Antioch's Historia chronica, 2) the Exc.Salm.II, which comprises excerpts from John Malalas' Chronographia, Cassius Dio's Historiae Romanae, and an unidentified lost chronicle that used a variety of late antique sources, and 3) a sylloge of excerpts from Agathias' Historiae.

The chapter 1) considers the manuscript transmission of the entire Excerpta Salmasiana, 2) surveys the relationship between the Excerpta Salmasiana and John of Antioch's chronicle, 3) undertakes a close analysis of the source texts each of the three syllogae depended on, 4) considers the selective use of historical material on the part of the compiler of the Excerpta Salmasiana, and 5) examines the methodological principles underlying the compilation process of the Excerpta Salmasiana. These last two points shall be undertaken on the basis of the third part, the excerpts from Agathias, which has hitherto received no scholarly attention at all.

\subsection{Manuscript transmission}

The Excerpta Salmasiana have been transmitted through three manuscripts, namely Vaticanus gr. 96 (mid-twelfth century), Vaticanus pal. 93 (mid-twelfth century), and Parisinus gr. 1763 (ca. 1606).

\subsubsection{Vaticanus graecus 96}

Bombyc., ff. IV + 229, $244 \times 175 \mathrm{~mm},(180 \times 105,187 \times 112,195 \times 97 \mathrm{~mm})$, II 28-35, sec. XII med. ${ }^{2}$

1 This manuscript is the codex Vaticanus pal. 93, about which see Section 3.1.2.

2 Biedl (1955), 52-60; Mercati and Franchi de' Cavalieri (1923), 108-109; Canart and Peri (1970), 370; Sotiroudis (1989), 187-188; Cook (2005), 190-193; Roberto (ed.) (2005b), LVII-LVIII; Mariev (2008), 26*-27*; Dorandi (2009), 8-9. 
Vaticanus graecus 96 contains: 1r-10r: Flavius Philostratus, Epistulae ${ }^{3} 11 \mathrm{r}-$ 18v: Polemon, Declamationes $;{ }^{4}$ 19r-29v: excerpts from ps.-Hesychius' De Viris Illustribus ${ }^{5}$ 29v-88r: excerpts from Diogenes Laertius' Vitae philosophorum; ${ }^{6}$ 88r-88v: anonymous, Excerpta gnomologii; ${ }^{7}$ 88v-89r: excerpts from Ps.Herodotus' Vita Homeri; ${ }^{8}$ 89r-97v: Flavius Philostratus, Lives of the Sophists; ${ }^{9}$ 97v-98v: excerpts from two Lives of Demosthenes by Zosimus ${ }^{10}$; 98v: an anonymous epitome of Philip's life ${ }^{11}$ 98v-99r: gnomai; ${ }^{12}$ 99r-100v: Joannes Antiochenus, Exc.Salm. I; 100v-102v + 106r-111v + 103rv: anonymous, Exc. Salm. II; 103v-105v + 112r-114v: Agathias scholasticus, Historiae; 114v-131v: Claudius Aelianus, Variae historiae; ${ }^{13} 131 \mathrm{v}-132 \mathrm{r}$ : Heraclides Lembus, Excerpta politiarum; 132r-157v: Claudius Aelianus' De natura animalium; ${ }^{14} 157 \mathrm{v}-159 \mathrm{r}$ : anonymous excerpts on marvels ${ }^{15} 159 \mathrm{r}-229 \mathrm{r}$ : Claudius Aelianus, De natura animalium. ${ }^{16} \mathrm{~F} .10 \mathrm{v}$ was left blank.

The codex transmits the series of historical excerpts under the heading:

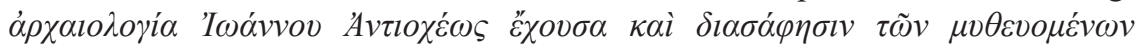
(f. 99r) ${ }^{17}$ The series of excerpts is interrupted by a marginal note bearing the new

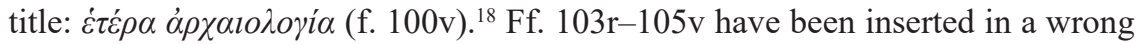
position by a later binder, probably in the fourteenth-fifteenth centuries. The correct position of the folia in the codex is after f. $111 \mathrm{v} .{ }^{19}$

In the margins, there are plenty of notes written in different hands. ${ }^{20} \mathrm{~N}$. G. Wilson argued that the codex was written by a scholar rather than a professional scribe. ${ }^{21}$ A. Biedl regards Vaticanus gr. 96 incomplete and dates the codex to the year $1300 .{ }^{22}$ Biedl compared the script of Vaticanus gr. 96 with the one of the

3 Kayser (ed.) (1964), 225-257.

4 Stefec (2013), 99-154; Stefec (ed.) (2016).

5 Marcovich (1999), 89-138.

6 Marcovich (1999), 140-320.

7 Published in Bertini-Malgarini (1986), 17-26.

8 Vasiloudi (2013), 93-108; The text is edited in Vasiloudi (2013), 156-158.

9 Kayser (ed.) (1838).

10 One of the two Lives is written by Zosimus of Ascalon, a grammarian who lived during the reign of Anastasius (491-518 ad). The other of the two Lives is anonymous. On Zosimus, see PLRE II, 1206. The two Lives were published by Westermann (1845), 297-309.

11 The text was edited in Cook (2005), 194.

12 See the text published in Cook (2005), 191, n. 11.

13 Dilts (1971), 3-12; Dilts (1974), vii-viii.

14 Part of the text in Vaticanus gr. 96 was published in De Stefani (1904), 154-158, 176-178.

15 Published in De Stefani (1903), 93-98.

16 See n. 14.

17 Transl. Mariev (ed.) (2008), 5: John of Antioch's archeology containing the explanation of the mythical tales.

18 A different archeology.

19 Biedl (1955), 53.

20 Sotiroudis (1983), 249-254.

21 Wilson (1977), esp. 221-222 and 235-237.

22 Biedl (1955), 53. 


\section{Excerpta Salamasiana}

codex Parisinus gr. 1671,23 prepared on behalf of Maximus Planudes in 1296, and proposed a terminus ante quem for Vaticanus gr. 96 after the year 1338. N. G. Wilson, instead, dated Vaticanus gr. 96 to the middle of the twelfth century. For his dating, he also relied on the script of the manuscript as well as on its relationship to the codex Vaticanus pal. 93. The latter is a direct copy from Vaticanus gr. 96 (ff. 10r-141r) and it was written before 1152, as a margin note on f. 10r reveals. Moreover, Wilson pointed out that at the bottom of f. 109 there are verses clearly written by a later hand. Wilson dated these verses between $1250-1280 .{ }^{24}$ Finally, C. Giannelli, based also on the analysis of the marginalia, proposed a date close to the middle of the twelfth century. ${ }^{25}$

The codex seems to have been kept in Constantinople by the end of the fifteenth century, being in the possession of various scholars such as Nicephorus Gregoras (1295-1359) and Matthaios Kamariotes (died 1490). ${ }^{26}$ Nothing is known of the circumstances under which the manuscript reached the Vatican Library, but it is certain that it was already there in $1518 .{ }^{27}$

\subsubsection{Vaticanus Palatinus 93}

Bombyc., ff. II + 191 (immo 192), $278 \times 199$ mm, (246 × 163 mm), II 29-42, sec. XII med. ${ }^{28}$

Vaticanus pal. 93 contains: 1r-2r: Joannes Damascenus, De Immaculato Corpore, ${ }^{29}$ 2r-v: Ps.-Caesarius, Quaestiones et Responsiones; ${ }^{30} 2 \mathrm{v}-3 \mathrm{v}$ : Florilegia, Definitiones; ${ }^{31}$ 4r-8r: Anastasius Sinaita, Definitiones, ${ }^{32} 8 \mathrm{v}-9 \mathrm{v}$ : Florilegia, Definitiones; ${ }^{33}$ 10r: Marcus Antonius Polemon In Cynaegirum; 10r: anonymous, Notae chronol. de rebus Constantinopolitanus; 10v-41v: Diogenes Laertius, Vitae philosophorum; 42r: anonymous, Excertpa gnomologii; 42r-46r: Flavius Philostratus, Vitae philosophorum; 46r-46v: Zosimus, excerpts from two Lives of Demosthenes; 46v: anonymous, epitome of Philip's life; 47rv: Joannes Antiochenus, Exc.Salm. I; 47v-52v: anonymous, Exc.Salm. II; 52v-55r: Agathias scholasticus, Historiae; 55r-64r: Claudius Aelianus, Variae historiae; 64r-64v: Heraclides Lembus, Excerpta politiarum; 64v-141v: Claudius Aelianus, De natura animalium; 141r-145r: Xenophon, Cyropaedia; 145r-146v: Xenophon,

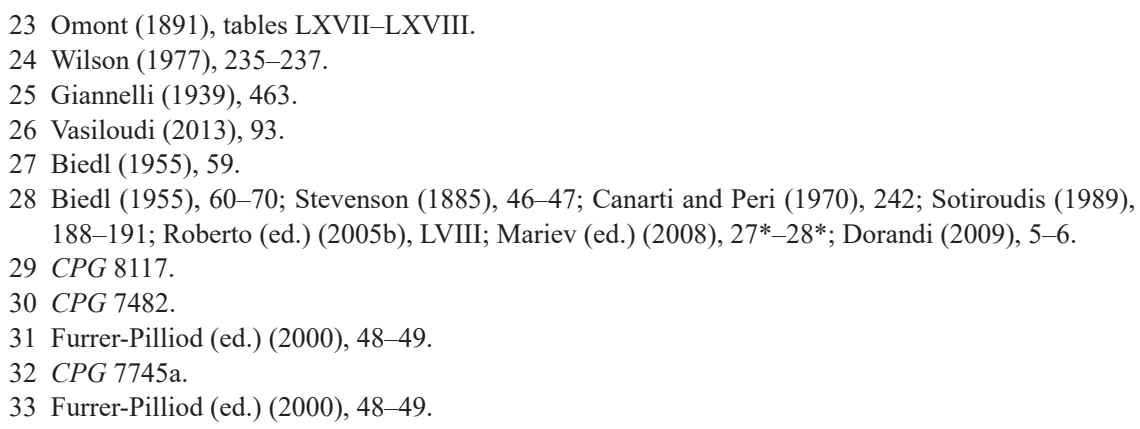


Anabasis; 146v-147r: Xenophon, Apologia Socratis; 147r-147v: Xenophon, Agesilaus; 147v-151r: Xenophon, Memorabilia; 151r-191ar: Herodotus, Historiae; 191bv: anonymous, Breve chronicum Constantinopolitanum (inc:

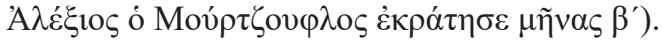

Vaticanus pal. 93 transmits the series of historical excerpts under the head-

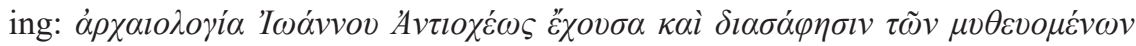

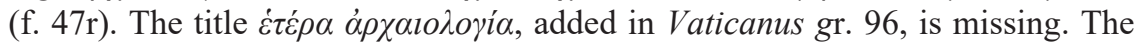
codex was written by one or two hands ${ }^{34}$ and as far as the Excerpta Salmasiana are concerned the codex is an exact copy of Vaticanus $g r .96 .{ }^{35}$ The excerpt collection seems to be embedded in a shared set of texts (Philostratus, Aelian). Nevertheless, Vaticanus pal. 93 contains a significant number of orthographic mistakes as well as omissions of words or even of entire passages. Unlike Vaticanus gr. 96, the codex Vaticanus pal. 93 is written in an untidy minuscule. According to Wilson, the manuscript was executed prior to $1152 .{ }^{36} \mathrm{Biedl}$, based on a reference at the end of the codex, suggested that Vaticanus pal. 93 was written in $1338 .{ }^{37}$ Wilson, however, showed that the reference derived from a different hand than the rest of the text.

An indication transmitted on f. 191bv suggests that the codex was in Constantinople at least up to the middle of the fourteenth century. We know nothing about its fate in the next two centuries. The manuscript was brought to the Bibliotheca Palatina in Heidelberg in 1584 and from there it was moved to Rome in $1623 .{ }^{38}$ The codex is deposited there till today.

\subsubsection{Parisinus graecus 1763}

Chartac. pp. 24, $206 \times 155 \mathrm{~mm},(190 \times 135 \mathrm{~mm})$, II 23-30, an. Ca. $1606{ }^{39}$

Parisinus gr. 1763 contains: 1-3: Joannes Antiochenus, Exc.Salm. I; 4-23: anonymous, Exc.Salm. II.

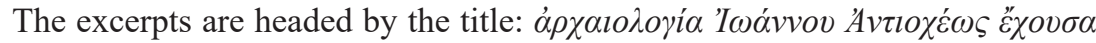

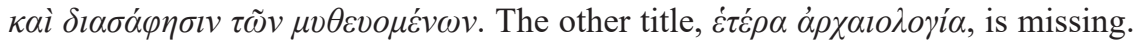
Page 24 is empty. Parisinus gr. 1763 was copied by Salmasius in Heidelberg

34 N. G. Wilson holds the view that folios 2-62 were not written by the same hand as the rest of the codex; cf. Wilson (1977), 237. In P. Sotiroudis' view a later hand has only included minor additions to the body text; cf. Sotiroudis (1989), 188-191.

35 Sotiroudis (1989), 190-191.

36 Wilson (1977), 237.

37 F. 191 bv transmits a short Chronic of Constantinople, the last sentence of which reads as follows:

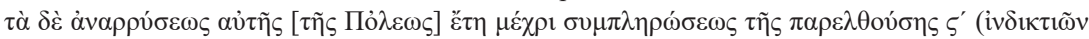
os) Eiđìv o $\zeta^{\prime}$. Accordingly, Biedl proposed the year 1338 since the text records that it was written 77 years after the liberation of Constantinople and the capture of the city by Michael VIII took place on 25 July 1261; Biedl (1955), 61.

38 Biedl (1955), 61.

39 Omont (1888b), 137; Sotiroudis (1989), 191-193; Roberto (ed.) (2005b), LVIII-LVIV; Mariev (ed.) (2008), 28*. 


\section{Excerpta Salamasiana}

around the year $1606 .{ }^{40}$ Parisinus gr. 1763 is a copy of Vaticanus pal. 93. Indeed,

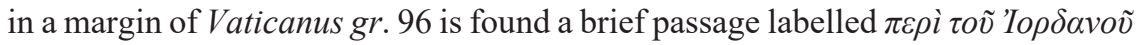

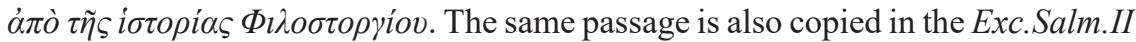
of Vaticanus pal. 93 and from this codex it was later copied in Parisinus gr. 1763. Cramer published the Excerpta Salmasiana from this manuscript in $1839 .{ }^{41}$ Three more manuscripts transmit the Excerpta Salmasiana but all of them are copies either from Vaticanus gr. 96 or Vaticanus pal.93. These codices are: Neapolitanus gr. 166 [II D 4], ${ }^{42}$ Parisinus gr. 3026, ${ }^{43}$ and Palatinus. gr. 129 (Heidelberg). ${ }^{44}$

With regard to the manuscript transmission of the two aforementioned

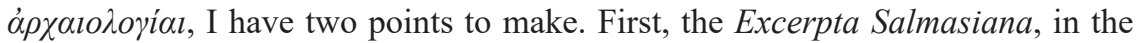
form they have been handed down to us, represent a compilation of three distinct collections of excerpts, which is, however, held together by a shared interest across the three of them. Each of the collections is based on a different historiographical tradition: 1) the Exc.Salm.I are transmitted under the name of John of Antioch. ${ }^{45}$ In S. Mariev's edition of John of Antioch the Exc.Salm.I are made up of thirty-nine excerpts. ${ }^{46}$ The Exc.Salm.I embrace excerpts, which retain coherence in terms of content and narrative sequence. It is difficult, however, to say if the selection of excerpts was made by the anonymous compiler of the entire Excerpta Salmasiana or if he copied a pre-existing sylloge. 2) With the Exc.Salm. II, an excerptor attempted to expand on the Exc.Salm.I by composing a sylloge running from the Deluge to the fifth century ad, relying mostly on Malalas ${ }^{47}$ and

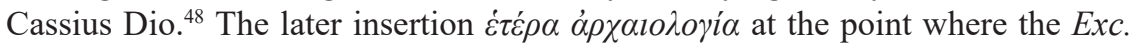
Salm.II begin is an indication that the two collections of excerpts stem from dif-

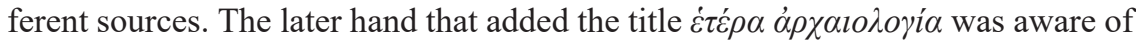
the fact that the second part of the Excerpta Salmasiana had not been excerpted from the same historical work containing the Exc.Salm.I, that is, the Historia

40 See Biedl (1955), 69.

41 Cramer (1839), 383-401.

42 On the codex: Gelzer (1894), 394-395; Eleutheri (1981), 17-18; Sotiroudis (1989), 193-197.

43 Vitelli (1895), 382-384; Sotiroudis (1989), 197-200.

44 Biedl (1948), 100-106; Sotiroudis (1989), 200-201.

45 John of Antioch's Historia chronica run from Adam to the reign of Justinian or to the year 610. The work is preserved in fragments. On the different views of the content of the Historia chronica, see Roberto (ed.) (2005b); Mariev (ed.) (2008), and Section 3.2. John of Antioch relied heavily on a variety of earlier historical accounts; on the sources used by John of Antioch, see Mariev (ed.) (2008), $32 *-41 *$.

46 Mariev (ed.) (2008) p. 4-10. In Roberto's edition the Exc.Salm.II consist of thirty-seven excerpts.

47 John Malalas (ca. 490-570) composed a historical account running from the Creation to the death of Justinian I (y. 565). His work, which is partially preserved, is likely to have been composed in two stages. The part dealing with the years after 532 shows a Constantinopolitan point of view (contrary to the Antiochene point of view of the earlier part). This part was either added by Malalas at some point or it was written by a different author; Van Nuffelen and Van Hoof (2020); Thurn (ed.) (2000); Meier, Radki-Jansen, and Schulz (2016); Carrara, Meier, and RadkiJansen (2017).

48 On Cassius Dio, see Section 2.2.3. 
chronica of John of Antioch. ${ }^{49}$ And 3) to these two was added the collection of excerpts from Agathias of Myrina's Historiae. ${ }^{50}$ Together, the Exc.Salm I and II plus the Agathias collection make up a single sylloge of excerpts that betrays a single interest. All the excerpts are concerned with omens, dreams, and superstition as well as cultural and religious beliefs of peoples surrounding Byzantium.

Second, the sylloge shows that late antique authors, such as Cassius Dio, John Malalas, John of Antioch, and Agathias circulated through excerpt collections throughout the Byzantine period. Specifically, the Exc.Salm.I show that the compiler intended to compile an excerpt collection from John of Antioch's historical work. The thematic homogeneity of Malalas excerpts in the Exc.Salm.II coupled with the fact that a significant part of these excerpts were also used by chroniclers in the tenth-eleventh centuries mirror the existence of a collection of Malalas excerpts, which the excerpts were taken from. ${ }^{51}$ Cassius Dio is the main source of the second part of the Exc.Salm.II. The fact that part of the excerpts are very similar to the excerpts taken from Dio in the tenth-century Excerpta Anonymi indicates that Cassius Dio circulated in an excerpt collection, which both, the Exc. Salm.II and the Excerpta Anonymi must have drawn on (see Section 3.3.2).

The structure and sources of the sylloge will be elucidated in the following sections. Before we proceed, however, a few remarks on the relationship between the collection and the historical work of John of Antioch are required.

\subsection{Excerpta Salmasiana and John of Antioch}

The Excerpta Salmasiana are often associated with the so-called Johannische Frage, ${ }^{52}$ which I need to discuss briefly, so as to lead us to a better understanding of a series of problems central to the nature of the collection. The oldest and best manuscript of the Excerpta Salmasiana is the codex Vaticanus gr. $96,{ }^{53}$ dated to the mid-twelfth century. As noted, the series of excerpts in the manuscript is

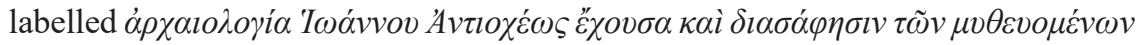

49 In fact, this point could support that the compiler of the Excerpta Salmasiana is not the compiler of the sylloge of John of Antioch. Even U. Roberto's view that the Exc.Salm.I derive from Julius Africanus does not change the fact that this part of the Excerpta Salamasiana compilation was excerpted from a historical treatise.

50 Agathias of Myrina's Historiae are dated to the second half of the sixth century. Agathias also wrote series of epigrams, the so-called Cycle and Daphniaka. An epigram identifies Agathias as curator civitatis in Smyrna (Cameron 1970, 2). The Agathian passages are edited for the first time in the appendix of this book; see Appendix I: Text II. On Agathias' life and works, see Cameron (1970); Kaldellis (1999); Kaldellis (2003); Schulte (2006).

51 See Section 3.3.2.

52 The debate amongst scholars about the historical excerpts that could or should not be ascribed to John of Antioch, author of the universal chronicle known as the Historia chronica. According to S. Mariev, John of Antioch wrote his chronicle in the first half of the sixth century; cf. Mariev (ed.) (2008), 8*. U. Roberto, instead, dates him to the early seventh century; cf. Roberto (ed.) (2005b), $\mathrm{XI}-\mathrm{XX}$.

53 On the codex, see above in Section 3.1.1. 


\section{Excerpta Salamasiana}

(f. 99r). However, a note was inserted in a different hand in the margin of f. 100v,

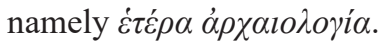

The insertion sparked a debate among scholars as to which of the two parts is originally derived from John of Antioch. The proposition that the first part (e.g., Exc.Salm.I) does not derive from John of Antioch was first advanced by Patzig, who argued that the second part (e.g., Exc.Salm. II) did..$^{54}$ De Boor, by contrast, put forward that solely Exc.Salm.I belong to John of Antioch, whereas the second part derives from an anonymous but now lost chronicle, ${ }^{55}$ which was also used by subsequent writers, such as Symeon Logothetes, Ps.-Symeon, George Cedrenus, and Constantine Manasses. ${ }^{56}$ U. P. Boissevain, in turn, proposed that only the first part of the Exc.Salm.II, namely up to Excerpt 44, derived from John of Antioch. ${ }^{57}$

This disagreement continues among the latest editors: S. Mariev follows de Boor and accepts only the Exc.Salm.I as the genuine work of John of Antioch ${ }^{58}$ and argues that Exc.Salm.II derive from a paraphrased version of Malalas' chronicle. ${ }^{59}$ U. Roberto, instead, regards the first part spurious, and ascribes the second part to John's historical work. ${ }^{60}$ Roberto assigns the Exc.Salm.I to Julius Africanus and argues that they represent an anonymous collection of excerpts extracted from Books III and IV of the Chronographiae by Julius Africanus. ${ }^{61}$ As far as the Exc. Salm.II are concerned, U. Roberto believes that they entirely stem from an epitome of the Historia chronica of John of Antioch. In his view, the anonymous compiler of the epitome downgraded the stylistic and linguistic register of the Historia chronica, in line with the working method of most of the excerptors at that time. ${ }^{62}$ In this way, he attempts to explain the obvious discrepancies between the Exc.Salm.II and the excerpts of the Historia chronica incorporated into the Excerpta Constantiniana (EC) in terms of style, language, and historiographical tradition. Indeed, from Exc.Salm.II 44 onwards the sylloge differs markedly from the $E C:^{63}$ the section dealing with Roman history in the Exc.Salm.II is based on Cassius Dio, whereas in the $E C$ it is derived from Eutropius. Indeed, the comparison of the excerpts in the EC and those in the Excerpta Salmasiana confirms that

54 Patzig (1900), 357-369.

55 De Boor (1899), 298-304; de Boor (1893), 195-211.

56 On the passages from the Exc.Salm.II found in Symeon Logothetes, Ps.-Symeon, Cedrenus, and Manasses, see Table 3.6 and Appendix II: Table V.

57 Boissevain (1887).

58 Mariev (ed.) (2008), esp. 16*.

59 Mariev (2009), 189-190.

60 Roberto (ed.) (2005b), LIII-LVII, LXXIII-LXXVII.

61 Julius Africanus' Chronographiae comprised five books and run from the Creation to $221 \mathrm{ad}$. The surviving fragments of his work were edited in Wallraff, Roberto, Pinggéra, and Adler (2007). On Julius Africanus and his prominent role in the development of Christian chronography, see the papers published in Wallraff (2006).

62 Roberto (ed.) (2005b), LXII.

63 The numbering of the excerpts is that of the edition of the Historia chronica by Roberto (ed.) (2005b). 
the Exc.Salm.II derive from a different historiographical tradition ${ }^{64}$ and that they cannot derive from John of Antioch. ${ }^{65}$ Therefore, the marginal note inserted in Vaticanus gr. 96 must refer to the material that follows it. ${ }^{66}$

The question to be raised, then, is what the source of the Exc.Salm.II was. In the following, I shall argue that the Exc.Salm.II were a sylloge of historical excerpts composed, at least partially, in the tenth century and then added to the Exc.Salm.I, so as to form a collection of historical excerpts on the topic of the legendary Greco-Roman past of the Byzantine Empire.

\subsection{Structure and sources of the Excerpta Salmasiana}

I shall now discuss the structure and the sources of each of the three syllogae constituting the Excerpta Salmasiana.

\subsubsection{Excerpta Salmasiana I ${ }^{67}$}

The Exc.Salm.I comprise thirty-nine excerpts taken from a single historical work, namely John of Antioch's Historia chronica. John of Antioch derived his information from Africanus' Chronographiae. ${ }^{68}$ In terms of content, the thirty-nine excerpts deal with Greek-Hellenistic, Jewish, and Egyptian history. H. Gelzer and E. Patzig argued that the selection of excerpts on the part of the excerptor was not accidental. ${ }^{6}$ Excerpts 1-24 are concerned with the interpretation of Greek myths. ${ }^{70}$ Chronologically, they cover the period from the Exodus to the first Olympiad and thematically, they reflect on Greek mythological history, while making references to contemporary Jewish and Egyptian persons or events. The last three excerpts of this group, namely excerpts 22-24, refer to the origins of Greek feasts associated with competitive games, such as the Isthmia in Corinth and the Pythia in Delphi. In addition, the entire group of excerpts exhibits an interest in synchronising Greek mythology and Jewish and Greek history. ${ }^{71}$

Excerpt 25 marks a turning point in the thematic sequence of excerpts by introducing us to Egyptian history. In particular, Excerpts 25-32 are dealing with the origins of Egyptian history, the first reigns of Egypt, and peculiar facts and wonders that occurred during the reigns of several pharaohs.

64 Boissevain (1887), 161-178; de Boor (1899), 298-304; Sotiriadis (1888), 1-126.

65 B. Bleckmann, Review of Roberto; Bleckmann (2009), 61-78; Van Nuffelen (2012), 439-440.

66 Mariev (2006), 546; Paschoud (2006), 333-334.

67 The numbering of the excerpts is that of the edition of the Historia chronica by Mariev (ed.) (2008).

68 Wallraff, Roberto, Pinggéra, and Adler (2007), esp. XXXIX-XLII.

69 Gelzer (1880), 118-119; Patzig (1900), 357-369, here 366-367. H. Gelzer, however, argued that both the Exc.Salm.I and the Exc.Salm.II are written by John of Antioch. According to H. Gelzer, there have been two versions of the Historia chronica: the original one and a reworked one.

70 The passages are originally derived from diverse ancient authors who attempted to rationalise texts on Greek mythology (Palaephatus, Philochorus, Didymus).

71 Roberto (2005a), 281-286. 
Finally, Excerpts 33 to 39 show some inconsistencies in terms of content. In particular, Excerpt 33 marks a shift to Greek history once more. Excerpt 34 transmits an etymology for the Peloponnese peninsula. Excerpts 35-38 turn back to the topic of Greek competitive games, and the final Excerpt 39 makes a seemingly irrelevant reference to Holofernes, the general of the Chaldean king of the NeoBabylonian Empire, Nebuchadnezzar II.

It becomes apparent, therefore, that the Exc.Salm.I are thematically divided into two parts. As concerns the first part (Exc. 1-24), the criterion of selection is the interest in mythological accounts. The second part (Exc. 25-39) is dominated by a concern about peculiar events and wonders associated with Oriental history. The excerptor intended to collect passages that rationally explain Greek mythical accounts. Accordingly, the careful selection of such passages and the arrangement of excerpts represent the activity of an excerptor who was interested in the

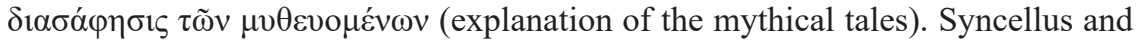
Eusebius drew on the same tradition of Julius Africanus. ${ }^{72}$ Whereas Syncellus and Eusebius cite Philochorus, ${ }^{73}$ Palaephatus, ${ }^{74}$ and Didymus ${ }^{75}$ as the original authors of the mythical accounts, the excerptor of Exc.Salm.I omit references to these authors. ${ }^{76}$ It is impossible to say whether the compiler of the Exc.Salm.I was in possession of the entire Historia chronica or made use of another excerpt collection.

\subsubsection{Excerpta Salmasiana II}

The Exc.Salm.II represent a selection of a variety of texts, which were re-edited and often extensively abridged before their inclusion in the sylloge. Occasionally, the original text is much changed pointing to either already summarised and contaminated texts which the compiler came across in another collection of excerpts or to efforts made by the compiler himself to epitomise and summarise the source texts he had at hand.

Provided that the Exc.Salm.II definitely does not derive from John of Antioch, the main issue that should trouble scholarship is the identification of its source or sources. The two main suggestions regarding the origin of the Exc.Salm.II are the following. U. P. Boissevain supported that from Excerpt 44 onwards the $s y l$ loge derives from a lost chronicle. ${ }^{77}$ De Boor, by contrast, argued that the entire

72 Wallraff, Roberto, Pinggéra, and Adler (2007), XXXI-XXXIV, XLII-XLIV.

73 Exc.Salm.I 7 = Sync. 185.23-26; Exc.Salm.I 8 = Sync. 188.25-26; Exc.Salm.I 18 = Eus.-Hier. Chron. 58a; Sync. 191.19-27.

74 Exc.Salm.I 9 = Eus.-Hier. Chron. 50d; Sync. 189.8-11; Exc.Salm.I 11 = Sync. 190.12-15; Exc. Salm.I 13 = Eus.-Hier. Chron.55h; Sync. 190.27-191.3; Exc.Salm.I 14 = Eus.-Hier. Chron. 56f; Sync. 183.25-27; Exc.Salm.I 17 = Eus.-Hier. Chron. 57d; Sync. 191.16-17; Exc.Salm.I 20 = Eus.Hier. Chron. $62 \mathrm{~h}$.

75 Exc.Salm.I 10 = Eus.-Hier, Chron. 52c-d; Sync. 189.29-190.4.

76 See also Roberto (2005a), esp. 261-288.

77 Boissevain (1887). 
Exc.Salm.II drew on a lost chronicle. ${ }^{78}$ Except for the ostensibly differing opinions, both scholars agree that a chronicle stands behind the entire or a part of the production of the Exc.Salm.II. S. Mariev highlighted the textual similarities between some excerpts in the Exc.Salm.II and some excerpts preserved in the codex Parisinus gr. 1630 and concluded that the excerpts in both came from a paraphrased version of Malalas' chronicle. ${ }^{79}$ In the following, I shall attempt to highlight some specific textual features of the sylloge that could shed some light on the question as to the original source of the Exc.Salm.II. First, let us have a look at the content of the Exc.Salm.II; the sylloge consists of eighty-two excerpts, which, in my view, can be divided into two main parts according to themes: the Exc.Salm.II 1-43 and the Exc.Salm.II 44-82.

\subsubsection{Exc.Salm.II A}

In Exc.Salm.II A (Exc. 1-43), the compiler shares with Malalas an interest in signs and oracles as well as in Euhemeristic interpretations of the Greek and oriental mythology. Excerpts 1-37 run from the creation to the Trojan War. According to Roberto, the compiler of the sylloge relied on the Chronographia by John Malalas. ${ }^{80}$ Indeed, the bulk of the Excerpts 1-37 are drawn from John Malalas, but not without exceptions; Exc. 16, Exc.18, Exc. 23, and Exc. 27-30 must be assigned to sources other than Malalas.

Table 3.1 shows that the first part of the Exc.Salm.II relies on Malalas as well as on Plutarch, Dictys, Charax, and Procopius. The compiler of this part appears to have made direct use of Dictys in the Excerpts 27-30, rather than indirect use through Malalas. ${ }^{81}$ With regard to the use of Procopius, U. Roberto, who sees John of Antioch as the author of the Exc.Salm.II, suggests an intermediate source between the sylloge and Procopius. Procopius is the source in the Exc.Salm.II 81 and 82 as well.

Table 3.1 Excerpts in the Exc.Salm.II $A$ that do not derive from John Malalas

\begin{tabular}{ll}
\hline Excerpt & Source \\
\hline Exc. 16 & Plutarch, fr. 187, 2 Bern \\
Exc. 18 & Procopius, De Bellis 4.10, 13-22 \\
Exc. 23 & Charax, FGrHist 103 F 37 \\
Exc. 27-30 & Dictys, III 15-16, II 27, II 45 \\
\hline
\end{tabular}

78 de Boor (1899), 298-304; de Boor (1893), 195-211.

79 Mariev (2009), esp. 179-185.

80 Roberto (ed.) (2005b), CXXV.

81 Sotiroudis (1989), 146. 
Excerpts 38-43 make up a mix of passages taken from Malalas, Suetonius, John Lydus, Diodorus, and Julius Africanus. Excerpt 38 marks a turning point with regard to the content and format of the first part of the Exc.Salm.II. Specifically, from Excerpt 38 onwards the text deals with prominent historical figures or Roman emperors. Interestingly, this focus on emperors is also applied, as shown below, in the second part of the Exc.Salm.II. Excerpts 39-41 dealing with the court and institutions in Ancient Rome derive from the De genere vestium

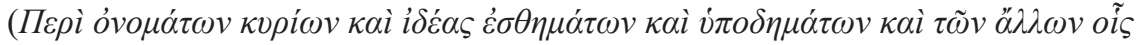

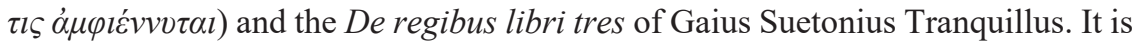
difficult to say whether the compiler used the Latin text or an intermediary work in Greek. ${ }^{82}$ Diodorus of Sicily is the source of Excerpt 42 . The original text underwent much alteration and was contaminated with information probably derived from Aelian's Varia Historia. ${ }^{83}$

\subsubsection{The codex Parisinus gr. 1630 (B) and Exc.Salm.II A}

Excerpts 1-23 of Exc.Salm.II $A$ bear significant similarities with the text transmitted on a series of folios $(234 \mathrm{r}-239 \mathrm{v})$ in the codex Parisinus gr. 1630 (B). B is a fourteenth-century, miscellaneous codex consisting of 278 folia of Oriental paper. ${ }^{84}$ It contains more than a hundred texts of different authors and literary genres: medical texts, epigrams, poems, theological texts, homilies, geometrical texts, epistles, and historical excerpts. The codex has also been subject to the so-called Johannische Frage. ${ }^{85}$ Cramer, was the first to attribute the text in B to Malalas. ${ }^{86}$ A few years later, G. Sotiriadis' research on the text in B demonstrated that the major part of the text in the codex derives from Malalas, but for a few excerpts, which must be attributed to John of Antioch. ${ }^{87} \mathrm{P}$. Sotiroudis confirmed G. Sotiriadis' arguments except that he attributed two more passages to John of Antioch. ${ }^{88}$

Recently, S. Mariev embarked upon a close analysis of the text in B and the corresponding passages in the Exc.Salm.II, the Suda, the direct tradition of

82 The Greek title of the De genere vestium has been handed down to us in the Suda; cf. Suda T 895 Тра́ $\gamma \kappa \nu \lambda \lambda о \varsigma$. The Latin title is transmitted in Serv. ad. Aen. $7.612=$ fr. 165 Reiff; cf. Power (2014), 231. Gelzer considered the Chronographiae of Julius Africanus as the Greek text transmitting Suetonius' passages; Gelzer (1880), 236.

83 Varia Historia VI 8.

84 On the codex, see Omont (1888b), 109-112; Sotiroudis (1989), 213-214; Thurn (ed.) (2000), 6-8.

85 I have already referred to Patzig's various surveys supporting that the Exc.Salm.II as well as almost all the excerpts in B come from John of Antioch; cf. Patzig (1892), (1896), (1897), (1900), and (1901). K. Müller shared a similar view: the text in B stems from John of Antioch; cf. Müller (1851), 540. U. P. Boissevain and C. de Boor, instead, were confident that the text in B was not from John of Antioch. U. P. Boissevain, as noted already, considered a chronicle now lost as the source behind both, the text in B and the Exc.Salm.II.; Boissevain (1887), esp. 173-178.

86 Cramer (1839), 379.

87 Sotiriadis (1888), esp. 84-91.

88 Sotiroudis (1989), esp. 19-25. 
Malalas' text, and the $E C{ }^{89} \mathrm{He}$ arrived at the conclusion that the first part of $\mathrm{B}$ (ff. 234r, 16-237r, 7) must derive from the direct Malalas tradition, whereas the second part of B (ff. 237r, 7-239, 7) deviates from it. Indeed, this part represents a much more shortened and altered version of Malalas's text. S. Mariev attributed the origins of the second part to a secondary Malalas tradition. In S. Mariev's view, the common passages between B and Exc.Salm.II $A$ must represent a common source. If we accept S. Mariev's argument, the Exc.Salm.II 1-12 must stem directly from Malalas' text and the Exc.Salm.II 13-23 must come from a secondary Malalas tradition, that is, a paraphrased Malalas text.

What could possibly shed light on the quest for the derivation of the passages in the Exc.Salm.II is the examination of the textual relationship between the Exc. Salm.II 1-12 and the direct tradition of Malalas (PV, O, A). This would help us comprehend the two thorny issues in S. Mariev's view: 1) the establishment of a common source between B and the Exc.Salm.II in relation to two distinct Malalas traditions in both texts, and 2) the source of the rest of the Exc.Salm.II, that is the excerpts after the last common excerpt in B (238v, 27-239r, 11) and in the Exc. Salm.II (Excerpt 23).

For the sake of clarity, I repeat the results of S. Mariev's survey: 1) B relied both on the direct tradition of Malalas (M) and a paraphrased version of this tradition (P), 2) the Exc.Salm.II and B relied on a common source, 3) the Exc.Salm.II, the Suda and B relied on the same source..$^{90}$

Table 3.2 depicts S. Mariev's view. The column under the siglum B bears the folia transmitting Malalas' texts in the Parisinus gr. 1630. The numeration of the excerpts from the Exc.Salm.II, in the third column, is the one given by U. Roberto in his edition of John of Antioch. In the first column, Malalas's text is represented by the direct tradition $(\mathrm{A}, \mathrm{PV}, \mathrm{O}=\mathrm{M})$ and the shortened version of it $(=\mathrm{P})$.

In what follows, I argue that the comparison between the Exc.Salm.II, B and the Suda indicates that the common Malalas passages in the Exc.Salm.II and the Suda derive from a common source X. X must have contained passages from Malalas, which had already been abridged $(\mathrm{T})$ and contaminated with passages taken from a variety of other texts, such as Plutarch and Charax (П). With ( $\Psi)$ I indicate the stage at which the shortened Malalas excerpts and passages from other authors were combined. The Suda remains closer to X, while the Exc.Salm. II shorten even further passages from X. Mariev showed that B, in its entirety, depended both, on the direct Malalas tradition $\mathrm{M}$ and on a paraphrased version of it (P). As I will show, the latter was not identical to X, though. It is more likely that $\mathrm{P}$ comes from the same source that $\mathrm{X}$ derives from. The situation could be illustrated as in the following scheme: Figure 3.1

First, it is noteworthy that, as Table 3.2 shows, two Salmasian excerpts, namely, fr.4 and fr.14 as well as a part of fr.17 are absent in B. What is not

89 Mariev (2009), 177-190.

90 The Suda used both, the direct Malalas tradition (M) and the paraphrased version of it (P); cf. Mariev (2009), 185. 
Table 3.2 Malalas' Chronographia in B and in the Exc.Salm.II

\begin{tabular}{|c|c|c|}
\hline Malalas, Chronographia & $B$ & Exc.Salm.II \\
\hline $1,7,39-1,11,18(\mathrm{M})$ & $235 \mathrm{r}, 15-235 \mathrm{v}, 10$ & fr. $1-3$ \\
\hline $1,11,9-18(\mathrm{M})$ & & fr.4 \\
\hline $1,12.19,30(\mathrm{M})$ & $235 \mathrm{v}, 10-14$ & fr. 5 \\
\hline $1,13,43-52(\mathrm{M})$ & $235 \mathrm{v}, 20-25$ & fr. 6 \\
\hline $1,14,53-87(\mathrm{M})$ & $235 \mathrm{v}, 25-32$ & fr.7 \\
\hline $1,15,88-10(\mathrm{M})$ & $236 r, 13-18$ & fr. 8 \\
\hline $2,1,1-22(\mathrm{M})$ & $236 r, 18-28$ & fr.9 \\
\hline $2,3,41-53(\mathrm{M})$ & $236 \mathrm{r}, 32-236 \mathrm{v}, 2$ & fr. 10 \\
\hline $2,4,54-76(\mathrm{M})$ & $236 \mathrm{v}, 2-18$ & fr.11 \\
\hline $2,6,81-28(\mathrm{M})$ & $236 \mathrm{v}, 18-27$ & fr. 12 \\
\hline $2,11,24-87(\mathrm{P})$ & $237 r, 9-21$ & fr. 13 \\
\hline $2,15(P)$ & & fr.14 \\
\hline \multirow[t]{2}{*}{$2,18,7-53(\mathrm{P})$} & $237 \mathrm{v}, 14-25$ & fr. 15 \\
\hline & $237 v, 28-29$ & fr.16 \\
\hline \multirow[t]{2}{*}{$3,9(\mathrm{P})$} & $238 \mathrm{r}, 5-17$ & fr.17 \\
\hline & $238 r, 20-21$ & fr. 18 \\
\hline $3,12,97-19(\mathrm{P})$ & $238 \mathrm{r}, 25-30$ & fr.19 \\
\hline $4,3,29-40(\mathrm{P})$ & $238 v, 1-3$ & fr. 20 \\
\hline $4,5,44-74(\mathrm{P})$ & $238 v, 4-8$ & fr.21 \\
\hline \multirow[t]{2}{*}{$4,9,91-24(\mathrm{P})$} & $238 \mathrm{v}, 27-239 \mathrm{r} 8$ & fr.22 \\
\hline & $238 r, 8-239 r, 11$ & fr. 23 \\
\hline
\end{tabular}

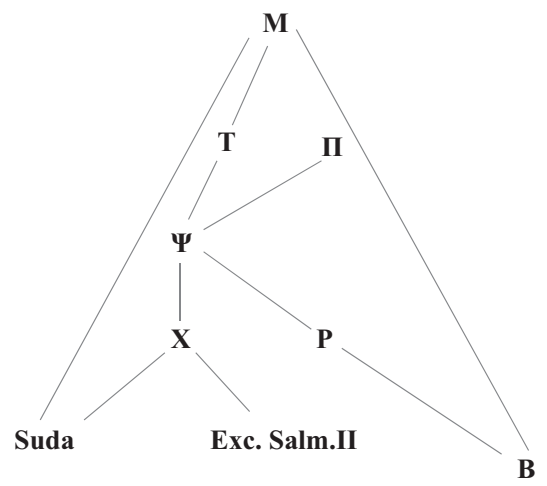

Figure 3.1 The codex Parisinus gr. 1630 (B) and the Exc.Salm.II A.

found in B is present in Malalas, though. Interestingly, the passages in question are present in what S. Mariev calls the direct tradition of Malalas' text, namely, in the codex Baroccianus 182 (O). This is an indication that the Exc.Salm.II did ultimately originate in Malalas' Chronographia.

With regard to the derivation of the Exc.Salm.II, the case of the fr.8 is of particular importance (Table 3.3). The passage is concerned with Hephaestus, the 
Table 3.3 The derivation of the Exc.Salm.II 8

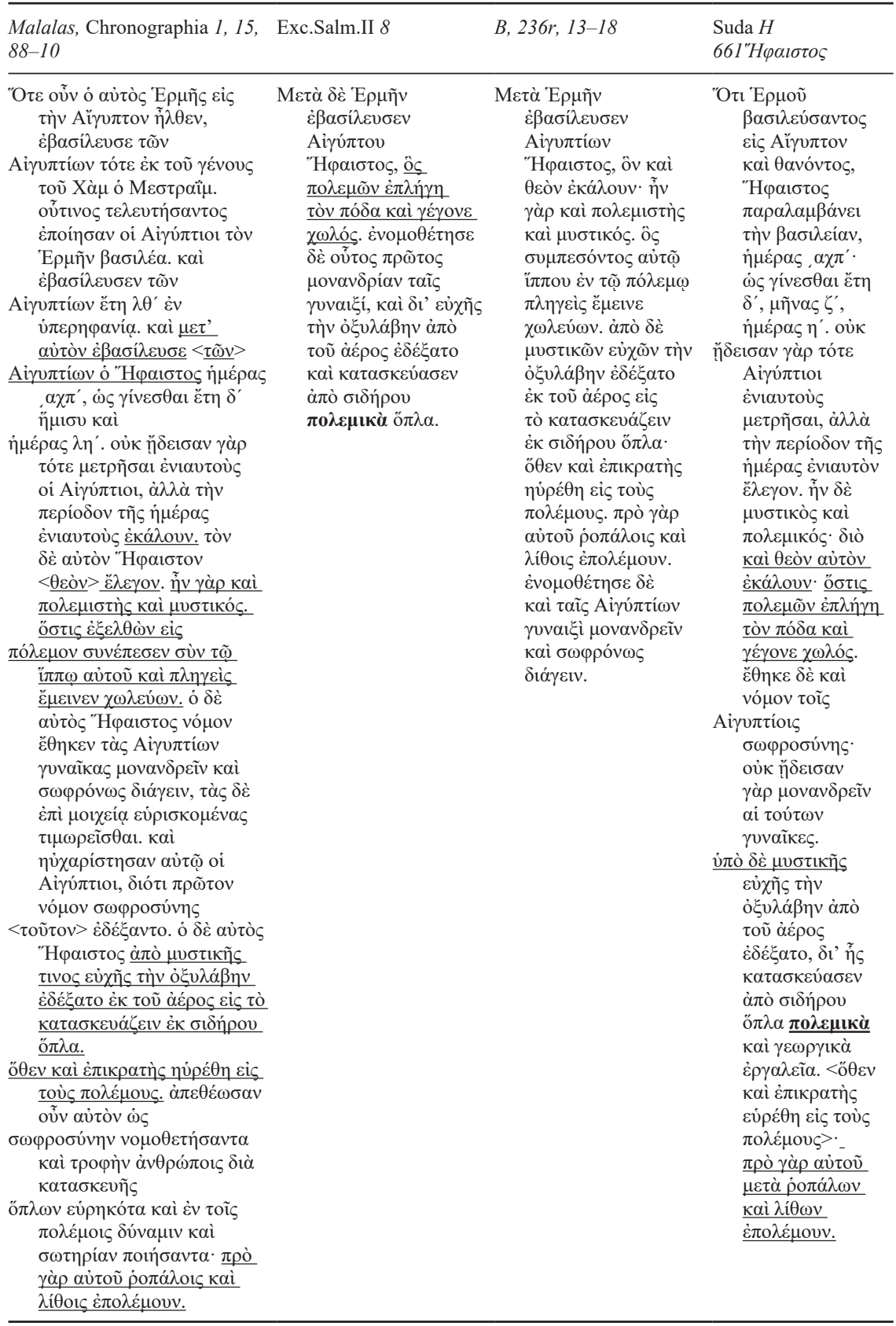


successor of Hermes to the throne of Egypt. The text records that Hephaestus was once wounded in war and went lame. According to the text, he was the king who introduced monogamy to the people of Egypt. Hephaestus received the tongs from the air, by which he constructed iron weapons for war.

The text is also preserved in Malalas, B and the Suda. Although both the Exc. Salm.II 8 and B transmit an abridged version of Malalas' text, the two versions differ markedly. First, I would like to draw attention to the phrase $\hat{\delta} \varsigma \pi 0 \lambda \varepsilon \mu \tilde{\omega} v$

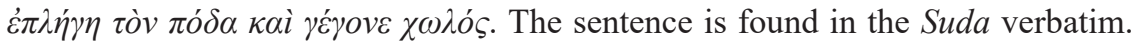
B transmits additional information as to how Hephaestus was wounded; he fell

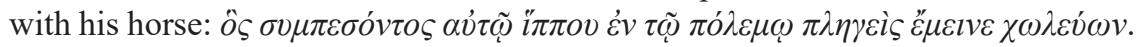

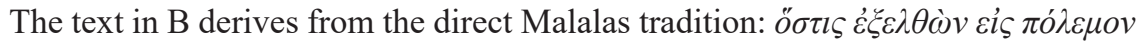

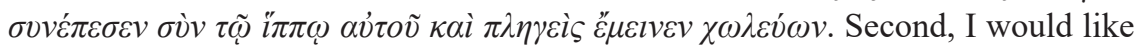
to highlight the adjective $\pi о \lambda \varepsilon \mu \imath \kappa \alpha \grave{\alpha}$ occurring at the end of both, the Exc.Salm.II 8 and the entry in the Suda. The adjective $\pi \circ \lambda \varepsilon \mu l \kappa \alpha$ summarises the following pas-

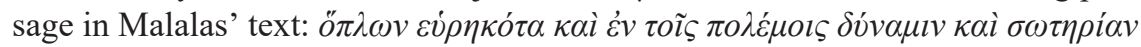
$\pi o i \dot{\sigma} \sigma \alpha v \tau$. On the other hand, the text in B comes, once again, directly from Malalas's text as it is preserved in the direct tradition. The identical beginning in

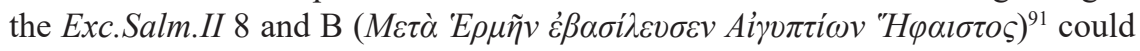
be explained by the existence of the common source $\Psi$ in the transmission of the shortened version of Malalas' text.

Table 3.2 also shows that three excerpts in the Exc.Salm.II (fr.16, fr.18, and fr.23) which are not found in Malalas exhibit similarities with the text in B. The three passages in question are included in the Suda, though: Exc.Salm.16= B = Suda I 422, Exc.Salm.18 = B = Suda X 79, Exc.Salm.II $23=\mathrm{B}=$ Suda $\Delta 250$. The textual comparison between the Exc.Salm.II, B and the Suda confirms that they all descend from a common text. Table 3.4 presents the case of the Exc.Salm.18= $\mathrm{B}=$ Suda $\mathrm{X} 79$.

The Exc.Salm.II 18 is, in fact, an abridged version of the text in the Suda. Passages exhibit literal similarities and the vocabulary is almost identical. The

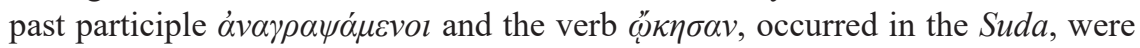

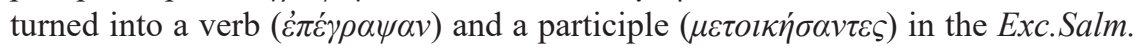
II 18 , respectively. The text in B is identical to the beginning of the entry in the Suda, too. B transmits also the exact year of Moses' death: $\dot{\varepsilon} \tau \tilde{\omega} v \rho \kappa^{\prime}$. This piece of information is absent in both the Suda and the Exc.Salm.II 18. It is obvious that the passage in B derives from the same tableau $(\Psi)$ as X, where the Suda X 79 and the Exc.Salm.II 18, also come from.

S. Mariev and Roberto have drawn attention to Exc.Salm.II 15. This excerpt, the corresponding passage in B, and the Suda share a common error when refer-

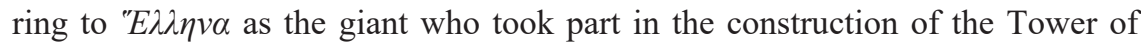
Babel..$^{92}$ According to S. Mariev, the error in the shortened version of Malalas' text points to a common source between its transmitters. However, as shown 
Table 3.4 The Exc.Salm.II 18, B and the Suda

\begin{tabular}{|c|c|c|}
\hline Exc.Salm.II 18 & $B, 238 r, 20-21$ & 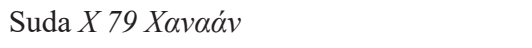 \\
\hline 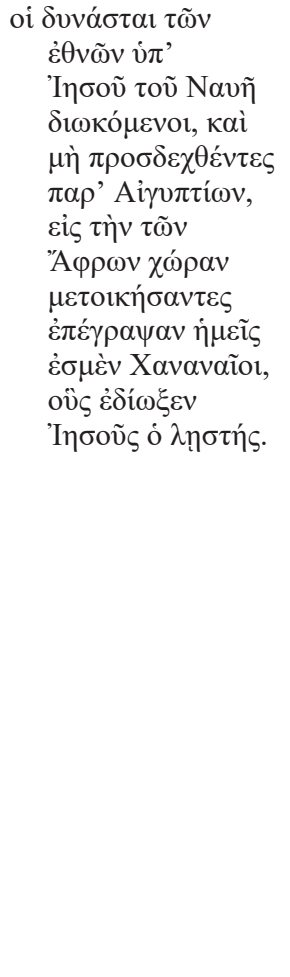 & 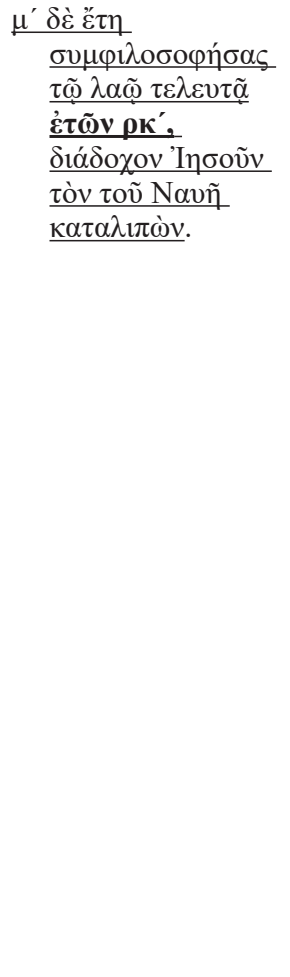 & 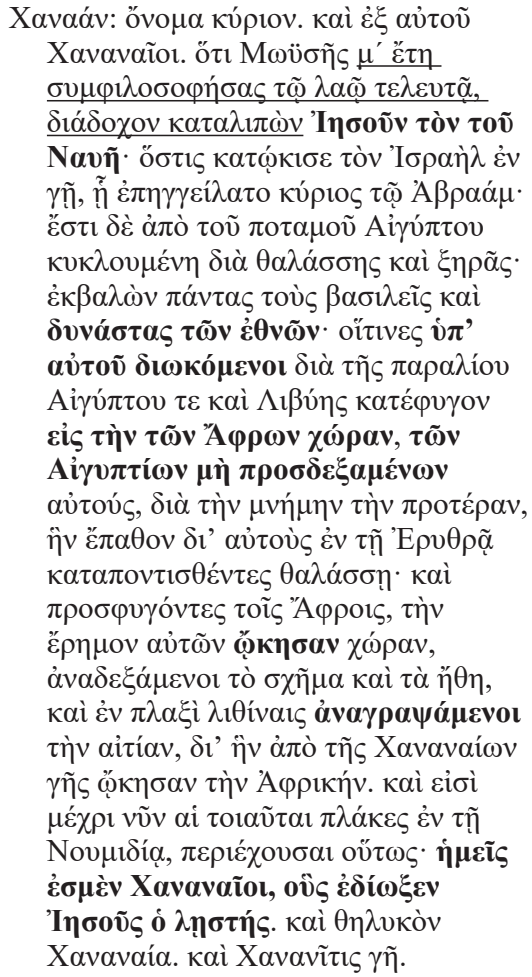 \\
\hline
\end{tabular}

above, the Exc.Salm.II and B are more likely to have included the mistake through different paths.

To sum up, the textual comparison between the Exc.Salm.II 1-23 and excerpts in B reveals a stage at which shortened passages from Malalas' Chronographia were contaminated with passages excerpted from a variety of other texts. I signify this stage in the stemma above with the siglum $\Psi$. The common Malalas passages in the Exc.Salm.II 1-23 and B belong to two different versions of $\Psi$, respectively. As can be seen in the stemma presented above, the Exc.Salm.II 1-23 derive from $\mathrm{X}$, whereas the corresponding passages in $\mathrm{B}$ derive from $\mathrm{P}$.

As already noted Exc.Salm.II 24-43 are not found in B. Yet, the majority of them originate in Malalas' Chronographia. ${ }^{93}$ Five of these excerpts are also preserved in the Suda: Exc.Salm.II. $24=$ Suda Aı 23, Exc.Salm.II. $26=$ Suda T 7, Exc. 
Table 3.5 The Exc.Salm.II 32, Malalas and the Suda

\begin{tabular}{|c|c|c|}
\hline $\begin{array}{l}\text { Malalas, Chronographia 5, } 12 \text {, } \\
9-12\end{array}$ & Exc.Salm.II 32 & Suda П 34 П $\alpha \lambda \lambda \dot{\alpha} \delta ı o v$ \\
\hline 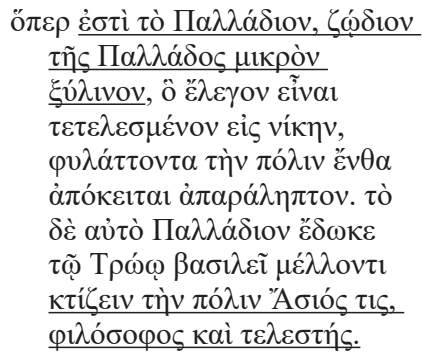 & 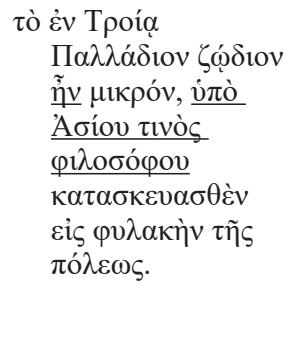 & 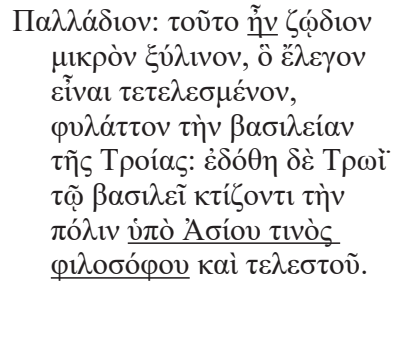 \\
\hline
\end{tabular}

Salm.II. $30=$ Suda P 146, Exc.Salm.II. $32=$ Suda П 34, Exc.Salm.II. $40=$ Suda A 4126. When comparing the Exc.Salm.II 24-43, Malalas' text and the Suda we arrive at the conclusion that a common source stands, once again, behind Exc.Salm. II 24-43 and the Suda. It is highly likely, therefore, that ( $\Psi)$ is the source of the entire Exc.Salm.II 1-43. Table 3.5 presents the case of the Malalas 5, 12, 9-12= Exc.Salm.II $32=$ Suda П 34.

The Exc.Salm.II 32 is concerned with the Palladium, a wooden statue, believed to guard the kingdom of Troy. ${ }^{94}$ I would like to draw attention a) to the use of the imperfect $\tilde{\eta} v$ in the Exc.Salm.II and the Suda, in the place of the present tense $\dot{\varepsilon} \sigma \tau i$

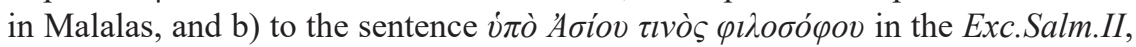
which is found in the Suda verbatim.

\subsubsection{The source of Exc.Salm.II $A, 1-43$}

Provided that what I call ( $\Psi)$ is the source of the Exc.Salm.II 1-43, the next question to be answered is what kind of text $(\Psi)$ was. To begin with, four historical works have made extensive use of excerpts included in Exc.Salm.II: Symeon Logothetes' Chronicon, Ps.-Symeon's Chronographia, George Cedrenus' Compendium historiarum, and Constantine Manasses' Breviarium Chronicum. ${ }^{95}$ Two of these, namely Ps.-Symeon's chronicle and a part of Symeon Logothetes' chronicle attached to the text of George the Monk, were produced in imperial circles in the tenth century. The histories show affinities in methodology, content, and sources. Accordingly, they quite often correlate with each other in terms of common references to the past, of mythological figures, exaggerated accounts, and geographical

94 The Exc.Salm.II 32 mistakenly transmits that the statue was constructed by a philosopher named Asios: the Palladium was given to the king of Troy, when he was founding the city, by a philosopher and priest called Asios. On the presence of Palladium in Malalas, see Praet (2016), 294-297. 95 See Appendix II: Table V. 
allusions. The phenomenon implies the existence of a common source. ${ }^{96}$ As has been mentioned, J. Signes Codoñer argued that the common source must have been a collection of historical excerpts. ${ }^{97}$ This could mean that Symeon Logothetes, Ps.Symeon, and the compiler of the Exc.Salm.II drew on a common source and not necessarily that the Exc.Salm.II were used directly by the historians. In addition to these two chronicles, the tenth-century Excerpta Anonymi bear significant similarities with the Exc.Salm.II in the selection of excerpts from Cassius Dio (on these excerpts, see below). Accordingly, my argument is that the Exc.Salm.II are likely to have drawn on a number of earlier collections of excerpts.

In my view, despite the contamination of the Malalas text, Exc.Salm.II 1-43 are very likely to have been derived from a single text, that is the $\Psi$ in the stemma presented above. To support my argument, I have two points to make. First, the textual transmission and composite nature of group 1-43 corroborate that it stems from a common source in its entirety. Excerpts 1-43 represent a conflation of different texts, but their basis must be the chronicle of Malalas. The compiler of $\Psi$ extracted and edited the Malalas material, while respecting its general structure and meaning. The passages taken from other sources, by contrast, underwent so much alteration that it is difficult to identify them. Obviously, the compiler of $\Psi-$ a collection of excerpts or a chronicle - contaminated the Malalas text with this other material to form a new text, from which the first part of the Exc.Salm.II stems.

My second point is related to the common use of passages between the Exc. Salm.II and the tenth-century Symeon Logothetes and Ps.-Symeon's tradition. These historical works contain texts found throughout the Exc.Salm.II. It is also accepted by contemporary scholars that both histories drew part of their material from collections of excerpts produced and circulated inside and outside imperial circles. ${ }^{98}$ When examining the textual relationship between the Exc.Salm.II and the two histories, we come to interesting conclusions. First, one common passage is not from John Malalas. The presence of Excerpt 40 in Ps.-Symeon indicates (a) a common source for Ps.-Symeon and the Exc.Salm.II or (b) the use of the Exc.Salm.II by the Ps.Symeon. Both possibilities point to an aggregation of material from Malalas and texts from other sources. Second, the augmented passages of Exc.Salm.II 1-43 are amongst those used on the part of Ps.-Symeon, but they are not used by Symeon Logothetes. The last fact could mean that Symeon Logothetes did not use the first part of the Exc.Salm.II but a collection of excerpts containing exclusively John Malalas' excerpts (Table 3.6).

\subsubsection{Exc.Salm.II $B$, 44-65}

Excerpts 44-65, dealing with Roman history from Julius Caesar to Commodus, derive, with one exception, from the Cassius Dio tradition; some excerpts show

96 See n. 208 in Chapter 2.

97 See n. 209 in Chapter 2.

98 Markopoulos (1994), 167; Markopoulos (2003), 189-190. 
Table 3.6 Passages in common between Malalas, the Exc.Salm.II 1-43, Symeon Logothetes' Chronicon and Ps.-Symeon's Chronographia

\begin{tabular}{|c|c|c|c|}
\hline $\begin{array}{l}\text { Malalas, } \\
\text { Chronographia }\end{array}$ & Exc.Salm.II & $\begin{array}{l}\text { Symeon Logothetes' } \\
\text { Chronicon }\end{array}$ & $\begin{array}{l}\text { Ps.-Symeon's } \\
\text { Chronographia }\end{array}$ \\
\hline Malalas I 7-8 & Exc.Salm.II. 1-3 & & \\
\hline Malalas I 11 & Exc.Salm.II. 4 & & Ps.-Sym. 27r, 25-32 \\
\hline Malalas I 12 & Exc.Salm.II. 5 & $\begin{array}{l}\text { Sym.Log. 28.4, } \\
\quad 19-21\end{array}$ & \\
\hline Malalas I 13 & Exc.Salm.II. 6 & & \\
\hline $\begin{array}{l}\text { Malalas } 1,14,53-87 \\
\quad(\mathrm{M})\end{array}$ & Exc.Salm.II. 7 & $\begin{array}{l}\text { Sym. Log. 28.5, } \\
\quad 23-24\end{array}$ & Ps.-Sym. 27r, 33-27v, 4 \\
\hline Malalas I 15 & Exc.Salm.II. 8 & & \\
\hline Malalas II 1 & Exc.Salm.II. 9 & & \\
\hline Malalas II 3 & Exc.Salm.II. 10 & & \\
\hline Malalas II 4 & Exc.Salm.II. 11 & & Ps.-Sym. 27v, 32-28r, 9 \\
\hline Malalas II 6 & Exc.Salm.II. 12 & & Ps.-Sym. 28r, 13-27 \\
\hline Malalas II 11 & Exc.Salm.II. 13 & & $\begin{array}{l}\text { Ps.-Sym. 28v, 23-29r, } \\
\quad 12\end{array}$ \\
\hline Malalas II 15 & Exc.Salm.II. 14 & & $\begin{array}{l}\text { Ps.-Sym. 29r, 38-29v, } \\
\quad 29\end{array}$ \\
\hline Malalas II 18 & $\begin{array}{l}\text { Exc.Salm.II. } 15 \\
\text { Exc.Salm.II. } 16\end{array}$ & & \\
\hline Malalas III 9 & $\begin{array}{l}\text { Exc.Salm.II. } 17 \\
\text { Exc.Salm.II. } 18\end{array}$ & & \\
\hline Malalas III 12 & Exc.Salm.II. 19 & & \\
\hline Malalas IV 3 & Exc.Salm.II. 20 & Sym. Log. 37.2, 6-7 & \\
\hline Malalas IV 5 & Exc.Salm.II. 21 & Sym. Log. 37.4, 20 & \\
\hline Malalas IV 9 & $\begin{array}{l}\text { Exc.Salm.II. } 22 \\
\text { Exc.Salm.II. } 23\end{array}$ & & \\
\hline Malalas IV 18 & Exc.Salm.II. 24 & & \\
\hline Malalas V 2 & Exc.Salm.II. 25 & & \\
\hline Malalas V 9 & $\begin{array}{l}\text { Exc.Salm.II. } 26 \\
\text { Exc.Salm.II. } 27\end{array}$ & & Ps.-Sym. 41v, 38-42r, 2 \\
\hline Malalas V 24 & Exc.Salm.II. 28 & & \\
\hline Malalas V 8 & $\begin{array}{l}\text { Exc.Salm.II. } 29 \\
\text { Exc.Salm.II. } 30\end{array}$ & & \\
\hline Malalas V 14 & Exc.Salm.II. 31 & & \\
\hline Malalas V 12 & Exc.Salm.II. 32 & & \\
\hline Malalas V 17-18 & Exc.Salm.II. 33 & & \\
\hline Malalas V 19-20 & Exc.Salm.II. 34 & & \\
\hline Malalas VII 4 & Exc.Salm.II. 35 & & \\
\hline Malalas V 43 & $\begin{array}{l}\text { Exc.Salm.II. } 36 \\
\text { Exc.Salm.II. } 37\end{array}$ & & \\
\hline Malalas VII 5 & $\begin{array}{l}\text { Exc.Salm.II. } 38 \\
\text { Exc.Salm.II. } 39 \\
\text { Exc.Salm.II. } 40 \\
\text { Exc.Salm.II. } 41 \\
\text { Exc.Salm.II. } 42 \\
\text { Exc.Salm.II. } 43\end{array}$ & & $\begin{array}{l}\text { Ps.-Sym. 70r, 20-33 } \\
\text { Ps.-Sym. 70v, 12-14 }\end{array}$ \\
\hline
\end{tabular}


similarities with Dio's direct tradition and some others exhibit textual congruence with Xiphlinus' epitome of Dio. ${ }^{99}$ Only Excerpt 61 derives from Eutropius. All excerpts have been selected thematically to correspond to subject matters, such as emperors' dreams and occult science. The compiler of this part excerpts passages on Roman emperors. The selected passages briefly reflect on personal traits, life, deeds, and deaths of certain emperors. It should be noticed that historical writings, where the narration was focused on a certain emperor's life, became fashionable from the tenth century onwards. ${ }^{100}$ Their aim was to laud the emperors and legitimise their political authority. Though the Exc.Salm.II are far from being an attestation of imperial legitimacy, the focus on emperors is striking. In addition, and as can be seen in Table 3.7, the Exc.Salm.II exhibit significant similarities with the mid-tenth century Excerpta Anonymi with regard to the selective use of passages in the section on Roman history. Both excerptors have chosen to excerpt and include the same passages from the Cassius Dio tradition and the wording is virtually identical. Accordingly, the excerptors appear to share an interest in occult science as well as in dreams predicting the future. They both incorporate texts dealing with emperors who mistakenly underrated the abilities of astrologers to foresee the future. The common selective use of passages testifies to the use of a common source, that is, an excerpt collection comprising excerpts from the Cassius Dio tradition ${ }^{101}$ about dreams and occult science. ${ }^{102}$ The textual relationship between the Excerpta Salmasiana and the Excerpta Anonymi was discussed in detail in Chapter 2 (see Section 2.4.4). Here I shall confine myself to presenting the shared historical excerpts in the two collections of excerpts (Table 3.7). The passages are originally derived from Cassius Dio and Peter the Patrician.

Table 3.7 Shared passages in the Exc.Salm.II and the Excerpta Anonymi

\begin{tabular}{llll}
\hline Exc.Salm.II & Excerpta Anonymi & Pet.Patr. & $C D$ \\
\hline Exc.Salm.II 44 & Excerpta Anonymi 29, & CD 44, 17, 1 and \\
& 19-21, 25-27 & $37,52,2$ \\
Exc.Salm.II 45 & Excerpta Anonymi 29, & CD 45, 1, 3-45, \\
& 28-30, 10 & 2,2 \\
Exc.Salm.II 54 & Excerpta Anonymi 31, & Pet.Patr. (ES 89) & CD 65, 1, 4 \\
& 24-30 & \\
Exc.Salm.II 56 & Excerpta Anonymi 32, 1-9 & CD 67, 16, 2-3 \\
Exc.Salm.II 57 & Excerpta Anonymi 32, & CD 67, 18, 1-2 \\
& 11-21 & \\
\hline
\end{tabular}

99 Much attention is needed in dealing with U. P. Boissevain's edition of Cassius Dio. See n. 183 in Chapter 2.

100 Markopoulos (1994), 159-170; Markopoulos (2006), 277-297.

101 It is noteworthy that Exc.Salm.II 53, 54, and 59 correspond to Peter the Patrician, ES 59, 89, and 112 , respectively.

102 See Section 2.4.4. 


\subsubsection{Exc.Salm.II B, 66-82}

Excerpts 66-82 represent a conflation of passages from ostensibly different sources (Table 3.8). Thematically, the passages deal with Roman emperors and generals.

U. Roberto considers Excerpts 66-82 as part of John of Antioch's chronicle. In his view, John of Antioch drew on Eutropius, Zosimus, Ammianus Marcellinus, and Priscus. ${ }^{103}$ Table 3.9 shows the parallel passages for each of the Excerpts 66-82 as suggested by U. Roberto. ${ }^{104}$

Excerpts 66 and 67 are not closely based on Dexippus and Zosimus, respectively (Table 3.10). The text in the Exc.Salm.II is largely abridged. The end of the

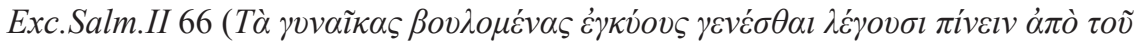
$\Sigma \tau \rho v \mu o ́ v o \varsigma ~ \pi о \tau \alpha \mu о \tilde{v ~ \kappa \alpha i ̀ ~ \kappa v ́ \varepsilon l v) ~ i s ~ a b s e n t ~ i n ~ t h e ~ p a s s a g e ~ a t t r i b u t e d ~ t o ~ D e x i p p u s ~ b y ~}$ Syncellus. There is no proof that the text was part of a lost fragment in Dexippus' Skythika. Moreover, the beginning of the Exc.Salm.II 66 departs from Dexippus in terms of language and style, as well. Similarly, Exc.Salm.II 67 deviates from Zosimus' text. Though, the Exc.Salm.II 67 transmits the piece of information found in Zosimus, the vocabulary is thoroughly different. For instance, the Exc.

Table 3.8 Exc.Salm.II B, 66-82

\begin{tabular}{ll}
\hline Exc.Salm.II & Theme \\
\hline Exc. 66 & Gallus (251-253) \\
Exc. 67 & Probus (276-282) \\
Exc. 68 & Numerian (283-284) \\
Exc. 69 & Carinus (283-285) \\
Exc. 71 & Diocletian (284-305); Maximian (286-305) \\
Exc. 72 & Constantine the Great (306-337) \\
Exc. 73 & Julian (360-363) \\
Exc. 74 & Constantine the Great (306-337) \\
Exc. 75 & Licinius (308-324) \\
Exc. 76-79 & Julian (360-363) \\
Exc. 80 & Valentinian I (364-375) \\
Exc. 81 & Galla Placidia, regent to Valentinian III (423-437); Bonifacius and \\
Exc. 82 & $\quad$ Flavius Aetius, both Roman generals \\
\end{tabular}

103 Roberto (ed.) (2005b), CXXV-CLV. Zosimus' Historia Nova covers the period from 238 AD to 410 AD in six books. Zosimus relied heavily on Dexippus, Eunapius, and Olympiodorus. His history has survived in a single manuscript, Vaticanus gr. 156 (eleventh c.). On Zosimus, see Ochoa (1990). Publius Herennius Dexippus (ca. 210-275 AD) wrote an account of the wars against the Heruls and the Goths, the so-called $\Sigma \kappa v \theta \imath \kappa \alpha$, the $T \alpha \dot{\alpha} \mu \varepsilon \tau^{\prime} A \lambda \dot{\varepsilon} \xi \alpha v \delta \rho o v$, and a universal chronicle up to $270 \mathrm{AD}$. On Publius Herennius Dexippus, see the introductory chapters to the editions of his texts by Mecella (2013) and Martin (2006).

104 Roberto (ed.) (2005b), CXXV-CLV. 
Table 3.9 The Exc.Salm.II B, 66-82 and parallel passages

\begin{tabular}{ll}
\hline Exc.Salm.II & Parallel passages \\
\hline Exc. 66 & Dexippus, FGrHist 100 F 22 \\
Exc. 67 & Zosimus, Historia nova I 67, 2 \\
Exc. 68 & Eutropius, Breviarium IX 18, 2 \\
Exc. 69 & Eutropius, Breviarium IX 19, 1 \\
Exc. 70 & Diodorus of Sicily, Bibliotheca historica IV 5, 2 \\
Exc. 73 & Ammianus Marcellinus, Res Gestae XV 8, 17 \\
Exc. 74 & Ammianus Marcellinus, Res Gestae XXI 14, 1 \\
Exc. 75 & Ammianus Marcellinus, Res Gestae XVI 10, 16; Zosimus, Historia \\
& nova II 27 \\
Exc. 78 & Ammianus Marcellinus, Res Gestae XVIII 1, 4 \\
Exc. 80 & Eunapius fr. 30 \\
Exc. 81 & Marcellinus Comes, Annales 432, 2-3; Procopius, De bellis \\
Exc. 82 & 3.3.14-36; Jordanes, Romana 330 \\
& Hydatius, Chronicon 167; Procopius, De bellis 4.4.16-28
\end{tabular}

Table 3.10 The Exc.Salm.II 66 and 67

\begin{tabular}{|c|c|}
\hline Exc.Salm.II 66 & $\begin{array}{l}\text { Dexippus } 100 \text { F } 22 \text { (cf. Syncellus, Ecloga } \\
\text { chronographica } 459,5-16)\end{array}$ \\
\hline 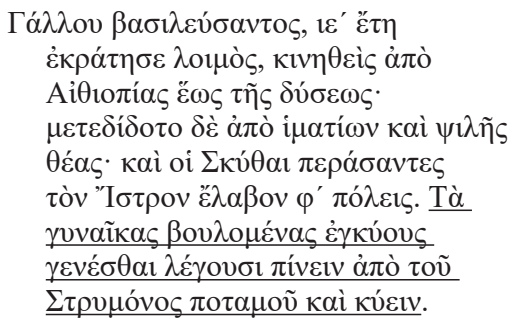 & 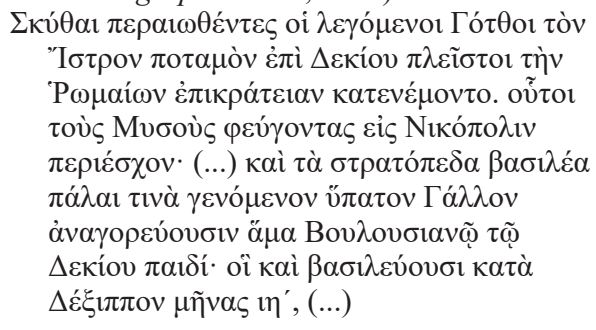 \\
\hline 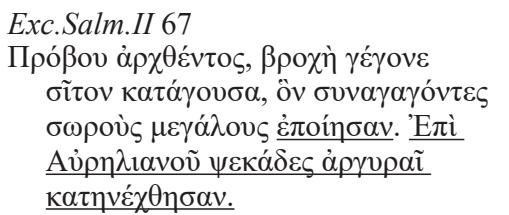 & 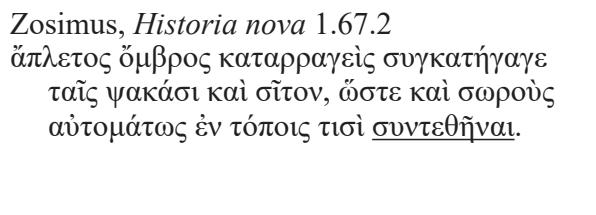 \\
\hline
\end{tabular}

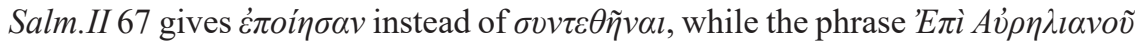
$\psi \varepsilon \kappa \alpha \dot{\delta} \varepsilon \varsigma \dot{\alpha} \rho \gamma v \rho \alpha \tilde{l} \kappa \alpha \tau \eta v \varepsilon \dot{\chi} \theta \eta \sigma \alpha v$ is absent in Zosimus.

The same holds true for Excerpts 68-69, which transmit a heavily summarised version of Eutropius' text (Table 3.11).

The textual discrepancies rule out any direct link between the Exc.Salm.II and the above presented passages from Dexippus, Zosimus, and Eutropius. Besides, such a link would be irreconcilable and incongruous with the excerpting method throughout the Exc.Salm.II. The Exc.Salm.II, as the employment of the excerpted 
Table 3.11 The Exc.Salm.II 68 and 69

\begin{tabular}{|c|}
\hline 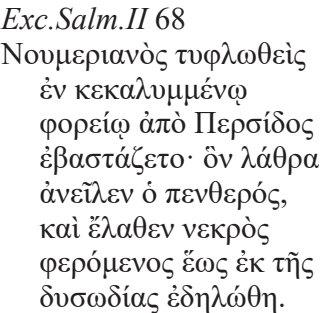 \\
\hline
\end{tabular}

Exc.Salm.II 69

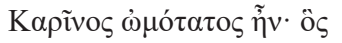

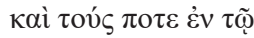
$\pi \alpha 1 \delta \varepsilon v \tau \eta \rho i \omega$

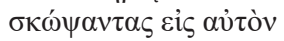
ทे

\section{Eutropius, Breviarium IX 18, 2}

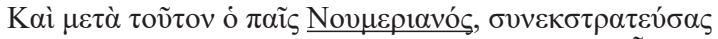

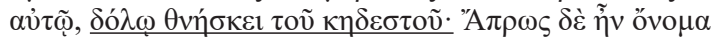

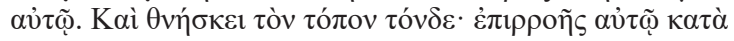

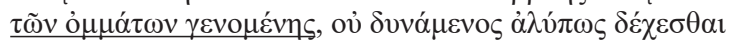

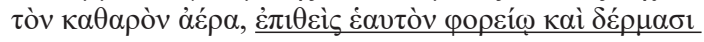

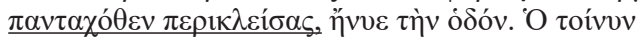

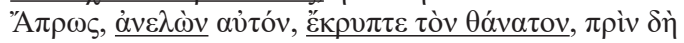

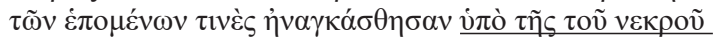

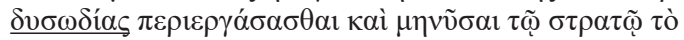

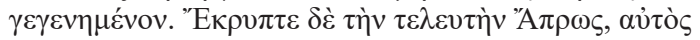
$\kappa \rho \alpha \tau \tilde{\eta} \sigma \alpha \iota \tau \tilde{\omega} \nu \pi \rho \alpha \gamma \mu \alpha \dot{\tau} \omega v \dot{\varepsilon} \pi \imath \theta v \mu \tilde{\omega} v$.

Eutropius, Breviarium IX 19

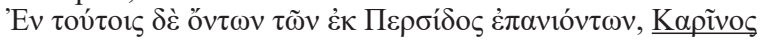

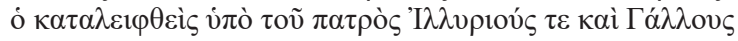

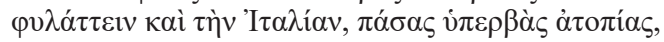

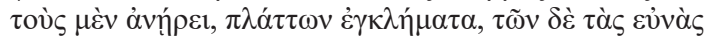

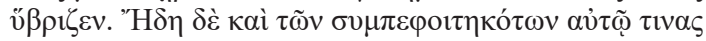

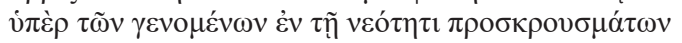

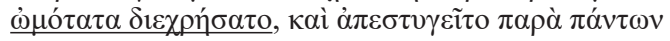

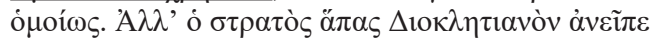

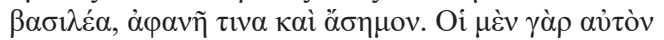

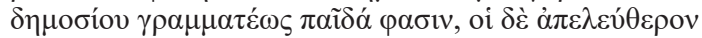

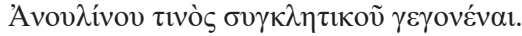

passages from Dio Cassius shows, remain close to their sources in terms of structure, vocabulary, and style. Such incompatibility in content and style between, on the one hand, the Exc.Salm.II and, on the other, Dexippus, Eutropius, and Zosimus seem to point to an intermediate stage of development of the information preserved in the three historians.

As far as Excerpts 73-78 are concerned, B. Bleckmann satisfactorily showed that they do not stem from Ammianus Marcellinus; the Exc.Salm.II and Ammianus made, instead, use of a common source. ${ }^{105}$ In particular, B. Bleckmann argues that the final part of the Exc.Salm.II derives, for the most part, from a high-quality late antique source. ${ }^{106}$ In B. Bleckmann's view, the Exc.Salm.II 66-79 draw on the socalled Leoquelle, a source covering events of the third and fourth centuries. The Leoquelle, which exhibits similarities with the history of Ammianus Marcellinus in content, was also used by Peter the Patrician as well as by a number of later

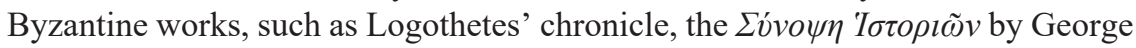




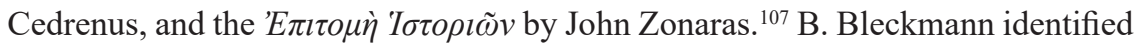
Nicomachus Flavianus as the author of the Leoquelle. ${ }^{108}$

On internal evidence (common pagan, anti-Constantinian, and philo-Julian elements) and on the basis of parallels with Zonaras and Symeon Logothetes, the Exc.Salm.II appear to have made use of the Leoquelle in the following excerpts (Table 3.12). ${ }^{109}$

Excerpts 68, 69, and 70 are also likely to derive from the Leoquelle, for they show affinities with pagan late antique historiography in content and style. ${ }^{110}$ Excerpts $71,76,80,81$, and 82, by contrast, do not belong to the same tradition. Excerpt 71 shows parallels with a passage in Manasses' Breviarium Chronicum, written ca. 1145. ${ }^{111}$ Excerpt 76, which deals with a dream of the emperor Julian, remains unidentified. Excerpt 80 is an excerpt from Malalas' Chronographia. ${ }^{112}$ According to Excerpt 80, the emperor Vallentinian I burned alive a man called Rhodanos who had seized some property from a widow. The anonymous compiler returns to

Table 3.12 The Exc.Salm.II and the Leoquelle

\begin{tabular}{|c|c|c|}
\hline Exc.Salm.II & Parallel & Other evidence \\
\hline Exc. 66 & Zonaras, Epitome historiarum 12, 21 & \\
\hline Exc. 67 & Zonaras, Epitome historiarum 12, 29 & \\
\hline Exc. 72 & & $\begin{array}{l}\text { Pagan and Anti-Constantinian } \\
\text { elements }\end{array}$ \\
\hline Exc. 73 & $\begin{array}{l}\text { Amm.Marcellinus, Res Gestae XV, } 8 \text {, } \\
17\end{array}$ & \\
\hline Exc. 74 & $\begin{array}{l}\text { Amm.Marcellinus, Res Gestae XXI, } \\
14,1\end{array}$ & \\
\hline Exc. 75 & $\begin{array}{l}\text { Amm.Marcellinus, Res Gestae XVI, 10, } \\
\text { 16; Zosimus, Historia nova II 27; } \\
\text { Zonaras, Epitome historiarum } 13,5\end{array}$ & \\
\hline Exc. 77 & & Philo-Julian elements \\
\hline Exc. 78 & $\begin{array}{l}\text { Amm.Marcellinus, Res Gestae XVIII } \\
\text { 1, 4; Zonaras, Epitome historiarum } \\
\text { 12,8-9 }\end{array}$ & \\
\hline Excerpt 79 & $\begin{array}{l}\text { Symeon Logothetes, Chronicon 91, p. } \\
115 \text { Wahlgren; Zonaras, Epitome } \\
\text { historiarum 13, } 14\end{array}$ & $\begin{array}{l}\text { Pagan and Philo-Julian } \\
\text { elements }\end{array}$ \\
\hline
\end{tabular}

107 In the 1980s, M. DiMaio argued that Zonaras drew on John of Antioch; cf. DiMaio (1980), 158-185. M. DiMaio's arguments relied on previous research on the matter done by E. Patzig; cf. Patzig (1896), 24-53 and Patzig (1897), 322-356. Their hypothesis was strongly questioned when P. Sotiroudis postulated that the Salmasian John of Antioch is spurious; cf. Sotiroudis (1989).

108 On Nicomachus, see 15, PLRE I, 347-349. See also Bleckmann (1995), 83-99.

109 Table 3.12 is based on Bleckmann (2010), 58-59.

110 Bleckmann (2010), 58-59.

111 On the dating of the Breviarium Chronicum, see Jeffreys (2012), 273-274.

112 Malalas, Chronographia 13, 31. 


\section{Excerpta Salamasiana}

Malalas and he, once again, singled out the most important pieces of information of Malalas' text and unified these in a new entity. Excerpt 81 records that Galla Placidia, regent to Valentinian III (423-437), had two generals: Bonifacius and Flavius Aetius. Bonifacius was given Libya to rule. Aetius was seized with jealousy and he plotted to overthrow Bonifacius. His plan, however, was not successful. Excerpt 82 records the assassinations of Aetius and Valentinian III, plotted by Petronius Maximus. Both passages show similarities with Procopius' De bellis. ${ }^{113}$ The record of events in the Exc.Salm.II and Procopius differ markedly with what is transmitted in the Constantinian John of Antioch, which is based on Priscus' account. ${ }^{114} \mathrm{~B}$. Bleckmann argues that the textual comparison of the Exc.Salm.II and Procopius' De bellis suggests that the Exc.Salm.II relied on an intermediary source containing Procopius. ${ }^{115}$

To sum up, the textual transmission of the Exc.Salm.II does not lead to a definitive conclusion regarding the sources used by the compiler. De Boor's view that the Exc.Salm.II was a sylloge of excerpts taken from a single chronicle does not seem to be tenable, given the difference in style and narrative technique in Excerpts 44-82. Boissevain's assertion that Excerpts 1-44 and 45-82 derive from two distinctive, now lost, chronicles, respectively, comes closer to the evidence detected above (see Tables 3.6, 3.7, and 3.8). Excerpts 45-65 and 66-82 obviously belong to two different traditions, though. Despite their thematic uniformity, it is not likely that they were excerpted from a single text (a chronicle in U. P. Boissevain's view). As mentioned above, the use of certain passages from Cassius Dio points to an earlier collection of Dio excerpts. In my view, the Exc. Salm.II appear to have been compiled from a) excerpts from a now lost work based on Malalas' text, from what I indicated ( $\Psi)$ in my stemma (Exc.Salm.II A), b) passages excerpted from a collection of excerpts from Cassius Dio and Peter the Patrician (Exc.Salm.II B, first part), and c) excerpts from a now lost source on events of the third and fourth centuries, possibly from what Bleckmann calls the Leoquelle. This series of excerpts was augmented with passages taken from later sources, namely Procopius and Malalas (Exc.Salm.II B, second part) (Table 3.13).

Table 3.13 The source texts of the Exc.Salm.II

\begin{tabular}{ll}
\hline Exc.Salm.II & Source text \\
\hline Exc.Salm.II A 1-43 & $(\Psi)$ \\
Exc.Salm.II B 44-65 & $\begin{array}{l}\text { A collection of excerpts from Cassius } \\
\text { Dio and Peter the Patrician } \\
\text { Eeoquelle }\end{array}$ \\
Exc.Salm.II B 66-82 & \begin{tabular}{l} 
Leoqu \\
\hline
\end{tabular}
\end{tabular}

113 Exc. 81 = Procopius, De bellis 3.3.14-36; Excerpt 82 = Procopius, De bellis 4.4.16-28.

114 This is a further indication that the Exc.Salm.II do not belong to the chronicle by John of Antioch.

115 Bleckmann (2010), 60-61. 


\subsubsection{The Agathias part}

The last part of the sylloge makes up a brief collection of excerpts extracted from a single historical work, namely the Historiae by Agathias of Myrina. ${ }^{116}$ The part comprises 50 excerpts on ethnography and geography and was attached to the so-called Excerpta Salmasiana in order to form a coherent sylloge of excerpts. Thematically, the excerpts deal with the Franks, the Goths, the Alamanni, the Colchians, and the Sassanians. In particular, the excerpts are thematically divided into three parts; Excerpts 1-13 and 50 are concerned with the West, Excerpts 14-41 are concerned with Egypt, the Caucasus, and Persia, and Excerpts 42-49 are concerned with Constantinople. The first group of excerpts takes up the narrative thread at the point where the Exc.Salm.II had left off, namely, western affairs. In terms of subject matter, the second group is similarly compatible with the Exc.Salm.I as well as with the first part of the Exc.Salm.II. Excerpts 44-49 deal with the two earthquakes that hit Constantinople in 557 and 558, respectively and record two tricks played by Anthemius, the architect of the Hagia Sophia, on Zeno. The 50 excerpts of the codex Vaticanus gr. 96 and Vaticanus Pal. 93 are edited for the first time in the appendix of this book. ${ }^{117}$ The edition is accompanied by a commentary.

\subsection{The selective use of historical material in the Excerpta Salmasiana}

The study of the content of the Agathias part enables us to contextualise the Excerpta Salmasiana and sheds light on the reciprocal influence between late antique texts and the tenth-century Constantinopolitan cultural environment. In what follows, I shall first discuss the function of the ethnographic passages in Agathias, and then consider the function they assume in the different cultural and political context within the Excerpta Salmasiana when they were compiled.

\subsubsection{Agathias on the others}

Following the example of Procopius, Agathias augmented his Historiae by a good deal of ethnographic and geographical accounts. Specifically, besides his short accounts of the Alamanni (Historiae 1.6.3-7), the Franks (Historiae 1.19.2, 2.5.2-8, 2.14.8-11), the Colchians (Historiae 2.18.4-5) and the Dilimnitai (Historiae 3.17.6-9), Agathias enriched his narrative with three long excursuses, one on the Franks (Historiae 1.2.1-7.7) and two on Persia (Historiae 2.22.6-27.9, 4.23.7-30.5). In all of them, Agathias reflects on the religion, culture, and military tactics of the barbarians. 


\section{Excerpta Salamasiana}

As far as the digression on the Franks is concerned, Agathias deviates from the traditional hostile representation of the Franks in late antique historiography. Scholarship has long recognised Agathias' eulogy of the Franks as well as the distortion of reality in their representation. ${ }^{118}$ Agathias' positive attitude towards the Franks has been read by scholarship in more than one way. Some scholars explained Agathias' eulogy of the Franks in the light of the political situation in Constantinople in the early 570s; the court was seeking Frankish help in driving the Lombards out of Italy. ${ }^{119}$ This view is, however, challenged by A. Kaldellis, who assigned Agathias' praise of the Franks to the historian's moral agenda, attested also in the preface to his work. According to this line of thinking, Agathias desired to teach Romans a moral lesson through a praiseful representation of the Franks. ${ }^{120}$ Whether one opts for the first or the second interpretation, what is certain is that Agathias' passages on Western or Eastern peoples reveal more about the Romans themselves than about the nations in question.

The first of the two long digressions on Persia are concerned with customs and religious beliefs of the Sassanians. ${ }^{121}$ The second digression deals with the annals of the Sassanian kings. ${ }^{122}$ For both, Agathias drew his material mostly from the Persian Royal Annals ${ }^{123}$ as recounted to him by Sergius, an interpreter at the Sassanian court. ${ }^{124}$ In addition to this source, Agathias supplemented his account with material derived from popular accounts of the Sassanians as well as from an earlier handbook of chronology. ${ }^{125}$ The content of the two accounts reveals that Agathias was very interested in representing the various Persian dynasties as well as the characteristics and qualities of the Persian kings. Even the first of the two excursuses on Persia, dealing ostensibly with Persian religious customs,

118 Gottlieb (1969); Cameron (1970); Lounges (2005); Kaldellis (2013). Procopius, De bellis 6.25.1-9 presents the Franks as utterly savage and faithless barbarians, Christians in name only; cf. Kaldellis (2013), 23.

119 Cameron (1968), 116, 138-139; Gottlieb (1969), 156-159; Cameron (1970) 50, 51, 120-121, 129; Lounges (2005), 35-37.

120 Kaldellis (1999), 206-252; Kaldellis (2013), 23-24.

121 Agathias, Historiae 2.22.6-27.9.

122 Agathias, Historiae 4.23.7-30.5.

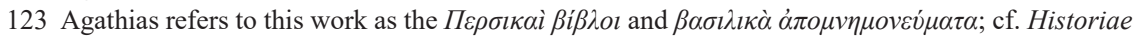
4.30.2 and 4.30.3. Av. Cameron has no doubt that the Annals must have originally been written in Pahlavi, that is Persian.; cf. Cameron (1969-1970), 162. From a different view, suggesting that the Royal Annals were first written in Syriac, see Baumstark (1894), 368-369. The Persian Royal Annals were extensively used by the now lost Book of Lords or Khvadhaynamagh. Later Arabic and Persian chroniclers drew heavily on the Khvadhaynamagh; cf. Cameron (1969-1970), 112. For the Persian archives, see Lee (1993), 177.

124 Agathias claims that his version should be preferred over that of Procopius because it is based on the Persian archives; cf. Historiae 4.30.5.

125 In fact, the excursus contains little material directly from the Annals. According to Av. Cameron, Agathias should have had no familiarity with earlier Greek historiographical accounts of the customs of the Sassanians. On the sources, in general, used by Agathias for the Sassanians' religion, see Cameron (1969-1970), 90-111. 
includes a brief chronological subsection cataloguing the Persian kingdoms from the Assyrian dynasty onwards (Historiae 2.25.4-26.1).

Throughout his Historiae, Agathias follows the traditional ethnographical model of differentiating between the superior Romans and the inferior foreigners in terms of culture but not in terms of military capacity. Indeed, besides Agathias, other writers of the same period hint at a possible admiration for the barbarians' achievements, both, in war and in diplomacy. Attention should be drawn to the fact that it is only the Oriental world that attracts such a positive portrayal in late antique historiography; ${ }^{126}$ Agathias, Procopius, Peter the Patrician, and Ps.Maurice's Strategicon provide us with sufficient evidence that the Romans had great respect for the Sassanian's patriotism, braveness on the battlefield, and diplomatic manoeuvres. ${ }^{127}$

By contrast, the attitude of late antique historians towards Western people was different. Procopius, for instance, when digressing briefly on the Vandals, the Heruls, and the people of Brittia, confines himself to only giving classical negative stereotypes. ${ }^{128}$ Thus, he emphasised the distinction between the uncivilised barbarians and the civilised Romans in his endeavour to justify Roman imperialism. ${ }^{129}$ The willingness of historians of late antiquity to accept that the Sassanians were not inferior to the Romans in war and diplomacy can be understood in relation to the political context of the sixth century. A possible explanation could be that those historians espoused a positive approach to the Persians after having met them at embassies or on diplomatic missions. ${ }^{130}$ Another reason could be sought in the need to create a strong adversary in order to juxtapose the qualities of the Byzantine Empire, all the more so since in late antiquity the Byzantines had already been defeated several times by the military strength of the Sassanians. ${ }^{131}$ But first and foremost, depictions of despotic Persian kings were meant to criticise

126 The Strategikon praises the Persians (cf. Ps.-Maurice, Strategikon 11.4). Menander represents favourably the Persian diplomat Yesdegusnaph (cf. Menander fr. 6.1.100-101). See also Agathias, Historiae 2.22.5, 2.28.1-6, 2.32.5 and Procopius, De bellis 1.2.1-10, 1.2.11-15, 1.7.29-35, 1.11.1-35. See also Peter the Patrician's positive view of Persia (cf. Peter the Patrician, fr. 13; FHG 188).

127 The topic has been treated in Canepa (2009), 79-121, 188-225; McDonough (2010), 55-66; Drijvers (2010), 67-76. On Strategicon, a military manual attributed to the emperor Maurice, see the edition by Dennis (1981).

128 Procopius, De bellis 4.6.5-14 on the Vandals; Procopius, De bellis 5.15, 6.14-15 on the Heruls and peoples of Thulle; Procopius, De bellis 8.20 on peoples of Brittia. Unlike Agathias, Procopius' opinion of the Franks was very negative as well (cf. Procopius, De bellis 6.25.1-9). It should be noticed that Agathias emphasises only the Frankish political institution and religion, which according to him are identical to those of the Romans. I would argue in favour of A. Kaldellis' view, that Agathias' account of the politeia of the Franks aimed to criticise the Roman social and political institution; cf. Kaldellis (2013), 21-25.

129 Maas (2003), 153-157. See also Section 2.5.3.1.

130 That could be the case of Procopius, Menander and Peter the Patrician; cf. McDonough (2010), 57-59.

131 An idea proposed by J. W. Drijvers, without, however, being further developed; cf. Drijvers (2010), 75. 
Roman emperors, whereas favourable portrayals of the Persian army or diplomacy should be interpreted as veiled attempts to disapprove of the diplomatic policies of Roman emperors. ${ }^{132}$

\subsubsection{The politics of ethnography in the Agathias part of the Excerpta Salmasiana}

In the following, I argue that the excerptor of the Agathias part must have made a heedful selection of passages from Agathias and imbued them with a new meaning. As noted, Agathias' ethnographic accounts of Western peoples as well as of the Sassanians serve certain literary purposes, namely, that of providing the Romans with moral paradigms and criticising current imperial policies. The sequence of excerpts in the Excerpta Salmasiana, instead, does not fulfil the same political function and objective. To my view, the Agathias part narrates the traditional cultural distinction between Romans and barbarians in order to reinforce the geographical and political frontiers already in place. The tenor of the concatenation of excerpts is determined by the political context of the tenth century. In what follows, the numeration of the excerpts from the Agathias part is the one given in my edition of the text presented in the appendix of this book (Appendix I: Text II).

Agathias' goals required him to digress on the political system of the Franks (Historiae A 19,2) and enrich his narrative with a comparison between the Franks and the Alamanni (Historiae A 6,3-7). The excerptor of the Agathias part, by contrast, excised any reference to the social order, government, or religion of the Franks or the Alamanni (see Excerpts 1 and 2). The Agathias part does not share Agathias' eulogy of the Franks either. In the Agathias part the Franks are like barbarians. The excerptor limits himself to briefly recording the derivation of the names of the Franks (Excerpt 1) and the Alamanni (Excerpt 2) and he stresses that the latter are a dark-skinned people (Excerpt 2). It should be noticed that Procopius (De bellis 4.6.5-14) correlated the darker skin with negative moral characteristics and when he portrays the Epthalitai favourably he puts emphasis on their white skin stating that they were not as ugly as the other Huns (Procopius, De bellis 1.3.2-7). The excerptor of the Agathias part depicts barbarians in a positive light, only when he comes to refer to their successes in war. For instance, during the siege of Cumae by the Byzantines, Aligern, a Goth military leader, killed Palladius, a Roman official and companion of the Roman general Narses (Excerpt 3). There is nothing negative in the description of Aligern. On the con-

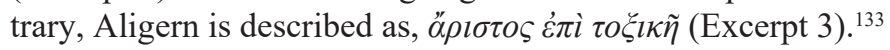

132 It is noteworthy that John Lydus' interest in Persian institutions should be viewed in the light of conveying implicit criticism of Justinian's institutional reforms; cf. John Lydus, De Magistratibus 3.34. On the politics of ethnography in late antique historiography, see Maas (1992); Kelly (1994), 161-176; Kaldellis, (2013), esp. 10ff.

133 Exc. 3: Aligern, one of the leaders of the Goths, was so excellent in throwing javelins that when he shot an arrow, even if it happened to strike against a stone or some other hard object, 
Similarly, the representation of the Persian burial customs (Excerpts 17 and 25), the Persian habit of incest (Excerpts 18 and 19), their pagan feasts (Excerpt 20), and their dualism (Excerpt 21) serve to enhance the cultural superiority of the Byzantines over the Persians. In the Agathias part any, even negative reference to the political system of the Sassanians is absent. In sixth-century Byzantium, such allusions served, as already mentioned, as a covert expression of political opposition and a criticism of the despotic system imposed by Justinian. In the tenth century, instead, such a strategy was out of date. Accordingly, in the Agathias part, Persian despotism is not topical anymore and what is needed to be emphasised is a) the false religion of the Persians as well as the danger of coming into contact with their infidel beliefs and customs and b) their brutality, savagery, and ferocity in war, from which the Romans had severely suffered in the past. Significantly, the latter implies, likewise, how many perils and hazards were to meet them again in a fight. Thus, the Roman emperor Valerian was captured, tortured, and eventually flayed to death (Excerpt 37 ). Cappadocia was savagely and fiercely pillaged by Sharpur's army (Excerpt 38). Persian kings tend to treat defeated rival leaders to the most lamentable and deplorable fate (Excerpt 39). From this perspective, the Agathias part is compatible with attempts to deal with Islam in Byzantine literature after the seventh century. After the Arab conquests, Byzantine historians, theologians, and philosophers view Arabs and their religion as a deviation of the true religion, that could threaten and contaminate Orthodox Christianity. ${ }^{134}$

To my mind, the Excerpta Salmasiana are witness to the ideological consequences of the shrinkage of the Empire after the seventh century. The snippets of ethnography in the collection of excerpts reveal, obliquely, the geopolitical position of Constantinople. The excerptor bases himself on classical models of representation of the other. Thus, like classical ethnographers, the excerptor of the Agathias part underscores the distinctiveness between Romans and barbarians. Unlike his late antique predecessors (Procopius, John Lydus, Peter the Patrician, Agathias, and Menander), he omits any outrightly or covertly positive assertion of the Persian civilisation, moral character or military capacity of individual Persian kings. The excerpts emphasise the otherness of opponents to Byzantium insofar as any contact with their irreconcilable and perilous beliefs as well as their cruelty and inhumanity in war are deemed to be dangerous and undesirable. Thus, the purpose of the ethnographical selection in the Exc.Salm. differs markedly from that of the late antique writers. The change of the geographical status-quo (the definite loss of the eastern provinces in the seventh century and of central and

it smashed it to pieces with the sheer force of its trajectory. He shot an arrow from the wall at Palladius, a general of the Romans, which ran through the man's shield, breastplate and body.

134 The examples of religious polemic in Byzantine literature given by Kaldellis (2013), 76 do not simply reflect theological attacks against Islam on the part of the Byzantines. The sources reveal also their concern about a likely contact with the infectious beliefs of Islam. On the hostile views of Byzantines towards Islam after Arab conquests, see Ducellier (1996), 146-174. 
Northern Italy in the ninth-tenth centuries) $)^{135}$ fundamentally altered the political context within which ethnography was written. ${ }^{136}$

\subsection{Towards the methodological principles of the Excerpta Salmasiana}

This section scrutinises the methodological principles underlying the compilation process of the Exc.Salm. The examination of the structure of the Exc.Salm. in the previous sections revealed how the historical excerpts were arranged in the collection of excerpts. This section sets out to embark upon a detailed analysis of single excerpts included in the Exc.Salm. The comparison of passages in the Exc.Salm. with the original texts, as preserved in earlier manuscripts, will shed light on the textual alterations as well as on structural modifications made by the excerptor of the Exc.Salm. The analysis of the textual interventions on the part of the excerptor of the Exc.Salm. enables us to reconstruct the three steps of redacting an excerpt collection as seen already in the EC and the Excerpta Anonymi: a. reading of the whole source text and selection of passages, b. rewriting of the source text, and c. composition of a new unity.

In what follows, I present a number of instances of the changes imposed on the original text in the course of the redaction of the Exc.Salm. The focus will be on the last part of the Exc.Salm., namely the Agathias part, which comprises 50 excerpts selected thematically, since ethnography and geography dominate the sylloge of excerpts. It is also noteworthy that the excerptor endeavoured to keep up to the original sequence of the passages. It is only in three cases that an excerpt breaks up the succession of the passages in Agathias' Historiae. ${ }^{137}$

Before discussing the textual alterations detected in the Agathias part, I would like to note that a significant portion of excerpts (19 out of 50 excerpts) is identical or very nearly identical to the text transmitted by the primary Agathias manuscript tradition. ${ }^{138}$ The rest of the excerpts exhibit textual deviations. The alterations do not modify the original narrative sequence, though. Accordingly, the excerptor of the Agathias part intervenes in the original text but he does not epitomise it. His principles of re-editing material extracted from a historical text are identical to those detected in the EC and the Excerpta Anonymi. The excerptor chose to appropriate rather than to synopsise the original narrative. In this way, he intervenes in the old text insofar as to make its content suitable for the aims of his collection.

135 On the impact of the Arab conquests on the Constantinopolitan policies, see Whittow (1996), esp. Chapter 6.

136 This altered perception of late antique ethnographic accounts is detected in the Excerpta Anonymi too. See Section 2.5.3.2.

137 Excerpts 21, 29, and 47.

138 On the primary Agathias manuscript tradition, see Keydell (ed.) (1967), XI-XXXIV. 


\section{a) Additions and excisions}

In 13 excerpts in particular one or more words, taken out of the original text, were added to the beginning of the excerpt. ${ }^{139}$ Such additions were intended to plug the gaps in the context that had arisen when extracting a single passage from the whole unit. Let us have a look at Agathias Excerpt 3 of the Exc.Salm (Table 3.14). The passage originally comes from the section where Agathias narrates the siege of the city of Cumae by the Byzantines. The Agathias part extracted the following episode: in the course of a fight, a Roman general named Palladius was killed by a Goth military figure named Aligern. The historical context of the episode is missing; e.g., the Byzantine attempt to subdue Cumae. Thus, the focus shifts to the proficiency of the Goth leader in throwing arrows.

As it becomes clear from the texts in the table, the opening of Excerpt 3

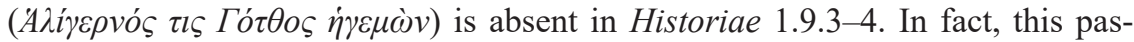
sage derives from an earlier section in Agathias' text. In Historiae 1.8.6 Agathias

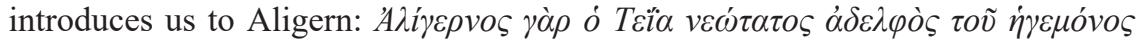
$\tau \tilde{\omega} v$ Гó $\tau \theta \omega v$. The excerptor of the Agathias part appears to be aware of the fact that splitting a text and extracting a piece of information from it might cause a certain incomprehensibility. Indeed, the insertion of the aforementioned phrase into Excerpt 3 makes the excerpt intelligible and transforms it into an independent piece of text. The same strategy to overcome such obstacles in excerpting a text is to be found in other collections of historical excerpts as well (the EC, the Excerpta Anonymi, the Epitome, and the Excerpta Planudea).

In most cases, that is, in 21 out of 50 excerpts material which was originally found in Agathias' text was reduced. On the one hand, such omissions served the

Table 3.14 The Agathias excerpt 3 of the Exc.Salm.

\begin{tabular}{|c|c|}
\hline Agathias, Historiae 1.9.3-4 & Exc.Salm. Excerpt 3 \\
\hline 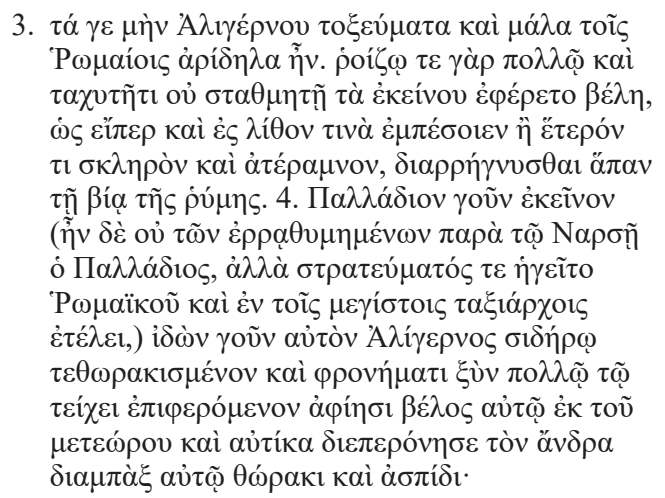 & 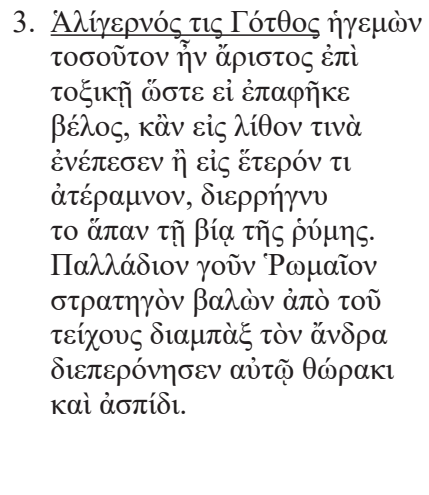 \\
\hline
\end{tabular}

139 See the numeration of excerpts in Table 3.19. 
Table 3.15 The Agathias excerpt 6 of the Exc.Salm.

\begin{tabular}{|c|c|}
\hline Agathias, Historiae 1.11.3 & Exc.Salm. Excerpt 6 \\
\hline 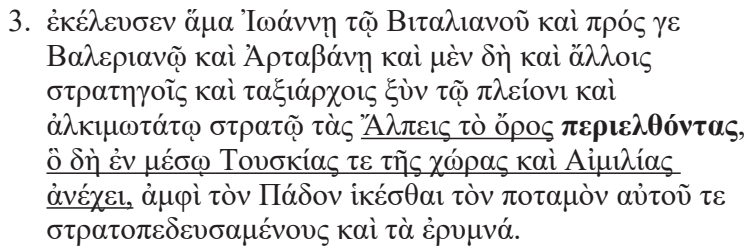 & 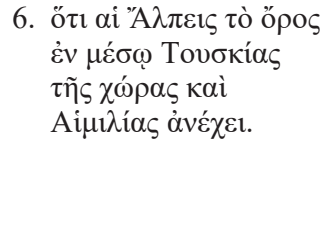 \\
\hline
\end{tabular}

compiler's intent to include as much thematically connected material as wanted. On the other hand, omissions served the compiler's aim at accuracy and brevity, principles which are outlined in the preface to the $E C .{ }^{140}$ Let us consider Excerpt 6, which like Excerpt 3, belongs to the context of Narses' expedition in Italy (Table 3.15).

In Agathias' text, Narses comes to realise that it was impossible to take Cumae at that time and so orders his forces to move to the region of Tuscany and attempt to restore control over the towns there. He therefore ordered Fulcaris, the new leader of the Heruls, to set off along with John, the nephew of Vitalian, with Valerian, and Artabanes, and other Roman generals and commanders for the area surrounding the river Po. Narses instructed them to go through the Alps, that is, between Tuscany and Emilia. The excerptor of the Agathias part left out the entire historical context and only singled out the geographical note on the Alps. The excerptor's awareness of the lack of context in the new excerpt leads him to a dual intervention: he adds the conjunction $\delta \tau^{\prime} t$ at the head of the excerpt and excises the $\pi \varepsilon \rho l \varepsilon \lambda \theta \dot{v} v \tau \alpha \varsigma$ (the participle would not make sense without the verb $\varepsilon^{\kappa} \kappa \dot{\lambda} \lambda \varepsilon v \sigma \varepsilon v$ and its historical context) originally found in the middle of the sentence.

Excerpt 15 represents a similar case, as well (Table 3.16). The rewriting of the original text consists in both textual insertions and omissions. Excerpt 15 deals with the origins of the Lazi. According to the ancient tradition, the Lazi are descended from the Egyptians.

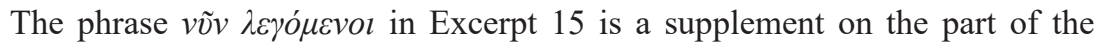
excerptor. The phrase, which is not transmitted throughout the relevant section in Agathias' text, can be found in Historiae 1.2.1, where Agathias refers to the origins of the Franks. The passage has, also, been excerpted in Excerpt 1 of the

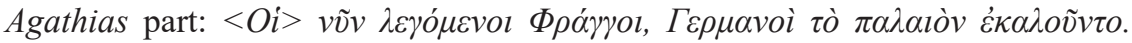

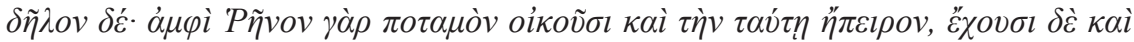

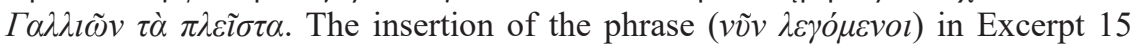
served to make the text clearer within its new context. The repetition of the same sentence at the beginning of Excerpt 15 points to a technique traced in the $E C$ as 
Table 3.16 Agathias-excerpt 15 of the Exc.Salm.

\begin{tabular}{|c|c|}
\hline Agathias, Historiae 2.1.4-5 & Exc.Salm. Excerpt 15 \\
\hline 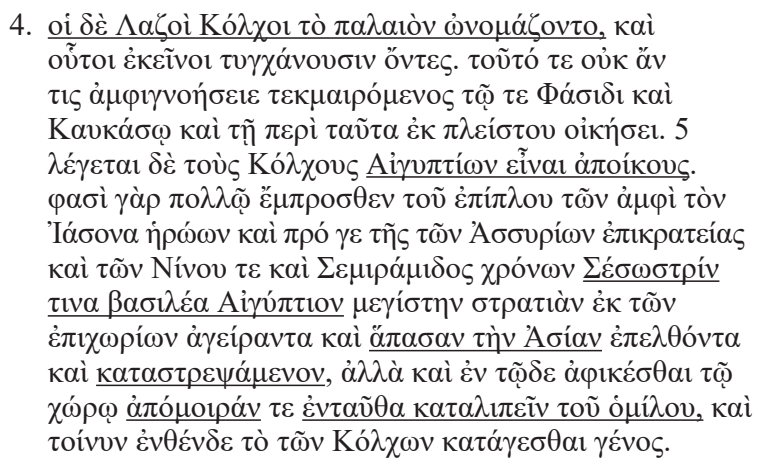 & 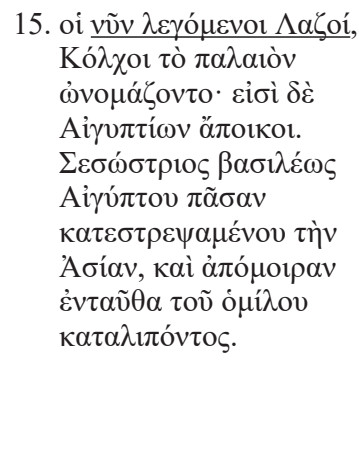 \\
\hline
\end{tabular}

well: there is an important number of cases in which the same text was included twice, as part of a different excerpt from the same author, in a single or in two different collections of the $E C$. D. Rafiyenko has spotted 54 such cases throughout the extant parts of the $E C .{ }^{141}$

\section{b) Repositions}

In three excerpts the intervention on the part of the excerptor consists in a. textual additions or omissions and b. in the rearranging of words within the old text. ${ }^{142}$ Excerpt 23 of the Agathias part, concerning the philosophical interests of Chosroes I, is a typical example (Table 3.17).

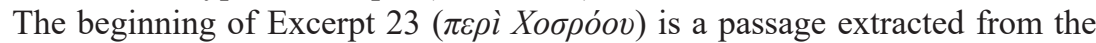
preceding paragraph in Agathias' text. The excerptor, once again, tackled the lack of context for the selected passage by enriching it with information taken from the original text.

\section{c) Changes in vocabulary}

In four other excerpts, the Agathias part transmits a text which shows marked dissimilarities from the original either in vocabulary or in changes in the word order of the original text. ${ }^{143}$ This is the case, for instance, with Excerpt 37 (Table 3.18).

141 The classification of the instances given by D. Rafiyenko seems to blur the methodological strategies of the excerptors even further. Especially the distinction of reiterations she makes between what she calls patchworking and extraction; Rafiyenko (2017), 291-324.

142 See Table 3.19.

143 See Table 3.19. 
Table 3.17 The Agathias excerpt 23 of the Exc.Salm.

\begin{tabular}{|c|c|}
\hline Agathias, Historiae 2.28.2 & Exc.Salm. Excerpt 23 \\
\hline 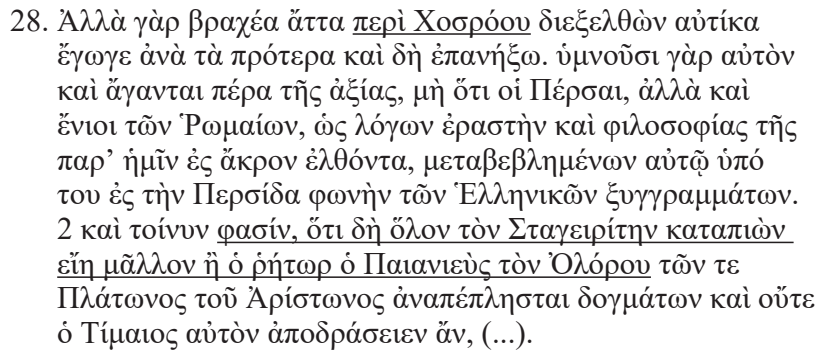 & 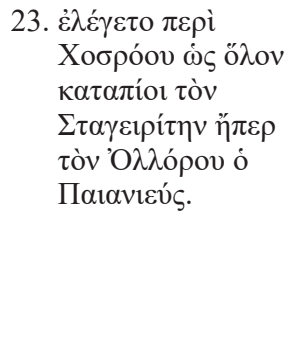 \\
\hline
\end{tabular}

Table 3.18 The Agathias excerpt 37 of the Exc.Salm.

\begin{tabular}{|c|c|}
\hline Agathias, Historiae 4.23.7 & Exc.Salm. Excerpt 37 \\
\hline 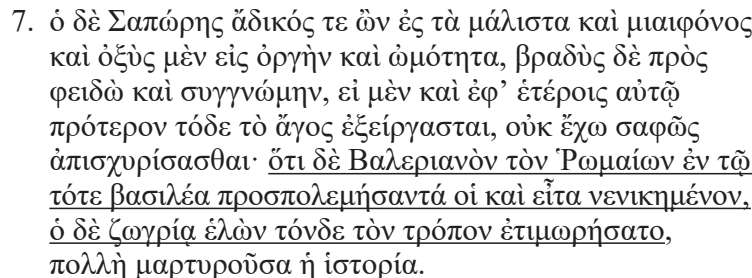 & 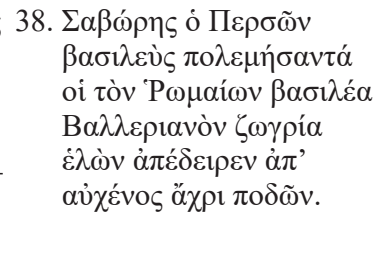 \\
\hline
\end{tabular}

Excerpt 37 transmits the lamentable fate of the emperor Valerian, who was flayed to death by Sharpur I. The phrase $\Sigma \alpha \beta \omega ́ \rho \eta \varsigma$ o Пย́ $\rho \sigma \tilde{\omega} v \beta \alpha \sigma \imath \lambda \varepsilon \dot{v} \varsigma$ introducing Excerpt 37 is not transmitted as such by Agathias. But the phrase summarises the context of the entire section in Agathias' text. The focus of Excerpt 37 lies on the savagery and cruelty of the Persian king. The verb ś $\tau \mu \omega \rho \dot{\eta} \sigma \alpha \tau o$ was, therefore, substituted with $\dot{\alpha} \pi \varepsilon \dot{\varepsilon} \delta \iota \rho \varepsilon v$ and the closing passage of Excerpt 37 ( $\dot{\alpha} \pi^{\prime} \alpha \dot{\chi} \chi \varepsilon \dot{\varepsilon} v o \varsigma$ $\ddot{\alpha} \chi \rho \imath \pi \circ \delta \tilde{\omega} v)$ is a supplement on the part of the excerptor.

Table 3.19 exhibits what was shown in the previously presented instances: a selected passage could involve two or even three types of changes, e.g., insertions and omissions of material or the rearranging and omission or addition of material.

The reworking of selected passages in the Agathias part involved textual changes similar to those in other collections of historical excerpts, such as the $E C$ and the Excerpta Anonymi. The compilation process in all the aforementioned collections was determined by similar principles and methods, as they are outlined in the preface to the $E C$. Accordingly, the prime goal of the compilers was the thematic arrangement of the selected material, presenting it with accuracy and brevity, while retaining the sequence of the original narrative. The compilers had to cope with the issue of flawed contextualisation caused by their excerpting 
Table 3.19 Type of textual changes in the Agathias part

\begin{tabular}{lcccc}
\hline No changes & Additions & Omissions & Rearranging & $\begin{array}{c}\text { Changes in } \\
\text { vocabulary }\end{array}$ \\
\hline Excerpts: 1,2, & Excerpts: 3, 5, & Excerpts: $3,4,5$, & Excerpts: 22, & Excerpts: 36, \\
$7,8,9,11$, & $14,15,22$, & $6,10,12,14$, & 35,46 & $40,42,50$ \\
$13,17,18$, & $23,31,33$, & $15,16,20,21$, & & \\
$19,22,24$, & $37,39,41$, & $25,30,38,39$, & & \\
$25,27,28$, & 46,47 & $40,40,41,42$, & & \\
$29,32,34$, & & 44,47 & \\
45 & & & \\
\hline
\end{tabular}

methods. It is evident that with all three collections the excerptors resorted to identical strategies in order to establish the context in the excerpted passages as follows: a) an introductory sentence, made up of material from the original text is inserted into the excerpts. As noted, this technique is detectable throughout the $E C$, as well. The excerptors of the $E C$ supplemented the excerpted passages with short sentences summarising the original text. ${ }^{144}$ This strategy is not an innovation on the part of Constantine VII's team, though. It was applied in the Excerpta Anonymi as well as in the so-called Epitome of the Seventh Century. ${ }^{145}$ Yet, shortening the original text shifted the thematic focus of passages in all of them, the EC, the Excerpta Anonymi, and the Epitome. b) omissions of text passages. This seems to have been the most common strategy on the part of the compilers. There are instances in the $E C$ in which the entire passage was omitted but for key phrases and names. ${ }^{146}$ It has been shown in Chapter 2 that a significant number of selected passages in the Excerpta Anonymi had been shortened before their inclusion in the sylloge.$^{147}$ And c) repetitions of passages. This method can also be seen in the $E C$, the Excerpta Anonymi, and the Epitome. ${ }^{148}$

\subsection{General conclusions on the Excerpta Salmasiana}

Chapter 3 concerned the study of the content and structure of the so-called Excerpta Salmasiana. Since the sylloge is often associated with the scholarly debate on the composition of the genuine corpus of John of Antioch, I first discussed this matter by offering an overview of the ongoing scholarly discussion. In this chapter, I argued that the Excerpta Salmasiana transmit a compilation of three distinct syllogae of excerpts: 1) the Exc.Salm.I, which consist of excerpts taken from a single 


\section{Excerpta Salamasiana}

historical work, namely John of Antioch's Historia chronica; 2) the Exc.Salm. II, which comprise excerpts from a variety of late antique texts. In particular, I distinguished between the Exc.Salm.II $A$ and the Exc.Salm.II B; each have their own characteristics in terms of sources. The Exc.Salm.II $A$ consist of excerpts from a now lost work based on Malalas' text. The Exc.Salm.II B are composed of excerpts from a collection of excerpts by Cassius Dio and Peter the Patrician as well as from passages derived from what B. Bleckmann calls the Leoquelle; and 3) a sylloge of passages on ethnography and geography excerpted from Agathias' Historiae. As I have suggested, the selection and the re-editing of excerpts in the Agathias part were determined by the political context of the tenth century. The passages reflect on a period in which the Empire had territorially shrunk and its civilising influence had been restricted. Finally, in this chapter I embarked upon a close analysis of the working method applied by the excerptor in the Agathias part. It became evident that the Agathias part reflects a traditional mode of selecting, re-editing, and presenting earlier historical material. The examination of the modifications which the selected text passages underwent, corroborated the view that the Agathias part shares compositional methods and excerpting techniques with all the other collections of historical excerpts examined in this book. 


\section{The Epitome of the Seventh Century}

A sylloge of passages taken from a number of historical works is known under the conventional title Epitome of the Seventh Century (hereafter Epitome). The Epitome comprises excerpts from the ecclesiastical histories by Eusebius of Caesarea, ${ }^{1}$ Gelasius of Caesarea ${ }^{2}$ and Theodorus Anagnosta ${ }^{3}$ as well as excerpts from John Diacrinomenus ${ }^{4}$ and Philip of Side, ${ }^{5}$ and a series of anonymous fragments. ${ }^{6}$

1 Eusebius (260/265-339) HE covered the period from Jesus Christ to 325 AD. Barnes (1980), 197198 ) argues that Eusebius wrote four different versions of his $H E$. According to W. Treadgold, Eusebius produced a fifth version around the year 326; in this version, a few references to Crispus were omitted; cf. Treadgold (2007), 39. Burgess (1997), 471-504 thinks that Eusebius produced three version of the HE. Cassin, Debié, and Perrin (2012) suggest the existence of one edition only; cf. Van Nuffelen and Van Hoof (2020).

2 Gelasius' $H E$, which have come down to us only in fragments, supplemented and continued that of Eusebius. Rufinus of Aquileia and Socrates of Constantinople drew heavily on Gelasius' work, although usually without mentioning him as their source. On the extant fragments from Gelasius' $H E$ see in Wallraff, Marinides, and Stutz (edd.) (2017). On the view that the text should be dated between 439 and 475 and, therefore, not to be assigned to Gelasius of Caesarea, see Van Nuffelen (2002), 621-640. According to Blaudeau, the extant fragments of Gelasius are the remains of an updated version of his original work by a later author; Blaudeau (2006), 500.

3 The $H E$ by Theodorus Anagnosta (late fifth- early sixth c.), which is partially preserved, dates back to the year 518. G. C. Hansen published the surviving books 1 and 2 of Theodorus' $H E$ in Hansen (ed.) (1995), 1-151. The text originally covered events from the reign of Constantine to the accession of Justin I (306-512); Van Nuffelen and Van Hoof (2020).

4 The composition date of Diacrinomenus' (late fifth-early sixth c.) historical work is placed after the year 512. The text has been handed down to us in fragments. The fragments have been published in Hansen (ed.) (1995), 152-157. On Diacrinomenus, see Pouderon (1997); Blaudeau (2001), 76-97.

5 The historical work by Philip of Side (first half of the fifth c.) covered the period from Adam down to his own time. The text was composed between 426-439; Van Nuffelen and Van Hoof (2020). The text was edited in Heyden (2006).

6 The codex Parisinus gr. 1555a transmits two series of anonymous fragments of the periods from 527 to $609 \mathrm{AD}$, and from 465 to $562 \mathrm{AD}$, respectively. G. Greatrex, B. Pouderon, and G. C. Hansen agree that only the first of the two anonymous series of fragments was part of the Epitome, whereas the second one was a later addition. Pouderon suggests a possible connection between the second series of fragments and John of Antioch; cf. Pouderon (1998), 170-174, 180-182. See also Hansen (ed.) (1995); Greatrex (2014b), 10-12. 
This chapter a) considers the manuscript tradition of the Epitome, b) demonstrates that the text is a collection of passages excerpted from different sources, contrary to the widely held opinion that the Epitome was the summary of a single work, ${ }^{7}$ c) reflects on the original structure of the Epitome, and d) examines the use of Eusebius' $H E$ by the compiler of the Epitome. In particular, the examination of the Eusebian excerpts shall help us establish how the manuscripts of the Epitome are related to each other and what distinctive contribution was made by the compiler, and determine the working method applied in the sylloge.

The passages excerpted from Eusebius are edited in the appendix (Appendix I: Text IV).

\subsection{Manuscript transmission}

The Epitome has been transmitted through five manuscripts, namely Parisinus supp. gr. 1156, ff. 26r-29v (tenth century), Auctarium E.4.18 (Oxford), ff. 136r-143v (tenth century), Athonensis, Vatopedinus graecus 286, ff. 91r-218r (thirteenth century), Parisinus gr. 1555 A, ff. 7r-23v (thirteenth-fourteenth centuries), and Baroccianus gr. 142, ff. 212r-224r, 236r-240r (fourteenth century) ${ }^{8}$

\subsubsection{Parisinus suppl. gr. 1156}

Bombyc., ff. 29, $192 \times 290 \mathrm{~mm}(150 \times 240 \mathrm{~mm}), 33$, sec. X-XI. ${ }^{9}$

Parisinus supp. gr. 1156 contains: 1: Leontius Hierosolymitanus presbyter, Hom. In Samaritanam; ${ }^{10}$ 1r-1v: Basilius Seleuciensis, In Duos Euangelii Caecos; ${ }^{11}$ 2r-2v: Joannes Chrysostomus, Thema: Prodigus; 3r-3v: Theodoretus Cyrrhensis, Interpretatio in Amos; ${ }^{12} 4 \mathrm{r}-4 \mathrm{v}$ : Theodoretus Cyrrhensis, Interpretatio in Abdiam; ${ }^{13}$ 5r-10v: Catenae in Psalmos; ${ }^{14}$ 11r: Ephraem Graecus, De His, Qui Animas Ad Impudicitiam Pelliciunt, ${ }^{15} 11 \mathrm{r}-12 \mathrm{v}$ : Ephraem Graecus, De Abstinendo Ab Omni Consuetudine Perniciosa ${ }^{16}$ 13r-14r: Aristoteles philosophus, Historia

7 Nautin (1994), 213-243; Pouderon (1998), 170-171; Greatrex (2014b), 10-11.

8 According to Nautin, Baroccianus gr.142 and Athonensis Vatopedinus 286 were copies from a common exemplar, different from the one that Parisinus gr. 1156 and Parisinus gr. 1555a come from; Nautin (1994), 214. According to G. C. Hansen, Parisinus suppl. gr. 1156 represents the Epitome better; Hansen (ed.) (1995), XXV, XXXIII-XXXIX. In P. Blaudeau's view, the scribe of Parisinus gr. 1555a has reduced by a quarter the records he found in Parisinus suppl. gr. 1156; cf. Blaudeau (2006), 537, esp. n. 217.

9 On the codex, see Hansen (ed.) (1995), XXIV-XXV.

$10 C P G 7912$.

$11 C P G 6656.36$.

12 CPG 6208.02; BHG 71-71a; $P G$ 81, col. 1697 C11-1701 A12.

13 CPG 6208.05; BHG 1-1d; $P G$ 81, col. 1713 B10-1716 D3.

$14 C P G \mathrm{C} 10-\mathrm{C} 40$.

$15 C P G 3998$.

$16 C P G 4000$. 
animalium; ${ }^{17}$ 15r-20v: Joannes Philoponus, In Aristotelis analytica priora commentarius; ${ }^{18}$ 21r-22v: Sextus Empiricus, Hypotyposes ${ }^{19}$ 23r-25v: Paulus Aegineta medicus, Epitome medica ${ }^{20}$ 26r-29v: Anonymous, Epitome.

The codex contains excerpts of the Epitome taken from Theodorus Anagnosta's and John Diacrinomenus' historical works. In particular, ff. $26 \mathrm{r}-27 \mathrm{r}$ and ff. 28r-29v transmit Theodorus Anagnosta's and John Diacrinomenus' passages, respectively. These excerpts were first published by E. Miller. ${ }^{21}$ They correspond to Excerpts E 477-496, E 520-524, and E 525-561 in the edition by Hansen. ${ }^{22}$ Unlike the excerpts from Theodorus Anagnosta, those from John Diacrinomenus

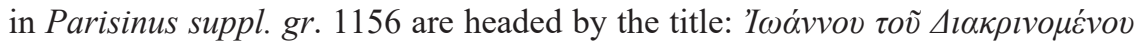

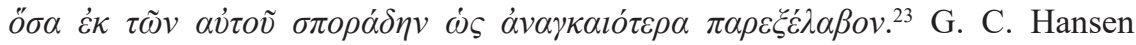
showed that the Parisinus suppl. gr. 1156 relied on a manuscript which was a direct copy of the original Epitome. ${ }^{24}$

\subsubsection{Oxford, Auctarium E.4.18}

Bombyc., ff. 1r-143v, sec. X

Auctarium E.4.18 contains: 1r-132v: Theodoretus Cyrrhensis, Historia Ecclesiastica; 132v-136r: Proclus Constantinopolitanus, Epistulae; 136r-143v: anonymous, Epitome.

Auctarium E.4.18 contains excerpts of the Epitome taken from Eusebius' $H E$.

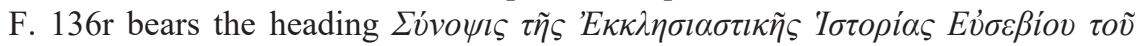
$\Pi \alpha \mu \varphi \dot{i} \lambda o v .{ }^{26}$ In its present state the manuscript lacks the folia bearing extracts from Eusebius' $H E$ 1.10-5.24. Yet the manuscript preserves Eusebian passages not found in the other witnesses of the Epitome.

\subsubsection{Parisinus graecus $1555 \mathrm{~A}$}

Chartac., ff. 10+194, II 29, sec. XIV. ${ }^{27}$

Parisinus gr. 1555a contains: A-J: mutilated folia containing historical frag-

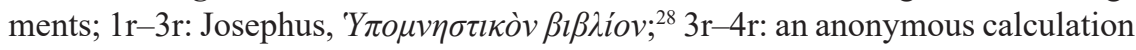

17 Berger (2005); Ronconi (2012), 137-166.

18 Wallies (ed.) (1905).

19 Excerpts from book 3; cf. Mutschmann (ed.) (1912).

20 See the edition by Heiberg (1921-1924).

21 Miller (1873), 396-403.

22 Hansen (ed.) (1995), 136-141 and 150-157.

23 John Diacrinomenus, all that I found scattered in his work and necessary to be excerpted.

24 Hansen (ed.) (1995), XXXV-XXXVII. The same had been supported by P. Nautin; cf. Nautin (1992), 173-174.

25 Parmentier and Hansen (1998), xii-xiii; Hansen (ed.) (1995), XXXVII.

26 Abridgment of the Ecclesiastical History by Eusebius (the student) of Pamphilus.

27 On the codex, see Omont (1898), XCIX; Hansen (ed.) (1995), XXV-XXVI; Pouderon (1998), 170-171.

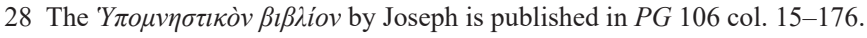


of the years from Adam to Christ; 4r-5r: anonymous, an incomplete list of Roman emperors as far as Tiberius II (578); 5r-7r: Eustathius historicus, Chronica Epitome; ${ }^{29}$ 7r-23v: anonymous, Epitome; 23v-27v: anonymous, Notitia Episcopatuum. ${ }^{30}$

The full text is in Greek and it is now deposited in the National Library of France. Parisinus gr. 1555a is a faithful copy of Parisinus suppl. gr. 1156, since it repeats the same orthographic errors of its prototype. ${ }^{31} \mathrm{~J}$. A. Cramer published the part of the Epitome preserved in this manuscript in $1839 .^{32}$

The text of the Epitome begins from the second column on $\mathrm{f} .7 \mathrm{r}$ bearing excerpts from Eusebius without being preceded by any title. The Eusebian text reaches as far as f. $9 \mathrm{v}$. What follows is a short series of excerpts attributed by scholars to Gelasius or to a pseudo-Gelasius (f. 9v) ${ }^{33}$ After these excerpts, Parisinus gr. 1555a sequentially transmits excerpts from the $H T$ (ff. $9 \mathrm{v}-15 \mathrm{v}$ ) and the $H E$ by Theodorus Anagnosta (ff. $15 \mathrm{v}-20 \mathrm{r}$ ), and also from the $H E$ by John Diacrinomenus (ff. 20r). None of these series of excerpts is preceded by a title. The Epitome ends with a series of anonymous excerpts down to the reign of Phocas (ff. $20 \mathrm{v}-21 \mathrm{v})$. It is unlikely that the series of excerpts which ensues (ff. $21 \mathrm{v}-23 \mathrm{v}$ ) was part of the original Epitome. ${ }^{34}$

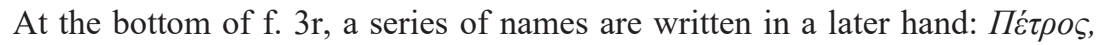

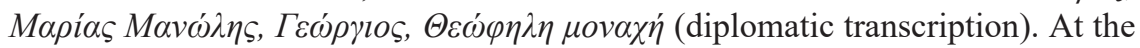

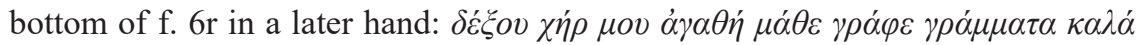
$\mu \eta \delta \alpha \rho \theta \dot{\eta} \varsigma \kappa \alpha i ̀ \pi \varepsilon \delta \varepsilon v \theta \tilde{\eta} \varsigma \kappa \alpha i ̀ ~ \sigma \tau \varepsilon \dot{\varepsilon} \rho \mu \varepsilon \tau \alpha v o \theta \tilde{\eta} \varsigma^{35}{ }^{35}$ The verses constitute an alternative version of a poem in seven syllables which appears quite often in Byzantine

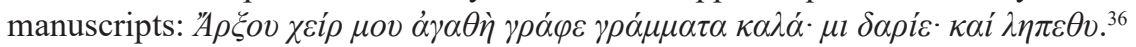

\subsubsection{Athonensis Vatopedinus graecus 286}

Bombyc., ff. 305, $220 \times 300$ mm, 19-22, sec. XIII. ${ }^{37}$

Athonensis Vatopedinus graecus 286 contains: 1-305: Iobius monachus, Opera; 62v-64v: Photius, Bibliotheca; ${ }^{38}$ 65r-90r: Hagiographica, Petrus et

29 The text bears the Epitome of Flavius Josephus' Antiquitates Judaicae by Eustathius of Epiphania. Eustathius' text is edited in Allen (1988). On Eustathius of Epiphania, see Brodka (2006), 59-78; Treadgold (2007), 709-745.

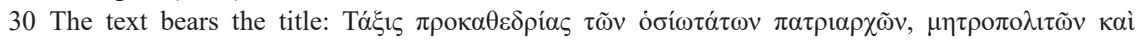

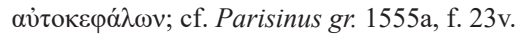

31 G. C. Hansen gives a number of cases in which Parisinus gr. 1555a faithfully follows the errors of its prototype; cf. Hansen (ed.) (1995), XXVI.

32 Cramer (1839), 87-114.

33 Nautin (1992); Van Nuffelen (2002). On the matter, see Section 4.3.

34 Pouderon (1998), 170-174, 180-182; Hansen (ed.) (1995), XXV; Greatrex (2014b), 10-12.

35 This is a diplomatic transcription of the text. An English translation of it would be: accept (it), my good hand, learn, write good letters, so as not to be beaten and chastised and later be regretful.

$36 \mathrm{cf}$. Athos, Vatopedi 58, f. 1r. See Vassis (2005), 77; Kadas (2000), 12. See also the occurrences of the poem in http://www.dbbe.ugent.be/typ/3084.

37 On the codex, see Hansen (ed.) (1995), XXVI-XXVII.

38 Bibliotheca, cod. 222. 
Paulus ap. (SS.), Commentarius metaphrasticus; ${ }^{39}$ 90v-91r: Ascetica; 91r-218r: anonymous, Epitome; 218v-221v: Maximus Confessor, De Duabus Christi Naturis; ${ }^{40}$ 221v-223r: Joannes Damascenus, Opera; 223r-285r: Theodorus Abucara, Opuscula varia; 223r-298r: Leontius scholasticus, Liber De Sectis; ${ }^{41}$ 285v-298r: varia florilegia; 298r-302v: Cyrillus Alexandrinus, Commentarii in Iohannem. ${ }^{42}$

Parts from the Epitome are preserved on ff. 91r-218v. In particular, ff. 91r-108r

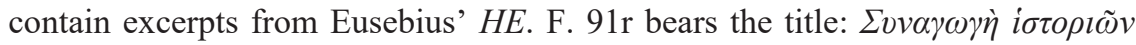

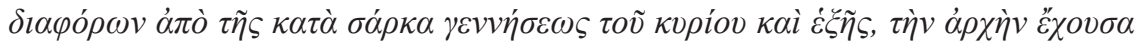

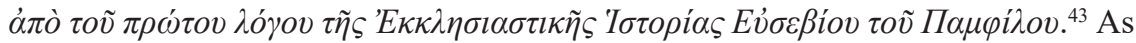
I shall demonstrate below, this heading must have been the original title of the Epitome and should be ascribed to its compiler. In addition to the aforementioned

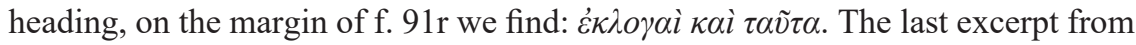
Eusebius is followed by a sentence added by the compiler of the Epitome: $\tilde{\varepsilon} \omega \varsigma$

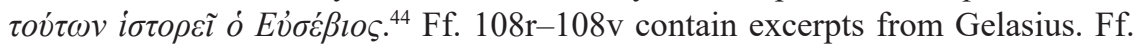
108v-201r transmit excerpts from Theodorus Anagnosta's HT. An ornamented initial letter $(M)$ on $\mathrm{f}$. $108 \mathrm{v}$ marks the beginning of the new section. The first excerpt from the HT in Athonensis Vatopedinus graecus 286 is excerpt E 5 in the edition by Hansen. ${ }^{45}$ Finally, ff. $201 \mathrm{r}-218 \mathrm{v}$ bear excerpts from Theodorus Anagnosta's $H E$.

\subsubsection{Baroccianus gr. 142}

Chartac., ff. 292, $165 \times 250 \mathrm{~mm}, 40-44$, sec. XIV. ${ }^{46}$

Baroccianus gr. 142 contains: 1r-9r: Nicephorus Callistus Xanthopulus, Tabula in Sozomeni Historiam; 9r-153v: Sozomenus, Historia Ecclesiastica; 154v-202v: Euagrius scholasticus, Historia Ecclesiastica; 155r-205r: Nicephorus Callistus Xanthopulus, Tabula In Euagrii Scholastici Historiam; 205r-211r: Nicephorus Callistus Xanthopulus, Opera;205r-212r: Flavius Josephus, Antiquitates Judaicae; 210v-211r: Flavius Josephus, Josephi vita; 212r-224r: anonymous, Epitome; 225r-235r: Theodoretus Cyrrhensis, Historia Ecclesiastica; 236r-240r: anonymous, Epitome; 240v-241v: Photius, Bibliotheca; 243r-261r: Philostorgius, Historia Ecclesiastica; 262r-v: Atticus Constantinopolitanus, Ep ad Cyrillum

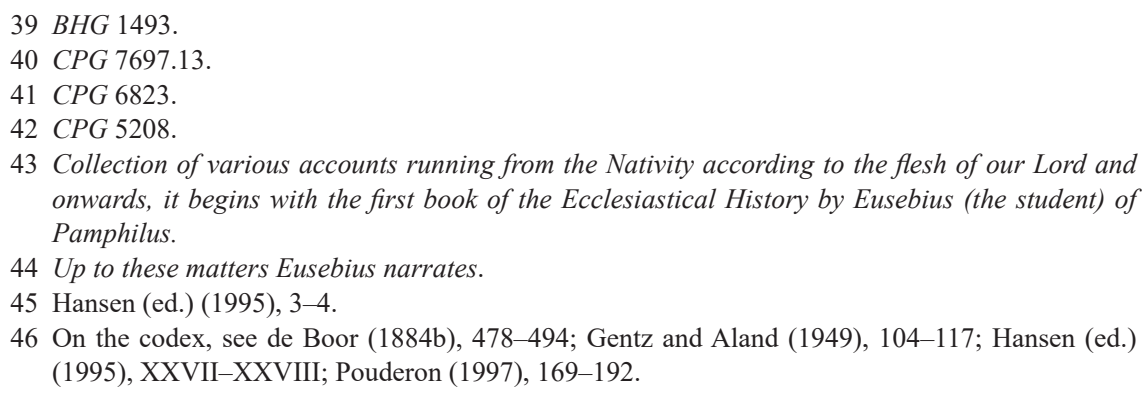

43 Collection of various accounts running from the Nativity according to the flesh of our Lord and onwards, it begins with the first book of the Ecclesiastical History by Eusebius (the student) of Pamphilus.

44 Up to these matters Eusebius narrates.

45 Hansen (ed.) (1995), 3-4.

46 On the codex, see de Boor (1884b), 478-494; Gentz and Aland (1949), 104-117; Hansen (ed.) (1995), XXVII-XXVIII; Pouderon (1997), 169-192. 
Alexandrinum; ${ }^{47}$ 262v-263r: Atticus Constantinopolitanus, Ep Ad Petrum Et Aedesium Diaconos Alexandrinos; ${ }^{48}$ 263r-264r: Cyrillus Alexandrinus, Ep 76 Ad Atticum; ${ }^{49}$ 263r-264r: Cyrillus Alexandrinus, Epistulae (1-92); 264r-v: Ps.Dionysius the Areopagita, Epistulae 1-10; ${ }^{50} 264 \mathrm{v}-265 \mathrm{v}$ : Basilius Caesariensis, Epistulae; 265v-268v: Manuel Charitopulus, Responsiones Canonicae; 266r-268v: Germanus Marcutzas III, Opera; 270r-276: Ius canonicum, Canones. 278r-279v: Hippolytus, Syntagma chronologicum,52 279v-280v: Eusebius Caesariensis, Historia Ecclesiastica; 279v-281v: Hegesippus, Hypomnemata: ${ }^{53}$ 282r: Epiphanius Monachus, De Vita B. Virginis $;{ }^{54}$ 282r: Nicephorus Callistus Xanthopulus, Historia Ecclesiastica; 282r-283v: Varia; 284r-288r: Epiphanius of Salamis, Index Apostolorum (cum Indice discipulorum ex Dorotheo), ${ }^{55}$ 288r-292v: Nicephorus Callistus Xanthopulus, De Patriarchis.

Due to the removal of some folios, the excerpts from the Epitome are preserved in two different parts in the manuscript. Ff. 212r-216r contain excerpts from Eusebius' $H E$ followed by excerpts from Gelasius (f. 216r), and the $H T$ (ff. $216 \mathrm{v}-224 \mathrm{r}$ ). The last Eusebian excerpt is followed by a sentence added by the

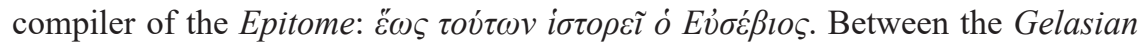
part and the excerpts from the $H T$, a long excerpt from Philip of Side appears (ff. $216 \mathrm{r}-216 \mathrm{v})$. The excerpt is absent from the other three attestations of the Epitome. G. C. Hansen does not exclude the inclusion of the excerpt in the Epitome but he has doubts about the original placing of it within the sylloge. ${ }^{56}$ The excerpts from the

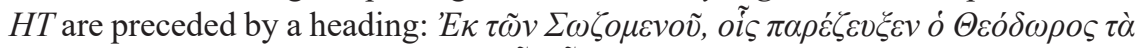

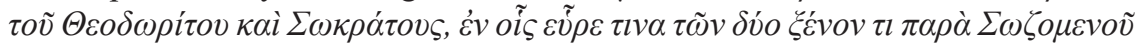
$i \sigma \tau o \rho \dot{\eta} \sigma \alpha \nu \tau \alpha .{ }^{57}$ In the present state of the manuscript the series of excerpts from the Epitome is interrupted by excerpts from Theodoret of Cyr (ff. 225r-235r). ${ }^{58}$ The excerpts from Theodorus Anagnosta's $H E$ are transmitted on ff. 236v-240r

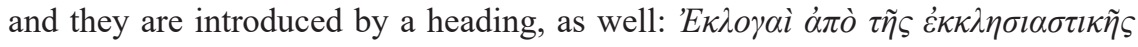

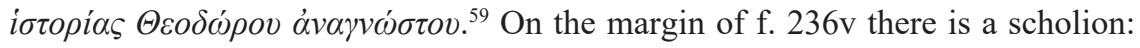

\author{
$47 C P G 5652, B H G 0873 \mathrm{~kb}$. \\ 48 CPG 5653. \\ $49 C P G 5376, B H G 873 \mathrm{~kb}$. \\ $50 C P G 6604-6613$. \\ $51 C P G 2900$. \\ 52 BHG 779h-779hd, 1046i. \\ $53 C P G 1302$. \\ 54 BHG 1049. \\ 55 BHG $152 \mathrm{k}$. \\ 56 Hansen (ed.) (1995), XXXVIII. de Boor considered the excerpt as part of the original Epitome; de \\ Boor (1884b), esp. 487 and de Boor (1888), esp. 173-174. Nautin appears to hold the same view \\ in Nautin (1994), esp. 224-233. Yet Pouderon (1994), esp. 163-190 suggests that B is based on a \\ reworked version of the Epitome from which the passage in question comes from. \\ 57 Excerpts from Sozomen, which Theodore joined with passages from Theodoret and Socrates, and \\ in which he identified what subject the two narrated differently from Sozomen. \\ 58 Theodoret (ca. 393-466) wrote an ecclesiastical history covering the period from 325 AD to $428 \mathrm{AD}$. \\ His work is fully preserved. See the edition of the text in Parmentier and Hansen (1998). \\ 59 Extracts from the Ecclesiastical History of Theodorus Anagnosta.
}




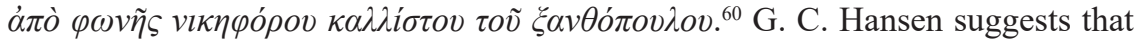
this part in Baroccianus gr. 142 could have been dictated by Nicephorus Callistus to the amanuensis or that the codex was copied on Nicephorus' initiative. ${ }^{61}$ According to G. C. Hansen, Nicephorus may have made extensive use of excerpts from a number of historical works preserved in Baroccianus gr. 142 including the Epitome. ${ }^{62}$ Some excerpts from the Epitome were placed on the margins of a number of folia in Baroccianus gr. 142 by a different hand. Nevertheless, they appear to have been copied from the same source just like the excerpts in the text body. G. C. Hansen marks the excerpts transmitted on the margins as B2. ${ }^{63}$ The series of excerpts from the $H T$ and the $H E$ by Theodorus Anagnosta have been handed down with several gaps, which can be identified when comparing Baroccianus gr. 142 with Athonensis Vatopedinus graecus $286 .^{64}$

\subsubsection{The ḋ $\pi \grave{\partial} \varphi \omega v \tilde{\eta} \varsigma$ in Baroccianus gr. 142}

The meaning of the expression $\dot{\alpha} \pi \dot{o} \varphi \omega v \tilde{\eta} \varsigma$ occurring in titles of works of various literary genres has long been debated. Yet after M. Richard's article on how the $\alpha \dot{\alpha} \dot{o} \varphi \omega v \tilde{\eta} \varsigma$ should be interpreted by modern scholars, there is not any other contribution to the subject. The French philologist showed, through a significant number of examples, that from the fifth to the eighth centuries the phrase $\dot{\alpha} \pi \dot{o}$ $\varphi \omega v \tilde{\eta} \varsigma$ in most cases precedes the name of a Byzantine professor or grammarian and should consequently be interpreted as 'd'après l'enseignement oral de' or 'pris au cours de' ${ }^{65}$ From the ninth century onwards, by contrast, the $\dot{\alpha} \pi \dot{o} \varphi \omega v \tilde{\eta} \varsigma$ always precedes the name of the author of a work mentioned in the title and it should be interpreted as 'de', 'par', 'selon', 'd'après'. ${ }^{66} \mathrm{M}$. Richard drew attention to titles preceding works covered by the umbrella term compilation literature, as well. He argued that in this sort of writings the $\dot{\alpha} \pi \dot{o} \varphi \omega v \tilde{\eta} \varsigma$ indicates the compiler of the work mentioned in the title. ${ }^{67} \mathrm{M}$. Richard presented as examples

60 According to Nicephorus Callistus Xanthopulos.

61 Hansen (ed.) (1995), XXVII.

62 G. C. Hansen runs counter to G. Gentz's thesis that Nicephorus Callistus drew on a better text than the one preserved in Baroccianus; cf. Hansen (ed.) (1995), XXVII, XXXIII-XXXV; Gentz and Winkelmann (1966), 188-190.

63 E 261, 262, 278, 318, 324, 381; cf. Hansen (ed.) (1995), XXVII.

64 On the excerpts from the Epitome that are missing, see Hansen (ed.) (1995), XXVIII.

65 Richard (1977), 206 and 220. There are a few exceptions though: the expression $\dot{\alpha} \pi \dot{o} \varphi \omega v \tilde{\eta} \varsigma$ in

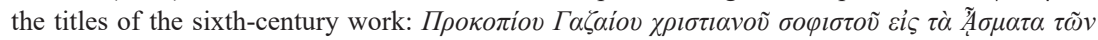

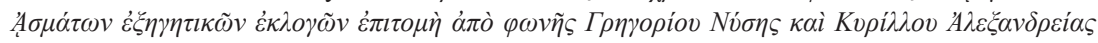

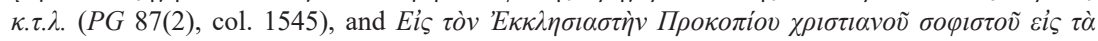

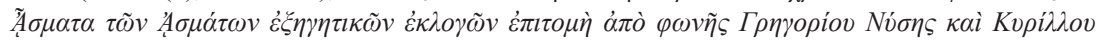
$A \lambda \varepsilon \xi \alpha v \delta \rho \varepsilon i \alpha \varsigma \kappa . \tau . \lambda$. (Devreesse (1928), col. 1163) as well as in the title of the seventh-century

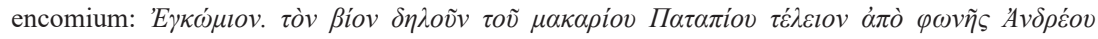

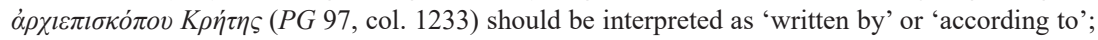
cf. Richard (1977), 197-199 and 205-206.

66 Richard (1977), 222.

67 Richard (1977), esp. 213-217. 


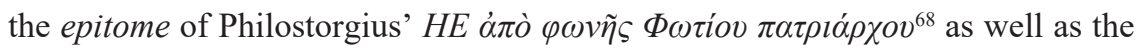

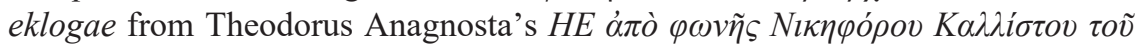
$\Xi \alpha \nu \theta 0 \pi \circ \dot{\lambda} \lambda o v$ written on f. $236 \mathrm{v}$ in Baroccianus gr. 142. Yet, in my view, a distinction should be made between the two aforementioned works. Photius gives a summary of Philostorgius' $H E$ in his Bibliothec ${ }^{69}$ and scholarship has long verified that Photius is the actual compiler of the epitome. On the other hand, we now know that Baroccianus gr. 142 transmits a sylloge of excerpts compiled centuries before Nicephorus Callistus lived, and attested also in three other codices. Nicephorus is not the author of the sylloge. Moreover, the sentence $\dot{\alpha} \pi \dot{\partial} \varphi \omega v \tilde{\eta} \varsigma$

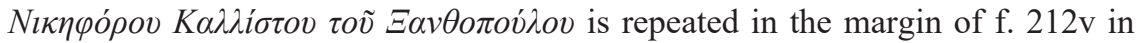

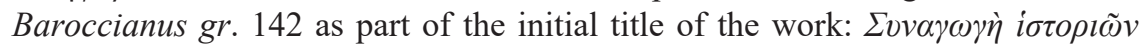

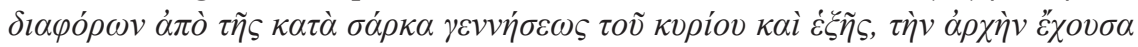

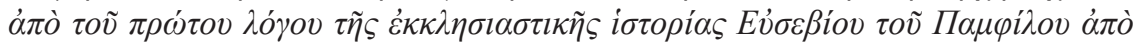

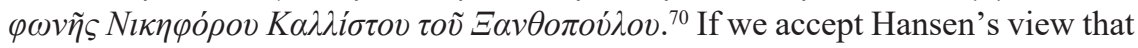
Nicephorus in writing his own chronicle relied on material found in Baroccianus $g r$. 142, the codex is likely to depict an intermediary stage in the preparation of his chronicle. In this case, the $\dot{\alpha} \pi \dot{o} \varphi \omega v \tilde{\eta} \varsigma$ is likely to signify that the so-called Epitome was copied in Baroccianus gr. 142 on Nicephorus' initiative. We cannot be certain, though. It is also likely that Baroccianus $g r$. 142 transmits a version of the Epitome edited by Nicephorus himself. It is noteworthy that Baroccianus gr. 142 and Athonensis Vatopedinus gr. 286 do not always transmit the same order of excerpts or they transmit a different excerpt while excerpting the same source text (see Appendix II: Table VI). The changes may be attributed to Nicephorus Callistus. I should add here that, as shall be shown below (see Section 4.4), the Epitome contains material that was not originally found in the selected passages. The additional material is recorded in all five manuscripts of the Epitome, though. It is not possible to attribute these insertions to Nicephorus. Regarding the insertions that occurred in Baroccianus gr. 142 only, we cannot be certain about the authorship.

To conclude, the interpretation of the $\dot{\alpha} \pi \dot{o} \varphi \omega v \tilde{\eta} \varsigma$ as meaning 'written by' in Baroccianus gr. 142 could be misleading. I would suggest that the rendering 'according to' better signifies the phrase in this case. For Nicephorus was neither the original compiler of the Epitome, nor the rewriter of a new version of it, that would be, a new autonomous text.

\subsection{The Epitome as an excerpt collection}

This seventh-century assemblage has, so far, only received attention for the passages it transmits. Accordingly, the Epitome has always been studied as a source of

68 Philostorgius, $H E, 4$.

69 Bibliotheca, cod. 40.

70 Collection of various accounts running from the Nativity according to the flesh of our Lord and onwards, it begins with the first book of the Ecclesiastical History by Eusebius (the student) of Pamphilus, according to Nicephorus Callistus Xanthopulos. 
the ecclesiastical excerpts included in it. In fact, the Epitome, apart from excerpts from Eusebius, Gelasius, and Philip of Side, preserves significant parts of the so-called $H T$ and the $H E$ by Theodorus Anagnosta, ${ }^{71}$ and excerpts from John Diacrinomenus' $\mathrm{HE}^{72} \mathrm{P}$. Nautin supported that the Epitome is descended from an earlier collection comprising the complete texts of a number of ecclesiastical histories. P. Nautin regarded Theodorus Anagnosta as the author of the aforementioned collection. ${ }^{73}$ Moreover, there appears to have been a consensus amongst P. Nautin, G. Greatrex, and B. Pouderon about the content of that compilation. ${ }^{74}$

The label Epitome assigned to the whole assemblage and its connection with a hypothesised earlier collection by Theodorus Anagnosta mirrors, in my view, the concentration of scholars on the content of the Epitome rather than on the structure and composition of the overall assemblage. Moreover, the designation Epitome for our seventh-century sylloge could be compatible, to a certain extent, with the abridged form of the incorporated texts, but is definitely incompatible, however, with the overall structure of the assemblage, for the so-called Epitome is a typical product of the culture of sylloge. The author of this sylloge constructs a new narrative on the basis of a series of excerpts. The arrangement of the excerpts in the Epitome shows that the compiler had initially devised a chronological framework, which, then, enabled him to place the collected passages. The Epitome makes up a unity of chronologically and thematically connected excerpts extracted from a number of different works and acts as a new and autonomous piece of literature. In the following, I argue that the Epitome is not the synopsis of a compilation made by Theodorus Anagnosta. In my view, the Epitome is an actual sylloge of excerpts created from different and separate sources. To argue this, I shall show that the initial title of the Epitome, as transmitted in the manuscript tradition, must be assigned to the excerptor of the Epitome, and that the structure and the format of the Epitome explain the origin of the actual sylloge.

To begin with, the Epitome itself transmits its material under the following titles.

For the headings in the manuscript transmission of the Epitome, please see Table 4.1.

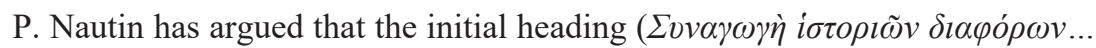

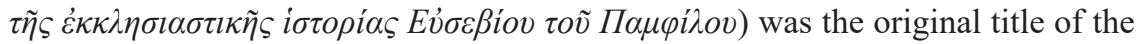
collection put together by Theodorus Anagnosta, which, in Nautin's view, is the

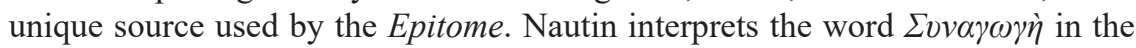

71 On the relationship between Theodorus Anagnosta and the compiler of the Epitome, see Greatrex (2014b), 121-142 and Nautin (1994) esp. 224-226, 233-238.

72 Blaudeau (2001), 76-97.

73 Nautin (1994), 213-243.

74 In P. Nautin's view, the compilation comprised the $H E$ by Eusebius of Caesarea with the addition of the history by Gelasius of Caesarea, the so-called HT (a compilation by Theodorus Anagnosta based on the histories by Socrates, Sozomen, and Theodoret) and the HE by Theodorus Anagnosta covering the period 439-518 AD; cf. Nautin (1994), 218-224 and 229-30; Greatrex (2014b), 10-11; Pouderon (1998), 170-171. On the HT, see Blaudeau (2006), 518; Treadgold (2007), 170. 
Table 4.1 The headings in the manuscript transmission of the Epitome

\begin{tabular}{|c|c|c|}
\hline Manuscript & Heading & Excerpts \\
\hline $\begin{array}{l}\text { Ath. Vat. } 286 \text { and } \\
\text { Barocc. } g r . \\
142\end{array}$ & 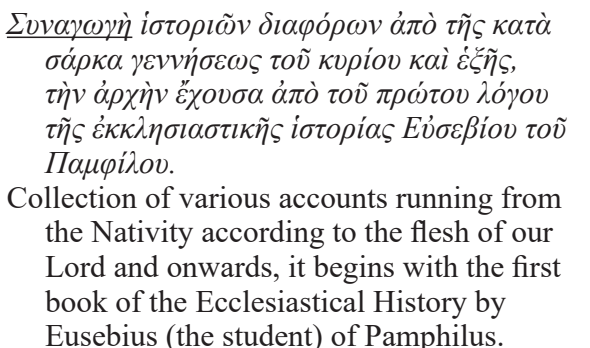 & $\begin{array}{c}\text { Eusebius, } H E \text { and } \\
\text { Gelasius, } H E\end{array}$ \\
\hline Barocc. gr. 142 & 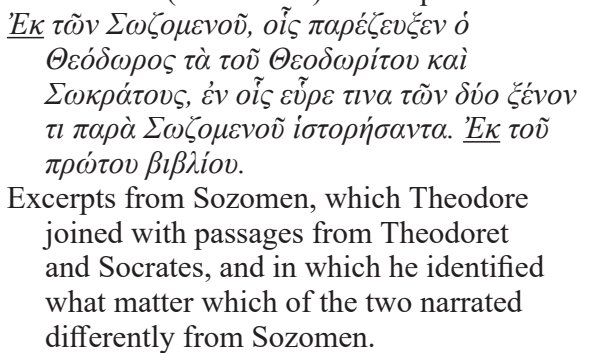 & $\begin{array}{l}\text { Theodorus Anagnosta, } \\
\qquad H T\end{array}$ \\
\hline Barocc. gr. 142 & 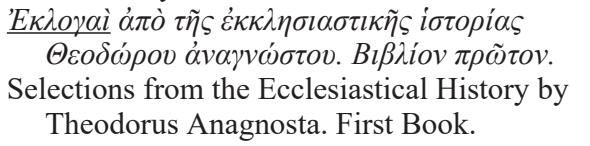 & $\begin{array}{l}\text { Theodorus Anagnosta, } \\
\qquad H E\end{array}$ \\
\hline $\begin{array}{l}\text { Parisinus suppl. } \\
\quad \text { gr. } 1156\end{array}$ & 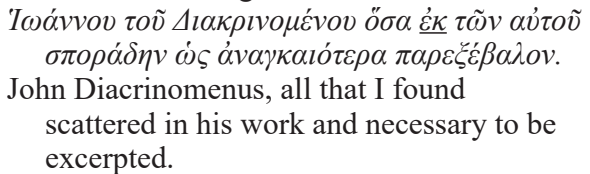 & $\begin{array}{l}\text { John Diacrinomenus, } \\
\quad H E\end{array}$ \\
\hline Auctarium E.4.18 & 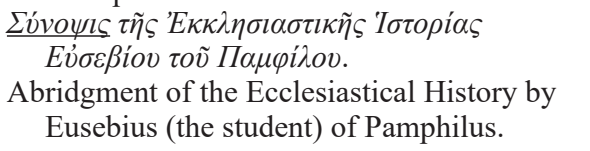 & Eusebius, $H E$ \\
\hline
\end{tabular}

title as the gathering and arrangement of complete historical texts, the first of which was the $H E$ by Eusebius of Caesarea. P. Nautin believes that Theodorus included Eusebius' entire work in a collection because (a) Theodorus refers to a similar intention of compiling a collection of complete ecclesiastical histories in the surviving prologue to his own $H E,^{75}$ (b) Theodorus mentions Eusebius of Caesarea in the preface, shortly before mentioning Socrates, Sozomen, and Theodoret, and

75 The prologue has been handed down to us through the codex Marcianus gr. 344, ff. 1-13; Hansen (ed.) (1995), 1. The codex, in fact, transmits only Books 1 and 2 of what is known as the Historia Tripartita. 
(c) excerpts from the HT, nominally assigned to Theodorus Anagnosta, are part of the Epitome as well. ${ }^{76}$

Nevertheless, Theodorus' $H E$ does not begin with Eusebius (as the Epitome does) but with Theodorus' HT. In addition to this, the prologue in the codex

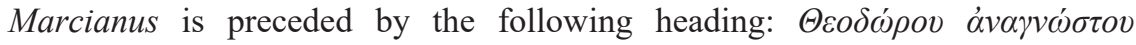

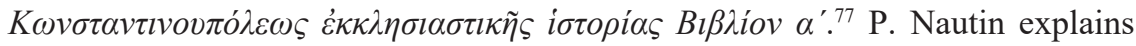
these inconsistencies by surmising the existence of two manuscripts for the entire hypothetical Theodorus' collection; one containing Eusebius' work and one containing the rest of the collection.

I would like to note that there is no such reference to Eusebius of Caesarea in the preface implying that Theodorus included Eusebius' work in a collection. ${ }^{78}$ On the contrary, Theodorus' use of the term $\sigma v v^{\prime} \tau \alpha \xi i v$ in identifying both his own and Eusebius' history in the prologue, shows that Theodorus regards himself as a continuator of Eusebius, not only in terms of content but in method and literary format, as well. ${ }^{79}$ The term $\sigma v v \tau \alpha \xi \xi \varsigma$ stresses the creation of a structure out of the collected sources. Theodorus, at this point, reveals his method in compiling his own history. Furthermore, Eusebius' excerpts in the Epitome are followed by passages from Gelasius. ${ }^{80}$ Theodorus does not mention Gelasius in his prologue. If Theodorus had really composed a collection comprising a number of ecclesiastical histories, he should also have mentioned Gelasius as one of Eusebius' continuators. $^{81}$

The title in Marcianus confirms that Theodorus was the author of the $H E$ and the content of Marcianus bears out that the $H T$ was part of it. ${ }^{82}$ The excerpts from

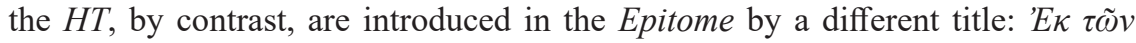
$\Sigma \omega \zeta o \mu \varepsilon v o \tilde{v}, \ldots \tau \imath \pi \alpha \rho \dot{\alpha} \Sigma \omega \zeta o \mu \varepsilon v o \tilde{v}$ i $\sigma \tau o \rho \dot{\eta} \sigma \alpha \nu \tau \alpha{ }^{83}$ And the excerpts from the $H E$ are

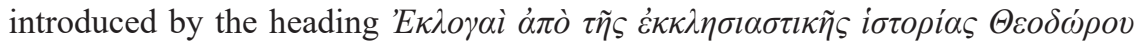
$\dot{\alpha} v \alpha \gamma v \omega ́ \sigma \tau o v .{ }^{84}$ The very last fact means that the compiler of the Epitome draws on two different sources when extracting Theodorus' $H T$ and $H E$, respectively. This could also be an indication that the two parts of the work circulated at some point independently from one another.

76 Nautin (1994).

77 The Ecclesiastical History by Theodorus anagnosta in Constantinople. First Book.

78 Delacenserie (2016), 70-75.

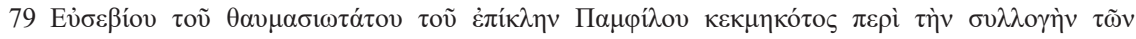

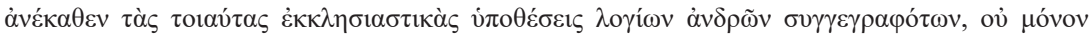

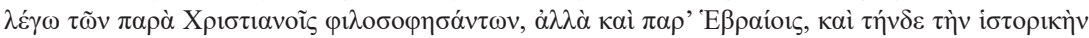

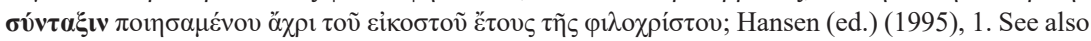
the translation of the passage in Delacenserie (2016), 69-70.

80 There is a disagreement as to the authorship of these excerpts; see Van Nuffelen (2002). See also Section 4.4.

81 Delacenserie (2016), 70-75.

82 The existence of the title in the prologue signifies according to Nautin that Theodorus did not write a continuation to the work of an earlier historian; Nautin (1992), 164-170.

83 Baroccianus gr. 142, f. $216 \mathrm{v}$.

84 Baroccianus gr. 142, f. 236v. 
P. Nautin also supported the idea that Book 1 of Theodorus' HE in the Epitome corresponds to Book 5 of the original $H E$ by Theodorus. With regard to this proposition of Nautin's, I have two points to make: (a) Theodorus does not himself name any Book 5 in his $H E$ and (b) even if we accept Nautin's argument, the fact that Book 5 of the $H E$ occurs as Book 1 in the manuscript transmission of the Epitome once again bears out the evidence that the excerptor of the latter must have relied on two different sources. Each source contained only one of the two texts.

Accordingly, the Epitome is made up of collections of selections. One should

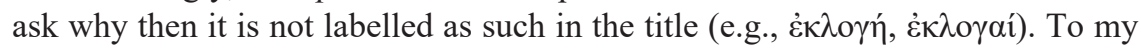
mind, the initial title in the Epitome transmitted in the codices Baroccianus gr.

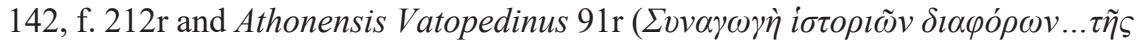

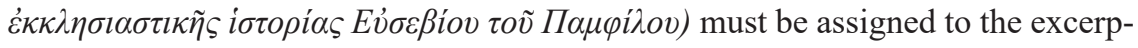
tor. For the term $\sigma v v \alpha \gamma \omega \gamma \dot{\eta}$ itself entails the notions of $\sigma v \lambda \lambda \sigma \gamma \dot{\eta}$ and $\dot{\varepsilon} \kappa \lambda \sigma \gamma \dot{\eta}$. In fact, $\sigma v v \alpha \gamma \omega \gamma \dot{\eta}$ points to the organisation of material accumulated ( $\sigma v \lambda \lambda \sigma \gamma \dot{\eta})$ through the process of selection ( $\dot{\varepsilon} \kappa \lambda \sigma \gamma \dot{\eta})$. The term $\sigma v v \alpha \gamma \omega \gamma \dot{\eta}$ fits in with the manner by which knowledge is transmitted through our text. ${ }^{85}$

The crucial question to be raised should be as to why the term epitome should be assigned to the title of the work by contemporary scholars. In its first edition by

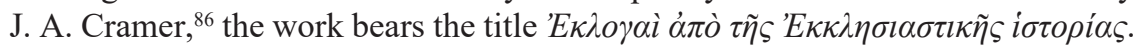
In fact, as we have seen, in the Byzantine period, the term identified collections of selections. ${ }^{87}$ In the case of the so-called Epitome, we have nothing less than a conflation of selected passages, such as in John Chrysostom's and Sopater's case. The use of the words $\sigma v v \alpha \gamma \omega \gamma \dot{\eta}, \sigma v \lambda \lambda o \gamma \dot{\eta}$, and $\dot{\varepsilon} \kappa \lambda \sigma \gamma \dot{\eta}$ by the Byzantines was discussed in Chapter 1. Here I will confine myself to noting that the examination of the headings preserved in the manuscript tradition of the Epitome of the Seventh Century points to the method applied by the compiler. The Epitome of the Seventh Century, is an $\dot{\varepsilon} \kappa \lambda \sigma \gamma \dot{\eta}$, or a $\sigma v \lambda \lambda o \gamma \dot{\eta}$ or a $\sigma v v \alpha \gamma \omega \gamma \dot{\eta}$ of different sources through the process of abridgement. The vocabulary transmitted in the headings ( $\Sigma v v \alpha \gamma \omega \gamma \dot{\eta}$, $\left.\dot{\varepsilon} \kappa \tau \tilde{\omega} v,{ }^{\prime} E \kappa \lambda o \gamma \alpha i\right)$ is identical to the one seen in the syllogae catalogued by Photius as well as in a significant number of works compiled on the basis of excerpts. ${ }^{88}$ Additionally, the excerpts from Eusebius were arranged under subheadings that indicate which book of the $H E$ each series of excerpts was taken from: $\dot{\varepsilon} \kappa$ $\tau o \tilde{v}$

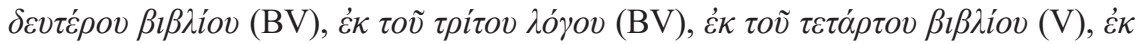

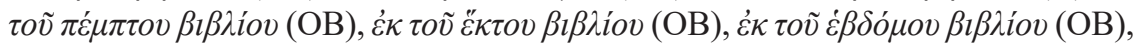

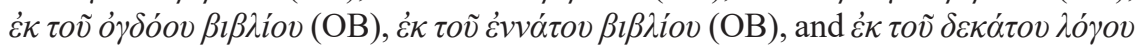
(OB). The subheadings hint at the selection of a number of passages to be embedded into the Epitome. The same holds true for a subheading introducing passages

85 See also Section 1.1.1.

86 Cramer (1839), 87-114.

87 See Chapter 1.

88 Odorico (2011a). 
from John Diacrinomenus in Baroccianus gr. 142. As already noted, the excerpts from John Diacrinomenus are preceded by a title only in Parisinus gr. 1555a. Nevertheless, a marginal note on f. 239v in Baroccianus gr. 142 reads as follows:

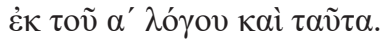

To conclude, the compiler of the sylloge put together excerpts selected from different sources, namely from Eusebius' work, Gelasius' history, a source only containing the first part of Theodorus' HE (i.d. Historia Tripartita), another source only containing the second part of Theodorus' $H E$, John Diacrinomenus' $H E$, and an unidentified chronicle (i.d. the anonymous series of excerpts). The text should be seen as a product of the culture of sylloge. The Epitome is an example of literature compiled by processes of compilation. In what follows, I shall discuss the structure of the Epitome as it is transmitted in the five extant manuscripts.

\subsection{The structure of the Epitome}

It has become clear by now that it is impossible to arrive at any definite conclusion as to the size of the original Epitome. The data provided by the content of the five manuscripts transmitting parts of the Epitome are shown in Table 4.2.

Table 4.2 The Epitome in the five extant manuscripts

\begin{tabular}{|c|c|c|c|c|c|}
\hline Epitome & $\begin{array}{l}\text { Parisinus } \\
\text { suppl. gr. } \\
1156\end{array}$ & $\begin{array}{l}\text { Parisinus } \\
\text { gr. } 1555 a\end{array}$ & $\begin{array}{l}\text { Athonensis } \\
\text { Vatopedinus } \\
\text { graecus } 286\end{array}$ & $\begin{array}{l}\text { Baroccianus } \\
\text { gr. } 142\end{array}$ & $\begin{array}{l}\text { Auctarium } \\
\text { E.4.18 }\end{array}$ \\
\hline $\begin{array}{l}\text { Excerpts from } \\
\text { Eusebius' } H E\end{array}$ & & ff. $7 r-9 v$ & ff. $91-108$ & ff. $212 r-216 r$ & ff. $136 \mathrm{r}-143 \mathrm{v}$ \\
\hline $\begin{array}{l}\text { Excerpts from } \\
\text { Gelasius' } H E\end{array}$ & & f. $9 v$ & ff. $108 \mathrm{r}-108 \mathrm{v}$ & ff. $216 \mathrm{r}$ & \\
\hline $\begin{array}{l}\text { Excerpts from } \\
\text { Philip of } \\
\text { Side's Historia } \\
\text { christiana }\end{array}$ & & & & ff. $216 \mathrm{r}-216 \mathrm{v}$ & \\
\hline $\begin{array}{l}\text { Excerpts from the } \\
\qquad H T\end{array}$ & & ff. $9 \mathrm{v}-15 \mathrm{v}$ & ff. $108 \mathrm{v}-201 \mathrm{r}$ & ff. $216 \mathrm{v}-224 \mathrm{r}$ & \\
\hline $\begin{array}{l}\text { Excerpts from } \\
\text { Theodorus } \\
\text { Anagnosta's } \\
H E\end{array}$ & ff. $26 \mathrm{r}-27 \mathrm{r}$ & ff. $15 \mathrm{v}-20 \mathrm{r}$ & ff. $201 r-218 v$ & ff. $236 \mathrm{v}-239 \mathrm{v}$ & \\
\hline $\begin{array}{l}\text { Excerpts } \\
\text { from John } \\
\text { Diacrinomenus' } \\
H E\end{array}$ & ff. $28 \mathrm{r}-29 \mathrm{v}$ & f. $20 \mathrm{r}$ & & ff. $239 \mathrm{v}-240 \mathrm{r}$ & \\
\hline $\begin{array}{l}\text { Anonymous series } \\
\text { of excerpts }\end{array}$ & & ff. $20 v-21 v$ & & & \\
\hline
\end{tabular}


The Epitome as it has been handed down in the Parisinus gr. 1555a comes immediately after excerpts from Flavius Josephus' Antiquitates Judaicae (ff. $5 \mathrm{v}-7 \mathrm{r}$ ). Interestingly, a similar sequence occurs in another manuscript transmitting the Epitome, namely Baroccianus gr. 142. Ff. 205v-211r of Baroccianus gr. 142 contain excerpts from Flavius Josephus' Antiquitates Judaicae and Vita. ${ }^{89}$ Nevertheless, Josephus should not be taken as part of the original Epitome: the excerpts from Josephus in Parisinus gr. 1555a are preceded by the name:

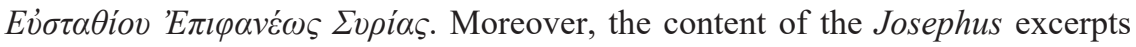
has nothing to do with the chronological arrangement of the excerpts of the Epitome. ${ }^{90}$

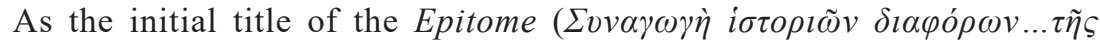

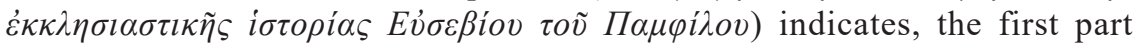
of the sylloge consisted of excerpts from Eusebius' $H E$. De Boor was the first to notice that excerpts from Eusebius had been supplemented with texts not originally derived from his $H E$. De Boor published his findings in an article in $1888 .{ }^{91}$ The concatenation of excerpts from Eusebius' $H E$ shall be discussed in detail in Section 4.4. The Eusebian part is followed by excerpts, the attribution of which to Gelasius of Caesarea is disputed. To begin with, de Boor argued that the excerpts which come immediately after Eusebius in the Epitome must be assigned to the Historia christiana by Philip of Side. ${ }^{92}$ P. Nautin and G. C. Hansen supported that the text must be assigned to Gelasius of Caesarea (fourth c.). ${ }^{93}$ By contrast, P. Van Nuffelen argued that the series of excerpts ensuing Eusebius in the Epitome is, originally, derived from an author of the fifth century. Van Nuffelen runs counter to the traditional view that Gelasius of Caesarea wrote a church history, which then served as unacknowledged source for Rufinus and Socrates. Van Nuffelen, by contrast, showed that the extant excerpts in the Epitome must postdate Rufinus and Socrates and are thus wrongly attributed to Gelasius. ${ }^{94}$ The excerpts from the text of the so-called ps.-Gelasius are not preceded by any heading in the manuscript transmission of the Epitome. As noted, in Baroccianus gr. 142, ps.-Gelasius is supplemented with a passage from Philip of Side. ${ }^{95}$ It is impossible to say if this passage was the only one

89 The two works, which survive complete, were edited in Niece (1887-1890) and Niece (repr. 1955), 321-389, respectively.

90 The same in Hansen (ed.) (1995), XXVII.

91 De Boor (1888), 169-171. The additions were republished in Nautin (1994), 219-220.

92 De Boor (1888), esp. 173.

93 Nautin (1992),163-183; Hansen (ed.) (1995), XXXVIII. De Boor published first the passages; de Boor (1888), 182-184. P. Nautin published the Greek text with a French translation; Nautin (1992), 174-178. See also the edition of the excerpts by Hansen (1995), 158-159. The latest edition of the extant fragments of Gelasius is by Wallraff, Marinides, and Stutz (2017).

94 Van Nuffelen (2002), 621-640.

95 See Section 4.1.5. The excerpt was published by Hansen (ed.) (1995), 160. 
excerpted from Philip of Side in the Epitome. ${ }^{96}$ The excerpt in Baroccianus

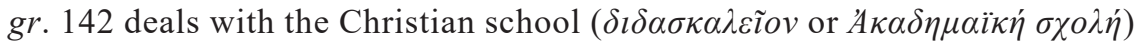
of Alexandria. The passage names the prominent figures that taught at the school during the first centuries of Christianity. Philip of Side is followed by excerpts from Theodorus Anagnosta's $H T$ and $H E$. The excerpts, which are introduced by two different headings in Baroccianus gr. 142, appear to have been excerpted from two distinct sources. ${ }^{97}$ The excerpts from the $H E$ are augmented with passages taken from the $H E$ by John Diacrinomenus. The Athonensis Vatopedinus graecus 286 does not contain any passages from John Diacrinomenus. The codex ends the arrangement of excerpts abruptly

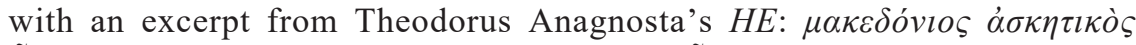

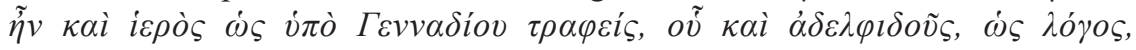
$\dot{v} \pi \tilde{\eta} \rho \chi \varepsilon v .^{98}$ The last part of the Epitome comprises a series of 18 anonymous excerpts which, chronologically, bring the sylloge down to the year 610 . These excerpts were published by Cramer. ${ }^{99}$ Excerpt 16 lists the popes from Vigilius to Boniface IV. ${ }^{100}$ The latter was Pope from 25 September 608 to his death in 615 .

For G. C. Hansen's edition of the Epitome, see Table 4.3.

\subsection{The Epitome and the $H E$ of Eusebius of Caesarea}

The manuscript transmission of the Epitome only leaves space for speculation about the accurate content of it. Nothing can be safely said about how much of the genuine collection has been handed down to us. Yet by combining the extant excerpts of the assemblage in the five codices, we can come to a number of verifiable conclusions about the structure, composition, and function of it. The focus of this section relies on the use of Eusebius' $H E$ by the seventh-century Epitome. Regardless of how much more Eusebian excerpts were initially included in the Epitome, the textual transmission of the sylloge permits us to study and explore the working method of the excerptor and the function of the sylloge. In what follows, I put forward what the transmission of the Eusebian excerpts reveals as to a) the relationship of the manuscripts of the Epitome, b) the textual additions by the compiler, and c) the working method applied in the sylloge.

96 The attribution of the excerpt to Philip of Side has been affirmed in Pouderon (1994) and Heyden (2006), esp. 214-215.

97 See Section 4.2. In Athonensis Vatopedinus graecus 286 the excerpts from the $H E$ come after those from the $H T$ without any distinctive sign.

98 This is Excerpt E 458 in the edition by G. C. Hansen.

99 Cramer (1839), 109, 26-111, 31.

100 Cramer (1839), 111, 20-23. 


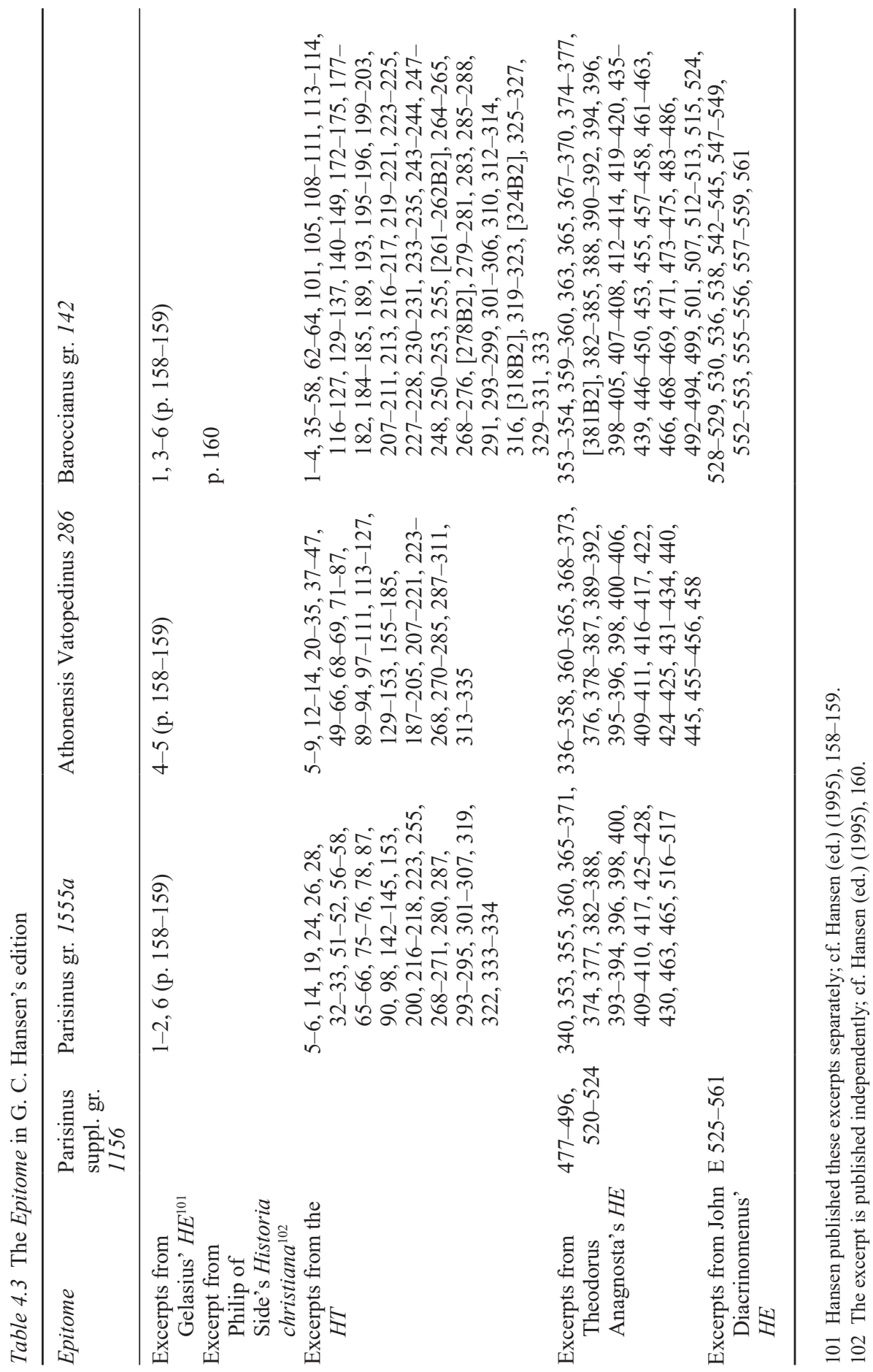




\subsubsection{The relationship between the manuscripts of the Epitome}

According to P. Nautin, Baroccianus gr. 142 (B) as well as Athonensis Vatopedinus graecus $286(\mathrm{~V})$ depend on a common copy of the Epitome, different from the one that Parisinus gr. 1155a (P) and Parisinus supp. gr. 1156 (M) descended from. ${ }^{103}$ Although Nautin republished the passages of several lost patristic authors inserted within the series of excerpts from Eusebius' $H E$, he strikingly neglected Auctarium E.4.18 (O), a significant witness of the first part of the so-called Epitome. ${ }^{104}$ Hansen's view deviates partially from Nautin's: Hansen indicates the common source of $\mathrm{B}$ and $\mathrm{V}$ as $\beta$. Yet, he found some common readings between BV and P. In Hansen's view, the similarities could be explained by the existence of the version $\alpha$, which both $\beta$ and $\mathrm{P}$ (and its prototype $\mathrm{M}$ ) come from. Hansen appears to be aware of the importance of $\mathrm{O}$ in the reconstruction of the Eusebian part of the Epitome ${ }^{105}$ yet his edition excludes the Eusebian part and his study of the relationship between the manuscripts of the Epitome is only based on BVP and M. As I shall show, though the textual comparison of the Eusebian excerpts of the Epitome provides us with a more complicated picture, it verifies Hansen's view.

The Epitome as preserved in P transmits 18 excerpts from Eusebius' work, covering chronologically the period from Christ's birth down to the reign of Maximinus II Daia (311-313 ad). In the present state of $\mathrm{M}$, the prototype of $\mathrm{P}$ for Theodorus Anagnosta's $H E$ and John Diacrinomenus' $H E$, the Eusebian excerpts are missing. $\mathrm{O}, \mathrm{B}$, and $\mathrm{V}$ add a significant number of excerpts. ${ }^{106} \mathrm{O}$, as mentioned, is missing a significant number of folia that originally must have contained extracted passages from Eusebius. The Epitome as preserved in $\mathrm{O}$ transmits 67 excerpts from Eusebius, covering chronologically the period from Christ's birth down to Constantine's victories against the emperors Maxentius and Licinius. B and V cover the same time span. B contains 97 excerpts from Eusebius whereas V transmits 74 Eusebian excerpts in total. ${ }^{107}$ In what follows, I shall look into the Eusebian excerpts preserved in OPBV. In nine cases, the four codices transmit a common excerpt from Eusebius' work. ${ }^{108}$ The numbering of excerpts is that given in my edition of the entire first part of the Epitome in the appendix (Appendix I: Text V) of the book.

a) O transmits the following significant mistakes: E 6,5; $\psi \varepsilon v \delta \tilde{\eta}$ VB: $\psi \varepsilon v \delta \tilde{\omega} v$

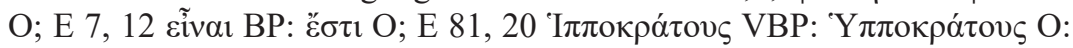

103 Nautin (1994), 213-214.

104 Nautin, (1994), 219-221.

105 Hansen (ed.) (1995), XXXVII.

106 A few of these fragments have been published by de Boor and Nautin; de Boor (1888), 169-171; Nautin 1994. 219-221. See also below Section 4.2.

107 On the common passages in the three codices, see Appendix II: Table VI.

108 These are Excerpts: 1, 6, 7, 81, 103, 110, 111, 117, and 118. In 31 cases an excerpt is only contained in B and V. In four cases an excerpt is only transmitted in P and B. In a single case, an excerpt is only preserved in $\mathrm{P}$ and $\mathrm{O}$. In 15 cases an excerpt is only preserved in $\mathrm{O}$ and $\mathrm{B}$ and in eight cases an excerpt is found only in $\mathrm{O}$ and $\mathrm{V}$. Most of the variants are orthographical mistakes that occurred in $\mathrm{P}$. The different readings are found in the apparatus of the edition of the excerpts in the Appendix I: Text V. 


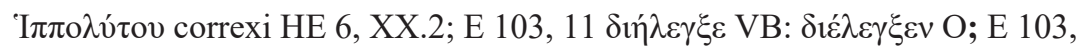

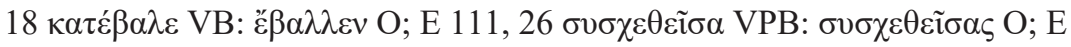

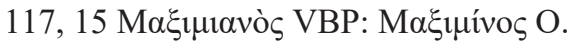

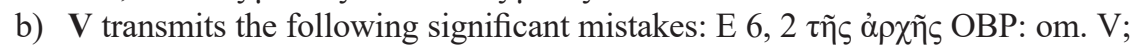

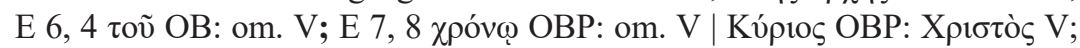

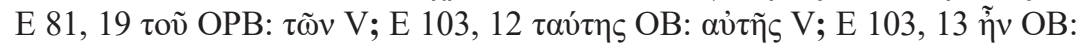

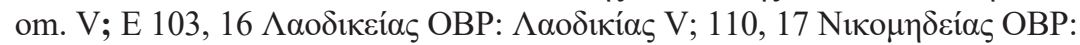

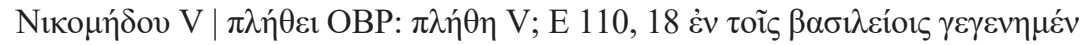

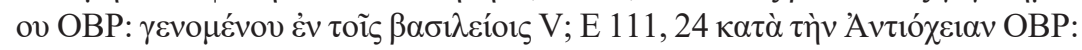

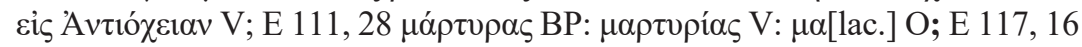

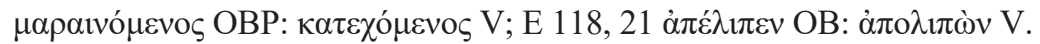

c) B transmits the following significant mistakes: E 1, $4 \mu \beta^{\prime}$ OVP: $\mu \alpha^{\prime}$ B; E 1, $7{ }^{\prime} \theta^{\prime}$

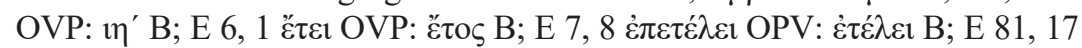

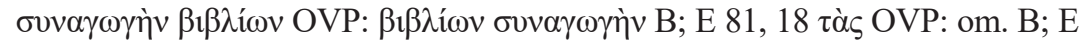

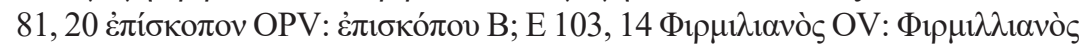

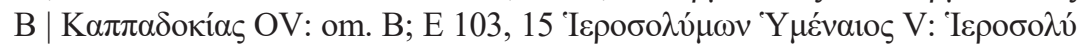

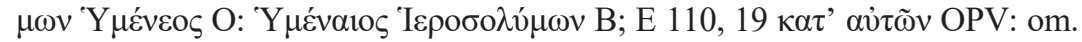

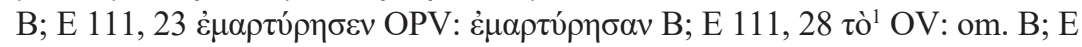

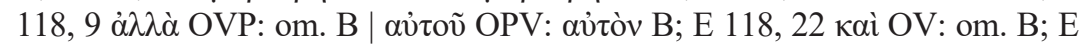

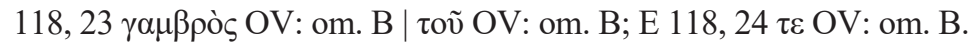

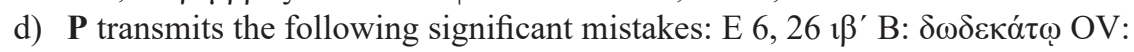
$\delta \dot{\varepsilon} \delta \varepsilon \kappa \alpha ́ \tau \omega \mathrm{P}$

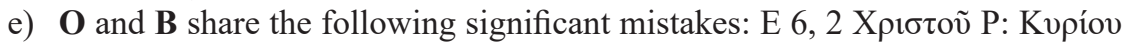

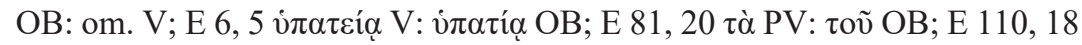
$\dot{\varepsilon} \mu \pi \rho \eta \sigma \mu о \tilde{~ P V: ~} \dot{\varepsilon} \mu \pi \nu \rho \imath \sigma \mu о \tilde{~ O B . ~}$

f) OV share the following significant mistakes: 103, 17 cíoív BP: cíoí OV; 103,

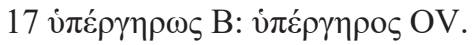

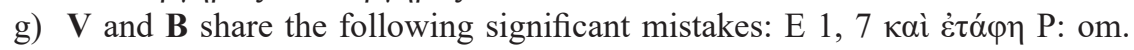

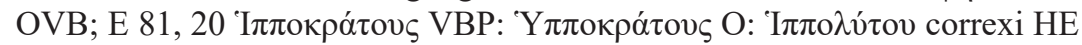
6, XX.2

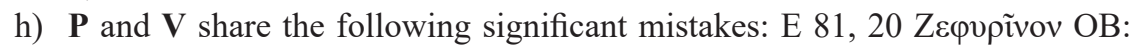

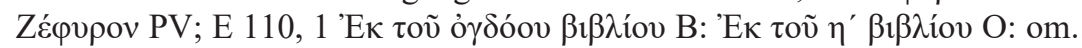

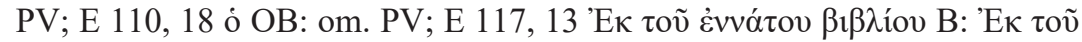

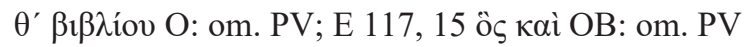

The results of the comparison between the shared passages in $\mathrm{O}, \mathrm{V}, \mathrm{B}$, and $\mathrm{P}$ can be summed up as follows: we identify: a) ten instances in which OBP have a common reading against $\mathbf{V}$, b) 11 instances in which OVP have a common reading against $\mathbf{B}, \mathbf{c}$ ) three instances in which $\mathbf{B V P}$ have a common reading against $\mathbf{O}$, and d) one instance in which $\mathbf{O B V}$ have a common reading against $\mathbf{P}$. The aforementioned results do not verify Nautin's view that $\mathbf{B}$ and $\mathbf{V}$ are copies from a template different from the one that $\mathbf{P}$ comes from. Hansen's view of the existence of a version of the Epitome, $(\boldsymbol{\alpha})$, used by the prototype of $\mathbf{B}$ and $\mathbf{V}$, namely $(\boldsymbol{\beta})$, as well as by the prototype of $\mathbf{P}$ seem to be more tenable.

The stemma in Hansen's view is as follows (Figure 4.1). 


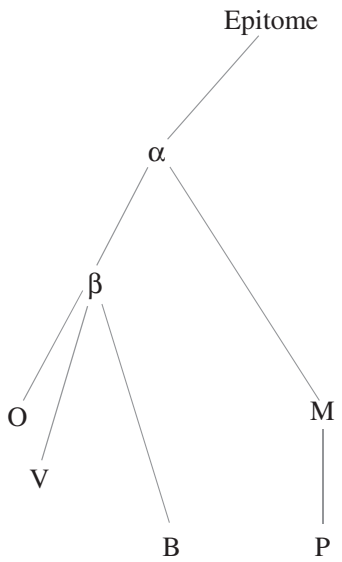

Figure 4.1 The relationship between the manuscripts of the Epitome.

\subsubsection{Passages added to the selected Eusebian text}

The study of the Eusebian passages in O, V, B, and P confirms de Boor's discovery, namely that the excerpts from Eusebius transmitted in the Epitome include material that is not originally found in Eusebius' $H E{ }^{109}$ Table 4.4 contains all the passages written by the compiler himself and added to the selected Eusebian text. As already mentioned, a number of these passages have already been edited by de Boor by relying on B. Nautin's republished de Boor's edition and he compared it with the text transmitted in $\mathrm{V}$ and $\mathrm{P}$. He also accompanied the Greek text with a translation in French. Yet Stevens, who recognised the significance of $\mathrm{O}$ with regard to the Eusebian part of the Epitome, provided a new and slightly expanded edition of de Boor's edition. ${ }^{110}$ De Boor's catalogue of excerpts includes Excerpts $5(\mathrm{O})=5(\mathrm{~B}) ; 12(\mathrm{~B}) ; 31(\mathrm{~B})=26(\mathrm{~V})=4(\mathrm{P}) ; 36(\mathrm{~B})=30(\mathrm{~V})=5(\mathrm{P}) ; 39(\mathrm{~B})=$ $33(\mathrm{~V}) ; 46(\mathrm{~B}) ; 47(\mathrm{~B})=38(\mathrm{~V}) ; 48(\mathrm{~B}) ; \mathrm{O} 47=84(\mathrm{~B})$ and $85(\mathrm{~B})$. Stevens added two more passages: $52(\mathrm{O})=60 \mathrm{~V}$ and $66(\mathrm{O})=97(\mathrm{~B})=73(\mathrm{~V})$. I augment his selection here by adding even more passages that must have been excerpted from a source other than Eusebius' $H E$. The additional material must be attributed to the excerptor of the Epitome, since the insertions are similar to those that occurred throughout all the source texts of the Epitome. ${ }^{111}$ The excerptor inserts into his source texts information on writings that Eusebius does not mention himself.

109 De Boor (1888), 167-184.

110 Stevens, (2018), esp. 635-639.

111 G. C. Hansen points out that though Theodorus Anagnosta rarely makes changes in his source texts (Theodoret, Socrates, and Sozomen), the excerptor of the Epitome, by contrast, intervenes in Theodorus' text more actively by adding data on a number of canons and epistles; Hansen (ed.) (1995). 
Table 4.4 Passages added to the selected Eusebian text

\begin{tabular}{|c|c|c|c|c|c|}
\hline Epitome & $(O)$ & (B) & $(V)$ & $(P)$ & \\
\hline Exc. 1 & Exc. 1 & Exc. 1 & Exc. 1 & Exc. 1 & 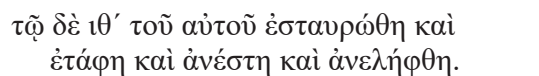 \\
\hline Exc. 5 & & Exc. 5 & & & 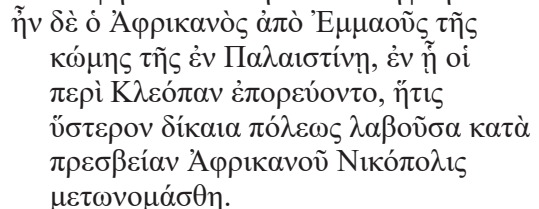 \\
\hline Exc. 6 & Exc. 6 & Exc. 6 & Exc. 3 & Exc. 2 & 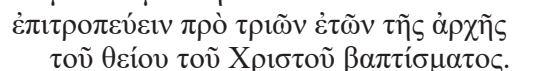 \\
\hline Exc. 7 & Exc. 7 & Exc. 7 & Exc. 3 & Exc. 3 & 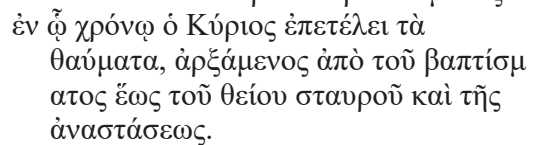 \\
\hline Exc. 7 & Exc. 7 & Exc. 7 & & Exc. 3 & 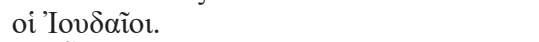 \\
\hline Exc. 7 & Exc. 7 & Exc. 7 & & Exc. 3 & 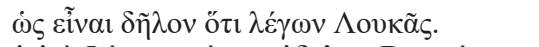 \\
\hline Exc. 8 & & Exc. 8 & Exc. 4 & & 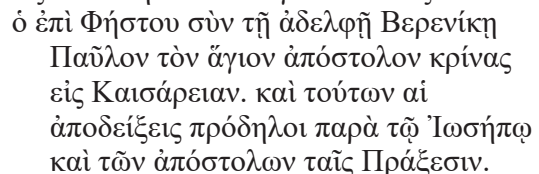 \\
\hline Exc. 10 & & Exc. 10 & Exc. 7 & & \\
\hline Exc. 11 & & Exc. 11 & Exc. 8 & & 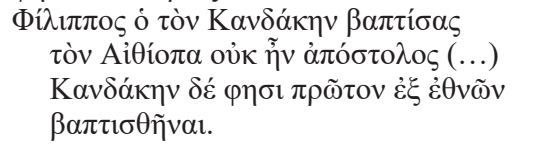 \\
\hline Exc. 12 & & Exc. 12 & & & 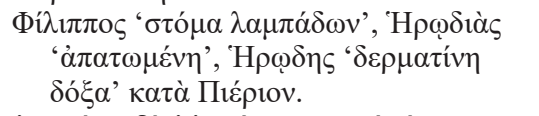 \\
\hline Exc. 33 & & Exc. 31 & Exc. 26 & Exc. 4 & 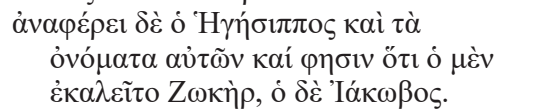 \\
\hline Exc. 33 & & Exc. 31 & & & 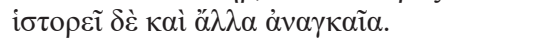 \\
\hline Exc. 38 & & Exc. 36 & Exc. 30 & Exc. 5 & 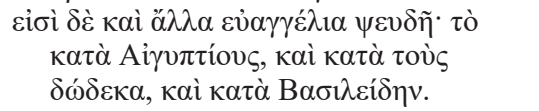 \\
\hline Exc. 39 & & Exc. 37 & & Exc. 6 & 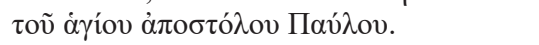 \\
\hline Exc. 42 & & Exc. 39 & Exc. 33 & & 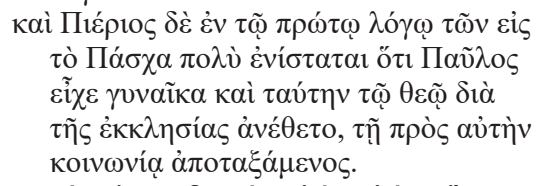 \\
\hline Exc. 49 & & Exc. 46 & & & 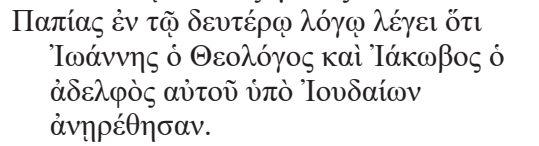 \\
\hline
\end{tabular}


Table 4.4 (Continued)

\begin{tabular}{llll}
\hline Epitome $(O)$ & $(B)$ & $(V)$ & $(P)$
\end{tabular}

$\begin{array}{ll}\text { Exc. } 51 \quad \text { Exc. } 48 & 0\end{array}$

Exc. 47 Exc. 38

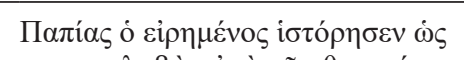

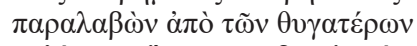

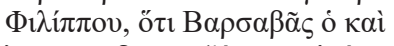

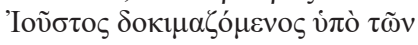

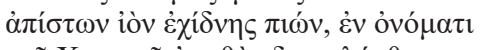

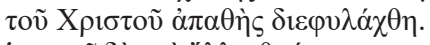

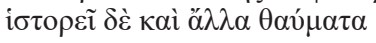

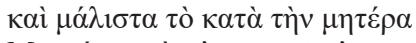

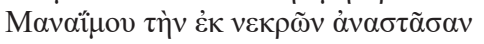

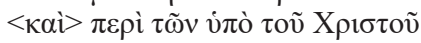

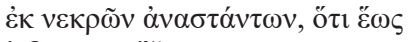

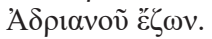

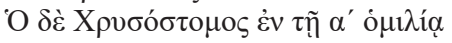

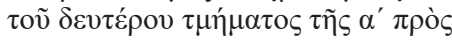

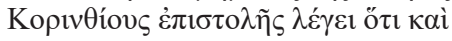

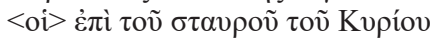

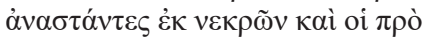

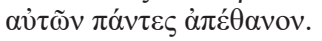

$\begin{array}{ll}\text { Exc. } 52 & \text { Exc. } 49 \\ \text { Exc. } 58 & \text { Exc. } 53 \\ \text { Exc. } 67 & \text { Exc. } 62\end{array}$

Exc. 69 Exc. 9

Exc. 77 Exc. 10

Exc. 78 Exc. 17

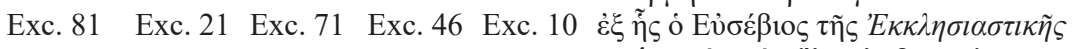

Exc. 83 Exc. 23 Exc. 73

$\begin{array}{lll}\text { Exc. } 91 & \text { Exc. } 31 & \text { Exc. } 77\end{array}$

Exc. 98 Exc. 39

Exc. 106 Exc. 45

Exc. 108 Exc. 47 Exc. 84
Exc. 44

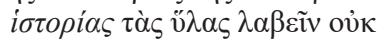
ทे

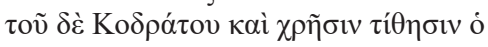

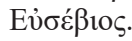

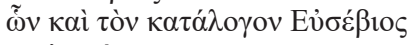

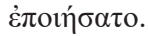

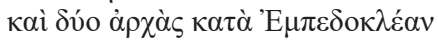

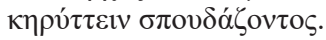

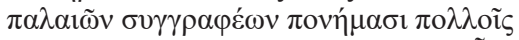

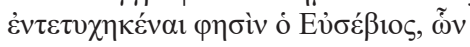
$\tau \grave{\alpha} \mu \grave{\varepsilon} v$ ỏvo $\mu \alpha \sigma \tau \grave{\alpha} \alpha \eta \rho i ́ \theta \mu \eta \sigma \varepsilon v \cdot \tau \grave{\alpha} \delta \grave{\varepsilon}$

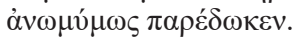

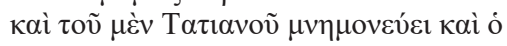

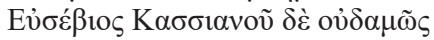

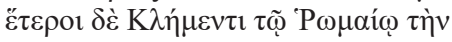

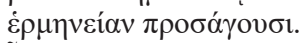

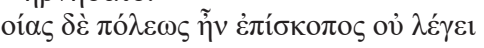
Eủøéßios.

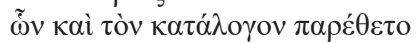

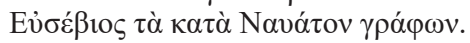

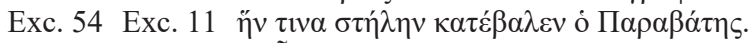

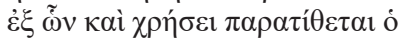

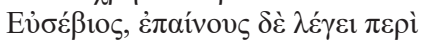

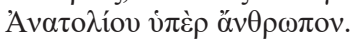

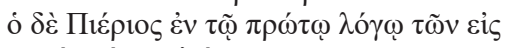

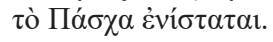


Table 4.4 (Continued)

\begin{tabular}{llll}
\hline Epitome $(O)$ & $(B)$ & $(V)$ & $(P)$
\end{tabular}

Exc. 108 Exc. 47 Exc. 85

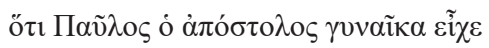

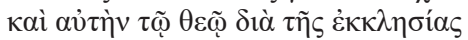

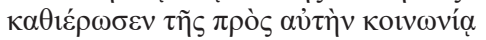

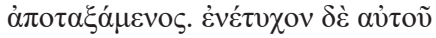

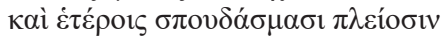

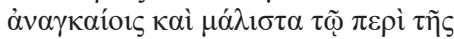

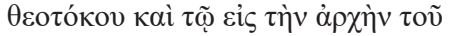

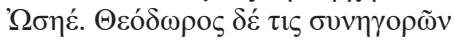

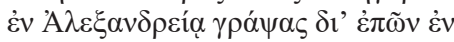

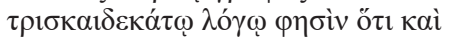

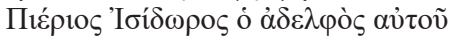

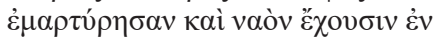

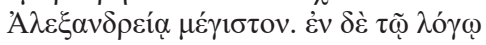

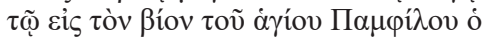

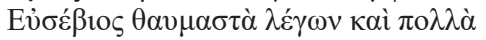

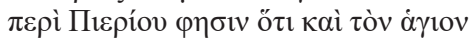

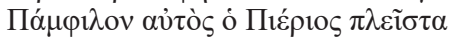

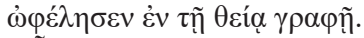

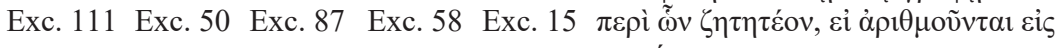

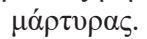

$\begin{array}{lll}\text { Exc. } 113 \text { Exc. } 52 & \text { Exc. } 60\end{array}$

Exc. 116 Exc. 55

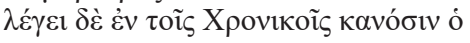

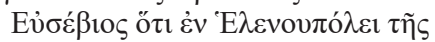

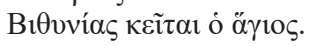

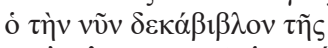

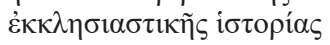

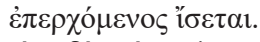

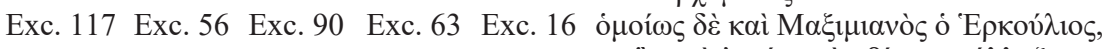

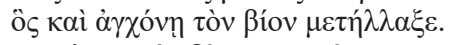

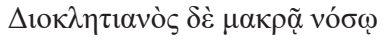

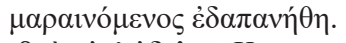

Exc. 118 Exc. 57 Exc. 91 Exc. 64

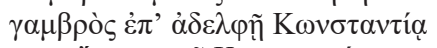

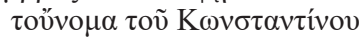

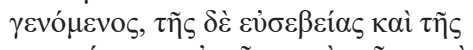

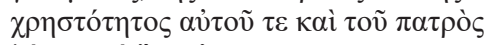

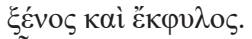

Exc. 129 Exc. 66 Exc. 97 Exc. 73

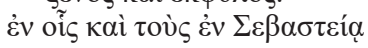

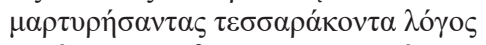

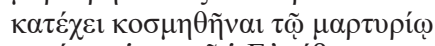

Exc. 130 Exc. 67 Exc. 97 Exc. 74

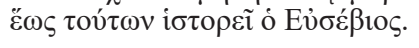

With regard to the passages quoted above, the following remarks can be made:

1) Excerpts $1 \mathrm{E}, 6 \mathrm{E}, 7 \mathrm{E}, 81 \mathrm{E}, 111 \mathrm{E}$, and $117 \mathrm{E}$ are included in all four manuscripts. As noted, $\mathrm{O}, \mathrm{B}, \mathrm{V}$, and $\mathrm{P}$ are likely to depend on a common version of the Epitome. Exc. $91 \mathrm{E}$ is transmitted by $\mathrm{O} 31,77 \mathrm{~B}$, and $51 \mathrm{~V}$. The additional sentence is not found in $51 \mathrm{~V}$, though. Exc. $118 \mathrm{E}$ is handed down by all four 
manuscripts: $57 \mathrm{O}, 91 \mathrm{~B}, 64 \mathrm{~V}, 17 \mathrm{P}$. The augmented passage by the compiler of the Epitome is only found in $57 \mathrm{O}, 91 \mathrm{~B}$, and $64 \mathrm{~V}$.

2) Seven excerpts from de Boor's catalogue are nominally assigned to three obscure authors of the second and the third centuries: Papias (46 B; $47 \mathrm{~B}=$ $38 \mathrm{~V} ; 48 \mathrm{~B}),{ }^{112}$ Hegesippus $(31 \mathrm{~B}=26 \mathrm{~V}=4 \mathrm{P})$, and Pierius $(12 \mathrm{~B} ; 39 \mathrm{~B}=33$ $\mathrm{V} ; \mathrm{O} 47=84 \mathrm{~B}, 85 \mathrm{~B})$.

3) Exc. $5 \mathrm{E}=5 \mathrm{O}=5 \mathrm{~B}$ transmits two pieces of information; (a) Cleopas walked (from Jerusalem) to Emmaus, a village in Palestine, and (b) Emmaus, the village in Palestine, assumed the name Nicopolis, when the historian Africanus was its ambassador. None of the information mentioned above is included in Eusebius' $H E$. Cleopas appears in Luke $(24,13-27)$ and Eusebius quoted Luke 24, 13 in two other writings, namely, the Onomasticon ${ }^{113}$ and the Supplementa ad quaestiones ad Marinum. ${ }^{114}$ Interestingly, the notice on the older name of Nicopolis reoccurs, in a totally different context, in the part of

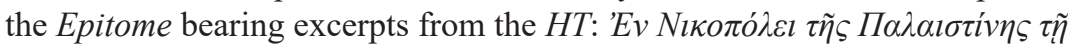

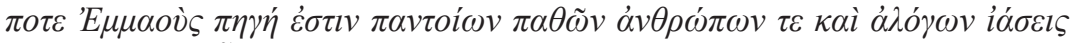

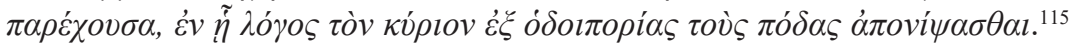
The passage in the $H T$ is originally derived from Sozomen's $H E$ V 21, 5-22, 1. Sozomen does not make any reference to Africanus' office either. The same holds true for the Latin version of Sozomen's $H E$, the compilation by Cassiodorus. ${ }^{116}$ It is Jerome's Latin translation of Eusebius' Chronicon, ${ }^{117}$ the Armenian translation ${ }^{118}$ of it, the Chronicon paschale, ${ }^{119}$ and George Syncellus' Ecloga chronographica ${ }^{120}$ that transmit a passage close to exc. 5 E. (See Table 4.5.)

Since the passage occurs in the Armenian translation of Eusebius' Chronicon, the text recorded in Jerome and the Chronicon paschale are literally identical. The notice on the old name of Nicopolis must be attributed to Eusebius' Chronicon. All three texts, Jerome's translation, the compiler of the Chronicon paschale and Syncellus do not include the remark about Cleopas' attempt to reach Emmaus (Luke 24, 13), though. Interestingly, Syncellus seems to be familiar with the passage in Luke. This can be inferred

112 The $48 \mathrm{E}=45 \mathrm{~B}=37 \mathrm{~V}$ is a fragment from Papias transmitted by the HE of Eusebius; cf. Eusebius, $H E$ 3, XXXIX.1-2, XXXIX.4.

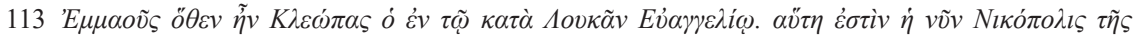

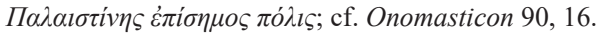

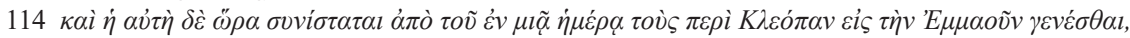

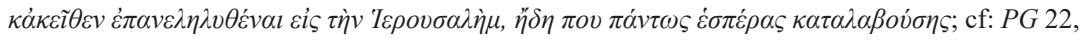
col. 1000, 38-42.

115 Cf. Hansen (ed.) (1995), 60, 23-25.

116 Cf. Cassiodorus, HE VI.42. I am indebted to Dr. Emerance Delacenserie for this remark.

117 Helm (ed.) (1956).

118 Karst (ed.) (1911). See also Drost-Abgarjan (2006), 255-262.

119 Dindorf (ed.) (1832); Whitby and Whitby (transl.) (1989). See also Treadgold (2007), 340-349; Burgess and Kulikowski (2013), 224-227.

120 Mosshammer (ed.) (1984); Adler and Tuffin (edd.) (2002). 


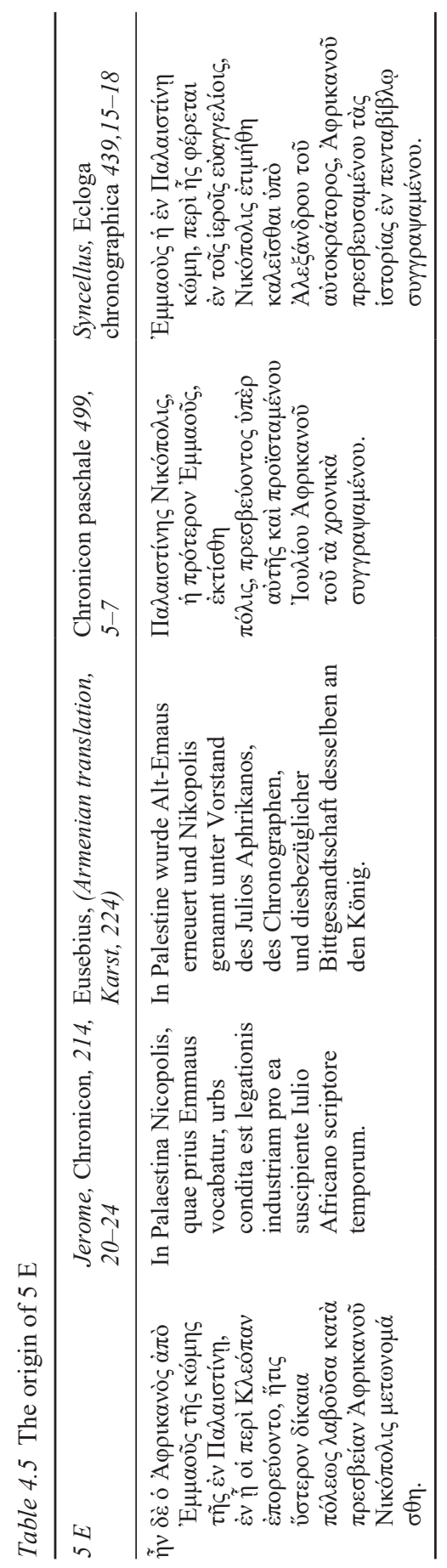




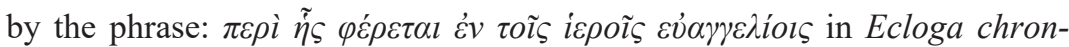
ographica 439, 16. The notice that Emmaus was Africanus' hometown is missing in Jerome, the Chronicon paschale, and Syncellus' chronicle, as well. The information on Africanus' origins is unique. The Suda, instead, calls him a Libyan ${ }^{121}$ and a fragment from Africanus' Cesti in the Papyrus Oxyrhynchus 412 transmits a controversial sentence about Africanus'

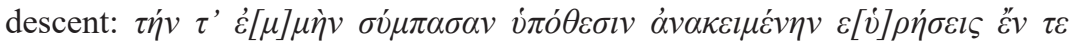

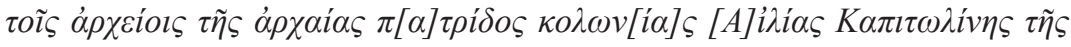
$\Pi \alpha \lambda \alpha l \sigma \tau i v \eta[\varsigma] \kappa \alpha \dot{\alpha} v \hat{v} \sigma \eta \tau \tilde{\eta} \varsigma K \alpha \rho i \alpha \varsigma .{ }^{122}$ According to this fragment, Africanus was originally from the Roman Near East. Jerusalem was given the name Colonia Ailia Capitolina after the refounding of the city under the Roman

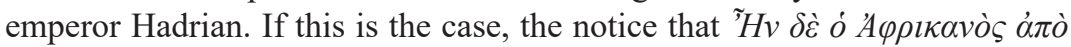

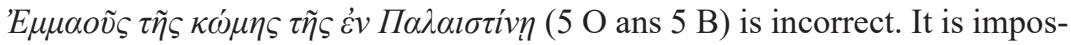
sible to know where the compiler of the Epitome drew the mistaken remark about Africanus' hometown from. It is tempting to think that, as far as exc. $5 \mathrm{E}$ is concerned, George Syncellus and the compiler of the Epitome made use of a common source. ${ }^{123}$ As already mentioned, a passage recording that the city of Nicopolis was initially called Emmaus is inserted in the part of the Epitome bearing excerpts from the HT. Africanus is absent there. The very last fact suggests that the two parts in the Epitome did not rely on a single text, as Nautin and Hansen support.

4) In $8 \mathrm{~B}=4 \mathrm{~V}$, the mention of Berenice, Agrippas II's sister, alludes to the Act. 25, 13-14 and Acts 26, 1-2. Berenice is not mentioned in Eusebius' $H E$ whatsoever. The possibility that the name of Agrippas II's sister is an addition by the compiler can by no means be excluded.

5) Exc. $11 \mathrm{~B}=8 \mathrm{~V}$ transmits that Candace, a man of Ethiopia, was promptly baptised in some nearby water by Philip the Evangelist. Both elements occur in the Act. 8, 26-40. Eusebius, instead, does not give the name of the Ethiopian man and records that the Ethiopian received from Philip by revelation the mysteries of the divine word. ${ }^{124}$

6) 113 E nominally assigns the information that Lucian the Martyr was buried at the city of Helenopolis to Eusebius' Chronicon. Helenopolis was formerly called Drepana and was given the name Hellenopolis by the emperor

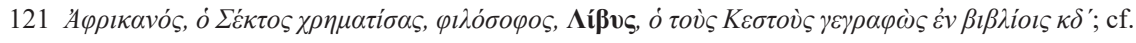
Suda, a 4647 Āpııкаvós.

122 And you will find my proposed passage in its entirety deposited in the archives of the former homeland, Colonia Aelia Capitolina of Palestine, and in Nysa of Caria; cf. Wallraff, Scardino, Mecella, and Guignard (edd.) (2012), 31. J. R. Vieillefond saw this passage as evidence of Africanus' Jewish origin. His theory has generally been rejected. On Vieillefond's interpretation of this passage, see Wallraff, Scardino, Mecella, and Guignard (edd.) (2012), XII-XIII.

123 M. Wallraff, in his edition of Julius Africanus' Cesti, includes George Syncellus' testimony on Africanus' descent. Nevertheless, M. Wallraff appears to be unaware of the existence of exc. 5 in the Epitome as preserved in Auctarium E.4.18 and Baroccianus gr. 142.

124 Eusebius, HE 2, I.13. 
Constantine (reign 306-337) to honour his mother Helena. ${ }^{125}$ Jerome and the Chronicon paschale, once again, transmit a blatantly identical passage on the refoundation of Drepana, an event that took place in the year 327. The dating of the refoundation of Dremana in 327 by Jerome makes it impossible that the passage originally derived from Eusebius' Chronicon, the last edition of which was completed in 325 AD. ${ }^{126}$ Interestingly, the passage on Drepana occurs in Theophanes' Chronographia, as well. Theophanes agrees with Jerome's chronology and the Chronographia appears to follow Jerome's text up to the year 346. Since Theophanes' text contains more information than Jerome's, R. W. Burgess concluded that the two chroniclers made use of a common source for the events from 325 up to 346 AD. ${ }^{127}$ (See Table 4.6).

R. W. Burgess postulated that the passage in common comes from the socalled Continuatio Antiochensis Eusebii, that is, an anonymous continuation of Eusebius' Chronicon, written in Greek and covering the years $325-350 .{ }^{128}$ In fact, the passage in question records two events. It connects the restoration of

Table 4.6 The origin of $113 \mathrm{E}$

\begin{tabular}{|c|c|c|c|}
\hline $113 E$ & $\begin{array}{l}\text { Jerome, Chronicon, } \\
231,22-25\end{array}$ & $\begin{array}{l}\text { Chronicon paschale, } \\
527\end{array}$ & $\begin{array}{l}\text { Theophanes, } \\
\text { Chronographia 28, } \\
\text { 3-4 }\end{array}$ \\
\hline 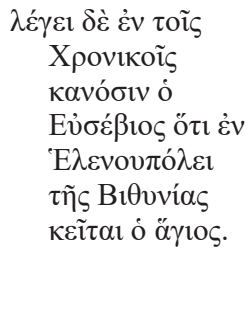 & $\begin{array}{l}\text { Drepanam Bithyniae } \\
\text { civitatem in } \\
\text { honorem martyris } \\
\text { Luciani ibi conditi } \\
\text { Constantinus } \\
\text { instaurane ex } \\
\text { vocabulo matris } \\
\text { suae Helenopolim } \\
\text { nuncupavit. }\end{array}$ & 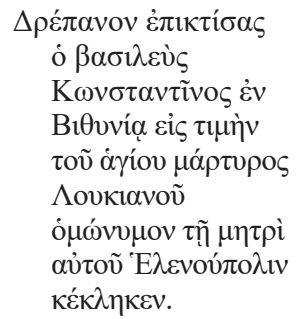 & 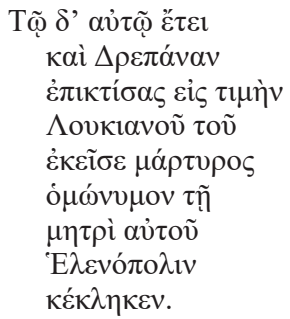 \\
\hline
\end{tabular}

125 According to Procopius, Drepana was the birthplace of Helena; cf. Procopius, De aedificiis 5.2.15. The renaming of the city is also attested in Eusebius' Vita Constantini 4, 61.1; Ammianus Marcelinus, Res Gestae 26, 8.1; Malalas, Chronographia 13, 12; Socrates, HE 1, 17. On Helena's hometown, see also Drijvers (1992), 9-19.

126 Burgess (1997), esp. 501-502.

127 The shared passages between Jerome and Theophanes are also found in a significant number of chronicles written in Greek (e.g., Chronicon paschale), Syriac, and Arabic. In all of them, the common passages must derive from a single source, now lost. See also the list of chronicles which made use of the now lost source in Burgess (1999), 116-117.

128 Burgess (1999), esp. 113-143. R. W. Burgess attempted to reconstruct the now lost text of the Continuatio by relying on textual parallels between chronicles that made use of the Continuatio, namely Jerome's Chronicon, Theophanes' Chronographia, the so-called Chron. 724, the Chronicon paschale, Michael the Syrian's chronicle and the so-called Chron. 1234; cf. Burgess (1999), 150-177. According to R. W. Burgess, the author of the Continuatio Antiochensis Eusebii was a 
Drepana with the martyrdom of Lucian: Constantine had restored the city in honour of Lucian the Martyr. ${ }^{129}$ Theophanes' information that Lucian was martyred

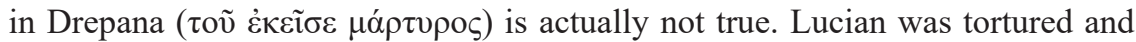
executed in Nicomedia. ${ }^{130}$ His dead body was then brought to Drepana and was buried there. ${ }^{131}$ The martyrdom and burial of Lucian at Drepana happened in 313, and Constantine's refounding of the city took place in $327 .{ }^{132}$ The latter, as noted, is unlikely to have been included in Eusebius' Chronicon. As far as the note on Lucian is concerned, it is absent in the Latin as well as the Armenian translation of Eusebian's Chronicon. It is impossible to know whether the phrase was recorded in Eusebius' original work. The notice is not attested in any of the chronicles we know that relied on Eusebius; it only occurs in the historical context of the renaming of Drepana in texts that drew on the Continuatio. ${ }^{133}$ The most likely explanation we can come up with is that the Epitome drew on the Continuatio, as well. The compiler of the Epitome might have been unaware of the fact he used a continuation to Eusebius' chronicle, though. This is logical if we reflect that the Continuatio has the same phrasing, wording, and structure as Eusebius' Chronicon. ${ }^{134}$ It is also possible that the Continuatio circulated together with the Chronicon without any distinction between the texts whatsoever.

\subsubsection{The redaction of the Eusebian part}

The aim of this section is to identify how a Byzantine compiler consciously selected, excerpted, put together, and organised material from earlier texts in order to form a coherent collection of historical excerpts. The study of the content of the Epitome generates marked results with respect to the excerpting method of its compiler: the deconstruction of texts and their reconstruction in a new context. In particular, the content and arrangement of the Eusebian excerpts reveal the three procedures of redacting an excerpt collection: a. reading of the whole source text and selection of passages, b. rewriting of the source text, and c. composition of a new unity. With regard to the Eusebian excerpts, the rewriting of the selected

Nicene; cf. Burgess (1999), 126. The fact that he accepts the deposition of Athanasius (339 AD) suggests that the author of the Continuatio has probably been pro-Arian. J. Reidy (2015), by contrast, identifies the author with Eusebius of Emesa. Such speculation is to be resisted; cf. Van Hoof and Van Nuffelen (2017).

129 On Lucian the Martyr, see Downey (1974), 337-342.

130 Eusebius' HE 8, XIII.2; 9, VI.2; PG 114, col. 408 (Vita Luciani).

131 Jerome, De Viris Illustribus 77: Passus est Nicemediae ob confessionem Christi sub persecution Maximini sepulusque Helenopoli Bithyniae. Philostorgius, HE 24, 23-27, records that the city of

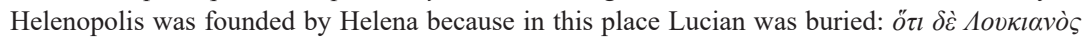

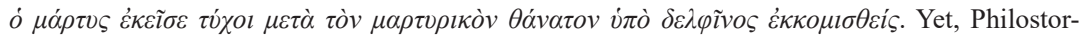
gius uses as source the Vita Luciani (PG 114, col. 397-416); cf. Bidez (1981), XCII-XCIV and CXLVII-CLI.

132 On the date of Helena's death, see Drijvers (1999), 13 and 73-76.

133 Philostorgius for the section on Lucian relied on the Vita Luciani; see above n. 131.

134 Burgess (1999), 122-131. 
passages involved changes in terms of their structure and content. The changes consist in a. rearranging of passages, and $\mathrm{b}$. textual additions.

Upon careful examination of the excerpted passages, it turns out that their synthesis in the Epitome was based on the principles revealed in the prooemium to the $E C$ as well as seen in the contents of other contemporary or later collections of excerpts. These principles are selection ( $\left.\dot{\varepsilon} \kappa \lambda \sigma \gamma \eta^{\prime}\right)$, brevity ( $\left.\sigma v v \tau o \mu i \alpha\right)$, and accuracy $(\dot{\alpha} \kappa \rho i \beta \varepsilon \imath \alpha)$. Likewise, we know from other collections that the excerptor had to select historical material according to certain precise themes. Successful selection in terms of themes would determine the tie between the various parts throughout the collection. In what follows, I put forward a number of instances of the aforementioned alterations in format and content of the excerpts in the course of the redaction of the Epitome. I shall confine myself to considering the 18 excerpts from the Epitome as preserved in $\mathrm{P}$ (see Table 4.7). Nine out of 18 excerpts in total in $\mathrm{P}$ are also found in the rest of the manuscripts of the Epitome $(\mathrm{O}, \mathrm{B}$, and $\mathrm{V})$.

Table 4.7 The redaction of the Eusebian part

\begin{tabular}{|c|c|c|c|c|c|}
\hline $\operatorname{Epitome}(E)$ & $\begin{array}{l}\text { Auctarium } \\
\text { E.4.18(O) }\end{array}$ & $\begin{array}{l}\text { Barocc. gr. } \\
142(B)\end{array}$ & $\begin{array}{l}\text { Ath. } \\
\text { Vat. } \\
286(V)\end{array}$ & $\begin{array}{l}\text { Paris. gr. } \\
1555 a(P)\end{array}$ & Eusebius' HE \\
\hline 1 & 1 & 1 & 1 & 1 & HE 1, V.1-2, X.1 \\
\hline 6 & 6 & 6 & 3 & 2 & HE 1, IX.2-4 \\
\hline 7 & 7 & 7 & 3 & 3 & HE 1, X.1-7 \\
\hline 33 & & 31 & 25,26 & 4 & $\begin{array}{l}\text { HE 3, XVII.1, } \\
\text { XVIII.1, XX.1-5; } \\
\text { Hegesippus fr.3 de } \\
\text { Boor } 1888\end{array}$ \\
\hline 38 & & 36 & 30 & 5 & $\begin{array}{l}\text { HE 3, XV.3-6; fontem } \\
\text { non inveni }\end{array}$ \\
\hline 39 & & 37 & & 6 & HE 3, XVII.1-6 \\
\hline 40 & & 38 & & 7 & $\begin{array}{l}\text { HE } 3 \text {, XVIII.1-2, } \\
\text { XVIII.6 }\end{array}$ \\
\hline 54 & & 50 & & 8 & HE 4, X.1, XI.2, XI.5 \\
\hline 64 & & 59 & & 9 & HE 5, V.1-3 \\
\hline 81 & 21 & 71 & 46 & 10 & HE 6, XX.1-2 \\
\hline 98 & 39 & & 54 & 11 & $\begin{array}{l}\text { HE 7, XVII.1, } \\
\text { XVIII.1-2 }\end{array}$ \\
\hline 100 & 40 & & & 12 & HE 7, XXV.1 \\
\hline 103 & 42 & 82 & 55 & 13 & $\begin{array}{l}\text { HE 7, XXVII.1-2, } \\
\text { XXVIII.1, XXIX.2, } \\
\text { XXXII.6, XXXII.13 }\end{array}$ \\
\hline 110 & 49 & 86 & 57 & 14 & HE 8, VI.6 \\
\hline 111 & 50 & 87 & 58 & 15 & $\begin{array}{l}\text { HE 8, III.1. XI.2 XII.3, } \\
\text { XII.5 }\end{array}$ \\
\hline 117 & 56 & 90 & 63 & 16 & HE 8, XIII.11 \\
\hline 118 & 57 & 91 & 64 & 17 & HE 8, XIII.12-15 \\
\hline 120 & 60 & & 67 & 18 & $\begin{array}{l}\text { HE 8, XIV.1-2, XIV.5, } \\
\text { XIV.7, XVI.1 }\end{array}$ \\
\hline
\end{tabular}


Four out of the 18 excerpts in $\mathrm{P}$ are only included in $\mathrm{B}$ and just a single excerpt in $\mathrm{P}$ is transmitted in $\mathrm{O}$.

The Epitome begins with the chronological calculation of Christ's birth, baptism, crucifixion, resurrection, and ascension (1 E). This account takes up the first three excerpts of the sylloge in OBVP. ${ }^{135}$ I would like to draw attention to the last

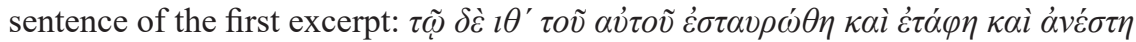
$\kappa \alpha i \dot{\alpha} v \varepsilon \lambda \dot{\eta} \varphi \theta \eta$. The sentence sums up the content of the following two excerpts in the Epitome and, therefore, it makes up a short introduction, composed by the compiler himself, who combined a few words of the original text. It should be remembered that the compilers of the EC and the Excerpta Anonymi often altered the beginning of a text in the same way. ${ }^{136}$

$6 \mathrm{P}$ erroneously records that Pilate was given the administration of Judea in the tenth year of Tiberius' reign. But Pilate was appointed procurator of Judea in the twelfth year of the reign. ${ }^{137} \mathrm{O}, \mathrm{B}$, and $\mathrm{V}$, instead, give $\tau \tilde{\omega} \imath \beta^{\prime}$ है $\tau \varepsilon \imath$ (in the twelfth year). The mistake in $\mathrm{P}$ must have been caused in the transmission of the text. The copyist of $\mathrm{P}$ is likely to have misread the manuscript he was using. The Epitome adds that Pilate's appointment took place three years before Christ's baptism ${ }^{138}$ and the following excerpt $(7 \mathrm{E})$ reports that the baptism occurred in the fifteenth year of Tiberius' reign. The compiler's addition at that point is crucial for the clarity of the passage since it corrects the chronological reckoning of the events; Pilate was given the administration of Judea in the twelfth year of the reign of Tiberius. $^{139}$

In $7 \mathrm{E}$ (see Table 4.8) the intervention on the part of the compiler consists in rearranging the passages as well as in replacing words with others that explain the text better. Let us have a look at the original context of the passage. Eusebius first quotes the Apostle Luke explaining that Jesus completed the whole time of his teaching while Annas and Caiaphas were high priests. Immediately after this quotation, Eusebius copies verbatim a passage from Josephus' Antiquitates Judaicae giving the names of the four high priests appointed after Annas and before Caiaphas. The compiler of the Epitome, instead, puts the passage taken from Josephus first and concludes with Luke's words. The rearrangement of the passages indicates that the compiler had first read through the text, and then made a copy of the selected passages he wanted to include in the Epitome. The draft copy made it easier for him to employ his selections independently. Finally, Eusebius transmits that the Romans entrusted the high priesthood to the $\ddot{\alpha} \lambda \lambda o l$, which in the text means different men. In the Epitome, by contrast, the $\alpha^{\prime} \lambda \lambda o r$ has

135 The three excerpts are taken from the second half (sections V-X) of the first book of Eusebius' $H E$. The BV transmit more excerpts taken from this part of Eusebius' work. On the excerpts transmitted in the BV but not in P, see Appendix II: Table VI.

136 See, for example, the cases in the EL 29 and the Excerpta Anonymi 29, 1-13.

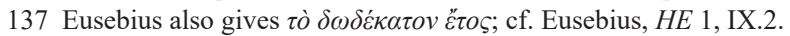

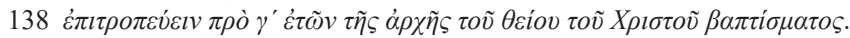

139 P. Nautin's argument is that the mistake must be due to the amanuenses, since the expression $\tau \tilde{\varphi}$

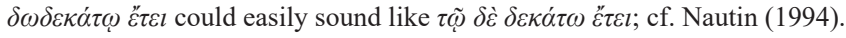


Table 4.8 7 E and Eusebius' $H E$

\begin{tabular}{|c|c|}
\hline $7 E$ & HE $1, X$ \\
\hline 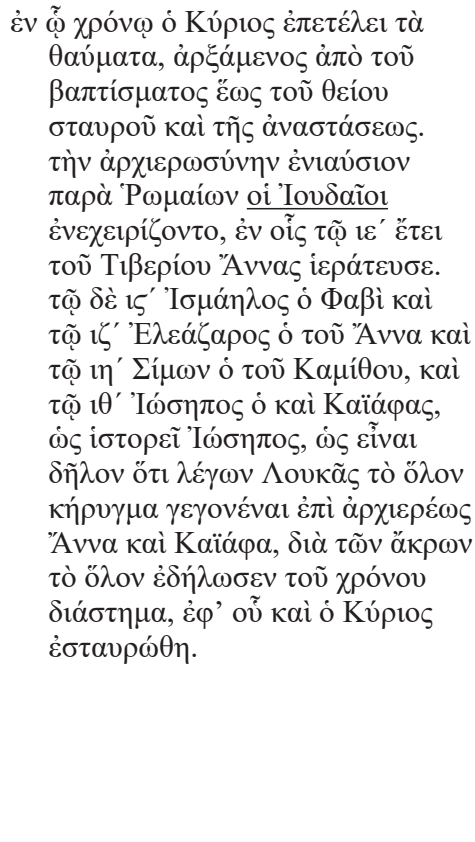 & 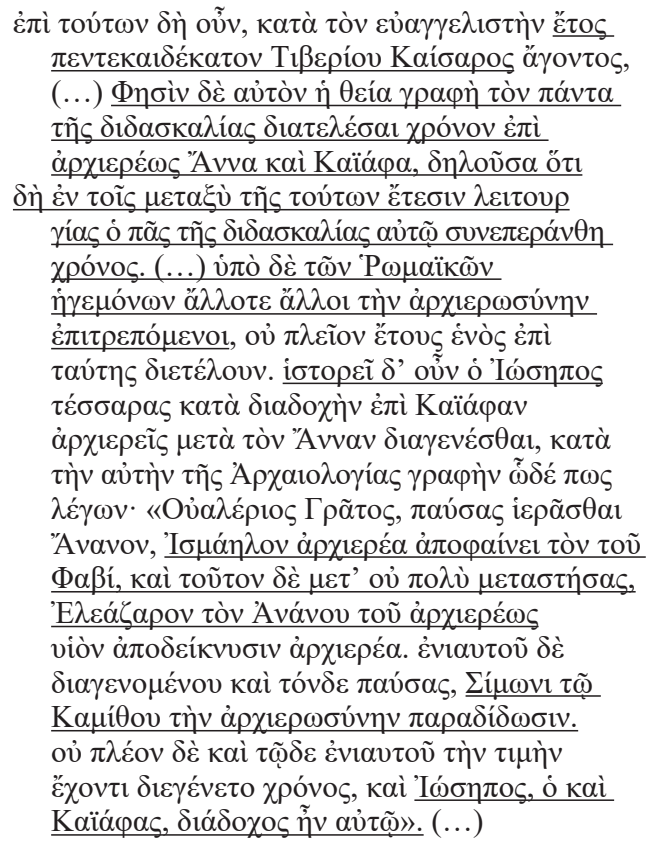 \\
\hline
\end{tabular}

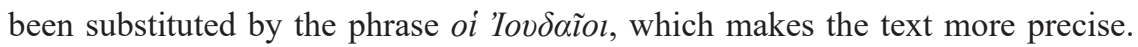

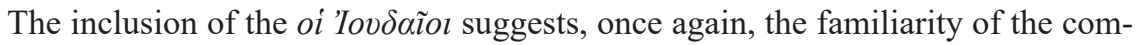
piler with the broader context of the text he finally extracted.

33 E transmits an Eusebian passage on Domitian, the last emperor of the Flavian dynasty. Turning back to the original context of the passage, we discern that the compiler omitted the description of the encounter between Domitian and Judas' sons completely. The compiler of the Epitome merely records that Domitian was crueller and more hostile to Christians than Nero himself. Domitian condemned John the Theologian to live on the island of Patmos. But when the emperor encountered the virtuous grandsons of Judas, the brother of Christ, he decreed the end to the persecution of the Church. $33 \mathrm{E}$ in the Epitome has been supplemented with a brief passage not originally found in Eusebius. The additional passage

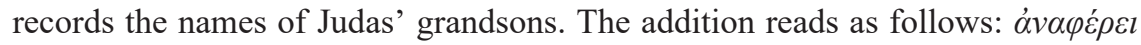

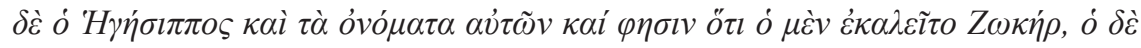
I'́x $\omega \beta$ s. As can be seen in Table 4.7, the additional reference is transmitted in all

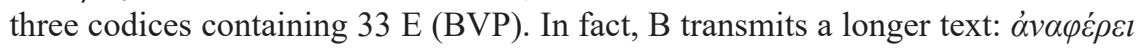

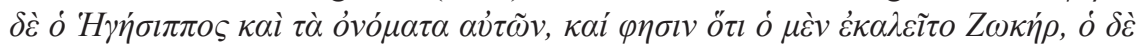

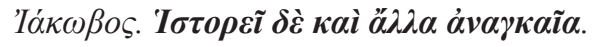


It is noteworthy that such additions on the part of the compiler of the Epitome are frequent throughout the entire sylloge of excerpts. Virtually all additions concern sources the compiler used supplementarily in the Epitome. ${ }^{140}$ G. C. Hansen and P. Nautin agree that the passages added to the Epitome should be assigned to the compiler of the Epitome. ${ }^{141}$

$5 \mathrm{P}$ is, likewise, a textual intervention on the part of the compiler of the Epitome.

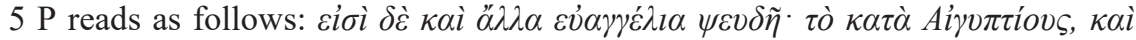

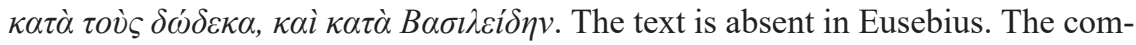
piler of the Epitome must have relied on a different source, at this point. In the $H E$ 4, VII, Eusebius only refers to the leaders of two heresies: Saturninus and Basilides. In $\mathrm{B}$ and $\mathrm{V}$, the excerpt $5 \mathrm{P}$ appears at the end of a passage excerpted from Eusebius but is absent in $\mathrm{P} .{ }^{142}$ The passage in $\mathrm{B}$ and $\mathrm{V}$ deals with epistles written by heretical figures and circulated under the names of apostles. P contains only what seems to have been written by the compiler of the Epitome himself. The absence of the Eusebian excerpt in P must not necessarily be attributed to the hypothesis that it descends from a different copy of the Epitome from the one that $\mathrm{B}$ and $\mathrm{V}$ come from. Besides, $\mathrm{P}$ transmits only a small portion of the series of excerpts from Eusebius' $H E$.

$39 \mathrm{E}$ and $40 \mathrm{E}$ are concerned with two heretical movements, the heresy of Ebionites and that of Cerinthus, respectively. In both excerpts, the original text is transmitted in the Epitome, shortened, and simplified. In Excerpt 39 E the phrase

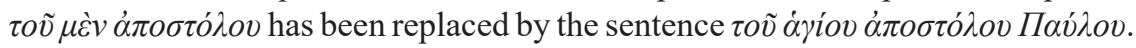
The substitution, like the one in Excerpt 7 E, makes the passage lucid. The name of the apostle is easily inferred from the general context of the original text.

Heresies and heretical figures appear to be the compiler's main interest, thematically. The theme of heresies is the focal point of Book 3 in Eusebius' $H E$. Book 3 contains three chapters, each of which deals with a heresy; the heresy of Ebionites, the heresy of Cerinthus, and the heresy of the Nikolaitans, respectively. At this point, B is, once again, most helpful in our effort to establish the contents of the Epitome. $39 \mathrm{~B}=33 \mathrm{~V}$ transmits an excerpt taken from the last part of Eusebius' Book 3. ${ }^{143}$ In the excerpt, the apostles are tested by the prospect of marriage. This subject matter refers to the beliefs of the heresy of the Nikolaitans. Accordingly, it turns out that the Epitome, in its original form, contained excerpts on all three heretical movements mentioned in Eusebius.

Excerpt $54 \mathrm{E}$ is thematically connected to the two preceding excerpts. Excerpt $54 \mathrm{E}$ is concerned with the heretical teachings by Valentinus and Cedro. The end of the original Eusebian passage $(H E 4, \mathrm{X})$ was singled out and moved to the beginning of Excerpt $54 \mathrm{E}$, serving as prefatory material to it. Thus, the compiler

140 See Section 4.4.2.

141 G C. Hansen and P. Nautin, however, see the so-called Epitome as a summary of Theodorus Anagnosta's collection of historical works in their entirety; Nautin (1994), 219-223; Hansen (ed.) (1995).

142 Eusebius, HE 3, XXV.3-6.

143 Eusebius, $H E$ 3, XXX.1-2. 
introduces us, first, to the two heretic teachers and then he excerpts the following Eusebian section ( $H E$ 4, XI) and briefly records their teachings. Again, there is nothing different from the method applied in the Excerpta Anonymi or the EC.

A similar intervention on the part of the excerptor occurs in $64 \mathrm{E}$ of the Epitome (see Table 4.9). The passage deals with a certain Alcibiades who used to partake solely of bread and water. The martyr Attalus, however, persuaded him to partake of everything without restraint and give thanks to God. The beginning of the passage in the Epitome reflects, once again, the compiler's method in synthesising his work. The passage begins with the statement that Alcibiades was one of the martyrs in France. The information derives from the end in Eusebius' original passage. Such internal changes suggest that the compiler worked on a copy of the entire passage.

$81 \mathrm{E}$ refers to the library at Aelia set up by Alexander, Bishop of Jerusalem. In the original text, Eusebius admits that he used material found in the library in composing his own history. Eusebius reports the names of several writers he drew from. The compiler of the Epitome transmits Eusebius' report of the valuable writings he discovered in the library in Jerusalem. Such a quotation would certainly reinforce the reliability of the Epitome.

98 E represents the story of a woman who found relief from her disease at the hands of the Saviour. Our compiler specifies that the story took place in Paneion, which is a piece of information derived from an earlier part of the Eusebian text. The compiler's intention was to clarify the text and make it more intelligible.

100 E condenses into a short passage of five lines two sections of the $H E$. The passage transmits Dionysius' view on the authorship of the Apocalypse. Eusebius,

Table 4.964 E and Eusebius' $H E$

\begin{tabular}{|c|c|}
\hline $64 E$ & Eusebius HE 5, III \\
\hline 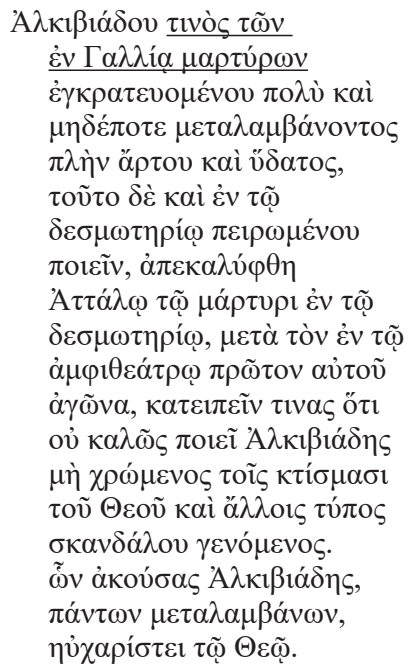 & 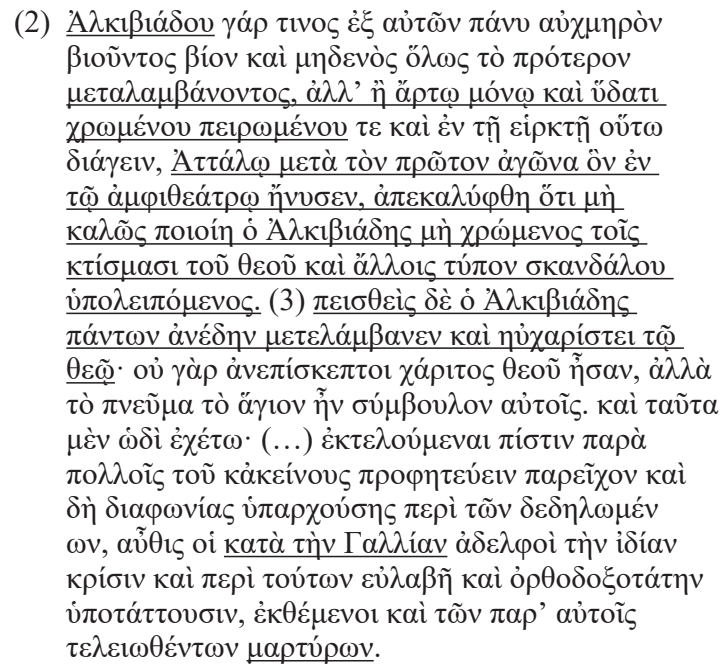 \\
\hline
\end{tabular}


through a long chapter, transmits almost verbatim a long extract from Dionysius' work, in which Dionysius presents opinions of several others on the authorship of the Apocalypse, while justifying his own slant on the matter. According to Dionysius the Apocalypse of John the Divine could have been written by someone called John, other than the Evangelist.

$103 \mathrm{E}$ is made up of passages taken from several sections of Book 7 of Eusebius' $H E$. Two of the passages were taken from $H E$ 7, XXXII. In Loeb's edition the section covers 20 pages. ${ }^{144} 103 \mathrm{E}$ is not the only excerpt from $H E 7$, XXXII was originally planned to be included in the Epitome, though. $\mathrm{O}$ transmits four further excerpts from the same Eusebian section: $44 \mathrm{O}$ and $45 \mathrm{O}$ concern Anatolius who became bishop in Laodicea, $66 \mathrm{O}$ concerns Agapius who succeeded Theotecnus in the episcopal see of Caesarea in Palestine, and $47 \mathrm{O}=84 \mathrm{~B}$ deals with Pierius, bishop of Alexandria, and Meletius, bishop of the churches in Pontus. ${ }^{145}$

$110 \mathrm{E}$ and $111 \mathrm{E}$ are concerned with the persecution under the emperor Diocletian. Eusebius' Book 8 deals with the persecutions of Christians and narrates the martyrdoms of several known bishops. $110 \mathrm{E}$ constitutes a reference to the martyrdom of Anthimus the bishop of Nicomedia. The compiler of the Epitome supplements the excerpt with a statement made up of passages taken from different parts of Book 8. The added text informs us that during the persecution

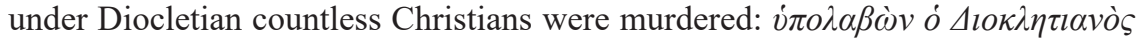

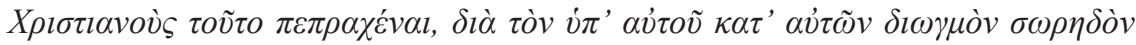

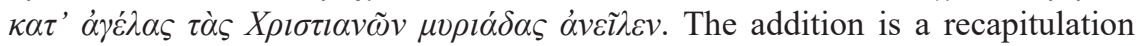
of what Eusebius describes throughout Book 8 of his $H E$. The insertion of brief passages summarising the original Eusebian text is typical of the method of the compiler of the Epitome.

Excerpt $111 \mathrm{E}$ opens by repeating the statement of the preceding passage:

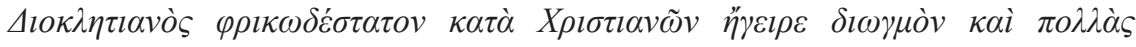

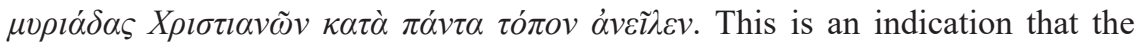
two passages were excerpted, copied, and re-edited separately and were then put together by the compiler. All instances in the Epitome discussed so far bear out that the abridgement and the excerpting were done simultaneously. What follows the opening statement is, once again, a gathering of passages from different parts of Book 8. 111 E reports the martyrdom of Adauctus and the story of a woman who threw her children and herself into the river in order to avoid the tortures by the soldiers. The passage closes with a question raised by our compiler himself, whether such kinds of death can be counted amongst the martyrdoms of Christians. It is noteworthy that $111 \mathrm{E}$ respects the original sequence of excerpts in Eusebius' HE. What follows is Excerpt $111 \mathrm{E}$. The corresponding passages in Eusebius are given in parentheses.

144 Kirsopp (ed.) (1965), 226-245.

145 Eusebius, HE 7, XXXII is devoted to the most conspicuous churchmen of Eusebius' age. The major part of the section is concerned with the Canons of Pascha by Anatolius. Eusebius quotes verbatim a long passage of the Canons. 


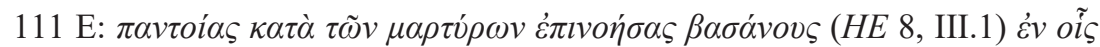

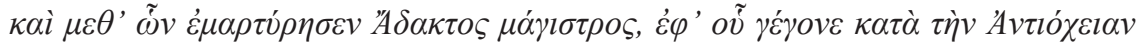

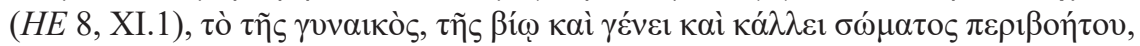

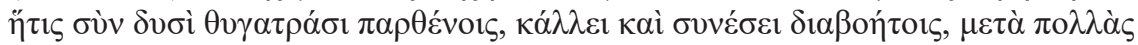

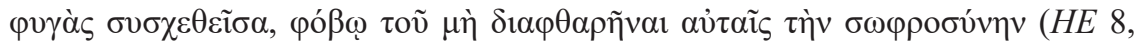

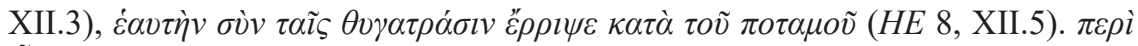

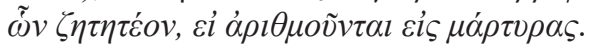

Excerpt 117 E recounts the bad end that Diocletian had in comparison with the glorious, successful, and happy life of Constantius presented in 118 E. Exc. 120 $\mathrm{E}$ is a brief summary of the following section of Eusebius' text, namely, Section XIV of Book 8. Excerpt 120 E refers to the tyrannical reigns of Maxentius and Maximin.

\subsection{General conclusions on the Epitome}

The study of the compositional structure and method of the so-called Epitome suggests that the work is not descended from a single collection comprising the complete texts of a number of church histories. The Epitome, instead, is a sylloge of excerpts extracted from different and separate sources. As I showed, the initial heading is congruent with the working method and compositional principles applied in the sylloge and it is likely that the heading was added by the excerptor himself. The manuscript transmission of the Epitome does not allow us to arrive at any tangible conclusion as to the exact size of the original sylloge, though. The examination of the excerpted passages from Eusebius' $H E$ revealed the three steps of redacting an excerpt collection: a) reading and selection, b) re-editing, and c) composition. The study of the working method in the Epitome lead to the following deductions: a) similar to the structure detected in the Excerpta Salmasiana, the excerptor of the Epitome made a careful selection of thematically connected passages and placed them in a predetermined chronological framework, b) in consonance with the arrangement of material in all the other collections of historical excerpts examined in this book, the Epitome retains the original series of excerpts, and c) the excerptor of the Epitome intervenes in the text by employing the same strategies as detected in the EC, the Excerpta Anonymi, and the Excerpta Salmasiana. 


\section{Excerpta Planudea}

A compilation of passages taken from a number of profane and religious texts and transmitted under the name of Maximus Planudes is known under the conventional titles $\Sigma v v \alpha \gamma \omega \gamma \dot{\eta}$ and Excerpta Planudea. ${ }^{1}$ In particular, the $\Sigma v v \alpha \gamma \omega \gamma \dot{\eta}$ comprises excerpts from classical geographers and philosophers, historians of the late antique and middle Byzantine period as well as Christian writings. This chapter 1) surveys the manuscript transmission of the $\Sigma v v \alpha \gamma \omega \gamma \eta$, 2) examines the content and structure of the collection, and 3) undertakes a close analysis of the excerpts on Roman history included in the $\Sigma v v \alpha \gamma \omega \gamma \eta$.

\subsection{Manuscript transmission}

\subsubsection{The codices}

The $\Sigma v v a \gamma \omega \gamma \eta \dot{~ h a s ~ b e e n ~ f u l l y ~ t r a n s m i t t e d ~ t h r o u g h ~ f i v e ~ m a n u s c r i p t s, ~ n a m e l y ~}$ Laurentianus Plut. 59, 30 (thirteenth/fourteenth centuries), Neapolitanus gr. 165 (fourteenth century), Vaticanus Pal. 141 (fourteenth/fifteenth centuries), Vaticanus gr. 951 (fifteenth century), and Parisinus gr. 1409 (fourteenth/fifteenth centuries).

\subsubsection{Laurentianus Plut. 59, 30 (=L)}

Bombyc. (ff. 1-103) et chartac. (ff. 104-346), sec. XIII-XIV. ${ }^{2}$

Laurentianus Plut. 59, 30 contains: 1r-103v: Maximus Planudes, Excerpta

Planudea; 104r-142v: Didymus Alexandrinus, Fragmenta in Proverbia; ${ }^{3}$ 142v-146v: Maximus Planudes, Locutiones populares collectae; ${ }^{4} 146 \mathrm{v}-148 \mathrm{v}$ :

1 On the sylloge of excerpts made by Maximus Planudes, see Boissevain (1895), CXI-CXXIII; Wünsch (1898), L-LIX; Diller (1937), 296-301; Wendel (1950), 2232-2236; Gallavotti (1987), 125-126; Pérez Martin (1997), 77.

2 On the codex, see Bandini (1768), 549-553; Wünsch (1898), LIII-LIV; Bühler (1987), 127-130; Sotiroudis (1989), 202-203; Ferroni (2011), 327-334.

3 On the text, see $C P G$ 2552; Bühler (1987), 126-135.

4 See Piccolomini (1879), 321-330; Kurtz (1886). 
Philostratus Flavius, Epistulae ${ }^{5}$ 148v-149r: Diogenianus, Proverbia $;{ }^{6} 149 \mathrm{r}-151 \mathrm{r}$ : Maximus Planudes, Epistulae; ${ }^{7}$ 151r-157r: Libanius, Epistulae ad Basilium magnum $;{ }^{8}$ 151r-157r: Basilius Caesariensis, Epistulae ad Libanium sophistam $;{ }^{9}$ $157 \mathrm{v}-159 \mathrm{v}$ : Libanius; 160-346r: Libanius, Orationes. ${ }^{10}$

In its current condition, $\mathrm{L}$ is an acephalous composite codex. ${ }^{11}$ It consists of three distinctive codicological units differing in material and in hand. As far as the dating of $\mathrm{L}$ is concerned, scholars agree that the different units were created between the late thirteenth and early fifteenth centuries ${ }^{12}$ and that the codex is not written by Planudes' hand. ${ }^{13}$ The first unit of L consists of the ff. $1-103,{ }^{14}$ made up of thirteen quaternions of oriental paper, ${ }^{15}$ and is written by a scholarly hand dated to the late thirteenth century. ${ }^{16}$ This part contains the $\Sigma v v \alpha \gamma \omega \gamma \dot{\eta}$ in its entirety. Perez-Martin identified the scribe of the first part of L (ff. 1-103v) with Leon Bardales, a disciple of Maximus Planudes. ${ }^{17}$ In Perez-Martin's view, the hand in L is also identical with the hand traced in Laurentianus Conv. Soppr. 71, Vaticanus gr. 253, 258, 1950, Cant. Add. 1732, part of Vindobonensis phil. gr. 21 and Ambrosianus $C 235$.

\subsubsection{Neapolitanus gr. $165(=N)$}

Chartac., ff. $238,308 \times 233 \mathrm{~mm}$, II. 42 , an. $1325 .^{18}$

Neapolitanus gr. 165 contains: 1r: various unidentified passages; 1v: Gregorius Nazianzenus, Ad Themistium epist. 38 et epist. $24 ;{ }^{19} 2 \mathrm{r}-2 \mathrm{v}$ : Gregorius Nyssenus, Epist. 2 De iis qui adeunt Hierosolyma; ${ }^{20}$ 3r: Idyllium (vv. 1-270);

5 Kayser (1871), XIV.

6 CPG 177-180.

7 Ep. 48 and 49 in Leone (ed.) (1991).

8 Foerster (1927), 223.

9 CPG 2900.d.

10 Foerster (1903), 417.

11 The first folio is missing. On the term composite codices, see Nyström (2009), 42-48.

12 Diller (1937), 297; Bühler (1987), 127; Ferroni (2011), 327-328.

13 Diller (1937), 297; Perez-Martin (1997), 77-80.

14 The second unit is dated to the fourteenth century. It comprises ff. $104 \mathrm{r}-159 \mathrm{v}$ made of western paper. The second unit contains proverbs by Zenobius, by Maximus Planudes, and by Diogenianus as well as epistles by Maximus Planudes and by Libanius. The third unit is dated to the fourteenthfifteenth centuries. It is made up of ff. 160r-346r made of oriental paper. The third unit transmits orations by Libanius; Bühler (1987), 127-140.

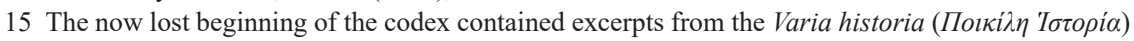
by Aelian; cf. Ferroni (2011), 327.

16 Diller (1937), 297. Ferroni argues in favour of Fryde's dating at the beginning of the fourteenth century; Fryde (1996); cf. Ferroni (2003), 99.

17 Perez-Martin (1997), 77-80. On Leon Bardales, see Taxidis (2011), 97-113.

18 On the codex, see Cirillo (1832), 146-155; Sotiroudis (1989), 203-205; Formentin (1995), 124131; Ferroni (2011), 334-335.

$19 P G$ 37, col. 80; $P G$ 37, col. 60 .

20 PG 46, col. 1009-1016. 
5r-92v: Maximus Planudes, Excerpta Planudea; 93r-140v: Euripides (Vita Euripidis, Hecuba, Orestes, Phoinissae, Troades); 141r-196v: Sophocles (Vita Sophoclis, Ajax, Electra, Oedipus tyrannus); 196v: Joannes Tzetzes, De Differentia Poetarum; ${ }^{21}$ 196v: Proclus, Vita Hesiodi; 197r-197v: Isaac Tzetzes, Vita Hesiodi; 198r-214v: Hesiodus, Opera et dies; 215r-236v: Theocritus, Vita Theocriti and Idyllia 1-0; 237r-237v: Pindarus, Vita Pindari, De lyricis, De lyra, Scholium in Olymp. I v. 1.

This is a miscellaneous codex, which is dated shortly after L and written in a calligraphic hand. ${ }^{22}$ The text of the Planudean sylloge is found on ff. $5 \mathrm{r}-92 \mathrm{v}$. In the upper left margin on $\mathrm{f}$. $5 \mathrm{r}$, the $\Sigma v v \alpha \gamma \omega \gamma \eta \dot{\eta}$ is preceded by the syllable $\mu \alpha \xi$, which is the abridgement for Más $\xi \mu o \varsigma$.

\subsubsection{Vaticanus Pal. 141 (= Pal)}

Chartac., ff. 378, $210 \times 145$ mm, II. 35-37, sec. XIV-XV. ${ }^{23}$

Vaticanus Pal. 141 contains: 2v-4r: Maximus Planudes, Stichera et canones in s. Diomedem; 4r-5r: Manuelis Philae, Versus; 5r-83r: Maximus Planudes, Epistulae et Epigrammata; 83v-90r: Maximus Planudes, Comparatio hiemis et veris; 90r-117v: Maximus Planudes, Laudatio SS. Petri et Pauli; 117v-118r: Maximus Planudes, Epigrammata; 118r-136r: Maximus Planudes, Encomiun in S. Diomedem m. Nicaeae; 136v: Maximus Planudes, Epigramma in s. Diomedem; 136v: Maximus Planudes, Tetrastichon in novercam suam; 136v: Maximus Planudes, Canon in S. Demetrium; 137v-138v: Maximus Planudes, Idiomela in S. Mocium; 138v-139r: Maximus Planudes, Epigrammata; 139r-140r: Maximus

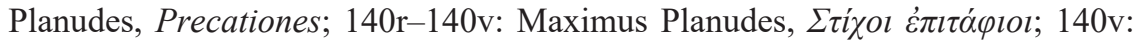

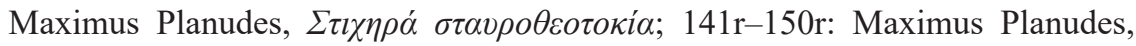
Oratio in sepulturam Christi; 150r-285r: Maximus Planudes, Excerpta Planudea; 285r-288r: anonymous Oracles; 288r-378r: Georgius Lacapenus, Epimerismi.

The codex is dated to the third decade of the fourteenth century ${ }^{24}$ and written in a calligraphic hand. The $\Sigma v v \alpha \gamma \omega \gamma \grave{\eta}$ by Maximus Planudes is transmitted on $\mathrm{ff}$. 150r-285r. The full title of the sylloge by Maximus Planudes is transmitted in Pal:

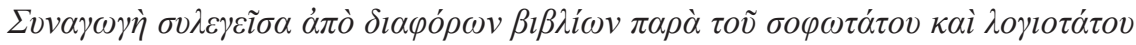

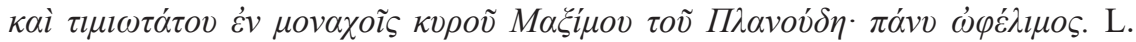
Ferroni, repeating E. Piccolomini's suggestion, finds it unlikely, on the grounds of the structure of the $\Sigma v v \alpha \gamma \omega \gamma \eta$, that this heading was the original title of Planudes' sylloge of excerpts. ${ }^{25}$ In the following I cast doubt on this, supporting that the title fits the format and structure of the $\Sigma v v \alpha \gamma \omega \gamma \eta$.

21 The text is edited in Gaisford, (1823), 12, 1. 22-14, 1. 2.

22 Diller (1937), 297.

23 On the codex, see Stevenson (1885), 71-73; Wünsch (1898), LIII-LIV; Canart and Peri (1970), 248; Sotiroudis (1989), 205-206; Ferroni (2011), 338-340.

24 Gallavotti (1987).

25 Ferroni (2011), 339-340; cf. Piccolomini, (1874), 101. 


\subsubsection{Vaticanus gr. $951(=\mathrm{V})$}

Chartac., ff. 260, II. 29-30, sec. XV. ${ }^{26}$

Vaticanus gr. 951 contains: 1r-8v: Heraclitus rhetor, Allegoriae; 9r-152v: Maximus Planudes, Excerpta Planudea; 152v-156v: Michael Psellus, Tõ

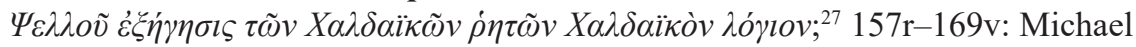

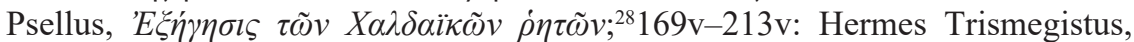

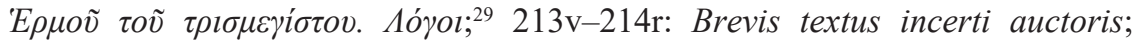
220r-260r: Maximus Planudes, Capita de caritate. ${ }^{30}$

$\mathrm{V}$ is a miscellaneous codex dated to the second half of the fourteenth century. ${ }^{31}$

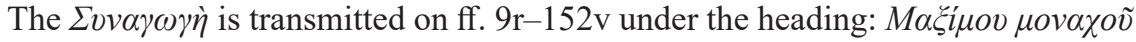

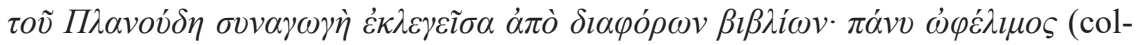
lection made up of selections from several books by Maximus Planudes, the monk, altogether useful). The title is similar to the one found in Pal. The title is a later addition, though. Diller attributes the insertion of the title to a seventeenthcentury cataloguer of the Vatican Library. ${ }^{32}$ Ff. $214 \mathrm{v}-219 \mathrm{v}$ in V were left blank.

\subsubsection{Parisinus gr. 1409 (= Par)}

Chartac., ff. A-D + 161, $210 \times 140 \mathrm{~mm}$, II. 22-38, sec. XIV. ${ }^{33}$

Parisinus gr. 1409 contains: 1r-134v: Maximus Planudes, Excerpta Planudea; 135v-139r: anonymous Proverbia Greco-barbara; 139r-140r: Pythagoras, Carmen aureum; 140r: anonymous, Aenigmata; 140v: Iulianus Flavius Claudius, Versus; 140v-141r: anonymous Oracula varia; 141v-143v: anonymous, Narratio utilis de Christi ordinatione; 144r-145v: anonymous, Opusculum de providentia; 146r-158v: Plutarchus, Ad Pollianum epistula;

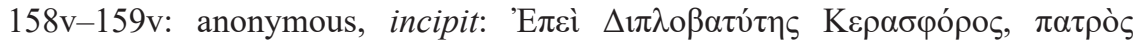

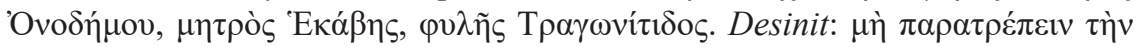

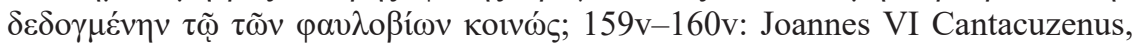

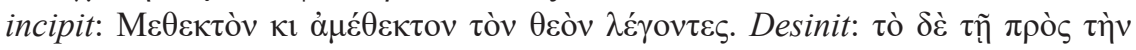

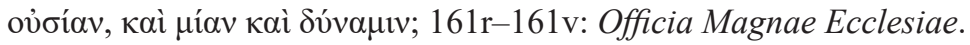

26 On the codex, see Wünsch (1898), LII; Canart and Peri (1970), 516; Sotiroudis (1989), 206-207; Ferroni (2011), 337-338.

27 O'Meara (ed.) (1989), 126-144. The text halts abruptly on f. 152v.

28 O’Meara (ed.) (1989), 126-146, 146-148, 148-151. Ff. 157r-169v transmit the $\dot{\varepsilon} \xi \dot{\eta} \gamma \eta \sigma l \varsigma \tau \tilde{\omega} v$

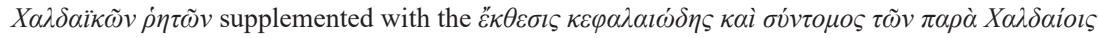

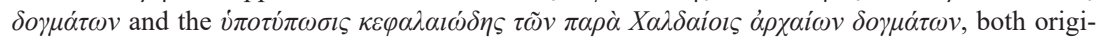
nally written by Psellus. See Ferroni (2011), 337-338.

29 See Nock, Festugière, and Ramelli (edd.), (2006).

30 PG 90, col. 959-1073.

31 Ferroni (2011), 337. Wünsch dates the codex to the sixteenth century; cf. Wünsch (1898), LII.

32 Diller (1937), 297.

33 On the codex, see Omont (1888b), 39; Wünsch (1898), LII-LIII; Sotiroudis (1989), 207-209; Ferroni (2011), 336-337. 
This is an acephalous codex dated to the end of the fourteenth or the beginning of the fifteenth century. ${ }^{34}$ It was copied by Manuel Phralites. ${ }^{35}$ The $\Sigma v v \alpha \gamma \omega \gamma \dot{\eta}$ by Maximus Planudes is found on ff. $1 \mathrm{r}-134 \mathrm{v} \cdot{ }^{36} \mathrm{~F}$. $135 \mathrm{r}$ was left blank. The texts transmitted by ff. $158 \mathrm{v}-159 \mathrm{v}$ and ff. $159 \mathrm{v}-160 \mathrm{v}$ are not mentioned in the inventory by H. A. Omont. L. Ferroni does not identify them, either. After inspection of the codex, I concluded that the text on ff. $159 \mathrm{v}-160 \mathrm{v}$ is actually a collection of passages from an epistle sent by the emperor John VI Cantacuzenus (reign 13471354) to Paul, the Latin Patriarch of Constantinople since $1366 .{ }^{37}$ The text on $\mathrm{ff}$. $158 \mathrm{v}-159 \mathrm{v}$ is very close to a legal text attributed to the Cardinal Isidore, a fervent supporter of the union between the Churches of East and West (1385-1463). ${ }^{38}$ If this is the case, the passage in Par is likely a later insertion.

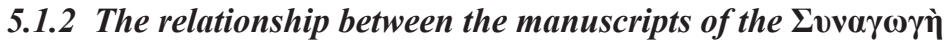

According to A. Diller, L was the archetype of the other four manuscripts transmitting the sylloge by Maximus Planudes, because a) L does not bear scribal mistakes which appeared in the rest of the codices and b) marginal notes of $\mathrm{L}$ were copied by the scribes of the other four manuscripts. ${ }^{39} \mathrm{C}$. Wendel holds a different view, without explaining his proposition, though. ${ }^{40}$ According to $\mathrm{C}$. Wendel, the L must not be taken as the archetype of the other manuscripts. L. Ferroni shares A. Diller's view that $\mathrm{L}, \mathrm{N}, \mathrm{V}, \mathrm{Pal}$, and Par stem from a single source and that $\mathrm{L}$ is the older and best manuscript transmitting the $\Sigma v v \alpha \gamma \omega \gamma \eta$. In his view, however, there are many cases in which $\mathrm{L}$ contains a reading different from the rest of the manuscripts of the $\Sigma v v \alpha \gamma \omega \gamma \eta{ }^{41}$ He based this on an examination of the part of the $\Sigma v v \alpha \gamma \omega \gamma \dot{\eta}$ containing Plato. Nevertheless, further research needs to be done on the matter, since the instances L. Ferroni presents are mainly orthographical variants between the $\mathrm{L}$ and the rest of the codices. Besides, L. Ferroni's conclusions are only based on a single part of the $\Sigma v v \alpha \gamma \omega \gamma \eta$. L. Ferroni also argued that $\mathrm{N}$ and $\mathrm{Pal}$ are dependent on a common text and that $\mathrm{V}$ is not copy of any of the rest of the manuscripts. ${ }^{42}$ Both points exclude that $\mathrm{L}$ was the archetype of the other codices. It should also be noted that the text transmitted in L has been subjected to textual corrections. Moreover, a number of notes and headings were inserted into the margins of the codex. It cannot be ruled out that the hand, which corrected the text in L in terms of grammar and

34 Wendel considers Par coeval to Pal; cf. Wendel (1950), 2232-2236. Wünsch dates the codex between the fourteenth and fifteenth centuries; cf. Wünsch (1898), LIII.

35 Diller (1956), 90; Gamillscheg (1989), 351.

36 Ferroni was the first to notice the incorrect description of the $\Sigma v v \alpha \gamma \omega \gamma \dot{\eta}$ in the Parisinus gr. 1409 by Omont. Ferroni corrected the description of the $\Sigma v v \alpha \gamma \omega \gamma \dot{\eta}$ in Ferroni (2011), 336-337.

37 The text of the epistle can be found in Tinnefeld and Voordeckers (1987), ep. 5.

38 See the text that is entitled Tò $\psi \eta \dot{\varphi} \varphi \imath \sigma \mu \alpha$ in Mercati (1926), 163-165. G. Mercati published the text transmitted on f. 188 in the codex Vaticanus gr. 914.

39 Diller (1937), 297.

40 Wendel (1950), 2232.

41 Ferroni (2011), esp. 340-346.

42 Ferroni (2011), 340-350. 
vocabulary and added the marginal notes, was identical with the hand that had copied the entire $\Sigma v v \alpha \gamma \omega \gamma \dot{\eta}$ in the manuscript. ${ }^{43}$ In line with A. Diller's and L. Ferroni's view, in what follows, I treat L as the best witness to Planudes' $\Sigma v v \alpha \gamma \omega \gamma \eta^{\prime}$.

Three more codices transmit parts of the $\Sigma v v \alpha \gamma \omega \gamma \eta^{\prime}$ : Ottobonianus gr. 345 (sixteenth century), Vaticanus Pal. gr. 209 (y. 1463), and Palatinus Heidelb. gr. 129 (fifteenth/sixteenth centuries). ${ }^{44}$ Excerpts from the $\Sigma v v \alpha \gamma \omega \gamma \grave{\eta}$ in Ottobonianus gr. 345 show significant textual similarities with $\mathrm{Pal}^{45} \mathrm{Ff}$. 263r-266r of Vaticanus Pal. gr. 209 contain a small number of excerpts from the $\Sigma v v \alpha \gamma \omega \gamma \eta$. The excerpts were copied by Isidore Ruthenus. ${ }^{46}$ The text on ff. $263 \mathrm{r}-266 \mathrm{r}$ is likely to derive from the $\Sigma v v \alpha \gamma \omega \gamma \dot{\eta}$ as it is preserved in V. ${ }^{47}$ Finally, ff. 90r-97r of Palatinus Heidelb. 129 transmit excerpts copied probably from L. ${ }^{48}$

\subsubsection{Maximus Planudes}

Maximus Planudes was born in Nicomedia around $1250 .{ }^{49}$ After the reconquest of 1261, he resided in Constantinople where he taught grammar, mathematics, harmonics, and rhetoric. ${ }^{50}$ Planudes embraced monastic life around the year 1283. He stayed at the monastery of Chora before he moved to the monastery of Christ Akataleptos by 1299. Planudes is considered one of the most prolific scholars of the Palaeologan Renaissance. Surviving manuscripts from his scriptorium reveal his manifold literary interests: poetry, ${ }^{51}$ epistolography, ${ }^{52}$ philosophy, ${ }^{53}$ geography, ${ }^{54}$ astronomy, ${ }^{55}$ geometry, ${ }^{56}$

43 Piccolomini (1874), 112.

44 On the codices, see Roberto (ed.) (2005b), CIX; Ferroni (2006), 99-109. On Ottobonianus gr. 345, see also Wünsch (1898), LII. On Vaticanus Pal. gr. 209, see also Wünsch (1898), LIV.

45 Diller (1937), 297.

46 Diller (1937), 297, n. 1. Isidore Ruthenus was an erudite scholar of the fifteenth century with a special interest in astronomy, mathematics, geography, and medicine. On manuscripts copied by Isidorus Ruthenus, see Mercati (1926).

47 Diller (1937), 297.

48 Diller (1937), 297.

49 On Maximus Planudes' life and literary activity, see also Wendel (1950), 2202-2253; Constantinides (1982), 66-89; Wilson (1996), 230-241; Mergiali (1996), 34-42.

50 Constantinides (1982), 68-71.

51 Planudes copied a series of poems by Gregory of Nazianzus in the codex Laurentianus Plut. 32,16; cf. Bandini (1961), 143-145; Fryde (2000), 234. On the codex, see below n. 65.

52 Planudes compiled a collection of his own letters. The collection comprised 121 letters, addressed to Andronicus II and other important figures of his time; cf. Leone (ed.) (1991).

53 Apart from excerpts from Plato which were included in the $\Sigma v v \alpha \gamma \omega \gamma \eta \dot{\eta}$, Planudes himself copied passages from Crito and Phaedo; Hunger (1961), 151-152; Turyn (1972), 214.

54 Excerpts from Strabo's Geographica and Pausanias' Graeciae descriptio were inserted into the Excerpta Planudea. Planudes edited, also, Ptolemy's Geographia, dated to the second c. AD. On the codices on Ptolemy's text owned by Planudes, see; Fryde (2000), 253-257.

55 Planudes was concerned with Aratus' Phaenomena, an astronomical poem, dated back to third c. bc.

56 Planudes partially edited the Arithmetica by Diophantos (third c. AD); cf. Tannery (ed.) (1895), 125-255. An arithmetical treatise by Planudes was edited by Allard (1981). 
proverbs,${ }^{57}$ rhetoric,${ }^{58}$ grammar, ${ }^{59}$ sermons,${ }^{60}$ biography,${ }^{61}$ and historiography. ${ }^{62} \mathrm{He}$ also knew Latin and translated into Greek Cicero's Somnium Scipionis, Macrobius' commentary on it, Boethius' De consolatione philosophiae and Ovid's Heroides and Metamorphoses. ${ }^{63}$ Maximus Planudes died in Constantinople around 1305. The $\Sigma v v \alpha \gamma \omega \gamma \dot{\eta}$ was composed at the end of the thirteenth century.

There is a number of manuscripts identified as copies from Planudes'scriptorium copied under his supervision. Diller regards the first part of L (containing the $\Sigma v v \alpha \gamma \omega \gamma \eta$ ) as written in the scriptorium of Maximus Planudes too. ${ }^{64}$ Other manuscripts attributed to Planudes' scriptorium are: Laurentianus Plut. 32,16 (a codex written in several hands, one of which is Planudes' $)^{65}$ and Laurentianus Plut. 59, 1. The latter contains works by Plato and it is written in two hands. Bianconi sees Maximus Planudes as one of the two scribes of the codex. ${ }^{66}$

In addition to the aforementioned codices, there are six surviving codices written in Planudes' own hand: 1) Marcianus 481, dated to 1301. The codex contains

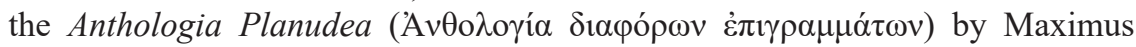

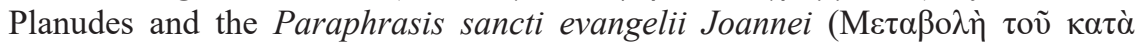

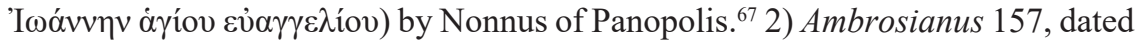
to $1292 / 1293 .{ }^{68}$ 3) Ambrosianus C 126, dated in $1294 / 1295$. The codex was partially written by Maximus Planudes, whereas part of the codex was copied by

57 Ff. 142v-146r in Laurentianus Plut. 59.30 transmit a collection of proverbs compiled by Planudes himself.

58 Planudes compiled a rhetorical collection, comprising passages from Hermogenes and Apthonius; cf. Fryde (1996), 360. See also the discussion on Planudes' grammatical notes, which are preserved in Laurentianus 55.7, in Fryde (2000), 216-217 and 246-248.

59 Planudes' interest in linguistics is reflected in his two treatises on this subject, the Dialogus de grammatica and the Dialogus de verborum constructione, respectively. The Dialogus de grammatica is partly edited in Robins (1993), 203-209. The Parisinus gr. 2667 transmits a lexicon attributed to Planudes; cf. Fryde (1996), 384.

60 Laurentianus 56.22, dated after the death of Planudes, bears a sermon On the burial of Our Lord, Jesus Christ, two homilies on saints Peter and Paul and another one of saint Diomedes, patron of his home town, Nicomedia; cf. Fryde (2000), 263.

61 Planudes edited Plutarch's Vitae Parallelae as well as a miscellany of Plutarch's philosophical and rhetorical writings, known as Moralia. On the Moralia, see Irigoin and Flacelière (1987) and Garzya, Giangrande, and Manfredini (1988).

62 See Section 5.3.

63 On the Latin works translated by Planudes into Greek, see Fryde (2000), 257-261.

64 Diller (1937), 297-301.

65 Turyn (1972), 31-39. On the codex, see also Kugeas (1909), 106-108. The codex contains a considerable number of Greek verse texts (Hesiod, Apopponios of Rhodes, Theokritos, Moschos of Syracuse, Nikander, Oppian of Cilicia, Oppian of Apamea, Gregory of Nazianzus), excerpts from the so-called Theosophia, a collection of oracles compiled by the Neoplatonist Porphyry, and a small number of epigrams. The Dionysiaca by Nonnos of Panopolis, covering a large part of the codex (ff. 9r-173r) were copied by a student of Planudes and revised by Planudes himself; cf. Fryde (2000), 235.

66 Bianconi (2005), 397-398.

67 Turyn (1972), 90-96.

68 Turyn (1972), 78-81. 
John Zarides, one of the most prominent students of Planudes. ${ }^{69}$ 4) Vaticanus Reginenses gr. 132 and 133, both dated to the early fourteenth century. ${ }^{70}$ And 5)

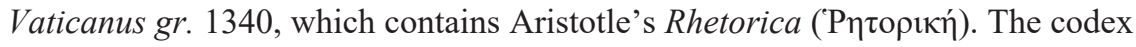
was executed by Planudes himself in collaboration with John Zarides. ${ }^{71}$

\subsection{Content and structure of the $\Sigma v v a \gamma \omega \gamma \eta$ '}

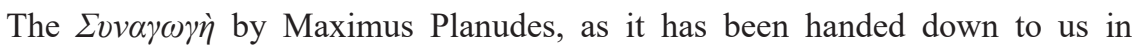
the extant manuscripts, begins with excerpts from two classical geographers,

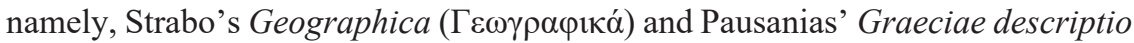

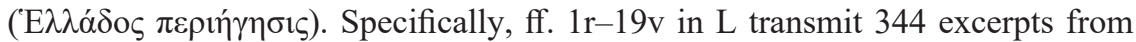
Strabo. ${ }^{72}$ The excerpts are not introduced by any heading and each excerpt begins with the word ö $\tau$. Diller was the first to note that Planudes made use of Parisinus gr. 1393, a codex containing the Geographica in its entirety. ${ }^{73}$

Strabo is followed by 154 excerpts from Pausanias. The arrangement of the Pausanias excerpts in L begins abruptly without any title on f. $19 \mathrm{v}$ and runs up to f. 30r. Planudes extracted passages from the entire work by Pausanias. In the margins of $\mathrm{L}$ the headings of the books of the Graeciae descriptio are in

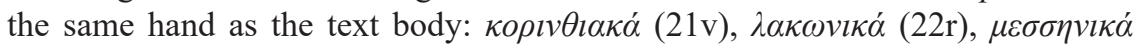

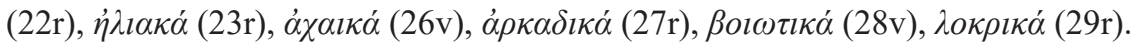
Except for a few slight differences, the headings are congruent with those transmitted in the best manuscripts of Pausanias' Graeciae descriptio, all dated, however, after L (Marcianus gr. 413, Laurentianus 56.11 and Parisinus gr. 1410). ${ }^{74}$ Interestingly, the title of Book 1 of the Graeciae descriptio is missing in both, that is, in Planudes' $\Sigma v v \alpha \gamma \omega \gamma \dot{\eta}$ and the best codices of Pausanias. ${ }^{75}$ It seems very likely that the three aforementioned codices of Pausanias derive from the codex that Planudes used for his $\Sigma v v \alpha \gamma \omega \gamma \eta{ }^{76}$

Ff. 30r-32r in L transmit forty-four excerpts on the Roman Republic from Romulus to Lucullus. In L they were inserted without any heading. Except for the first five excerpts, they are assigned to John of Antioch. ${ }^{77}$

Ff. 32r-47v in L contain 291 passages on Roman imperial history taken from the Epitome of Cassius Dio by John Xiphilinus (269 excerpts), from Paeanius'

69 Turyn (1972), 81-87.

70 Vaticanus Reginenses gr. 132 is in Planudes' hand; cf. Wilson (1978), 390. The codex Vaticanus Reginenses gr. 133 is written in the same hand; Ferroni (2011), 332.

71 Pérez Martin (1997), 76. On the codex, see also Pérez Martin (1996).

72 S. L. Radt used the Planudean excerpts from Strabo in his edition of the Geographica; Radt (2002).

73 Diller (1397), 297-298. On the Parisinus gr. 1393, see Sbordone (1963), XXVII-XXVIII.

74 The three codices transmitting Pausanias' work contain $\dot{\eta} \lambda \iota \alpha \kappa \tilde{\omega} v \alpha^{\prime}, \beta^{\prime}, \dot{\alpha} \chi \alpha \iota \kappa \tilde{\omega} v$ and $\varphi \omega \kappa \iota \kappa \grave{\alpha}$ $\lambda о \kappa \rho \tilde{\omega} v \dot{o} \zeta \alpha \lambda \tilde{\omega} v$; Diller (1956), 90-91. On the manuscripts of Pausanias' Graeciae descriptio, see Diller (1957), 169-188.

75 Only the codex Matrit. 4564 (fifteenth c.), ff. 13r-38v, which contains only a small part of the

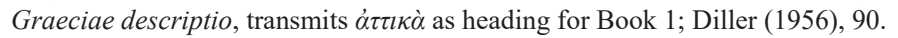

76 Diller (1937), 298-299; Diller (1956), 90-91; Ferroni (2011), 329.

77 See Table 5.2 and Table 5.3. On these excerpts, see Section 5.3.1. 
historical work (eighteen excerpts), and from an unidentified chronicle now lost (four excerpts).$^{78}$ Chronologically, the excerpts run from Lucullus to Gratian. The excerpts come immediately after the forty-four excerpts on the Roman Republic and $\mathrm{f}$. $32 \mathrm{r}$ does not bear a sign that the compiler changes his source at this point. On the upper margin on $\mathrm{f} .35 \mathrm{r}$ in $\mathrm{L}$ a heading occurs. The marginal reads as fol-

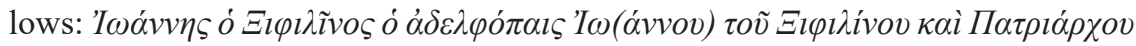

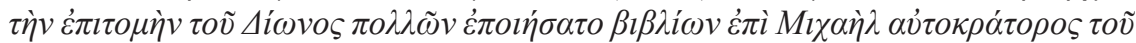
$\Delta o v ́ \kappa \alpha .{ }^{79}$ The same heading is also found in Parisinus gr. 1409. ${ }^{80}$ The sentence was extracted from Xiphilinus' Epitome. ${ }^{81}$

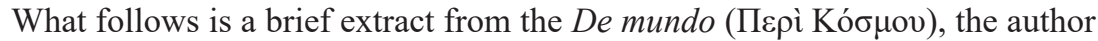
of which remains unknown. ${ }^{82}$ The De mundo has been, falsely, transmitted under the name of Aristotle. This is the reason why the author of the work is usually referred to as Ps.-Aristotle. The text takes up ff. $47 \mathrm{v}-48 \mathrm{r}$ in $\mathrm{L}$ and is followed by a brief passage from Plato. ${ }^{83}$ This passage takes up f. $48 \mathrm{r}$ in L. On the left margin of f. $48 \mathrm{r}$, next to the excerpt, the heading $\pi \lambda \dot{\alpha} \tau \omega v o \varsigma$ occurs.

Ff. $48 \mathrm{r}-50 \mathrm{v}$ in L transmit a series of anonymous philosophical excerpts, etymologies, and riddles. ${ }^{84}$ The excerpts exhibit textual similarities with passages

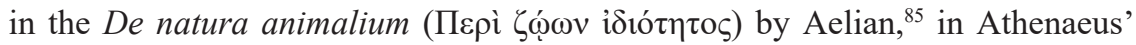

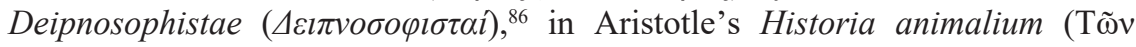

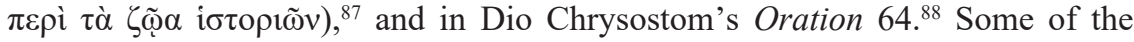

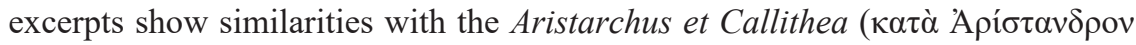

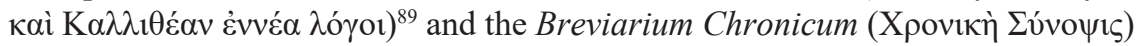
by Constantine Manasses. ${ }^{90}$

78 See Table 5.4.

79 John Xiphilinus, the nephew of John Xiphilinus the Patriarch, compiled an epitome out of the many books of Dio, during the reign of Michael Doukas.

80 The marginal was omitted in N, Pal and V; cf. Diller (1937), 299.

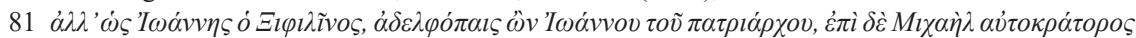

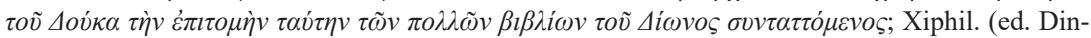
dorf, vol. V, 87).

82 The dating of the De mundo is disputed. It must have been written between the second half of the first century AD and the first half of the second century AD; Forster (1914).

83 Leges, II, 661 D. 1-5, and 661 A 7-661 C 5.

84 These excerpts were published by E. Piccolomini; cf. Piccolomini (1874), 150-160. E. Piccolomini divided the excerpts (sixty-nine in total in L) into four thematic categories: philosophy, paradoxigraphy, etymology, and enigmas; Piccolomini (1874), 149.

85 Excerpts 2, 31, 32, 35, 37 in Piccolomini (1874) correspond to Aelian, De natura animalium, 6.1, $4.22,4.23,4.21,7.5$, respectively.

86 Excerpts 19, 20, 21, 27, 28, 29, 30 in Piccolomini (1874) correspond to Athenaeus, Deipnosophistae, $10.9,10.13,7.102,9.58,10.73,10.75,10.84$, respectively.

87 Excerpt 26 in Piccolomini (1874) corresponds to Aristotle, Historia animalium, 9.40 (624b).

88 Excerpt 41 in Piccolomini (1874).

89 Excerpts 2-38 in Piccolomini (1874) were attributed to the Aristarchus et Callithea by Mazal (1967), 34-61. See also Jeffreys (2012), 273-337.

90 Excerpts 57, 58, 59 in Piccolomini (1874) derive from the Breviarium Chronicum; cf. Lampsides (1984), 1-2. 
Ff. $50 \mathrm{v}-52 \mathrm{v}$ in L contain twenty-seven excerpts from various texts attributed to Synesius (ca 370-413 AD), a Neoplatonist who became bishop of Ptolemais in Pentapolis some years before he died..$^{91}$ In particular, the excerpts were extracted from Epistulae 1 and $131^{92}$ as well as from the works Dio, sive de suo

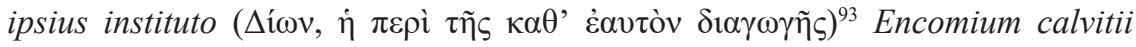

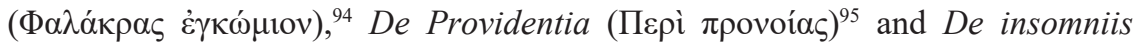

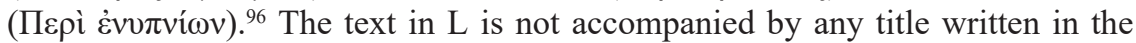
body text. On the left margin on $\mathrm{f} .50 \mathrm{v}$, next to the first passage from Synesius, the word $\sigma v v \varepsilon \sigma i o v$ is written.

Ff. $52 \mathrm{v}-59 \mathrm{r}$ in L transmit passages from the De Mensibus by John Lydus. The text is not preceded by a heading. On the left margin on f. $52 \mathrm{v}$, next to the first

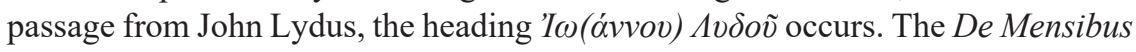
survived only in fragments. The excerpts preserved in the $\Sigma v v \alpha \gamma \omega \gamma \eta \dot{\eta}$ by Planudes are unique. ${ }^{97}$

The excerpts from John Lydus are followed by a concatenation of anonymous excerpts (ff. $59 \mathrm{r}-74 \mathrm{v}$ in L) taken from various unidentified Christian writings.

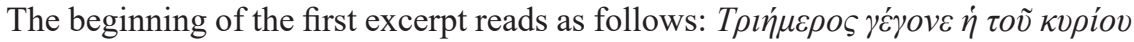
$\dot{\alpha} v \alpha \dot{\sigma} \sigma \alpha \sigma \iota \varsigma .{ }^{98} \mathrm{~A}$ number of notes are written in the margins: f. 59v: $\alpha \pi \dot{o} \kappa \alpha v o ́ v \omega v, \mathrm{f}$.

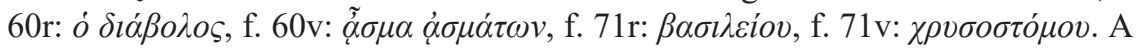
number of the excerpts have been safely assigned by L. Ferroni to Hermas' Pastor

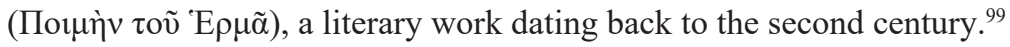

The anonymous excerpts are followed by passages taken from Plato. In L, the Plato-section is marked by an initial in red ink projecting into the left margin on $\mathrm{f}$. $74 \mathrm{v}$. In particular ff. 74v-94v transmit passages from Plato's tetralogies I to VII, supplemented with excerpts from the spurious Platonic dialogues. ${ }^{100}$ According to E. Piccolomini and A. Diller, Maximus Planudes made use of a single codex containing Platos' dialogues, namely, the thirteenth-century codex Parisinus gr. $1808 .{ }^{101}$ L. Ferroni, by contrast, showed that the Parisinus gr. 1808 was not the

91 On Synesius' life, education, and career see Bregman (1982); Hagl (1997). On Synesius' affiliations to Neoplatonism, see Dimitrov (2008), 149-170.

$92 P G$ 66, col. 1321-1323 and $P G$ 66, col. 1515-1517.

93 PG 66, col. 1111-1163.

$94 P G 66,1167-1206$.

$95 P G 66,1210-1281$.

$96 P G 66,1281-1320$.

97 Wünsch (1898), L-LIX.

98 The resurrection of the Lord took place after three days.

99 Ferroni (2003), 99-109. For an edition of the Pastor, see Körtner and Leutzsch (1998), 105-497. On the date and structure of the Pastor, see Carlini (1983), 95-112; Verheyden (2007), 63-71.

100 The following texts, though transmitted under the name of Plato, are most likely not Plato's: Alcibiades ii, Alcibiades i, Hipparchus, Meno, Amatores, Theages, Clitophon, Demodocus, Sisyphus, Eryxias, Axiochus. Some of the spurious Platonic dialogues have been included in the Platonis Opera in the Oxford Classical Texts collection; cf. Duke (1995-1999).

101 Piccolomini (1874), 162-163; Diller (1983), 255. 
only manuscript on which Planudes drew for his section on Plato. Some readings in $\mathrm{L}$ point to other Platonic apographa. ${ }^{102}$

The last part of the $\Sigma v v \alpha \gamma \omega \gamma \dot{\eta}$ is made up of a second concatenation of excerpts taken from Christian authors (ff. 95r-103v). This series of excerpts in L (and in $\mathrm{N}$ ) is not introduced by any title. The first passage comes immediately after the last excerpt from Plato without any indication of a change of source. Pal and Par, instead, transmit the title $\pi \varepsilon \rho i \tau \tilde{\omega} v \dot{\alpha} \zeta \tilde{b} \mu \omega v,{ }^{103}$ written in red ink. In $\mathrm{V}$ the heading

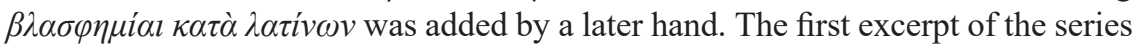

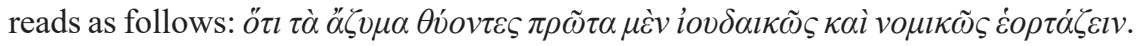

It should be noted that a) in $\mathrm{N}$ the second series of passages from Christian authors is followed by passages taken from George Cedrenus. The excerpts from George Cedrenus (ff. 83v-85r) are not transmitted in L as part of the $\Sigma v v \alpha \gamma \omega \gamma \dot{\eta}$ by Maximus Planudes, and b) ff. $85 \mathrm{r}-85 \mathrm{v}$ in $\mathrm{N}$ (see Table 5.1) transmit passages on a number of oracles found also in Laurentianus Plut. 32, 16, f. 379, as part of an anthology of epigrams. ${ }^{104}$ The text is also contained in Pal. Since N and Pal are possibly copies from a common exemplar (see Section 5.1.2) different from the one that L comes from, it seems more likely that the $\Sigma v v \alpha \gamma \omega \gamma \eta \dot{~ e n d e d ~ w i t h ~ t h e ~}$ series of passages from Christian authors and that at some point it was expanded with the two aforementioned sets of passages attested in $\mathrm{N}$ and Pal.

\subsection{The excerpts on Roman history in the

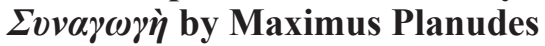

In what follows, the focus lies on the passages on Roman history included in the $\Sigma v v \alpha \gamma \omega \gamma \dot{\eta}$ by Maximus Planudes. In particular, I shall consider a) the original derivation of the selected passages, b) the source text which the $\Sigma v v \alpha \gamma \omega \gamma \dot{\eta}$ drew from, c) the working method applied by Maximus Planudes, and d) the political function served by the sequence of excerpts in Planudes' $\Sigma v v \alpha \gamma \omega \gamma \dot{\eta}^{\prime}$.

\subsubsection{The origins of the passages on Roman history}

Ff. 30r-32r in L transmit forty-four excerpts on the Roman Republic, inserted without any heading to precede them. Chronologically, they run from Romulus to Lucullus. Initially, A. Mai erroneously attributed them to Cassius Dio. ${ }^{105}$ But C.

102 Ferroni (2006), 275-302.

103 The text, which remains unedited, comprises a significant number of extracts from writings by Eustratius, bishop of Nicaea at the beginning of the twelfth century, as well as from sermons by John Chrysostom and John of Damascus.

104 The passages belong to the so-called Theosophia Tubingensis. The text is an epitome, dated between the eighth and the thirteenth centuries, of books 8-11 of the work $\Pi \varepsilon \rho i$ i $\tilde{\eta} \varsigma \dot{\delta} \rho \theta \tilde{\eta} \varsigma \pi i \sigma \tau \varepsilon \omega \varsigma$ compiled probably in Alexandria at the end of the fifth century. The passages were edited in Wolf (1856), 231-240, 173-186. On the oracles preserved in N and V, see Gallavoti (1987), 3-16. On the Theosophia Tubingensis, see Erbse (1995). On Laurentianus Plut. 32, 16, see Bandini (1961), 141-146; Turyn (1972), 32-39.

105 Mai published the series of excerpts on Roman history as it is contained in Pal and V; cf. Mai (1827), 527-555. 
Table 5.1 Content and structure of the $\Sigma v v \alpha \gamma \omega \gamma \eta^{\prime}$

\begin{tabular}{|c|c|c|c|}
\hline $\begin{array}{l}\text { Laur. } \\
\text { pl. } 59,30\end{array}$ & $\begin{array}{l}\text { Neap. } \\
\text { gr. } 165\end{array}$ & $\begin{array}{l}\text { Paris. } \\
\text { gr. } 1409\end{array}$ & \\
\hline $1 \mathrm{r}-19 \mathrm{v}$ & $5 \mathrm{r}-18 \mathrm{v}$ & $1 \mathrm{r}-26 \mathrm{v}$ & Strabo, Geographica \\
\hline $19 v-30 r$ & $18 v-27 \mathrm{r}$ & $26 v-44 r$ & Pausanias, Graeciae descriptio \\
\hline $30 \mathrm{r}-32 \mathrm{r}$ & $27 v-33 r$ & & $\begin{array}{l}\text { Manasses, Breviarium Chronicum; Paeanius, } \\
\text { Breviarium ab urbe condita; John of Antioch, } \\
\text { Historia chronica }\end{array}$ \\
\hline $32 \mathrm{r}-47 \mathrm{v}$ & $33 r-42 r$ & $44 \mathrm{r}-70 \mathrm{r}$ & $\begin{array}{l}\text { Xiphilinus' Epitome; Constantine Manasses, } \\
\text { Breviarium Chronicum; Paeanius, } \\
\text { Breviarium ab urbe condita; }\end{array}$ \\
\hline $47 v-48 r$ & $42 \mathrm{r}-42 \mathrm{v}$ & $70 \mathrm{r}-70 \mathrm{v}$ & Ps.-Aristotle, De mundo \\
\hline & $42 \mathrm{v}$ & & Plato, Leges \\
\hline $48 \mathrm{r}-50 \mathrm{v}$ & $42 v-44 v$ & & $\begin{array}{l}\text { Aelian, De natura animalium; Athenaeus, } \\
\text { Deipnosophistae; Aristotle, Historia } \\
\text { animalium Dio Chrysostom, Oration 64; } \\
\text { Manasses, Aristarchus et Callithea; Manasses, } \\
\text { Breviarium Chronicum }\end{array}$ \\
\hline $50 v-52 v$ & $44 v-46 r$ & $74 \mathrm{v}-77 \mathrm{r}$ & $\begin{array}{l}\text { Synesius, Epistle } 1 \text { and } 131 \text {; Dio, sive de suo } \\
\text { ipsius instituto; Encomium calvitii; De } \\
\text { Providentia; De insomniis }\end{array}$ \\
\hline $52 \mathrm{v}-59 \mathrm{r}$ & $46 r-51 r$ & $77 \mathrm{r}-99 \mathrm{v}$ & John Lydus, De Mensibus \\
\hline $59 \mathrm{r}-74 \mathrm{v}$ & $51 r-63 r$ & $99 \mathrm{v}-103 \mathrm{v}$ & Anonymous excerpts from Christian authors \\
\hline $74 v-94 v$ & $63 \mathrm{r}-78 \mathrm{v}$ & $\begin{array}{l}70 \mathrm{v}-74 \mathrm{v} \\
103 \mathrm{v}-130 \mathrm{r}\end{array}$ & $\begin{array}{l}\text { Plato, Euthyphro; Apologia Socratis; Crito; } \\
\text { Phaedo; Cratylus; Theaetetus; Sophista; } \\
\text { Politicus; Parmenides; Philebus; Symposium; } \\
\text { Phaedrus; Alcibiades i; Alcibiades ii; } \\
\text { Hipparchus; Theages; Charmides; Laches; } \\
\text { Lysis; Euthydemus; Protagoras; Gorgias; } \\
\text { Meno; Hippias maior; Hippias minor; } \\
\text { Ion; Menexenus; De iusto; De virtute; } \\
\text { Demodochus; Sisyphus; Eryxia; Axiochus }\end{array}$ \\
\hline \multirow[t]{3}{*}{$95 \mathrm{r}-103 \mathrm{v}$} & $78 v-83 v$ & \multirow[t]{3}{*}{$130 \mathrm{r}-134 \mathrm{v}$} & Anonymous excerpts from Christian authors \\
\hline & $83 v-85 r$ & & $\begin{array}{l}\text { Excerpts from George Cedrenus ( } P G 121 \text {, col. } \\
\quad 440 \text { B 5-452 C 14) }\end{array}$ \\
\hline & $85 \mathrm{r}-85 \mathrm{v}$ & & Theosophia (16 Oracula) \\
\hline
\end{tabular}

Mommsen noted in 1872, that this was mistaken. C. Mommsen conjectured that John of Antioch was the original author of the excerpts in the $\Sigma v v \alpha \gamma \omega \gamma \eta^{\prime}{ }^{106}$ Indeed,

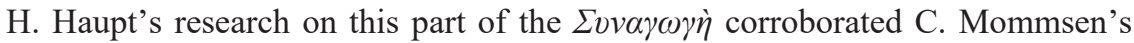
view. H. Haupt concluded that a) Excerpts 5-44 come from John of Antioch, b) Excerpts 1-2 derive from the chronicle by Constantine Manasses, and c) Excerpts 3-4 derive from Paeanius' translation of Eutropius' Breviarium. ${ }^{107}$ A few years later, the discovery of the codex Athonensis Iviron 812 by Sp. Lambros

106 Mommsen (1872), 82-91.

107 Haupt (1879). 
corroborated that all the forty-four excerpts come from the chronicle by John of Antioch, except for the first four excerpts. ${ }^{108}$ Excerpt 5, as S. Kugeas showed, is a passage compiled by Planudes himself by merging a passage from John Lydus' De magistratibus with a notice from John of Antioch's Historia chronica. ${ }^{109}$ In fact, Planudes intervenes twice in the De magistratibus: a) he simplifies the $\delta \tau^{\prime}$

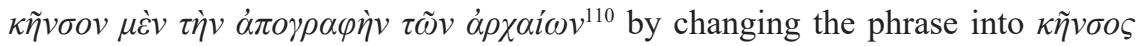
$\gamma \grave{\alpha} \rho \dot{\eta} \tau o \tilde{v} \pi \lambda \dot{\eta} \theta o v \varsigma \dot{\alpha} \pi \alpha \rho i \theta \mu \eta \sigma l \varsigma,{ }^{111}$ and b) he contaminates the Lydian text with the

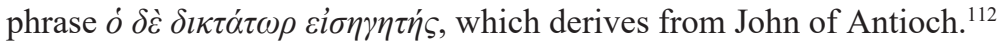

The series of excerpts on Roman history was first published by U. P. Boissevain, who attributed Excerpts 6-44 to John of Antioch. ${ }^{113} \mathrm{~S}$. Mariev, in his edition of John of Antioch's chronicle, considered the series of excerpts on the Roman Republic as deriving from John, except for the first four excerpts. ${ }^{114} \mathrm{~S}$. Mariev considered also Excerpt 5 as a passage of the Historia chronica. Roberto, in his own edition of John of Antioch, included Excerpt 2, as well. ${ }^{115}$ In fact, Excerpts 1 and 2 show resemblances with the Breviarium Chronicum by Constantine Manasses (ca. 1130-ca. 1187): cf. Table 5.2.

That the excerpts do not come directly from Manasses was proved by G. Sotiriadis. ${ }^{116}$ S. Kugeas reaffirmed G. Sotiriadis' assertion and argued further that Planudes and Manasses made use of a common source; a chronicle written in prose. Manasses not only used the chronicle but also versified it. ${ }^{117}$ Accordingly, S. Kugeas sees those two passages as parts of a chronicle, traces of which can be found in Manasses, in Cedrenus, in the anonymous compiler of the Exc.Salm.II and in other Byzantine chronicles. ${ }^{118}$ De Boor was the first to postulate the existence of such a chronicle, now lost, used by the entire Exc.Salm.II. ${ }^{119}$

108 Kugeas (1909), 126-146. On Athonensis Iviron 812 and Kugeas' inspection of it, see Section 5.3.2.1.

109 Kugeas (1909), 134.

110 That the registration of capital is called census; cf. Bandy (ed.) (1983), 128.

111 The enumeration of the population is called census.

112 Fr. 32, 15 Mariev; fr. 80.1, 7-8 Roberto. The text in the De Magistratibus reads as follows: $\tau \dot{\nu} v$

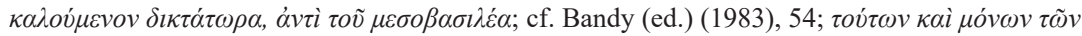

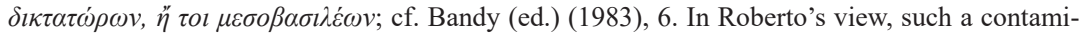
nation on the part of Planudes, indicates the importance of John of Antioch as a historian of the Roman Republic; Roberto (ed.) (2005b), CVI.

113 It should be noticed that U. P. Boissevain published the excerpts transmitted in Pal and V; Boissevain (1884); Boissevain (1895), CXI-CXIV and CXIV-CXXIII.

114 Mariev (ed.) (2008).

115 Roberto attributes Excerpt 2 to John of Antioch, on the grounds of the fact that the excerpt shows similarities with Dionysius of Halicarnassus, who was one of John of Antioch's main sources; Roberto (ed.) (2005b), CXI.

116 G. Sotiriadis' argument runs counter to that of H. Haupt (1879), 291-297; cf. Sotiriadis (1888), 51-52.

117 Kugeas (1909), 135.

118 Kugeas (1909), 136.

119 See Chapter 3. 
Table 5.2 The EPL and Manasses' chronicle

\section{EPL 1 (Laurentianus Plut. 59, 30,} 30r)

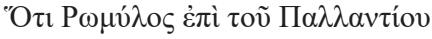

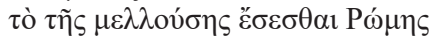

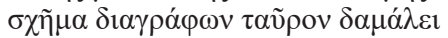

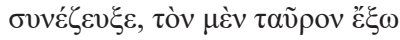

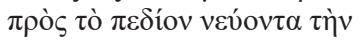

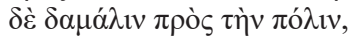

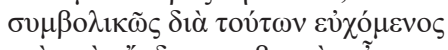

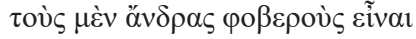

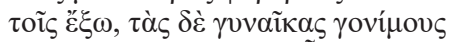

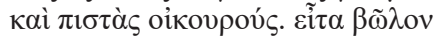

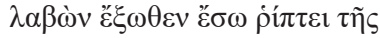

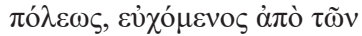

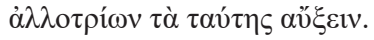

\section{EPL 2 (Laurentianus Plut. 59, 30,} 30r) $)^{120}$

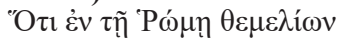
ỏ

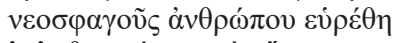

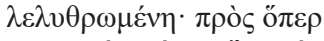

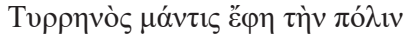
$\kappa \varepsilon \varphi \alpha \lambda \eta े \nu \pi \circ \lambda \lambda \tilde{\omega} v \dot{\varepsilon} \theta v \tilde{\omega} v \ddot{\varepsilon} \sigma \varepsilon \sigma \theta \alpha l$,

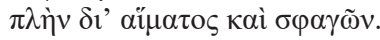

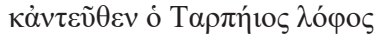

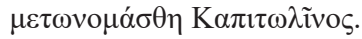

Manasses, Breviarium Chronicum 1620-1631

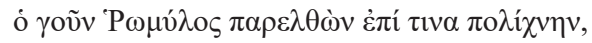

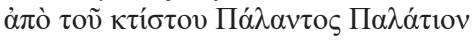

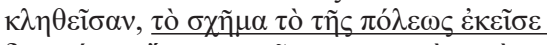

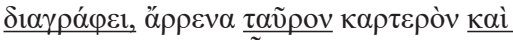

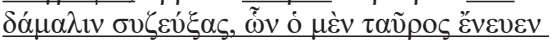

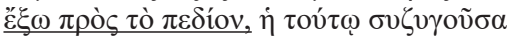

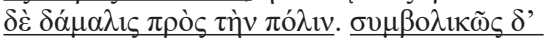

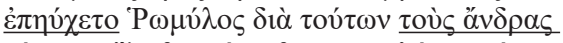

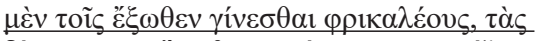

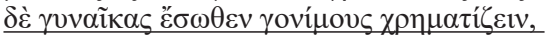

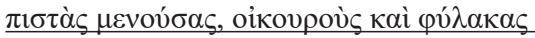

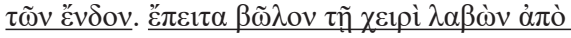

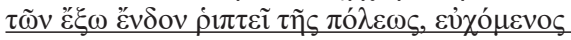

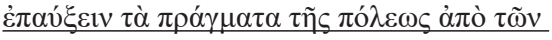
$\dot{\alpha} \lambda \lambda \mathrm{o \tau \rho} \rho \dot{\omega} \omega \mathrm{v}$.

Manasses, Breviarium Chronicum 1671-1681

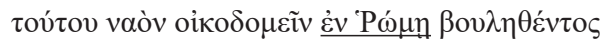

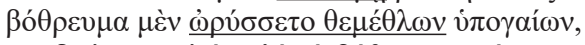

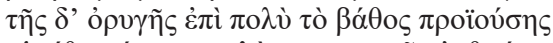

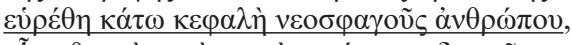

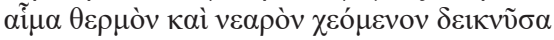

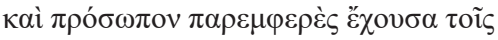

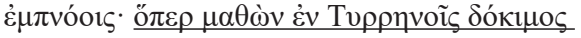

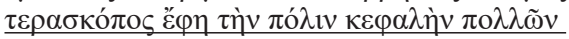

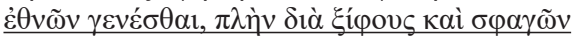

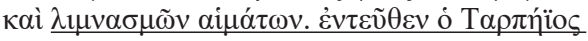
$\mu \varepsilon \tau \omega v 0 \mu \alpha ́ \sigma \theta \eta \lambda$ ó

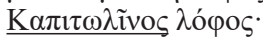

Excerpts 3 and 4 are safely attributed to Paeanius' translation of the Breviarium Historiae Romanae by Eutropius (see Table 5.3).

Excerpt 45 marks a change in the primary source used by Planudes, namely John of Antioch. More specifically, ff. 35r-47v in L contain 291 passages on Roman imperial history taken from: a) the Epitome of Cassius Dio by John Xiphilinus (269 excerpts), b) Paeanius (eighteen excerpts), and c) the now lost chronicle also used by Manasses (four excerpts).

Excerpts 264-267, which derive from Paeanius, are only transmitted in L and Pal and were published by U. P. Boissevain. ${ }^{121}$ One excerpt, which is labelled Excerpt 83 in Mai's edition, is not transmitted in L. ${ }^{122}$ The excerpt is on the life of

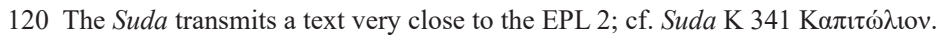

121 Boissevain (1884), 15.

122 The passage is transmitted in Pal. 
Table 5.3 The EPL and Paeanius

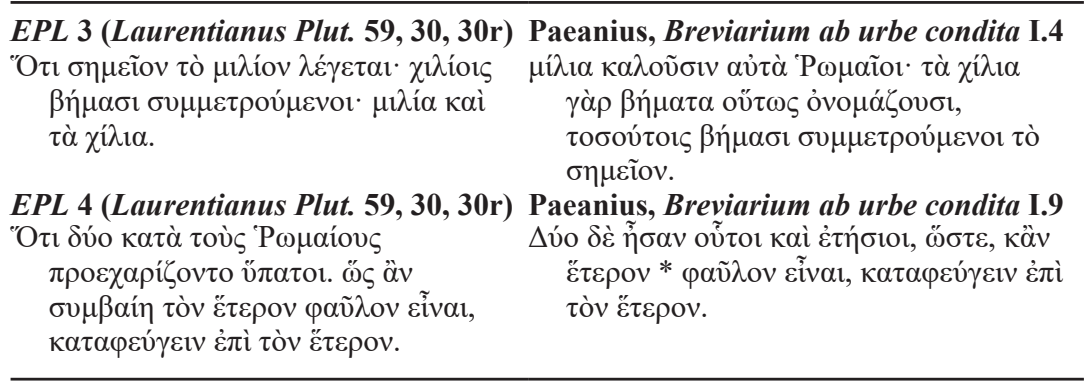

Caligula and derives from Flavius Josephus' Antiquitates Judaicae. ${ }^{123}$ Possibly, the excerpt is a later addition and should not be counted amongst the excerpts on Roman history in the $\Sigma v v \alpha \gamma \omega \gamma \eta^{\prime}$.

To sum up, Maximus Planudes, for the section on Roman history, drew primarily from John of Antioch and Xiphilinus. Planudes enriched the sequence of excerpts on Roman history with excerpts from Paeanius and a lost chronicle, traces of which can be encountered in Manasses and other Byzantine texts from the middle Byzantine period. Table 5.4 shows that the inclusion of the augmented passages possibly served to fill historical gaps in the primary arrangement of excerpts

Table 5.4 Excerpts 45-328 in Laurentianus Plut. 59, 30

\begin{tabular}{|c|c|c|}
\hline Excerpt & Period & Source \\
\hline Excerpts 45-119 & $\begin{array}{l}\text { Last year of the Roman Republic to } \\
\text { the first years of the Principate }\end{array}$ & Xiphilinus \\
\hline Excerpt 120 & Augustus & Lost chronicle \\
\hline Excerpts $121-125$ & From Augustus to Tiberius & Xiphilinus \\
\hline Excerpt 126 & On Tiberius & Lost chronicle \\
\hline Excerpts $127-128$ & On Tiberius & Xiphilinus \\
\hline Excerpt 129 & On Tiberius & Lost chronicle \\
\hline Excerpts $130-250$ & On Tiberius up to Titus & Xiphilinus \\
\hline Excerpts $251-255$ & On Titus & Paeanius \\
\hline Excerpts 256-263 & On Titus & Xiphilinus \\
\hline Excerpts 264-267 & On Traian & Paeanius \\
\hline Excerpts 268-273 & On Traian and Hadrian & Xiphilinus \\
\hline Excerpt 274 & On Hadrian & Paeanius \\
\hline Excerpts $275-325$ & From Hadrian to Sardanapal & Xiphilinus \\
\hline Excerpt 326 & Maximian & Paeanius \\
\hline Excerpt 327 & Constantine Chlorus & Paeanius \\
\hline Excerpt 328 & Gratian & Lost chronicle \\
\hline
\end{tabular}




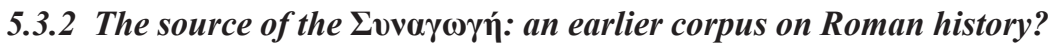

The significance of the codex Athonensis Iviron 812 in identifying the excerpts transmitted in the $\Sigma v v \alpha \gamma \omega \gamma \eta \dot{\eta}$ has already been mentioned. The discovery of the codex by Sp. Lambros corroborated that excerpts in the $\Sigma v v \alpha \gamma \omega \gamma \grave{\eta}$ must be attributed to John of Antioch. In addition to this, the content of Athonensis Iviron 812 led Sp. Lambros to support that excerpts on Roman history in the $\Sigma v v \alpha \gamma \omega \gamma \dot{\eta}$ must have been drawn from an earlier corpus on Roman history compiled by Planudes himself. In what follows, I will present the codex Athonensis Iviron 812 and provide a brief overview of earlier surveys of the relationship between the excerpts transmitted in the $\Sigma v v \alpha \gamma \omega \gamma \dot{\eta}$ and Athonensis Iviron 812.

\subsubsection{The codex Athonensis Iviron 812}

Chartac., ff. 301, $253 \times 165 \mathrm{~mm}(210 \times 120 \mathrm{~mm}), 32-35$ (excerpts from Paeanius); $255 \times 170 \mathrm{~mm}(196 \times 120 \mathrm{~mm}), 30$ (excerpts from John of Antioch); $225 \times 175$ $\mathrm{mm}(208 \times 120), 24-28$ (excerpts from Xiphilinus), saec. XIV. ${ }^{124}$

\begin{tabular}{|c|c|c|}
\hline Folios & Author & Work \\
\hline $1 \mathrm{r}-2 \mathrm{v}, 7 \mathrm{r}-10 \mathrm{v}, 15 \mathrm{r}-92 \mathrm{r}$ & Paeanius & Translation of the Breviarium by Eutropius \\
\hline $3 \mathrm{r}-6 \mathrm{v}, 11 \mathrm{r}-14 \mathrm{v}$ & John of Antioch & excerpts from Historia chronica \\
\hline $92 \mathrm{r}-98 \mathrm{v}$ & Anonymous & 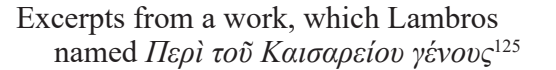 \\
\hline ff. $99 \mathrm{r}-301 \mathrm{v}$ & Xiphilinus & $\begin{array}{l}\text { Epitome of Cassius Dio's Historiae } \\
\text { Romanae }\end{array}$ \\
\hline
\end{tabular}

Many of the folia in Athonensis Iviron 812 are severely damaged to the extent that the text is barely legible. Due to this fact, the observations and remarks made by Sp. Lambros and S. Kugeas on the codex are indispensable for our research. Athonensis Iviron 812 is written in four different hands. According to P. Sotiroudis, the oldest hand is the one that copied the excerpts from Paeanius and the acephalous text titled

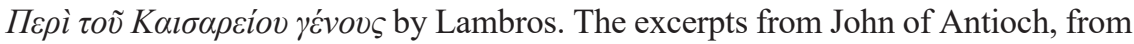
Xiphilinus as well as ff. 208 and 215 were all copied in different hands. ${ }^{126}$

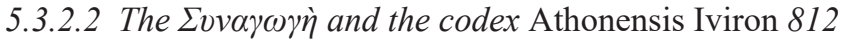

The section on Roman history in the $\Sigma v v \alpha \gamma \omega \gamma \dot{\eta}$ by Planudes consists of excerpts from 1) Paeanius, 2) John of Antioch, 3) Xiphilinus, and 4) an unknown chronicle.

124 On Athonensis Iviron 812, see Lambros (1900), 228; Sotiroudis (1989), 159-164; Roberto (ed.) (2005b), CXII-CXV; Mariev (ed.) (2008), 20-21.

125 The text is concerned with the genealogies of Roman emperors from Gaius Octavius to Nero. The author of the text remains anonymous. Sp. Lambros dated the text to the beginning of the second century AD; 278Lambros (1904), 139. 271Kugeas (1909), 138. Kugeas (1909, 138, n. 6)

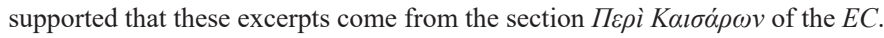

126 Sotiroudis (1989), 162. 
Athonensis Iviron 812 consists of excerpts from the same texts, except for the

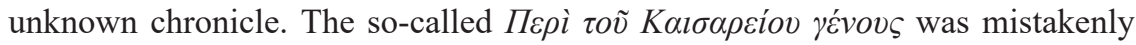
inserted between the excerpts from Paeanius and Xiphilinus by one of the copyists of Athonensis Iviron 812. ${ }^{127}$ It is impossible to know whether Athonensis Iviron 812 also contained parts of the same lost chronicle used by Planudes because the Athonite codex is mutilated both at the beginning and at the end. The congruence in content between the codex Athonensis Iviron 812 and the series of excerpts on Roman history in the $\Sigma v v \alpha \gamma \omega \gamma \dot{\eta}$ is striking, though. S. Kugeas found that excerpts in the $\Sigma v v \alpha \gamma \omega \gamma \eta \dot{\eta}$ exhibit significant textual similarities with excerpts in Athonensis Iviron $812 .{ }^{128}$ Moreover, passages from Athonensis Iviron 812 correspond literally with the EV 17 and EV 18 from John of Antioch. ${ }^{129}$ Depending on this evidence, S. Kugeas showed that a) the $\Sigma v v \alpha \gamma \omega \gamma \dot{\eta}$ definitely transmits passages from John of Antioch and b) all the excerpts on ff. $3 \mathrm{r}-6 \mathrm{v}$ and $\mathrm{ff} .11 \mathrm{r}-14 \mathrm{v}$ in Athonensis Iviron 812 belong to John of Antioch too.

After scholars have come to the conclusion that the excerpts in the $\Sigma v v \alpha \gamma \omega \gamma \dot{\eta}$ could safely be attributed to John of Antioch, the next question that remained open was whether Planudes made direct use of John of Antioch's chronicle or not. To U. P. Boissevain and G. Sotiriadis it seemed likely that Planudes drew from a sylloge of excerpts taken from John of Antioch. ${ }^{130}$ In G. Sotiriadis' view, the $\Sigma v v \alpha \gamma \omega \gamma \dot{\eta}$ and Athonensis Iviron 812 drew on a different tradition. ${ }^{131}$ This view was contradicted by S. Kugeas' textual comparison between the $\Sigma v v \alpha \gamma \omega \gamma \dot{\eta}$ and Athonensis Iviron 812. S. Kugeas found that excerpts in L on both the Roman Republic (excerpts from John of Antioch) and the Roman imperial period (excerpts from Xiphilinus and Paeanius), bear significant textual similarities with excerpts in Athonensis Iviron 812. ${ }^{132}$ Despite the textual similarities, S. Kugeas was not convinced that Athonensis Iviron 812 was a direct copy from the $\Sigma v v \alpha \gamma \omega \gamma \eta$. Indeed, there are textual variations between Athonensis Iviron 812 and the $\Sigma v v \alpha \gamma \omega \gamma \dot{\eta}$, which do not support an immediate dependence of Athonensis Iviron 812 on the $\Sigma v v \alpha \gamma \omega \gamma \eta{ }^{133}$ The textual congruences indicate that the common excerpts between

127 Kugeas (1909), 138-139.

128 In particular, seven excerpts (37-43) correspond to passages in Athonensis Iviron 812: EPL $37=$ 17, 10 Lamb.; EPL 38 = 20, 5 Lamb.; EPL 39 = 21, 16 Lamb.; EPL 40 = 25, 24 Lamb.; EPL $41=$ 26, 24 Lamb.; EPL 42 = 28, 9 Lamb.; EPL 43 = 30, 3 Lamb.; cf. Kugeas (1909), 128-132.

129 See Appendix I: Text V.

130 Sotiriadis (1888), 51; Boissevain, Cas.Dio. v.I, praef. CXII.

131 Sotiriadis (1888), 51.

132 It is certain that Athonensis Iviron 812 is dated shortly after Planudes' death. The excerpts from John of Antioch preserved in Athonensis Iviron 812 were first published by Sp. Lambros; cf. Lambros (1904), 13-31. Emendations and additions to the text were published by Sp. Lambros in Lambros (1904), 244, 495-498; Lambros (1905), 240-241, 503-506; Lambros (1906), 124-126; see also Mariev fr. 98 and Roberto fr. 145.1-3. On the excerpts from John of Antioch, see also Walton (1965), 236-251.

133 Kugeas (1909), 141. Diller argued in favour of a direct relationship between the two manuscripts, as well. According to him, Athonensis Iviron 812 is a copy from a Planudean manuscript, though; cf. Diller (1937), 299. 
the $\Sigma v v \alpha \gamma \omega \gamma \dot{\eta}$ and Athonensis Iviron 812 derive from a manuscript which was either the archetype of Athonensis Iviron 812 or a codex stemming from the same archetype as Athonensis Iviron 812. ${ }^{134}$

Furthermore, S. Kugeas attempted to reconstruct the manuscript now lost

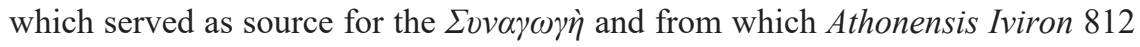
possibly is an exact copy. He conjectured that the lost manuscript must have contained texts on Roman history only, written by Paeanius, John of Antioch, Xiphilinus, and perhaps an unknown chronicle used by Manasses and other Byzantine authors. ${ }^{135}$ Such a collection could only have been made after the eleventh century. ${ }^{136}$ S. Kugeas conjectured Maximus Planudes himself as the compiler of this collection and he argued that the excerpts on Roman history in Planudes' $\Sigma v v \alpha \gamma \omega \gamma \eta \dot{\eta}$ must be passages extracted and re-edited from the manuscript of the aforementioned collection. ${ }^{137}$ The assiduous research carried out by P. Sotiroudis on the subject confirmed S. Kugeas' assertion on the Planudean authorship of the manuscript used as source for the $\Sigma v v \alpha \gamma \omega \gamma \eta^{138}$

Finally, S. Kugeas ascribed the presence of Excerpts $1-5$ at the beginning of the series (excerpts that are not from John of Antioch) to the fact that the manuscript used by Planudes was mutilated. ${ }^{139}$ That is why Planudes attempted to fill the gap in John of Antioch's deficient manuscript in his possession by drawing on a) an unknown chronicle (Excerpts 1-2), b) Paeanius (Excerpts 3-4), and c) John Lydus (Excerpt 5).

\subsubsection{Excerpting John of Antioch and Xiphilinus}

The establishment of the textual relationship between the $\Sigma v v \alpha \gamma \omega \gamma \dot{\eta}$ and Athonensis Iviron 812 enables us to study and comprehend the excerpting method applied by Planudes in the section on Roman history of the $\Sigma v v \alpha \gamma \omega \gamma \eta$.

\section{a) John of Antioch}

As already mentioned, the first part on Roman history in the $\Sigma v v \alpha \gamma \omega \gamma \dot{\eta}$ is mainly made up of passages taken from John of Antioch. A large number of excerpts in the $\Sigma v v \alpha \gamma \omega \gamma \eta$ are unique and thus essential for the reconstruction of the chronicle by John of Antioch as transmitted through the EC, the Suda, the Exc.Salm.I, and Athonensis Iviron 812. The passages in the Suda derive from the EC, whereas as shown above (Section 5.3.2), the Evva survived in the Athonensis Iviron 812 tradition; most likely from the archetype of Athonensis Iviron 812. The textual comparison of the two passages common

134 Kugeas (1909), 142.

135 The mutilated Athonensis Iviron 812 is not helpful on that.

136 The Epitome of Dio by Xiphilinus was prepared by order of Michael VII Doukas (1071-1078).

137 Kugeas (1909), 144-146.

138 Sotiroudis (1989), 163-164.

139 Kugeas (1909), 136. 
to the EC and Athonensis Iviron 812 (see Appendix I: Text V) demonstrates a) that the author of the archetype of Athonensis Iviron 812 had direct access to the chronicle by John of Antioch and b) Athonensis Iviron 812 contains a text impressively close to the $E C$, which, in turn, makes it seem likely that Athonensis Iviron 812 is probably an exact copy of its archetype.

Given these facts, in studying the excerpting method of Planudes, it would be safer to rely on a comparison between the $\Sigma v v \alpha \gamma \omega \gamma \eta$ with both, Athonensis Iviron 812, as well as the $E C$ tradition of John of Antioch. In particular: a) sixteen

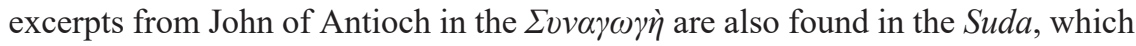
reflects the $E C$ tradition, ${ }^{140}$ and b) seven Planudean excerpts from John are also transmitted in Athonensis Iviron 812, ${ }^{141}$ c) three of the latter excerpts are also included in the Suda, and d) three Planudean excerpts from John of Antioch are preserved in the $E C$.

Upon closer examination of the common passages in the aforementioned works, we come to the following particular conclusions about Planudes' excerpting method: Planudes' intervention in the original text is restricted to a) textual additions, b) to the replacing of words with others that explain the text better, and c) to textual omissions. Planudes resorted to the aforementioned strategies to solve the problem of inadequate contextualisation resulting from taking a passage out of its original textual context. Let us see how the strategies play out in passages excerpted from John of Antioch.

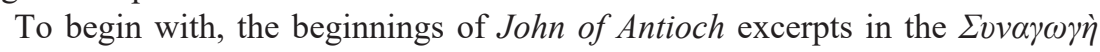
deviate in vocabulary and syntax from the texts transmitted both in the Suda and in Athonensis Iviron 812. ${ }^{142}$ In fact, the opening of each excerpt always sums up the context of the respective passage in the Suda and Athonensis Iviron 812. The rest of the Planudean excerpts, correspond in general but not without exceptions to the text as preserved either in the Suda or the Athonensis Iviron 812. To give but a number of examples, the EPL 35 is an excerpt included in both the $E C$ and

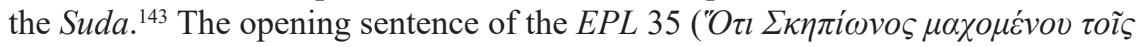
'I $\beta \eta \rho \sigma l v)^{144}$ serves to introduce us to the historical context of the passage, presented in detail at the beginning of the excerpt in the $E C$ (EI 22). What follows in the EPL 35 is textually very close to the text in both the EI 22 and the Suda B 396.

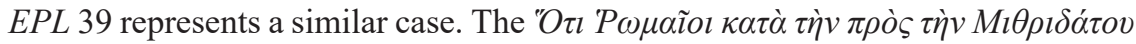

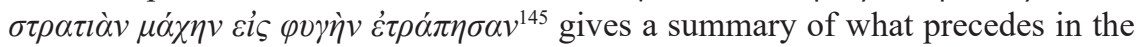
text of Athonensis Iviron 812. The rest of the EPL 39 is copied verbatim from the original John of Antioch. The closing sentence in the EPL 39 ( $\kappa \alpha i \tau \tilde{\omega} v \pi o \lambda \varepsilon \mu i \omega v$ $\varepsilon \kappa \rho \alpha \dot{\tau} \eta \eta \sigma \nu)^{146}$ epitomises the last part of the text in the Athonensis Iviron 812.

140 See Mariev (ed.) (2008), esp. 8*-13*.

141 See n. 128.

142 All passages are published in Appendix I: Text VI.

143 See Appendix I: Text VI.

144 That when Scipio fought against the Iberians.

145 That the Romans, in the face of Mithridates' army, fled during the battle.

146 And they prevailed over their enemies. 
The same strategy is detected in passages from the Evvaywri preserved in the Suda only (see Table 5.5). To cite but some instances, the first sentence in EPL 11 sums up the context of the first half of the Suda T 791. The rest of the EPL 11 coincides verbally with the entry in the Suda. The introductory statement "O $O \tau$

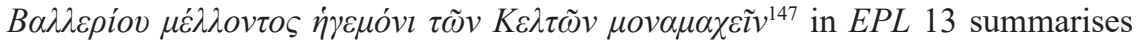
the first half of the Suda K 1307. EPL 22 is identical with the Suda $\Phi 5$ but for the first two lines, which are abbreviated in the $\Sigma v v \alpha \gamma \omega \gamma \dot{\eta}$. EPL 25 transmits a text that is contained in the Suda P 126. The beginning and the ending of the EPL 25 are summaries of the equivalent parts in the Suda, but the rest is preserved.

Notwithstanding this clear pattern, the case of EPL 12 should be indicative of the caution with which to examine the relationship between the $\Sigma v v \alpha \gamma \omega \gamma \eta \dot{\text { and the }}$

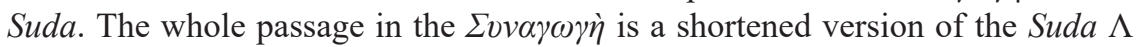

Table 5.5 The EPL in the Athonensis Iviron 812, the Suda, and the EC

\begin{tabular}{|c|c|c|c|}
\hline$E P L^{148}$ & $\begin{array}{l}\text { Athonensis Iviron } \\
812\end{array}$ & Suda & $E C$ \\
\hline 5 (fr. $32 \mathrm{M})$ & & $\Delta 1112, \Delta 1 \kappa \tau \alpha ́ \tau \omega \rho$ & \\
\hline 6 (fr. $21 \mathrm{M})$ & & В 451, Воvодойбкоч & \\
\hline $10($ fr. $41 \mathrm{M})$ & & 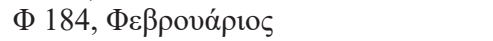 & \\
\hline 12 (fr. $22 \mathrm{M})$ & & 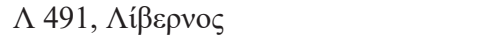 & \\
\hline 11 (fr. $45 \mathrm{M})$ & & Т 791, Торкоча̃ $\tau о \varsigma$ & \\
\hline 13 (fr. $47 \mathrm{M})$ & & 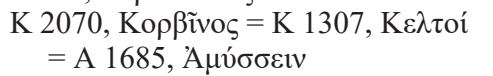 & \\
\hline 15 (fr. $46 \mathrm{M})$ & & 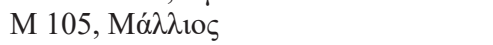 & \\
\hline $16($ fr. $50 \mathrm{M})$ & & 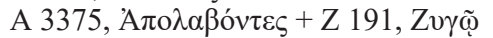 & \\
\hline 22 (fr. $60 \mathrm{M})$ & & 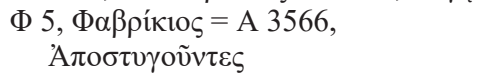 & \\
\hline 25 (fr. $64 \mathrm{M})$ & & 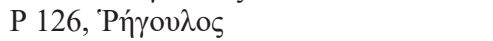 & \\
\hline 27 (fr. $73 \mathrm{M})$ & & 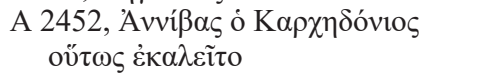 & \\
\hline 33 (fr. $83 \mathrm{M}$ ) & & 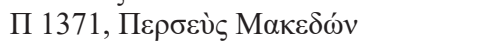 & \\
\hline 35 (fr. $91 \mathrm{M})$ & & 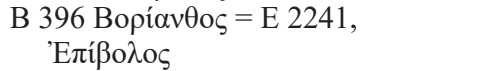 & EI 22 \\
\hline 37 (fr. $98.7 \mathrm{M}$ ) & p. $118.3-120.6 \mathrm{M}$ & $\Sigma 1337, \Sigma \hat{\lambda} \lambda \lambda \alpha_{\varsigma}$ & \\
\hline 38 (fr. $98.11 \mathrm{M})$ & p. $126.1-11 \mathrm{M}$ & 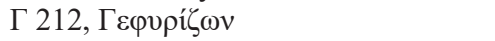 & \\
\hline 39 (fr. $98.12 \mathrm{M})$ & p. $128.6-11 \mathrm{M}$ & & \\
\hline 40 (fr. $98.19 \mathrm{M})$ & p. $136.9-16 \mathrm{M}$ & $\Sigma 1337, \Sigma v ́ \lambda \lambda \alpha \varsigma$ & \\
\hline 41 (fr. $98.21 \mathrm{M})$ & p. $140.2-142.6 \mathrm{M}$ & & $\begin{array}{c}E V 18(\mathrm{p} .172 \\
3-173,9)\end{array}$ \\
\hline 42 (fr. $98.21 \mathrm{M}$ ) & p. $144.1-7 \mathrm{M}$ & & $\begin{array}{c}E V 18(\text { p. } 172, \\
3-173,9)\end{array}$ \\
\hline 43 (fr. $98.23 \mathrm{M}$ ) & p. $146.15-17 \mathrm{M}$ & & \\
\hline
\end{tabular}

147 That Valerius who is about to fight in single combat against the Gallic leader.

148 The numeration of the excerpts in the parenthesis is the one given by Mariev (ed.) (2008) in his edition of John of Antioch. 
491, even if the structure was not changed. There is a difference in vocabulary, though: the $\sigma v v i o ́ v \tau o \varsigma$ and the $\kappa \alpha \rho \pi \circ \tilde{v} \tau \alpha l$ are words not present in the Suda, pointing either to a different tradition or additions on the part of Planudes himself. The same holds true for EPL 10. EPL 10 summarises the text in the Suda $\Phi$ 184, with the exception of the last sentence, which is literally transmitted in the Suda,

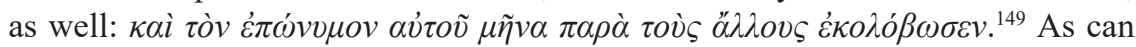
be seen in Appendix I: Text VI, EPL 37, EPL 38, and EPL 40 transmit passages from John of Antioch, preserved in both Athonensis Iviron 812 and the Suda. ${ }^{150}$ It is noteworthy that the beginning of EPL 38 ("O

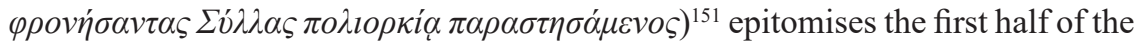
respective passage in Athonensis Iviron 812. EPL 40 presents a shortened version of the text in Athonensis Iviron 812 and the Suda $\Sigma 1337$ by omitting a significant part of the original text.

The vocabulary that Planudes uses when summarising the original text, is not always transmitted in the entries of the Suda, but it is difficult to assign such additions to Planudes himself. Table 5.5 shows that we are in the fortunate position of having three excerpts from John of Antioch that were transmitted in the $\Sigma v v \alpha \gamma \omega \gamma \eta$, the codex Athonensis Iviron 812 and the Suda, two excerpts preserved in the $\Sigma v v \alpha \gamma \omega \gamma \eta$, the codex Athonensis Iviron 812 and the EC, and one excerpt found in the $\Sigma v v \alpha \gamma \omega \gamma \eta$, the Suda and the EC, respectively. As shown in Appendix I, Text VI, each deviation between the $\Sigma v v \alpha \gamma \omega \gamma \dot{\eta}$ and the $E C$ tradition (including the $S u d a$ ) comes through the Athonensis Iviron 812 tradition. I cite two examples:

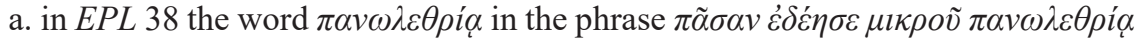

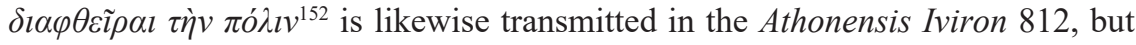

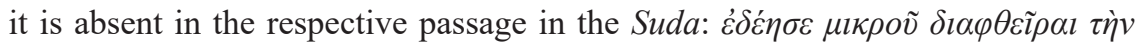
$\pi o ́ \lambda l v$, and b. the case of the EPL $40=$ Athonensis Iviron $812($ fr. $98.19 \mathrm{M})=S u d a$ $\Sigma 1337$ is revealing. The text in Planudes is obviously derived from the Iviron tradition as the occurrences of the $\sigma \pi \tilde{\alpha} \sigma \alpha l$ and $\tau \grave{\eta} v$ indicate. ${ }^{153}$

Finally, there are excerpts in the $\Sigma v v \alpha \gamma \omega \gamma \dot{\eta}$ preserving a text better than the one surviving in the $E C$ tradition of John of Antioch. EPL 16 transmits a text longer than the one recorded in the Suda. In fact, the beginning of the Planudean passage helped the last two editors of John of Antioch to restore the text of two entries in

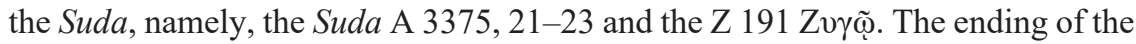
$E P L 16$ is only recorded in the $\Sigma v v \alpha \gamma \omega \gamma \eta$. Similarly, EPL 27 and EPL 33 appear to enrich passages from John of Antioch transmitted in the Suda in terms of content.

149 The month named after him was also shortened in comparison with other months; cf. Mariev (ed.) (2008), 55.

150 I would like to note that the text in Athonensis Iviron 812 is strikingly close to the one in the Suda. Once again this indicates that the archetype of Athonensis Iviron 812 contained the original by John of Antioch in its entirety and that Athonensis Iviron 812 must be an exact copy of its archetype.

151 That after the Athenians sided with Methridates, Sulla was prompted to besiege (the city).

152 Almost destroying the city completely; cf. Mariev (ed.) (2008), 127.

153 Appendix I: Text VI. 


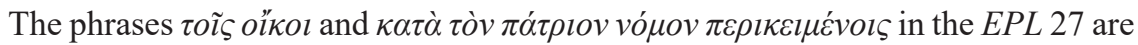

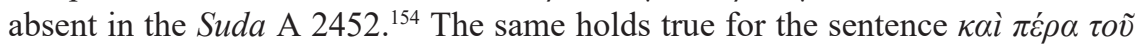

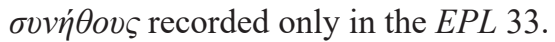

\section{b) Xiphilinus}

The second section on Roman history comprises passages from the Epitome of Cassius Dio by John Xiphilinus, excerpted by employing a method similar to the one applied to the chronicle by John of Antioch. The compiler keeps to the narrative sequence within each passage. The content and structure of the passages survive unaltered. The text was copied, in the main verbatim, from the original. Changes on the part of Planudes consist in omissions and simplifications.

Table 5.6 provides us with the text of two excerpts from Xiphilinus. In EPL 45

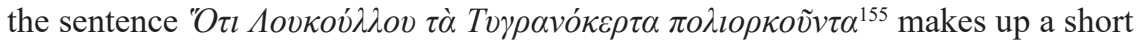
introduction, composed by Planudes himself, who combined a few words from the original text. The beginning of the text is altered in EPL 47 in the same way:

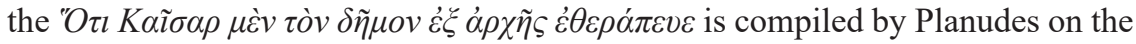
basis of words taken from the original text.

Table 5.6 Xiphilinus' Epitome in the EPL

\section{EPL 45}

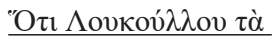

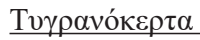

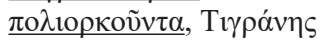

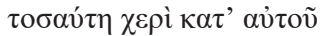

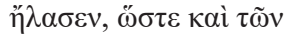
$\dot{\varepsilon} \kappa \varepsilon \tilde{\imath}{ }^{\top} \mathrm{P} \omega \mu \alpha \dot{i} \omega v$

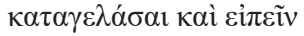

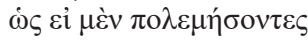

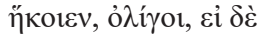
$\pi \rho \varepsilon \sigma \beta \varepsilon v ́ \sigma o v \tau \varepsilon \varsigma, \pi \circ \lambda \lambda \mathrm{oì}$ $\pi \alpha \rho \varepsilon \tilde{\imath} \varepsilon v$.

\section{EPL 47}

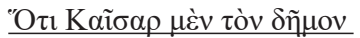

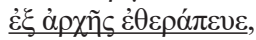

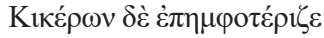
$\tau \hat{\alpha} \pi \mathrm{o} \lambda \lambda \grave{\alpha} \kappa \alpha \grave{~} \pi \mathrm{o} \tau \dot{\varepsilon} \mu \dot{\varepsilon} v$ $\tau \tilde{\omega} \delta \dot{\eta} \mu \omega, \pi \mathrm{o} \tau \dot{\varepsilon} \delta \dot{\varepsilon} \tau \tilde{\eta}$

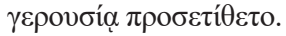

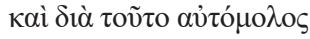

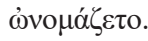

\section{Xiphilinus, Epitome p. 1-2 ed. Dindorf}

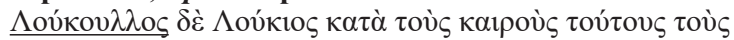

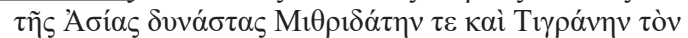

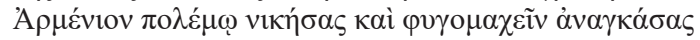

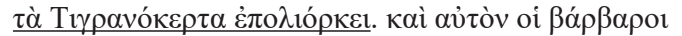

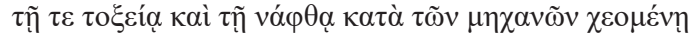

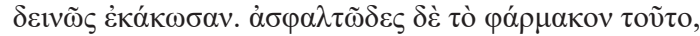

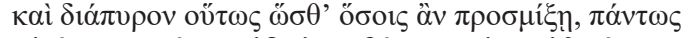

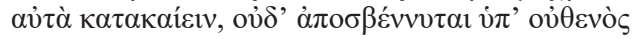

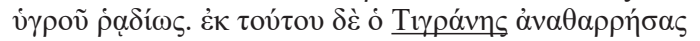

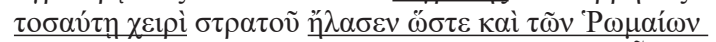

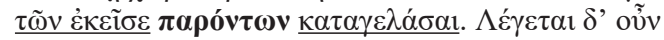

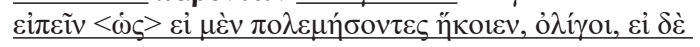
$\pi \rho \varepsilon \sigma \beta \varepsilon v ́ \sigma 0 v \tau \varepsilon \zeta, \pi 0 \lambda \lambda$ ò̀ $\pi \alpha \rho \varepsilon \tilde{\varepsilon} \varepsilon v$.

Xiphilinus, Epitome p. 5 ed. Dindorf

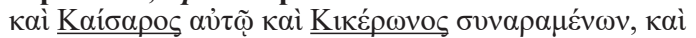

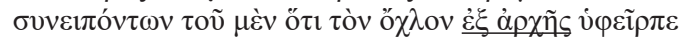

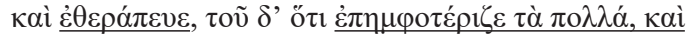

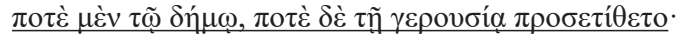

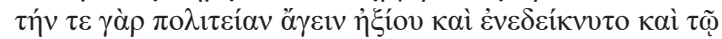

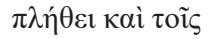

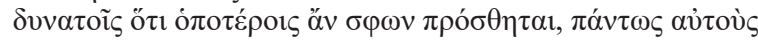

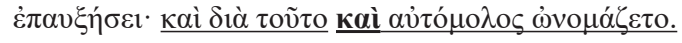


To sum up, the process of redacting the $\Sigma v v \alpha \gamma \omega \gamma \eta \dot{\eta}$ was based on compositional principles seen in earlier collections of historical excerpts. Planudes retained the language and style of the original text, respected the original sequence of excerpts, and aimed at brevity and accuracy. The analysis of single excerpts on Roman history in L showed that Planudes was familiar with the issue of flawed contextualisation caused by the excerpting method. It became manifest that in reediting selected passages from John of Antioch and Xiphilinus, Planudes resorted to the same strategies as earlier compilers of excerpt collections: a) addition of an introductory sentence into the excerpts - the insertion was made up of material from the original text, b) omissions, and c) substitution of words.

\subsubsection{Thematisation ${ }^{156}$ of history in the Excerpta Planudea}

This section considers the literary and political function served by the sequence of excerpts on Roman history in Planudes' $\Sigma v v \alpha \gamma \omega \gamma \eta$. In particular, in what follows it shall be shown that Planudes made a conscious extraction of thematically connected historical passages on Roman history. His material selection hints at his aim a) to supply people with moral examples concerning behavioural patterns and b) to shape cultural and political thinking. These two objectives of Planudes will be discussed in the following by focusing on excerpts $1-44$, that is, the passages on the Roman Republic.

\subsubsection{Andronicus II}

Before presenting my views of the function of the passages on Roman history in the $\Sigma v v \alpha \gamma \omega \gamma \eta \dot{n}$, a few preliminary considerations are needed. Andronicus II (1282-1328) succeeded his father Michael VIII (1259-1282) to the throne in 1282. He was much more educated than his father but proved to be less competent in military and political affairs. His reign signified what came to be called in histories of Byzantium the beginnings of the decline of the Empire. ${ }^{157}$ Militarily, the Empire lost control over most of the cities in Asia Minor. ${ }^{158}$ In fact, the situation in Anatolia begun to deteriorate largely during the reign of his father. ${ }^{159}$ Michael VIII's political agenda had been dominated by his desire to unify the Eastern and Western Churches. As a result, Michael VIII busied, primarily, himself with the diplomatic negotiations with the West and neglected, to a catastrophic extent, the defences in Asia Minor. Only shortly before his death, he seemed to realise

156 The term is borrowed from Signes Codoñer (2016), 250. J. Signes Codoñer uses the term to identify historical texts in which the material was ordered according to themes. J. Signes Codoñer seems, however, to share A. Németh 's assertion that such texts were only produced during Constantine Porphyrogenitus' reign.

157 See esp. Laiou (1972).

158 After 1304, the Turks controlled virtually all of Asia Minor; cf. Laiou (1972), 290; Fryde (2000), 93.

159 In 1255 the Mongols invaded eastern and central Anatolia and caused many Turkic people to gradually spread across western Anatolia; Gregory (2005), 303. 
the necessity of paying more attention to Anatolia. His son, Andronicus II, being aware of the plight of the Byzantine lands in the east, passed three years (12901293) in Asia Minor striving to strengthen the defences there. He also attempted to face the situation by appointing members of the imperial family as provincial governors, that is, sort of semi-independent rulers of parts of the Empire. His policies, partly influenced by Western concepts of political power, gave a lot of power to provincial aristocrats who in turn used their strength to avoid paying taxes. ${ }^{160}$ The difficult economic situation led Andronicus to a series of economic measures: a) he imposed a new tax, the so-called sitokrithon which was a tax on land paid in kind, b) he eliminated tax exemptions and, c) he reduced the army and the navy. Such retrenchment affected the military capacity of the Empire and made any territorial recovery in the Balkans and in Asia Minor impossible. By the beginning of the fourteenth century, Asia Minor had been divided into many Turkic emirates. ${ }^{161}$

On the other hand, Andronicus II was much interested in culture and education. Pachymeres and Gregoras' histories call attention to Andronicus II's intellectual interests (theological, philosophical, and scientific). ${ }^{162}$ It is not a coincidence that his circle involved highly educated men, such as Nikephoros Chumnos and Theodore Metochites ${ }^{163}$ Scholars active in the Paleologan period were fond of recovering and restoring ancient Greek texts. ${ }^{164}$ Andronicus II was a generous patron of scholars in Constantinople as well as in other cities. John Pediasimos, Thomas Magistros, and Demetrios Triklinios, for instance, are three prime examples of Paleologan scholars who lived and worked in Thessaloniki. ${ }^{165}$ There is some evidence that, from the end of the thirteenth century, more people - not necessarily members of aristocratic families - could have access to higher education. If this was the case, the audience for ancient Greek literature would have been broader in the Paleologan period. It is notable, that during Andronicus II's reign, a considerable number of ancient poetic and prose texts were edited and commented. ${ }^{166}$ Most of the texts were intended to

160 Gregory (2005), 299.

161 On the matter, see Vryonis (1971).

162 Laiou (1972), 8.

163 Chumnos was a chief minister of Andronikos II for eleven years (1294-1305). He composed significant treatises on philosophy and cosmology. Metochites succeeded Chumnos as chief minister (1305-1328). He wrote on philosophy and astronomy as well as a collection of poems. Metochites was also a patron of the arts. He commissioned the restoration and decoration of the church attached to the monastery of Chora. On Chumnos, see Verpeaux (1959); Chrestou (2002); Amato and Ramelli (2006), 1-40. On Metochites' life and writings, see Fryde (2000), 322-337; Bazzani (2006), 32-52; Polemis (2017). On the personal relationship of the two Byzantine scholars, see Ševčenko (1962).

164 On the editorial activities of scholars of the Paleologan period, see Wilson (1996), 241-264; Ševčenko (1984), 144-171. Fryde (2000), 144-164 provides us with bibliography on Byzantine editions of ancient Greek literature.

165 On the scholarly writings and teaching activities of Triklinios and Magistros in Thesaloniki, see Nicol (1986), 121-131; Fryde (2000), 213-224, 268-290; 297-301; Niels (2011).

166 An overview of the editions of classical literary works by prominent figures of the Paleologan period (Triklinios, Thomas Magistros, Moschopoulos) is provided by Fryde (2000); Niels (2011). On Pediasimos, see Constantinides (1982), 116-122. On Triklinios' editions of the three Athenian dramatists 
be used in schooling, since most of the scholars of the Paleologan period were also teachers at schools in Constantinople and in Thessaloniki. ${ }^{167}$

\subsubsection{Planudes' advice literature}

Maximus Planudes was amongst those highly educated men favoured by Andronicus II. ${ }^{168}$ It is worth mentioning, that the emperor entrusted Planudes with two important diplomatic missions, the first to Cilician Armenia in 1295, and the second to Venice in $1297 .{ }^{169}$ In the year 1294, Michael IX, the son of Andronicus II, was crowned co-emperor. ${ }^{170}$ The emperor invited Planudes to deliver a panegyric celebrating the coronation. Planudes wrote and delivered his

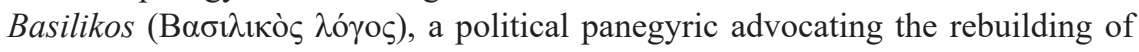
the Byzantine military fleet and an aggressive military policy against Byzantium's enemies. In the Basilikos, praise of the new co-emperor is combined with criticism of Andronicus II's military achievements. ${ }^{171}$ The text appears a) to provide the new co-emperor with advice on imperial external policy and b) to disapprove of Andronicus' decision to dismantle the Byzantine fleet in 1285. ${ }^{172}$

Composers of panegyrics aimed at self-promoting as well as at advertising their standpoints in terms of politics. As D. Angelov showed, rhetoricians of the last decades of the fourteenth century were not hesitant to deal with imperial foreign and military policy. Orators were willing to use their speeches in order to voice views on imperial policy. ${ }^{173}$ Their interest in conveying political messages

(Aeschylus, Sophocles, Euripides), of Aristophanes' comedies, and of poems by Hesiod, Pindar, and Theocritus, see Wilson (1996), 249-256; Fryde (2000), 268-290. On Thomas Magistros' lexicon of Attic words, see Ritschl (ed), 1832; Wilson (1996), 247-248. A recension of a number of Pindar's poems is attributed to him by Triklinios; cf. Irigoin (1952), 181. On Thomas' commentaries on the three ancient Greek tragedians, see Schartau (1973); Kopff (1976); Fryde (2000), 299-301.

167 During the reign of Michael VIII (1258-1282), George Akropolites, Gregory of Cyprus, and George Pachymeres were active as teachers in Constantinople. George Akropolites was in charge of a school of higher education. Gregory of Cyprus presided over a school at the monastery of Akataleptos in Constantinople from 1274 until 1283; cf. Constantinides (1982), 32-34, 59, 64; Fryde (2000), 87-88. Under the reign of Andronicus II, Maximus Planudes, Manuel Holobolos, and Manuel Moschopoulos taught at schools attached to imperial monasteries in Constantinople. John Pediasimos, Demetrios Triklinos, and Thomas Magistros are three Byzantine scholars who lived and taught in Thessaloniki; Constantinides (1982), 54, 68-71, 116-122; Fryde (2000), 297-301.

168 Planudes rediscovered a manuscript containing the Geographia of Ptolemy (second c. AD), a fact that was much appreciated by Andronicus II. Planudes prepared and donated the emperor a luxurious copy of the text (Vaticanus Urbinatus 82); Fryde (2000), 92.

169 Planudes did not, finally, take part in the mission to Armenia in 1295; cf. Treu (ed.) (1890), 159. See also in Laiou (1972). On the mission to Venice, see Pachymeres, III.ix.21, 269-271.

170 Laiou (1972), 50.

171 The text was edited by Westerink (1966), 98-103; (1967), 54-67; (1968), 34-50. Modern scholars classify the text as a political panegyric; Angelov (2003), 55-63. The genre of political panegyric is discussed by Planudes in his commentary on the Hermogenian corpus; Angelov (2006), 168.

172 Angelov (2003), 55-63; Angelov (2006), esp. 172-178.

173 Angelov (2006), esp. 169-178. 
to their emperors and audiences should be viewed against the military and political circumstances of the period. Indeed, parts of their speeches often address the weakness of the Empire to protect its lands in the Balkans and in Asia Minor, and to get rid of the Latins in Constantinople. ${ }^{174}$ Planudes, as his Basilikos reveals, was not an exception to this tendency. ${ }^{175}$ Yet, the political agenda attested in his political panegyric is also detected in the $\Sigma v v \alpha \gamma \omega \gamma \eta$. The $\Sigma v v \alpha \gamma \omega \gamma \eta \dot{\eta}$ as a whole, no doubt, was meant to advance Planudes' literary interests. The structure and content of the $\Sigma v v \alpha \gamma \omega \gamma \dot{\eta}$ suggest that it consists of passages selected for teaching. ${ }^{176}$ Yet, the selective use of passages on Roman history indicates that their source (the collection of historical excerpts which the Roman section in the $\Sigma v v \alpha \gamma \omega \gamma \dot{\eta}$ and Athonensis Iviron 812 come from) ${ }^{177}$ targeted a broader readership. For instance, among the target audience of Planudes must also have been literate men fleeing Anatolia to Constantinople at the end of the thirteenth century. ${ }^{178}$ Beside an edifying moral purpose, the section on Roman history bears a veiled criticism on Andronicus II's external policies. The hypothesis that Planudes could also aim to convey a political message to the emperor himself cannot be excluded. The case of the Basilikos shows that criticism was also a form of counselling the emperor.

The genre of political panegyric was definitely a direct way of giving advice in the context of an encomium. ${ }^{179} \mathrm{~A}$ panegyric enabled orators to mix praise and counsel. Planudes' admiration of the abilities of Michael IX, in the Basilikos, reveals Planudes' hope that the new emperor would be more eager to fight the Turks in Anatolia. ${ }^{180}$ And a little further on in the same text, Planudes counsels the emperor to have no confidence in the words of his enemies; the emperor, instead, must prefer warfare to diplomacy in dealing with them. ${ }^{181}$ Planudes voiced similar views on imperial policy in his selection of passages on Roman history. Elements of counsel and political opinion, seen in the Basilikos, were introduced by Planudes in his collection of historical excerpts. Specifically, as shall be shown in the next section, in order to promote his own political agenda and convert the readers to his point of view, Planudes employed rhetorical strategies he borrowed from the genre of political panegyric, namely praise and irony. ${ }^{182}$ Both rhetorical

174 See for instance the speeches by Planudes, Metochites, and Chumnos discussed by Angelov (2006), 161-180.

175 Planudes was well acquainted with rhetoric as well as the political use of panegyrics; Angelov (2006), 177.

176 See Kugeas (1909), 134; Fryde (2000); Ferroni (2011), 342.

177 On Planudes' authorship of the collection, see Section 5.3.2.

178 Vryonis (1971), esp. 249-255. Browning mentions that some of them, such as George Karbones, became notable scholars and teachers in Constantinople; cf. Browning (1989), 230-231.

179 Angelov (2003), 58.

180 Angelov (2006), 176.

181 Basilikos, 44.1226-1230.

182 Orators of the Paleologan period resorted heavily to such rhetorical devices. It is noteworthy that Planudes discusses the literary form of the political panegyric in his scholia on Hermogenes; Angelov (2006), 173-174. 
devices enabled Planudes to criticise imperial policy and promote his own political views.

\subsubsection{The arrangement of excerpts on Roman history}

This section argues that the selection of passages on Roman history in the $\Sigma v v \alpha \gamma \omega \gamma \eta \dot{\eta}$ aimed a) to set out the standard arsenal of Roman virtues and b) to convey messages to the emperor and his entourage about imperial foreign policy. As it shall be shown, the $\Sigma v v \alpha \gamma \omega \gamma \eta \dot{y}$ abounds with edifying examples taken from the Republic history. The presentation of the actions of emperors in a period during which a war is taking place is an element that Planudes borrowed from panegyrics. ${ }^{183}$ By stressing imperial wartime virtues, Planudes offered a veiled criticism of the current emperor. The excerpted passages point out the traditional warrior skills of the Romans and highlight the fact that the Romans had always been a warlike people and enjoyed great victories over their enemies. The focus lies in the military successes of Roman emperors and in the glorious past of the city of Rome. For the Byzantines considered the Romans as their honoured ancestors, and Constantinople as the new Rome. It is not a coincidence that in the Basilikos, Planudes stresses the fact that the emperor should regard himself a descendant of the Romans. ${ }^{184}$ What follows in the Basilikos is a laudation of the Romans' warrior abilities and their victories at war. ${ }^{185}$ Planudes concluded that the Romans have always been disposed towards military actions. ${ }^{186}$ The passages in the $\Sigma v v \alpha \gamma \omega \gamma \dot{\eta}$ make clear that Romans' superiority over their enemies at war was due to traditional Roman virtues, such as military excellence, strict discipline, and patriotism. Like in the case of the Basilikos, the praise of the Romans in the $\Sigma v v \alpha \gamma \omega \gamma \dot{\eta}$ is meant to urge immediate military action on the part of Andronicus II.

\section{a) Praise}

To begin with, a considerable number of excerpts are concerned with the virtue of military excellence. The passages praise the edifying conduct of individual Roman emperors or generals. Specifically, EPL 6 transmits that Marcius,

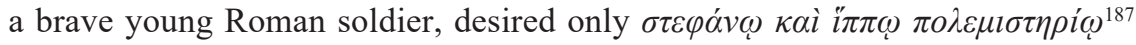
as a reward for his deeds. According to EPL 10, Camillus was falsely accused of plotting usurpation by a Gallic consul called Februarius. After the truth was

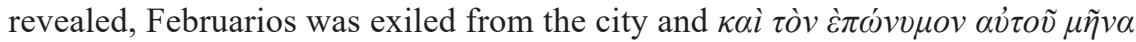

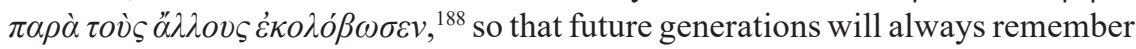

183 On this aspect of panegyrics, see Angelov (2006), 168.

184 Basilikos, 61.475-478.

185 Basilikos, 62.529-532.

186 Basilikos, 61.472-475. The Romans were not primarily traders like the Phaenicians and not farmers like the Egyptians; Basilikos, 62.259-538.

187 A garland for valour and a warhorse; cf. Mariev (ed.) (2008), 33.

188 The month named also after him was shortened in comparison with other months; cf. Mariev (ed.) (2008), 55. 
Februarios' punishment. EPL 11 and 12 accentuate the ancient Roman virtue of heroic self-sacrifice. In EPL 11, Manlius' bravery on battlefield is rewarded

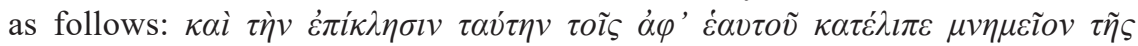

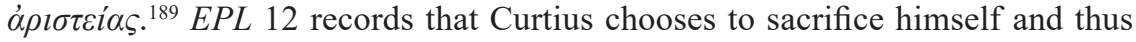
saves the city. For his brave death, he was offered annual heroic rites. A similar case is contained in EPL 14: a diviner foretold that if a Roman consul 'consecrated himself to the chthonic deities' ${ }^{190}$ the Romans would defeat the Latins; Decius, the consul, decided to be the one sacrificing himself, granting the Romans with the victory. EPL 15 foregrounds the Roman virtue of strict discipline. The passage records that Manlius $\dot{\omega} \varsigma \mu \dot{\varepsilon} v \dot{\alpha} \rho \iota \sigma \tau \dot{\varepsilon} \alpha \dot{\varepsilon} \sigma \tau \varepsilon \varphi \dot{v} v \omega \sigma \varepsilon v$ his son after the latter defeated a Latin adversary. Shortly afterwards, however, Manlius beheaded his son for disobeying his orders. The episode was meant to show that all the Romans should equally be obedient to their rulers. It should be pointed out that the theme of obedience to the laws of the state reappears in two Platonic dialogues, namely, the Crito and the Phaedo, copied on Planudes' commission in the Viennese codex Phil. gr. $21 .{ }^{191}$ The dialogues are copied by Planudes' collaborators, except for a number of excerpts from the end of both dialogues; these excerpts, dealing with Socrates' decision to obey the law of the state (and thus to die), were copied by Planudes himself. The very last fact is indicative of the importance Planudes assigned to the value of law. Indeed, he was very interested in the subject of the ruler who devotes his entire life to the service of the state and of his citizens. It is not a coincidence that the $\Sigma v v \alpha \gamma \omega \gamma \dot{\eta}$ includes the Leges ${ }^{192}$ and that Planudes opted to translate into Greek Cicero's Dream of Scipio, a dialogue that was meant to underscore the Roman virtues of justice, bravery, and devotion to the service of the state. ${ }^{193}$ The selection of passages conveying edifying messages complies with Planudes' literary interests in general. It should be noted that, when copying poems by Gregory of Nazianzus in Laurentianus Plut. 32, 16, Planudes made a selection of only those verses bearing a moral message. ${ }^{194}$ Moreover, Planudes' willingness to furnish the reader with behavioural paradigms becomes evident in his choice to edit the Lives of the Illustrious Greeks and Romans of Plutarch. ${ }^{195}$

A second group of excerpts aimed to emphasise the glorious past of the Roman Republic. Eleven excerpts (EPL 1, 2, 3, 7, 8, 9, 13, 36, 37, 40, and 43) deal with oracles and divine signs relating to the foundation of Rome as well as the glorious future that the city was about to enjoy. The passages underline a)

189 And he bequeathed this name to his descendants as a memento of his bravery; cf. Mariev (ed.) (2008), 57.

190 Mariev (ed.) (2008), 59-61.

191 On Vindobonensis Phil. gr. 21, see Hunger (1961), 151-152; Turyn (1972), 214; Menchelli (2014), 193-204.

192 The text is copied on f. $48 \mathrm{r}$ in $\mathrm{L}$ and on $\mathrm{f} .42 \mathrm{v}$ in N; see Section 5.2.

193 On Cicero's text, see Büchner (1976).

194 Fryde (2000), 234.

195 On Plutarch, see Flacelière (1993). 
the distinguished role Rome was destined to play in world history and b) confirm that such miracles could only take place in Rome. ${ }^{196}$ Three further excerpts (EPL 4, 5, and 26) deal with Roman institutions. In ten out of forty-four excerpts, the centre of gravity is military successes of the Roman past. In EPL 16, Rome repudiated a shameful agreement made by a number of captive Roman consuls. EPL 17 narrates the superiority of the Romans over the Etruscans. EPL 19 highlights the military capacity of the Roman army. EPL 20 and 21 convey a laudation on the bravery of the Romans on the battlefield, as well. In EPL 20, Pyrrhus admires

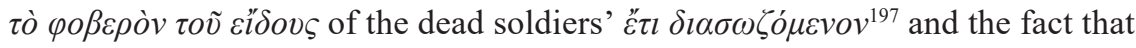

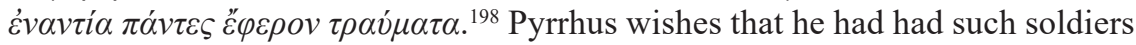
as allies. In EPL 21, Cineas, a rhetor and envoy, reports to Pyrrhus that 'all the Romans were just as virtuous as the Greeks believed him (Pyrrhus) to be'. ${ }^{199}$ $E P L$ 30, 31, and 35 depict the magnitude of the Roman state under Scipio. In $E P L$ 30, Scipio managed to bring 'the whole of Iberia under his control by an upright policy towards its inhabitants' ${ }^{200}$ In EPL 31, Scipio refused to take hos-

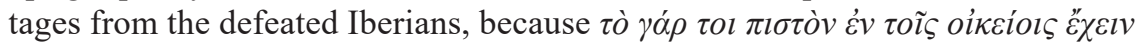
ö $\pi \lambda o l \varsigma .{ }^{201}$ In EPL 35, Scipio refused to reward the Iberian consuls who murdered Virianthus, an Iberian enemy of the Romans: Roman customs do not dictate 'praise for plots against generals committed by their subordinates' ${ }^{202}$ EPL 32 and 38 refer to military successes of the Romans: their victory over Perseus, the last king of the Macedonians (EPL 32), and the conquest of the city of Athens by Sulla (EPL 38).

\section{b) Irony}

The second rhetorical device by which Planudes voiced his opinion about important political matters was irony. ${ }^{203}$ There is sufficient evidence that orators of the Paleologan period, often, opted to commend a virtue, which an emperor lacked. The rhetorical device of irony was familiar to the courtly audience of the time. ${ }^{204}$ Planudes inserts into his $\Sigma v v \alpha \gamma \omega \gamma \grave{\eta}$ excerpts dealing with Romans'

196 This is in line with the thought taken up by the Byzantines concerning the exceptional character of Constantinople, that is, the New Rome. Constantinople became the city where the plan of God was always represented through miracles and omens. This scheme had been inherited from the Roman Empire, whose Byzantium was the continuation. On the subject, see Odorico (2011b), 33-47.

197 The fierce expression still preserved on their faces; cf. Mariev (ed.) (2008), 69.

198 That they all bore frontal wounds; cf. Mariev (ed.) (2008), 69.

199 Mariev (ed.) (2008), 69.

200 Mariev (ed.) (2008), 92.

201 He held his own military force to be sufficient guarantee; cf. Mariev (ed.) (2008), 93.

202 Mariev (ed.) (2008), 99.

203 On irony, see Kennedy (1983); Magdalino (1993); Angelov (2003), 70-71.

204 Angelov (2003), 70-71. 
adversaries. In three cases (EPL 23, 24, and 27) the focus of the excerpt lies on the military successes on the part of the Carthaginians. In EPL 23, Xanthus the Spartan helps the Carthaginians to destroy the Roman army. In EPL 27, the Carthaginian general Hannibal, wanting to show his countrymen the extent of his victory over the Romans, 'sent to Libya three Attic medimni full of golden rings, which he had stripped as spoils from men of equestrian and senatorial rank' ${ }^{205}$ In EPL 24, Planudes excerpts a passage on the construction of triremes by the Carthaginians and on how the Carthaginians are getting prepared for war: the entire city joins the preparation. The authorities melt down statues and 'take the wood-work of private and public buildings" ${ }^{206}$ in order to construct the triremes; women cut and offer their hair, which is reused in constructing war machines. Given the praise of the Romans throughout this section, such a favourable depiction of a barbarian people in the aforementioned passages is striking.

To my mind, the praise of both, the Romans and the barbarians, serves the same function, namely, that of criticising Planudes' contemporary imperial policies under the reign of Andronicus II. The passages must be read against the current historical circumstances: the destruction of the military fleet by Andronicus $\mathrm{II}^{207}$ and the unsuccessful negotiations on the marriage of the future emperor Michael IX to the daughter of the titular emperor of Constantinople Philip I of Courtenay, Catherine of Courtenay. ${ }^{208}$ The marriage was meant to ensure that the Latins would not seek to reconquer Constantinople in the future. EPL 24 depicts the significance the Carthaginians assigned to

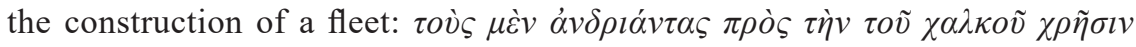

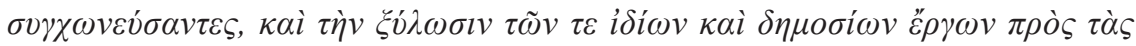

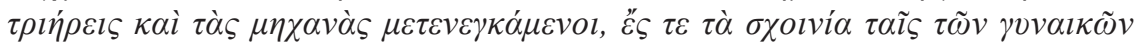

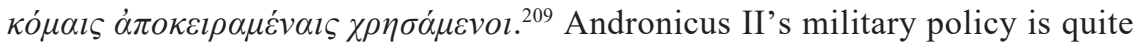
a contrast to the Carthaginians' zeal for making triremes in the shortest time. Indeed, the political context of the end of the fourteenth century sheds light on the advisory function of the text. The failure of a marriage alliance with the West necessitated the construction of a new Byzantine fleet. The fact that Asia Minor was constantly under the Turkish threat required a more offensive military policy towards them. The last general to strive to rid the Turks from Asia

205 Mariev (ed.) (2008), 81.

206 Mariev (ed.) (2008), 73.

207 Andronicus II decided to dismantle the Byzantine military fleet after the death of Charles of Anjou, the King of Sicily, in 1285; Ahrweiler (1966), 374-378. On Charles of Anjou's hostile foreign policy against Byzantium, see Dunbabin (1998).

208 The negotiations for the marriage took place after the coronation of Michael IX as co-emperor in 1294; Pachymeres, II.iii, 269-272. Finally, in 1301 Catherine of Courtenay married Charles of Valois, brother of the King of France Philp IV; see Laiou (1972), esp. 48-56.

209 By melting down statues to gain the bronze, by reusing the wood-work of private and public buildings for the triremes and war engines and by using clippings of women's hair for the ropes; cf. Mariev (ed.) (2008), 73. 
Minor was Alexios Philanthropenos in 1294. ${ }^{210}$ Byzantium's defences in the Balkans and the Epiros were collapsed and the lands were under constant raids, as well. In 1292, Michael Tarchaneiotes Glabas, a general under Andronicus II, launched a campaign in Epiros. The expedition was initially successful. The Byzantine army reached Ioannina, but failed to siege the city. ${ }^{211}$ The selective use of passages transmitted in the $\Sigma v v \alpha \gamma \omega \gamma \dot{\eta}$ reflects the severe problems the Empire was dealing with at the end of the fourteenth century. In my opinion, Planudes appears to offer counsel to the emperor in the form of criticism. Interestingly, it was during the $1290 \mathrm{~s}$ - the period when the $\Sigma v v \alpha \gamma \omega \gamma \dot{\eta}$ was composed - that rhetoricians extensively employed their speeches as a form of counselling the emperor. There are speeches transmitted from that period, which appeal not to the emperor, but to his advisers or to the people in attendance. ${ }^{212}$

To conclude, passages on Roman history included in the $\Sigma v v \alpha \gamma \omega \gamma \dot{\eta}$ transmit historical paradigms which a) stress the superiority of the Romans over their opponents and b) criticise the contemporary social and political situation. In this section, I argued that Planudes' selection of excerpts on the Roman Republic (see Table 5.7) was meant to urge military action on the part of the emperor. Planudes, as a master in rhetoric, resorted to the political usage of court oratory.

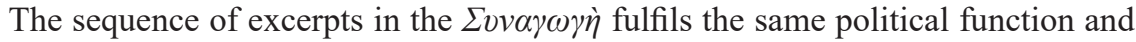
objective as his Basilikos, a political panegyric addressed to Andronicus II and his son. The highlight of traditional imperial virtues, through his selection of texts in the $\Sigma v v \alpha \gamma \omega \gamma \eta$, was intended to be prescriptive. The hortatory and didactic elements in his collection of excerpts aimed to present military offensive action as a general imperial policy. These elements do not serve the spirit of self-promotion. This is a function only served by such elements in the speeches court. ${ }^{213}$ Planudes reads history in the light of contemporary concerns. The section on Roman history does not just accumulate historical knowledge of a particular subject matter. The concatenation of excerpts by Planudes serves a) to supply the reader with moral examples and b) to shape cultural and political thought. From this perspective, the section on Roman Republic in the $\Sigma v v \alpha \gamma \omega \gamma \grave{\eta}$ represents another way of writing history.

210 Alexios Philanthropenos revolted against the emperor in 1296. The rebellion was unsuccessful and Alexios was blinded. Though Planudes was a close friend of his, he did no fall into disfavour; Laiou (1978), 89-99.

211 Laiou 1972 (40); Nicol (1984), 37-42.

212 See for instance the speech by Nikephorus Chumnos in Laourdas (1955), 290-327. See also the two speeches composed by Demetrios Kydones, PG 154, col. 961-1008, 1009-1039; cf. Angelov (2006), 166.

213 Angelov, 2006, 168. 


\section{Excerpta Planudea}

Table 5.7 The selection of excerpts on the Roman Republic by Maximus Planudes

EPL 1 On the Palatine, the place where Romulus decided to found Rome.

EPL 2 On an omen predicted that Rome would become the capital of many nations. The city legend starts with the recovery of a human skull when foundation trenches were being dug for the Temple of Jupiter at Tarquin's order. The word for head in Latin is caput and the place was given the name Capitoline.

EPL $3 \quad$ On the Capitoline Hill.

$E P L 4 \quad$ On the number of consuls that the Romans used to elect.

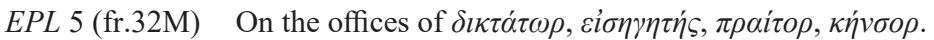

$E P L 6$ (fr.21M) On Marcius' generosity.

EPL 7 (fr.34M) On a Roman custom: one of the Vestal Virgins was buried alive.

$E P L 8$ (fr.40M) Romans who had found refuge in the Capitol got saved by a miracle.

EPL 9 (fr.42M) On the Sibyl's oracle about the great future of the Capitol.

EPL 10 (fr.41M) The punishment of Februarius for lying that Camillus was aiming at usurpation.

EPL 11 (fr.45M) On Manlius' bravery on battlefield.

EPL 12 (fr.22M) On a Sibylline oracle and Curtius' death. He was offered heroic rites annually.

EPL 13 (fr.47M) On a divine sign and how Corvinus took up his name.

EPL 14 (fr.48M) On Decius' bravery and philopatria.

EPL 15 (fr.46M) Manlius beheaded his own son for disobeying him.

EPL 16 (fr.47M) On Roman policies.

$E P L 17$ (fr.54M) On the superiority of the Romans over the Etruscans.

$E P L 18$ (fr.55M) A geographical reference to the Tiber.

EPL 19 (fr.57M) On Roman strategies.

$E P L 20$ (fr.58M) On the bravery of the Romans at war.

EPL 21 (fr.59M) On the bravery of the Romans at war.

EPL 22 (fr.60M) The Roman Fabricius refuses to defeat Pyrrhus by deceit.

$E P L 23$ (fr.62M) On strategic manoeuvres at war.

$E P L 24$ (fr.63M) Carthaginians are preparing for war.

EPL 25 (fr.64M) Regulus, a Roman general, denied saving his life.

EPL 26 (fr.66M) On a Roman law decreed by Marcus Claudius and Titus Sempronius.

EPL 27 (fr.73M) On a custom of the Carthaginians.

EPL 28 (fr.79M) The cruel king of Egypt, Ptolemy, received a divine punishment for his cruelty.

EPL 29 (fr.80M) A reference to Jesus son of Sirach.

EPL 30 (fr.86M) On Scipio's external policies.

EPL 31 (fr.87M) On Scipio's decision not to accept the hostages from the defeated Iberians.

EPL 32 (fr.81M) On a Roman win over Perseus.

EPL 33 (fr.83M) A mythological reference to the ship of Perseus.

EPL 34 (fr.88M) A reference to Scipio the younger. He became general at the age of 24.

EPL 35 (fr.91M) Scipio refuses to reward the Iberian consuls who murdered Virianthus, an Iberian enemy of the Romans.

EPL 36 (fr.89M) A reference to the foundation of Rome.

EPL $37 \quad$ A portend reported by Livy and Diodorus.

(fr.98.7M) 


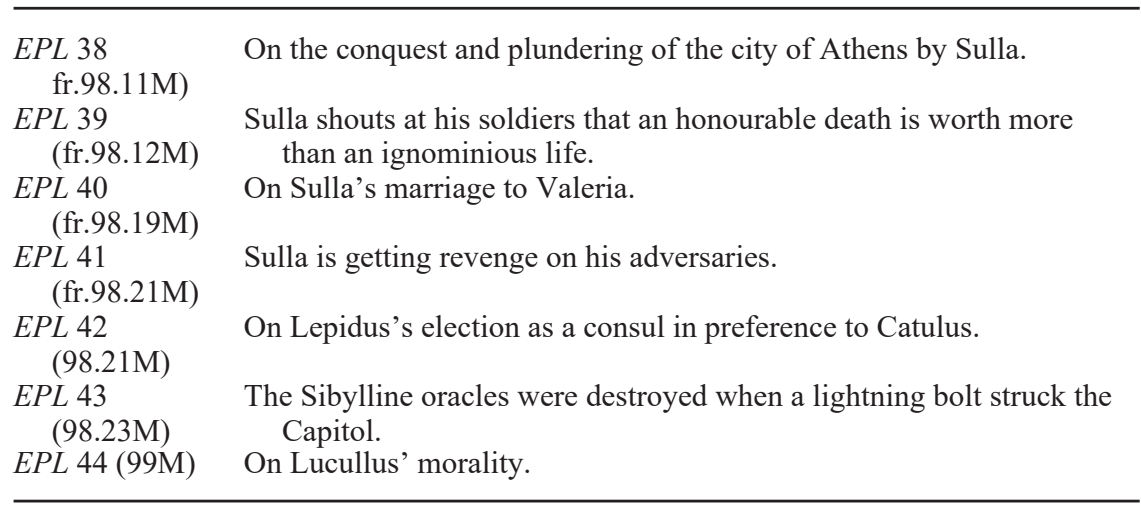

\subsection{Conclusions}

After studying the manuscript tradition of the entire Excerpta Planudea and presenting their content and structure, I focused on the sequence of excerpts on Roman history. As regards their origin, they are excerpts from John of Antioch, Paeanius, Xiphilinus, and a now lost chronicle also used by Manasses. I have further argued that the passages on Roman history are drawn from an earlier collection of historical passages, which had probably been compiled by Maximus Planudes himself. It probably comprised a larger number of excerpts taken from the same authors as the ones preserved in the Excerpta Planudea. Regarding his working method when excerpting passages from John of Antioch and Xiphilinus, Planudes used a series of strategies already detected in earlier syllogae of excerpts, namely the Epitome, the Excerpta Anonymi, the Excerpta Salmasiana, and the EC. Finally, regarding the literary and political function of the excerpts, Planudes made a conscious selection of thematically connected historical passages on Roman history, centred on the Roman military excellence and the glorious past of the Roman Republic. Its political aim was to recommend to the emperor a militaristic policy towards the enemies of the Empire. 


\section{Collections of historical excerpts as a specific locus for (re)writing history}

This chapter argues that the four excerpt collections should be understood as historiography and studied next to chronicles and histories as part of Byzantine historiography. In fact, excerpt collections have very rarely, so far, been seen as autonomous pieces of literature. Their importance as works in their own right has been obfuscated by their anonymity and the underestimation of their originality. As a result, scholars usually study them as tools to transmit historical material but not as histories in their own right. This is illustrated by the fact that no history of historiography includes them as autonomous pieces of historical writing, next to histories and chronicles.

This, inevitably, raises the issue of how modern scholarship has thought about Byzantine genres of historiography. In fact, over the last two decades, the generic theory imposed by K. Krumbacher, H. G. Beck, and H. Hunger has been modified and enriched by contemporary Byzantinists. ${ }^{1}$ According to H. G. Beck, classicising histories a) cover a limited period of time, b) use a continuous narrative of thematically connected events, and c) are written in classical Greek. ${ }^{2}$ Chronicles, by contrast, a) cover the history of the world (from creation to the time of the chronicler), b) are structured chronologically, and c) are written in colloquial language. Though, recently, scholars have started to view fixed generic boundaries as posing constraints on our understanding of how and why Byzantines wrote history, ${ }^{3}$ the traditional division of Byzantine historical writing into histories and chronicles has never been seriously challenged. P. Magdalino in his contribution to the Oxford History of Historical Writing, admits the necessity of generic categories. The examples he gives illustrate the freedom with which late antique and Byzantine historians handled traditional historical genres, though. ${ }^{4}$

$1 \mathrm{~K}$. Krumbacher was the first to distinguish between histories and chronicles. His theory of the monk's chronicle was proved to be wrong, though. See especially Beck (1965), 196-197. H. G. Beck's view was repeated by H. Hunger (1978), 252-254. K. Krumbacher's views of historical writing were recently discussed by P. A. Agapitos (2015), 1-52.

2 Beck (1965), 196-197.

3 Magdalino (2012), 218-237; Signes Codoñer (2016), 227-256.

4 Magdalino (2012). 
As a consequence, current discussions of genre are often inconclusive. ${ }^{5}$ J. Signes Codoñer, for instance, suggested that the rigid classification of historical texts based on their language, content, and structure could be hazardous if not ill-fated. ${ }^{6}$ More significantly, he noted that compilations of thematically connected passages should also be seen as a third way of structuring historical narrative. ${ }^{7}$

In what follows, I shall first present the classification of Byzantine historical writing as suggested by J. Signes Codoñer. Then, I shall show how the generic criteria suggested by him play out in collections of historical excerpts. I shall argue, in particular, that collections of historical excerpts merit being seen as a distinct type of text for the following reasons. First, they show linguistic and stylistic uniformity. Historical collections avoid using classicising language and tend to turn their source text into a simpler Greek. Second, collections of historical excerpts share compositional methodologies ${ }^{8}$ and textual borrowings amongst historical collections link them as a distinct genre. This indicates the awareness of their compilers that they belonged to a common tradition of historical writing. Third, collections of historical excerpts represent a distinct approach to the past. Their compilers represented history according to themes. The isolation of thematically connected passages, the rewriting of them and their rearrangement in a new receptacle altered significantly the meaning the passages had conveyed in their original textual environment.

\subsection{J. Signes Codoñer's classification of Byzantine historical writing}

In this section, I shall briefly set out the criteria proposed by J. Signes Codoñer for analysing and classifying Byzantine historiography. His criteria are based on the list of characteristics of types of historical writings for the period of $900 \mathrm{AD}-1400$ AD made by P. Magdalino. ${ }^{9}$ By collating P. Magdalino's and J. Signes Codoñer's propositions, the criteria to classify historical writings could be summed up in the following: 1) the linguistic and stylistic register of the text and the intended readership, 2) the period of time that the text covers and consequently the kind of sources the author was based on and, 3) the narrative structure. Those writing history in late antiquity and the Byzantine period were very flexible in merging the above criteria, a fact that poses obstacles in forming rigid categories of historical writing.

5 Ljubarski (1998), Kazhdan (2006), Scott (2009), Magdalino (2012), Markopoulos (2015), Signes Codoñer (2016), Macrides (2016).

6 Signes Codoñer (2016), 251.

7 Signes Codoñer (2016), 250 and 253.

8 As discussed in Chapter 1 it is only after the fourth century that the copying-pasting technique takes on significance as cultural expression. This is what P. Odorico attempted to define with the concept of culture of sylloge. See also in Van Nuffelen (2015), 15.

9 Magdalino (2012), 218-237. 
J. Signes Codoñer divides historical texts into three main categories: instrumental, derivative, and original works. He labels instrumental works those texts intended for a later use by chroniclers in compiling their works. Such texts were lists of rulers, catalogues of patriarchs, and chronological tables. The category includes the Chronicon paschale and Nicephorus' Chronographia brevis. ${ }^{10}$ J. Signes Codoñer calls derivative those works that were summaries of earlier texts. The category contains Nicephorus' Breviarium historicum, Psellos' Chronographia, Symeon Logothete's Chronicon (version B), Ps.-Symeon' Chronographia, John Scylitzes' Synopsis historiarum, and John Zonaras' Epitome historiarum. The category seems to have been formed on the basis of the working method applied to these texts rather than the way the material is arranged. ${ }^{11}$ Yet, the rewriting process (in the form of summary or interpolation of the source text), which, according to J. Signes Codoñer, is the main characteristic of this category, is definitely involved in the last category too, namely original works. The category original works contains texts dealing with contemporary history (written in classical Greek and relying on autopsy) as well as works concerned with history of the past (written either in learned Greek or in simpler Greek and based on written sources). The category includes Syncellus' Ecloga chronographica, Theophanes' Chronographia, and George the Monk' s Chronicon, who structured their works chronologically, along with the $E C$, the $D T$, the $D A I$, and the $D C$, whose material is obviously arranged thematically. One could also say that the $D T, D A I$, and $D C$ are not histories by genre. They can only be seen as secondary historical sources for regions and people surrounding Constantinople or for internal affairs in the capital, just like hagiography can be employed as a marginal or alternative source of information for important individual figures or foreign lands. ${ }^{12}$ Besides, it is only the $E C$ that consist of earlier historical texts.

It becomes evident that J. Signes Codoñer's classification of the texts into the three aforementioned categories does not always correspond to the three criteria for classifying Byzantine historiography. This problem led J. Signes Codoñer to foreground criterion 3 (the narrative structure). ${ }^{13}$ J. Signes Codoñer attributes three types of literary structures in middle Byzantine period-historical writing: chronological, narrative, and thematic structure. In fact, J. Signes Codoñer's classification of Byzantine historical writing corroborates the changing nature

10 On the Chronicon paschale see Treadgold (2007), 340-349; Burgess and Kulikowski (2013), 224227. On the Chronographia Brevis see de Boor (ed.) (1880); Mango (1990), 2-4.

11 See Section 1.2.2.

12 It has been in recent years that studies suggest the necessity in viewing texts that are not considered historiographical in the strict sense of the term as historical approaches to events or individual figures. Rhetorical writings, lives of patriarchs, and historical biographies (Vita Basilii, Alexias) are, occasionally, either referred to as historical witnesses or classified as histories. On the Vita Basilii, see n. 314 in Chapter 2. On the Alexias, see Reinsch and Kambylis (edd.) (2001).

13 R. Macrides considered the chronological span covered as the most consistent difference; Macrides (2016), 258-259. 
of Byzantine literature. ${ }^{14}$ In addition, texts themselves and manuscripts were not stable entities but subject to modifications. ${ }^{15}$ Contemporary demands as well as personal and social goals played a marked role in authorial choices in terms of content and structure. ${ }^{16}$ Indeed, individual choice, politics, and social conditions are likely to have led writers to the merging of traditional methods of writing history or to the inclusion of alien features into historiography. ${ }^{17}$ This is now seen in positive terms. Concepts such as originality, innovation, and change have been increasingly substituted with classical tradition and imitation in scholarship over the last decade. ${ }^{18}$ Yet, such originality is hidden creatively behind the mask of tradition. ${ }^{19}$ It turns out that criteria in terms of style, language, and structure can help us understand Byzantine historical writing insofar as we do not too rigidly adhere to them, for Byzantine writers did not do this either. From this perspective, I find J. Signes Codoñer's attempt to classify historical texts by their literary structures to be going in the right direction. One could say that there are even cases in which the structure within the same historical work changed. This is the case, for

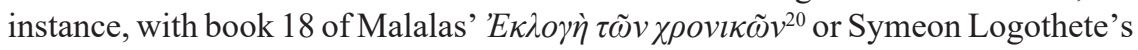

14 Modern scholarship agrees on that. See P. Magdalino (2010), Markopoulos (2015), Van Nuffelen (2015), Signes Codoñer (2016), Macrides (2016).

15 Van Nuffelen (2012), 11-20.

16 Byzantine historians were eager to import changes into the literary tradition because they addressed a medieval audience, which differed significantly from the audience of antiquity; cf. Magdalino (2012). See also Neville (2016), 265-276; Signes Codoñer (2016), 234 and 252-253. Burgess and Kulikowski, by contrast, appear strictly adherent to the idea that a text should perfectly fit within a specific tradition of historical writing in order to be labeled as such. In Burgess and Kulikowski's view, Eusebius' chronicle is the unique representative of the genre in the Greek language. After Eusebius, chronicles appeared only in Latin, on the basis of which Burgess and Kulikowski define the genre in late antiquity. They finally argue that after Eusebius, it was only the anonymous author of the Chronicon paschale and Theophanes who wrote a proper chronicle. The rest are either universal breviaria (Malalas, George the Monk, Nicephorus, Symeon the Logothete, Ps-Symeon, Cedrenus, Glycas, Zonaras, Manasses) or compact epitomes (Nicephorus' Хроvоүрафıко̀

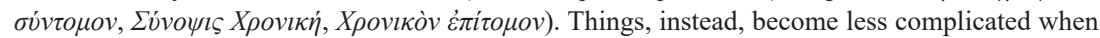
they come to treat what in modern histories of Byzantine literature is referred to as histories. In line with them, Burgess and Kulikowski find that Zosimus, Procopius, Agathias, Menander, and Theophylact wrote classicizing narrative histories; Burgess and Kulikowski (2016), 93-117. See also the forthcoming R. Scott's paper in the proceedings of the conference Chronicles as Literature at the Crossroad of Past and Present which was held in Munich in 2016. R. Scott defends the use of the term chronicle for a group of writings produced after Malalas.

17 The influence of rhetoric should be mentioned here. Those writing history had passed through rhetorical schools and got training to write not only history. Some of them had evidently written texts of different genres (e.g., Procopius and Agathias). On the matter, see especially Markopoulos (2003), 185-186; Holmes (2003), 187-199; Mullett (2010), 227-238; Kaldellis (2014), 115-130. As J. Signes Codoñer notices, a number of recent publications are disposed to put aside any categorization of historical writings and focus, instead, on the reliability or unreliability of the events they narrate. Truthfulness came, thus, to set a distinctive line between attempts to transmit historical facts and attempts to distort them; Kaldellis (2016), 293-306; cf. Signes Codoñer (2016), 250.

18 Ljubarski (1998), 5.

19 Papaioannou (2013), 20.

20 This is the title transmitted in the manuscript tradition of Malalas' text. Nevertheless, his work is 
Chronicon, which adopts a different narrative structure when it comes to deal with contemporary events. ${ }^{21}$ Provided that texts should be viewed and assessed as a whole, I see J. Signes Codoñer's prioritisation of the structure-criterion over the language and the use of sources as being particularly essential.

In what follows, I put forward how the criteria of J. Signes Codoñer can be observed in historical collections of excerpts too. We shall see that they exhibit a series of common characteristics, which identify them as a distinct body of literature, and which highlights their proximity to works traditionally ranked as historiographical. The body of texts, which I shall discuss, consists of the syllogae studied in the previous chapters (the so-called Epitome of the Seventh Century, the Excerpta Constantiniana, the Excerpta Anonymi, the Excerpta Salmasiana, and the Excerpta Planudea) as well as a number of manuscripts transmitting selections of excerpts taken from late antique historians, namely Polybius, Diodorus of Sicily, and Dionysius of Halicarnassus.

\subsection{Literary features in Byzantine collections of historical excerpts}

\subsubsection{Language, style, function}

A significant number of historical texts in late antiquity and the Byzantine period were written in classical Greek. Byzantinists label them as classicising histories. The authors of these texts preferred the use of long periods and complex syntax as well as direct speech and rhetorical devices. Such histories usually dealt with recent past and contemporary events and their authors relied on autopsy or oral witnesses. Things are not so consistent, though. There are historical texts written in classical Greek, which deal with the past and, therefore, resort extensively to earlier written sources. These texts cannot be called universal chronicles; they are not concerned with the distant past (e.g., from creation or Adam) and the events are not presented chronologically. ${ }^{22}$ In turn, texts usually labelled as universal chronicles by Byzantinists were written in a simpler Greek. Their authors preferred short periods and simpler syntax. These historical texts, running from the creation down to the time of the author, made an extensive use of written sources and aimed at being as concise as possible. A number of them was formed on the basis of passages excerpted from earlier chronicles. The excerpted passages were often re-edited and rewritten before their inclusion into the new text. The material

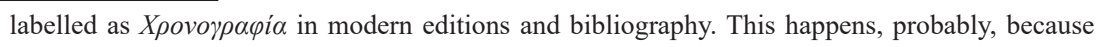
that is what it is called by John of Damascus in the eighth century; cf. Burgess and Kulikowski (2016), 94.

21 Magdalino (2012), 225.

22 This is the case with Genesius' Regum Libri Quattuor and Theophanes Continuatus. The compositional features of the latter were treated by J. Signes Codoñer, who classifies it as 'history of the (recent) past'; Signes Codoñer (2016). 
was organised and arranged in chronological order; the approach to chronology can vary from chronicle to chronicle, though. ${ }^{23}$

Let us have a look at our group of texts. Collections of historical excerpts consist of a series of passages culled from earlier historical texts. The study of their structure and methodological principles in the previous chapters revealed that 1 ) the excerpted passages underwent changes in vocabulary and syntax - the excerptors, at times, felt the necessity to substitute words that were out of use with others that would make the passage more intelligible and palatable to the reader, 2) the excerptors respected the sequence of passages in the original text, and 3) they were aware of the lack in context when a passage was extracted from a whole unit. Consequently, they applied a number of strategies to tackle this problem: a) additions or omissions of text, b) rearrangement of words, and c) repetition of words or phrases. In Chapter 2, we saw that the compiler of the Excerpta Anonymi often broke the intended alphabetical order of excerpts in order to make their content clearer. He occasionally inserted brief statements justifying his choices as to the selection of excerpts. This strategy is detected in other collections of excerpts too. When excerpting Eusebius, the compiler of the Epitome adds statements of his own, which clarify the content and explain the text better. To give but one example, an insertion by the compiler in E 33 reads as follows: $\alpha v \alpha \varphi \varepsilon ́ \rho \varepsilon l$

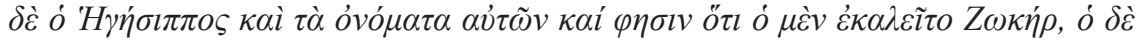

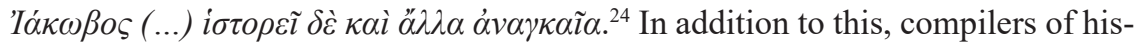
torical collections quite frequently composed phrases by combining a few words of the original text: such phrases served the role of a brief introduction for a series of excerpts and provided the reader with the historical context. Chapter 5 showed that Maximus Planudes has been particularly prone to this strategy. Yet, compilers' aim at maintaining the narrative sequence and at accuracy aligns with statements that occurred in the prooemium of the EC. As noted, compilers of excerpt collections tended to correct the excerpted text when the meaning was not clear. We have seen in Chapter 2 that when excerpting the Parastaseis, the compiler of the Excerpta Anonymi often needed to alter words in the source text by others that clarified the content better. The same strategy was detected in the three syllogae of excerpts constituting the Excerpta Salmasiana (see Section 3.5), in the Epitome when excerpting Eusebius' HE (see Section 4.4.3), and in the Excerpta Planudea when excerpting John of Antioch and Xiphilinus (see Section 5.3.3).

Occasional stylistic simplifications and corrections may imply that collections of historical excerpts addressed a wide audience. We see that historical excerpt collections share similarities with Byzantine universal chronicles in terms of language and use of sources. Chronicles were meant for a wider public too, ${ }^{25}$ and

23 Ljubarski (1998), 11-12.

24 Hegesippus records their names too. And he says that one was called Zoker and the other Jacob (...) He narrates other things that are trustworthy too.

25 On the target audience of historians, see Croke (2010); Markopoulos (2015), 53-74. The issue of literacy in Byzantium has been explored in Cavallo and Odorico (2006); Cavallo (2006), 97-109; Markopoulos (2014), 3-15. 
Chapter 1 of this book made clear that a chronicle could be an aggregation of different excerpts. The method used, for instance by George the Monk, is identical to the one used by the compiler of the EC or the Excerpta Anonymi (see Section 1.2.2). What set the last two apart from Georges' Chronicon is the distinct structure through which the excerpts are presented in an excerpt collection (see Section 6.2.3) and the different function.

Collections of excerpts exhibit a multiplicity of functions. The possibility that they could serve didactical purposes and were used in schooling can by no means be excluded. As shown in Chapter 1, the word $\delta l \delta \alpha \sigma \kappa \alpha \lambda i \alpha$ occurs in a comment by the compiler of the Excerpta Anonymi when excerpting John Lydus' De

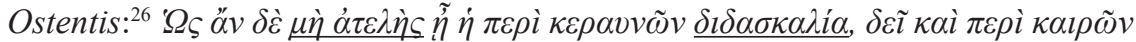

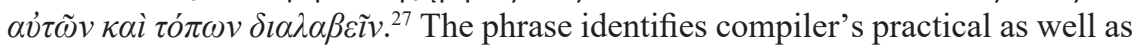
didactical purposes. As discussed in detail in Chapter 1, similar requirements are highlighted in the prooemium of the EC. As noted, the rest of the historical collections are not preceded by any prooemium. Their practical aims are traced in their selection of material, though. The collection on Roman history by Planudes has been transmitted as part of his Excerpta Planudea, a sylloge of passages on a variety of themes. The content and structure of the entire Excerpta Planudea indicates that they were intended to be used for teaching at schools as well. ${ }^{28}$

The thematic homogeneity that characterises the collection of historical passages by Planoudes, the Excerpta Salamasiana, the Excerpta Anonymi, and the Epitome indicate that such collections could just teach readers moral lessons through a series of historical paradigms, or as they definitely accumulate historical knowledge they would help the reader search for a subject matter he was particularly interested in. Such intention is also explicitly stated in the prooemium of the $E C$. This is certainly not a role that chronicles were destined for, as chronicles recorded a series of thematically unrelated events presented in a strict chronological order. Yet, the accumulation and transmission of the memory of the past is definitely a role served by historical writing in general.

Collections of excerpts could, finally, function as an intermediate stage in the process of compiling a chronicle based on citation. These collections were depositories of material intended for the private use of the compiler. ${ }^{29}$ Theophanes in the preface to his Chronographia refers to a sylloge of passages used by Syncellus in compiling his Ecloga chronographica. ${ }^{30}$ It is now accepted that the Theophanes

26 Excerpta Anonymi, 47, 25-26.

27 So that the elucidation of thunderbolts will not be incomplete, the seasons and the places (concerning thunderbolts) need to be treated.

28 See Kugeas (1909), 134; Fryde (2000); Ferroni (2011), 342.

29 There should be collections where the material to be exploited later, was first gathered. That is what is meant by the word $\sigma v \lambda \lambda \dot{\varepsilon} \xi \alpha v \tau \varepsilon \varsigma$ used by Cedrenus in the prooemium of his work; cf. Odorico (2014a), 382.

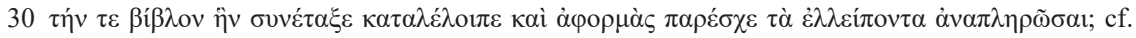
Theophanes, Chronographia, 4.1-2. 
Continuatus and Genesius drew on a preparatory dossier of sources now lost. ${ }^{31}$ Another such collection representing an intermediate stage to a final work is the codex Parisinus gr. 1336, which dates to the eleventh century and is the exact copy of a codex created in the tenth century now lost. ${ }^{32}$ The codex Baroccianus gr. 142 can be considered as a further example of such collections. As noted in Chapter 4, marginal notes in the codex are likely to indicate that Nicephorus Callistus has edited parts of the Epitome in order to use them later on in compiling his own chronicle. ${ }^{33}$

\subsubsection{Period covered and use of sources}

Regarding the period of time covered, all texts in our group dealt with the distant past and relied on earlier written sources. Besides, Chapter 1 which examined how an excerpt collection was redacted identified common steps and procedures in the process of redacting a sylloge of historical excerpts. The redaction of a collection of historical excerpts involved the following procedures: reading and selection, editing, and composition.

The so-called Epitome of the Seventh Century is a sylloge of excerpts extracted from different historical writings, notwithstanding the title assigned to it by modern scholarship (see Chapter 4). ${ }^{34}$ In particular, the Epitome comprises excerpts from Eusebius of Caesarea, Gelasius of Caesarea, and Theodorus Anagnosta, as well as excerpts from John Diacrinomenus and Philip of Side, and a series of anonymous fragments. The study of the Eusebian excerpts of the Epitome (see Section 4.4) revealed that its compiler augmented the passages taken from Eusebius' $H E$ with a) passages extracted from other writings by Eusebius, b) material taken from a variety of ecclesiastical writers of the third and fourth centuries AD (Papias, Hegesippus, Pierius, and c) phrases compiled by the compiler himself.

The major enterprise of the tenth century, the $E C$, are made up of collections consisting almost entirely of excerpts from ancient and Byzantine historians, compiled under the auspices of the emperor Constantine Porphyrogenitus. In particular, the EC transmit excerpts from twenty-six historiographers from the fifth century $\mathrm{BC}$ to the ninth century $\mathrm{AD}$. The excerpts have been singled out and grouped thematically under fifty-three subject-categories. As noted, the prooemium preceding each of the Constantinian collections as well as the content of the surviving collections reveal the method used, that is, the process of excerpting as well as the extent of intervention in the selected pieces on the part of the excerptors (see Chapter 1).

31 Featherstone and Signes Codoñer (2015), 12. See also Markopoulos (2009), 137-150; Magdalino (2013c), 200-206.

32 On the codex, see Odorico (2014a), 382-384.

33 See esp. Section 4.1.5.

34 See esp. Sections 4.2 and 4.4 . 
It is now accepted that the practice of selecting, copying, synthesising, and presenting material was widespread during the tenth century, when the Excerpta Anonymi were compiled. The Excerpta Anonymi are dated to the second half of the tenth century. The Excerpta Anonymi excerpted a considerable number of historical works as well as earlier collections of late antique historiography. ${ }^{35}$ Thematically, the excerpted passages in the Excerpta Anonymi deal with prophecies and oracular powers hidden in statues and dreams as well as with geography and ethnography. The compiler of the collection remains anonymous and the work is not accompanied by any preface. As mentioned, the compiler of the Excerpta Anonymi enriched the concatenation of excerpts with his own comments, which contain information regarding his working method (see Section 2.3).

The Excerpta Salmasiana, in the form they have been handed down to us, represent a compilation of three distinct collections of excerpts: the Exc.Salm.I and II plus the Agathias collection make up a sylloge of excerpts like those compiled in Byzantium (see Chapter 3). The Exc.Salm.I consist of excerpts taken from John of Antioch's Historia chronica. It is difficult to say with certainty whether the compiler made use of a complete text or an earlier collection of excerpts from John of Antioch. The Exc.Salm.I are a unique source for John of Antioch's text. It seems unlikely, however, that John of Antioch drew directly on Julius Africanus. ${ }^{36}$ The passages run the period from the Exodus to the fifth century BC. The Exc.Salm. II consist of passages from Malalas, Cassius Dio, and an anonymous late antique source on the events of the third and fourth centuries. The Agathias excerpts were exclusively extracted from Agathias' Historiae, which was concerned with events that took place during the reign of Justinian. The exact date of the Excerpta Salmasiana is difficult to establish. Scholarship appears to agree to a dating between the ninth and the eleventh centuries.

Finally, the $\Sigma v v \alpha \gamma \omega \gamma \dot{\eta}$ by Maximus Planudes comprises excerpts from classical geographers and philosophers, historians of late antiquity and the middle Byzantine period, as well as Christian writings. As shown in Chapter 5, the passages on Roman history come from an earlier collection of excerpts compiled probably by Planudes himself. The hypothesis is based on the existence of an Athonite codex which also transmits this part of the Excerpta Planudea. These passages are taken from Paeanius (late fourth century), John of Antioch (first part of the seventh century), Xiphilinus (second half of the eleventh century), and an unidentified chronicle now lost which also served as source for Manasses' chronicle. The passages run from the foundation of Rome to the reign of Gratian (Roman emperor from 367 to 383).

It becomes evident that there is coherence to the use of sources in collections of historical excerpts. Their compilers never relied on autopsy, which is an essential feature of classicising histories. From this point of view, excerpt collections show, once again, affinity with Byzantine universal chronicles, which were dependent on

35 On the date and the content of the collection, see Section 2.1.

36 Mariev (ed.) (2008), 41* and Wallraff (ed.) (2006). 
written sources too. It is worth mentioning that collections of historical excerpts quite often drew on earlier excerpt collections. The Excerpta Anonymi probably made use of material gathered in the first place by the compilers of the $E C$ : the Excerpta Anonymi possibly drew on Constantinian collections on geography and on political prophesy. ${ }^{37}$ As shown in Chapter 2, it cannot be excluded that the author of the Excerpta Anonymi may have had direct contacts with the excerptors of Constantine VII or was part of the intellectual circle around the emperor. In the same chapter (see Section 2.4.4) I showed that the Excerpta Anonymi relied also on a collection of excerpts by Cassius Dio and Peter the Patrician. It is highly likely that the same collection on Roman history was used by the Exc.Salm.II (see Excerpts 44-65), which exhibit similarities with the Excerpta Anonymi in content and ideology, a fact that would lead to a dating for the Excerpta Salamasiana to the mid-tenth century. ${ }^{38}$ Chapter 3 also showed that a collection of excerpts from Malalas' Chronographia stands behind the initial part of the Exc.Salm. II (see Excerpts 1-43). ${ }^{39}$ Chapter 4 showed that the codex Baroccianus gr. 142 transmits parts of the so-called Epitome as edited by Nicephorus Callistus in the thirteenth century. ${ }^{40}$ Chapter 5 confirmed S. Kugeas' assertion that the section on Roman history in the Excerpta Planudea is made up of passages (Paeanius, John of Antioch, Xiphilinus, and a now lost chronicle) taken from an earlier collection on Roman history that was possibly compiled by Planudes himself. I also showed that the codex Athonensis Iviron 812 transmits a sylloge of historical passages which were copied from the same source as the section on Roman history in the Excerpta Planudea. Finally, excerpts from John of Antioch preserved in Athonensis Iviron 812 are identical to passages preserved in the EC. ${ }^{41}$

It may be said that the aforementioned intertextual borrowing link collections of historical excerpts as a distinct and recognisable genre. And it is worth noting that R. Scott refers to intertextual borrowing among chroniclers as a proof for the continuation of chronicle-writing in Byzantium. ${ }^{42}$ Indeed, chronicles drew quite often on earlier chronicles only, which indicates that their authors were aware of the fact they were composing their works within the chronicle tradition.

Each excerpt in Parisinus suppl. gr 607a, the unique manuscript preserving the Excerpta Anonymi, in Auctarium E.4.18 transmitting part of the Epitome, in Laurentianus Plut. 59, 30, the best manuscript of Planudes' $\Sigma v v \alpha \gamma \omega \gamma \eta$, and in the extant manuscripts of the $E C$ is identified with the conjunction ${ }^{\prime \prime} \tau$ placed at the beginning of each text. The use of $\sigma^{\prime} \tau \imath$ to indicate the beginning of a new passage

37 Sections 2.4.2-2.4.3.

38 The Excerpta Anonymi and the Excerpta Salmasiana share passages on political prophesy by Cassius Dio and Peter the Patrician; see Sections 2.4.4 and 3.3.2.4.

39 See Sections 3.3.2.1-3.3.2.2.

40 See Section 4.1.5.

41 See Section 5.3.2.2.

42 See the forthcoming paper by R. Scott in the proceedings of the conference Chronicles as Literature at the Crossroad of Past and Present held in Munich in 2016. 
can be seen as a further indication that the texts belong to the same tradition, that of collections of excerpts, and that they employed traditional methods.

\subsubsection{Structure}

Let us consider the last criterion: the selected narrative framework within which the material is placed. On the basis of the historical texts preserved, J. Signes Codoñer was able to distinguish the following narrative structures: 1) a continuous narrative of thematically connected events: the narrative is thematically developed rather than chronologically; 2) a chronological structure: the narrative is formed by unrelated events put together in chronological order and the final text is a sequence of micro-narratives arranged chronologically; and 3) a thematic structure: this is what J. Signes Codoñer called thematisation of history. ${ }^{43}$ The historical material is arranged according to subject matter.

Our group contains texts all constructed according to number 3 . The contents of the collections examined in this book indicate that their compilers made a heedful selection of thematically connected passages. The selection criteria were shaped by a combination of causes: cultural and literary trends, contemporary circumstances, ideological restrictions, and individual interests. The selection and arrangement of material play a crucial role here, for the originality of works composed by processes of compilation is to be approached through their structure. What makes the receptacle of selected texts an independent piece of literature is the new concatenation of excerpts in it. The EC, the Excerpta Anonymi, the Excerpta Salmasiana, the Epitome, and the section on Roman history in the Excerpta Planudea were compiled on the basis of selected passages synthesised by their compilers into a new sequence. Chronology does not play any particular role in the selection of passages. The fact that the compilers of excerpt collections respect the sequence of passages in the original texts, at times, creates the impression of a chronological order.

In the case of the Excerpta Anonymi, thematic arrangement and alphabetical order were combined. Yet, in Chapter 2, I presented cases in which the compiler of the Excerpta Anonymi breaks the alphabetical order in favour of the thematic grouping. The compiler of the Excerpta Anonymi at times inserted brief statements outlining his aim at maintaining thematic coherence and narrative sequence. The passages he extracted from the Parastaseis, Herodotus, Appian, Cassius Dio, Procopius, and John Lydus concerned ethnography as well as omens and political prophesy. The group of passages corresponding to letter $B$, in particular, begins with excerpts from Procopius' De Bellis and Cassius Dio's Historiae Romanae on Brittia and on peoples inhabiting the island. Unlike in Procopius and in Cassius Dio, the description of peoples and places in the Excerpta Anonymi does not aim to supplement descriptions of fights. The Excerpta Anonymi are not concerned with the sequence of events recorded in Procopius and Cassius Dio, either. In the 
Excerpta Anonymi, the excerpts are parts of a sequence of passages on the subject matter of barbarian peoples surrounding Byzantium and on the otherness of nonByzantines. As discussed in Chapter 2 (see Section 2.5.3), the excerpts assumed a new meaning in the Excerpta Anonymi. In the new receptacle, the passages bear witness to a period in which the transformative power and civilising influence of the Byzantine Empire had been restricted. The new circumstances are reflected in the selection of excerpts as well as omissions and distortions of passages on the part of the compiler of the Excerpta Anonymi. The same section (letter B) in the Excerpta Anonymi contains a series of Cassius Dio excerpts on Roman emperors. The passages deal with the decision by certain Roman emperors to ignore dreams that envisage their death. The Excerpta Anonymi intentionally omitted any further information on the reign of emperors transmitted in the original text. The Excerpta Anonymi were aimed at the accumulation of passages dealing with these particular themes, namely ethnography and omen.

The Excerpta Salmasiana, as mentioned already, comprise three syllogae of excerpts. Each of them was constructed on the basis of a series of excerpts connected thematically. The content and arrangement of the excerpts reveal a principle of selection rather than a copying at random and it can, therefore, be inferred that the excerpts were put together with the intention of structuring a narrative. The Exc.Salm.I (excerpts from John of Antioch) exhibit an interest in Greek and Egyptian mythological accounts. The Exc.Salm.II (excerpts from Malalas, Cassius Dio, Leoquelle) deal with signs and oracles as well as Euhemeristic interpretation of the Greek and Egyptian mythology. The final part of the Excerpta Salmasiana is made up of excerpts on ethnography and geography taken from Agathias' Historiae. Agathias' historical work aimed to narrate the Frankish invasion of Italy in the 560's, the Lazic war in the Caucasus, and Belisarius' last campaigns. Nothing of the aforementioned themes appear in the Excerpta Salamasiana, though. When excerpting Agathias, the compiler of the Agathias part constantly leaves out the historical framework. The passages in the Excerpta Salmasiana were extracted from Agathias' digressions on the Franks and on the Sassanians, respectively. Chapter 3 (see Sections 3.4.1-3.4.2) showed how the selective use of excerpts and the new sequence of them in the Excerpta Salmasiana changed their meaning. In the new receptacle, excerpts on ethnography sketch out the traditional cultural distinctiveness between Romans and barbarians in order to reinforce the geographical and political frontiers already in place. In this way, the Excerpta Salmasiana represented Agathias' history in a different light.

The so-called Epitome is made up of a sequence of passages dealing with heresies and martyrs. The Epitome was compiled in a period in which authoritative religious texts (such as the Scriptures, Church Fathers' writings, Acts of Councils) were used extensively in a variety of works composed by processes of compilation: florilegia, quaestiones et responsiones, catenae, saints' lives, and homilies. ${ }^{44}$ These texts were products of the polemical literature of the age: they engaged 
in dogmatical disputes between religious groups in Constantinople, in particular between the Imperial Christian Church and supporters of Monothelistism. ${ }^{45}$ Yet the Epitome consists of a series of collections of excerpts extracted from a number of ecclesiastical texts. Ecclesiastical history as a specific subgenre of historical writing narrated the development of the early Christian Church as well as reflected on prominent bishops, heretical figures, theologians, and martyrs. ${ }^{46}$ Ecclesiastical history stopped being written in Greek after the sixth century. ${ }^{47}$ Yet the history of early Christianity and the establishment of the Church never stopped to interest Byzantine writers. ${ }^{48}$ The $E H$ by Eusebius, for instance, continue to be used, adapted, and copied by chroniclers throughout the Byzantine millennium. The aim of ecclesiastical historiography was to engage in dogmatical disputes, to celebrate Christianity, as well as establish local or religious groups too. ${ }^{49}$ Chronicles that drew on ecclesiastical historiography appeared to have served similar goals. Theophanes and George the Monk, for instance, both celebrated the triumph of Orthodoxy by writing a chronicle. From this point of view, chronicles can be construed as vehicles of imperial ideology. The inclusion of excerpts from ecclesiastical histories in the seventh-century Epitome does serve similar goals. What separates the Epitome from chronicles is the different time spans they cover and the structure through which the selected passages were presented.

The Excerpta Planudea preserve two series of excerpts on Roman Republic and Roman imperial history, respectively. Both series go back to an earlier collection of excerpts by Planudes. The excerpted passages deal with Roman virtues on the battlefield by recording exceptional deeds on the part of Roman emperors and officials. The passages highlight the glorious Roman past and supply contemporary readers with moral examples. Chapter 5 (see Section 5.3.4) showed that Planudes made a selective use of passages on Roman history in order to propagate political opinions: he recommends a militaristic imperial policy towards the enemies of the Empire.

\subsection{Other collections of historical excerpts}

There is a number of syllogae which comprise passages extracted from a single historical work. The tenth-century codex Vaticanus Urb. gr. 102 transmits a series of excerpts from Polybius' Historiae,$^{50}$ two fifteenth-century manuscripts,

45 Cameron (1996a).

46 On the development of ecclesiastical history in late antiquity, see De Vore (2015); Van Nuffelen (2018).

47 The reasons for the breakdown of ecclesiastical historiography have long been a subject of analysis. The traditional view is that the genre had nothing to serve in a Christianised Empire; Van Nuffelen (2018).

48 Ecclesiastical histories 'were considered an authoritative account' of the period of early Christianity; cf. Van Nuffelen (2018).

49 Van Nuffelen (2018).

50 On Vaticanus Urb. gr. 102, see Moore (1965), 19-20. 
Ambrosianus A 80 sup. and Ambrosianus G 13, transmit a collection of excerpts taken from an epitome of Dionysius of Halicarnassus' Antiquitates Romanae made in the ninth or the tenth centuries, ${ }^{51}$ and the so-called Excerpta Hoescheliana is made up from passages extracted from Diodorus of Sicily. ${ }^{52}$ It is unfortunate that we know nothing about the origin of the Excerpta Hoescheliana. The collection was published by D. Hoeschel; it was appended to his publication of the $E L$ in $1603 .^{53}$ It is difficult to say how much of the original excerpt collection on Diodorus of Sicily was copied in the Excerpta Hoescheliana, though. Moore rejects Krumbacher's suggestion that the collection of Polybian excerpts was made during the preparation of the $E C .^{54}$

Yet the existence of such collections verifies that, similarly to the case of John of Antioch or John Malalas, other late antique historians did circulate in Byzantine excerpt collections. ${ }^{55}$ Polybius' Historiae comprised 40 books covering the period from 220 to $168 \mathrm{BC}$. The work recounts the rise of Rome as the dominant power in the Mediterranean. Books 1-5 survive complete. Books 6-40 have come down to us in collections of excerpts, namely the so-called Excerpta Antiqua and the EC. Bibliotheca historica, by Diodorus of Sicily, comprised 40 books, of which only books 1-5 and 11-20 survive complete. The rest is transmitted in collections of excerpts such as the EC and the so-called Excerpta Hoescheliana, as well as in Photius' Bibliotheca. ${ }^{56}$ Antiquitates Romanae, by Dionysius of Halicarnassus, originally comprised 20 books retelling the history of Rome from the mythical times to 264 BC. Books 1-9 survive in their entirety; books 10-11 have been transmitted nearly complete; and books 12-20 have come down to us in fragments in the $E C$ and in the epitome excerpts of which are preserved in the two Ambrosiani codices.

Although these collections appear to lack any strong thematic coherence which characterises syllogae consisting of passages from a variety of authors, the selection of passages was contingent on the interests on the part of the compilers. Moore has noticed that Vaticanus Urb. gr. 102 transmits a selection of passages from Polybius different from that in the extant copies of the $E C .{ }^{57}$ There is no sufficient evidence to establish whether the aforementioned syllogae were intended to function as sources for chronicles; this hypothesis is not substantiated by the surviving historical texts compiled after the tenth century. All that can be said is that collections made up from excerpts taken from a single author applied methodologies similar to these seen in syllogae consisting of excerpts thematically selected from a variety of historians. The examination, for instance, of the two

51 On the two Ambrosiani codices, see Sautel (2000), 73-76.

52 Bertrac (1993), CXXXVII-CXXXVIII.

53 Hoeschel (1603).

54 Moore (1965), 55.

55 On the manuscript transmission of Polybius' text, see Moore (1965).

56 Bibliotheca, cod. 244.

57 Moore (1965), 55. 
Ambrosiani by Sautel has corroborated that excerpts taken from Dionysius of Halicarnassus underwent textual changes before their inclusion in them. ${ }^{58}$

\subsection{Conclusion}

In the past scholars have long deemed works that consist of selections of excerpts to lack originality or seen the cut and paste technique employed in these works as a sign of intellectual decline. ${ }^{59}$ It is this view that the present book attempted to revise by considering syllogae of historical excerpts in their individuality and within the particular context they appeared. The present study built on scholarship of the last decade that begun to view collections of excerpts as a particular way of ordering, organising, and disseminating knowledge in Byzantium. Since P. Odorico has described the Byzantine society as 'a culture of sylloge', scholars tended mostly to deal with collections of patristic citations or chronicles made up of selections of passages taken from earlier texts. In addition to the fact that citations from authoritative sources enhanced the validity of arguments, such collections of excerpts offered a unified and cogent vision of the present on the basis of extant pieces of representations of the past. Notwithstanding modern scholarship has been disposed towards examining manuscripts in their own right, rather than as mere sources for the ancient texts they preserve, receptacles of passages taken from histories have always been neglected. With the exception of the $E C$, no other such sylloge of historical passages had ever been viewed as a systematic effort to reorganise knowledge in Byzantium. The present book has shown that the method, execution, and use of the $E C$ was similar to those detected in a number of other syllogae of historical excerpts. By assigning an innovative character to the $E C$, some modern scholars tended to limit their function to the facilitation of the reader's consultation of the various topics included in the $E C$. The examination of the $E C$ in light of other syllogae of historical excerpts showed that the selection of passages in the various collections of the $E C$ was dependent on contemporary ideology as well as cultural tendencies.

It should be noted that a distinction must be made between those texts consisting of extracted passages and works that simply made use of one or more sources. The texts discussed in this book are composed on the basis of citations and in all of them a new narrative was formed on the basis of excerpts. Yet the rewriting of the text was involved in syllogae through which gatherings of selected historical passages were given. As we have seen, the different degrees of adaptation of selected excerpts varied among syllogae even of the same sort of texts. The entire assemblage was, however, formulated according to the compositional pattern which is perceptible in earlier catenae, gnomologies, or collections of theological questions-and-answers: a series of selections taken from their original context and assembled in a single container, according to a particular ordering principle. The

58 Sautel (2000), esp. 76-88.

59 Dusil, Swedler, and Schwitter (2017). 
composition of syllogae of historical excerpts was shaped by similar methods as well as the same desire to collect thematically connected material and to represent it according to a new order. Throughout the text in the Excerpta Anonymi, the prooemium to the EC, and in the headings of the so-called Epitome, the Exc.

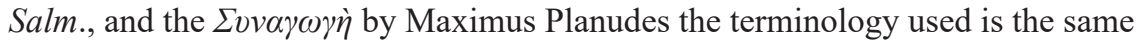
as the terminology that occurred in other texts defined as syllogae as well. The terminology points to the late antique and medieval practice of excerpting and to a common textual approach to older texts: the culture of sylloge.

In the previous pages, I have also considered how the classification criteria proposed by J. Signes Codoñer and P. Magdalino play out in collections of historical excerpts. The conclusion to be drawn is that collections of historical excerpts represent a specific group within historiography. In fact, the works examined in this book share methodological and structural principles, which make them a distinct body of texts. In our group of texts, the material was thematically extracted from a variety of earlier historical works. The extent to which compilers re-edited the selected passages differs among the four texts. The compilation process in historical excerpt collections was determined by similar principles and methods, though: a) accuracy, b) brevity, c) retaining the sequence of the original narrative. The examination of single excerpts from each of the collections revealed identical strategies by the compilers in dealing with the lack of context that was because of the copying-pasting technique: a) deletions and insertions, and b) substitutions of words for others that explained the text better. I have also shown that the selection of material in collections of historical excerpts was shaped by contemporary ideology as well as personal interests and intentions. We saw that omissions and alterations in the course of the redaction of the Excerpta Anonymi point to political attitudes and the perception of the world current in the period they were compiled. Their compiler appears to serve the dominant imperial policy of the time. Passages on ethnography in the Agathias part of the Excerpta Salmasiana mirror similar preoccupations and politics. In the thirteenth century, the collection of passages on Roman history by Planudes was meant to counsel the emperor Andronicus II.

From this perspective, the collections of historical excerpts presented and examined in this book not only contain history, as scholars usually tend to think, but they are histories themselves. For collections of historical excerpts served the role of history, as manifested in traditional historical genres, that is, in classicising histories and universal chronicles: a) to preserve the memory of the past, b) to supply people with examples concerning behavioural patterns, and c) to shape cultural and political thinking. From this point of view, collections of historical texts merit being considered as cultural forms in their own right and part of Byzantine historiography. 
$\because$ Taylor \& Francis

Taylor \& Francis Group

http://taylorandfrancis.com 


\section{Appendix I: Texts}

\section{The six Procopian excerpts on ethnography in the Excerpta Anonymi}

\section{Excerpt 1}

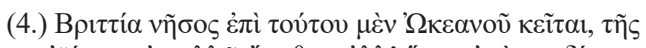
ịióvo

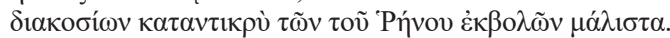

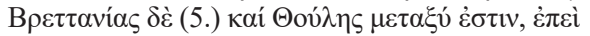

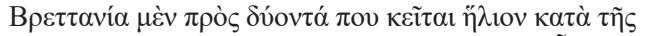

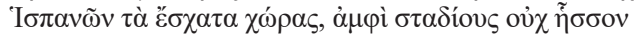

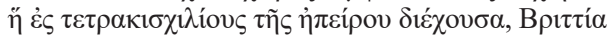

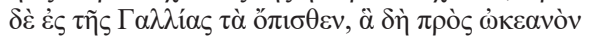

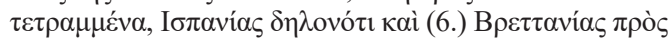

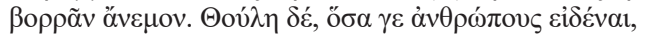

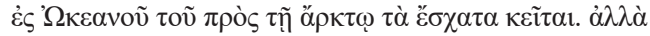

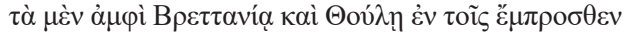

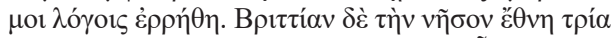

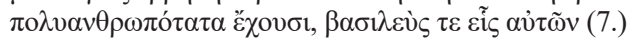

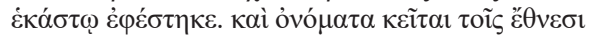

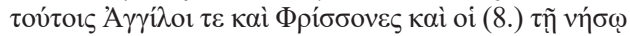

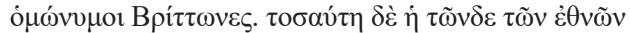

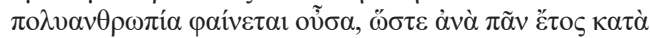

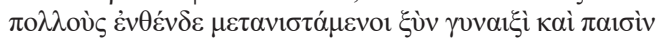

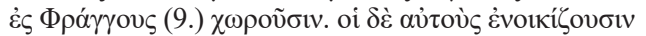

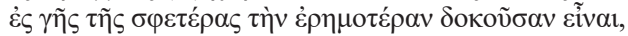

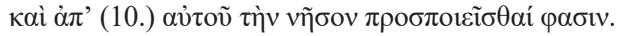

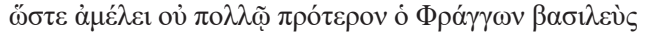

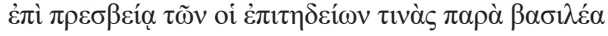

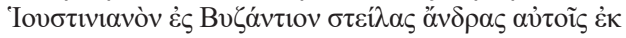

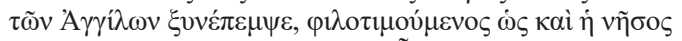

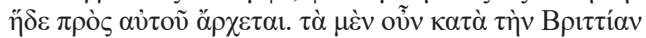

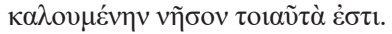

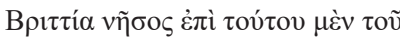

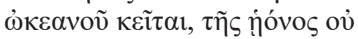

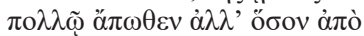
$\sigma \tau \alpha \delta \dot{\omega} \omega v \sigma^{\prime} \kappa \alpha \tau^{\prime} \alpha \dot{\alpha} \tau \iota \kappa \rho \grave{~} \tau \tilde{\omega} v$

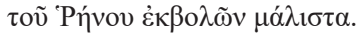

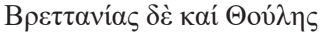

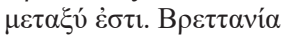

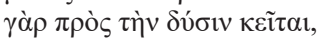

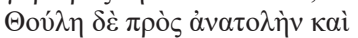

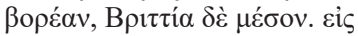

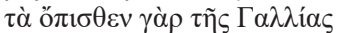

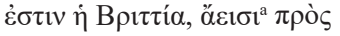

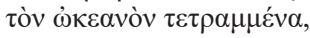

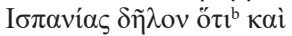

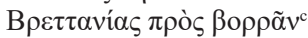

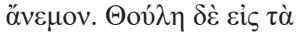

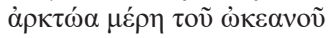

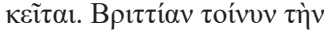

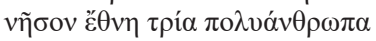

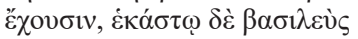

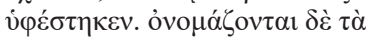
है $\theta v \eta$ A

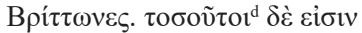

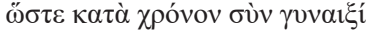

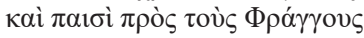
$\pi \mathrm{o} \lambda \lambda$ ov̀ $\varsigma \dot{\alpha} \pi \varepsilon \dot{\varepsilon} \chi \varepsilon \sigma \theta \alpha \mathrm{\alpha} \dot{\alpha} \pi \mathrm{ou \kappa í \alpha}$

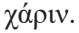

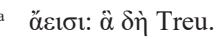

$\delta \tilde{\eta} \lambda$ ov ö $\tau$ : $\delta \eta \lambda$ ovó $\tau$ Treu.

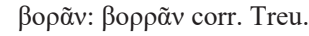

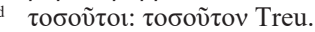




\section{Appendix I}

\section{Excerpt 2}

Procopius, De bellis 8.20.2-4 and 18

Excerpt 2 = Excerpta

Anonymi 23.26-23.29

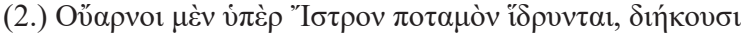

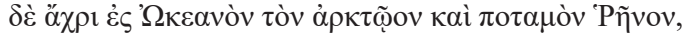

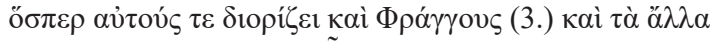

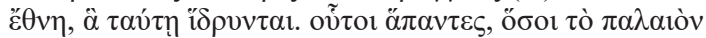

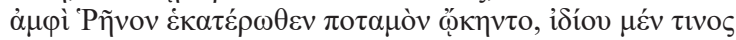

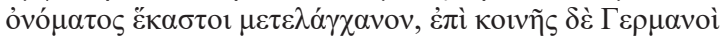

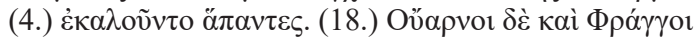

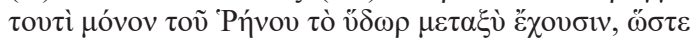

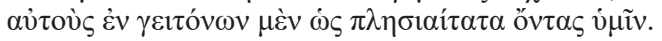

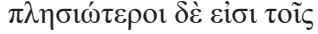

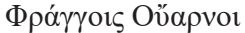

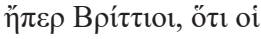

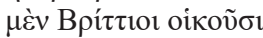

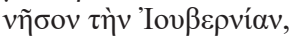

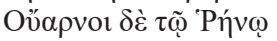

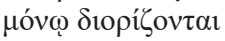
$\tau \tilde{\omega} \nu \Phi \rho \alpha ́ \gamma \gamma \omega v$, oủ oi

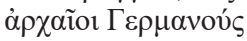

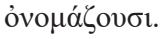

\section{Excerpt 3}

Procopius, De bellis 8.20.23-24
Excerpt $3=$ Excerpta

Anonymi 23.30-23.32

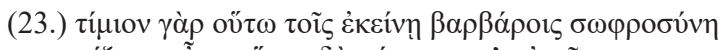

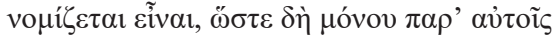

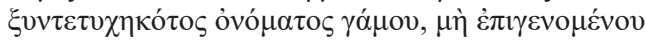

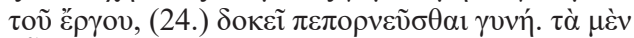

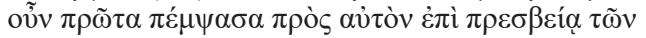

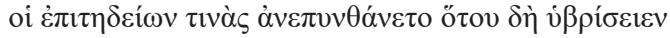

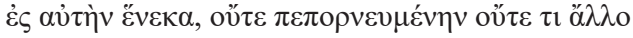

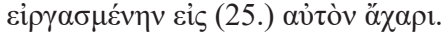

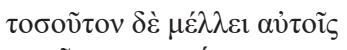
$\tau \tilde{\eta} \varsigma \sigma \omega \varphi \rho \circ \sigma u ́ v \eta \varsigma$

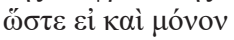
$\tau 1 \varsigma \mu v \eta \sigma \tau \varepsilon v \sigma \alpha ́ \mu \varepsilon v o \varsigma$

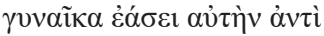

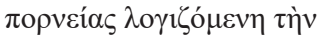
$\mu \nu \eta \sigma \tau \varepsilon i ́ \alpha v$ ov̉ $\pi \alpha v ́ \sigma \eta \tau \alpha$,

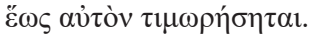

\section{Excerpt 4}

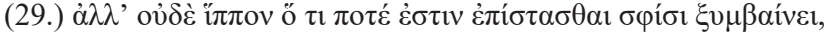

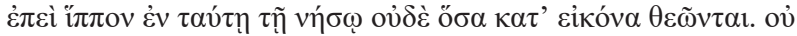

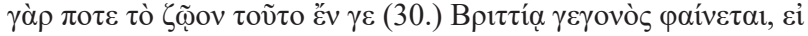

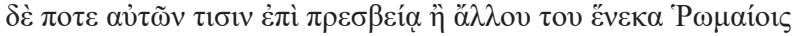

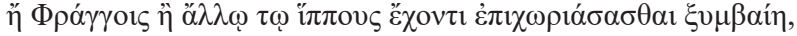

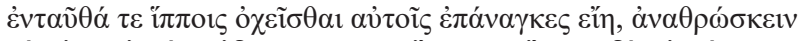

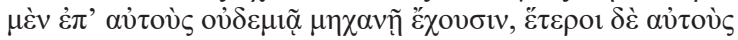

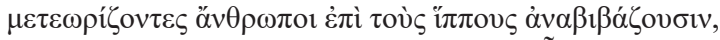

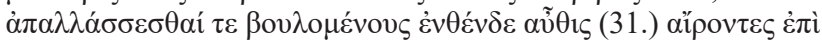

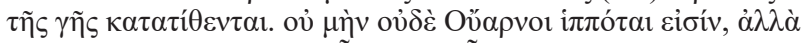

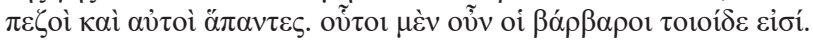

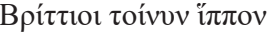

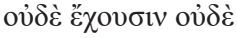
$\gamma v \omega \rho i ́ \zeta o v \sigma v, \alpha \dot{\alpha} \lambda \lambda \dot{\alpha}$ $\pi \varepsilon \zeta o i ̀ ~ \mu \alpha ́ x o v \tau \alpha 1$,

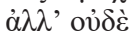
Oǔ $\alpha \rho v o$. 


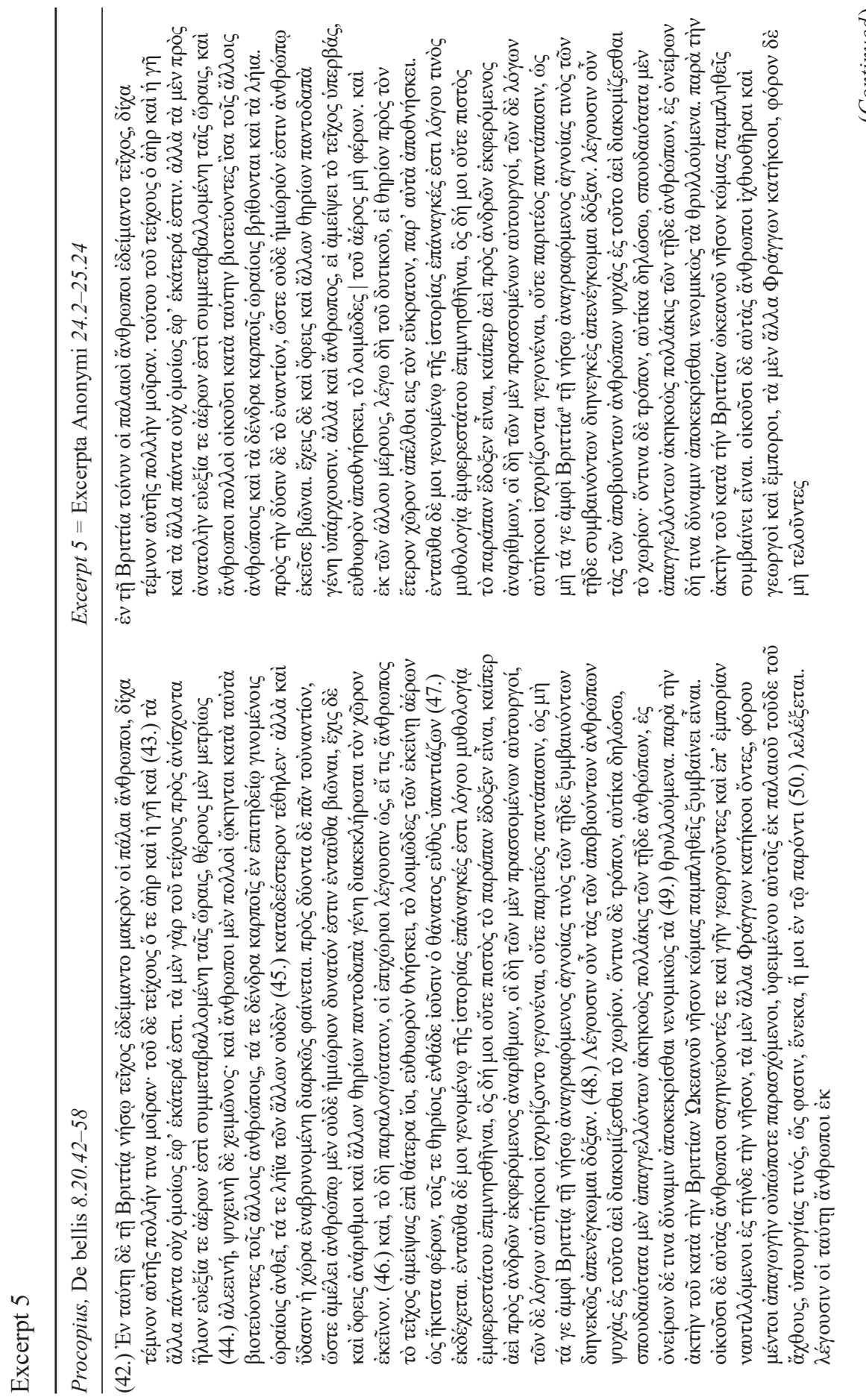



言. दै

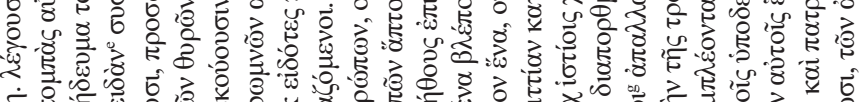

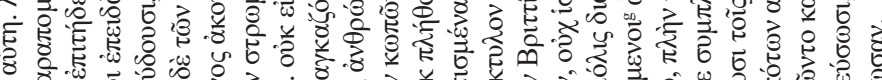
$\downarrow$ क

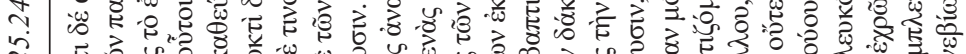

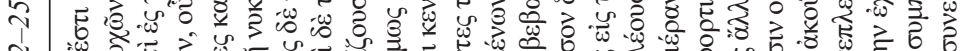
y

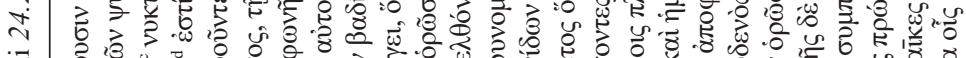
, च है

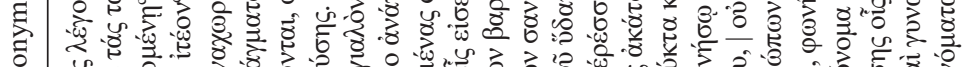

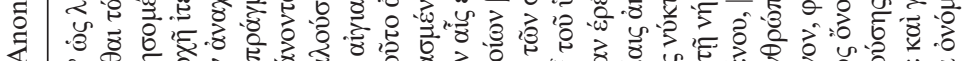
य

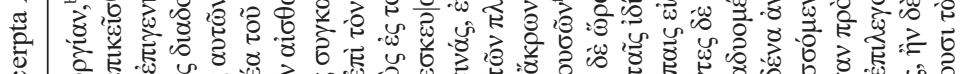
氙

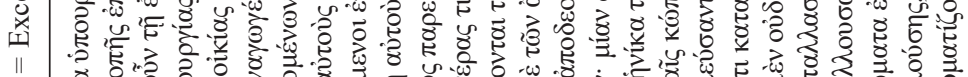
II n

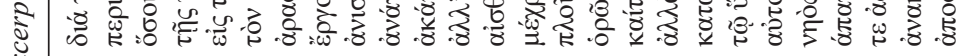
通

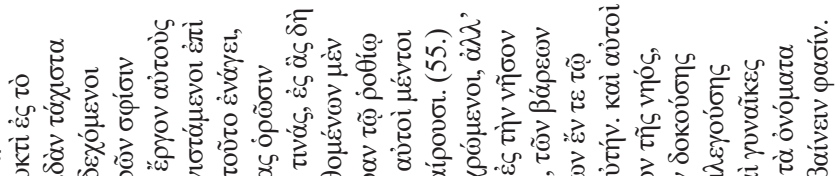
"F ठे

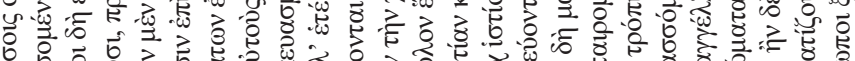

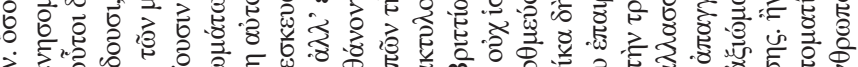

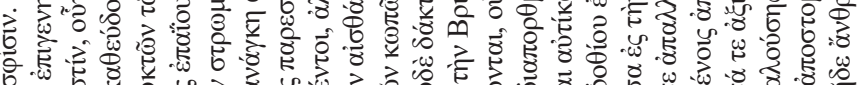

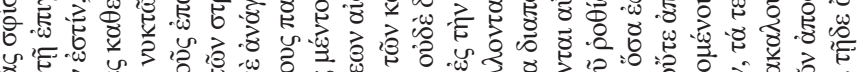

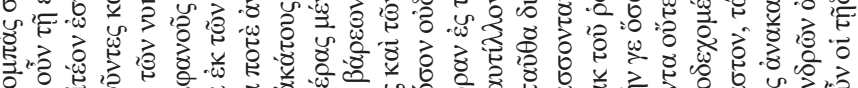

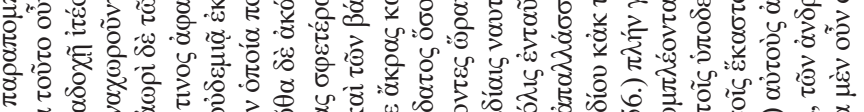

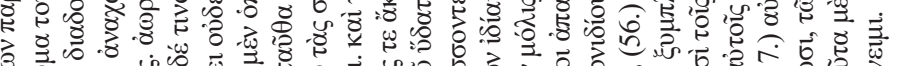

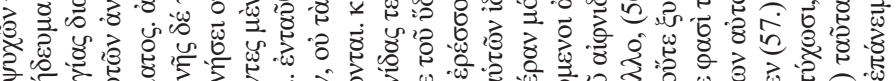

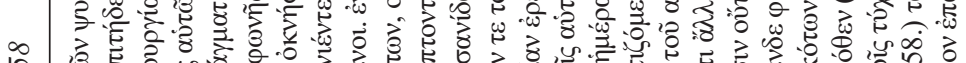

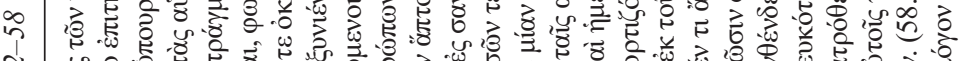
当

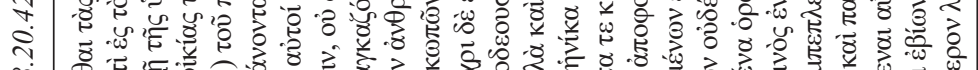
क

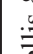

离

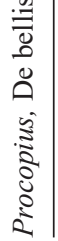

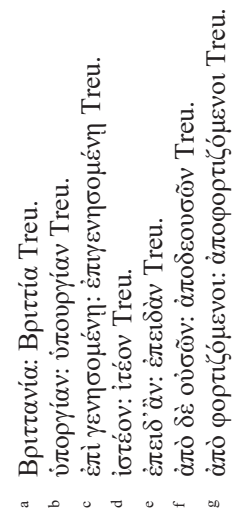




\section{Excerpt 6}

Excerpt $6=$ Excerpta

Anonymi 25.25-26.4

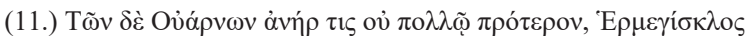

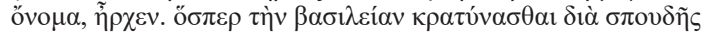

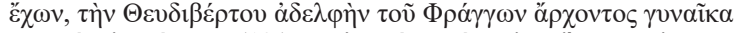

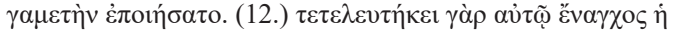

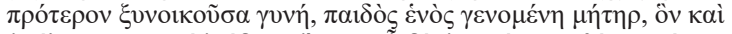

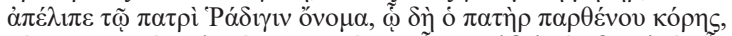

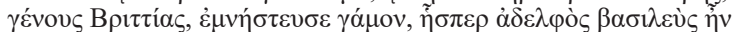

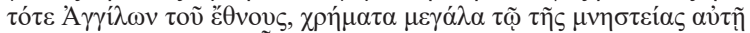

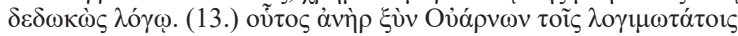

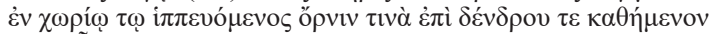

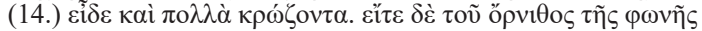

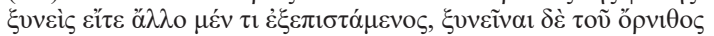

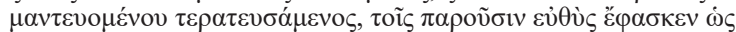

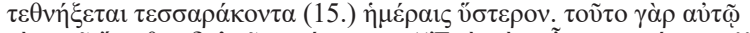

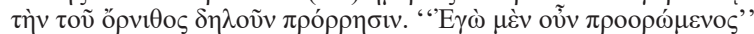

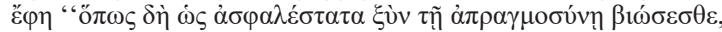

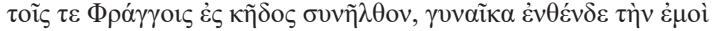

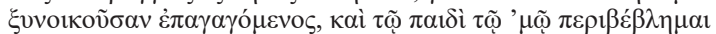

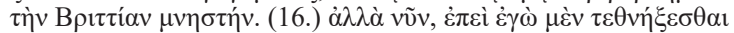

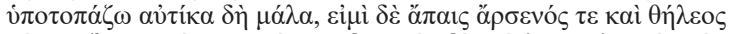

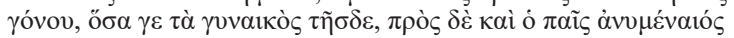

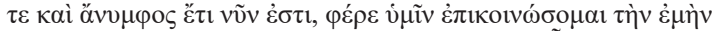

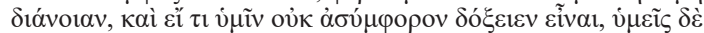

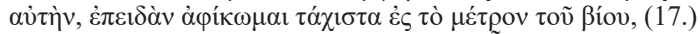

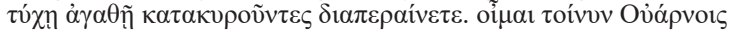

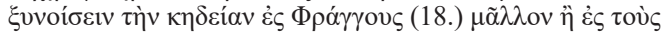

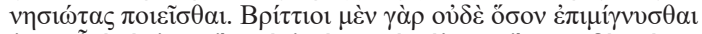

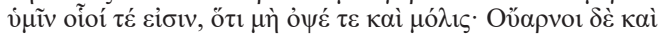

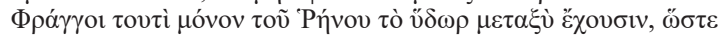

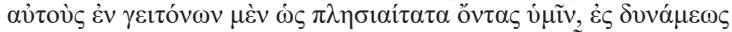

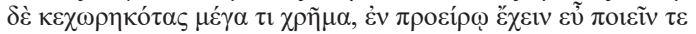

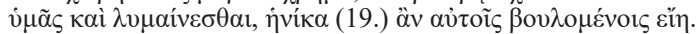

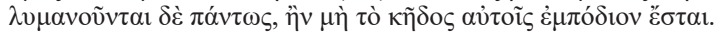

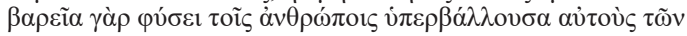

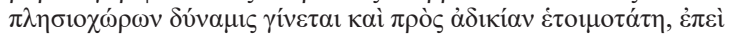

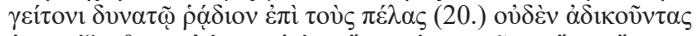

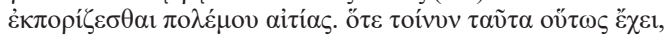

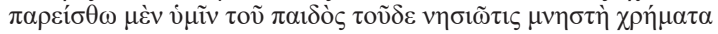

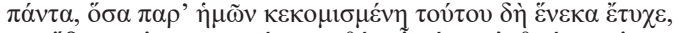

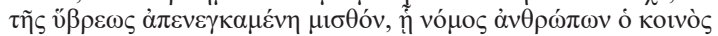

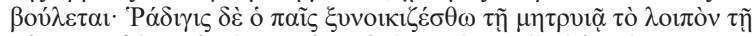

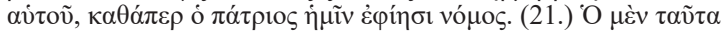

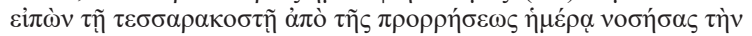

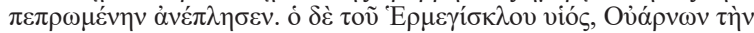

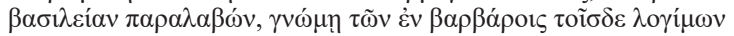

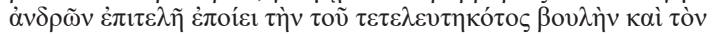

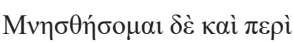

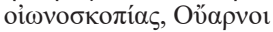

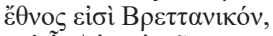

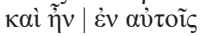

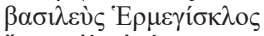

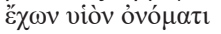
'Pó $\gamma 1 \delta t v . \tau \varepsilon \lambda \varepsilon v \tau \eta \sigma \alpha ́ \sigma \eta \varsigma$

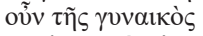

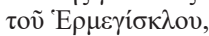

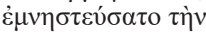

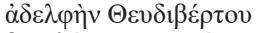

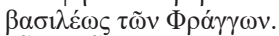

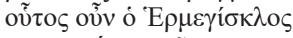

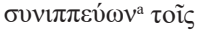

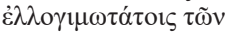

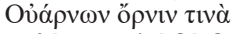
$\kappa \alpha \theta \dot{\mu} \mu \varepsilon v o v \dot{\varepsilon} \pi \grave{~} \delta \varepsilon ́ v \delta \rho \circ v$

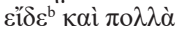

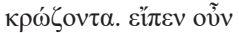

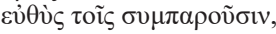
$\dot{\omega} \varsigma \mu \varepsilon \tau \dot{\alpha} \tau \varepsilon \sigma \sigma \alpha \rho \alpha ́ \kappa o v \tau \alpha$ $\dot{\eta} \mu \varepsilon \dot{\varepsilon} \rho \alpha_{\varsigma} \tau \varepsilon \theta v \dot{\xi} \xi \varepsilon \tau \alpha 1$.

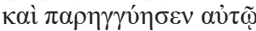

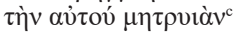

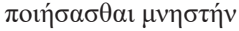

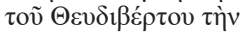

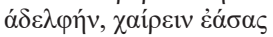

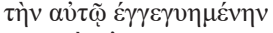

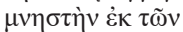

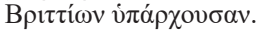

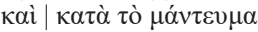
$\tau \tilde{n} \tau \varepsilon \sigma \sigma \alpha \rho \alpha \kappa о \sigma \tau \tilde{\eta}$

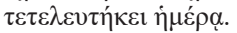

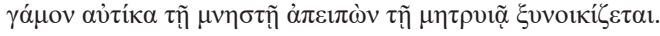

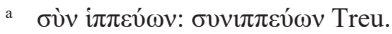

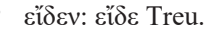

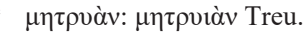




\section{Appendix I}

\section{The Agathias excerpts transmitted in the Excerpta Salmasiana}

The numbers in bold throughout the text body indicate the beginning of a new excerpt. The edition of the text is accompanied by an apparatus fontium and an apparatus criticus. The apparatus fontium gives the passages in Agathias' Historiae to which each excerpt in the Exc.Salm. corresponds. The sigla given at the beginning of the apparatus criticus indicate the manuscripts transmitting the excerpts. The text is a compilation of excerpts from a single historical text. Given the particular nature of a collection of excerpts, the present edition intends to give the text as evidenced and transmitted in the extant manuscripts of the Exc.Salm. rather than to present a corrected version of the text. In passages where the manuscript transmission is divergent, the examination of the textual context of the Agathias excerpts and the study of the original source used by the Exc.Salm. have been helpful in deciding which reading is more likely to be original. Detection of possible deletions, additions, interpolations, and syntactical and grammatical corruptions of the text is performed. The restoration of the punctuation is a difficulty that editors of Byzantine texts always face. Studies on the correct use of punctuation in critical editions of ancient Greek and Byzantine texts by D. J. Murphy (1995), and J. Noret $(1995,1998)$ help us understand how modern editors deal with such editorial problems. On editing the excerpts, I rely on the traditional editorial method proposed in the handbooks on textual criticism and editorial techniques by Maas (1958) and West (1973). The Thesaurus Linguae Graecae (TLG), a special research project of the University of California, Irvine, which has collected and digitised most literary texts written in Greek from Homer to $1453 \mathrm{AD}$, is consulted when necessary. The excerpts are accompanied by a commentary. The commentary serves to explain internal inconsistencies of the Agathias-part and contains informative references to figures, places, and events central to the selection of excerpts.

\section{Tabula Notarum in Apparatu Critico Adhibitarum}

\section{Codices}

V Vaticanus gr. 96 (s. XII med.)

Pal Vaticanus Pal. 93 (s. XII med.)

\section{Editores et emendatores}

M C. Müller

\begin{tabular}{ll} 
Cetera & \\
\hline$[\ldots]$ & litterae deperditae \\
$<>$ & litterae additae \\
\{\} & litterae deletae \\
corr. & correxit \\
del. & delevit \\
mg. & margen \\
om. & omittit, omittunt \\
suppl. & supplevit \\
v.l & varia lectio \\
\hline
\end{tabular}




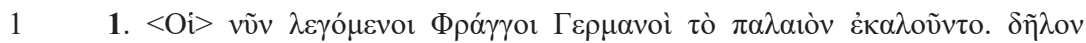

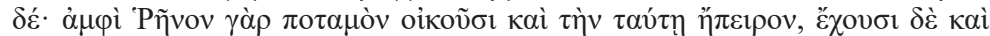

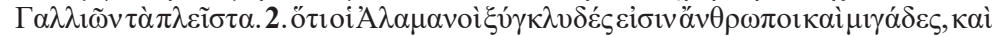

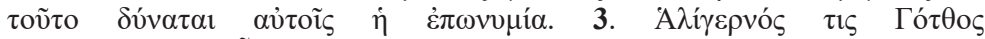

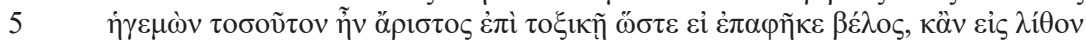

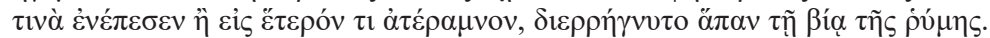

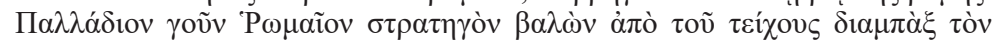

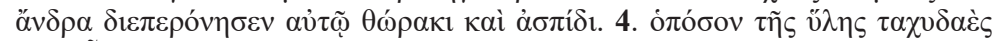

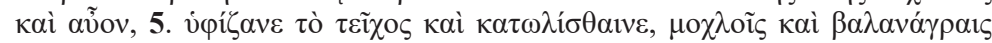

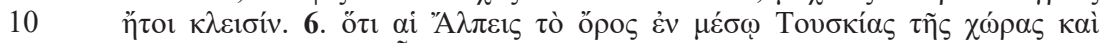

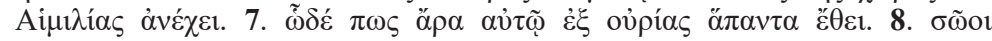

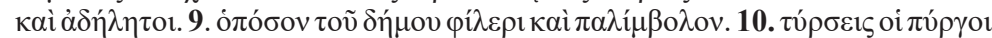

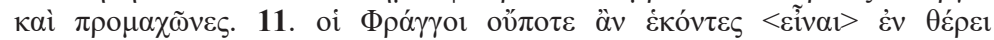

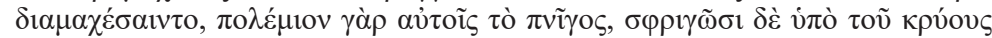

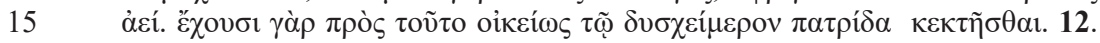

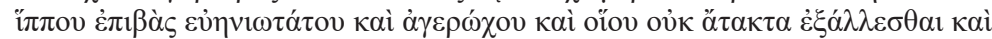

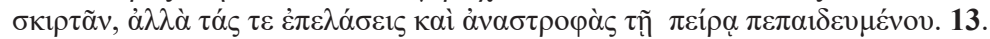

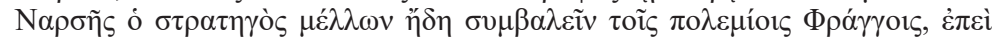

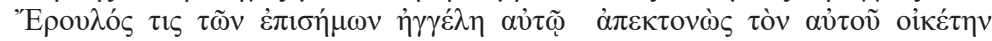

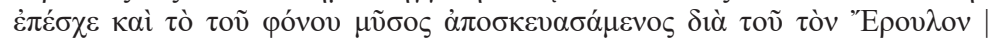

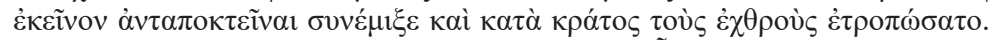

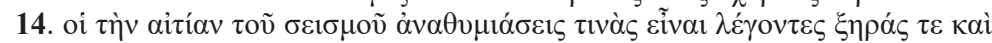

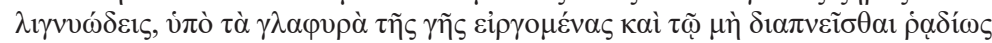

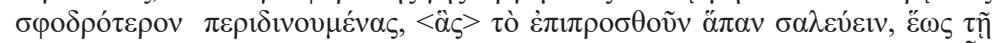

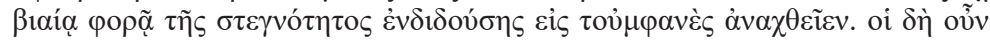

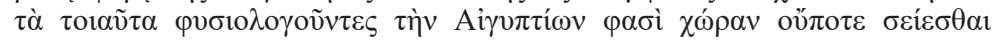

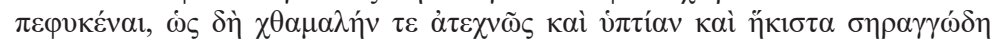

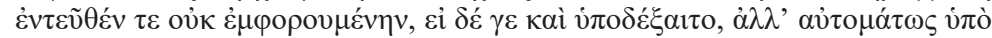

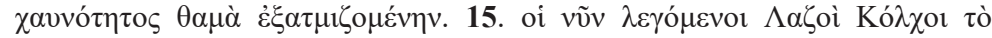

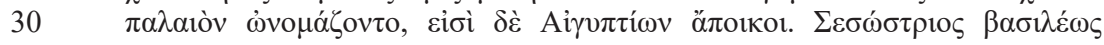

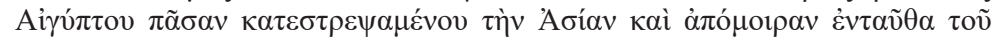

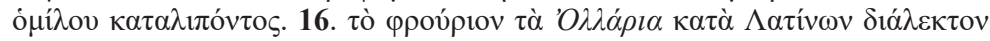

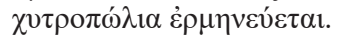

Codd. VPal 1.1 vข̃v - $3 \pi \lambda \varepsilon \tilde{\sigma} \sigma \tau$ : Historiae 1.2.1 2.3 ö $\tau 1-4 \dot{\varepsilon} \pi \omega v v \mu$ ía: Historiae

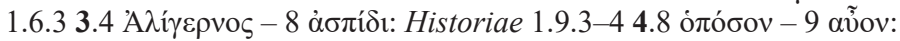

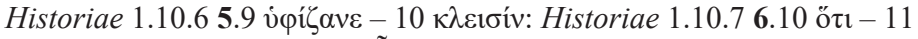

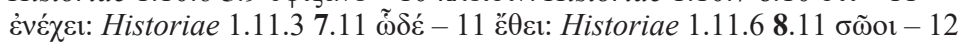

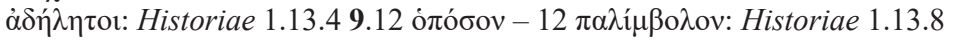

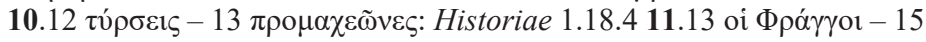

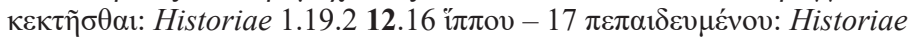

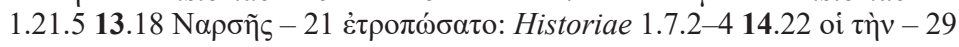

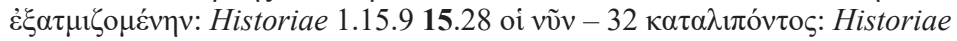

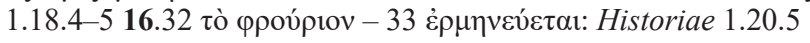

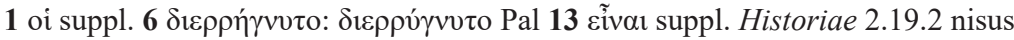

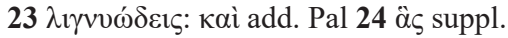




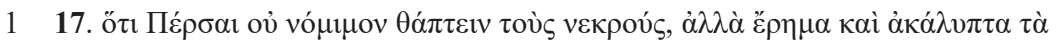

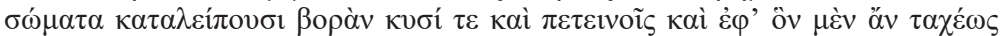

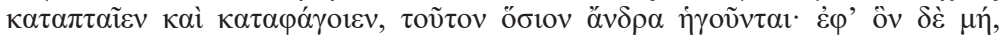

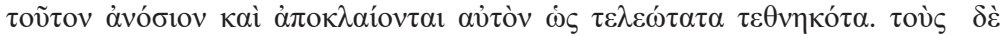

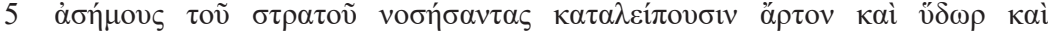

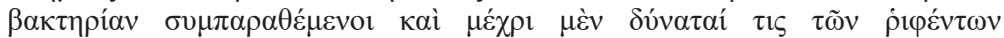

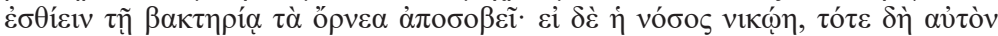

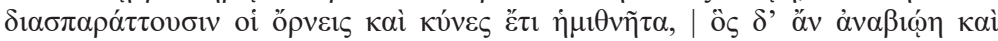

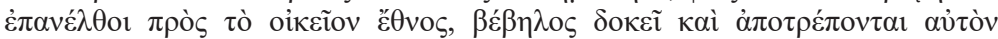

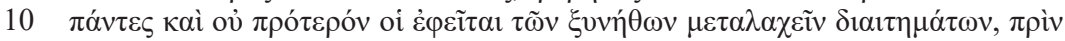

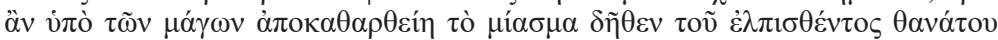

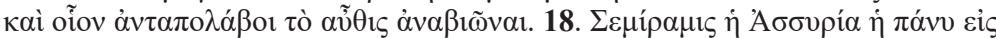

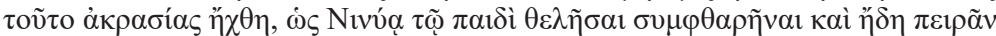

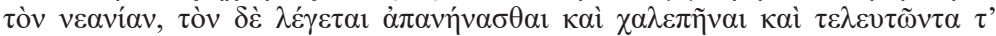

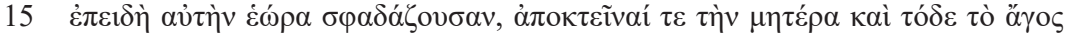

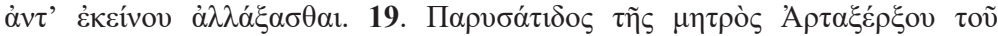

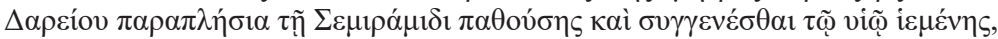

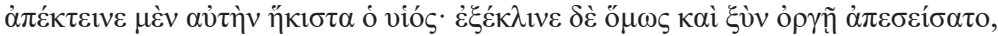

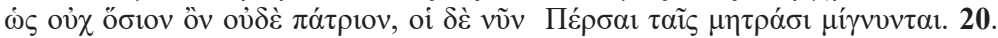

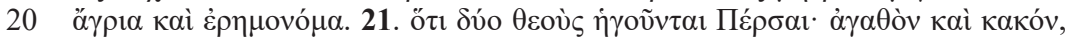

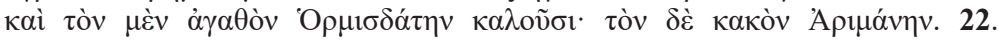

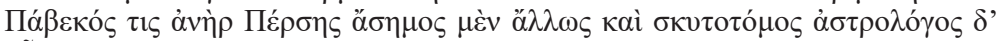

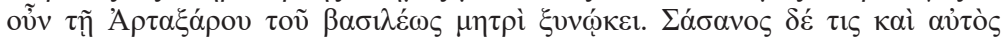

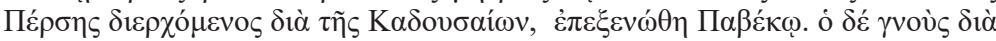

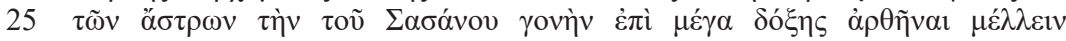

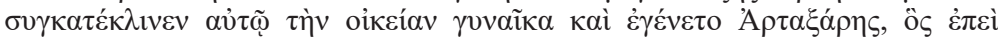

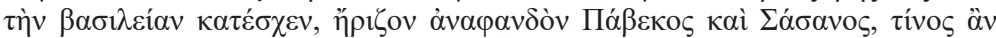

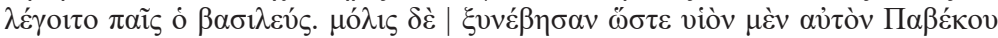

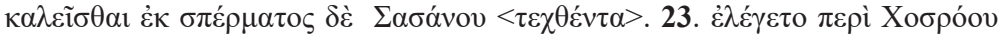

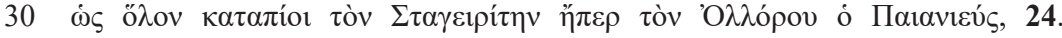

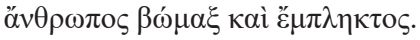

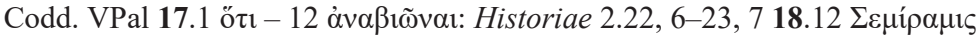

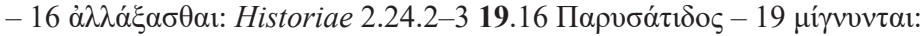

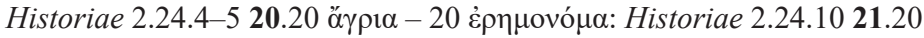

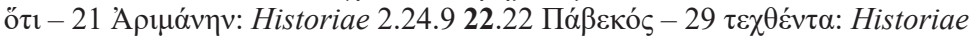

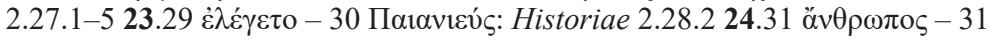

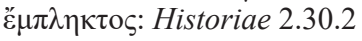

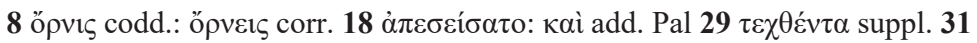
$\beta \omega ́ v \alpha \xi$ codd: $\beta \omega \dot{\mu} \alpha \xi$ corr. Historiae 2.30.2 nisus 


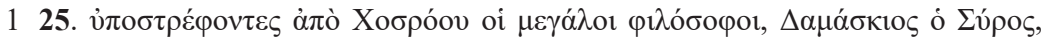

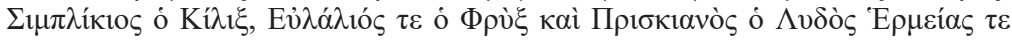

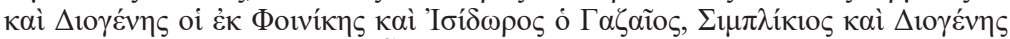

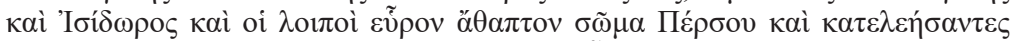

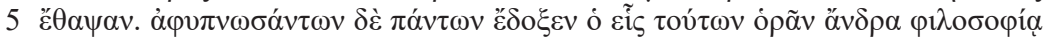

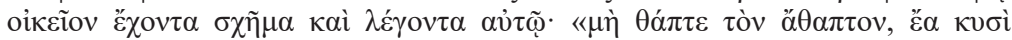

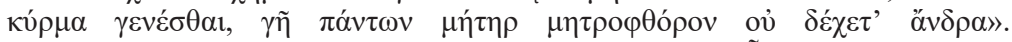

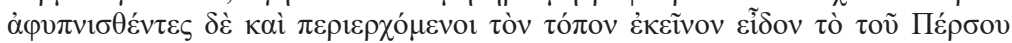

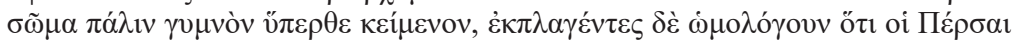

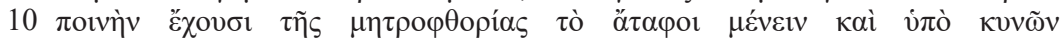

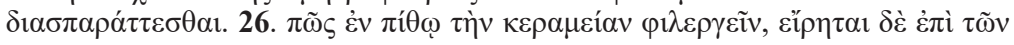

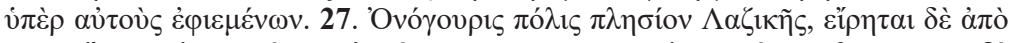

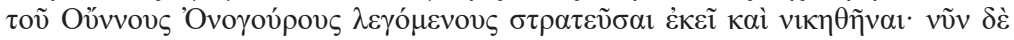

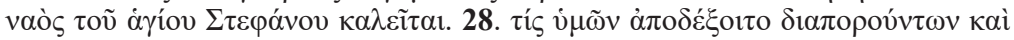

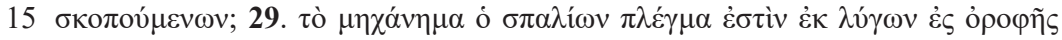

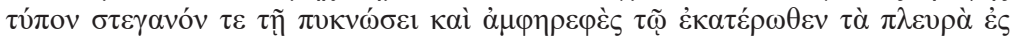

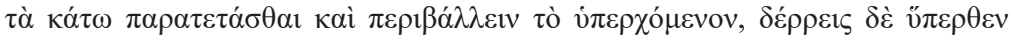

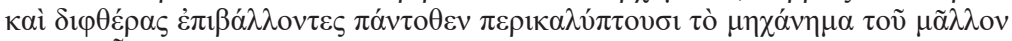

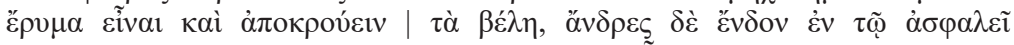

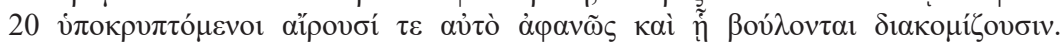

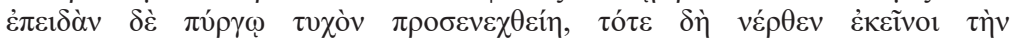

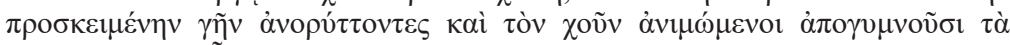

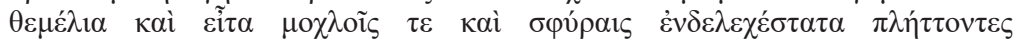

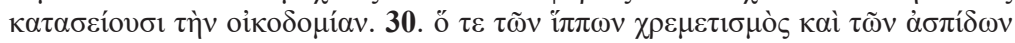

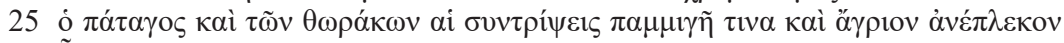

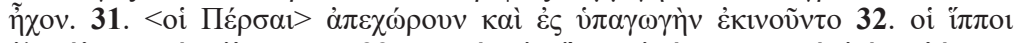

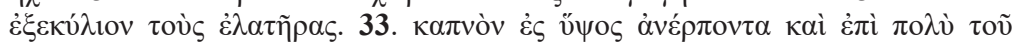

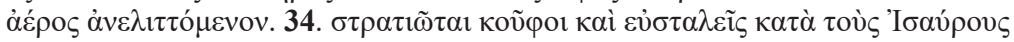

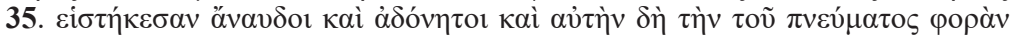

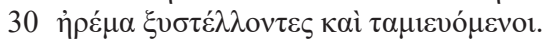

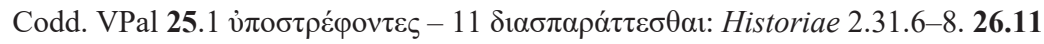

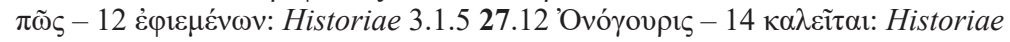

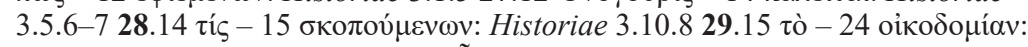

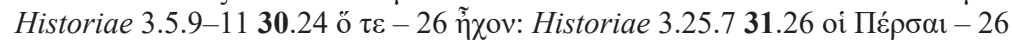

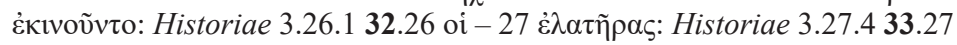

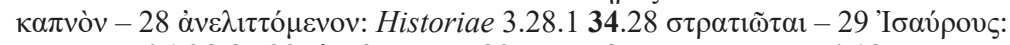

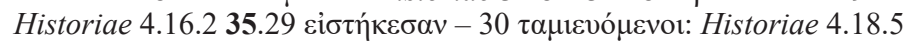

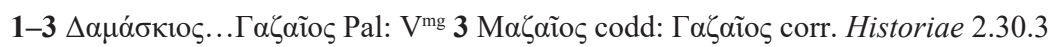

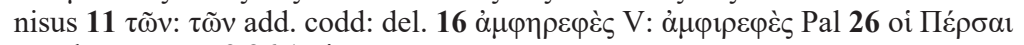
suppl. Historiae 3.26.1 nisus 


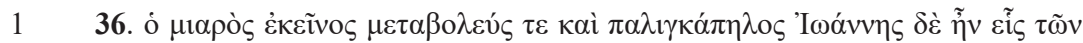

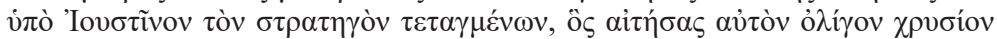

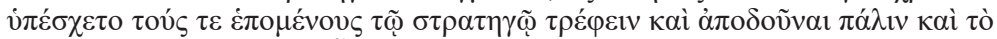

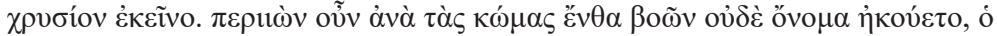

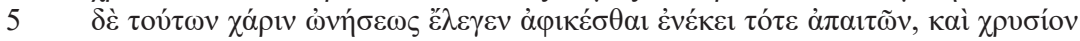

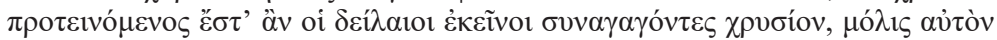

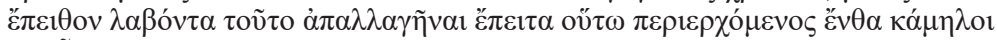

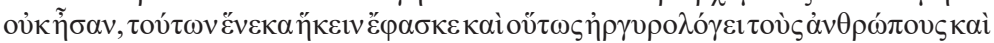

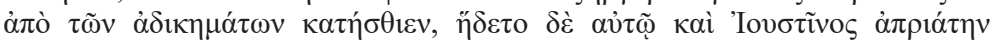

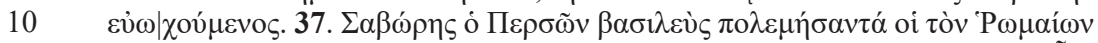

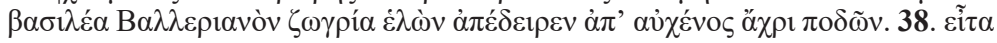

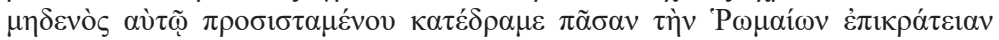

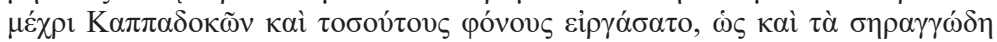

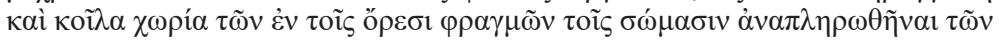

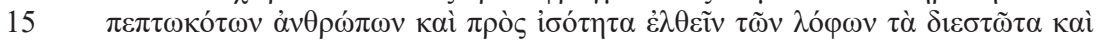

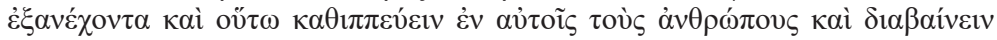

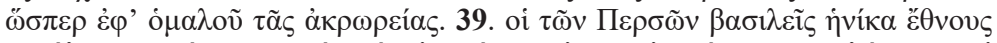

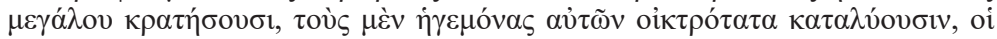

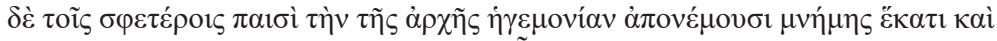

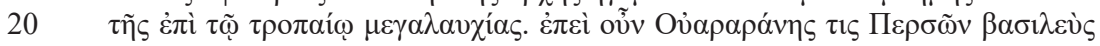

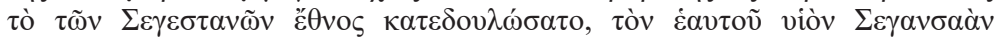

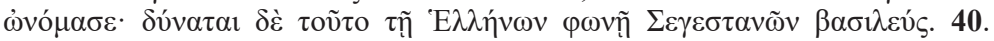

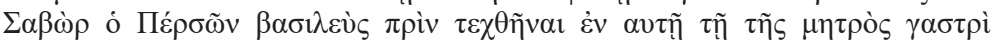

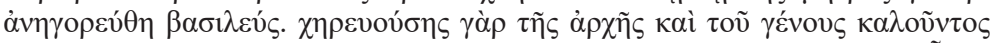

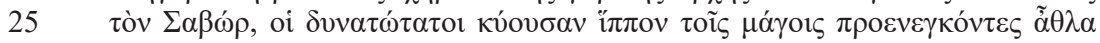

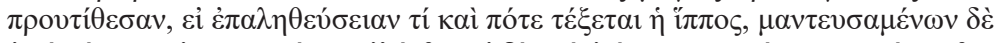

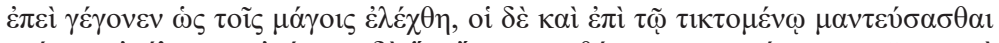

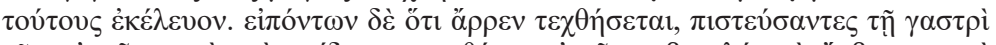

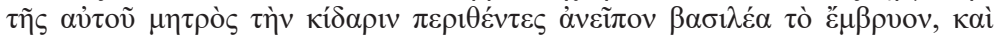

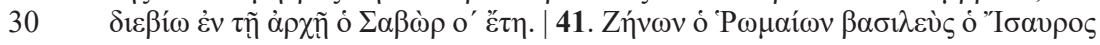

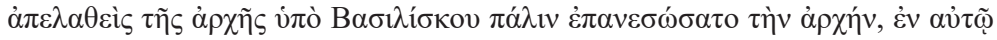

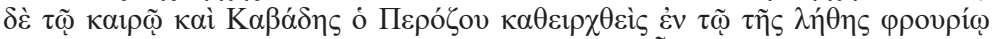

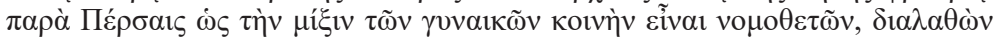

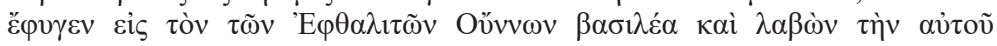

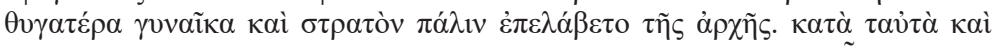

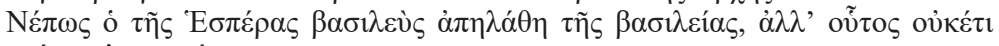

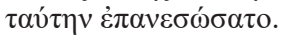

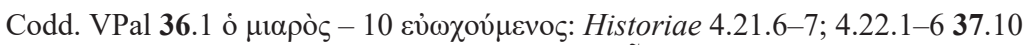

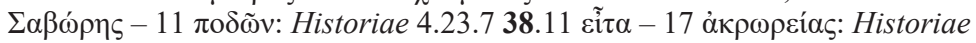

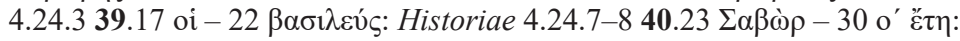

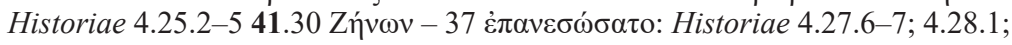
$4.28 .3 ; 4.28 .4 ; 4.29 .2-3$

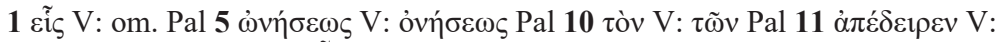

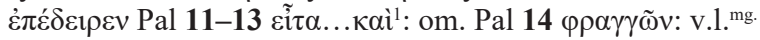




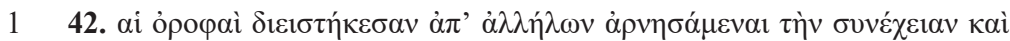

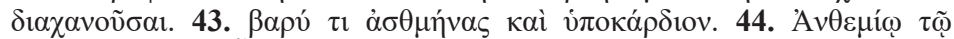

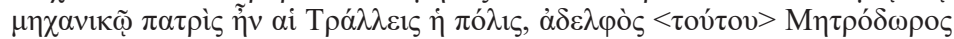

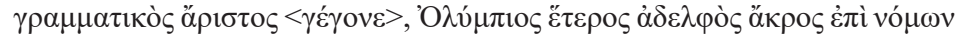

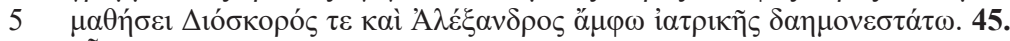

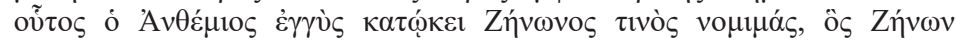

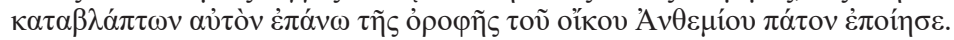

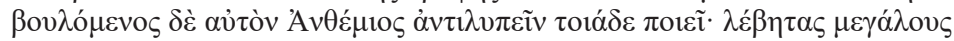

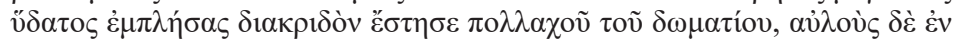

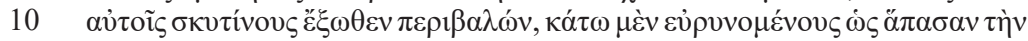

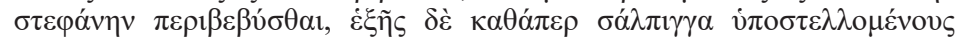

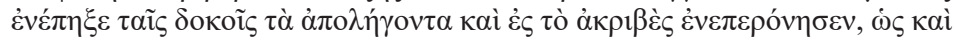

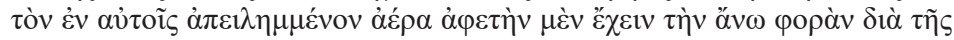

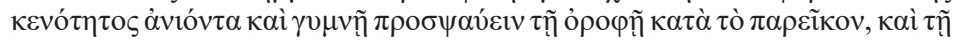

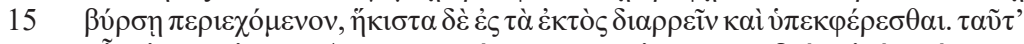

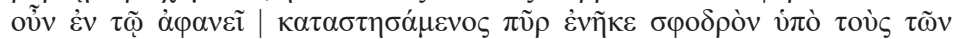

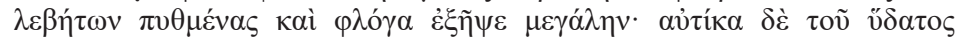

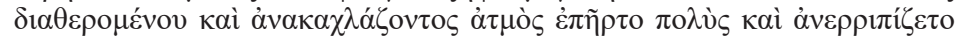

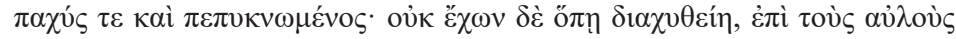

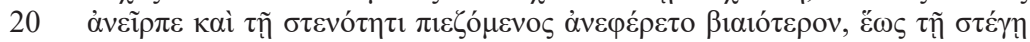

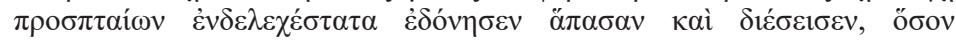

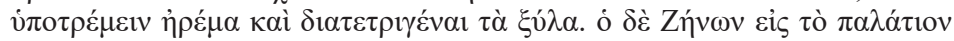

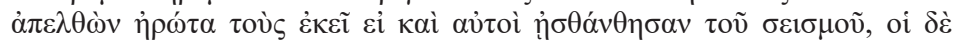

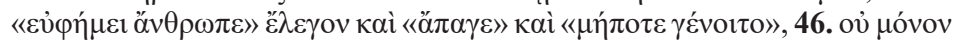

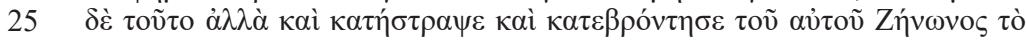

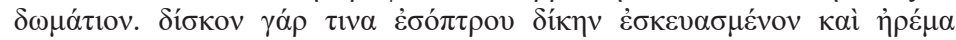
نं

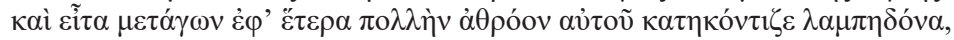

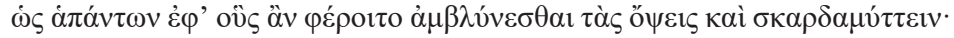

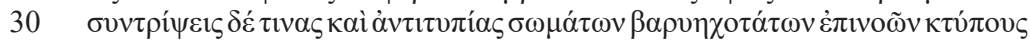

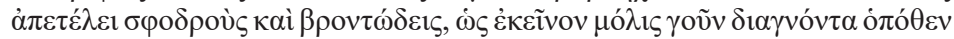

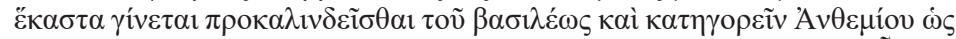

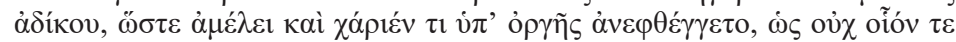

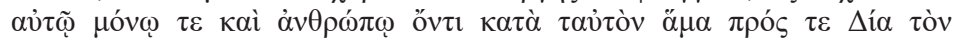

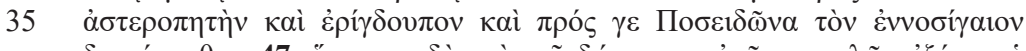

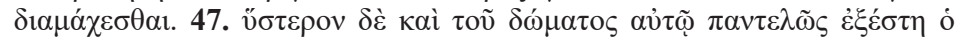

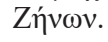

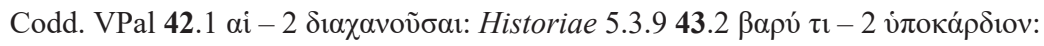

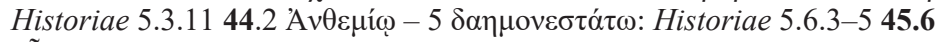
ỡ

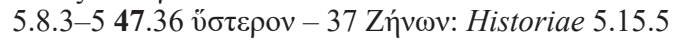

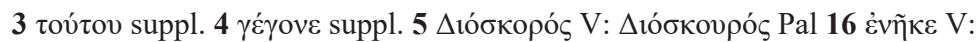

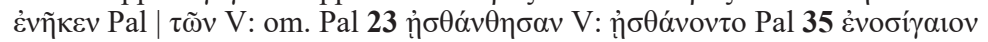
codd: Ėvvoбíralov corr. 


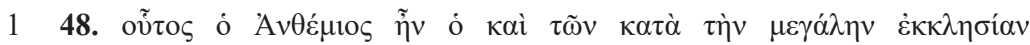

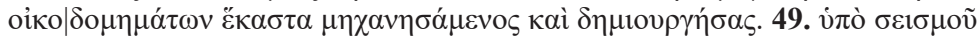

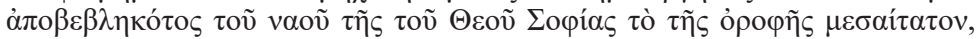

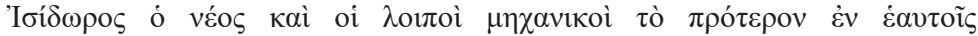

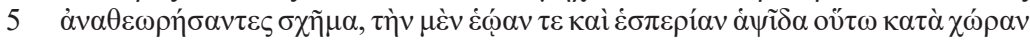

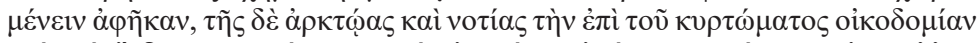

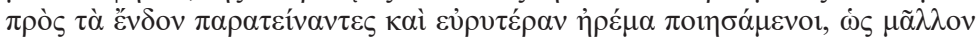

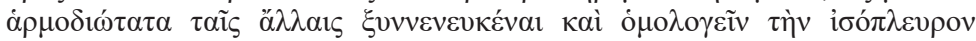

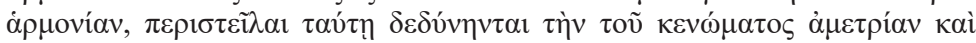

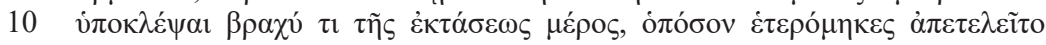

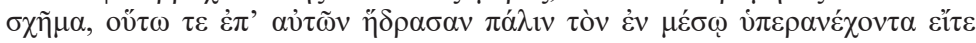

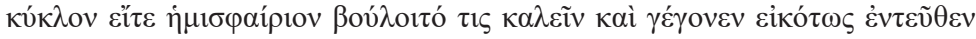

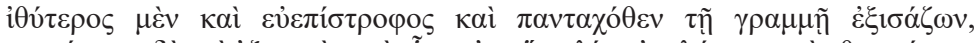

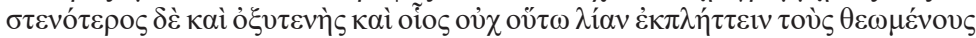

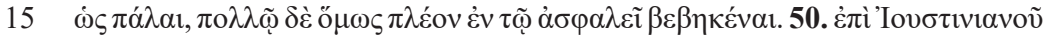

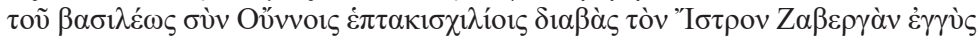

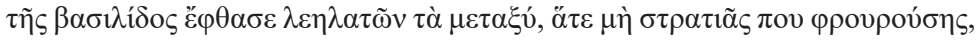

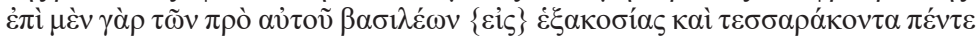

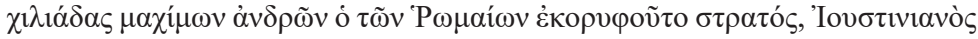

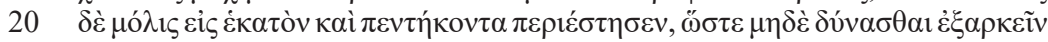

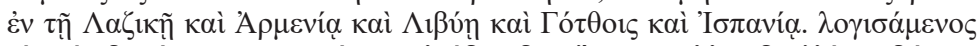

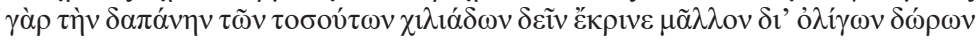

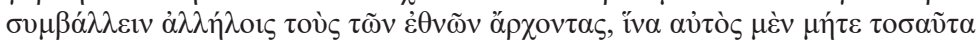

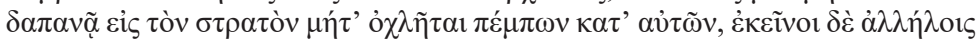

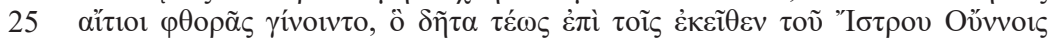

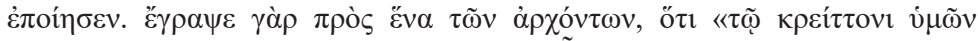

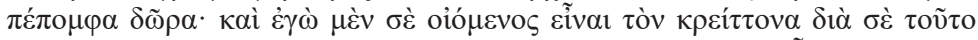

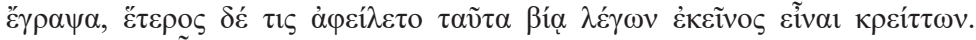

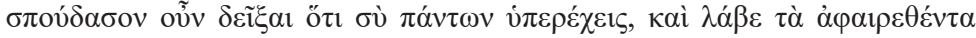

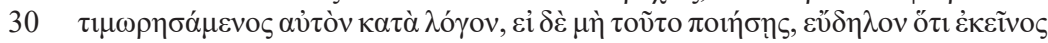

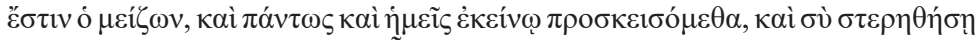

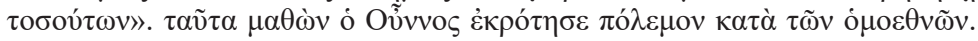

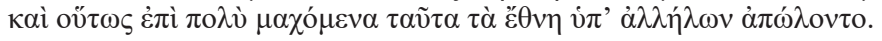

Codd. VPal 48.1 oṽ

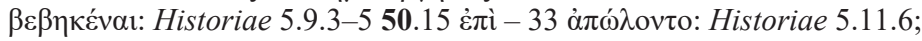
$5.13 .4 ; 5.13 .7-8 ; 5.24 .2-7 ; 5.25 .3-5$

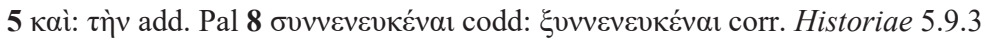

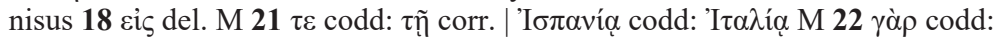

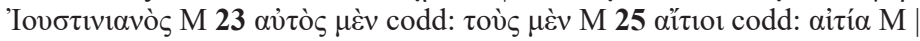

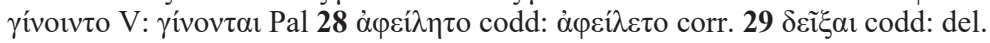

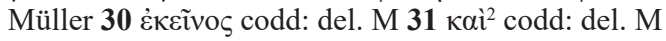

\section{Commentary on the Agathias excerpts}

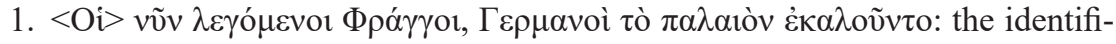
cation is drawn from Procopius (De bellis 5.11.29). Theophact Simocatta's

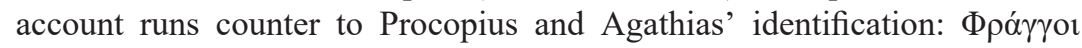




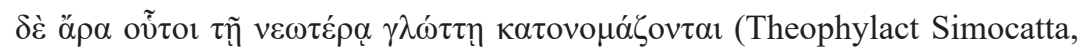
Historiae 6.3, 6). Agathias gives no hint about the sources he drew on for his ethnographic digression on the Franks; cf. Cameron (1970), 39. In Cameron's view, Agathias must have made no use of any written source on the Franks. The use of oral sources seems more likely. His informant may have been a member of Narses' staff; Cameron (1970), 40. There is also the possibility that Agathias drew his information on the Frankish affairs from the embassy of King Sigibert to Constantinople in 571; cf. Cameron (1968), 133-134.

2. 'A $\lambda \alpha \mu \alpha v o i ̀$ the passage in the Exc.Salm. is extracted from Agathias' ethnographical digression on the Alamanni (Historiae 1.6.3-1.7.7). This fragment displays the compiler's interest in etymology. According to Agathias, the Alamanni follow the Franks in matters of government and differ from them only in religion; the Alamanni are pagans (Historiae 1.7.1). Agathias, however, believes that frequent contact with the Franks would help them abandon paganism (Historiae 1.7.2). Av. Cameron sees the excursus on the Alamanni as deliberately inserted by Agathias in order to explain the unsuccessful invasion of the Frankish-Alamanni into Italy in 554. They failed because the Alamanni were sinful in contrast to the virtuous Byzantines; cf. Cameron (1970), 54. Agathias mentions the source of the short passage on the etymology of the Alamanni, namely Asinius Quadratus. The reference, however, was not included in the Agathias-part. On the Alamanni in general, see Drinkwater (2007).

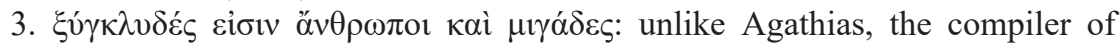
the Exc.Salm. had no interest in a comparison between the Franks and the Alamanni in terms of their way of life. Thus, he differs from Agathia's positive treatment of the Franks. Accordingly, the compiler of the Exc.Salm. only extracts a notice on the origin of the name of the Alamanni by emphasising the fact that the Alamanni were a dark-skinned people. It should be noticed that Procopius (De bellis 4.6.5-14) correlated their darker skin with negative moral characteristics and when he portrays the Ephthalitai favourably he puts emphasis on their white skin and on the fact that they were not as ugly as the other Huns (De bellis 1.3.2-7). The conclusion to be drawn is that the compiler of the Exc.Salm. reinforces the traditional distinction between Romans and barbarians.

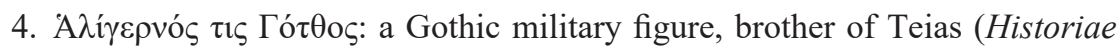
1.8.6), the last king of the Goths (552-553). Procopius (De bellis 8.34.19) records, mistakenly, that Aligern was the brother of the Gothic King Totila (541-552). Agathias appears to be well informed on Aligern as he also knows his father's name, namely Fritigern (Historiae pref. 31 and 1.20.1). During the siege of Cumae by the Byzantines, Aligern killed Palladius, a Roman official highly respected by Narses (Historiae 1.9.2-4). Aligern finally ceded Cumae to Narses in early 554 (Historiae 1.20.3).

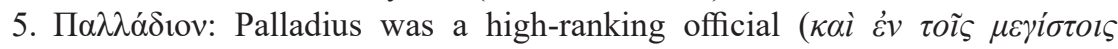

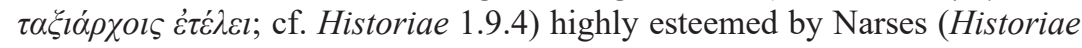
1.9.3). It is notable that Narses' name is omitted in the Exc.Salm. 


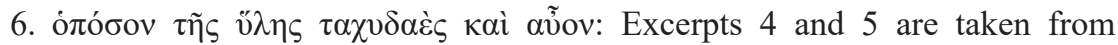
Agathias' account of the siege of Cumae. Both passages present Narses' plan of besieging the fortress. Narses' name has not been transmitted in the Exc. Salm. Throughout the Historiae, Agathias uses two terms for forests, namely

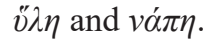

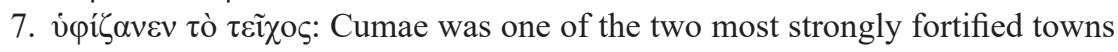
described by Agathias (the other one was the fortress of the Misimians, called Siderun for this reason (Historiae 4.16.4). The wall of Cumae had been built

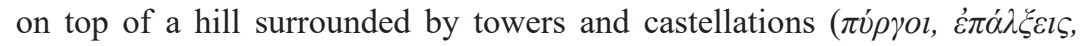
$\mu \varepsilon \tau \alpha \pi \dot{v} \rho \gamma \imath \alpha, \pi \rho о \mu \alpha \chi \varepsilon \tilde{\omega} \nu \varepsilon \varsigma ;$ cf. Historiae 1.8.3, 1.9.2, 1.10.3).

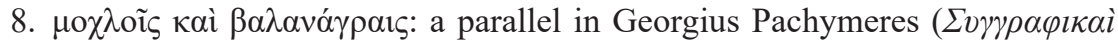

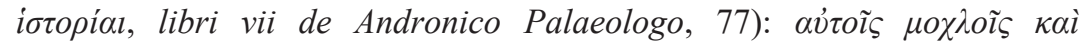

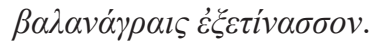

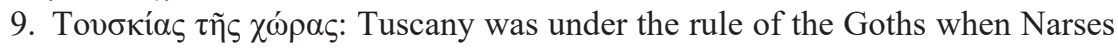
arrived in Italy (Historiae 1.1.6).

10. Aipı $\lambda$ ías: at the time of Narses' campaign in Italy, Emilia was in the possession of the Goths (Historiae 1.15.7). Agathias names, erroneously, the Alps as the natural border between the neighbouring regions of Emilia and Tuscany (Historiae 1.11.3): the two regions were separated by the Apennine mountains; to the north the River Po formed Emilia's border with the district of Venice (Historiae 1.11.3, 2.3.2).

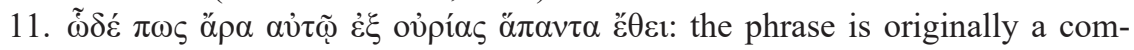
ment by Agathias upon Narses' success in restoring order in Southern Italy. The passage has been included in the Agathias-part without the name of the Byzantine general. On various occasions of battles or sieges, Narses resorted to special strategical tricks. Beside the one used in the course of the siege of Cumae (Historiae 1.10.1-9), Narses made use of a Hunic stratagem in a fight against the Franks (Historiae 1.22.1-5). On the effectiveness and efficacy of the Byzantine generals, see Ringrose (2003).

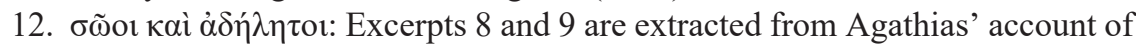
the ruse used by Narses to capture Lucca. Nevertheless, Narses' name is not inserted in the Agathias-part.

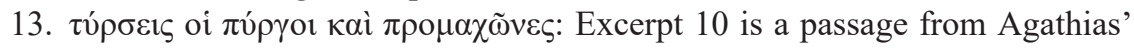
account of the siege of Lucca by Narses (Historiae 2.18).

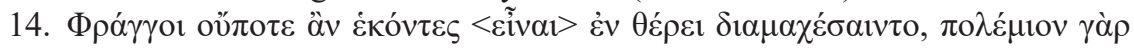

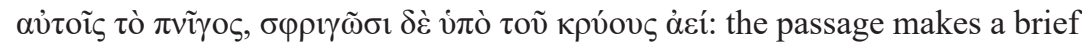
ethnographical description of the Franks. They cannot bear the heat and they prefer to fight in the winter as they are well adapted to cold conditions. It should be noticed that Procopius, in his account of the Moors (De bellis 4.6.5-14), draws an analogy between being primitive and having the ability to endure difficult conditions.

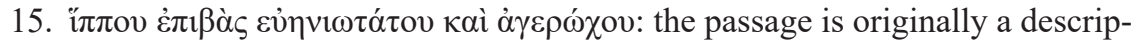
tion of Narses' horse, which was obedient, well trained, and experienced in fights (Historiae 1.21.5). Narses is not referred to in the excerpted passage. 


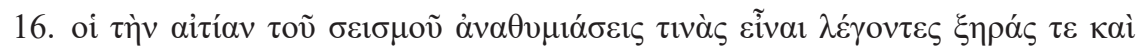

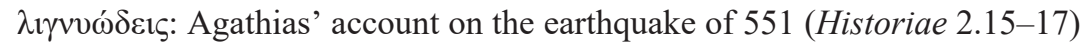
and of 557 (Historiae 5.3-9). For the complex moral strategy of Agathias' earthquake accounts, see Kaldellis (1999). Agathias' account of the earthquake of 551 was used as a model by Attaliates in his account of the earthquake of 1063; cf. Attaliates, Historia, 90.

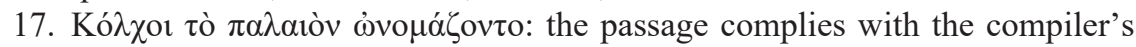
interest in the origins of peoples. In fact, the excerpt represents the view that the Colchians descended from the Egyptians. Agathias (Historiae 2.18.5) claims that this account is found in Diodorus of Sicily (Diodorus of Sicily, Bibliotheca historica 1.55.4-5) and in many other ancient writers. Herodotus (Historiae 2,104) records a similar story and Agathias probably had him in mind. A little further on, Agathias appears to keep himself aloof from the

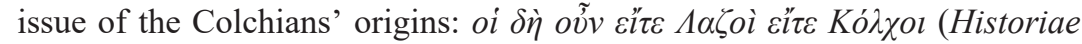
2.18.4-6). On the Colchians, see Braund (1994).

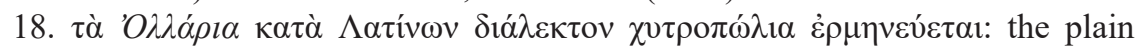
called Chytropolia was located seven stades distant from the fortress of

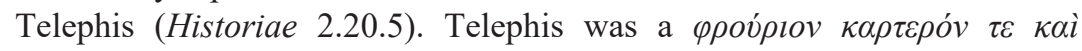

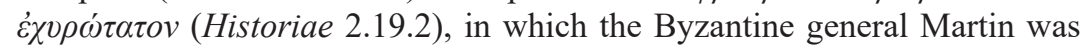
stationed with his army. The plain was given the name Chytropolia due to the pottery market there. The plain was initially called Ollaria from the Latin word olla, which in Greek gives Chytropolia. On the fortifications in the reign of Justinian, see Foss and Winfield (1986), 7-13.

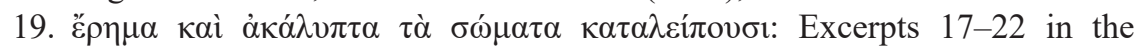
Agathias-part derive from the first of the two aforementioned Agathias' excursuses on Persia. In particular, Excerpt 17 deals with illegal Persian burial customs, a practice which is also mentioned by Herodotus (Historiae 1.140), Plutarch (Artaxerxes 18), and Procopius (De bellis 1.12.4, 2.24.2). On the custom in general, see Russell (1982), 561-563.

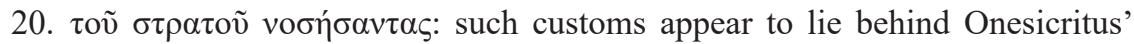
tale, quoted by Strabo (Geographica 11.11.3) according to which, in Bactria those suffering from old age or sickness were thrown alive to dogs kept for that purpose, which they called undertakers. The use of such a term accords well with Chrysippus' account, which was corroborated by the Chinese traveller Wei-jie, who wrote of Samarkand soon after 605 AD; cf. Boyce and Grenet (1991), 6-7, 190 n. 159.

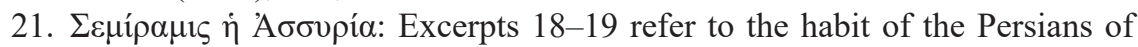
committing incest. On Semiramis, see Nagel (1982). As Av. Cameron noted, the episode of Semiramis as well as that of Parysatis (Excerpt 18) originate in Ctesias (FGrHist 688, F 14 and F 16); cf. Cameron (1969-1970), 92-93.

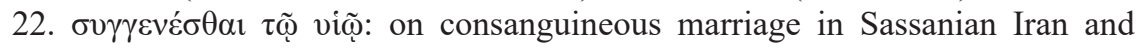
before, see Macuch (1991), 141-154; Herrenschmid (1994), 113-125.

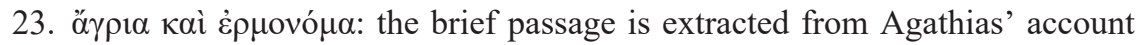
of a Persian festival, in which noxious animals, regarded as belonging to Ahriman (see Excerpt 21), were killed. That this was considered a religious 
duty becomes manifest in the Zoroastrian religious literature; $\mathrm{cf}$. Cameron (1969-1970), 98-99. Plutarch (De Iside et Osiride, 46) refers to the ritual as well. On the attitude of Byzantines to the Manichaean views in late antiquity, see Cameron (2003), 481-482.

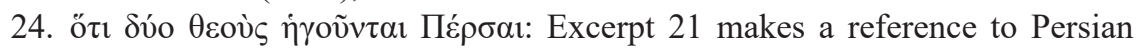
dualism. On Persian dualism, see Henning (1951); Bianchi (1978), 361-389; Boyce and Grenet (1991), 412, 423-424, 463-466.

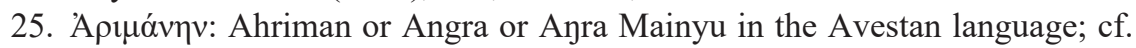
Duchesne and Guillemin (1984), 670-673. For the Greeks it was the equivalent of Hades as the Greek grammarian Hesychius of Alexandria transmits

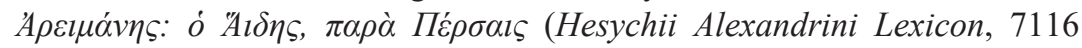

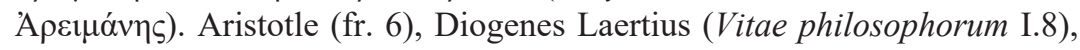
Damascius (De principiis I.323), Eudemus (fr. 150), and Plutarch (De Iside et

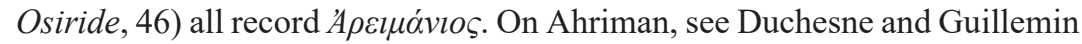
(1953); Shaked (1967), 227-234; Boyce (1975), 243-246; Boyce (1982), s.v. Angra Mainyu.

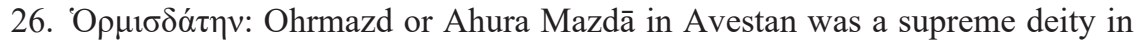
Zoroastrianism; cf. Duchesne and Guillemin (1984), 670-673. The name occurs as ' $\rho о \mu \alpha ́ \sigma \delta \eta \varsigma$ in Arist.Fr.6; Eudemus, fr. 150; Diogenes Laertius, Vitae philosophorum I.8; Damascius, De principiis I.323. ' $\rho \circ \mu \alpha \dot{\zeta} \zeta\rceil$ occurs in Plutarch, De Iside et Osiride, 46. On Ohrmazd, see Duchesne and Guillemin (1953); Kuiper (1976), 25-42.

27. The excerptor of the Agathias-part seems to have no interest in forming a chronological account of the Persian kingdoms, which appears to be the primary goal of the two excursuses on Persia in Agathias. Accordingly, the entire Agathias' subsection of the Persian kingdoms is absent in the Agathias-part. In fact, Excerpt 22 introduces us to the Sassanian dynasty by transmitting the birth story of the founder of the dynasty, Ardasher I. Instead of proceeding with the presentation of other members of the dynasty, the compiler keeps to the original narrative sequence and excerpts whatever is relevant to Persia. Accordingly, Excerpt 22 is ensued by a series of excerpts dealing with Persian customs and beliefs still alive during the reign of Chosroes. Ardasher's successor, Sharpur I, only appears in Excerpts 38 and 39. Furthermore, the compiler overlooks the six subsequent members of the Sassanian dynasty and inserts two passages dealing with Sharpur II (Excerpts 41, 42).

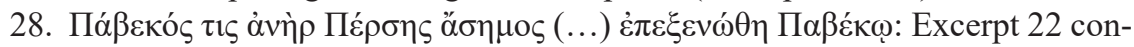
tains an account of Ardashir's conception. Papak was the father of Ardasir, the founder of the Sassanian dynasty. The dynasty was named after Sassan, though. Agathias' version differs from that found in Islamic literature (e.g., Tabari, I, p. 813) in which Papak is the son of Sassan. Agathias' account is not based on the Annals but echoes a popular tradition; cf. Cameron (19691970), 109. On the various versions about Ardasir's parentage, see Frye (1988), 298-299.

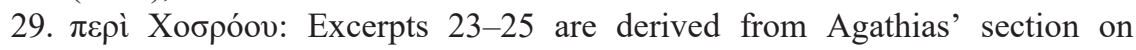
Chosroes I in Book 2 (Historiae 2.28-32). 


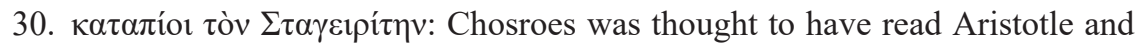
Plato translated in Pahlavi. Chosroes is also described as a philosopher-king by John of Ephesus (HE, VI.20). It appears that it was widely believed among educated Romans that the Sassanian kings took great interest in Greek philosophy: Eunapius, for instance, presents Sharpur II as being attracted to philosophy (Eunapius, Vitae sophistarum 6.5.1-10). See also McDonough (2010), 55-66.

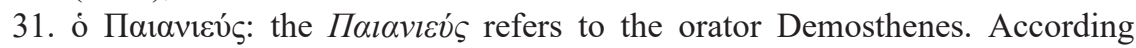
to Aeschines (In Ctesiphontem, 171), Demosthenes' father belonged to the

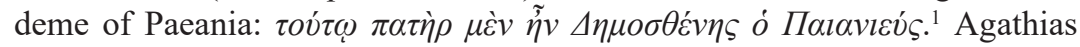
repudiates that Chosroes was a well-educated and well-read king. Agathias' arguments are a) that it was impossible to translate the deep meanings of the Greek philosophical works into the barbaric language of the Persians and b) that Chosroes' barbarous upbringing would prevent him from understanding philosophy. On the different views of the value of philosophical translations between Theodoret and Agathias, see Ševčenko (1964), 228.

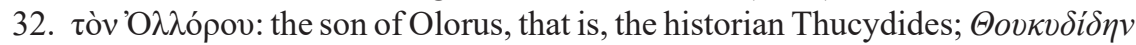

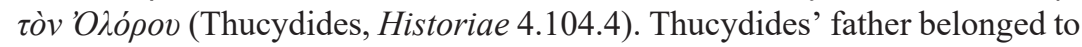
the Athenian deme of Halimous but he also owned gold mines in Thrace.

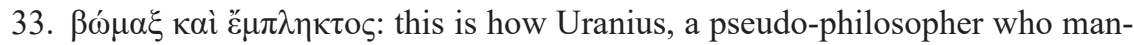
aged to gain Chosroes' trust, is referred to by Agathias. Uranius' name is not recorded in the Agathias-part along with the two aforementioned abusive epithets. Thus, both negative appellations appear to accompany Chosroes. The compiler is aligned with the typically Byzantine, scornful attitude towards the Sassanian emperor. Agathias' contemptuous view on Chosroes becomes manifest when dealing with his philosophical interests (Historiae 2.28.1-3). Procopius is similarly tendentious (De bellis 2.9.8-9, 2.11.26; Anecdota 18.26ff.).

34. Excerpt 25 is also recorded in the Suda, $\pi$ 2251. The seven philosophers were forced to abandon Athens after the closure of the school by Justinian in 529 (Malalas, Chronographia, 451). They returned to Athens after 532; cf. Cameron Al. (2015), 223. Simplicius wrote many commentaries on several philosophers (see PLRE iiib, 1153). On Damascius, see Goulet (1994), 541-593. Priscianus is the author of an epitome of Theophrastus' On SensePerception and of a treatise containing answers to philosophical issues raised at the court of Chosroes during his exile in Persia. The latter survives only in a Latin translation. The attribution of a commentary on Aristotle's On the Soul to Priscianus rather than to Simplicius is disputed; see Hadot (2002), 159-199.

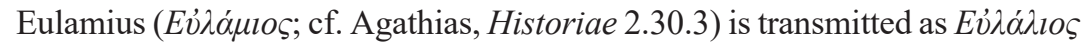
in Vaticanus gr. 96 and Vaticanus Pal. 93 as well as in the Suda $\pi 2251$.

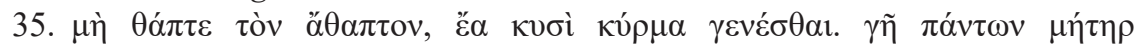

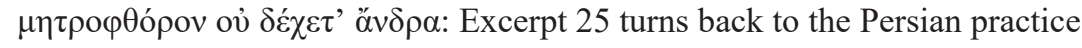

1 His father was Demosthenes of Paeania. 
of not burying the dead. The two hexameters are found in Anthologia Graeca IX 498. They have, similarly, been included in the $E S$, p. 14 of the $E C$.

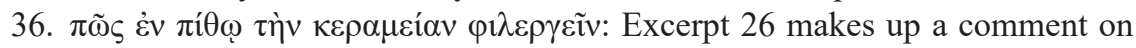
the military ambitions of the Persians. Agathias is using this figurative phrase to anticipate a certain degree of criticism on the part of his readers. The compiler of the Agathias-part has excerpted the passage from its original context and put it immediately after the passage on the Persians' burial customs, thus producing a passage with a different meaning: it is now the Persians who aspire to run before they can walk.

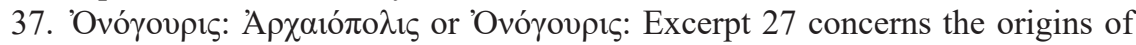
the name of the fort of Onoguris. According to Agathias, Onoguris was a fort set up by the Persian general Mermeroes in the district of Archaeopolis and used as a hostile base against the Byzantines (Historiae 2.22.3 and 4.9.6). On the use of the ancient name Onoguris by Agathias, see Cameron Av. and Cameron Al. (1964), esp. 320.

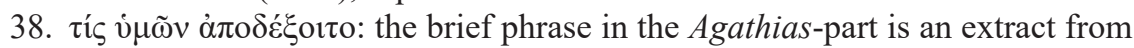
the speech given by Aeetes, a Colchian, in the aftermath of the Byzantines' defeat at Onoguris; the battle is recounted by Agathias (Historiae 3.6.127.11). Before the battle, the king of the Lazi, called Gubazes, who had refused to offer military aid, was killed by two Byzantine generals (Historiae 3.4.56). After the Byzantine defeat, Aeetes delivered a speech to encourage the Colchians to defect to the Persians by reminding them of the unjust end of Gubazes. A. Kaldellis considers Aeetes and the entire episode fictitious and invented by Agathias himself; cf. Kaldellis (2003), 297-298.

39. o $\sigma \pi \alpha \lambda i \omega v$ : Excerpt 29 is a detailed description of the wicker roof, a siege machine used by the Romans during the siege of the fort of Onoguris. The passage was copied verbatim in the $\operatorname{Suda}(\Sigma 901 \Sigma \pi \alpha \lambda i \omega v o \zeta)$. The excerpt in the Agathias-part was extracted from Agathias' description of the preparation of the Byzantines to march against Onoguris (Historiae 3.5.9-11).

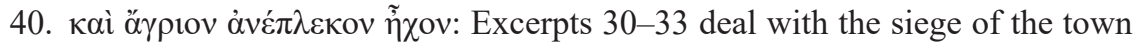
Phasis by the Persians and the way in which their fighting men fled precipitately. In particular, Excerpt 31 makes up a brief ethnographical description concerning the Persian cavalry's attitude during the siege of the town of Phasis.

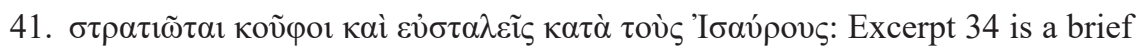
ethnographical description of the army of the Isaurians. In Byzantine literature, the Isaurians are represented as marauders who live by banditry. In the fourth century, John Chrysostom makes a reference to the Isaurian raiders

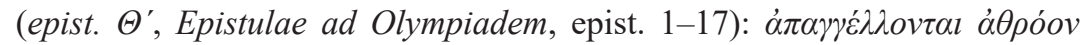

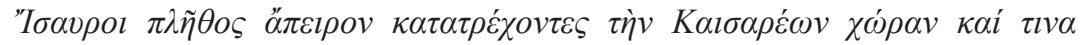

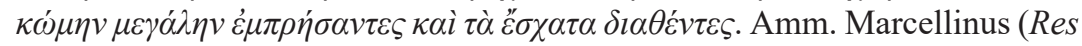
Gestae 27.9,6-7) also refers to them as raiders who devastate cities of Asia Minor. In the fifth century, Priscus (fr. 10, p. 242, Blockley) mentions that the Romans were also afraid of the Isaurians, whose banditry was reviving. 
The same tendentious representation of the Isaurians is found in a passage, originally derived from Candidus, in John of Antioch (fr. 229 ed. Mariev = EI 90). ${ }^{2}$

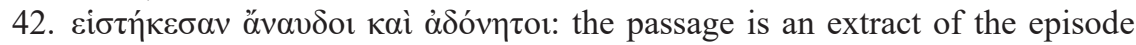
narrating the attempt of the Romans to take over the Misimian fortress of Siderun (Historiae 4.17.1-20.9). The passage points out the discipline and smartness of the Romans in the course of the siege.

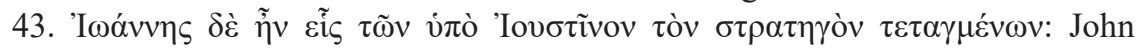
the Lybian was one of the aides of Justin's, son of Germanicus. (Historiae 4.21.5).

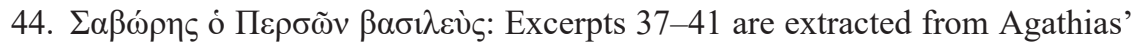
second excursus on Persia. It is primarily a representation of the Sassanian kings. The original section is a chronological account of the Sassanian dynasty from Ardasher I to Chosroes I as reported to Agathias by Sergius (Historiae 4.30.2-4). Agathias also includes material from Procopius, stories from his own reading (e.g., the accounts of Semiramis, Parysatis, and Smerdis), and his comments and deductions; cf. Cameron (1969-1970), 76.

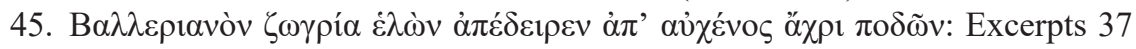
and 38 reveal Sharpur I's cruelty. In particular, Excerpt 38 transmits that Valerian was flayed by Sharpur I. Agathias calls Sharpur I twice wicked (Historiae 4.23.7, 4.24.2) and once bloodthirsty (Historiae 4.23.7). The compiler of the Agathias-part confines himself to excerpt the flaying of Valerian (Excerpt 37) and the pillage of Cappadocia (Excerpt 38) without transmitting those designations for Sharpur I. Agathias appears to follow the tradition first found in Lactantius (De mortibus persecutorum 5.2), according to which Valerian was killed by being flayed alive; Eusebius (Vita Constantini IV.11 and Constantini imperatoris oratio ad coetum sanctorum 24.2) is aligned with the Christian version that have persecutors of Christians die fitting deaths. The same version is recorded by Orosius (VII.27). Peter the Patrician transmits the same kind of death for Valerian (EL 12, 393.10-394.17). In Peter's history, the centre of gravity is not, by contrast, in the anti-Christian acts of Valerian. Peter, instead, emphasises the abominable method of Valerian's death and the rising indignation against the Persians. From this point of view, Peter's account is closer to that of Agathias, in which Valerian's repugnant end serves to intensify the hostile depiction of Sharpur. Finally, Valerian is portrayed in fulsome terms in the Scriptores Historiae Augustae (Script. Hist. Aug. Gallen.1, Valer. 4-5).

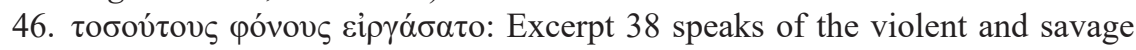
pillage of Cappadocia by Sharpur's army; see Excerpt 37. According to Av.

2 Candidus the Isaurian wrote a classicising history in Greek covering the period from 457 ad to 491 ad. His work survives in fragments only. His text was used by John of Antioch and the Suda. On Candidus, see Roberto (2000), 685-727; Brandt (2014), 161-170; Meier (2014), 171-194. 
Cameron, the passage does probably not derive from the Annals; cf. Cameron (1969-1970), 140.

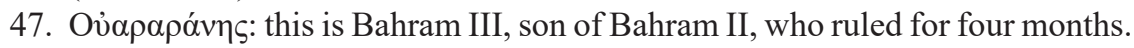
On Bahram III, see Klíma (2012), 514-522.

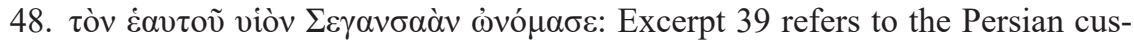
tom not to slaughter its people whenever a Persian king captured its territory: the Persian king deposed the defeated king and bestowed the title of the enslaved kingdom on his own son. On the custom, see Herzfeld (1924), 42ff; cf. Cameron (1969-1970), 143. Likewise, the son of Sharpur, Vahram IV, was given the title Kermanshah after Sharpur subdued a nation named Kerman (Historiae 4.26.2). Agathias compares the Persian custom to the Roman practice of some, by which a general assumed a name after the name of a nation he had subdued (Historiae 4.26.2).

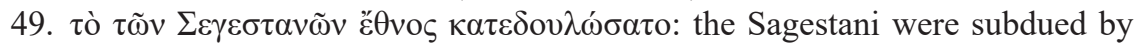
Bahram II. On the people of Sagestani, see Rawlinson (1873), 272-294.

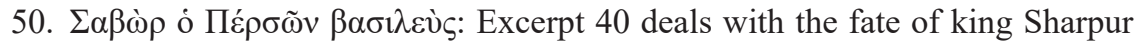
II: he had been designated king while his mother was still carrying him. The passage is read within the context of the Exc.Salm.II 75. The latter informs us that Narseh had three more sons by another wife. The first, called Adhirnarseh

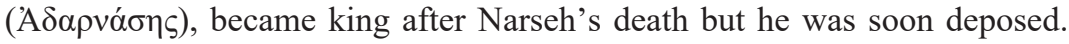
The second son was blinded (by Sharpur II) and the third, called Ormisdas, was held in jail. Ormisdas managed to escape with the help of his mother. The same story is found in Zosimus (Historia nova 2.27.1-3) and Ammianus (Res Gestae XVI 10.16). Narseh's legitimite heir to the throne was, according to Agathias (Historiae 4.25.1), Hormizd II. There is nothing in Agathias as to whether Hormizd II had a son or not. According to Tabari, Hormizd did not have any son; cf. Cameron (1969-1970), 144. The Persian throne was inheritable by the kings' sons, in principle. But not without exception: Ardashir acceded to the throne after killing Artabanus (Historiae 2.26.2). Zamasp assumed the throne through conspiracy against Kavad but his accession was considered legal as he also was a son of Peroz (Historiae 4.28, 2).

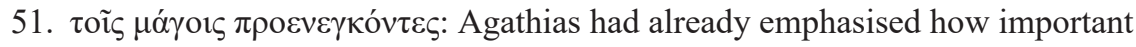
the Magi were deemed in Persia in the sixth century (Historiae 2.26.5). On the prominent role of the Magi in Persia, see Neusner (1966), 169-178.

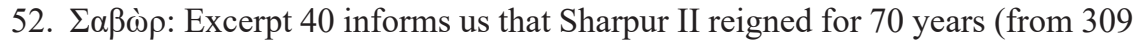
to $379 \mathrm{ad})$. He was the longest reigning monarch of the Sassanian dynasty (224-651 AD).

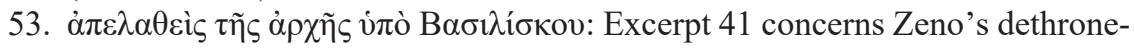
ment. The passage presents the congruences between Zeno's troubles and those of Persian kings: the deposition of Cavadh I, his escape from prison, his flight to the Ephthalitai, his return to Persia, and his ascension back to the throne. Julius Nepos had a similar fate as well. The first revolt against Zeno took place in $475 / 476$ when Illus managed to dethrone the emperor. The second revolt against Zeno occurred in 484. On Julius Nepos, see PLRE 
II, 777-778; Kazhdan (1991), 1081. Malchus and Candidus treated his reign and deposition (Bibliotheca, cod. 78 and cod. 79). ${ }^{3}$

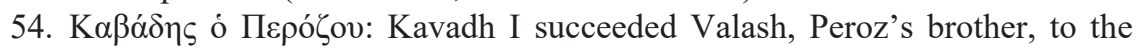
throne. On Cavadh I's reign, see Altheim and Stiehl (1953); Crone (1991), 21-42; Wiesehöfer (2009), 391-409. Peroz was the son of Yazdegerd II. Peroz succeeded his brother, Hormizd III. Agathias records Peroz's campaign against the Ephalites, during which Peroz died (Historiae 4.27.3-4). On Peroz, see Schippmann (2012), 631-632.

55. غ่v $\tau \tilde{\varphi} \tau \tilde{\eta}_{\varsigma} \lambda \dot{\eta} \theta \eta \varsigma$ $\varphi \rho o v \rho i ́ \omega:$ Agathias' text is very close to that of Procopius (De bellis 1.5.7-9). The place is also mentioned in the Oriental sources; cf. Christensen (1936), 307.

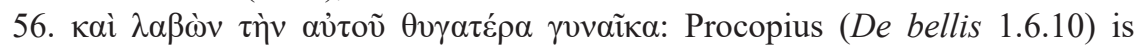
the source of the passage in Agathias. On the reliance of Agathias on the Khvadhaynamagh tradition for the passage, see Cameron (1969-1970), 158.

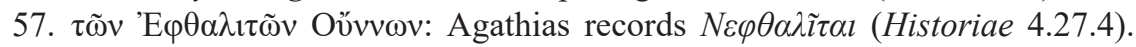
The $N \varepsilon \varphi \theta \alpha \lambda i \tau \alpha l$ is first found in Flavius Josephus (Antiquitates Judaicae 5, 86). The term was reproduced by Stephanus Byzantius, ${ }^{4}$ the Strategicon, ${ }^{5}$

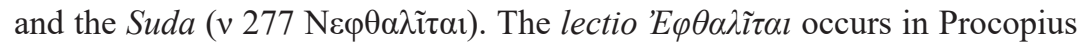
(De bellis 1.3.1, 1.3.2, 1.4.3, 1.7.1). Photius, in his entry on the sixth-century historian Theophanes of Byzantium, used 'E $E \theta \alpha \lambda \tilde{i} \tau \alpha l^{6}$ too (Bibliotheca, cod.

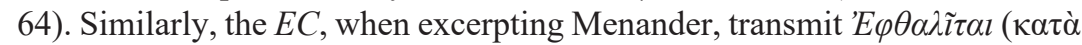

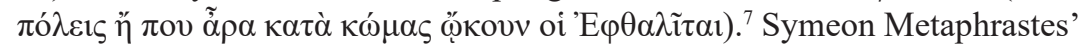
version of the Martyrium sanctorum Christi martyrum et confessorum Guriae, Samonae et Abibi refers to the 'E $E \theta \alpha \lambda \tilde{i} \tau \alpha l$ as an exasperated and barbaric people ( $P G 116$, col. 145). Procopius (De bellis 1.3.2-7) describes the Ephthalitai as a white-skinned people that are not so ugly as the other Huns. On the Ephthalitai, see Ghirshman, R. and Ghirshman, T. (1948), $115 f$.

58. Excerpt 42 is a brief notice taken from Agathias' description of the earthquake that struck Constantinople in 557 (Historiae 5.3.1-9). On the date of the earthquake, see Malalas, Chronographia, 488; Theop. AM 6050. According to Agathias, many amazing events occurred in the course of the night of the earthquake (Historiae 5.3.9).

59. Excerpt 43 is extracted from Agathias' account of Anatolius' death. Anatolius was the only member of the senate (he was a curator domus divinae) who lost his life during the earthquake of 557 (Historiae 5.3.10).

3 Malchus' historical work covered the period from 305 ad to 480 ad and it is preserved in fragments only. The EC and Photius' Bibliotheca appear to only know of a portion of his entire work covering the years 474-480; On Malchus, see Baldwin (1977), 91-107; Blockley (1983), 402-455.

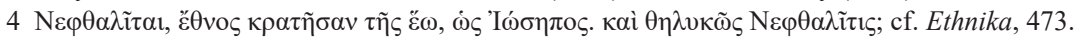

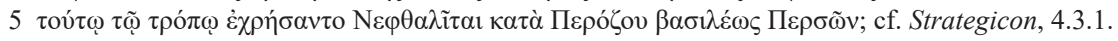

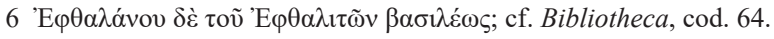

7 Excerpta de legationibus, 452. 


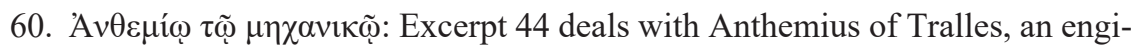
neer or architect by profession (Procopius, De aedificiis I 1.24, 1.50; Agathias,

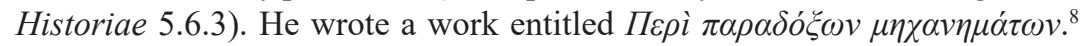
He was summoned to Constantinople (Historiae 5.6.6) and commissioned by Justinian I to design the Hagia Sophia, after the earlier church on the site had burned down in 532 during the Nika Revolt (Agathias, Historiae 5.9.2; Paul. Silentiarius, 552-555). He was already dead when Constantinople was struck by the high magnitude earthquake of May 7, 558 (Agathias, Historiae 5.9.4). On Anthemius, see Huxley (1959).

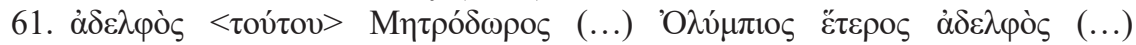

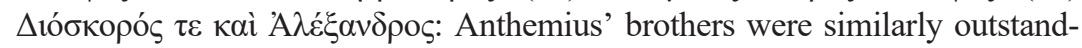
ing in their fields: Metrodorus was an eminent grammatikos, who, together with his brother Anthemius, was summoned to Constantinople by Justinian; Olympius was a famous advocate (Historiae 5.6.5); Dioscorus and Alexander were prominent doctors. Dioscorus practised his profession in Tralles, where he died. Alexander, instead, relocated to Rome (Historiae 5.6.5). Alexander

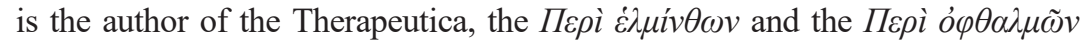
(the works were edited by Theodor Puschmann, Alexander von Tralleis, I-II, Vienna, 1878-1879). Agathias' description of Anthemius' family exhibits affinities with Herodotus' account of Cleobis and Biton; cf. Cameron (1970), 61.

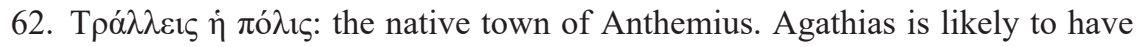
passed Tralles on his way back from Alexandria; cf. Cameron (1970), 8.

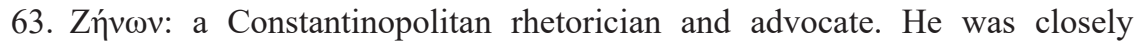
acquainted with the emperor Justinian (Historiae 5.6.7).

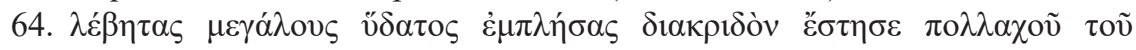

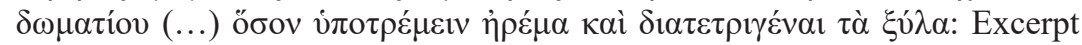
45 is an account of a mechanical trick that Anthemius played on Zeno, a Constantinopolitan rhetorician and his next-door neighbour. The account of Anthemius' steam machine is an allusion to the Aristotelian theory about the cause of earthquakes. According to Aristotle, the cause of earthquakes lies in exhalations trapped in cavities within the earth. ${ }^{9}$ Agathias resorts, similarly, to Aristotle's theory when dealing with the earthquake that hit Egypt (Historiae 2.15.9). Agathias is likely to have become familiar with Aristotle's theory through the works of John Philoponus; Cameron (1970), 113-114. On the impact of Aristotle's theories on Late Antiquity, see Lehmann (2013).

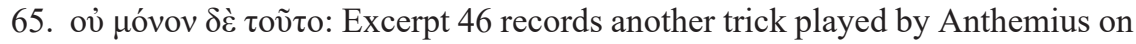
Zeno.

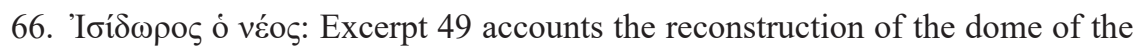
Hagia Sophia, which had collapsed during the earthquake of 558. Isidore

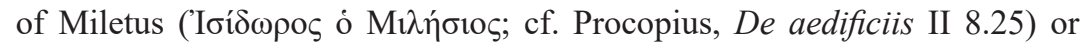

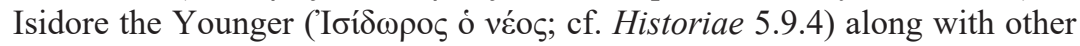
architects replaced the destroyed dome. Isidore the Younger was the nephew

8 Huxley (ed.) (1959).

9 On Aristotle's explanation of earthquakes, see Aristotle, Meteorologica 2, 365a-366b. 
of Isidore of Miletus. Isidore the Younger designed the new dome to replace the old one destroyed by the earthquake of 558. This second restoration of the church was completed in 532 (John Malalas, Chronographia 495; Theophanes, Chronographia 238, 18-19).

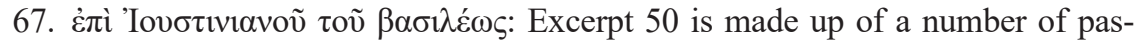
sages taken from the last part of Book 5 of Agathias' Historiae. A. Biedl sug-

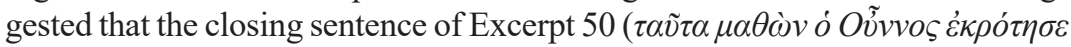

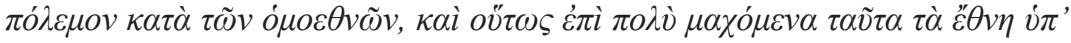
$\dot{\alpha} \lambda \lambda \dot{\eta} \lambda \omega \nu \dot{\alpha} \pi \dot{\omega} \lambda o v \tau o$ ) is not originally derived from Agathias. ${ }^{10}$ His proposition has been refuted by Keydell (ed.) (1967), XVIII. In fact, the sentence is a shortened version of Historiae 5.25.5. Müller published the entire Excerpt 50 in his edition of John of Antioch's Historia chronica; cf. Müller (1851), 621-622.

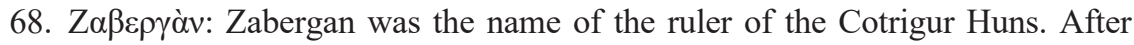
Zabergan crossed the frozen river Istros with his soldiers, he started planning an attack against Constantinople (Historiae 5.11.6). His soldiers first plundered and ravaged fields as well as towns surrounding Constantinople (Historiae 5.12.4-6). The Cotrigurs put up as an excuse for the attack their hostility with the Utigurs, a rival Hunnic tribe: the leader of the Utigurs, Sandilch, was an ally of the Byzantines and the Utigurs were frequently receiving payments from the Byzantine emperor (Historiae 5.11.6). The Cotrigurs were finally defeated by the Byzantine army led by the general Belisarius (Historiae 5.19.2-20.2).

\section{The Eusebian excerpts transmitted in the Epitome of the Seventh century}

The numbers in bold throughout the text body indicate the beginning of a new excerpt. The edition of the text is accompanied by an apparatus fontium and an apparatus criticus. The apparatus fontium gives the immediate passages upon which each excerpt in the Epitome is based. Further information on the principles of this apparatus is provided in Section 4.4.2. The sigla given at the beginning of the apparatus criticus indicate the manuscripts upon which the text is based. Editing a text consisting of excerpts taken from earlier sources poses a series of problems to the editor. The text is a collection of selections which in most cases must have retained the wording of the sources. We are in the unfortunate position, however, to ignore which versions of Eusebius' $H E$ or other sources the compiler had at his disposal. We have seen that excerptors or compilers were prone to textual changes, especially textual omissions and additions. Yet when the surviving manuscripts of the Epitome transmit a mistake or an incongruous reading, we cannot be certain whether a) the reading was present in the source text, b) the original text was corrupted by the compiler, or c) such mistakes are scribal errors. Provided the particular structure of an excerpt collection, therefore, the present edition intends to give the text as evidenced and transmitted in the extant manuscripts of the Epitome rather than to present a corrected version of the text. In cases where the text differs

10 Biedl (1955), 56, n. 1. 


\section{Appendix I}

from the source text, the present edition gives the readings as they occurred in the manuscript tradition of the Epitome and indicates in the apparatus criticus possibilities offered by modern scholarship. Proper names which are misspelled in the extant manuscripts are emended and information is provided in the apparatus criticus. Most of the orthographic variations are common spelling variants in later Greek, such as alternation between $\varepsilon 1,1$, and $\eta$ or between $\alpha \imath$ and $\varepsilon$. It should be said that variant spellings that occurred in the manuscripts are regularly emended in conformity with the readings found in the Liddell-Scott-Jones (LSJ) lexicon for classical Greek or Thesaurus Linguae Graecae (TLG). For the modern reader's convenience, variant spellings are not indicated in the apparatus criticus. Detection of possible deletions, additions, interpolations, and syntactical and grammatical corruptions of the text is performed. On editing the excerpts, I rely on the traditional editorial method proposed in the handbooks on textual criticism and editorial techniques by Maas 1958 and West 1972. The TLG is consulted when necessary.

\section{Tabula Notarum in Apparatu Critico Adhibitarum}

Codices

O Auctorium E.4.18 (s. X)

P Parisinus suppl. gr. 1156 (s. X-XI med.)

V Athonensis Vatopedinus gr. 286 (s. XIII)

B Baroccianus gr. 142 (s. XIV)

Editores et emendatores

B de Boor

G De Groote

$\mathrm{N}$ Nautin

Cetera

\begin{tabular}{ll}
\hline$[\ldots]$ & litterae deperditae \\
$<>$ & litterae additae \\
\{\} & litterae deletae \\
add. & addit, addidit \\
cod. & codex \\
codd. & codices \\
coni. & coniecit \\
corr. & correxit \\
del. & delevit \\
ins. & inseruit \\
mg. & margen \\
om. & omittit, omittunt \\
suppl. & supplevit \\
v.l & varia lectio \\
\hline
\end{tabular}




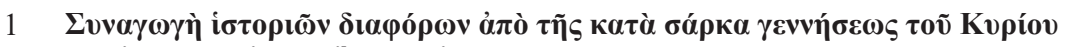

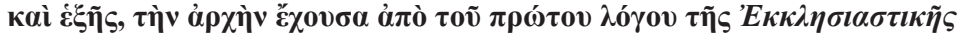

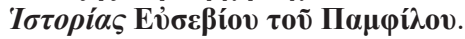

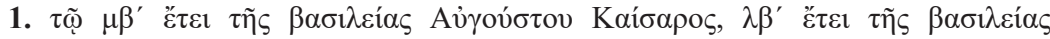

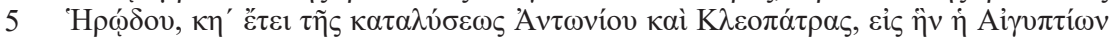

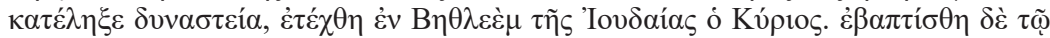

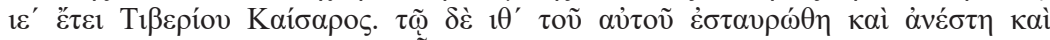

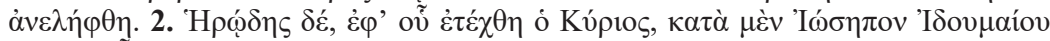

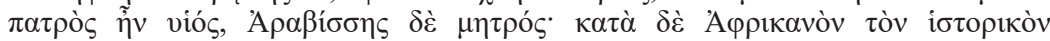

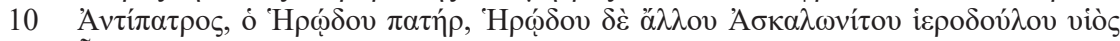

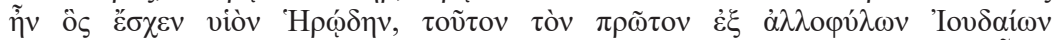

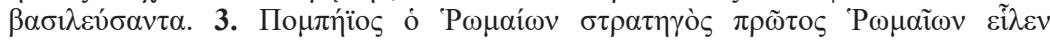

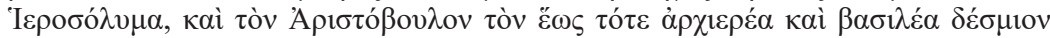

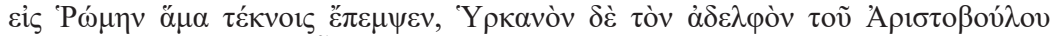

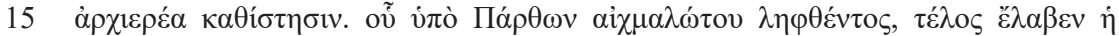

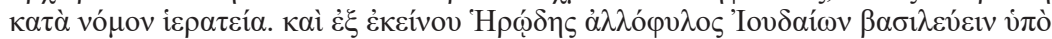

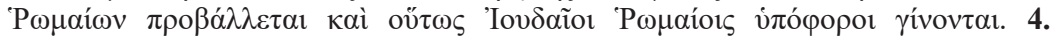

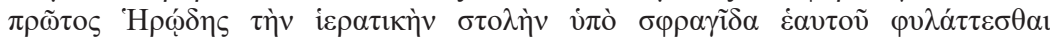

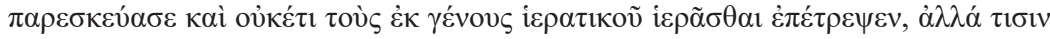

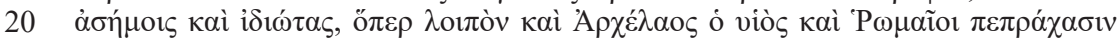

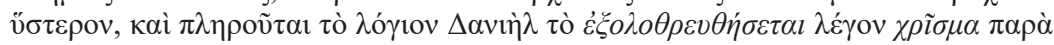

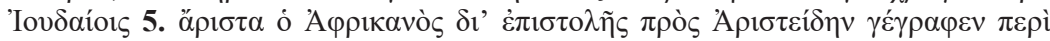

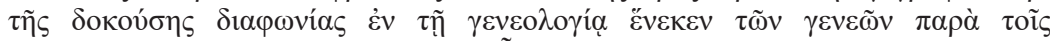

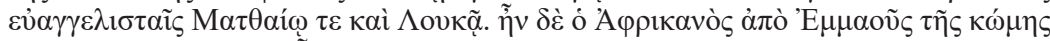

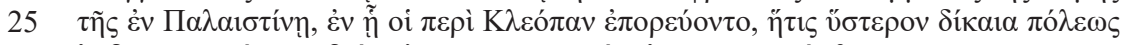

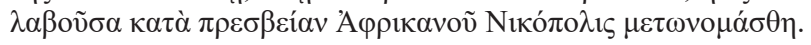

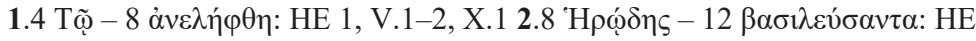

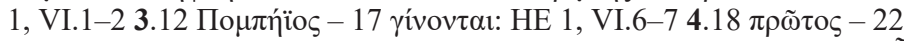

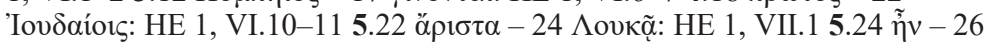
$\mu \varepsilon \tau \omega v o \mu \alpha ́ \sigma \theta \eta$ : Luc. 24, 13; Chron. pasch. 499, 5-7; Georg. Sync. 439, 15-18.

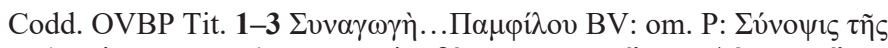

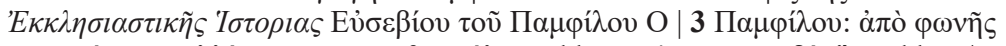

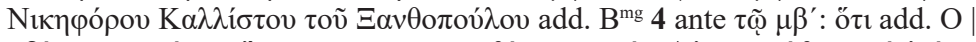

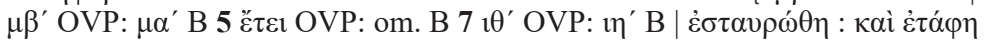
add. P 8-26 "O $\tau$ 'H

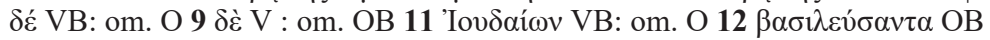

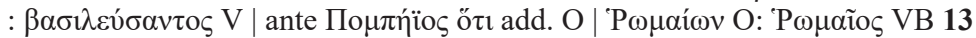

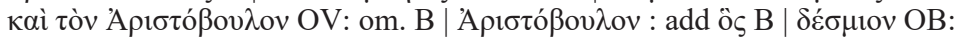

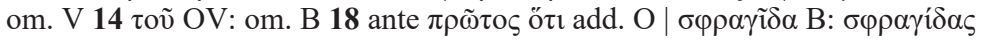

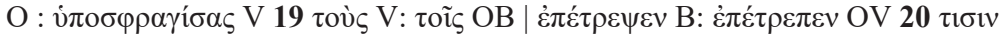

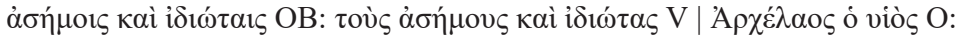

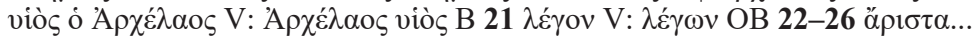

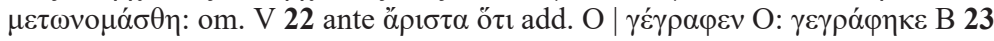
$\gamma \varepsilon v \varepsilon \tilde{\omega} \nu$ B: $\gamma \varepsilon \nu \tilde{\omega} \nu \mathrm{O}$ 


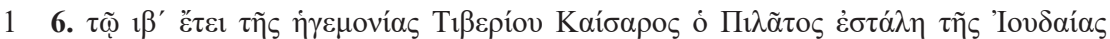

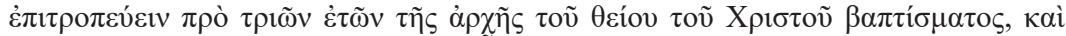

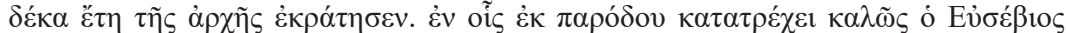

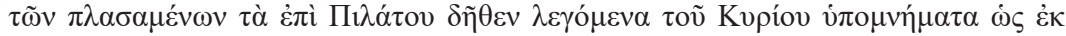

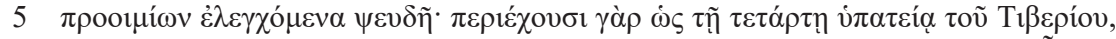

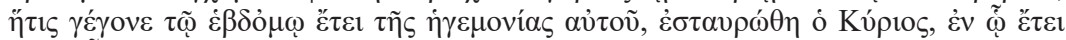

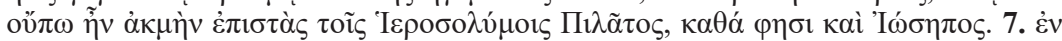

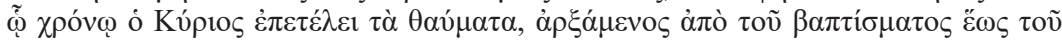

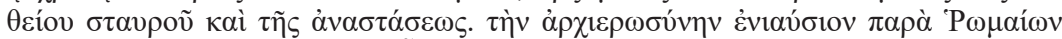

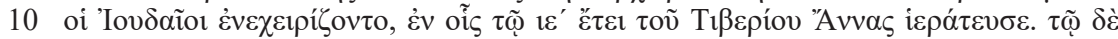

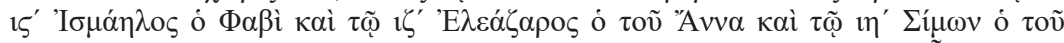

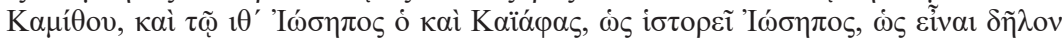

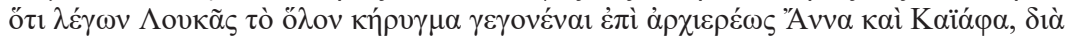

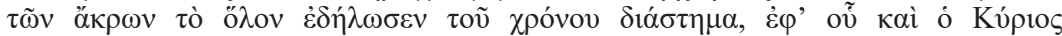

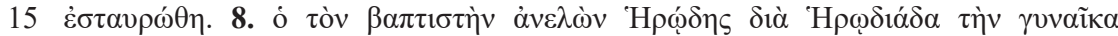

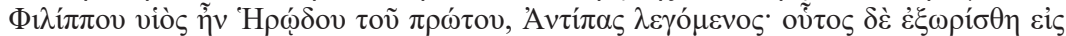

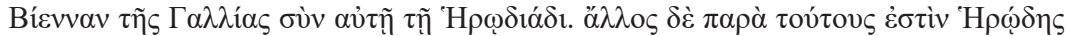

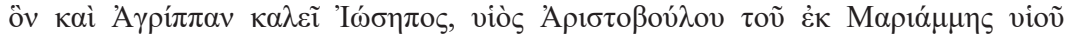

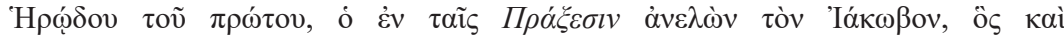

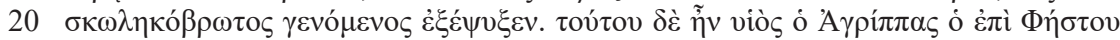

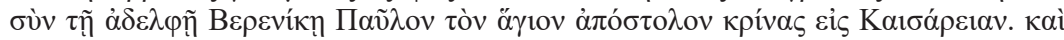

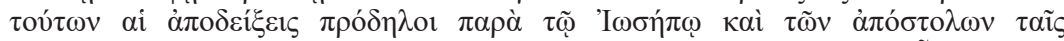

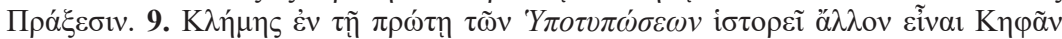

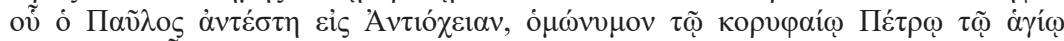

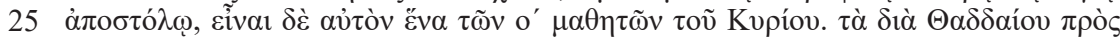

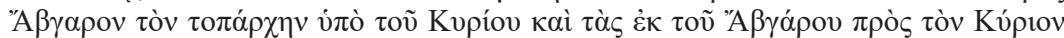

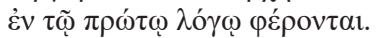

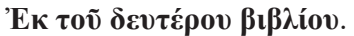

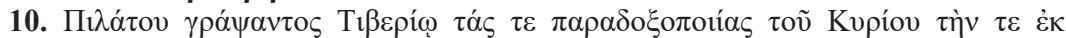

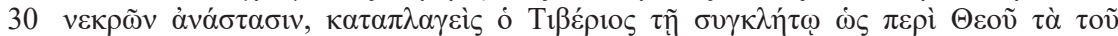

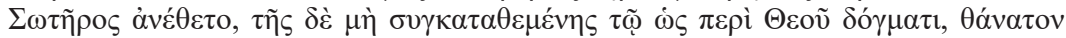

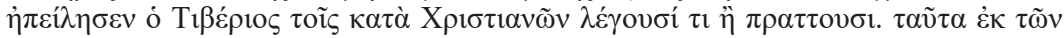

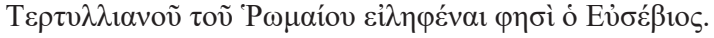

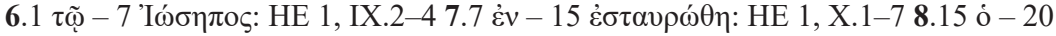

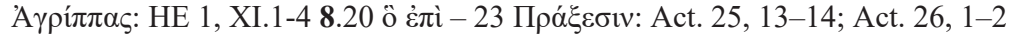

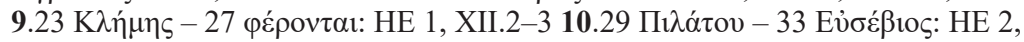
II.1-4, II.6

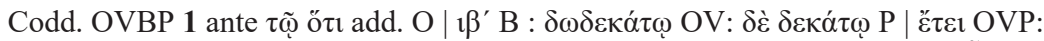

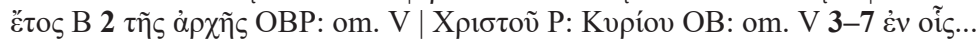

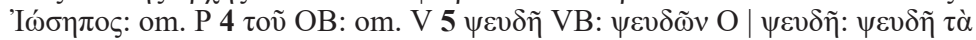

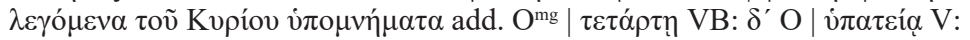

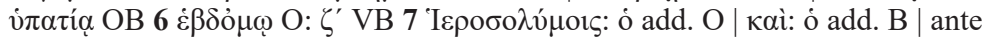

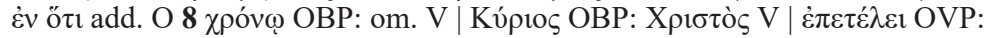

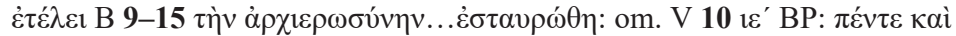

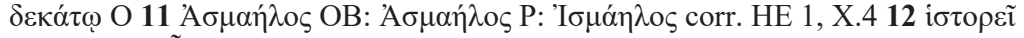

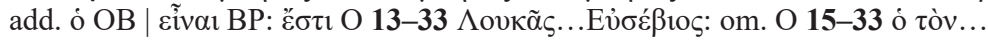

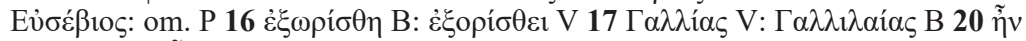

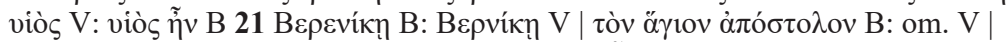

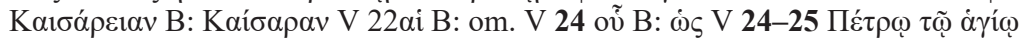

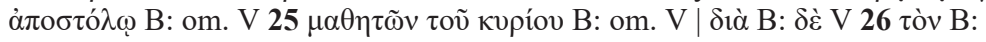

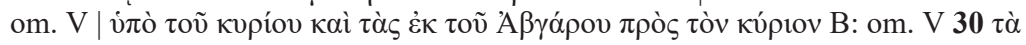
$\mathrm{V}$ : om. B $31 \tau \tilde{\mathrm{V}} \mathrm{V}$ : $\alpha$ $\tau \tilde{\omega} \mathrm{B}$ 


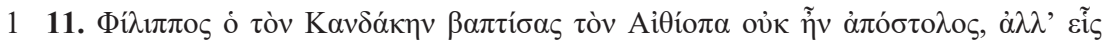

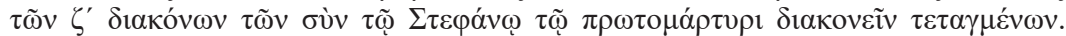

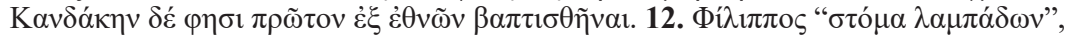

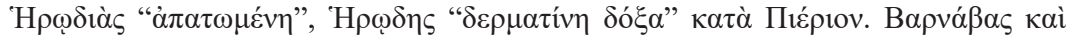

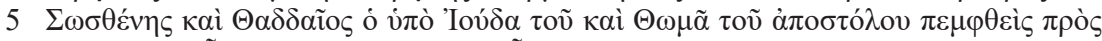

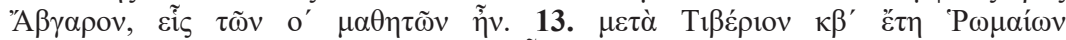

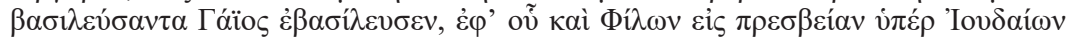

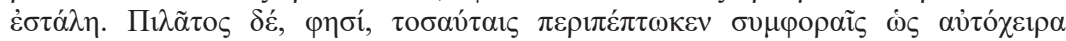

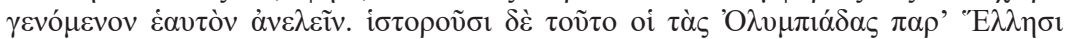

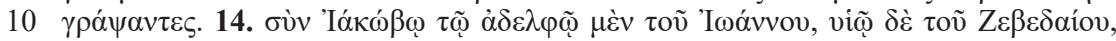

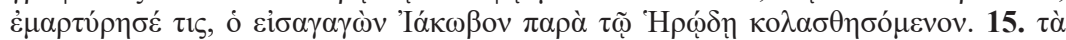

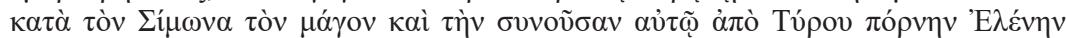

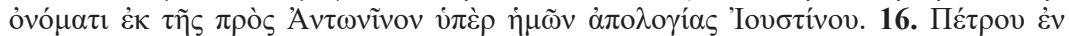

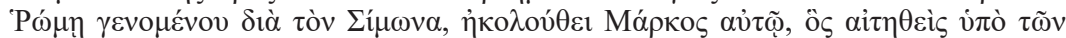

15 'P

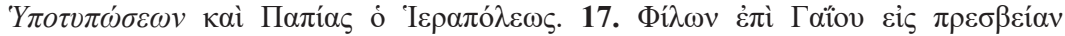

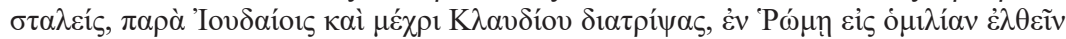

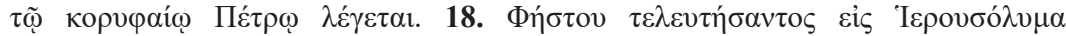

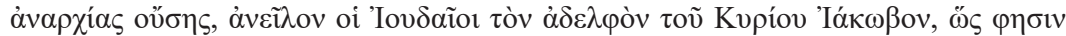

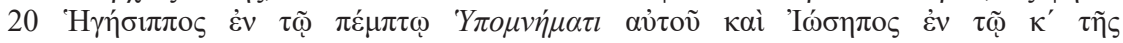

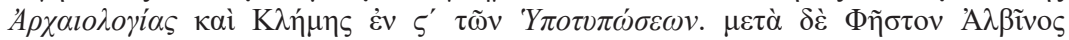

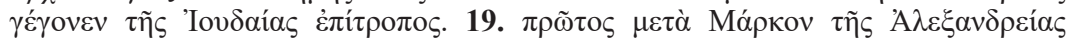

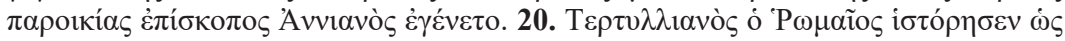

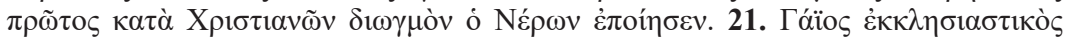

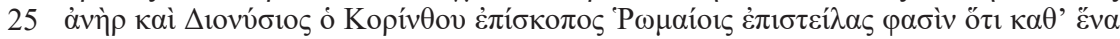

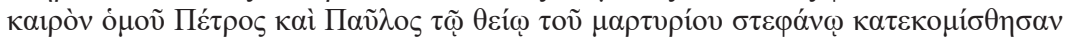

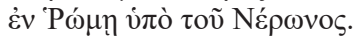

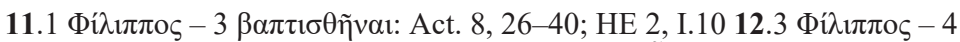
Пı⿱㇒́p

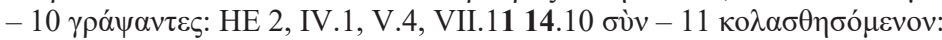

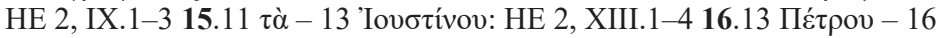

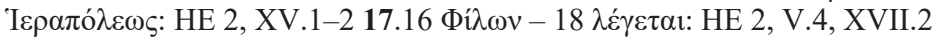

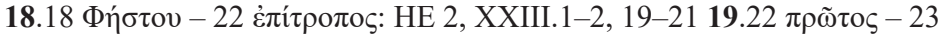

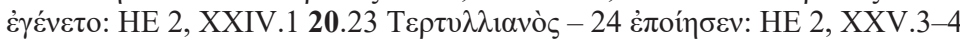

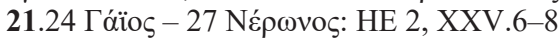

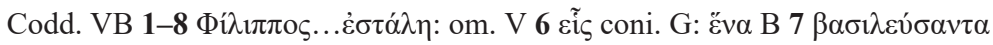

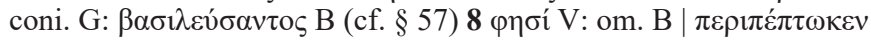

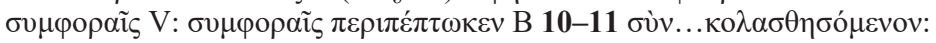

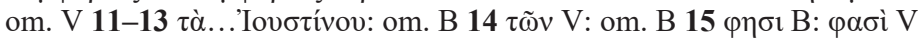
18 коричаí B: om. V 19 oi B: om. V 20 Y

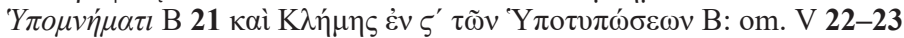

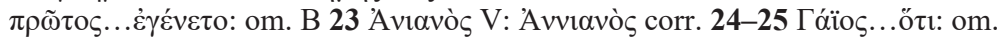

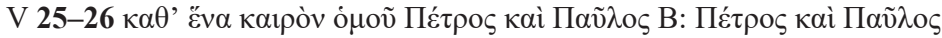

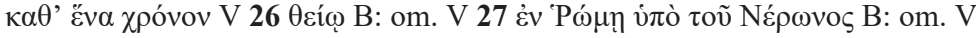




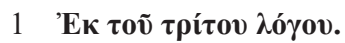

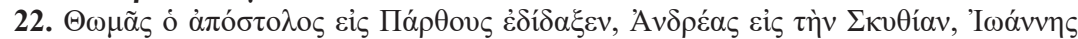

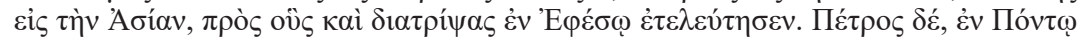

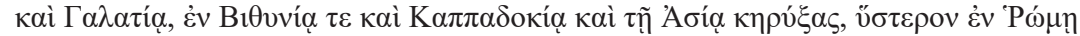

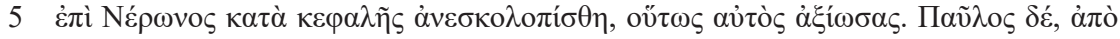

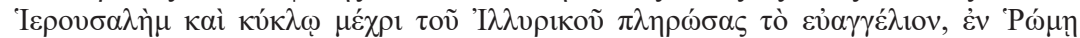

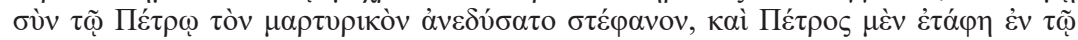

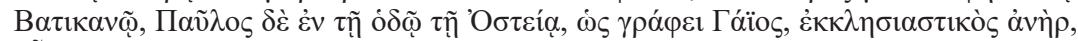

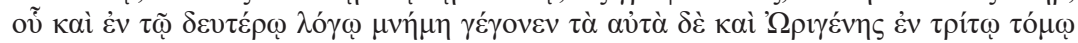

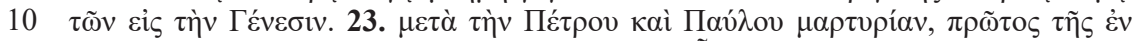

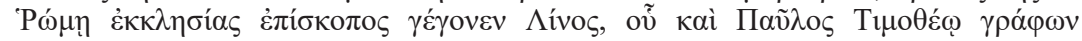

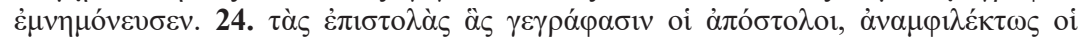

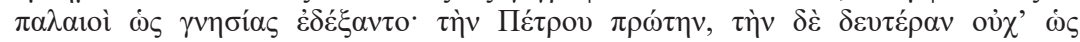

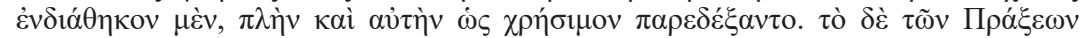

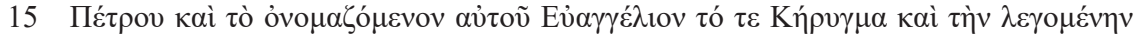

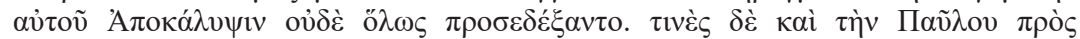

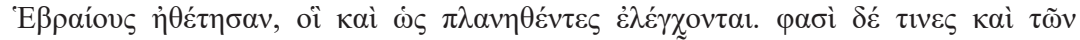

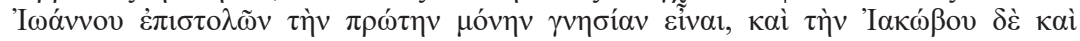

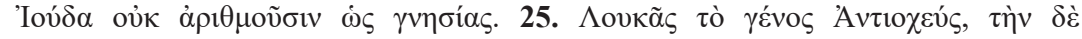

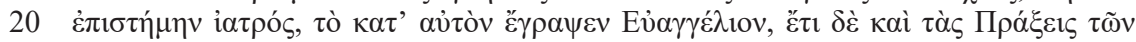

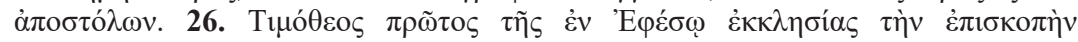

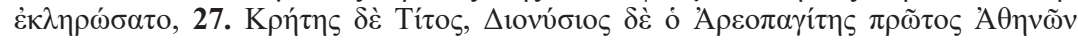

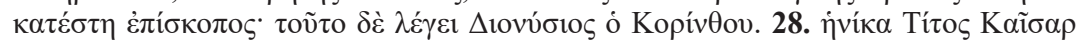

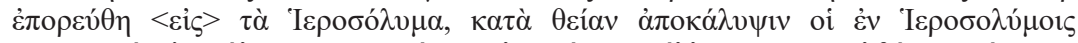

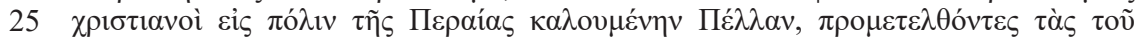

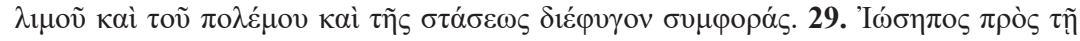

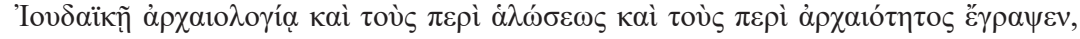

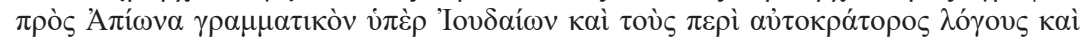

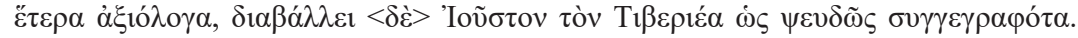

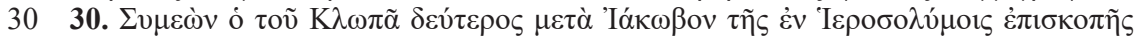

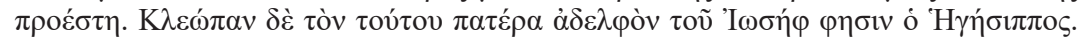

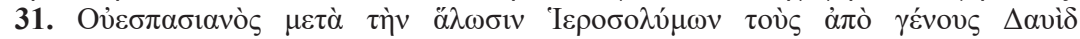

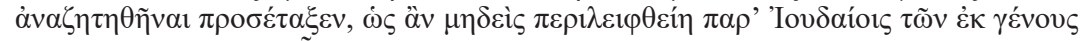

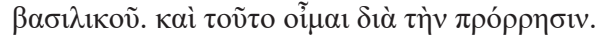

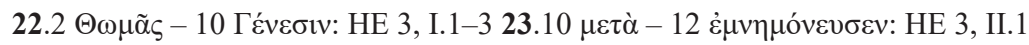

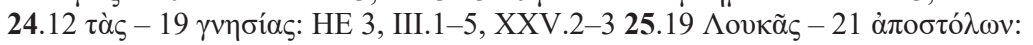

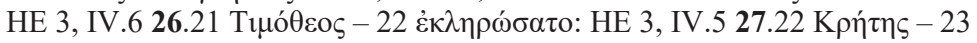

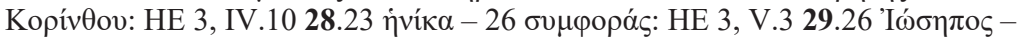

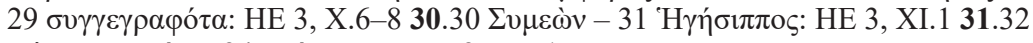

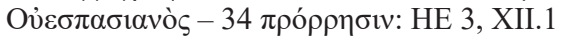

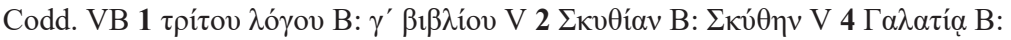

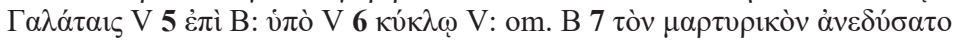

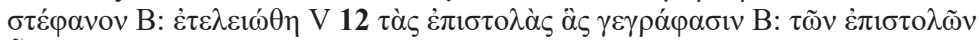

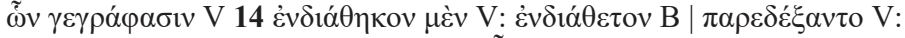

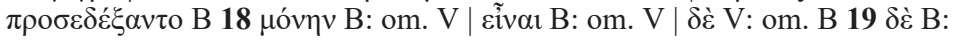

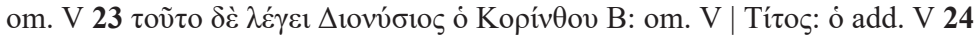

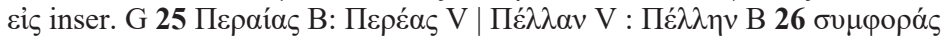

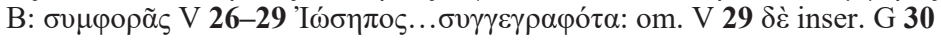

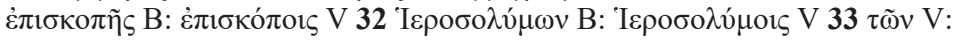

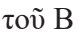




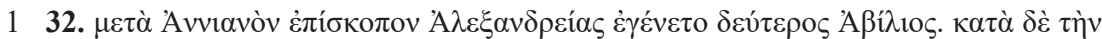

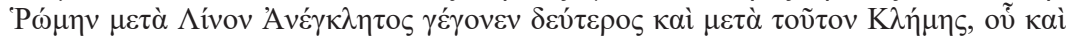

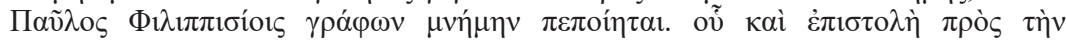

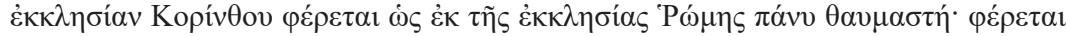

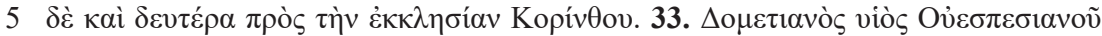

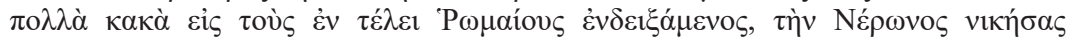

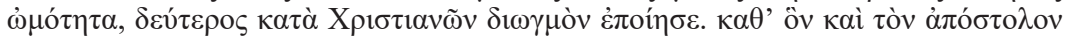

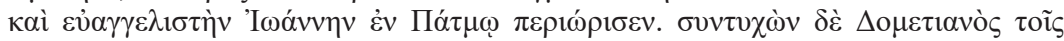

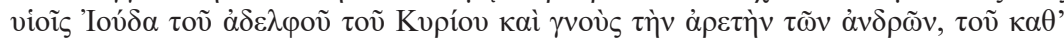

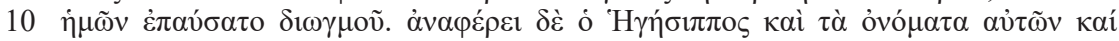

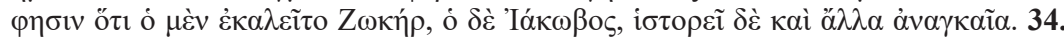

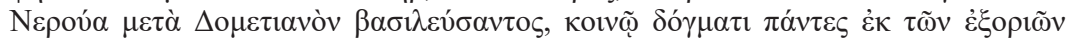

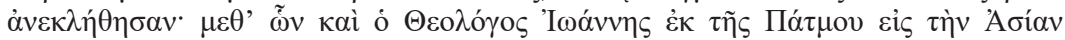

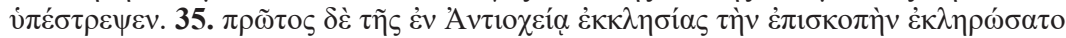

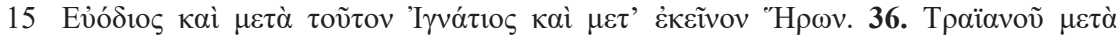

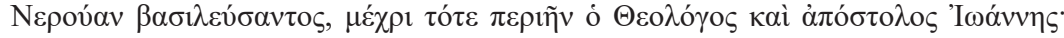

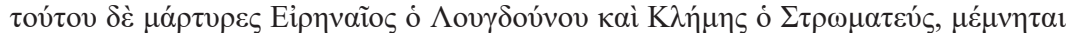

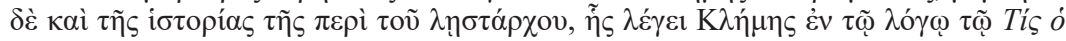

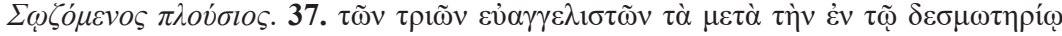

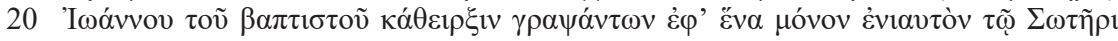

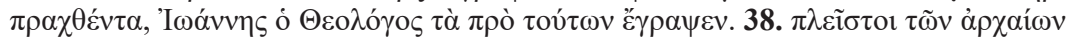

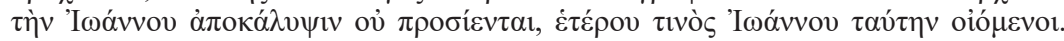

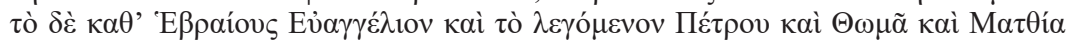

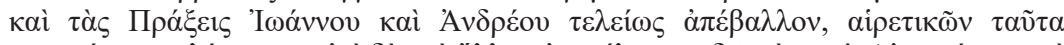

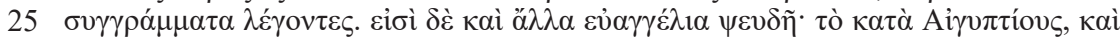

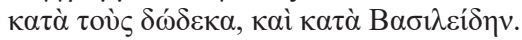

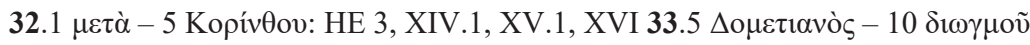

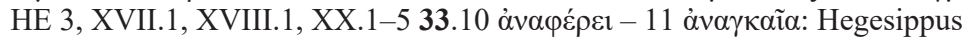

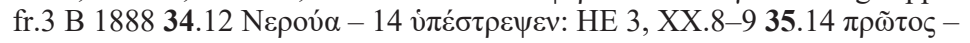

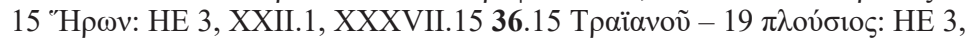
XXI.1, XXIII.2-4 $37.19 \tau \tilde{\omega} v-21$ है $\gamma \rho \psi \varepsilon v$ : HE 3, XXIV.8 38.21 $\pi \lambda \varepsilon \tilde{\sigma} \sigma \tau \circ-25$

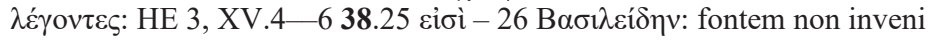

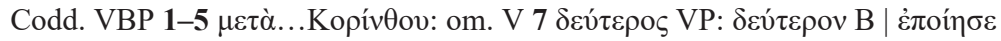

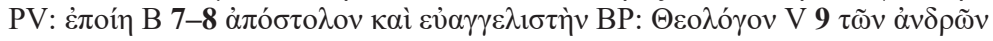

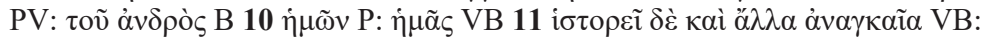

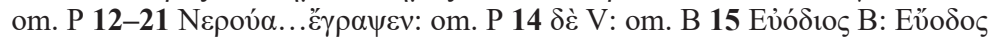

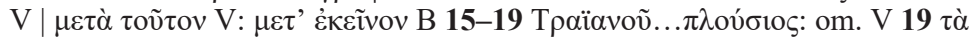

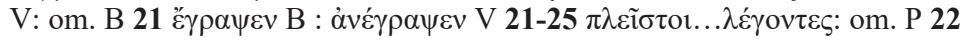

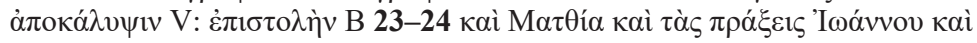

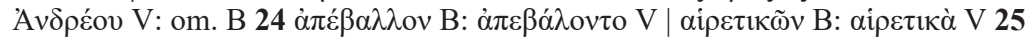

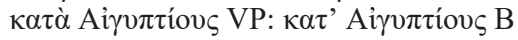




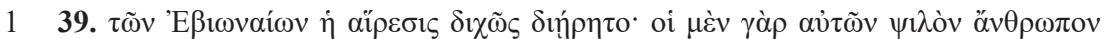

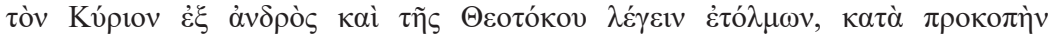

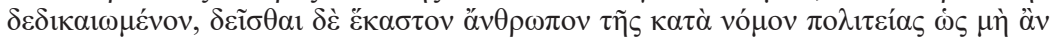

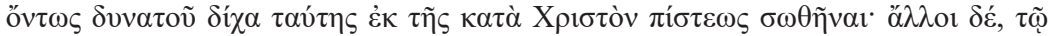

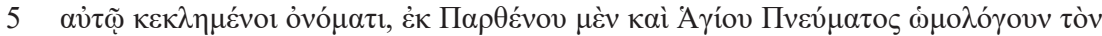

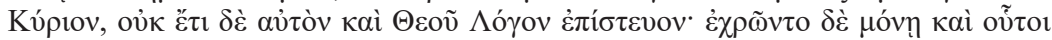

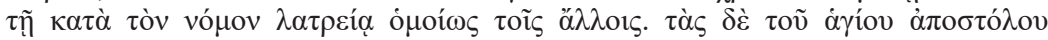

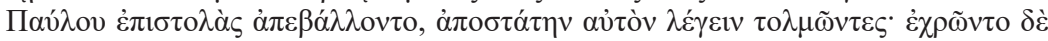

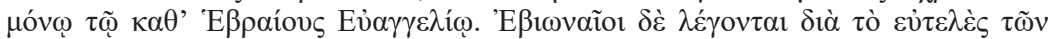

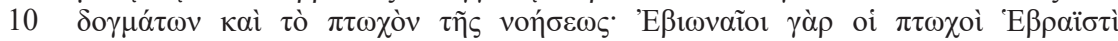

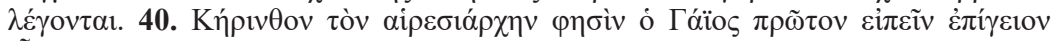

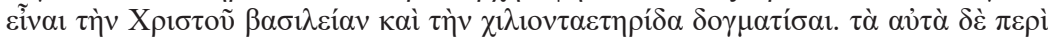

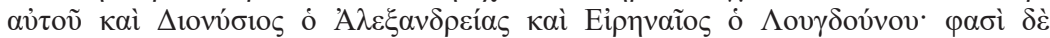

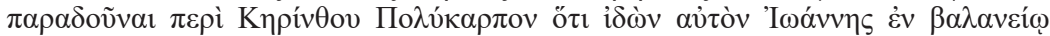

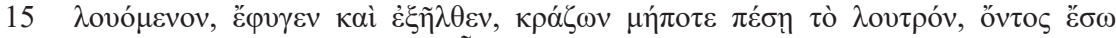

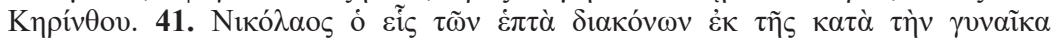

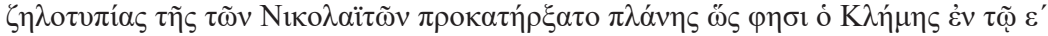

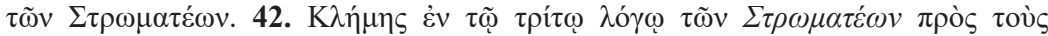

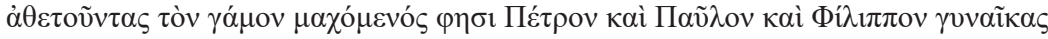

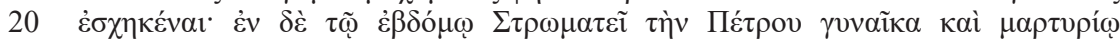

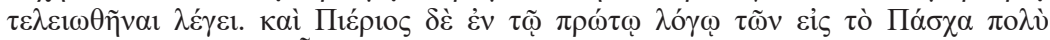

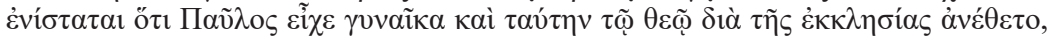

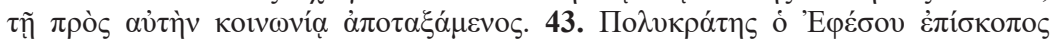

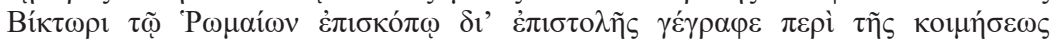

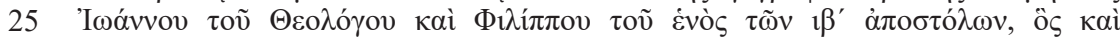

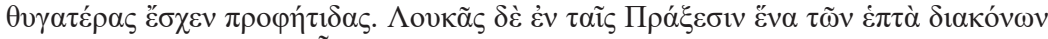

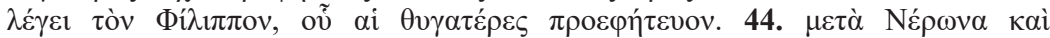

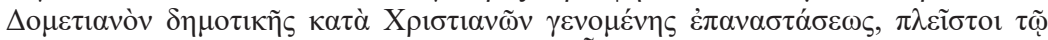

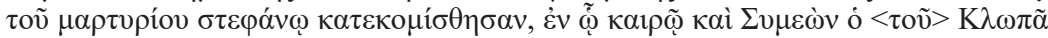

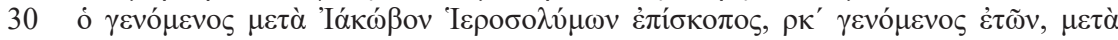

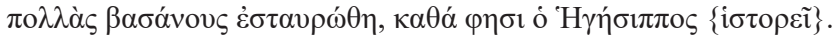

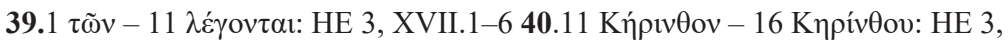

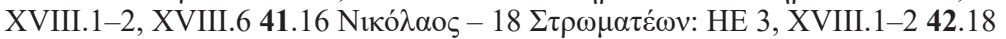

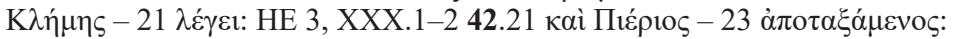

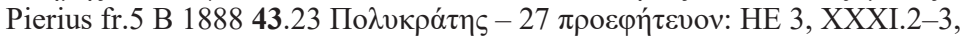

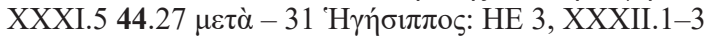

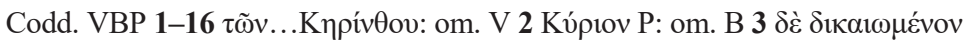

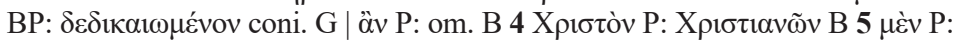

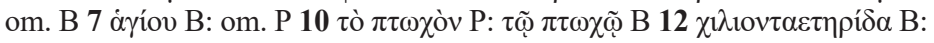

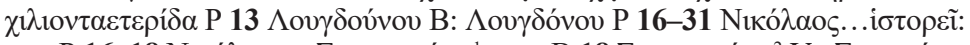

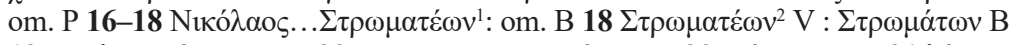

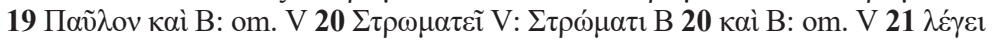

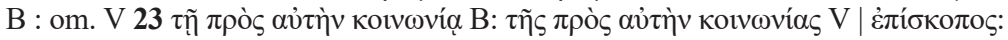

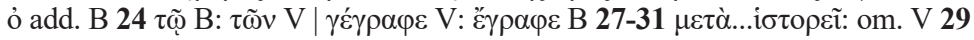

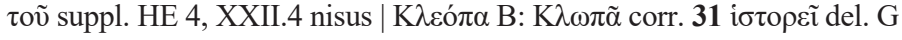




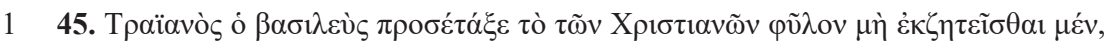

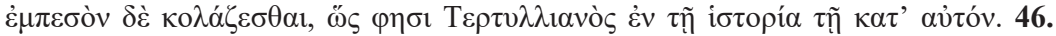

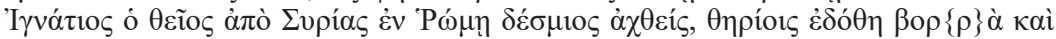

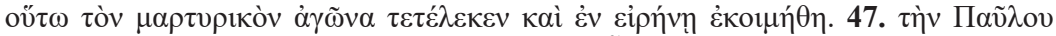

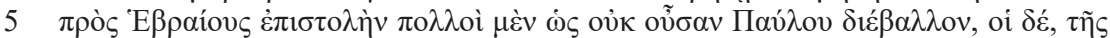

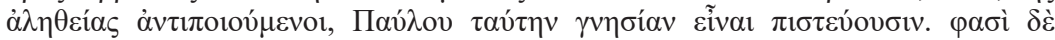

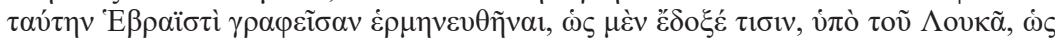

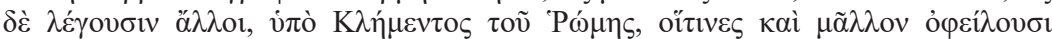

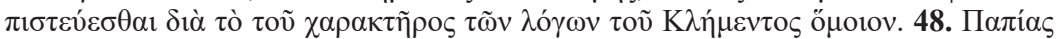

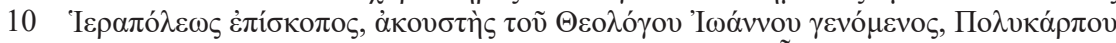

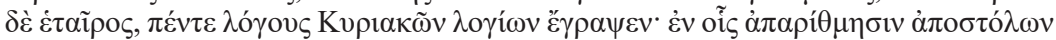

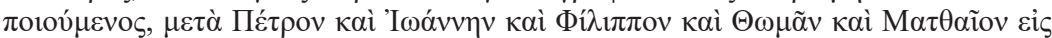

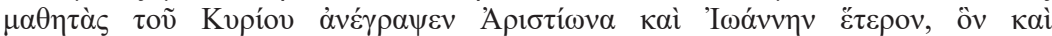

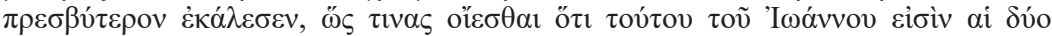

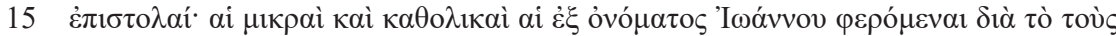

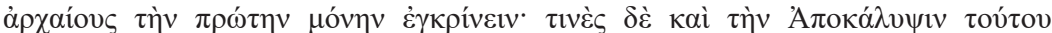

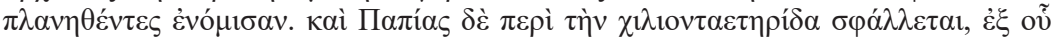

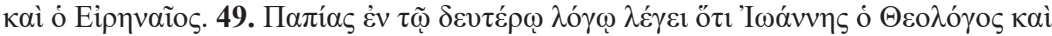

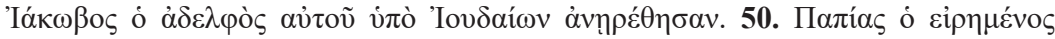

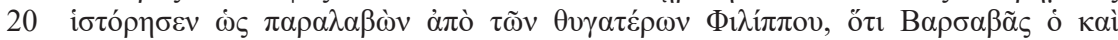

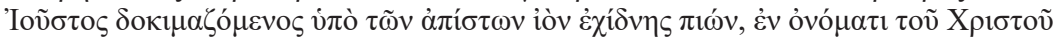

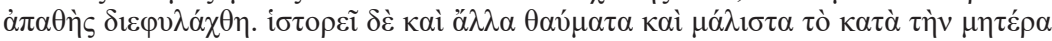

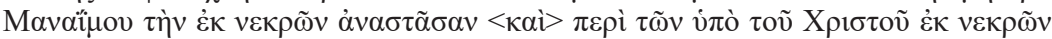

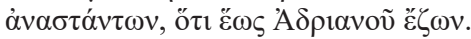

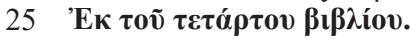

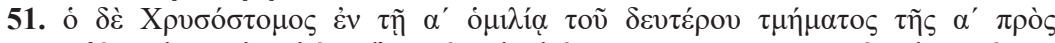

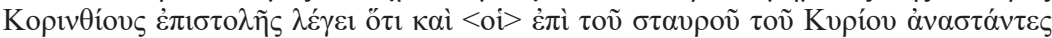

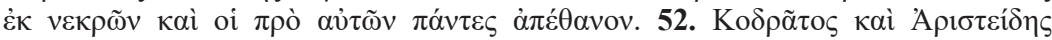

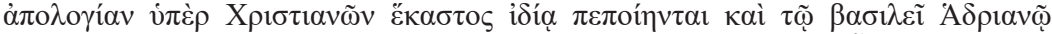

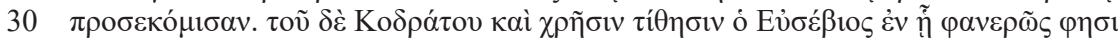

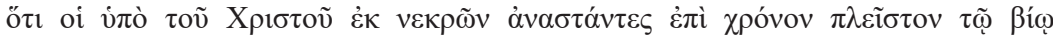

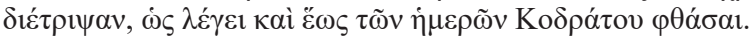

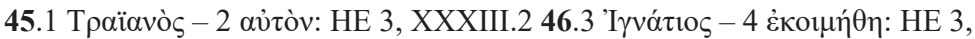

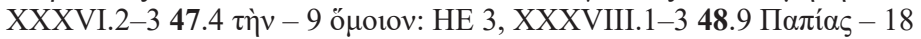

Eipqvaĩos: HE 3, XXXIX.1-2, XXXIX.4; Papias fr.6 B 188849.18 Палías- 19

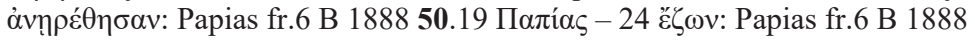

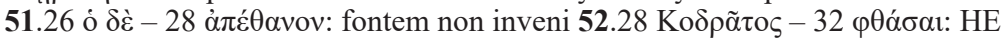
4, III.1-3

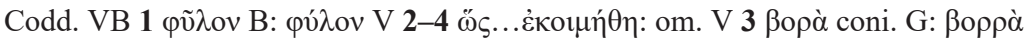

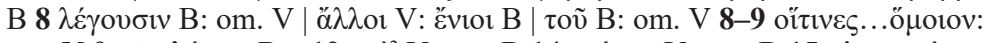

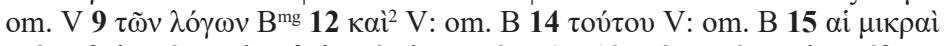

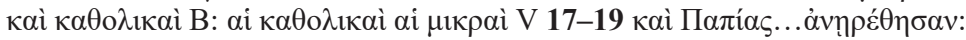

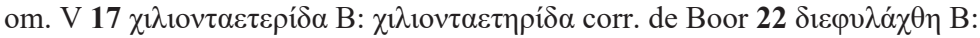

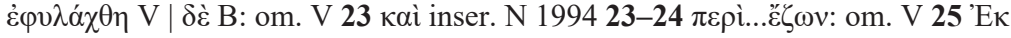

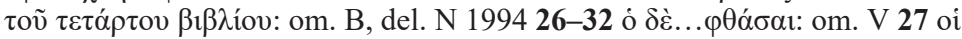
inser. B 1888 


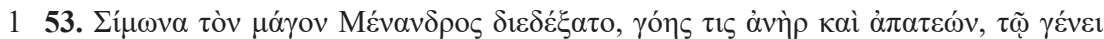

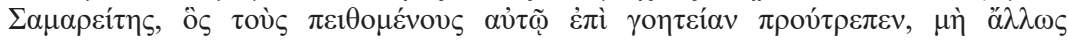

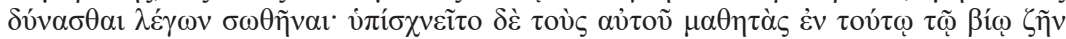

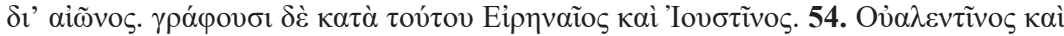

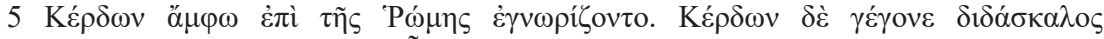

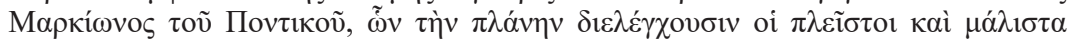

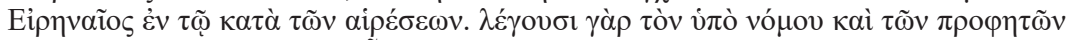

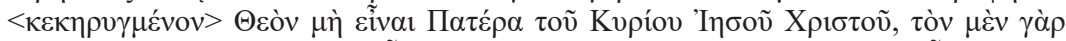

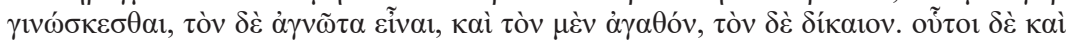

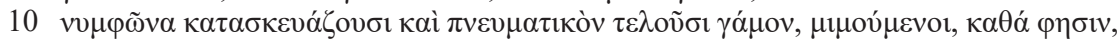

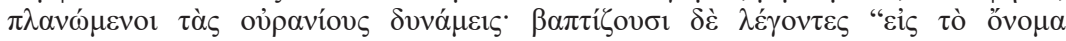

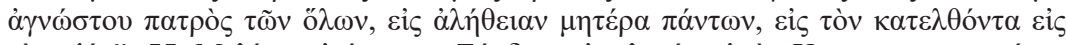

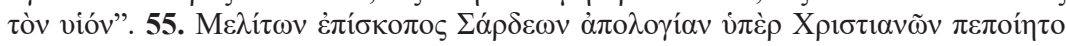

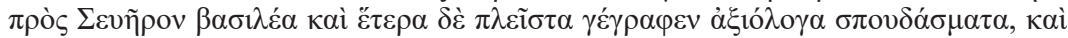

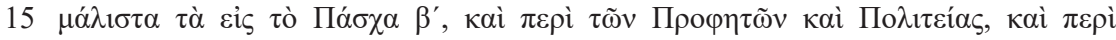

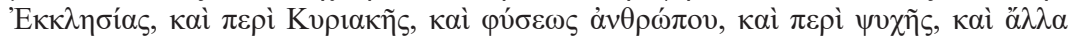

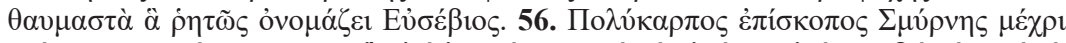

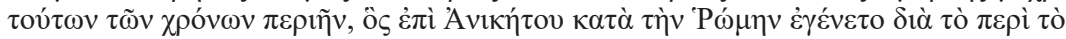

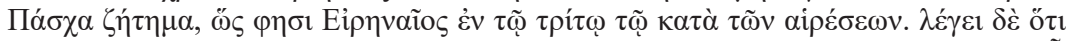

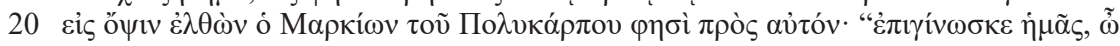

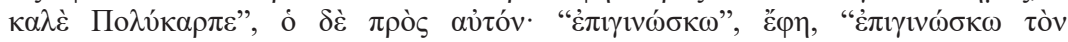

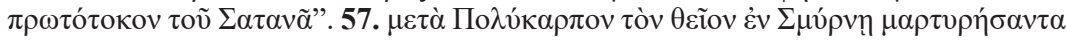

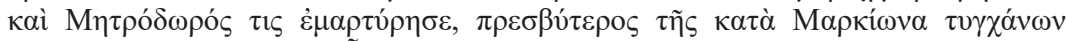

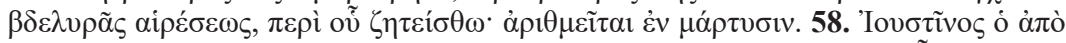

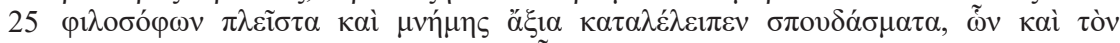

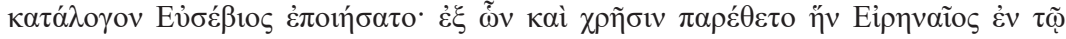

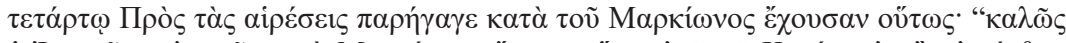

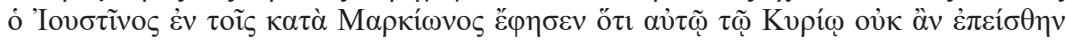

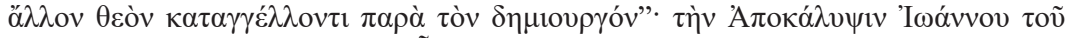

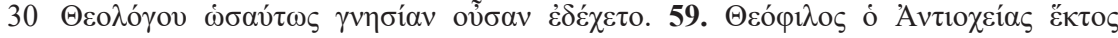

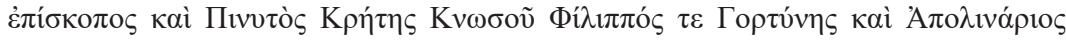

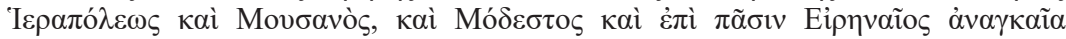

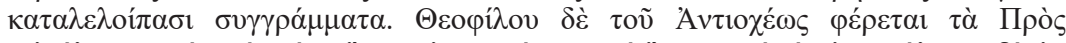

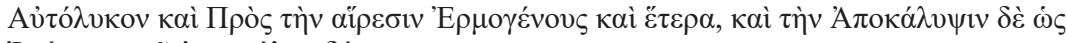

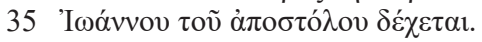

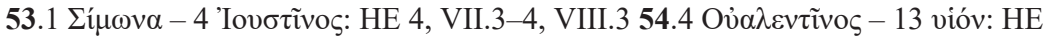

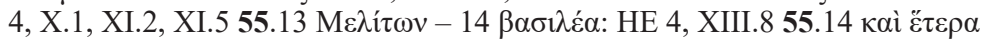

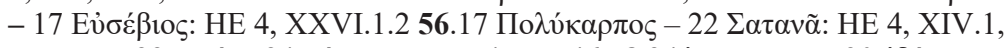

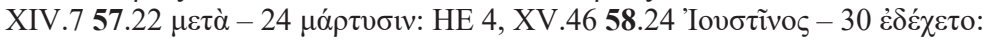

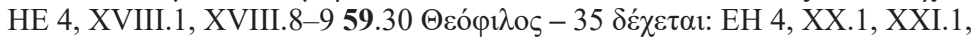
XXIV.1

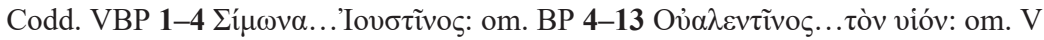

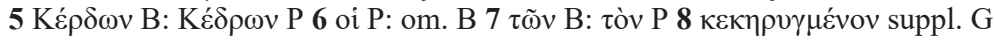

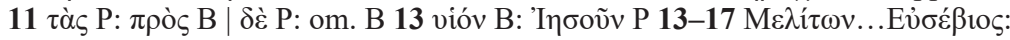

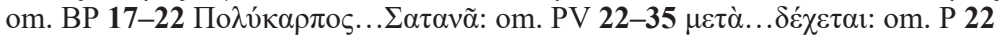

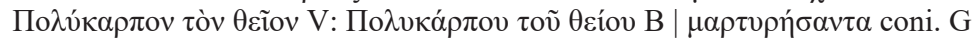

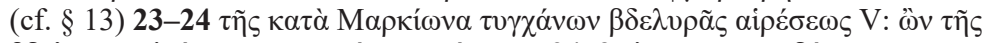

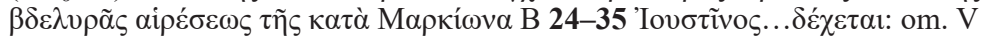




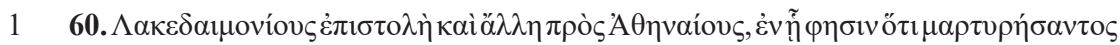

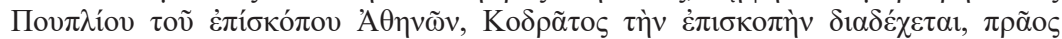

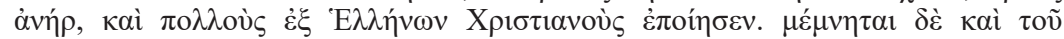

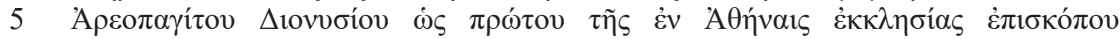

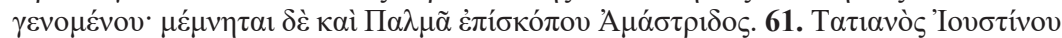

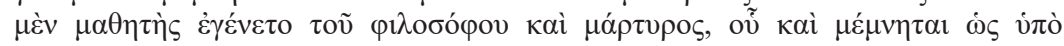

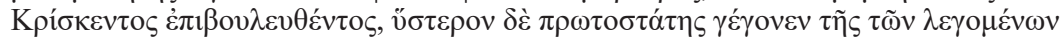

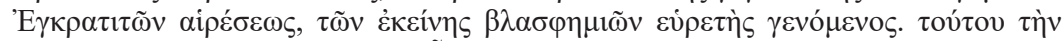

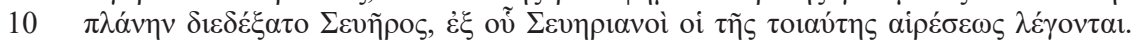

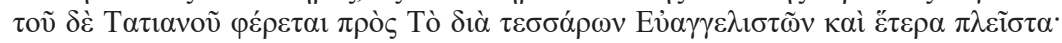

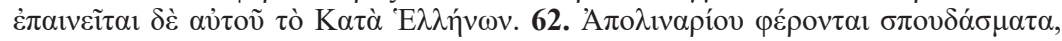

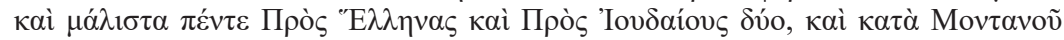

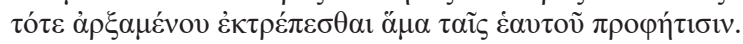

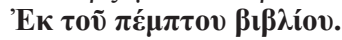

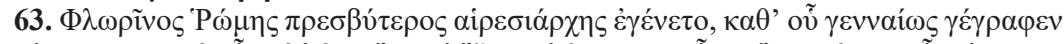

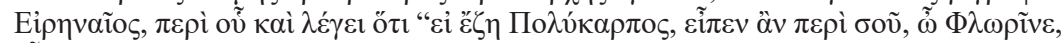

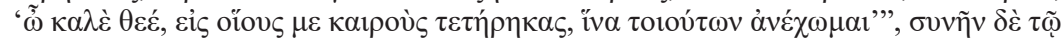

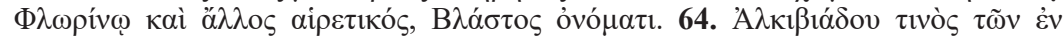

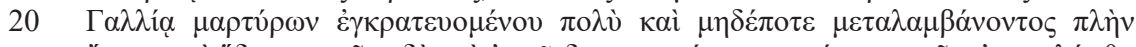

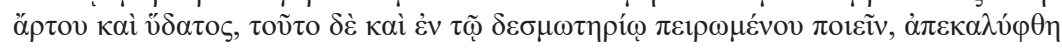

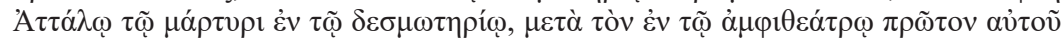

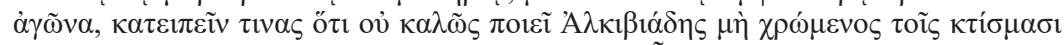

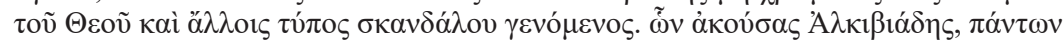

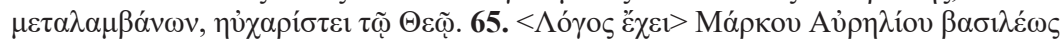
Р

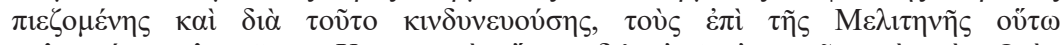

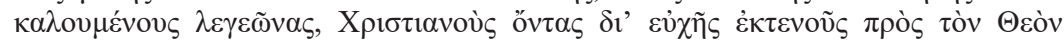

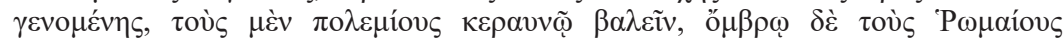

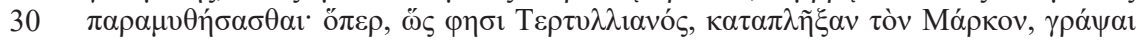

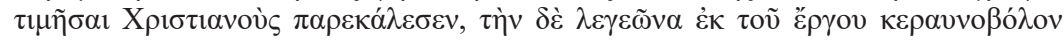

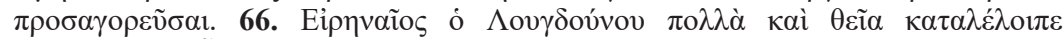

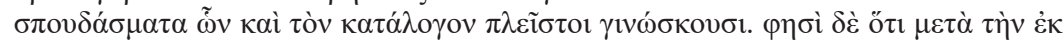

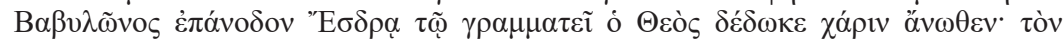

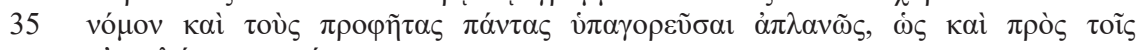

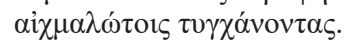

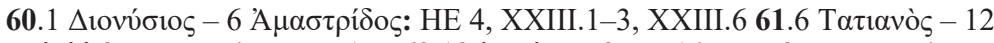

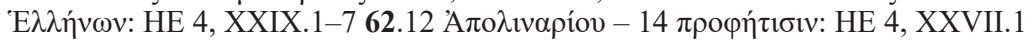

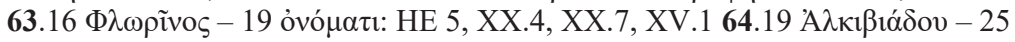

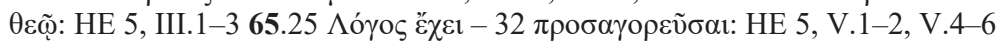

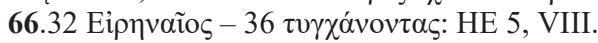

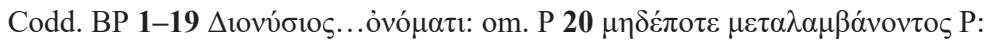

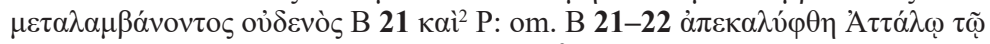

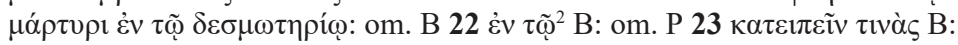

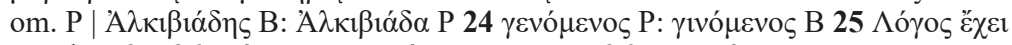

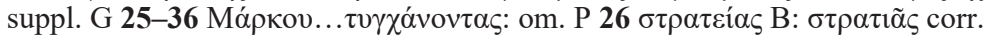
Eusebius' EH 5, V.1 nisus 


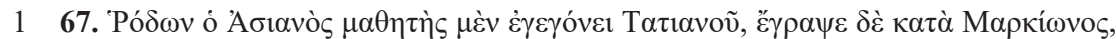

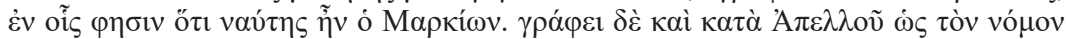

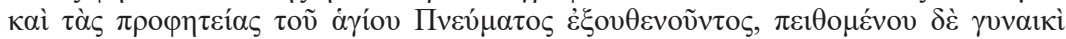

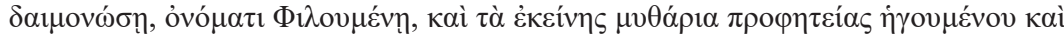

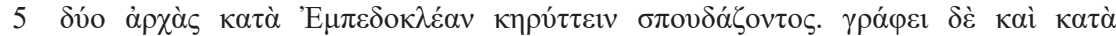

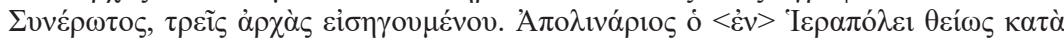

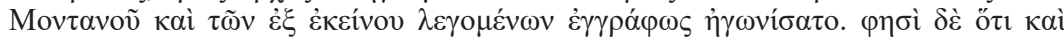

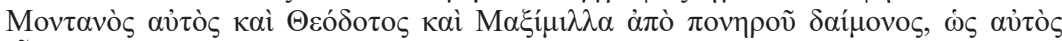

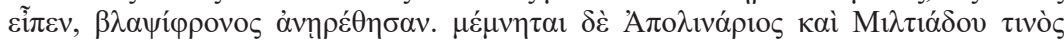

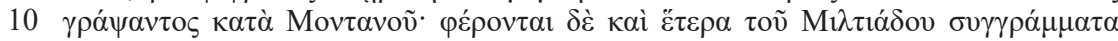

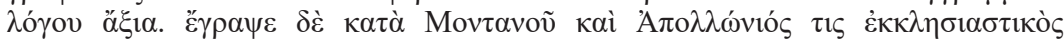

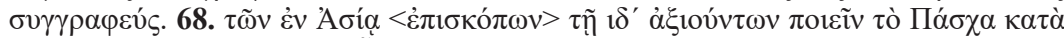

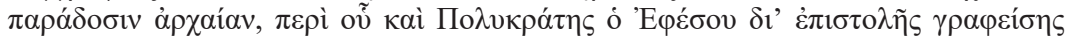

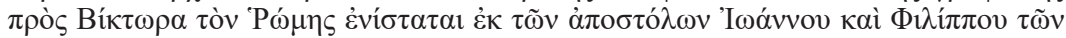

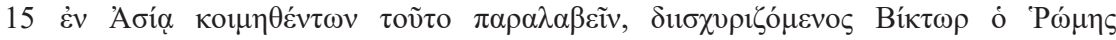

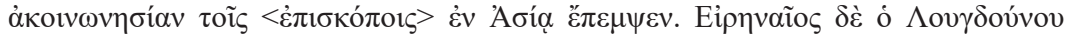

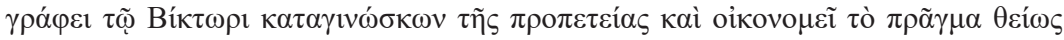

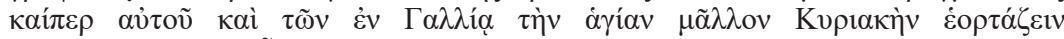

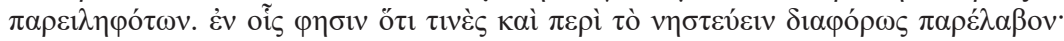

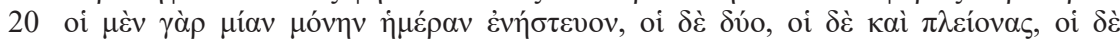

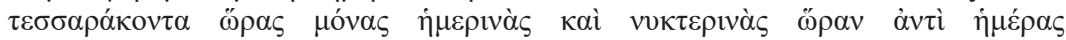

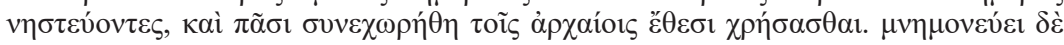

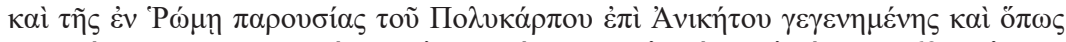

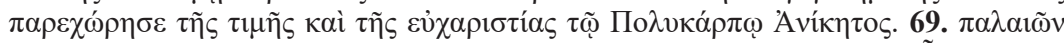

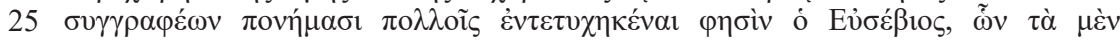

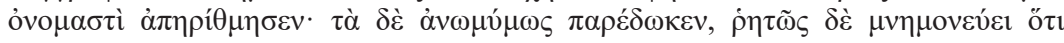

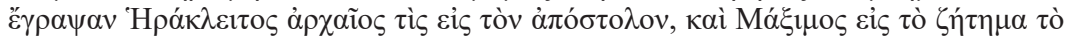

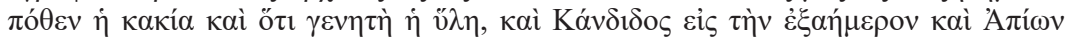

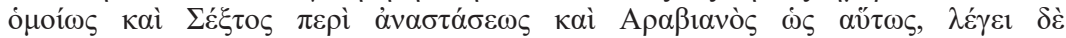

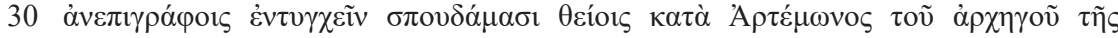

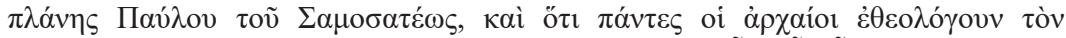

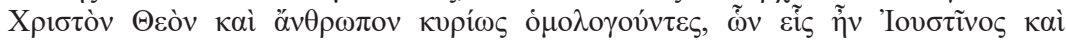

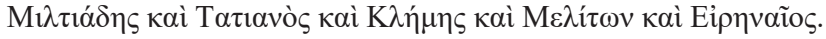

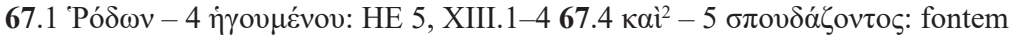

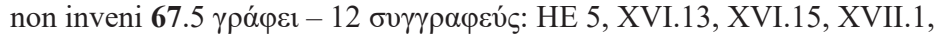

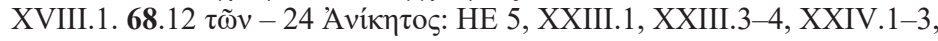
XXIV.12, XXIV.17 69.24 $\pi \alpha \lambda \alpha i \tilde{\omega} v-33$ Eipqvaĩos HE 5, XXVII.1

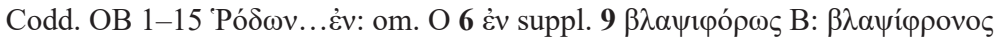
corr. Eusebius' HE 5, XVI.13 nisus 12 غ̇ंıбкó $\pi \omega v$ suppl. HE 5, XXIV.1 nisus

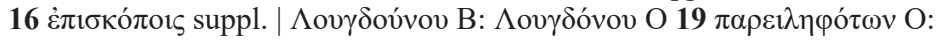

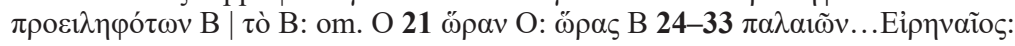

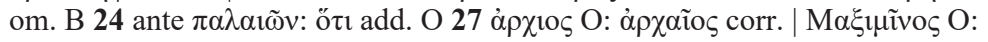

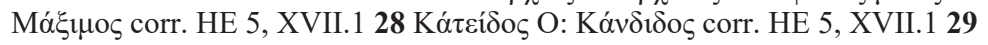

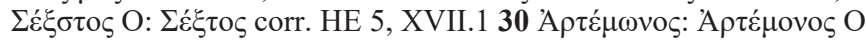




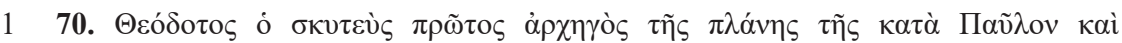

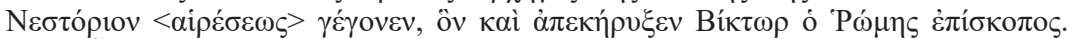

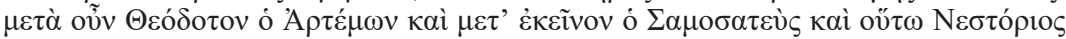

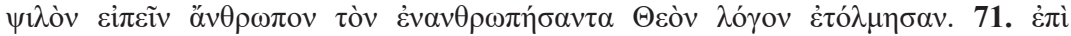

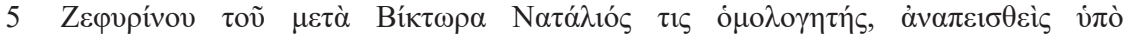

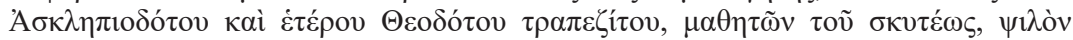

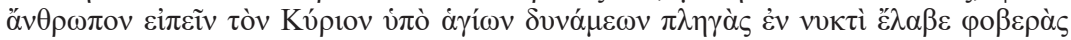

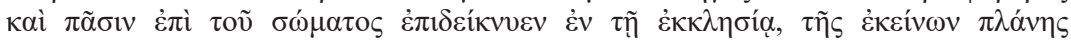

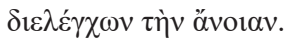

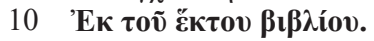

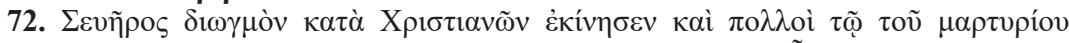

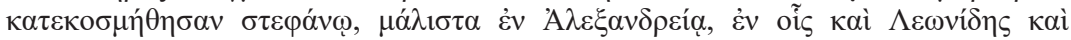

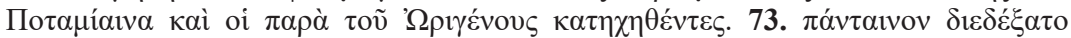

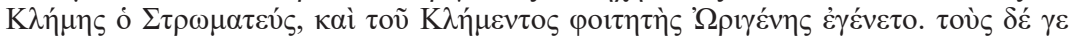

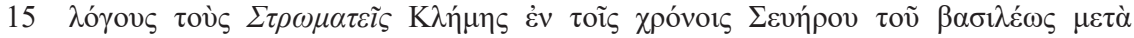

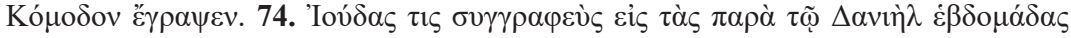

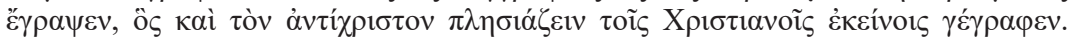

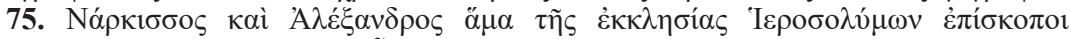

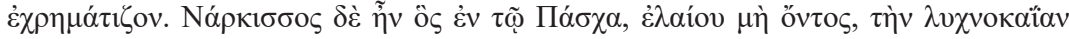

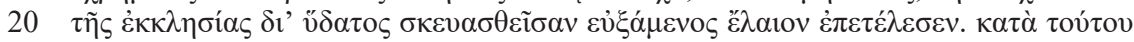

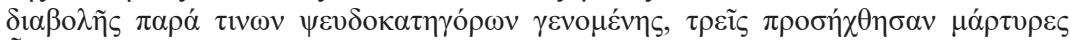

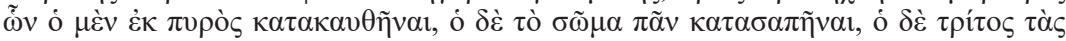

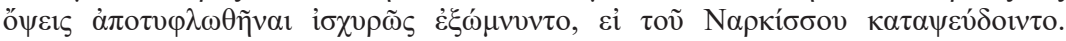

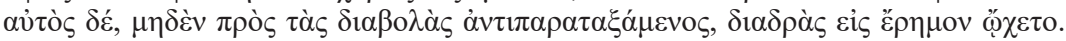

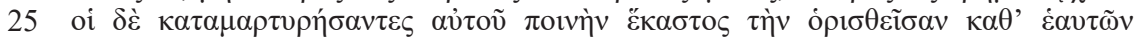

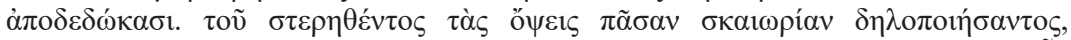

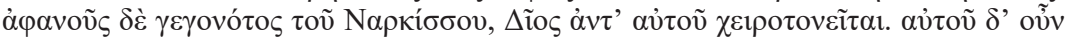

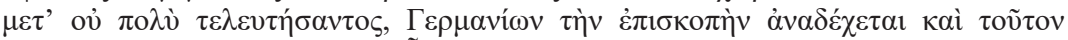

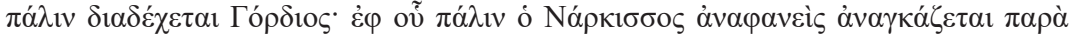

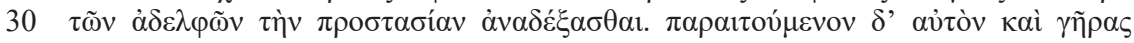

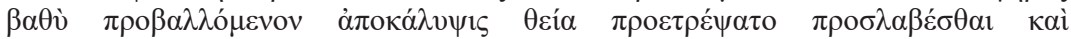

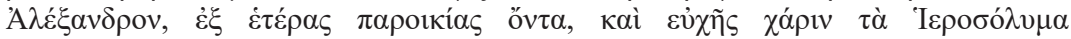

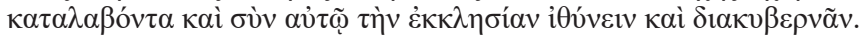

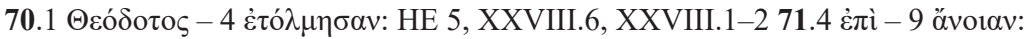

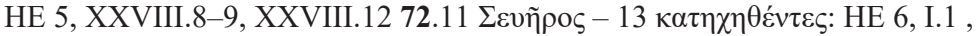

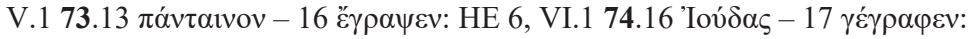

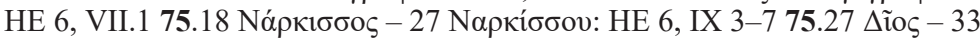
$\delta 1 \alpha \kappa \nu \beta \varepsilon \rho v \tilde{\alpha} v:$ HE 6, X.1, XI.1.2

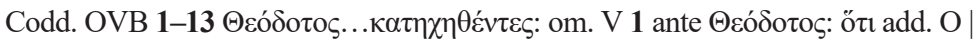

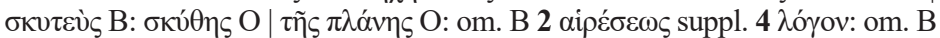

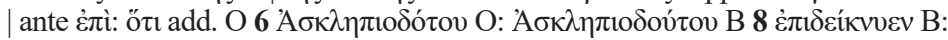

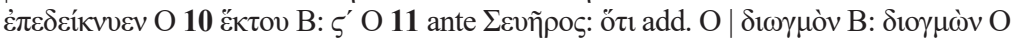

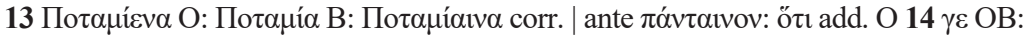

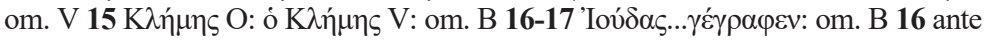

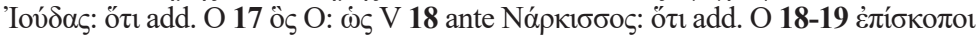

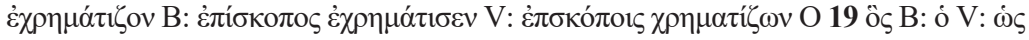

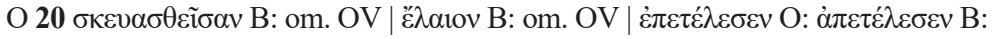

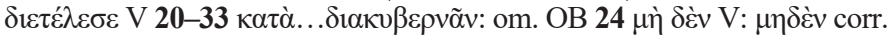




\section{Appendix I}

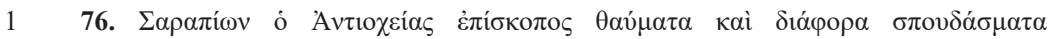

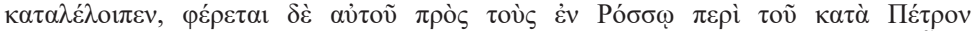

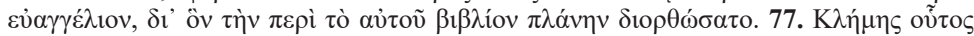

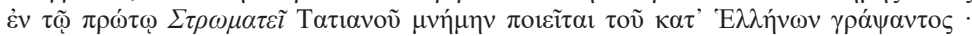

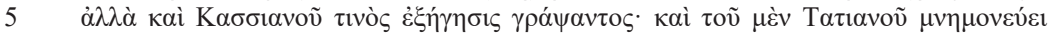

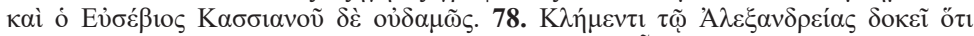

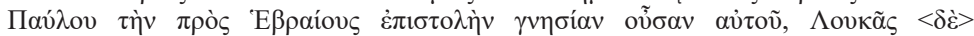

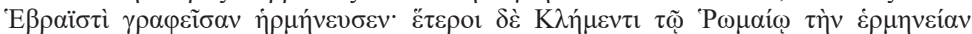

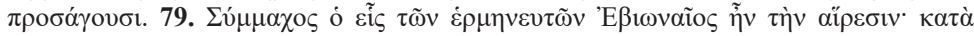

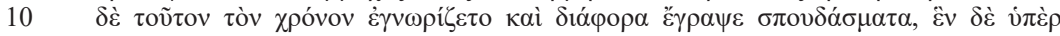

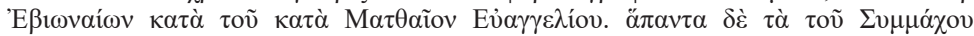

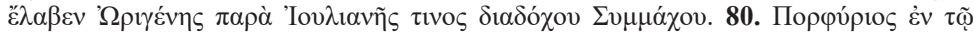

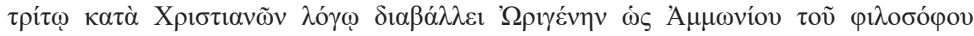

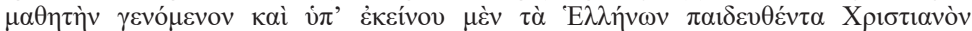

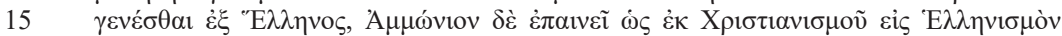

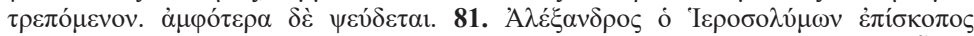
$\beta ı \beta \lambda$ เо

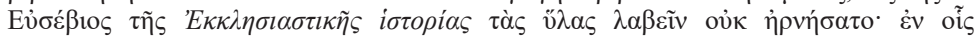

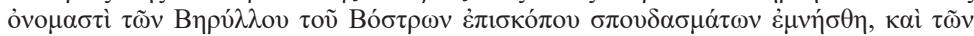

20 I I $\pi$ o

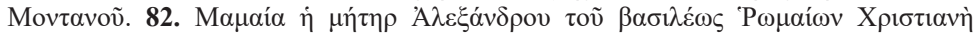

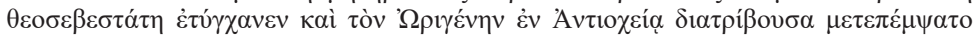

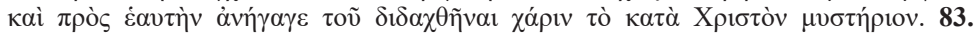

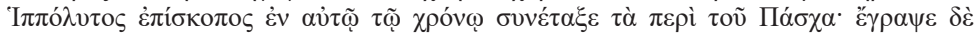

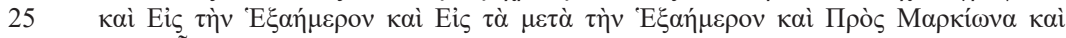

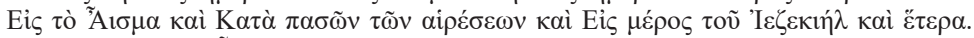

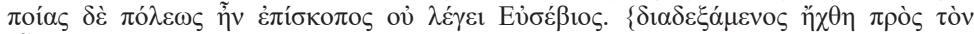

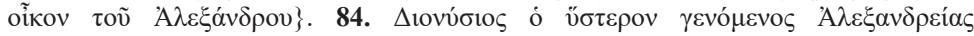

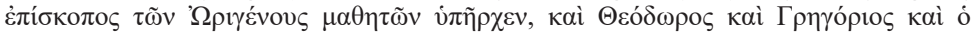

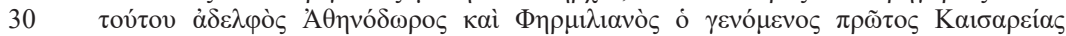

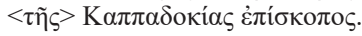

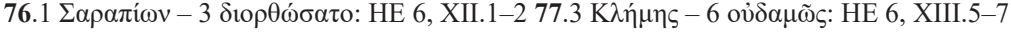

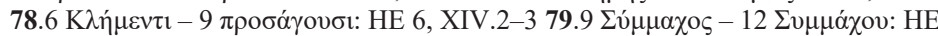

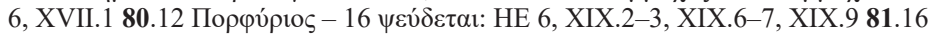

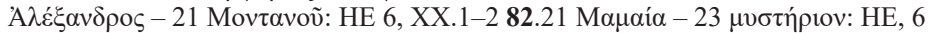

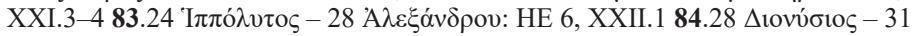
غ̇ंíбколос: HE 6, XXVII.1

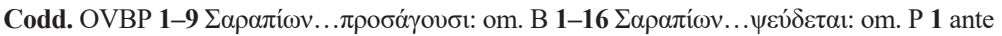

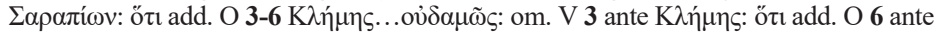

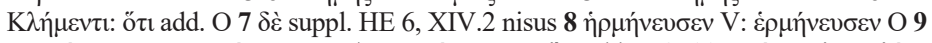

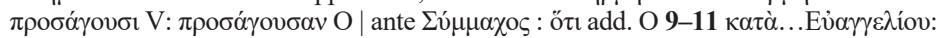

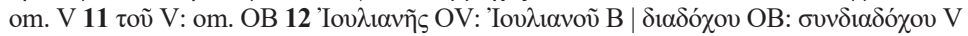

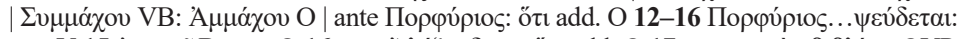

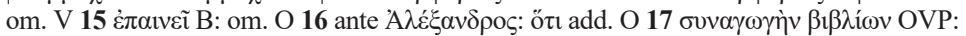

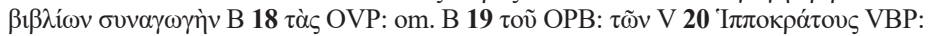

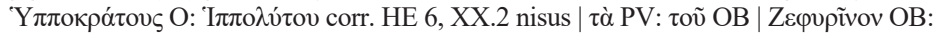

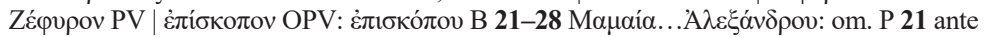

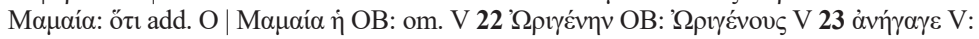

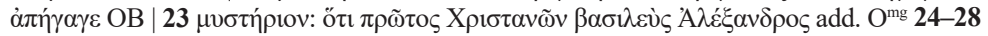

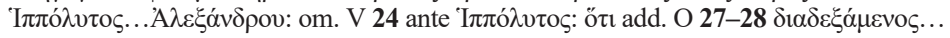

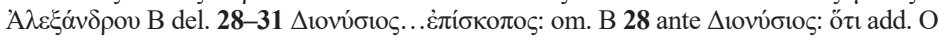

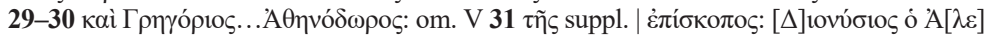

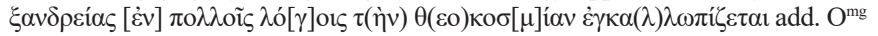




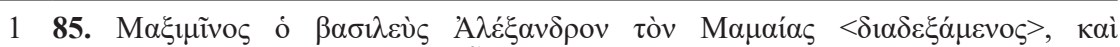

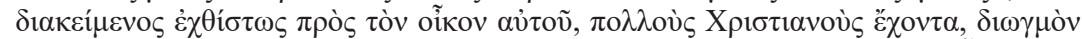

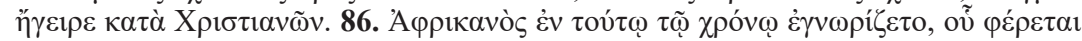

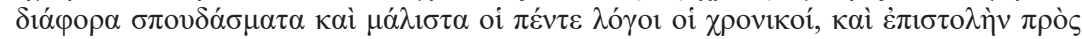

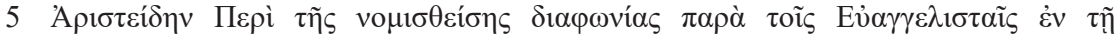

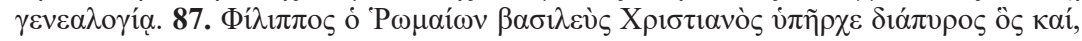

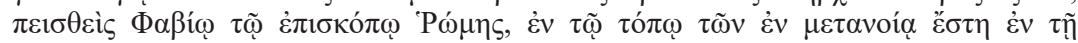

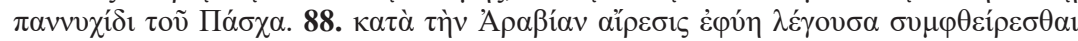

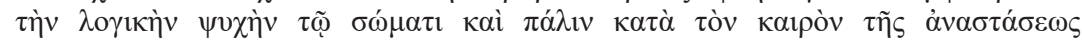

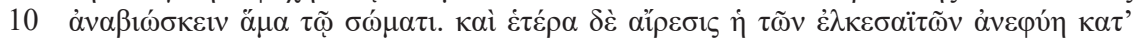

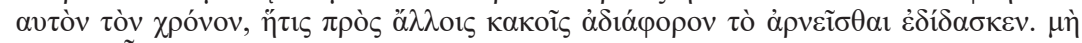

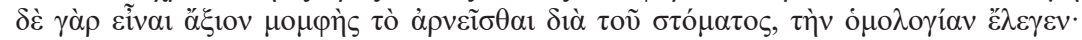

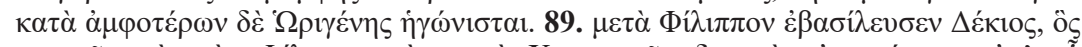

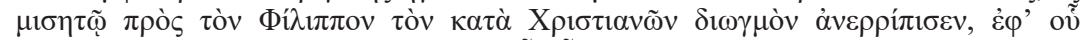

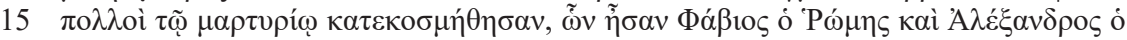

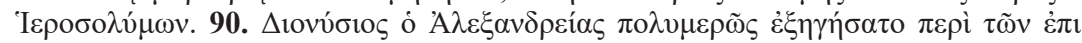

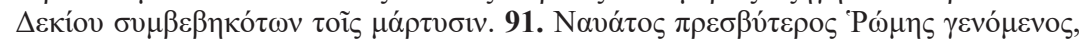

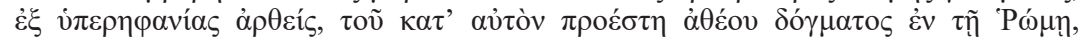

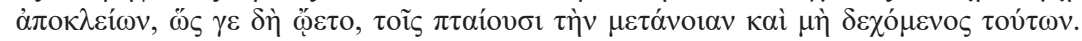

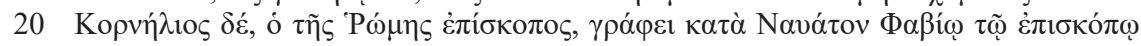

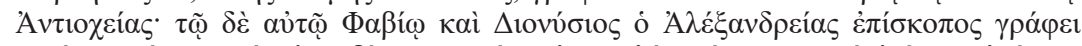

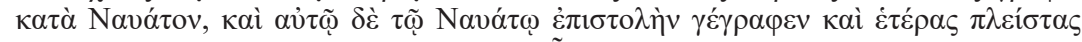

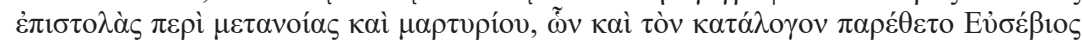

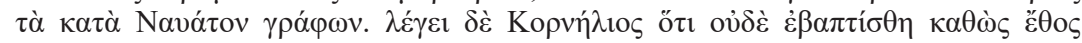

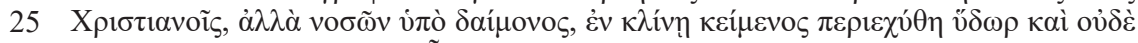

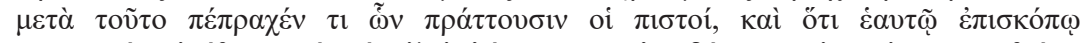

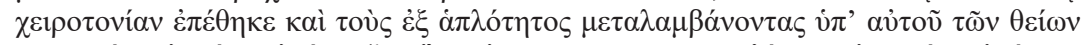

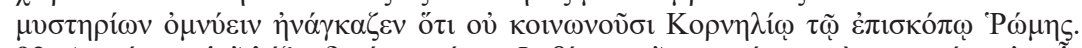

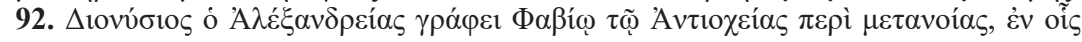

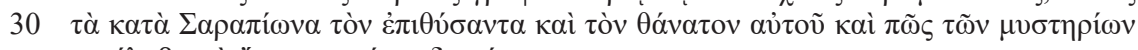
$\mu \varepsilon \tau \varepsilon ́ \lambda \alpha \beta \varepsilon, \tau \alpha \grave{~ \varepsilon ̌ \sigma \chi \alpha \tau \alpha ~ \pi v \varepsilon ́ \omega v, ~ \delta i \eta \gamma \eta ́ \sigma \alpha \tau o . ~}$

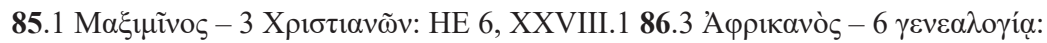

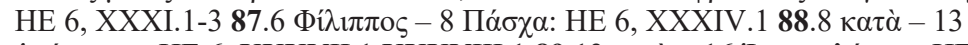

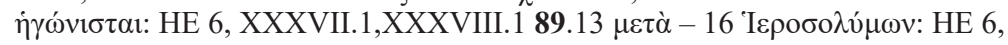

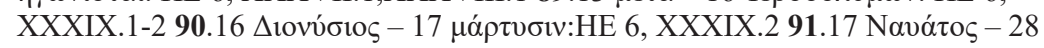

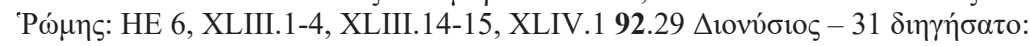
HE 6, XLIV.1-2

Codd. OVB 1-3 M $\alpha \xi \mu$ ĩvos...X X

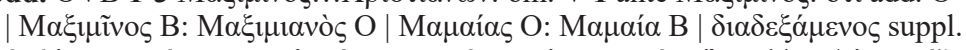

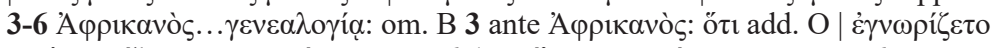

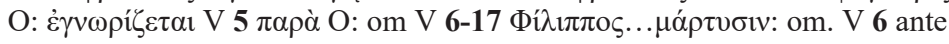

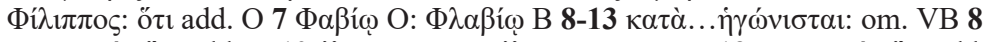

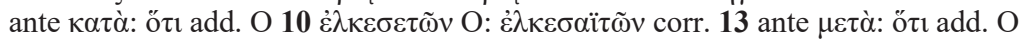

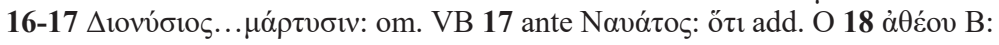

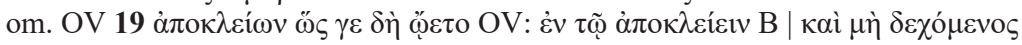

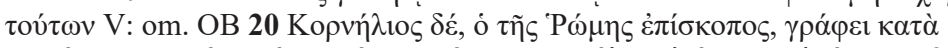

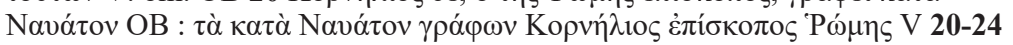

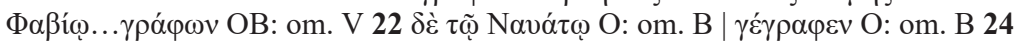

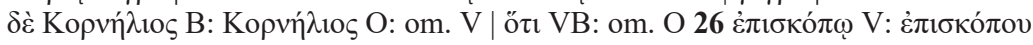

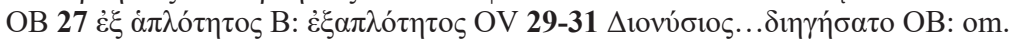

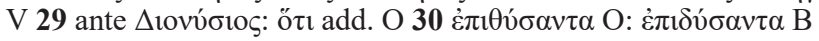




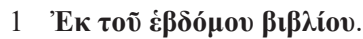

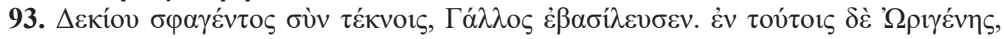

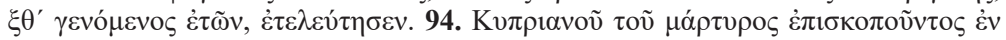

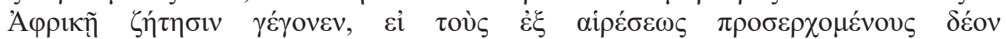

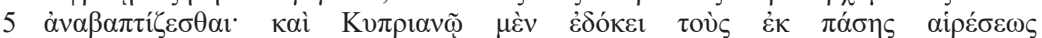

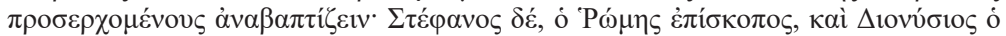

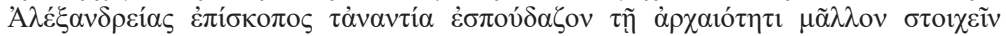

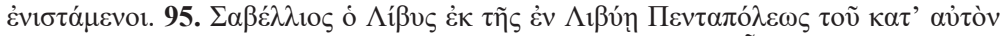

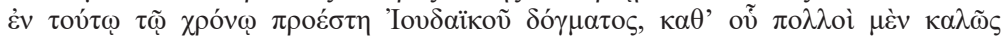

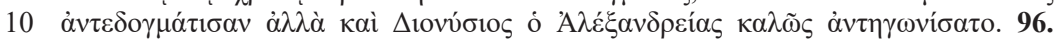

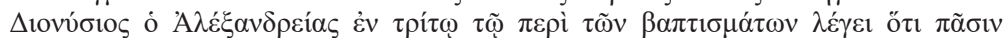

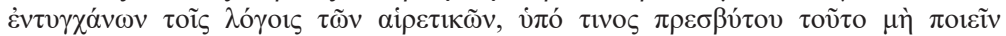

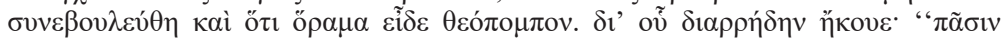

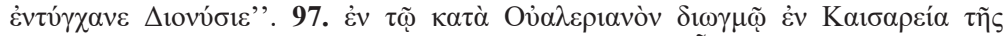

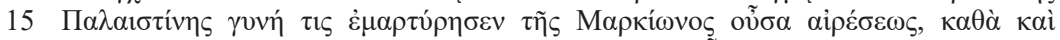

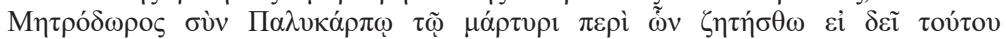

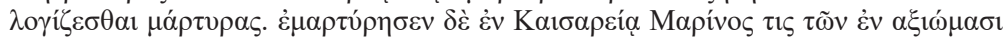

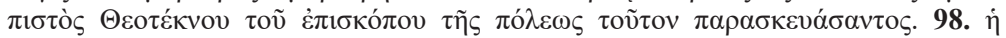

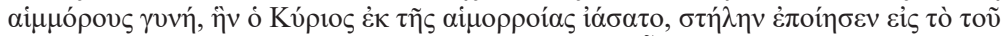

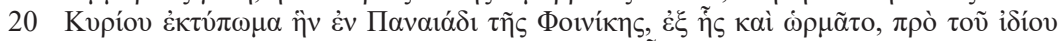

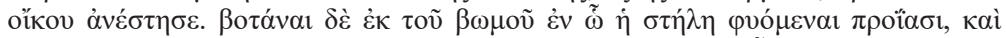

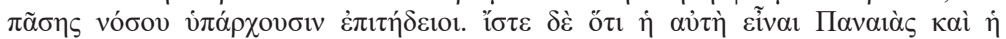

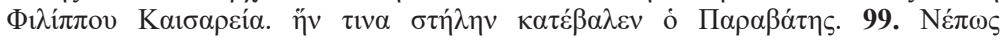

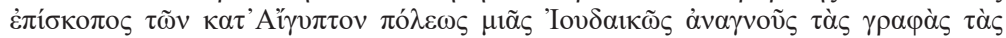

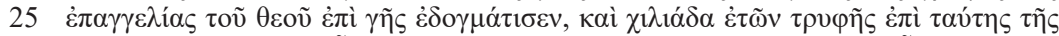

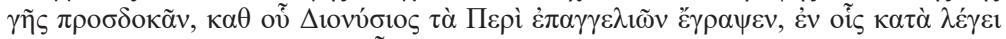

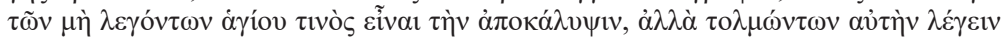

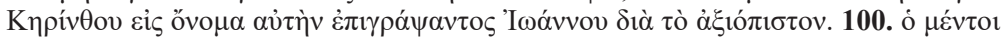

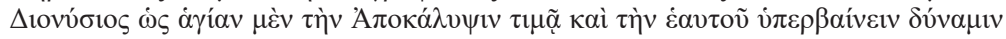

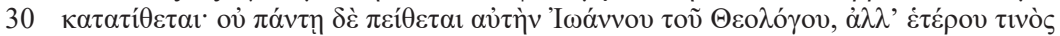

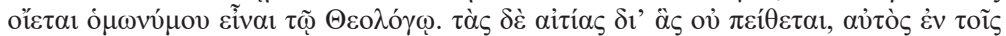

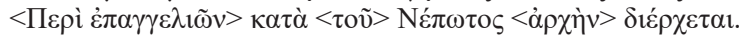

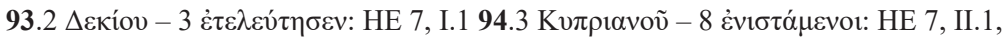

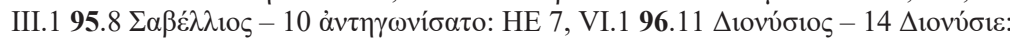

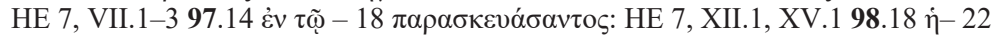

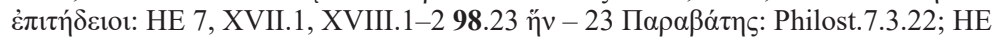

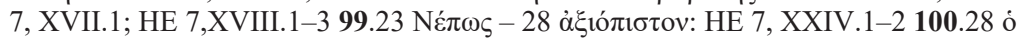

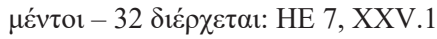

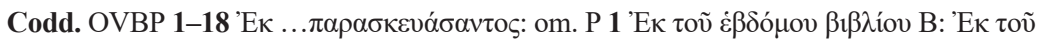

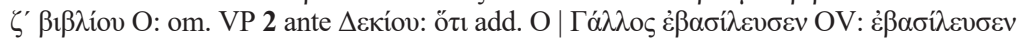

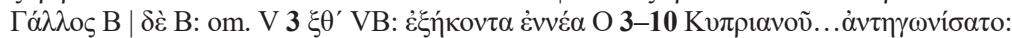

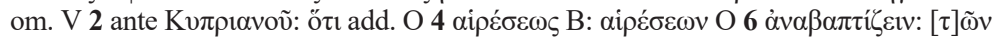

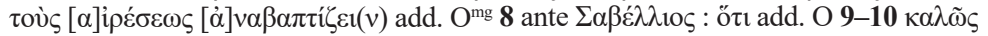

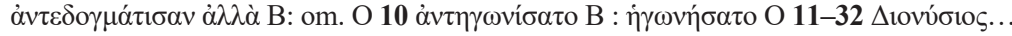

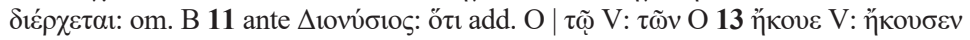

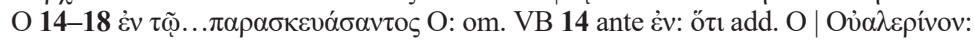

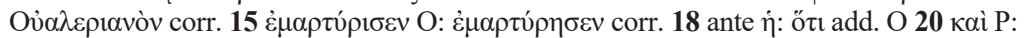

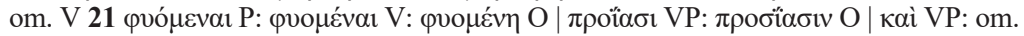

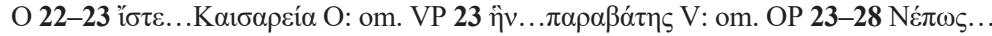

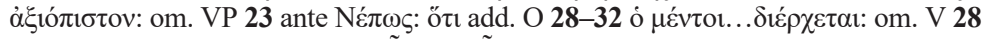

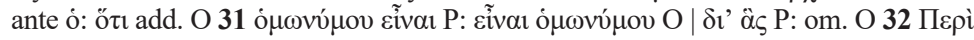

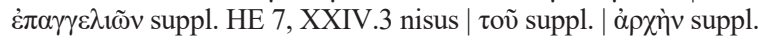




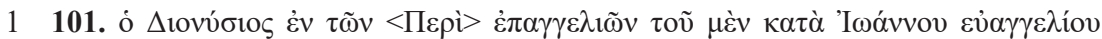

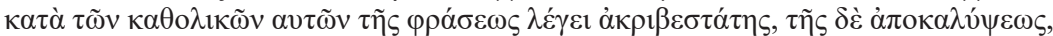

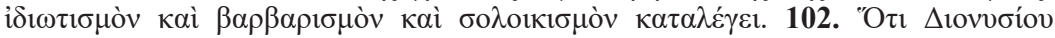

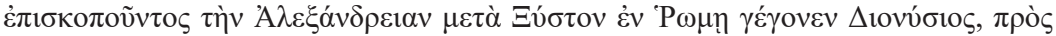

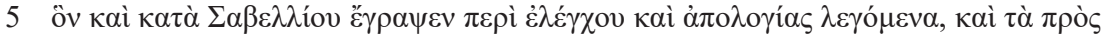

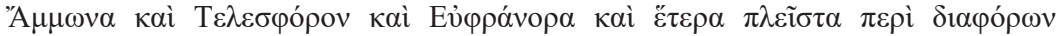

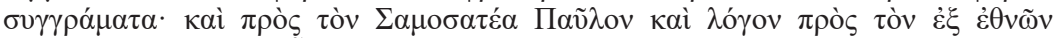

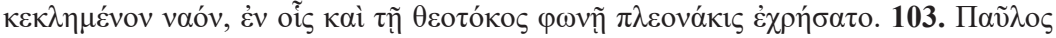

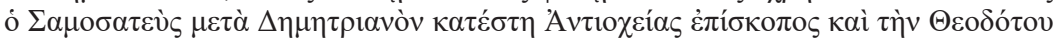

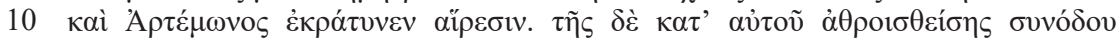

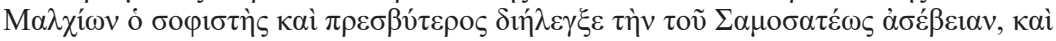

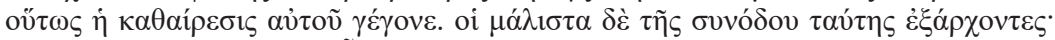

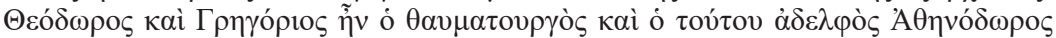

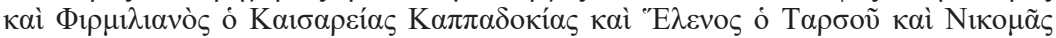

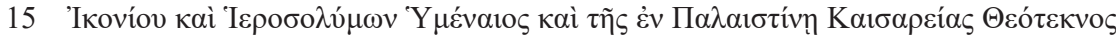

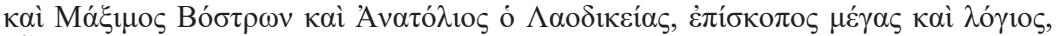

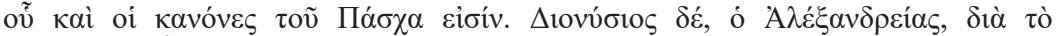

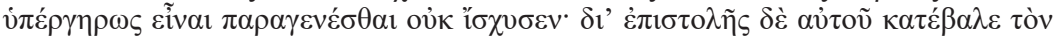

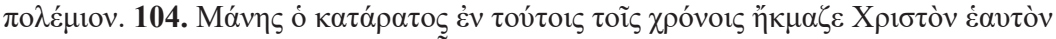

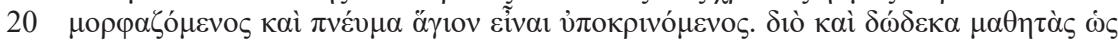

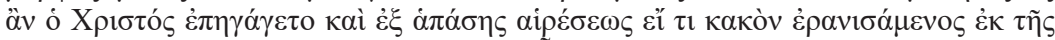

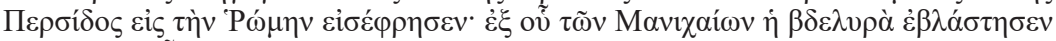

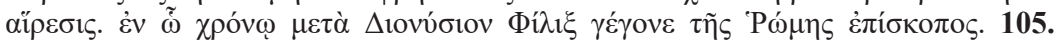

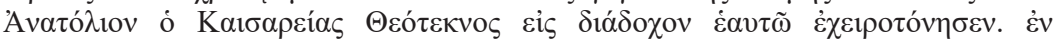

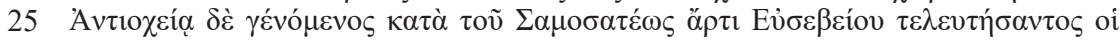

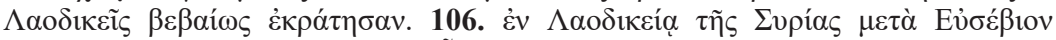

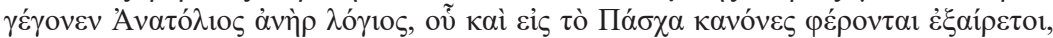

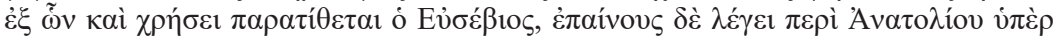

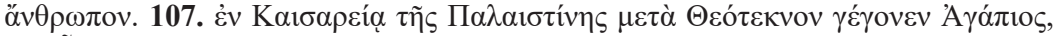

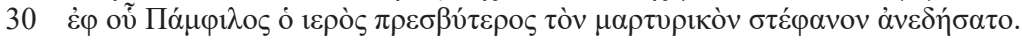

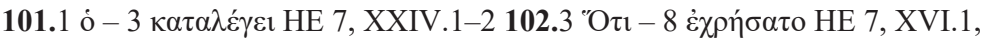

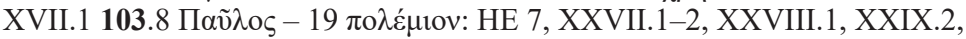

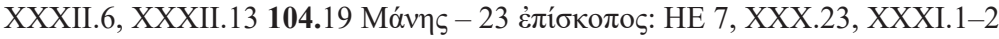

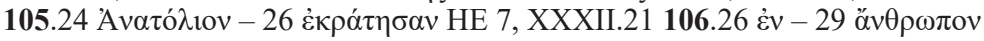

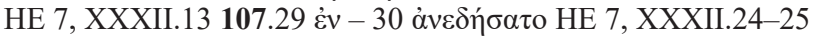

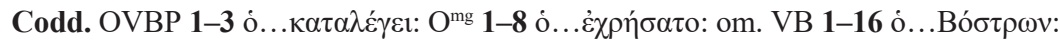

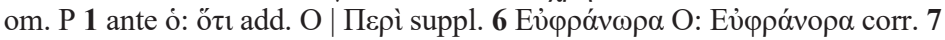

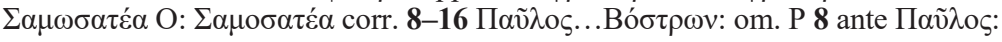

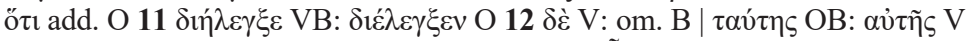

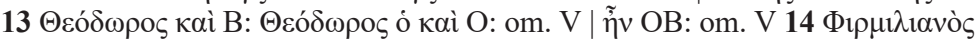

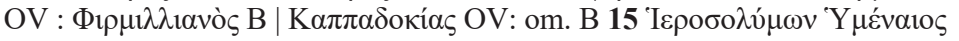

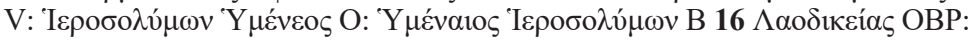

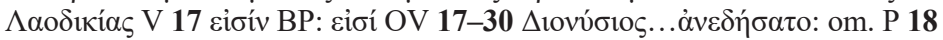

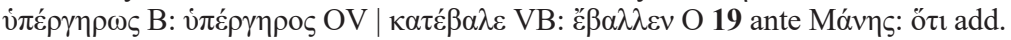

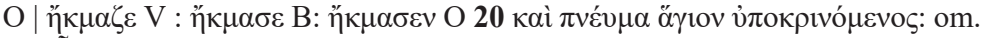

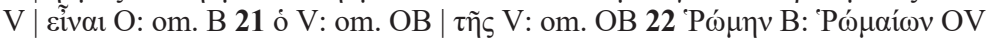

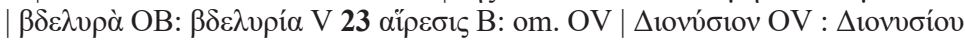

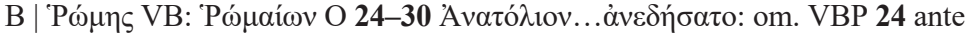

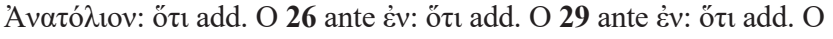




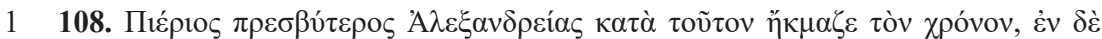

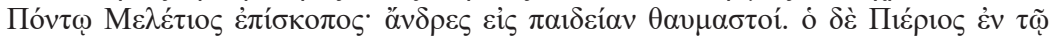

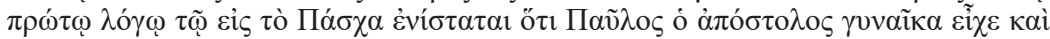

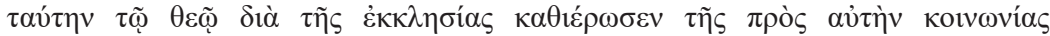

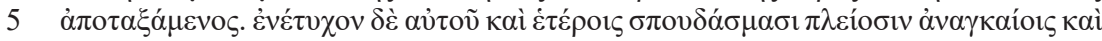

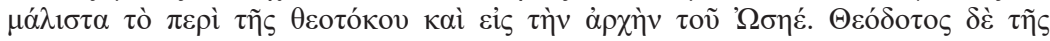

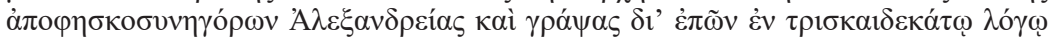

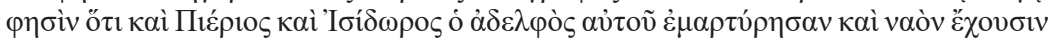

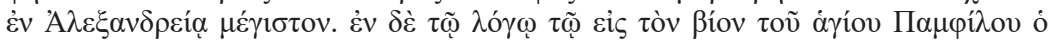

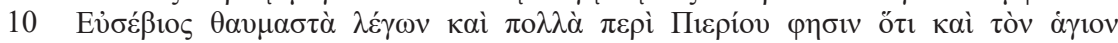

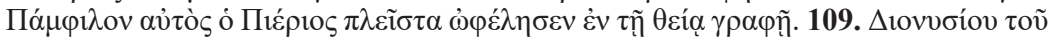

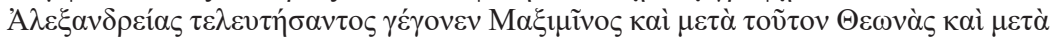

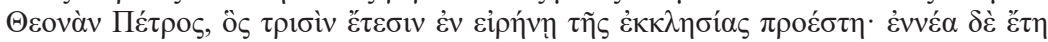

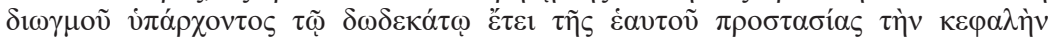

$15 \dot{\alpha} \pi \mathrm{o} \tau \varepsilon \dot{\varepsilon} \mu \varepsilon \tau \alpha 1$.

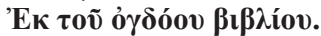

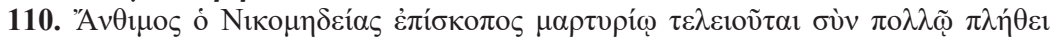

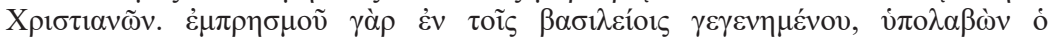

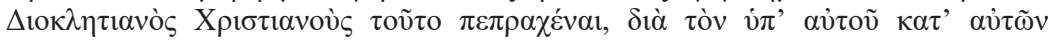

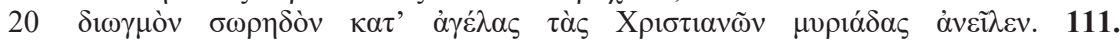

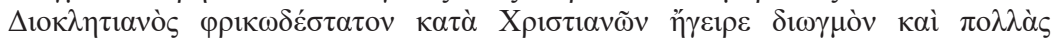

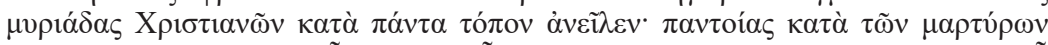

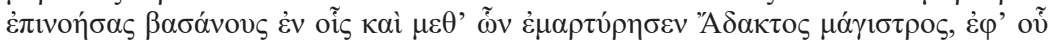

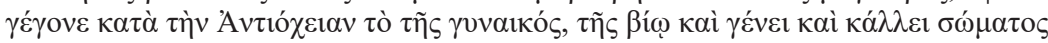

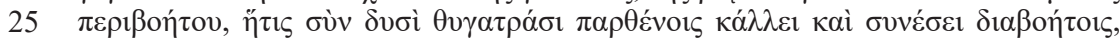

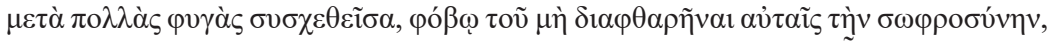

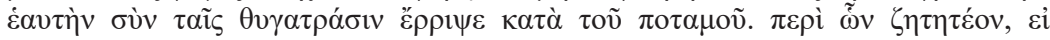

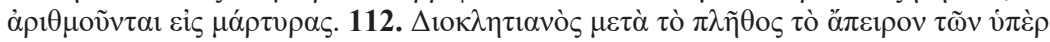

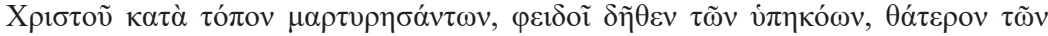

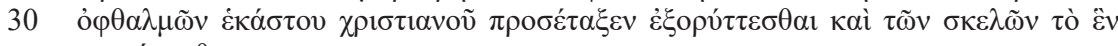
$\kappa \alpha \tau \varepsilon \alpha ́ \gamma \varepsilon \sigma \theta \alpha$.

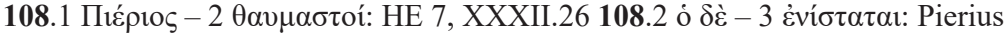

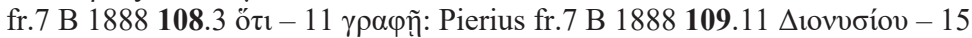

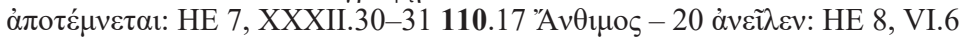

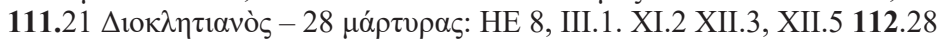

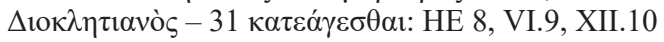

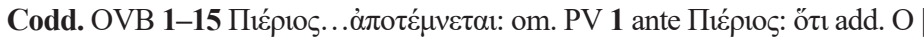

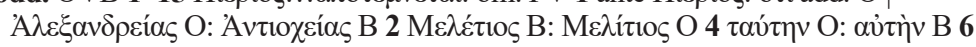

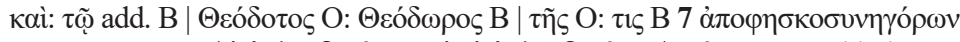

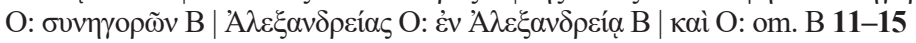

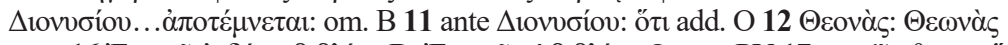

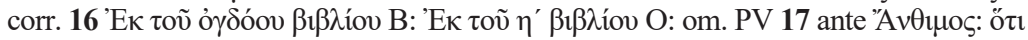

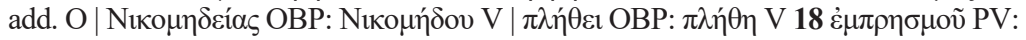

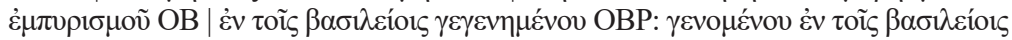

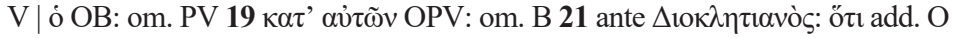

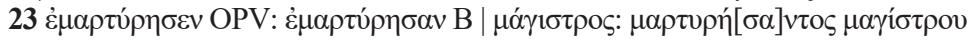

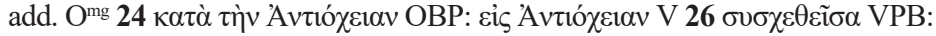

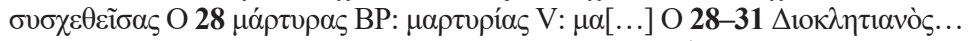

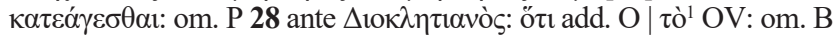




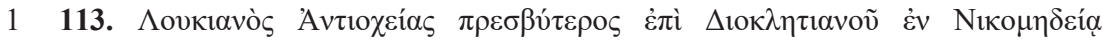

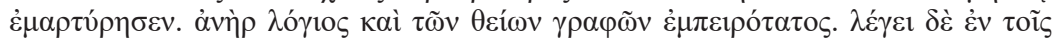

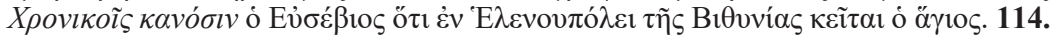

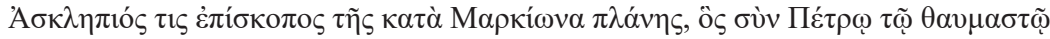

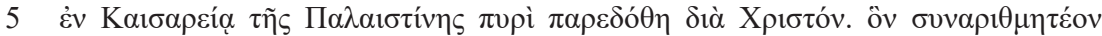

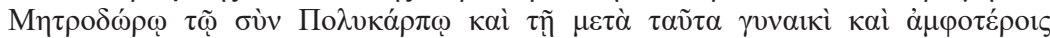

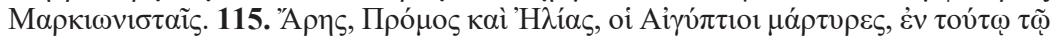

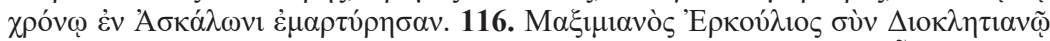

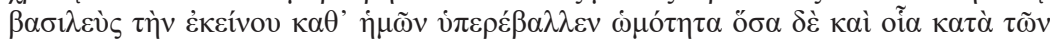

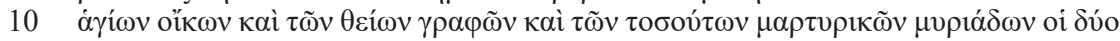

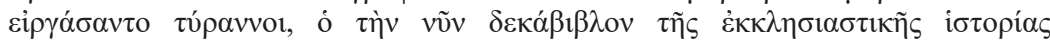
$\dot{\varepsilon} \pi \varepsilon \rho \chi 0 ́ \mu \varepsilon v \circ \varsigma^{i} \sigma \varepsilon \tau \alpha 1$.

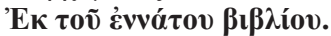

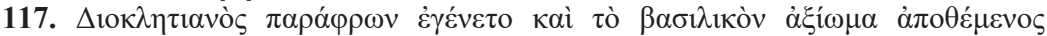

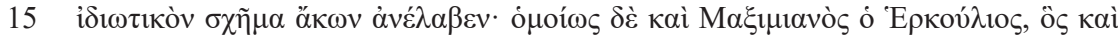

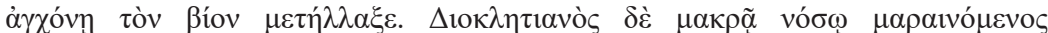

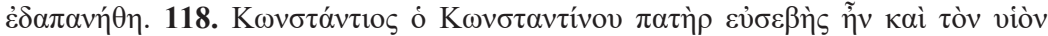

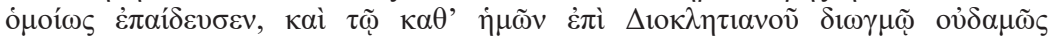

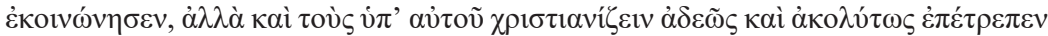

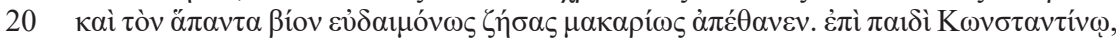

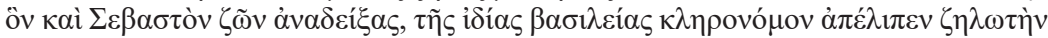

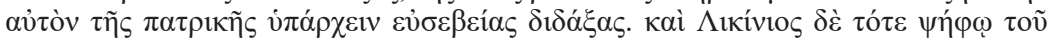

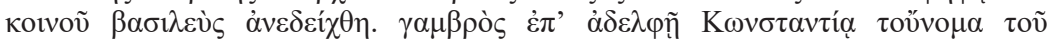

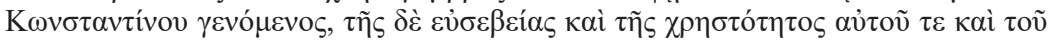

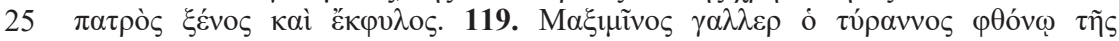

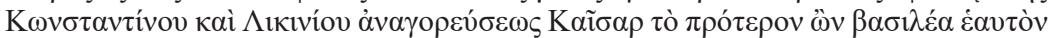
$\grave{\alpha} v \alpha \delta \varepsilon i ́ \kappa v v \sigma l$.

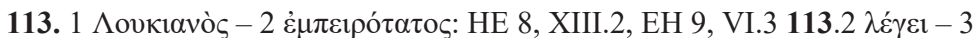

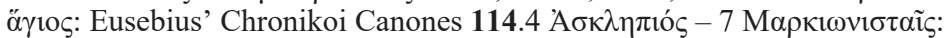
De martyribus Palaestinae (recension brevior), X.3, HE 4, XV.46 115.7

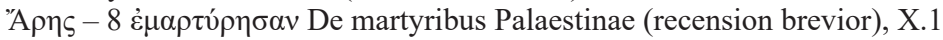

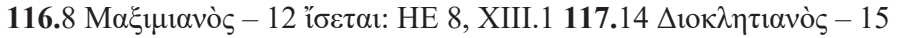

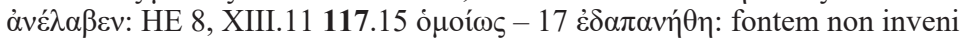

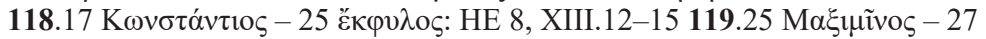

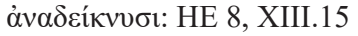

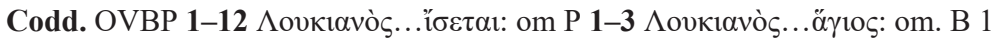

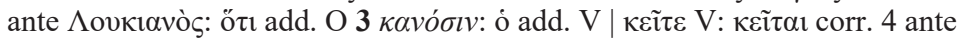

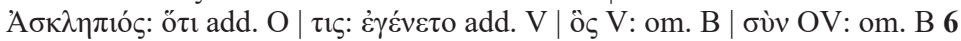

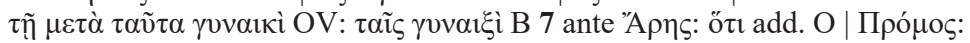

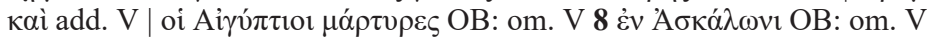

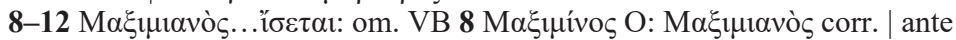

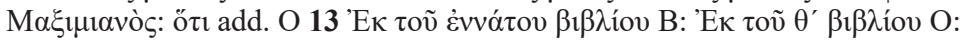

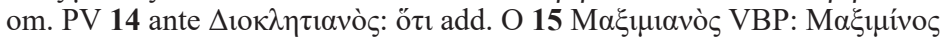

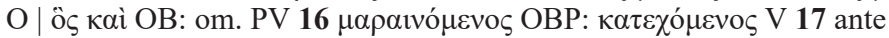

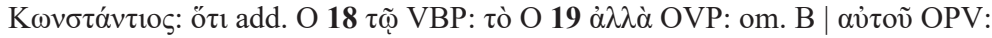

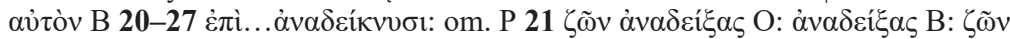

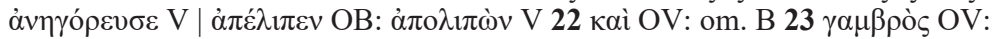
om. B |

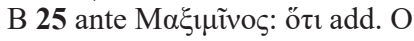




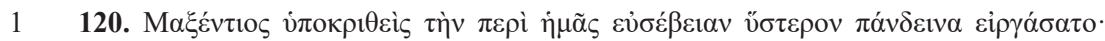

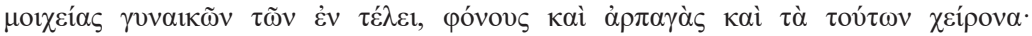

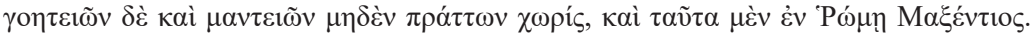

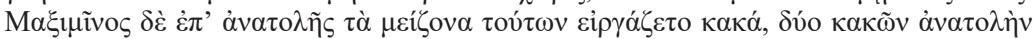

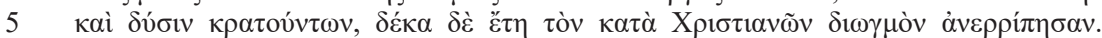

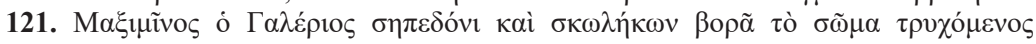

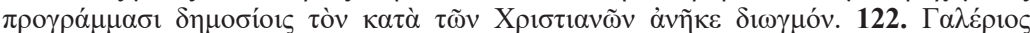

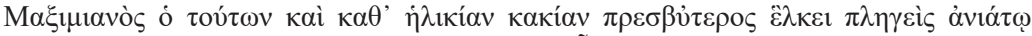

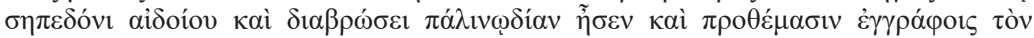

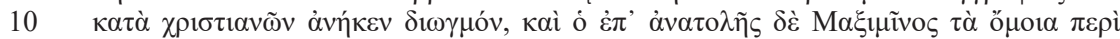

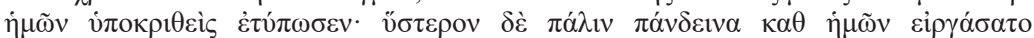

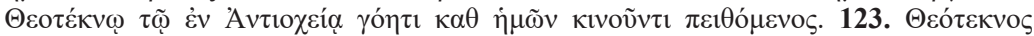

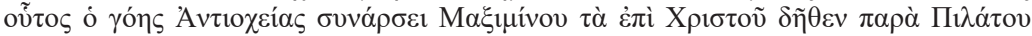

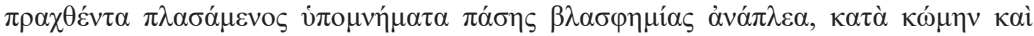

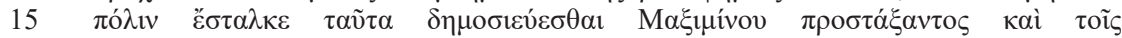

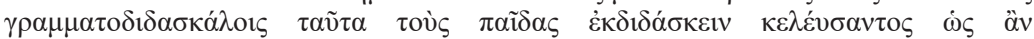

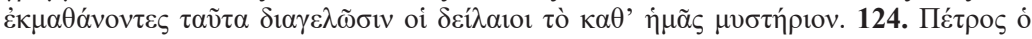

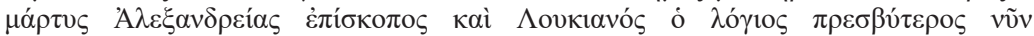

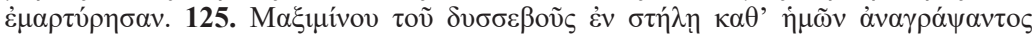

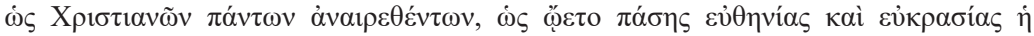

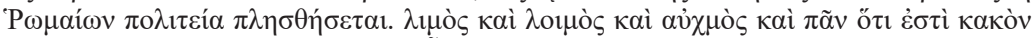

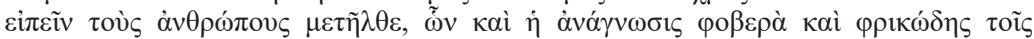

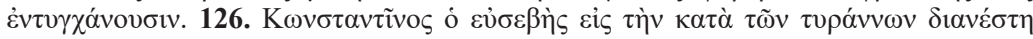

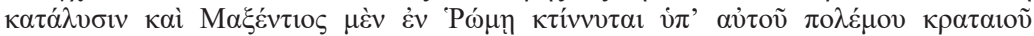

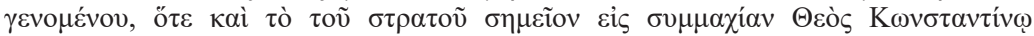

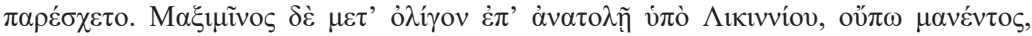

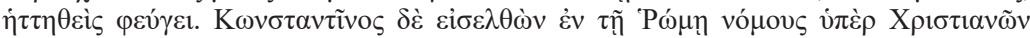

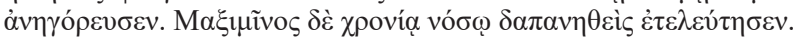

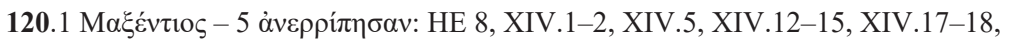

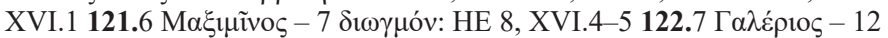

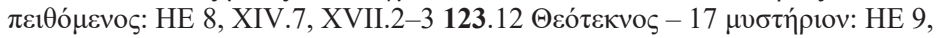

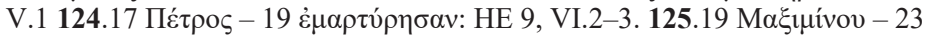

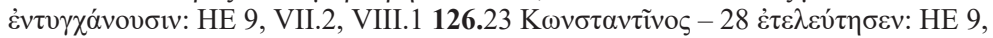
IX.1, IX.3, IX.12

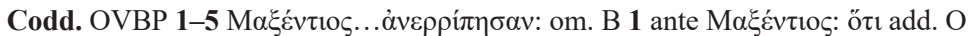

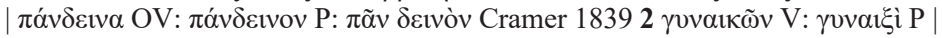

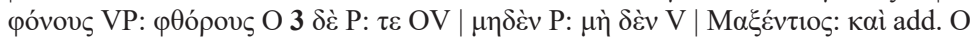

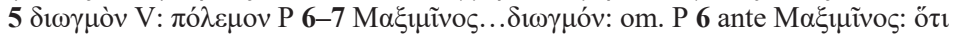

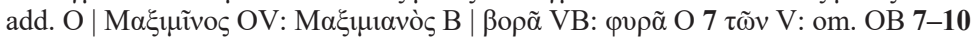

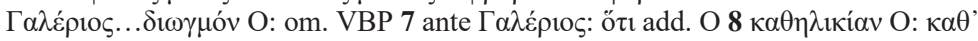

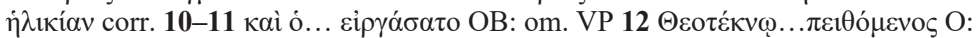

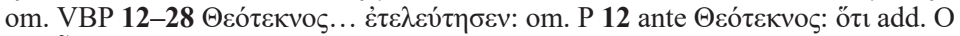

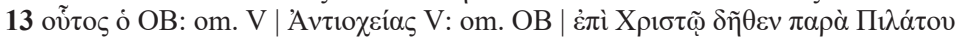

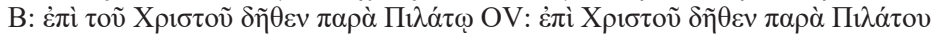

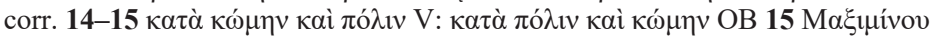

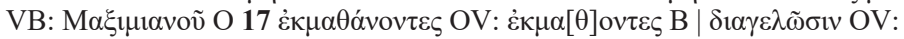

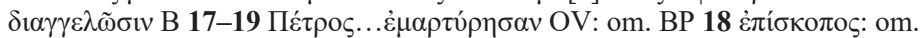

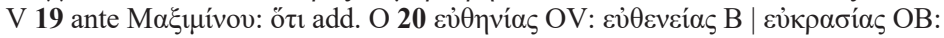

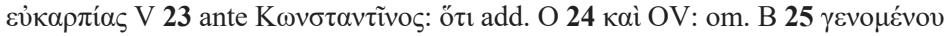

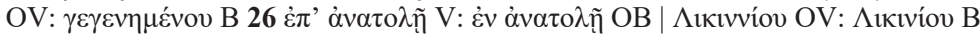

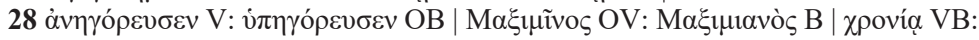

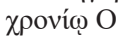




\section{Passages in common between the $E V$ and the Codex Athonensis Iviron 812 11}

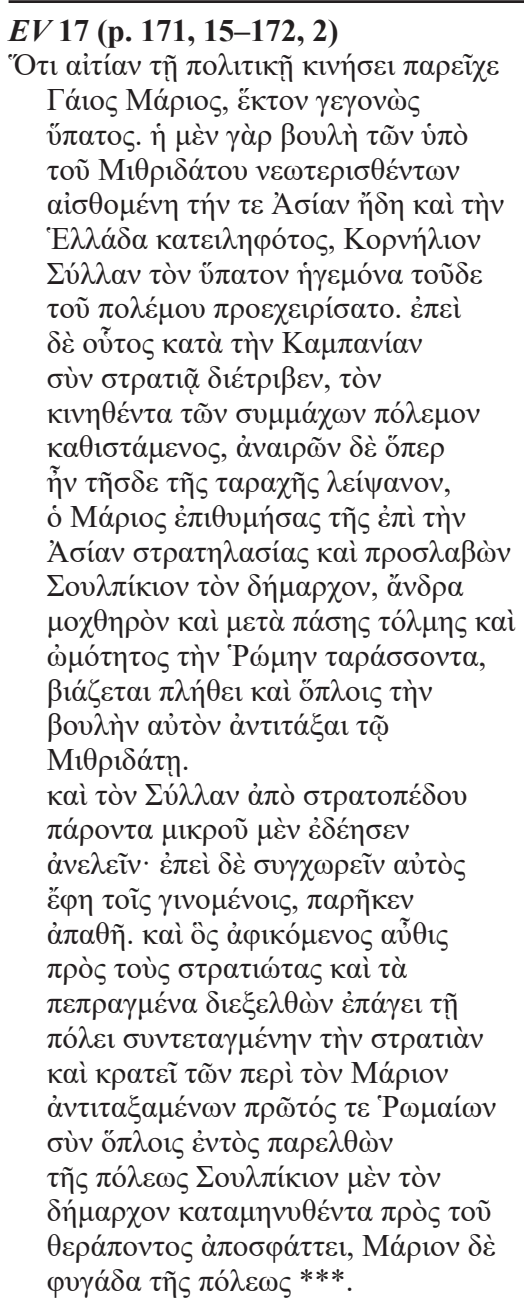

EV 18 (p. 172, 3-173, 9)

"O $\tau \iota \lambda \eta \xi \dot{\alpha} v \tau \omega \nu \tau \tilde{\omega} v \dot{\varepsilon} \mu \varphi v \lambda i ́ \omega v \pi \mathrm{o} \lambda \dot{\varepsilon} \mu \omega v$

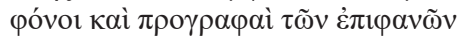

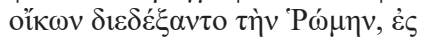

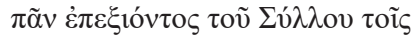

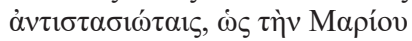

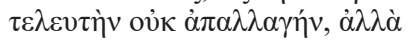

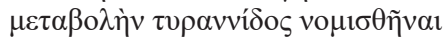

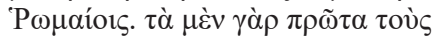

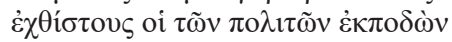

Athonensis Iviron 812 (fr. 98.8 M)

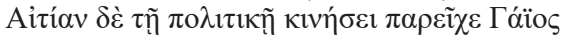

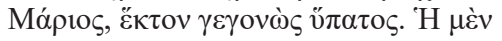

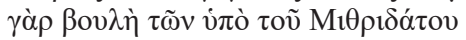

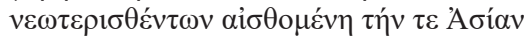

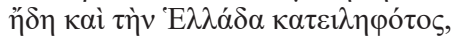

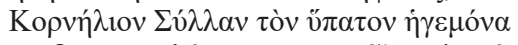

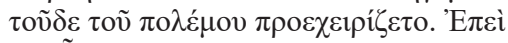

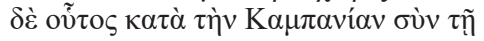

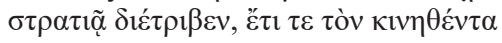
$\mu 1 \kappa \rho \tilde{\varphi} \pi \rho \sigma_{\sigma} \theta \varepsilon v$,

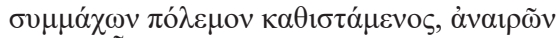
$\tau \varepsilon$ ö $\pi \varepsilon \rho \tilde{\eta} \nu \tau \tilde{\eta} \sigma \delta \varepsilon \tau \tilde{\eta} \varsigma \tau \alpha \rho \alpha \chi \tilde{\eta} \varsigma \lambda \varepsilon \dot{\psi} \psi \alpha v o v$,

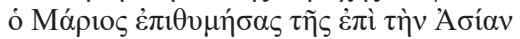

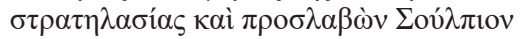

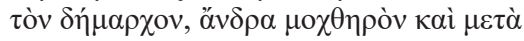

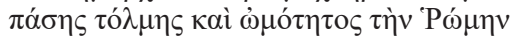

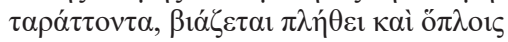

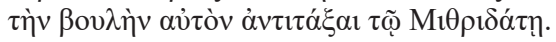

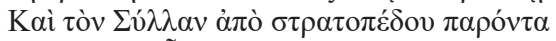

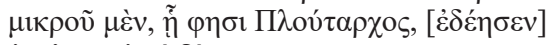

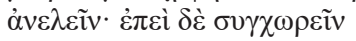

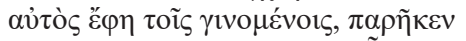

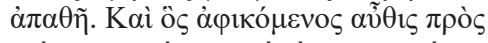

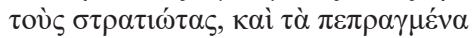

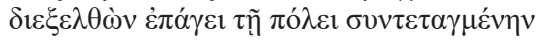

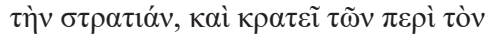

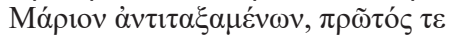

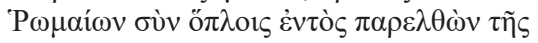

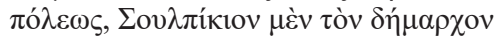

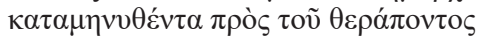

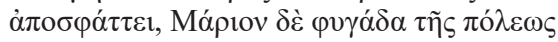

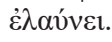

\section{Athonensis Iviron 812 (fr. 98.21 M)}

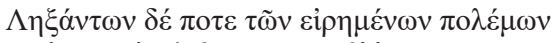

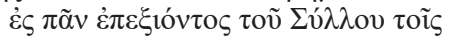

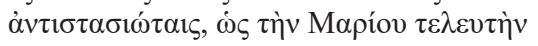

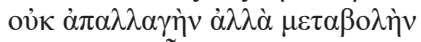

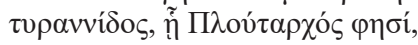

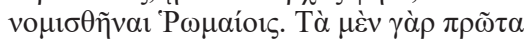

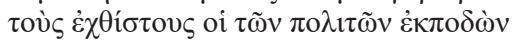

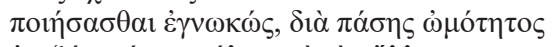

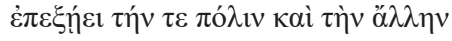

(Continued) 


\section{(Continued)}

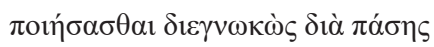

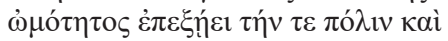
$\tau \eta े v ~ \alpha ̋ \lambda \lambda \eta v ' I \tau \alpha \lambda i ́ \alpha v$. $\tau \varepsilon \lambda \varepsilon v \tau \tilde{\omega} v \delta \dot{\varepsilon}$

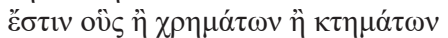

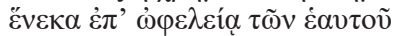

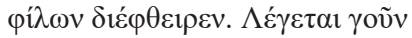

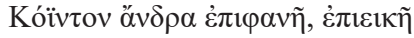

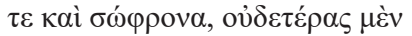

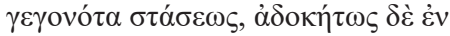

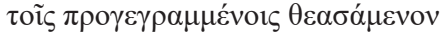

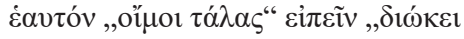

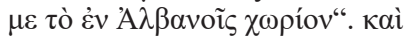

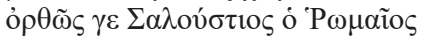

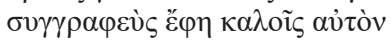

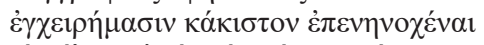

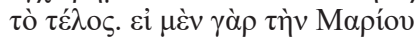

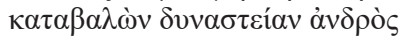

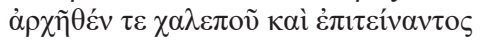

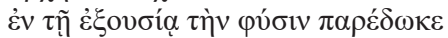

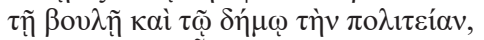

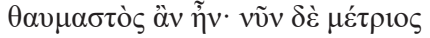

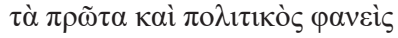

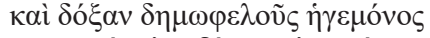

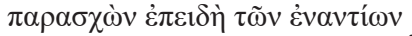

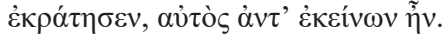

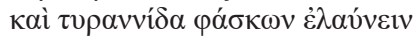

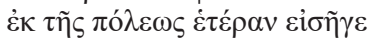

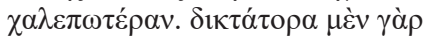

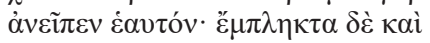

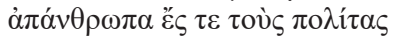

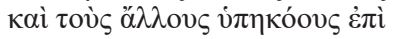

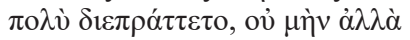

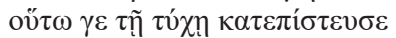

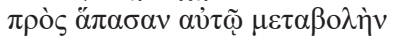

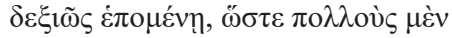

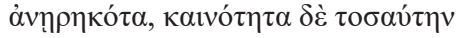

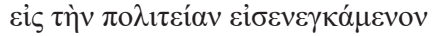

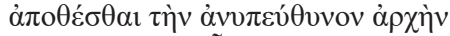

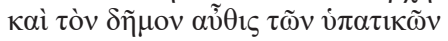

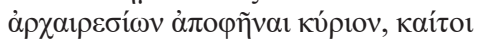

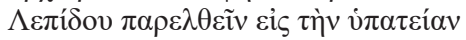

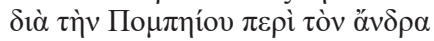

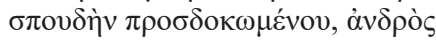

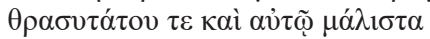

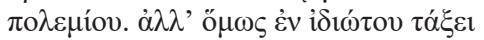

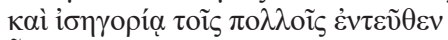

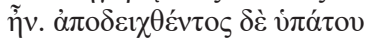

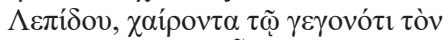

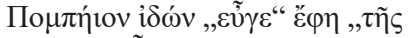

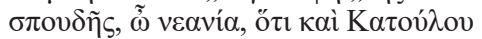

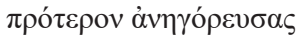

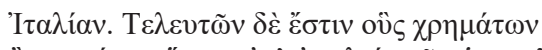

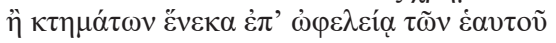

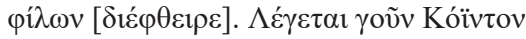

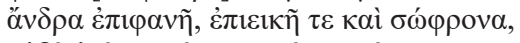

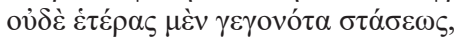

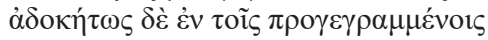

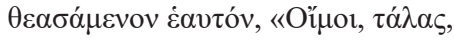

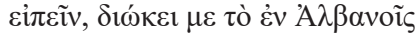

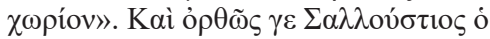

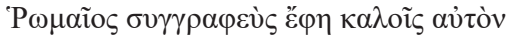

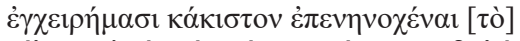

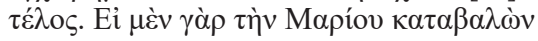

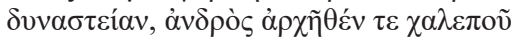

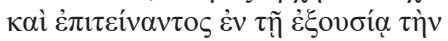

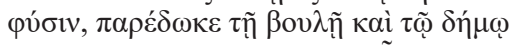

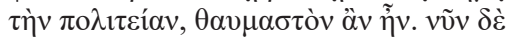

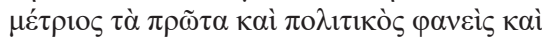

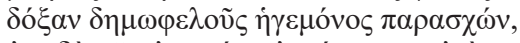

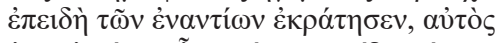

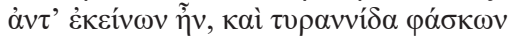

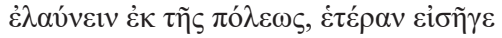

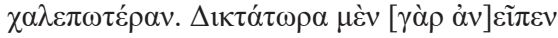

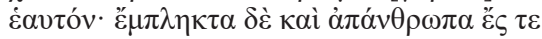

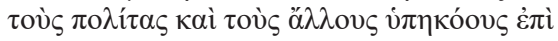

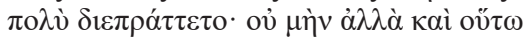

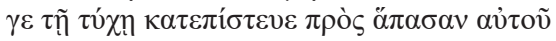

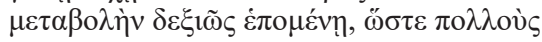

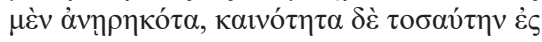

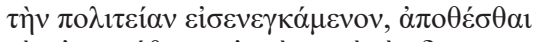

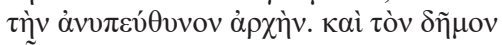

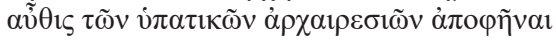

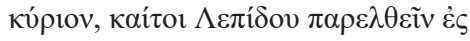

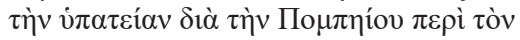

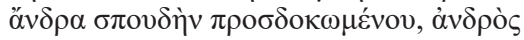

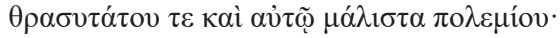

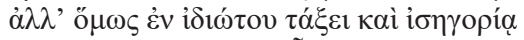

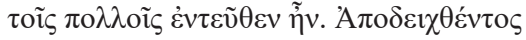

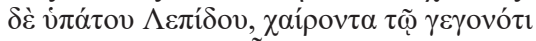

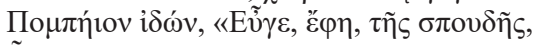

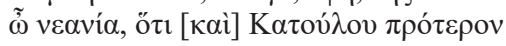

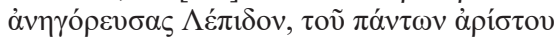

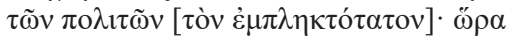

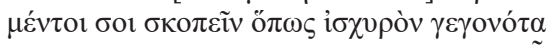

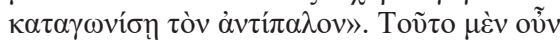

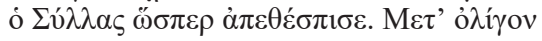

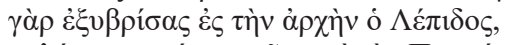

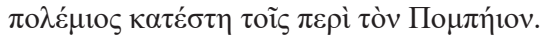




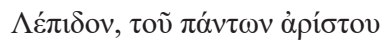

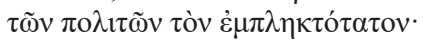

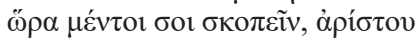

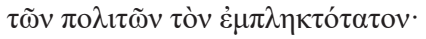

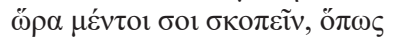

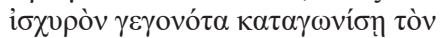

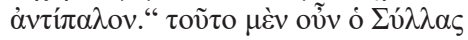

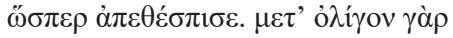

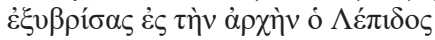

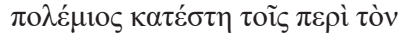
Понли́tov.

EV 18 (p. 173, 10-26)

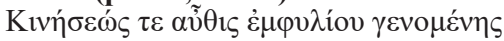

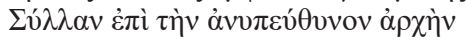

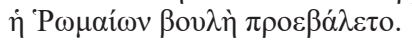

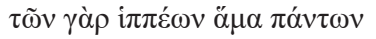

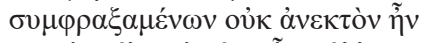

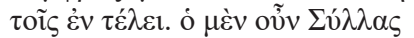

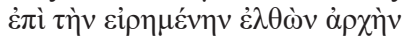

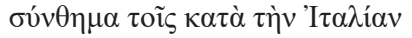

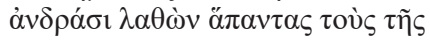

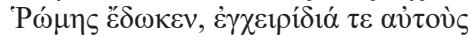

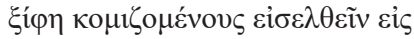

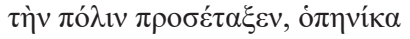

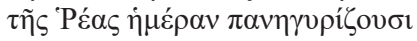

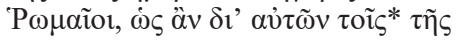

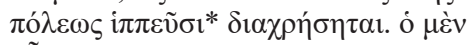

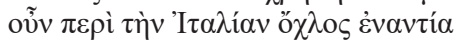

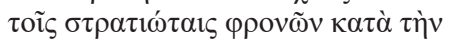

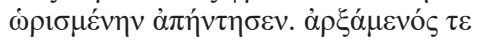

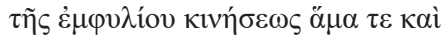

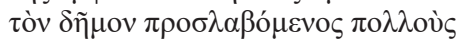

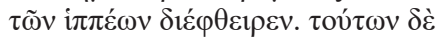

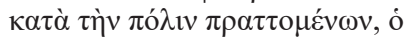

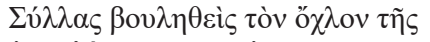

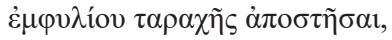

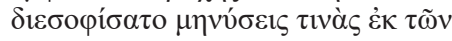

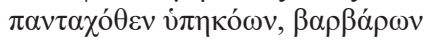

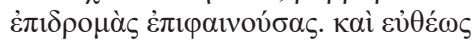

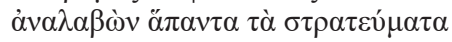

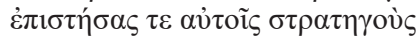

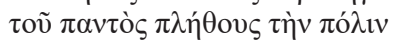
$\dot{\alpha} \pi \hat{\eta} \lambda \lambda \alpha \xi \varepsilon v$.

\section{Athonensis Iviron 812 (fr. 98.22 M)}

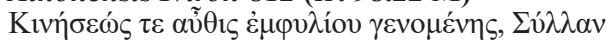

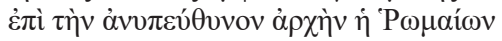

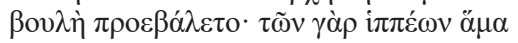

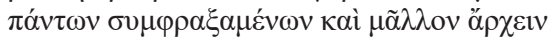

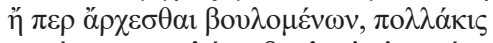

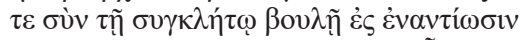

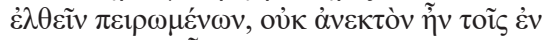

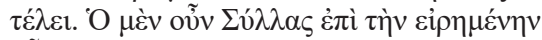

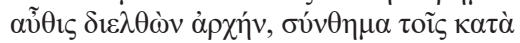

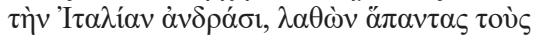

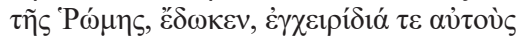

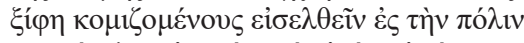

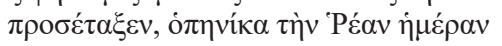

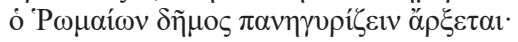

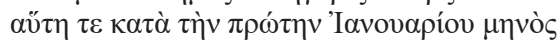

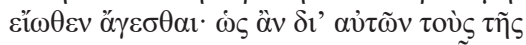

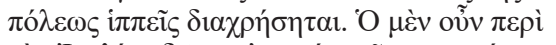

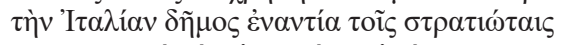

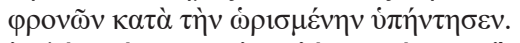

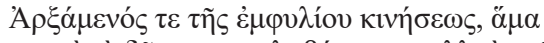

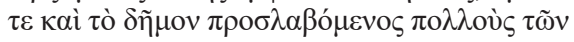

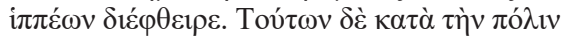

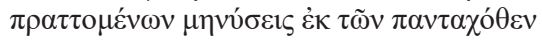

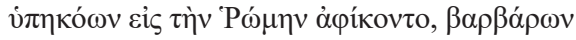

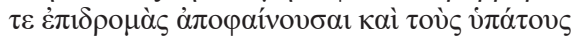

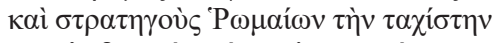

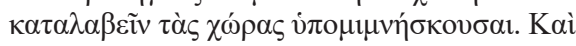

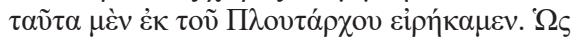

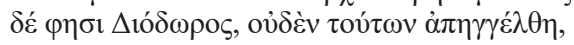

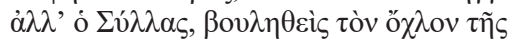
$\dot{\varepsilon} \mu \varphi v \lambda i ́ o v ~ \tau \alpha \rho \alpha \chi \tilde{\eta} \varsigma \alpha \dot{\alpha} \pi 0 \sigma \tau \tilde{\eta} \sigma \alpha 1, \tau \alpha \tilde{v} \tau \alpha$

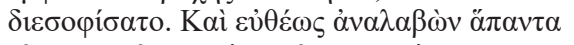

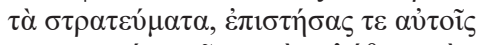

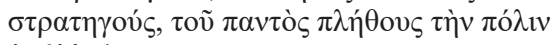
$\dot{\alpha} \pi \dot{\eta} \lambda \lambda \alpha \xi \varepsilon$. 


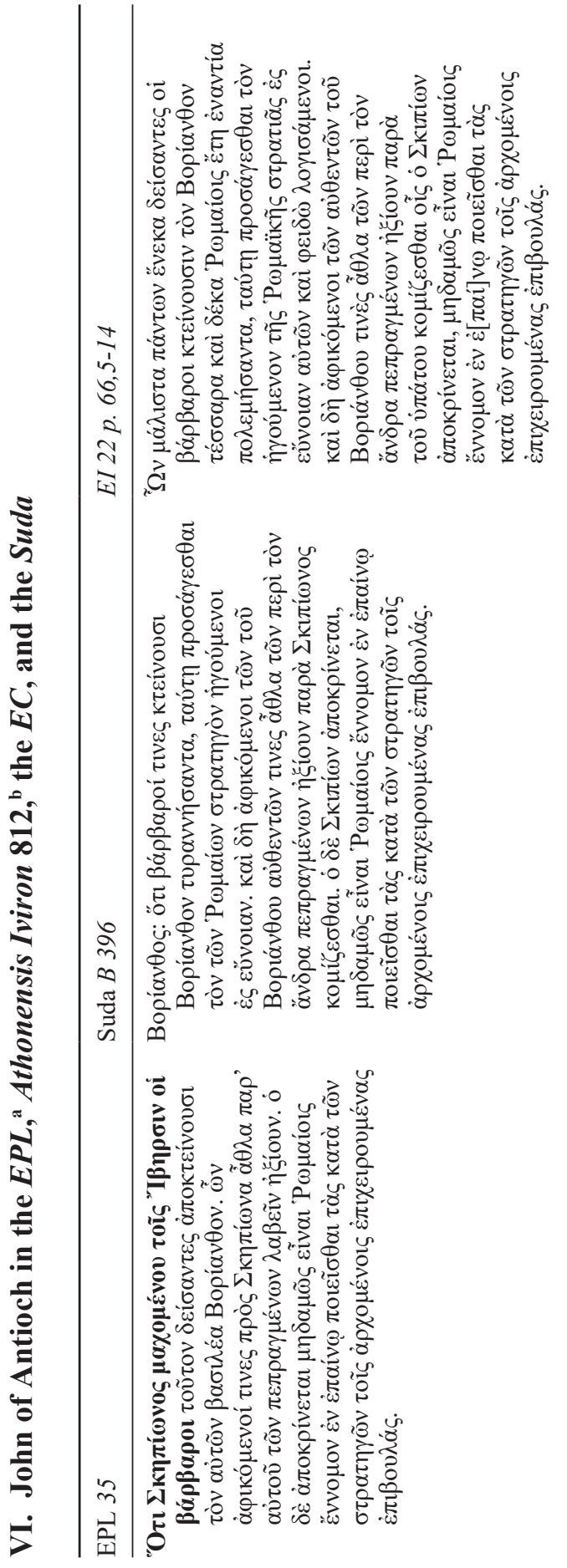




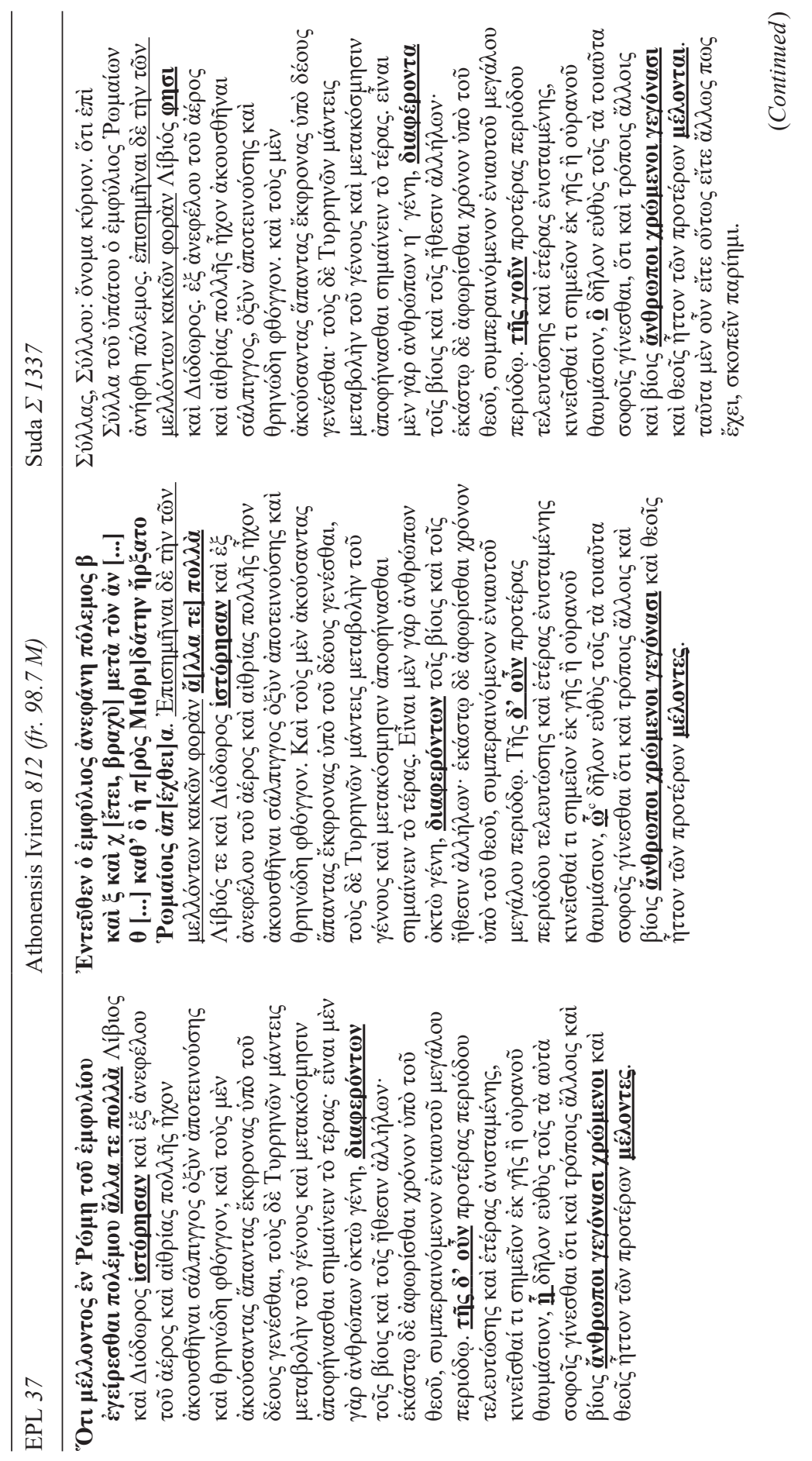




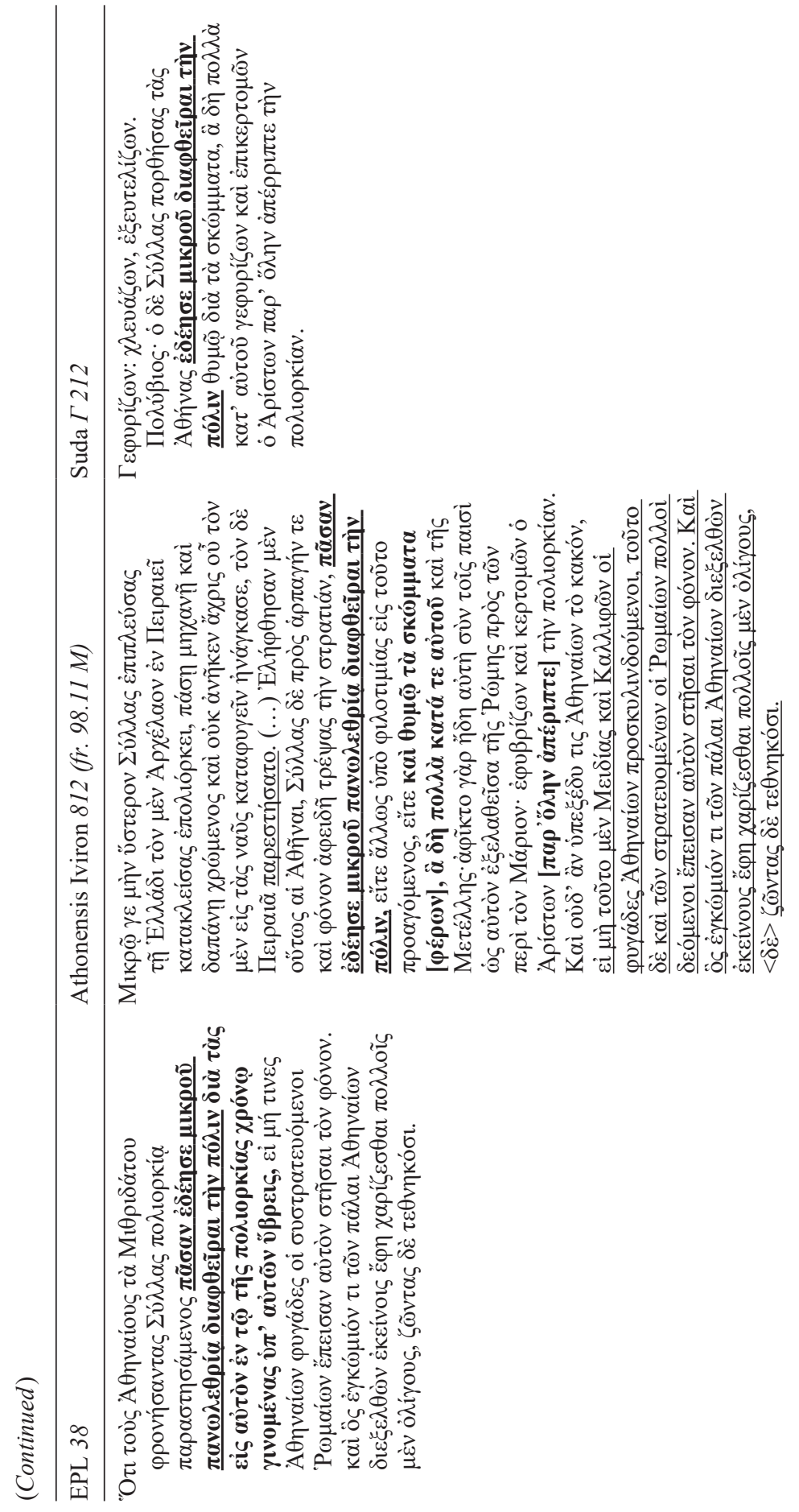




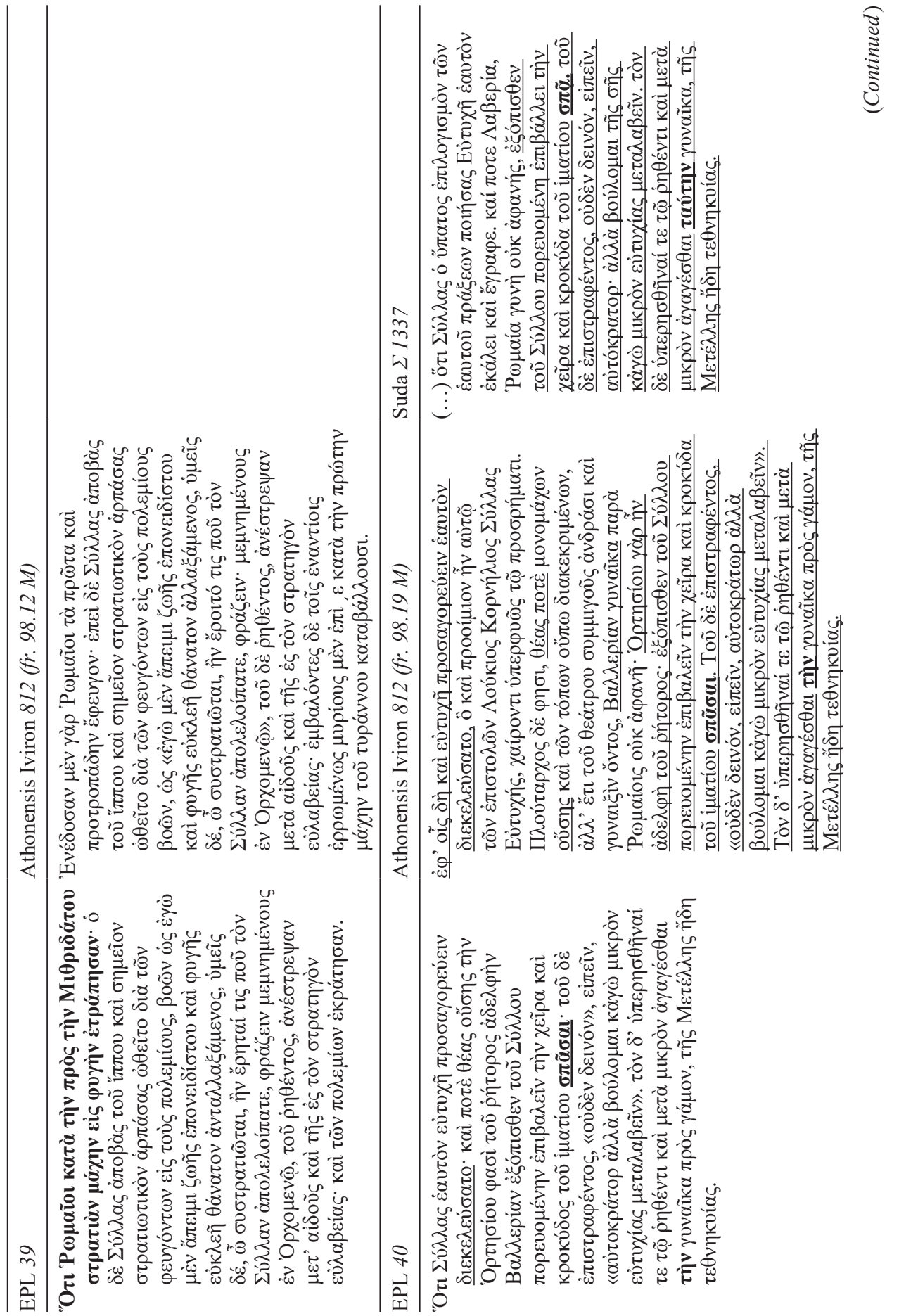




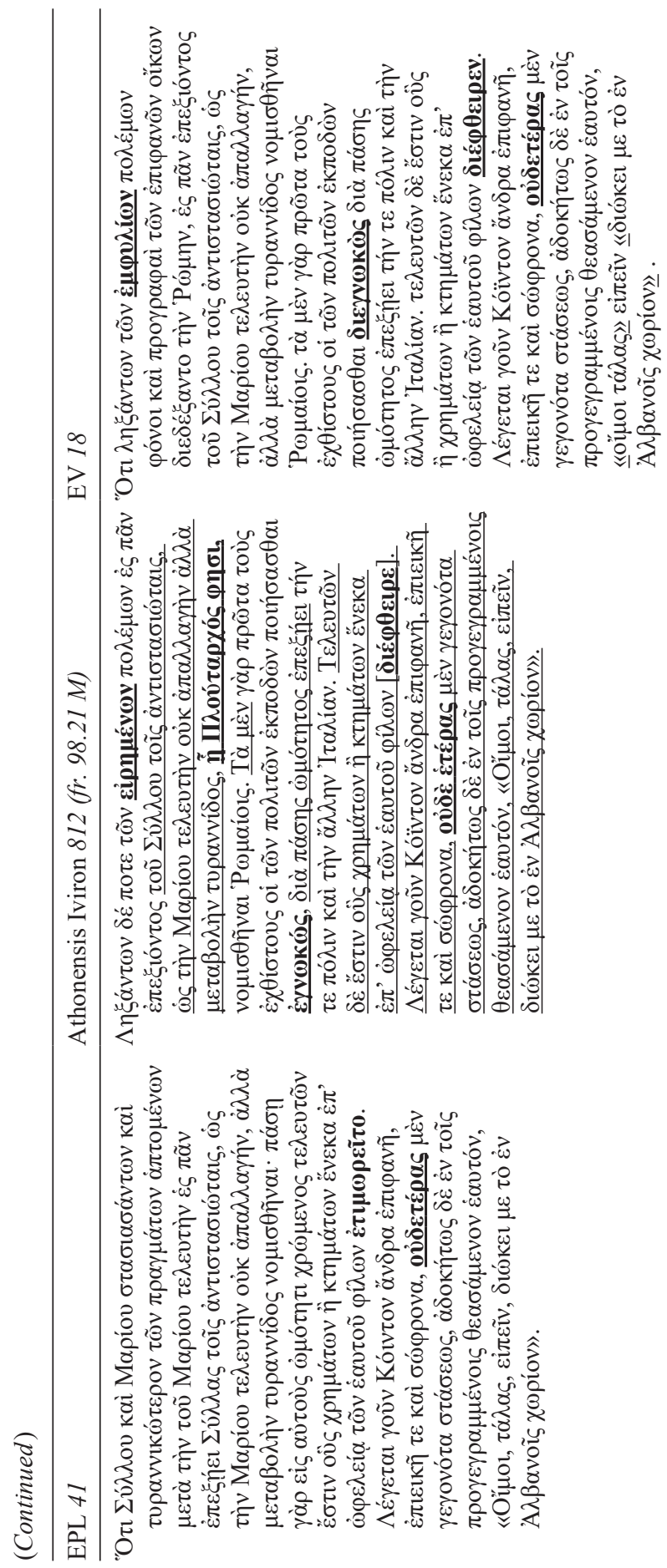




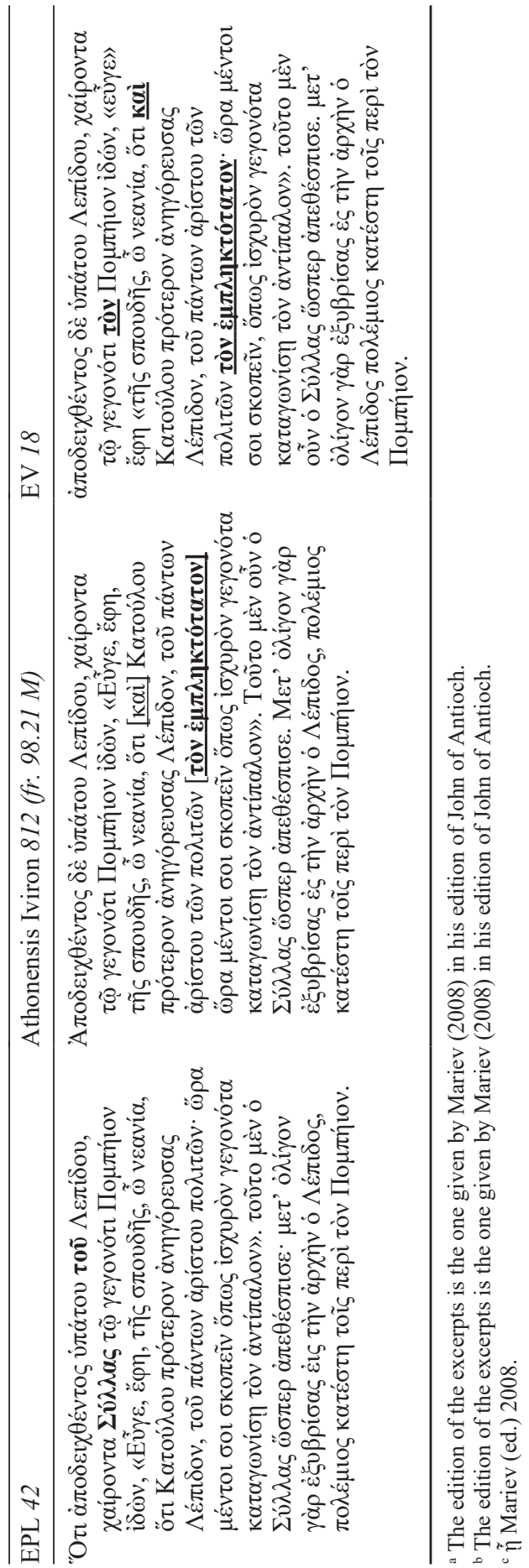




\section{Appendix II: Tables}

\section{The Excerpta Anonymi and the Parastaseis}

\begin{tabular}{|c|c|c|c|}
\hline Excerpta Anonymi & Par. & Excerpta Anonymi & Par. \\
\hline 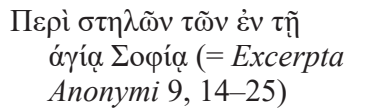 & Ch. 11 & 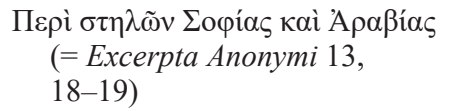 & Ch. 35 \\
\hline 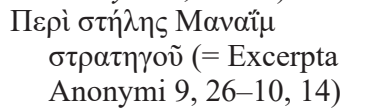 & Ch. 12 & 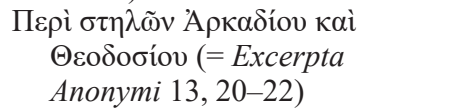 & Ch. 35a \\
\hline 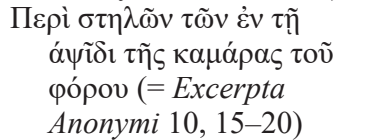 & Ch. 16 & 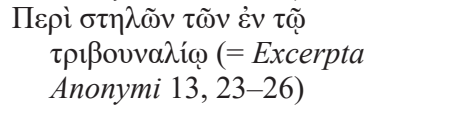 & Ch. 36 \\
\hline 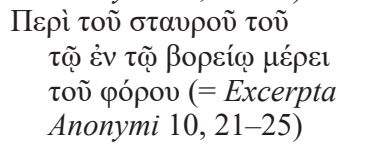 & Ch. 17 & $\begin{array}{c}\Theta \varepsilon \dot{\varepsilon} \alpha \mu \alpha \alpha^{\prime}(=\text { Excerpta Anonymi } \\
13,27-14,13)\end{array}$ & Ch. 37 \\
\hline 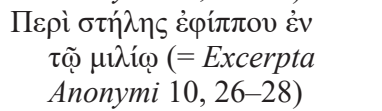 & Ch. 18 & $\begin{array}{c}\Theta \varepsilon \dot{\varepsilon} \alpha \mu \alpha \beta^{\prime}(=\text { Excerpta Anonymi } \\
14,14-24)\end{array}$ & Ch. 38 \\
\hline 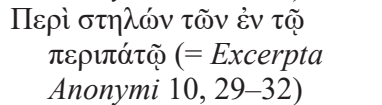 & Ch. 19 & $\begin{array}{l}\text { Пврі̀ Apsíov (= Excerpta Anonymi } \\
\text { 14, 25-31) }\end{array}$ & Ch. 39 \\
\hline 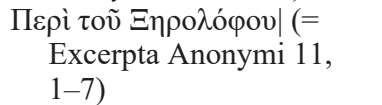 & Ch. 20 & 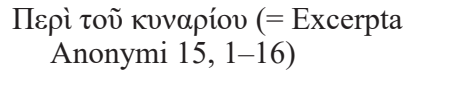 & Ch. 40 \\
\hline 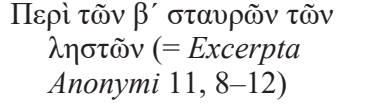 & Ch. 23 & 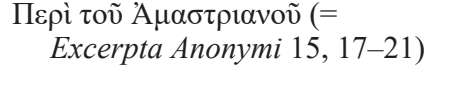 & Ch. 41 \\
\hline 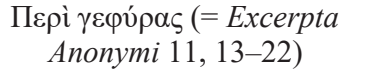 & Ch. 22-24 & 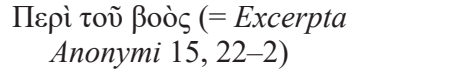 & Ch. 42 \\
\hline 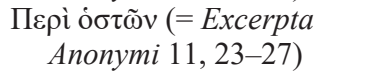 & Ch. 25 & 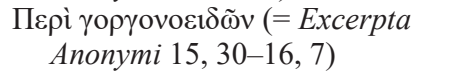 & Ch. $44 \mathrm{a}$ \\
\hline 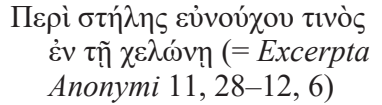 & Ch. 26-27 & 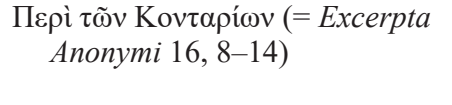 & Ch. 53 \\
\hline
\end{tabular}

(Continued) 


\begin{tabular}{|c|c|c|c|}
\hline Excerpta Anonymi & Par. & Excerpta Anonymi & Par. \\
\hline 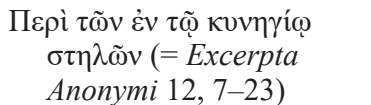 & Ch. 28 & 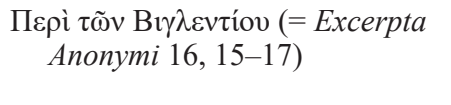 & Ch. $54-55$ \\
\hline 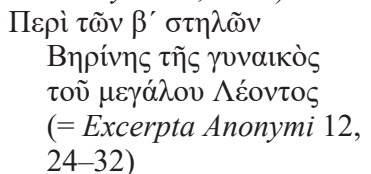 & Ch. 29 & 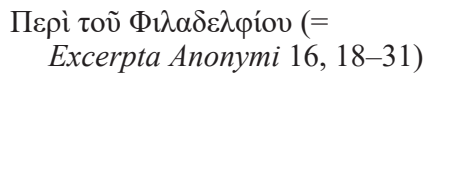 & Ch. $56-57$ \\
\hline 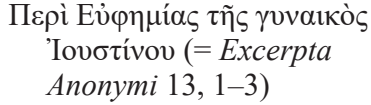 & Ch. 30-31 & 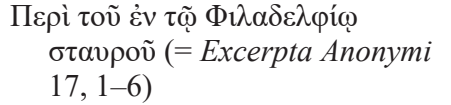 & Ch. 58 \\
\hline 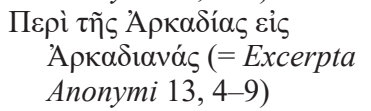 & Ch. 32 & 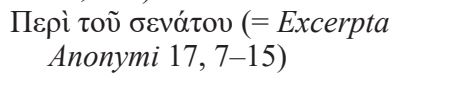 & Ch. 59 \\
\hline 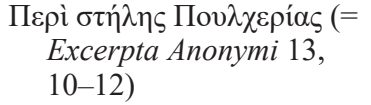 & Ch. 33 & 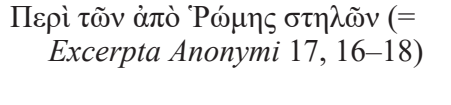 & Ch. 60 \\
\hline 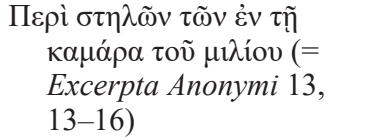 & Ch. 34 & 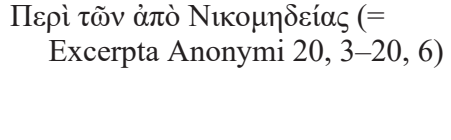 & Ch. 76 \\
\hline 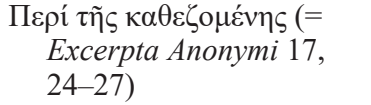 & Ch. 61b & 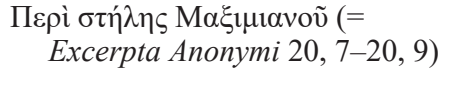 & Ch. 77 \\
\hline 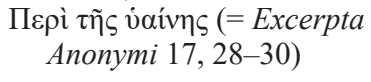 & Ch. 62 & 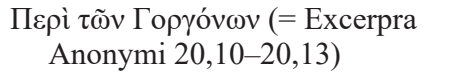 & Ch. 78 \\
\hline 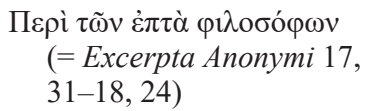 & Ch. 64 & 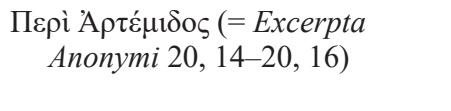 & Ch. 79 \\
\hline 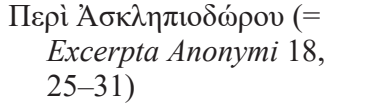 & Ch. 65 & 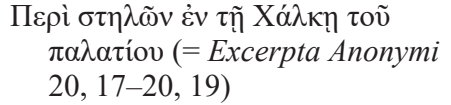 & Ch. 80 \\
\hline 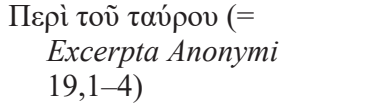 & Ch. 66-69 & 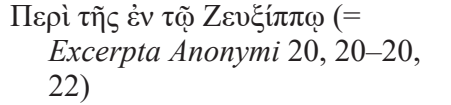 & Ch. $82-83$ \\
\hline 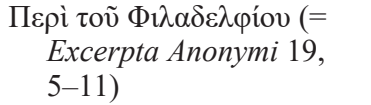 & Ch. 70 & 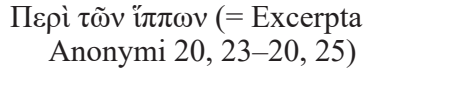 & Ch. 84 \\
\hline 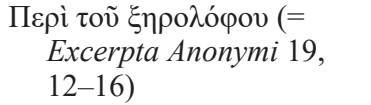 & Ch. 71 & 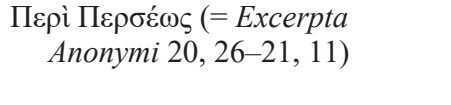 & Ch. 85 \\
\hline 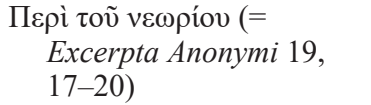 & Ch. 72 & 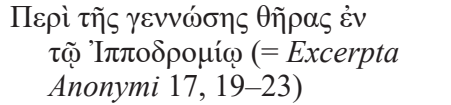 & Ch. 61a \\
\hline 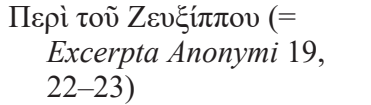 & Ch. 73 & $\begin{array}{l}\text { Пврі̀ Aetíov (= Excerpta Anonymi } \\
\text { 21, 12-21, 15) }\end{array}$ & Ch. 87 \\
\hline
\end{tabular}


(Continued)

\begin{tabular}{|c|c|c|c|}
\hline Excerpta Anonymi & Par. & Excerpta Anonymi & Par. \\
\hline 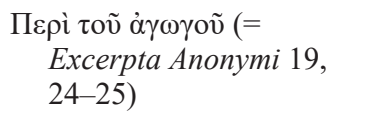 & & 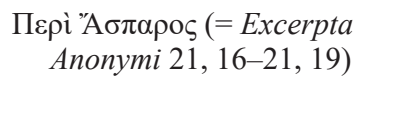 & Ch. 88 \\
\hline 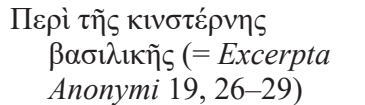 & Ch. 74 & 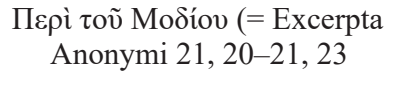 & Ch. 12 \\
\hline 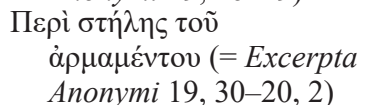 & Ch. 75 & & \\
\hline
\end{tabular}

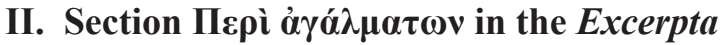 Anonymi, the Patria II, the Codex Vaticanus gr. 468 (V), and John Lydus' De Mensibus}

\begin{tabular}{|c|c|c|c|}
\hline Excerpta Anonymi & Patria II & $\begin{array}{l}\text { Vaticanus gr. } \\
468(V)\end{array}$ & $\begin{array}{l}\text { John Lydus' De } \\
\text { Mensibus }\end{array}$ \\
\hline 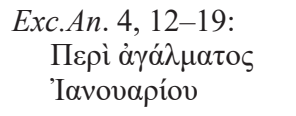 & 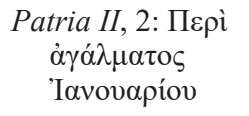 & 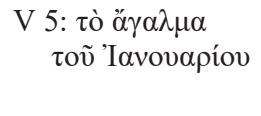 & De Mensibus 4.1.16-22 \\
\hline 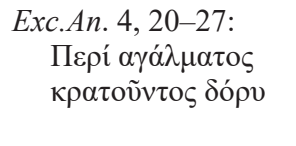 & 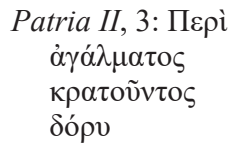 & 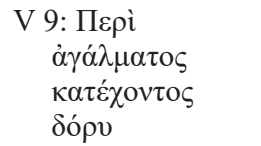 & \\
\hline 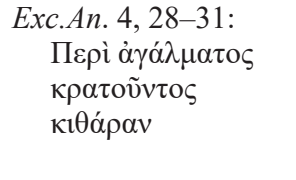 & 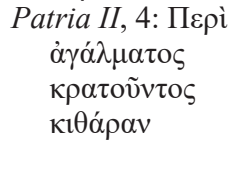 & 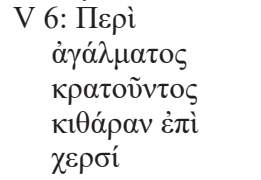 & De Mensibus 4.51.25-26 \\
\hline 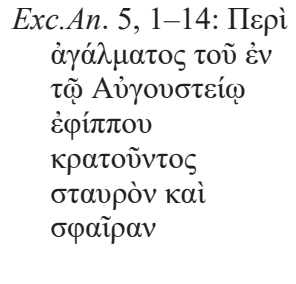 & 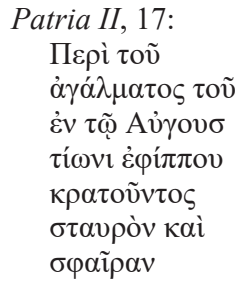 & & \\
\hline 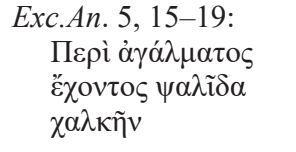 & 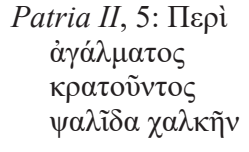 & 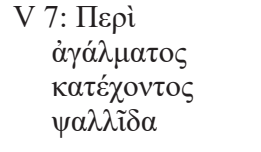 & \\
\hline 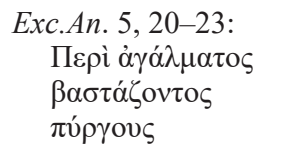 & 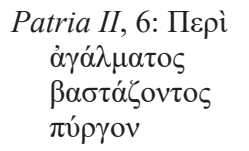 & 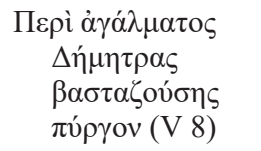 & De Mensibus 4.63.2-3 \\
\hline
\end{tabular}




\begin{tabular}{|c|c|c|c|}
\hline Excerpta Anonymi & Patria II & $\begin{array}{l}\text { Vaticanus gr. } \\
468(V)\end{array}$ & $\begin{array}{l}\text { John Lydus' De } \\
\text { Mensibus }\end{array}$ \\
\hline 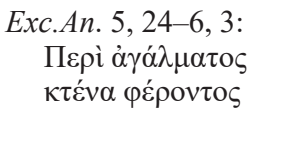 & 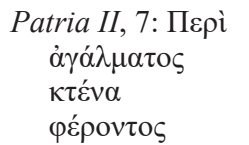 & & $\begin{array}{l}\text { De Mensibus 2.11.14-16 } \\
\text { and 4.64.57-59 }\end{array}$ \\
\hline 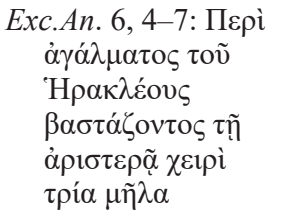 & 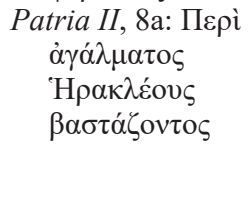 & & \\
\hline 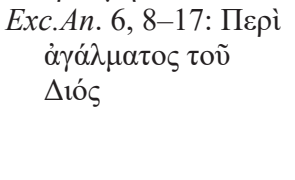 & 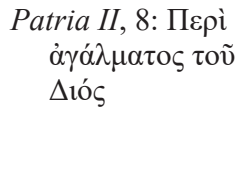 & 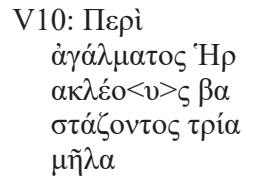 & De Mensibus 4.67.11-12 \\
\hline 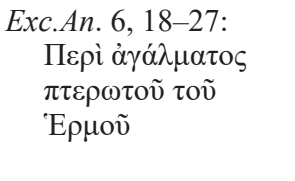 & 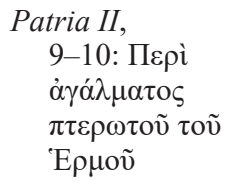 & 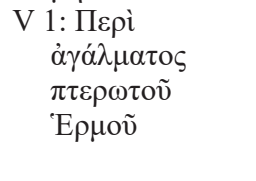 & De Mensibus 4.76.59-73 \\
\hline 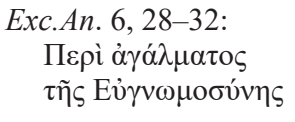 & 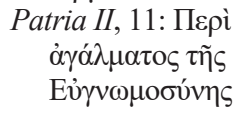 & 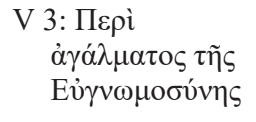 & \\
\hline 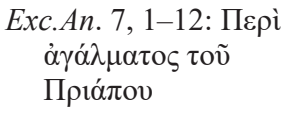 & 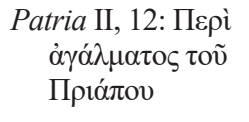 & & \\
\hline 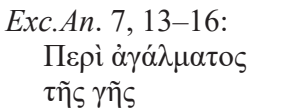 & 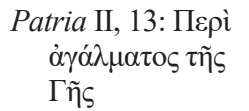 & V 4: $\alpha ̋ \gamma \alpha \lambda \mu \alpha \Gamma \tilde{\eta} \varsigma$ & \\
\hline 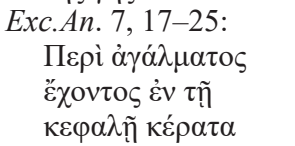 & 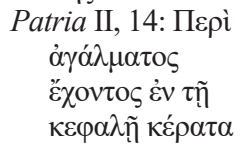 & & \\
\hline 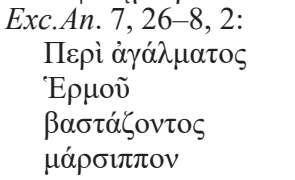 & 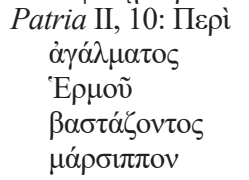 & 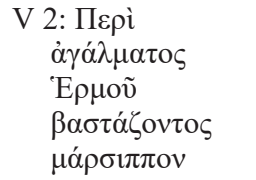 & \\
\hline
\end{tabular}




\section{The transmission of Malalas' Chronographia through the Exc.Salm.II, the Suda, and the Codex Parisinus gr. 1630 (B)}

\begin{tabular}{|c|c|c|c|}
\hline Malalas, Chronographia & Exc.Salm.II & Suda & $B(f f .235 r-239 r)$ \\
\hline Chronographia I 7-8 & Exc.Salm.II. 1-3 & & $235 \mathrm{r}, 15-235 \mathrm{v}, 10$ \\
\hline Chronographia I 11 & Exc.Salm.II. 4 & Suda Z 160 & \\
\hline Chronographia I 12 & Exc.Salm.II. 5 & Suda $\Theta 417$ & $235 \mathrm{v}, 10-14$ \\
\hline Chronographia I 13 & Exc.Salm.II. 6 & $\begin{array}{l}\text { Suda } П 1500, \\
\quad 14-17\end{array}$ & $235 \mathrm{v}, 20-25$ \\
\hline Chronographia I 14 & Exc.Salm.II. 7 & & $23 \mathrm{v}, 25-32$ \\
\hline Chronographia I 15 & Exc.Salm.II. 8 & Suda H 661 & $236 r, 13-18$ \\
\hline Chronographia II 1 & Exc.Salm.II. 9 & & 236r, 18-28 \\
\hline Chronographia II 3 & Exc.Salm.II. 10 & Suda $\Sigma 867$ & $236 \mathrm{r}, 32-236 \mathrm{v}, 2$ \\
\hline Chronographia II 4 & Exc.Salm.II. 11 & Suda E 3038 & $236 v, 2-18$ \\
\hline Chronographia II 6 & Exc.Salm.II. 12 & Suda I 453 & $236 \mathrm{v}, 18-27$ \\
\hline Chronographia II 11 & Exc.Salm.II. 13 & Suda M 406 & $237 \mathrm{r}, 9-21$ \\
\hline Chronographia II 15 & Exc.Salm.II. 14 & & \\
\hline \multirow[t]{2}{*}{ Chronographia II 18} & Exc.Salm.II. 15 & $\begin{array}{c}\text { Suda } \Sigma 253,5-8 \\
\quad \Sigma 254,30-34\end{array}$ & $237 \mathrm{v}, 14-25$ \\
\hline & Exc.Salm.II. 16 & Suda I 422 & $237 \mathrm{v}, 28-29$ \\
\hline \multirow[t]{2}{*}{ Chronographia III 9} & Exc.Salm.II. 17 & & $238 \mathrm{r}, 5-17$ \\
\hline & Exc.Salm.II. 18 & Suda X 79 & $238 \mathrm{r}, 20-21$ \\
\hline Chronographia III 12 & Exc.Salm.II. 19 & Suda K 2078 & $238 \mathrm{r}, 25-30$ \\
\hline Chronographia IV 3 & Exc.Salm.II. 20 & Suda П 2506, 2-8 & $238 \mathrm{v}, 1-3$ \\
\hline Chronographia IV 5 & Exc.Salm.II. 21 & $\begin{array}{l}\text { Suda П } 2506, \\
\quad 8-21\end{array}$ & $238 v, 4-8$ \\
\hline \multirow[t]{2}{*}{ Chronographia IV 9} & Exc.Salm.II. 22 & & $238 v, 27-239 r, 8$ \\
\hline & Exc.Salm.II. 23 & Suda $\Delta 250$ & 238r, 8-239r, 11 \\
\hline Chronographia IV 18 & Exc.Salm.II. 24 & Suda Aı 23 & \\
\hline Chronographia $\mathrm{V} 2$ & Exc.Salm.II. 25 & & \\
\hline Chronographia V 9 & $\begin{array}{l}\text { Exc.Salm.II. } 26 \\
\text { Exc.Salm.II. } 27\end{array}$ & Suda T 7 & \\
\hline Chronographia V 24 & Exc.Salm.II. 28 & & \\
\hline \multirow[t]{2}{*}{ Chronographia $\mathrm{V} 8$} & Exc.Salm.II. 29 & & \\
\hline & Exc.Salm.II. 30 & Suda P 146 & \\
\hline Chronographia V 14 & Exc.Salm.II. 31 & & \\
\hline Chronographia V 12 & Exc.Salm.II. 32 & Suda П 34 & \\
\hline Chronographia V 17-18 & Exc.Salm.II. 33 & & \\
\hline Chronographia V 19-20 & Exc.Salm.II. 34 & & \\
\hline Chronographia VII 4 & Exc.Salm.II. 35 & & \\
\hline \multirow[t]{2}{*}{ Chronographia $\mathrm{V} 43$} & Exc.Salm.II. 36 & & \\
\hline & Exc.Salm.II. 37 & & \\
\hline \multirow[t]{6}{*}{ Chronographia VII 5} & Exc.Salm.II. 38 & & \\
\hline & Exc.Salm.II. 39 & & \\
\hline & Exc.Salm.II. 40 & Suda A 4126 & \\
\hline & Exc.Salm.II. 41 & & \\
\hline & Exc.Salm.II. 42 & & \\
\hline & Exc.Salm.II. 43 & & \\
\hline
\end{tabular}




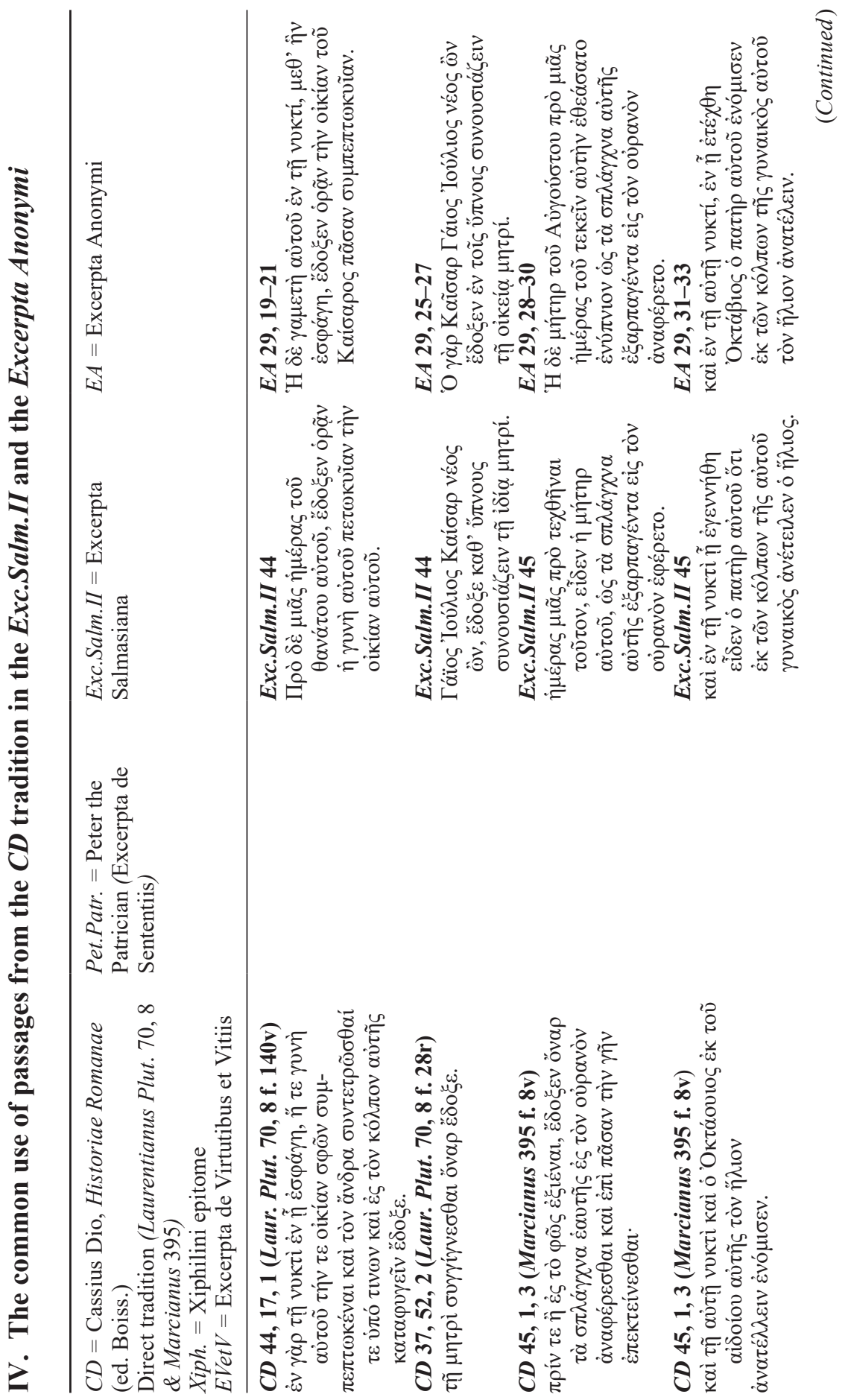



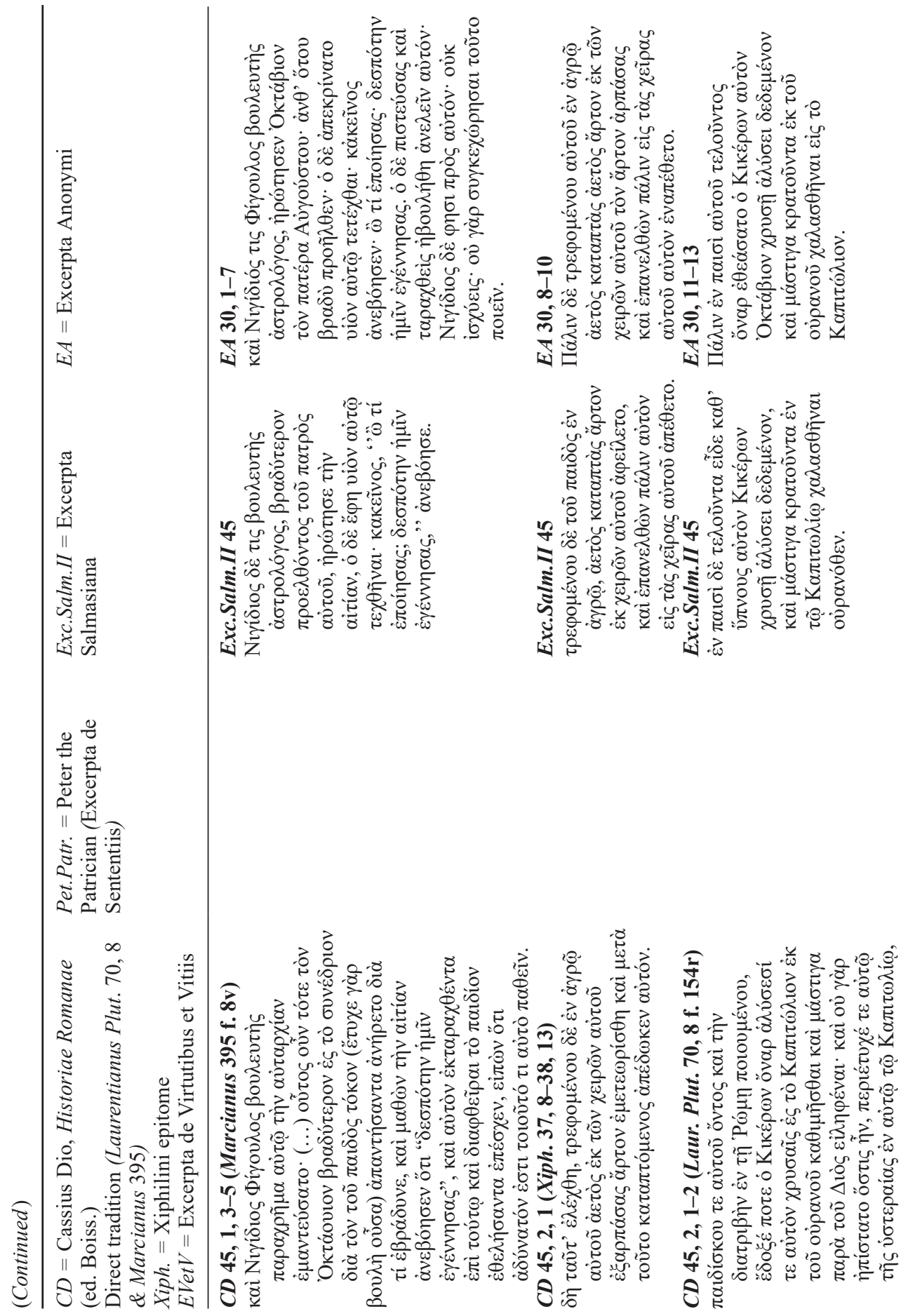


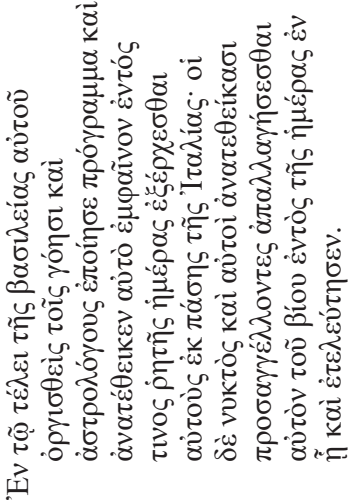

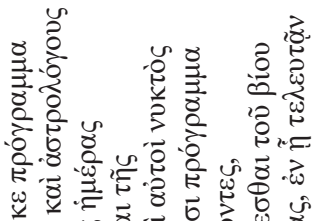
4.

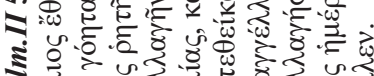

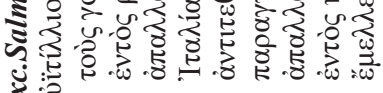
这

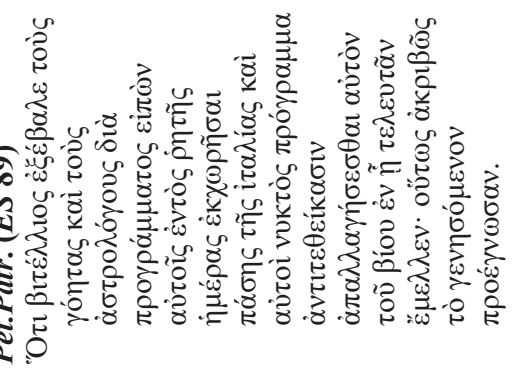

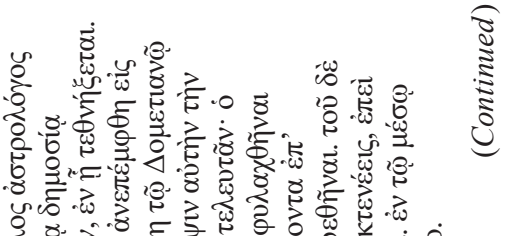

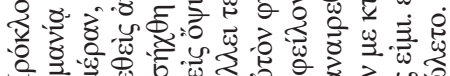

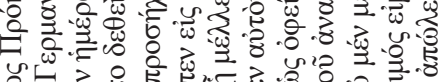

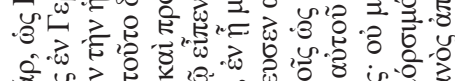

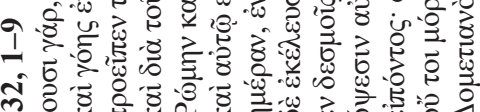

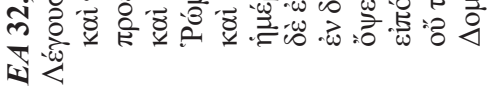

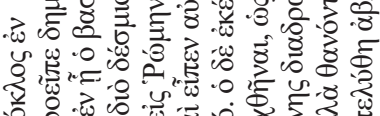

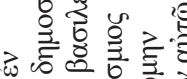

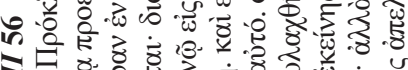

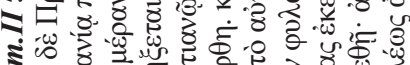

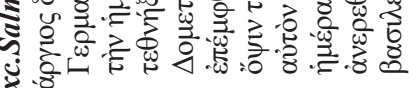

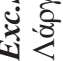

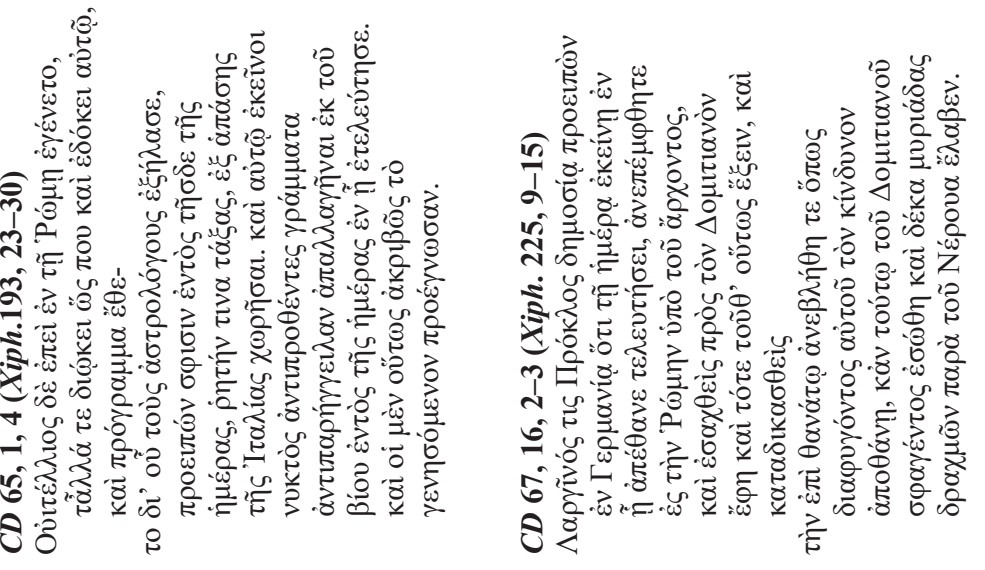




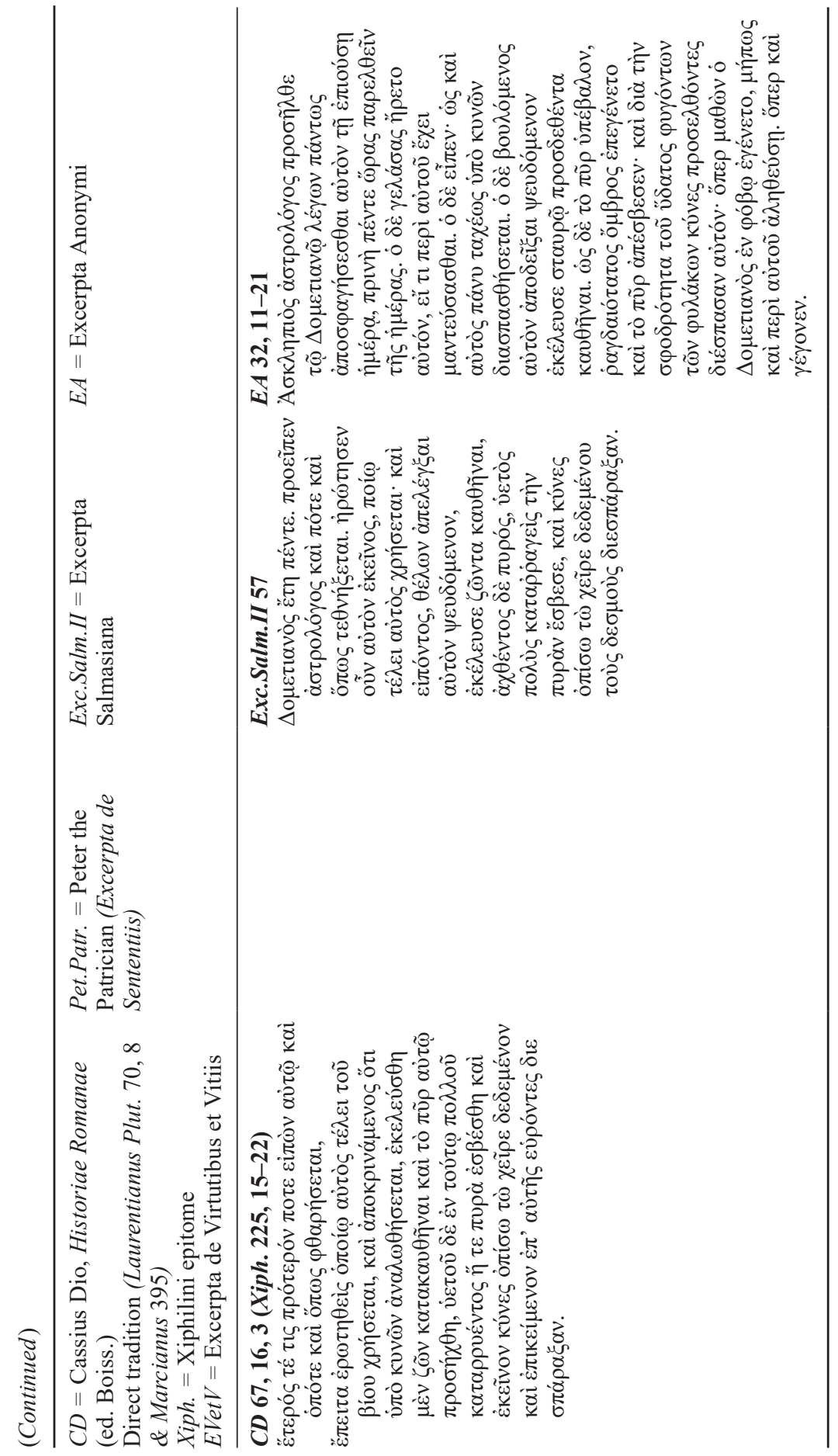




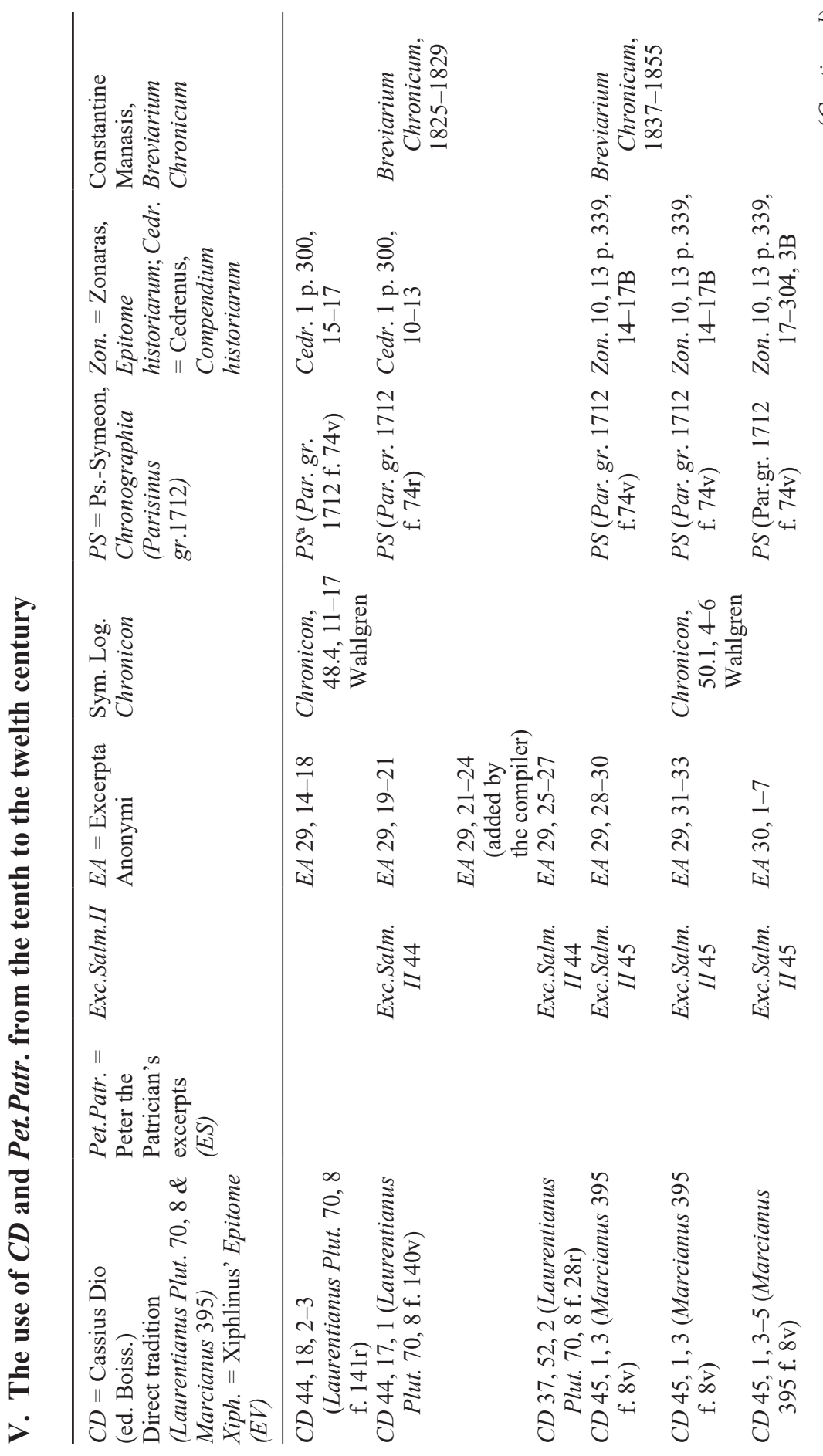




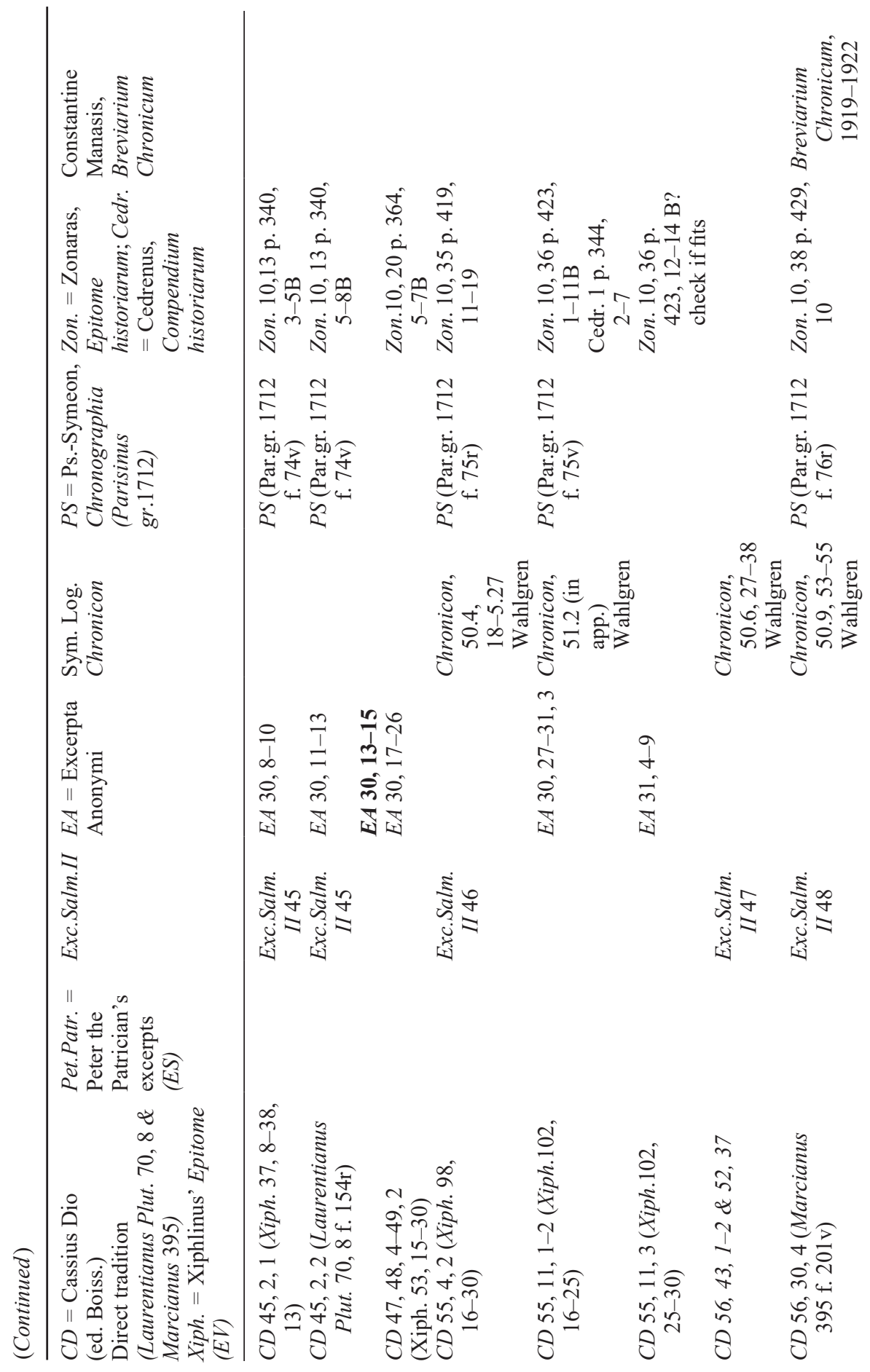




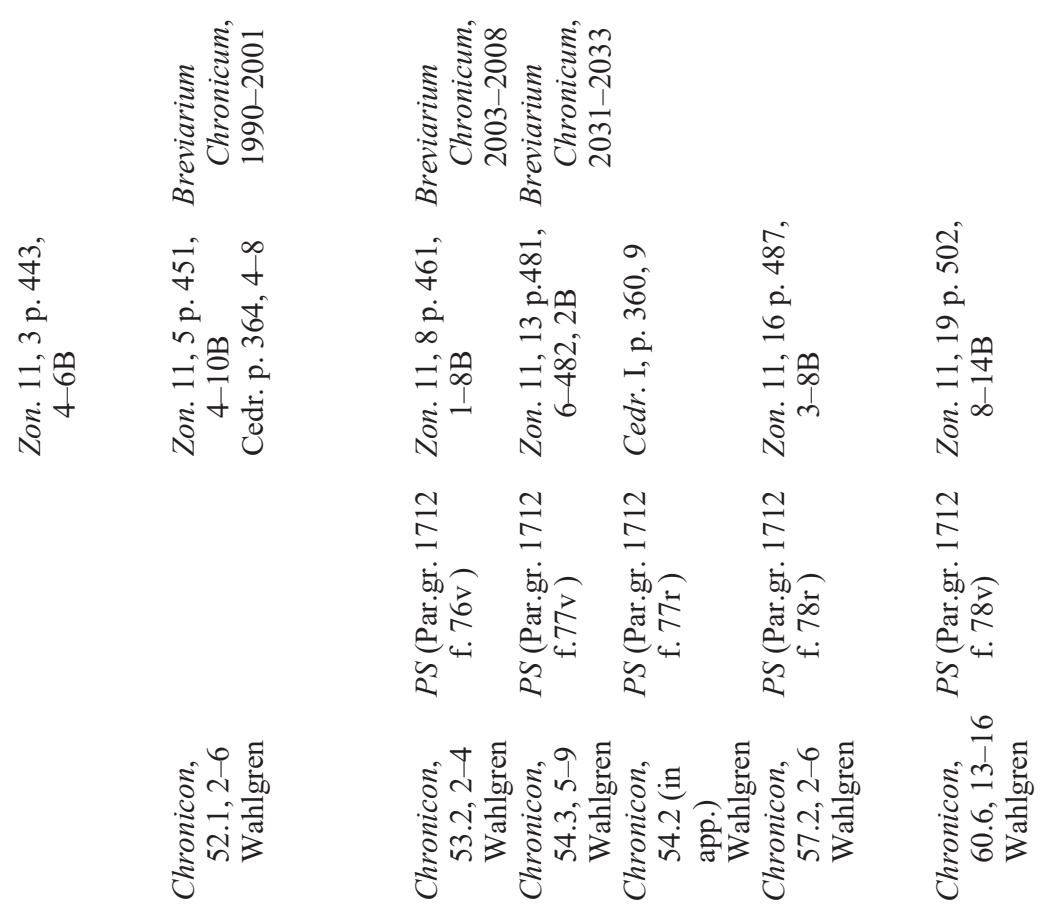

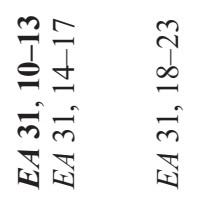

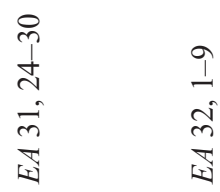

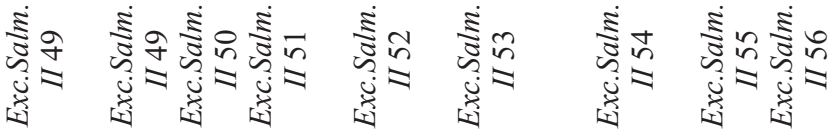

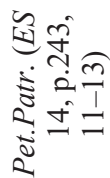

这包

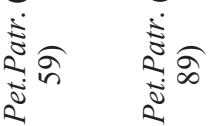

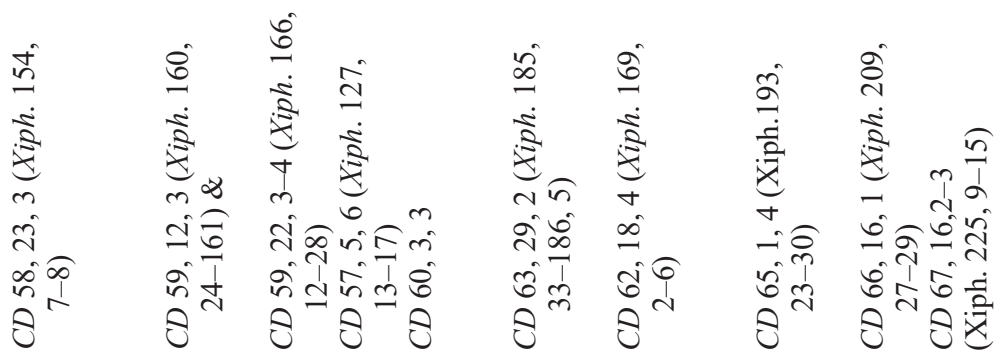




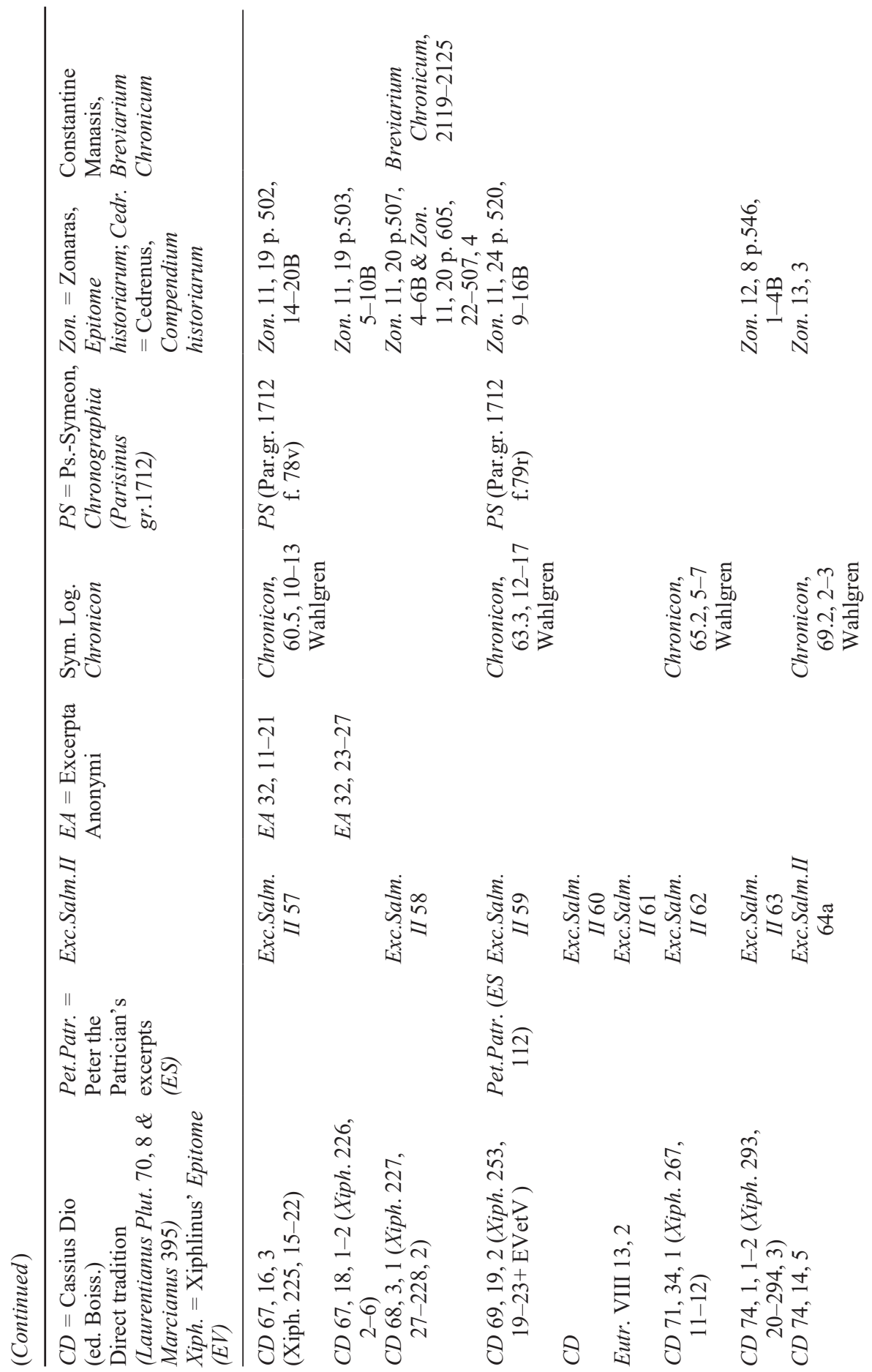


Appendix II 295

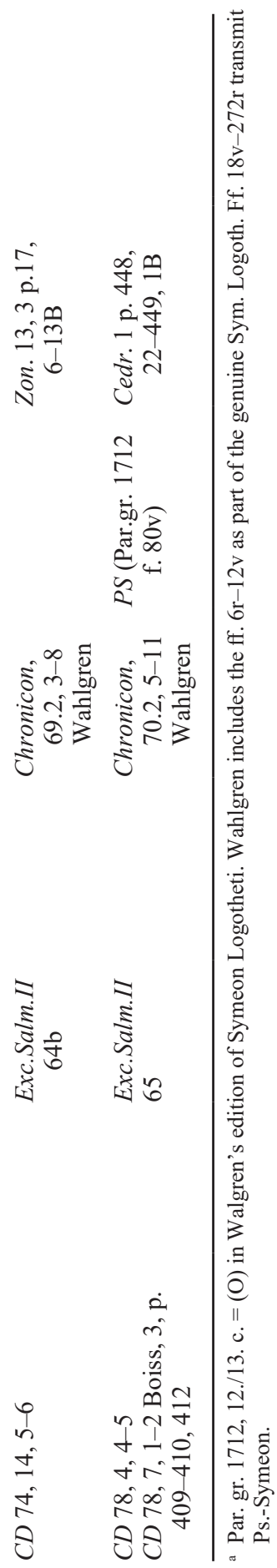




\section{The Epitome and the HE of Eusebius of Caesarea}

\begin{tabular}{|c|c|c|c|c|c|}
\hline Epitome & $\begin{array}{l}\text { Auctarium } \\
\text { E.4.18 } \\
(136 \mathrm{r}-143 \mathrm{v})\end{array}$ & $\begin{array}{l}\text { Barocc. } \\
\text { gr. } 142 \\
(212 r-216 r)\end{array}$ & $\begin{array}{l}\text { Ath. } \\
\text { Vat. } 286 \\
(91 \mathrm{r}-108 \mathrm{r})\end{array}$ & $\begin{array}{l}\text { Paris. gr. } \\
1555 \mathrm{a} \\
(7 \mathrm{r}-9 \mathrm{v})\end{array}$ & Eusebius' $E H$ \\
\hline Exc. 1 & 1 & 1 & 1 & 1 & $E H$ 1, V.1-2, X.1 \\
\hline Exc. 2 & 2 & 2 & 1 & & $E H$ 1, VI.1-2 \\
\hline Exc. 3 & 3 & 3 & 2 & & EH 1, VI.6-7 \\
\hline Exc. 4 & 4 & 4 & 2 & & EH 1, VI.10-11 \\
\hline Exc. 5 & 5 & 5 & & & $\begin{array}{c}\text { EH 1, VII.1; Luke 24, } \\
\text { 13; Chron. Pasch. } \\
\text { 499, 5-7; Georg. } \\
\text { Sync. 439,15-18. }\end{array}$ \\
\hline Exc. 6 & 6 & 6 & 3 & 2 & $E H$ 1, IX.2-4 \\
\hline Exc. 7 & 7 & 7 & 3 & 3 & EH 1, X.1-7 \\
\hline Exc. 8 & & 8 & 4 & & $\begin{array}{r}E H 1 \text {, XI.1-4; Acts 25, } \\
13-14 \text {; Acts 26, 1-2 }\end{array}$ \\
\hline Exc. 9 & & 9 & 5,6 & & $E H$ 1, XII.2-3 \\
\hline Exc. 10 & & 10 & 7 & & EH 2, II.1-4, II.6 \\
\hline Exc. 11 & & 11 & 8 & & $\begin{array}{l}\text { Acts } 8,26-41 ; E H 2 \text {, } \\
\text { I. } 10\end{array}$ \\
\hline Exc. 12 & & 12 & & & $E H$ 1, XII, XII \\
\hline Exc. 13 & & 13 & 9 & & $\begin{array}{c}E H \text { 2, IV.1, VII.1, } \\
\text { VII.4, VII.1 }\end{array}$ \\
\hline Exc. 14 & & 14 & & & EH 2, IX.1-3 \\
\hline Exc. 15 & & & 10 & & $E H 2$, XIII.1-4 \\
\hline Exc. 16 & & 15 & 11 & & EH 2, XV.1-2 \\
\hline Exc. 17 & & 16 & 12 & & EH 2, V.4, XVII.2 \\
\hline Exc. 18 & & 17 & 13 & & $\begin{array}{c}E H 2, \text { XXIII.1-2, } \\
19-21\end{array}$ \\
\hline Exc. 19 & & & 16 & & EH 2, XXIV.1 \\
\hline Exc. 20 & & 18 & 14 & & EH 2, XXV.3-4 \\
\hline Exc. 21 & & 19 & 15 & & EH 2, XXV.5-8 \\
\hline Exc. 22 & & 20 & 17 & & $\begin{array}{l}E H 3, \text { I.1-3, EH 2, } \\
\text { XXV.7 }\end{array}$ \\
\hline Exc. 23 & & 21 & 18 & & EH 3, II.1 \\
\hline Exc. 24 & & 22 & 19 & & $\begin{array}{c}E H 3, \text { III.1-5, } \\
\text { XXV.2-3 }\end{array}$ \\
\hline Exc. 25 & & 23 & 20 & & $E H 3$, IV.6 \\
\hline Exc. 26 & & 24 & 21 & & $E H 3$, IV.5 \\
\hline Exc. 27 & & 25 & & & $E H 3$, IV.10 \\
\hline Exc. 28 & & 26 & 22 & & EH 3, V.3 \\
\hline Exc. 29 & & 27 & & & $E H 3$, X.6-8 \\
\hline Exc. 30 & & 28 & 23 & & $E H 3$, XI.1 \\
\hline Exc. 31 & & 29 & 24 & & EH 3, XII.1 \\
\hline Exc. 32 & & 30 & & & $\begin{array}{l}E H 3, \text { XIV.1, XV.1, } \\
\text { XVI.1 }\end{array}$ \\
\hline Exc. 33 & & 31 & 25,26 & 4 & $\begin{array}{l}\text { EH 3, XVII.1, } \\
\text { XVIII.1, XX.1-5; } \\
\text { Hegesippus }\end{array}$ \\
\hline
\end{tabular}

(Continued) 
(Continued)

\begin{tabular}{|c|c|c|c|c|c|}
\hline Epitome & $\begin{array}{l}\text { Auctarium } \\
\text { E.4.18 } \\
(136 \mathrm{r}-143 \mathrm{v})\end{array}$ & $\begin{array}{l}\text { Barocc. } \\
\text { gr. } 142 \\
(212 r-216 r)\end{array}$ & $\begin{array}{l}\text { Ath. } \\
\text { Vat. } 286 \\
(91 \mathrm{r}-108 \mathrm{r})\end{array}$ & $\begin{array}{l}\text { Paris. gr. } \\
1555 \mathrm{a} \\
(7 \mathrm{r}-9 \mathrm{v})\end{array}$ & Eusebius' $E H$ \\
\hline Exc. 34 & & 32 & 27 & & $E H 3$, XX.8-9 \\
\hline Exc. 35 & & 33 & 28 & & $\begin{array}{l}\text { EH 3, XXII.1, } \\
\quad \text { XXXVII.15 }\end{array}$ \\
\hline Exc. 36 & & 34 & & & $\begin{array}{l}\text { EH 3, XXI.1, } \\
\text { XXIII.2-4 }\end{array}$ \\
\hline Exc. 37 & & 35 & 29 & & EH 3, XXIV.8 \\
\hline Exc. 38 & & 36 & 30 & 5 & $\begin{array}{l}\text { EH 3, XXV.4-6; } \\
\text { fontem non inveni }\end{array}$ \\
\hline Exc. 39 & & 37 & & 6 & EH 3, XXVII.1-6 \\
\hline Exc. 40 & & 38 & & 7 & $\begin{array}{l}\text { EH 3, XVIII.1-2, } \\
\text { XVIII.6 }\end{array}$ \\
\hline Exc. 41 & & & 32 & & EH 3, XVIII.1-2 \\
\hline Exc. 42 & & 39 & 33 & & $E H 3$, XXX.1-2 \\
\hline Exc. 43 & & 40 & 34 & & $\begin{array}{l}E H 3, \text { XXXI.2-3, } \\
\text { XXXI.5 }\end{array}$ \\
\hline Exc. 44 & & 41 & & & EH 3, XXXII.1-3 \\
\hline Exc. 45 & & 42 & 35 & & $E H 3$, XXXIII.2 \\
\hline Exc. 46 & & 43 & & & EH 3, XXXVI.2-3 \\
\hline Exc. 47 & & 44 & 36 & & EH 3, XXXVIII.1-3 \\
\hline Exc. 48 & & 45 & 37 & & $\begin{array}{l}\text { EH 3, XXXIX.1-2, } \\
\text { XXXIX.4 }\end{array}$ \\
\hline Exc. 49 & & 46 & & & Papias \\
\hline Exc. 50 & & 47 & 38 & & Papias \\
\hline Exc. 51 & & 48 & & & Fontem non inveni \\
\hline Exc. 52 & & 49 & & & EH 4, III.1-3 \\
\hline Exc. 53 & & & 31 & & EH 4, VII.3-4, VIII.3 \\
\hline Exc. 54 & & 50 & & 8 & EH 4, X.1, XI.2, XI.5 \\
\hline Exc. 55 & & & 39 & & $\begin{array}{l}E H 4, \text { XIII.8, } \\
\text { XXVI.1.2 }\end{array}$ \\
\hline Exc. 56 & & 51 & & & EH 4, XIV.1, XIV.7 \\
\hline Exc. 57 & & 52 & 40 & & $E H 4$, XV.46 \\
\hline Exc. 58 & & 53 & & & $\begin{array}{l}\text { EH 4, XVIII.1, } \\
\text { XVIII.8-9 }\end{array}$ \\
\hline Exc. 59 & & 54 & & & $\begin{array}{l}E H 4, \text { XX.1, XXI.1, } \\
\text { XXIV.1 }\end{array}$ \\
\hline Exc. 60 & & 55 & & & $\begin{array}{l}E H 4, \text { XXIII.1-3, } \\
\text { XXIII.6 }\end{array}$ \\
\hline Exc. 61 & & 56 & & & EH 4, XXIX.1-7 \\
\hline Exc. 62 & & 57 & & & EH 4, XXVII.1 \\
\hline Exc. 63 & & 58 & & & $\begin{array}{l}E H 5, \text { XX.4, XX.7, } \\
\text { XV.1 }\end{array}$ \\
\hline Exc. 64 & & 59 & & 9 & EH 5, V.1-3 \\
\hline Exc. 65 & & 60 & & & EH 5, V. 1-2, V.4-6 \\
\hline Exc. 66 & & 61 & & & EH 5, VIII.15 \\
\hline Exc. 67 & & 62 & & & $\begin{array}{c}E H \text { 5, XIII.1-4, fontem } \\
\text { non inveni, EH 5, } \\
\text { XVI.13, XVI.15, } \\
\text { XVII.1, XVIII.1 }\end{array}$ \\
\hline
\end{tabular}


(Continued)

\begin{tabular}{|c|c|c|c|c|c|}
\hline Epitome & $\begin{array}{l}\text { Auctarium } \\
\text { E.4.18 } \\
(136 \mathrm{r}-143 \mathrm{v})\end{array}$ & $\begin{array}{l}\text { Barocc. } \\
\text { gr. } 142 \\
(212 r-216 r)\end{array}$ & $\begin{array}{l}\text { Ath. } \\
\text { Vat. } 286 \\
(91 \mathrm{r}-108 \mathrm{r})\end{array}$ & $\begin{array}{l}\text { Paris. gr. } \\
1555 \mathrm{a} \\
(7 \mathrm{r}-9 \mathrm{v})\end{array}$ & Eusebius' $E H$ \\
\hline Exc. 68 & 8 & 63 & & & $\begin{array}{l}\text { EH 5, XXIII.1, } \\
\text { XXIII.3-4, } \\
\text { XXIV.1-3, } \\
\text { XXIV.12, XXIV.17 }\end{array}$ \\
\hline Exc. 69 & 9 & & & & $H E$ 5, XXVII.1 \\
\hline Exc. 70 & 10 & 64 & & & $\begin{array}{c}\text { EH 5, XXVIII.6, } \\
\text { XXVIII.1-2 }\end{array}$ \\
\hline Exc. 71 & 11 & 65 & & & $\begin{array}{c}\text { EH 5, XXVIII.8-9, } \\
\text { XXVIII.12 }\end{array}$ \\
\hline Exc. 72 & 12 & 66 & & & EH 6, I.1, V.1 \\
\hline Exc. 73 & 13 & 67 & 41 & & EH 6, VI.1 \\
\hline Exc. 74 & 14 & & 42 & & EH 6, VII.1 \\
\hline Exc. 75 & 15 & 68 & 43 & & $\begin{array}{l}E H \text { 6, IX 3-7, X.1, } \\
\quad \text { XI.1.2 }\end{array}$ \\
\hline Exc. 76 & 16 & & & & $H E$ 6, XII.1-2 \\
\hline Exc. 77 & 18 & & & & $H E$ 6, XIII.5-7 \\
\hline Exc. 78 & 17 & & 44 & & EH 6, XIV.2-3 \\
\hline Exc. 79 & 19 & 69 & 45 & & EH 6, XVII.1 \\
\hline Exc. 80 & 20 & 70 & & & $\begin{array}{l}E H \text { 6, XIX.2-3, } \\
\text { XIX.6-7, XIX.9 }\end{array}$ \\
\hline Exc. 81 & 21 & 71 & 46 & 10 & EH 6, XX.1-2 \\
\hline Exc. 82 & 22 & 72 & 47 & & $E H, 6$ XXI.3-4 \\
\hline Exc. 83 & 23 & 73 & & & EH 6, XXII.1 \\
\hline Exc. 84 & 25 & & 48 & & EH 6, XXVII.1 \\
\hline Exc. 85 & 24 & 74 & & & EH 6, XXVIII.1 \\
\hline Exc. 86 & 26 & & 49 & & EH 6, XXXI.1-3 \\
\hline Exc. 87 & 27 & 75 & & & EH 6, XXXIV.1 \\
\hline Exc. 88 & 29 & & & & $\begin{array}{c}H E \text { 6, XXXVII.1, } \\
\text { XXXVIII.1 }\end{array}$ \\
\hline Exc. 89 & 28 & 76 & & & EH 6, XXXIX.1-2 \\
\hline Exc. 90 & 30 & & & & $H E$ 6, XXXIX.2 \\
\hline Exc. 91 & 31 & 77 & 50,51 & & $\begin{array}{l}\text { EH 6, XLIII.1-4, } \\
\text { XLIII.14-15, } \\
\text { XLIV.1 }\end{array}$ \\
\hline Exc. 92 & 32 & 78 & & & EH 6, XLIV.1-2 \\
\hline Exc. 93 & 33 & 79 & 52 & & $E H 7$, I.1 \\
\hline Exc. 94 & 34 & 80 & & & EH 7, II.1, III.1 \\
\hline Exc. 95 & 35 & 81 & & & EH 7, VI.1 \\
\hline Exc. 96 & 36 & & 53 & & EH 7, VII.1-3 \\
\hline Exc. 97 & 38 & & & & $H E$ 7, XII.1, XV.1 \\
\hline Exc. 98 & 39 & & 54 & 11 & $\begin{array}{c}\text { EH 7, XVII.1, } \\
\text { XVIII.1-2, } \\
\text { Philost.7.3.22 }\end{array}$ \\
\hline Exc. 99 & 40 & & & & $H E$ 7, XXIV.1-2 \\
\hline Exc. 100 & 40 & & & 12 & EH 7, XXV.1 \\
\hline Exc. 101 & 37 & & & & $H E$ 7, XXIV.1-2 \\
\hline Exc. 102 & 41 & & & & HE 7, XVI.1, XVII.1 \\
\hline
\end{tabular}

(Continued) 
(Continued)

\begin{tabular}{|c|c|c|c|c|c|}
\hline Epitome & $\begin{array}{l}\text { Auctarium } \\
\text { E.4.18 } \\
(136 \mathrm{r}-143 \mathrm{v})\end{array}$ & $\begin{array}{l}\text { Barocc. } \\
\text { gr. } 142 \\
(212 \mathrm{r}-216 \mathrm{r})\end{array}$ & $\begin{array}{l}\text { Ath. } \\
\text { Vat. } 286 \\
(91 \mathrm{r}-108 \mathrm{r})\end{array}$ & $\begin{array}{l}\text { Paris. gr. } \\
1555 \mathrm{a} \\
(7 \mathrm{r}-9 \mathrm{v})\end{array}$ & Eusebius' $E H$ \\
\hline Exc. 103 & 42 & 82 & 55 & 13 & $\begin{array}{l}E H 7, \text { XXVII.1-2, } \\
\text { XXVIII.1, XXIX.2, } \\
\text { XXXII.6, XXXII.13 }\end{array}$ \\
\hline Exc. 104 & 43 & 83 & 56 & & $\begin{array}{l}\text { EH 7, XXX.23, } \\
\quad \text { XXXI.1-2 }\end{array}$ \\
\hline Exc. 105 & 44 & & & & $H E 7$, XXXII. 21 \\
\hline Exc. 106 & 45 & & & & $H E$ 7, XXXII.13 \\
\hline Exc. 107 & 46 & & & & HE 7, XXXII.24-25 \\
\hline Exc. 108 & 47 & 84,85 & & & $\begin{array}{l}\text { EH 7, XXXII.26; } \\
\quad \text { Pierius }\end{array}$ \\
\hline Exc. 109 & 48 & & & & HE 7, XXXII.30-31 \\
\hline Exc. 110 & 49 & 86 & 57 & 14 & $E H$ 8, VI.6 \\
\hline Exc. 111 & 50 & 87 & 58 & 15 & $\begin{array}{l}E H \text { 8, III.1. XI.2 XII.3, } \\
\quad \text { XII.5 }\end{array}$ \\
\hline Exc. 112 & 51 & 88 & 59 & & EH 8, VI.9, XII.10 \\
\hline Exc. 113 & 52 & & 60 & & $\begin{array}{l}\text { EH 8, XIII.2, EH 9, } \\
\text { VI.3, Eusebius' } \\
\text { Chronikoi Canones }\end{array}$ \\
\hline Exc. 114 & 53 & 89 & 61 & & $\begin{array}{l}\text { De martyribus } \\
\quad \text { Palaestinae } \\
\quad \text { (recension brevior), } \\
\text { X.3, HE 4, XV.46 }\end{array}$ \\
\hline Exc. 115 & 54 & 89 & 62 & & $\begin{array}{l}\text { De martyribus } \\
\quad \text { Palaestinae } \\
\quad \text { (recension brevior), } \\
\text { X.1 }\end{array}$ \\
\hline Exc. 116 & 55 & & & & $H E 8$, XIII.11 \\
\hline Exc. 117 & 56 & 90 & 63 & 16 & EH 8, XIII.11 \\
\hline Exc. 118 & 57 & 91 & 64 & 17 & EH 8, XIII.12-15 \\
\hline Exc. 119 & 59 & & 66 & & EH 8, XIII.15 \\
\hline Exc. 120 & 60 & & 67 & 18 & $\begin{array}{l}E H \text { 8, XIV.1-2, XIV.5, } \\
\text { XIV.7, XVI.1 }\end{array}$ \\
\hline Exc. 121 & 58 & 91 & 65 & & $E H 9$, V.1 \\
\hline Exc. 122 & 61 & & & & $\begin{array}{c}H E \text { 8, XIV.7, } \\
\text { XVII.2-3 }\end{array}$ \\
\hline Exc. 123 & 62 & 92 & 69 & & $E H 9, \mathrm{~V} .1$ \\
\hline Exc. 124 & 61 & & 68 & & EH 9, VI.2-3 \\
\hline Exc. 125 & 62 & 93 & 70 & & EH 9, VII.2, VIII.1 \\
\hline Exc. 126 & 63 & 94 & 71,72 & & $\begin{array}{l}E H 9, \text { IX.1, IX.3, } \\
\text { IX.12 }\end{array}$ \\
\hline Exc. 127 & 64 & 95 & 72 & & $E H$ 9, XI.6 \\
\hline Exc. 128 & 65 & 96 & & & $\begin{array}{l}E H \text { 10, II.2, III.1-4, } \\
\text { IV.1 }\end{array}$ \\
\hline Exc. 129 & 66 & 97 & 73 & & $\begin{array}{l}\text { EH 10, VIII.2-3, } \\
\text { VIII.9-10 }\end{array}$ \\
\hline Exc. 130 & 67 & 97 & 74 & & $H E$ 10, IX.4, IX.6 \\
\hline
\end{tabular}




\section{Bibliography}

\section{Primary references}

Aesch ines

The Speeches of Aeschines, ed. Charles Darwin Adams, Cambridge, 1919 [1988].

Agathias Scholasticus

Agathiae Myrinaei Historiarum Libri Quinque, ed. Rudolf Keydell (CFHB 2), Berolini, 1967.

The Histories, ed. Joseph D. Frendo, Berlin, 1975.

Ammianus Marcellinus

Ammiani Marcellini Rerum Gestarum libri qui supersunt, ed. Wolfgang Seyfarth Liselotte Jacob-Karau, Leipzig, 1978.

Anastasius Sinaiticus

Anastasii Sinaitae Quaestiones et Responsiones, edd. Marcel Richard - Joseph A. Munitiz (CCSG 59), Turnhout-Louvain, 2006.

Anna Comnena

Annae Comnenae Alexias, I-II, edd. Diether Roderich Reinsch - Athanasios Kambylis (CFHB 40, 1-2), Berlin, 2001.

Anthologia Palatina

Epigrammatum Anthologia Palatina: cum Planudeis et appendice nova epigrammatum veterum ex libris et marmoribus ductorum, III, ed. Edme Cougny, Parisiis, 1871.

Anthologia Palatina: Codex palatinus et Codex Parisinus phototypice editi, I-II, ed. Carl

Preisendanz (Codices Graeci et Latini photographice depicti duce Scantone De Vries 15), Lugduni Batavorum, 1911.

Anthologia Palatina, I-IV, ed. Hermann Beckby, München, 1957-1958.

Anthologie Grecque. 9: Anthologie Palatine, Livre X, Première Partie, edd. Jean Irigoin -

Francesca Maltomini - Pierre Laurens, Paris, 2011.

Appianus Alexandrinus

Appiani Historia Romana, edd. Paul Viereck - Antoon Gerard Roos, Lipsiae, 1939.

Appian's Roman History, I-IV, ed. Horace White, London, 1955. 
Aratus Solensis

Arati Solensis Phaenomena et Diosemea Graece et Latine ad codd. mss. et optimarum editionum fidem recensita, ed. Johann Theophilus Buhle, Lipsiae, 1793-1801.

Aulus Gellius

Noctium Atticarum libri XX, ed. Martini Hertz, Lipsiae, 1853.

Basilius I

Procheiros Nomos

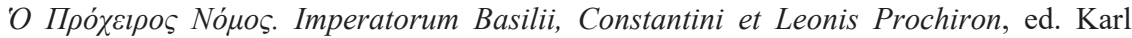
Eduard Zachariä Von Lingenthal, Heidelbergiae, 1837 [Johannes D. Zepos, Jus Graecoromanum, Athinai, 1931].

Cassius Dio

Dionis Cassii Cocceiani Historiarum Romanarum Quae Supersunt, I-IV, ed. Ursul Philip Boissevain, Berolini, 1895-1931 [1955].

Dio's Roman History, I-IX, edd. Earnest Cary - Herbert Balswin Foster, London, 1954-1955.

Chronicon paschale

Chronicon Paschale, ed. Ludwig August Dindorf (CSHB), Bonn, 1832.

Chronicon Paschale 284-628 AD (Translated texts for historians 7), edd. Mary WhitbyMichael Whitby, Liverpool, 1989.

Claudius Aelianus

Claudii Aeliani de Natura Animalium Libri XVII. Varia Historia. Epistolae Framenta, I-II, ed. Rudolf Hercher, Lipsiae, 1864-1866.

Constantinus Porphyrogenitus

De Administrando Imperio

Constantinus Porphyrogenitus, De Administrando Imperio, edd. Gyula Moravcsik Romilly J. H. Jenkins (CFHB 1), Washington D.C., 1967.

De ceremoniis

Constantini Porphyrogeniti Imperatoris De ceremoniis Aulae Byzantinae libri duo Graece et Latine, I-II, ed. Johann Jacob Reiske (CSHB 16-17), Bonnae, 1829-1830.

Constantin VII Porphyrogénète: Le Livre des Cérémonies, Texte établi et traduit, I-IV, ed. Albert Vogt, Paris, 1967.

Constantine Porphyrogennetos. The book of Ceremonies, I-II, edd. Ann Moffatt-Maxeme Tall, Canberra, 2012.

De Thematibus

Constantino Porfirogenito De Thematibus, ed. Agostino Pertusi (Studi e Testi 160), Roma, 1952.

EC

Excerpta Historia Iussu Imperatoris Constantini Porphyrogeniti Confecta, I-IV, ed. Carolus De Boor, Berolini, 1903-1910. 


\section{Bibliography}

Excerpta de Legationibus, ed. Carolus De Boor, Berolini, 1903.

Excerpta de Insidiis, ed. Carolus De Boor, Berolini, 1905.

Excerpta de Sententiis, ed. Ursul Philip Boissevain, Berolini, 1906.

Excerpta de Virtutibus et Vitiis I, ed. Theodor Büttner-Wobst, Berolini, 1906.

Excerpta de Virtutibus et Vitiis II, ed. Antoon Gerard Roos, Berolini, 1910.

\section{Geoponica}

Geoponica sive Cassiani Bassi Scholastici de Re Rustica Ecloge, ed. Henricus Beckh, Lipsiae, 1895 [Stuttgart, 1994].

Geoponika: Farm Work, ed. Andrew Dalby, Totnes, 2011.

\section{Vita Basilii}

Theophanes Continuatus, Ioannes Cameniata, Symeon Magister, Georgius Monachus, ed. Immanuel Bekker (CSHB 45), Bonnae, 1838, 211-353.

Chronographiae Quae Theophanis Continuati Nomine Fertur Liber Quo Vita Basilii Imperatoris Amplectitur, ed. Ihor Ševčenko (CFHB 42), Berlin-New York (NY), 2011.

Damascius

Difficulties and Solutions of First Principles

Damascii Successoris Dubitationes et Solutiones, I-II, ed. Charles-Émile Ruelle, Parisiis, 1889-1899 [Amsterdam, 1966].

Diodorus Siculus

Diodori Siculi Bibliotheca Historiae Quae Supersunt, I-V, edd. Friedrich Vogel - Curt Theodor Fischer - Ludwig Dindorf, Lipsiae, 1888-1906 [Stuttgart, 1985].

Doctrina Patrum de Incarnatione

Doctrina Patrum de Incarnatione Verbi. Ein griechisches Florilegium aus der Wende des 7. und 8. Jahrhunderts, edd. Franz Diekamp - Evangelos Chrysos, Münster, 1981.

Diogenes Laertius

Vitae Philosophorum

Diogenis Laertii Vitae Philosophorum, ed. Miroslav Marcovich, Stuttgart, 1999.

\section{Epitome}

Anecdota Graeca e codd. Manuscriptis Bibliothecae regiae Parisiensis, II, ed. John Anthony Cramer, Oxonii, 1839, 87-109.

Eudemus Rhodius

Eudemos von Rhodos, ed. Fritz Wehrli (Die Schule des Aristoteles 8), Basel, 1969, 11-72.

Eunapius Sardianus

Eunapius Sardianus, Historiarum Fragmenta, ed. Carl Müller (FHG IV), Parisiis, 1851, $7-56$.

Fragmentary Classicising Historians of the Later Roman Empire, II, ed. and trans. Roger C. Blockley, Liverpool, 1983, 2-151. 
Eunape, Olympiodore, Zosime: Scripta Minora, ed. François Paschoud, Bari, 2006, 499-553.

Eusebius Caesariensis

Historia ecclesiastica

Eusebius: The Ecclesiastical History, I-II, ed. Lake Kirsopp, London, 1965.

\section{Chronicon}

Eusebii Pamphili Chronographia. Die Chronik des Eusebius aus dem Armenischen übersetzt, ed. Josef Karst, Leipzig, 1911.

Eusebii Pamphili Chronici Canones. Die Chronik des Hieronymus, ed. Rudolf Helm, Berlin, 1956.

Eustathius Thessalonicensis

Eustathii Archiepiscopi Thessalonicensis Commentarii ad Homeri Iliadem Pertinentes, ed. Marchinus Van Der Valk, Leiden, 1971-1987.

Excerpta Anonymi

Excerpta Anonymi Byzantini ex Codice Parisino Suppl. Gr. 607 A, ed. Maximilianus Treu, Ohlau, 1880.

Excerpta Salmasiana

Anecdota Graeca e Codd. Manuscriptis Bibliothecae Regiae Parisiensis, II, ed. John Anthony Cramer, Oxonii, 1839, 383-401.

Flavius Eutropius

Eutropii Breviarium ab Urbe Condita, ed. Hans Droysen (MGH, AA., II,), Berolini, 1878, 9-179.

Eutropii Breviarium ab Urbe condita, ed. Carolus Santini, Leipzig, 1979.

Gelasius of Caesarea

Gelasius of Caesarea. Ecclesiastical History. The Extant Fragments, edd. Martin Wallraff - Nicholas Marinides - Jonathan Stutz (Die griechischen christlichen Schriftsteller der ersten Jahrhunderte: Neue Folge 25), Berlin, 2017.

Georgius Cedrenus

Georgii Cedreni Compedium Historiarum, I-II, ed. Immanuel Bekker (CSHB 8-9), Bonnae, 1838-1839.

Georgii Cedreni Historiarum Compendium, ed. Luigi Tartaglia, Roma, 2016.

Georgius Monachus

Georgii Monachi Chronicon, I-II, ed. Carolus De Boor, Lipsiae, 1904 [Peter Wirth, Stuttgart, 1978).

Georgius Syncellus

Georgius Syncellus. Ecloga chronographica, ed. Alden A. Mosshammer, Leipzig, 1984.

The Chronography of George Synkellos: A Byzantine Chronicle of Universal History from the Creation, edd. William Adler - Paul Tuffin, 2002, Oxford. 


\section{Bibliography}

Hesychius Alexandrinus

Lexicon

Hesychii Alexandrini Lexicon, ed. Kurt Latte, 1 (A-4), 2 (E-O), Hauniae, 1953-1966.

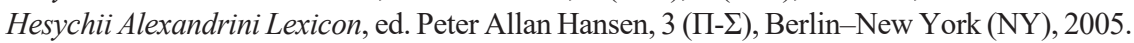

Hesychii Alexandrini Lexicon, edd. Peter Allan Hansen - Ian Cunningham, 4 (T- $\Omega$ ), Berlin-New York (NY), 2009.

\section{Herodotus}

Herodoti Historiae, I-II, ed. Haiim B. Rosén, Leipzig, 1987-1997.

Herodoti Historiae, I-II, ed. Nigel G. Wilson, Oxford, 2015.

Hierocles

Le Synekdèmos d'Hiéroklès et l'Opuscule Géographique de Georges de Chypre, ed. Ernest Honigmann, Bruxelles, 1939.

Ioannes Antiochenus

Ioannis Antiocheni Fragmenta ex Historia Chronica, ed. Umberto Roberto (Texte und Untersuchungen zur Geschichte der Altchristlichen Literatur 154), Berlin-New York (NY), 2005b.

Ioannis Antiocheni Fragmenta Quae Supersunt Omnia, ed. Sergei Mariev (CFHB 47), Berlin, 2008.

Ioannes Damascenus

Sancti Joannis Damasceni Opera Omnia Quae Exstant, II, ed. Michael Lequien, Parisiis, 1712.

Die Schriften des Johannes von Damaskus, II, ed. Bonifatius Kotter (PTS 12), Berlin-New York (NY), 1973.

Die Schriften des Johannes von Damaskos, III, ed. Bonifatius Kotter (PTS 17), BerlinNew York (NY), 1975.

Ioannes Lydus

De Magistratibus Populi Romani

Ioannes Lydus. On Powers or the Magistracies of the Roman State, ed. Anastasius C. Bandy, Philadelphia (PA), 1983.

De Mensibus

Ioannis Laurentii Lydi Liber de Mensibus, ed. Richard Wünsch, Lipsiae, 1898.

On the Months (De Mensibus), ed. Anastasius C. Bandy, Lewiston, 2013.

Ioannes Malalas

Ioannis Malalae Chronographia, ed. Ioannes Thurn (CFHB 35), Berlin-New York (NY), 2000.

Ioannes Scylitzes

Ioannis Scylitzae Synopsis Historiarum, ed. Ioannes Thurn (CFHB 5), Berlin, 1973.

A Synopsis of Byzantine History: 811-1057, ed. John Wortley, Cambridge (MA), 2011. 
Iordanes

Iordanis De Origine Actibusque Getarum, edd. Francesco Giunta - Antonino Grillone (Fonti per la Storia d'Italia 117), Roma, 1991.

Iulius Africanus

Cesti

Les Cestes de Julius Africanus: Étude sur l'ensemble des Fragments Avec Édition, Traduction et Commentaires, ed. Jean René Viellefond, Paris, 1970.

Cesti. The Extant Fragments, edd. Martin Wallraff - Carlo Scardino - Laura Mecella Christophe Guignard, Berlin, 2012.

Chronographiae

Chronographiae: The Extant Fragments. Sextus Julius Africanus, edd. Martin Wallraff Umberto Roberto - Karl Pinggéra - William Adler, Berlin, 2007.

Josephus Genesius

Iosephi Genesii, Regum Libri Quattuor, edd. Anna Lesmüller-Werner - Ioannes Thurn (CFHB 14), Berlin, 1978.

Genesios, On the Reigns of the Emperors, ed. Anthony Kaldellis (Byzantina Australiensia 11), Canberra, 1998.

Leo VI

Basilica

Basilicorum libri LX, edd. Herman Jan Scheltema - Nicolaas Van Der Wal, Groningen, 1955-1988.

Book of the Eparch

Das Eparchenbuch Leons des Weisen, ed. Johannes KODER (CFHB 33), Wien, 1991.

Taktika

The Taktika of Leo VI, ed. George Dennis (Dumbarton Oaks Texts 12), Washington D.C., 2010.

Leo Diaconus

The History of Leo the Deacon. Byzantine Military Expansion in the Tenth Century. Introduction, Translation, and Annotations, edd. Alice-Mary Talbot-Denis F. Sullivan (Dumbarton Oaks Texts 41), Washington D.C., 2005.

Malchus

Malco di Filadelfia, Frammenti, ed. Lia Rafaella Cresci, Napoli, 1982.

The Fragmentary Classicising Historians of the Later Roman Empire: Eunapius, Olympiodorus, Priscus, and Malchus, II, ed. Roger C. Blockley, Liverpool, 1983, 402-455.

On Syntax

Lexica Segueriana. Anecdota Graeca, ed. Immanuel Bekker, Berolini, 1814. 


\section{Bibliography}

Paraphrases in Dionysium Periegetam

Geographi Graeci Minores, II, ed. Carl Müller, Parisiis, 1861 [Hildesheim, 1965], 409-425.

\section{Parastaseis Syntomoi Chronikai}

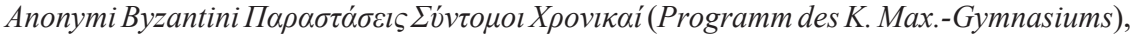
ed. Theodorus Preger, München, 1898.

Scriptores Originum Constantinopolitarum, I, ed. Theodorus Preger, Lipsiae, 1901, 19-73. Constantinople in the Early Eighth Century: The Parastaseis Syntomoi Chronikai, edd. Averil Cameron - Judith Herrin, Leiden, 1984.

Patria of Constantinople

Scriptores Originum Constantinopolitarum, I, ed. Theodorus Preger, Lipsiae, 1901.

Scriptores Originum Constantinopolitarum, II, ed. Theodorus Preger, Lipsiae, 1907.

Accounts of Medieval Constantinople: The Patria, ed. Albrecht Berger, Cambridge (MA), 2013.

Paulus Silentiarius

Prokop. Werke, ed. Otto Veh, 5, München, 1977, 306-358.

Petrus Patricius

Historici Graeci Minores, I, ed. Ludwig Dindorf, Lipsiae, 1870, 425-437.

The Lost History of Peter the Patrician: An Account of Rome's Imperial Past from the Age of Justinian, ed. Peter Thomas BANCHICH, New York (NY), 2015.

Philippus Sidetes

Die Christliche Geschichte des Philippos von Side, mit einem kommentierten Katalog der Fragmente, ed. Katharina Heyden, in: Julius Africanus und die Christliche Weltchronistik, ed. Martin Wallraff, Berlin, 2006, 209-243.

Philostorgius

Kirchengeschichte. Mit Dem Leben Des Lucian Von Antiochien und Den Fragmenten Eines Arianischen Historiographen, ed. Joseph Bidez, Berlin, 1981.

Photius

Amphilochia

Photii Patriarchae Constantinopolitani Epistulae et Amphilochia, IV-VI, edd. Vasileios Laourdas - Leendert G. Westerink, Leipzig-Stuttgart, 1986-1998.

Bibliotheca

Photius: Bibliothèque, I-IX, edd. René Henry - Jacques Schamp, Paris, 1959-1991.

Lexicon

Photii Patriarchae Lexicon, ed. Christos Theodoridis, Berlin, 2013.

Plato

Platonis Opera, I-V, ed. E. A. Duke, New York (NY), 1995-1999. 
Plutarchus

Plutarchi Vitae Parallelae, II.2, ed. Konrat Ziegler, Leipzig, 1968, 253-337.

Procopius Caesariensis

De aedificiis

Procopius, Buildings, VII, edd. Henry Bronson Dewing - Glanville Downey, London, 1971.

De bellis

Procopius, History of the Wars, I-V, edd. Henry Bronson Dewing - Glanville Downey, London, 1968-1979.

\section{Historia arcana}

Procopius, the Anecdota or Secret History, VI, edd. Henry Bronson Dewing - Glanville Downey, London, 1969.

The Secret History: With Related Texts, ed. Anthony Kaldellis, Indianapolis, 2010.

Psellus

Chronographia

Michael Psellus. Imperatori di Bisanzio: Cronografia, I-II, edd. Dario Del Corno Salvatore Impellizzeri - Ugo Criscuolo - Silvia Ronchey, Milano, 1984.

Orationes

Michaelis Pselli Scripta Minora, I, edd. Eduard Kurtz - Franciscus Drexl, Milano, 1936, 94-107.

Michaelis Pselli Orationes Hagiographicae, ed. Elisabeth A. Fischer, Stuttgart-Leipzig, 1994, 269-288.

Ps.-Apollodorus

Apollodorus. The Library, I-II, ed. James George Frazer, Cambridge, 1961-1963.

Ps.-Caesarius

Pseudo-Kaisarios. Die Erotapokriseis, ed. Rudolf Riedinger, Berlin, 1989.

Ps.-Dionysius Areopagita

Pseudo-Dionysius Areopagita. De Coelesti Hierarchia De Ecclesiastica Hierarchia, De Mystica Theologia, Epistulae, 2., Überarbeitete Auflage, edd. Günter Heil - Adolf Martin Ritter (PTS 67), Berlin, 2012.

Ps.-Symeon

Historiae Byzantinae Scriptores Post Theophanem, ed. Franciscus Combefis, Parisiis, $1685,401-498$.

Theophanes Continuatus, Ioannes Cameniata, Symeon Magister, Georgius Monachus, ed. Immanuel Bekker (CSHB 45), Bonnae, 1838, 603-760. 


\section{Bibliography}

Publius Herennius Dexippus

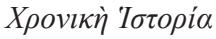

Dexippos von Athen (100) ed. Felix Jacoby, in: Die Fragmente der Griechischen Historiker Part I-III, [consulted online on 15 September 2017 http://dx.doi.org/10.1163/1873 -5363_boj_a100].

Dexipp von Athen: Edition, Übersetzung und begleitende Studien, ed. Günther Martin, Tübingen, 2006.

Dexippo di Atene: Testimonianze e Frammenti, ed. Laura Mecella, Tivoli, 2013.

Scholia in Dionysi orbis descriptionem

Geographi Graeci Minores, II, ed. Carolus Müller, Parisiis, 1861, 427-457.

Dionysius Periegetes: Description of the Known World, ed. Jane L. Lightfoot, Oxford, 2014.

Sophronius

Die Weihnachtspredigt von Sophronius, ed. Hermann Usener, in: RhM 41(9) (1886), 500-516.

Sophronii Anacreontica, ed. Marcello Gigante, Roma, 1957.

Stephanus Byzantius

Stephan von Byzanz. Ethnika, ed. August Meineke, Berolini, 1849.

Stephani Byzantii Ethnica, I-IV, ed. Margarethe Billerbeck, Berlin-New York (NY), 2006-2016.

Stobaeus

Ioannis Stobaei Florilegium, I-IV, ed. Augustus Meineke, Lipsiae, 1855-1857.

Ioannis Stobaei Anthologium, 1-2, ed. Curt Wachsmuth, Berolini, 1884.

Ioannis Stobaei Anthologium, 3-5, ed. Otto Hense, Berolini, 1894-1912.

Strabo

Strabonis Geographika, I-IV, Mit Übersetzung und Kommentar, ed. Stefan Radt, Göttingen, 2002-2011.

\section{Strategicon}

Mauricius. Arta Militara, ed. Haralambie Mihăescu (Scriptores Byzantini 6), Bucaresti, 1970.

Das Strategikon des Maurikios, ed. George T. Dennis, Wien, 1981.

Suda

Suidae Lexicon, I-V, ed. Ada Adler, Stuttgart, 1928-1938 [1971].

Symeon Logotheta

Symeonis Magistri et Logothetae Chronicon, I, ed. Stephanus Wahlgren (CGHB 44, 1), Berlin, 2006.

Synaxarium Ecclesiae Constantinopolitanae

Synaxarion Ecclesiae Constantinopolitanae, Propylaeum as Acta Sanctorum Novembris, ed. Hippolyte Delehaye, Bruxellis, 1902. 
Theodoret Cyr

Theodoretus: Kirchengeschichte, edd. Léon Parmentier - Günther Christian Hansen (Die griechischen christlichen Schriftsteller der ersten Jahrhunderte. N. F. 5), Berlin, 1998.

Theodorus Anagnosta

Theodoros Anagnostes Kirchengeschichte, ed. Günther Christian Hansen, Berlin, 1971 [1995].

Theophanes Confessor

Theophanis Chronographia, I, ed. Carolus De Boor, Lipsiae, 1883 [Hildesheim, 1963].

The Chronicle of Theophanes Confessor. Byzantine and New Eastern History AD 284813, edd. Cyril Mango - Roger Scott - Geoffrey Greatrex, Oxford, 2006.

Theophanes Continuatus

Theophanes Continuatus, Ioannes Cameniata, Symeon Magister, Georgius Monachus, ed. Immanuel Bekker (CSHB 45), Bonnae, 1838, 3-211.

Chronographiae Quae Theophanis Continuati Nomine Fertur Libri, I-IV, edd. Jeffrey Michael Featherstone - Juan Signes Codoñer (CFHB 49), Berlin, 2015.

Theophylactus Simocatta

Theophylacti Simocattae Historiae, ed. Carolus De Boor, Lipsiae, 1887 [1972], 20-314.

Thucydides

Thucydidis Historiae, I-II, edd. Henry Stuart Jones - Johannes Enoch Powell, Oxford, 1942 [1967-1970].

Zosimus

Zosimi Historia Nova, ed. Ludovicus Mendelssohn, Lipsiae, 1887.

Zosimus. New History, English trans. Ronald D. Ridley, Canberra, 1982.

Zosime. Historia Nouvelle, I-III, ed. and French trans. François Paschoud, Paris, 1971-1989.

\section{Secondary references}

Adler, Ada, Suda Lexicon, I, Stuttgart, 1928, viii-xxx.

Adler, Ada, "Suidas", RE 4(A1) (1931), 675-717.

Afinogenov, Dmitry, "The Date of Georgius Monachus Reconsidered", BZ 92 (1999), 437-447.

Afinogenov, Dmitry, "Le manuscript grec Coislin 305: la version primitive de la Chronique de Georges le Moine", Revue des études byzantines 62 (2004), 237-246.

Agapitos, Panagiotis A., "Karl Krumbacher and the History of Byzantine Literature", BZ 108(1) (2015), 1-52.

Agapitos, Panagiotis A., "The Politics and Practices of Commentary in Komnenian Byzantium", in Preserving, Commenting, Adapting: Commentaries on Ancient Texts in Byzantium", edd. Baukje van den Berg, Divna Manolova, and Przemysław Marciniak, Cambridge, 2020 (forthcoming).

Agati, Maria Luisa, "Note paleografiche all'Antologia Palatina", BollClass 5 (1984), $43-59$. 
Agati, Maria Luisa, La minuscola 'bouletée' (Littera antiqua 9), Città del Vaticano, 1992.

Ahrweiler, Hélène, Byzance et la mer: la marine de guerre, la politique et les institutions maritimes de Byzance aux VIIe-XVe siècles, Paris, 1966.

Ahrweiler, Hélène, L'idéologie politique de l'Empire byzantine, Paris, 1975.

Alexakis, Alexander, Parisinus Graecus 1115, Washington D.C., 1996.

Alexander, Paul Julius, "The Iconoclastic Council of St. Sophia (815) and Its Definition”, DOP 7 (1953), 35-66.

Allard, André, Maxime Planude. Le Grand Calcul selon les Indiens, Louvain, 1981.

Allen, Pauline, "An early epitomator of Josephus, Eustathius of Epiphaneia", BZ 81 (1988), 1-11.

Altheim, Franz and Stiehl, Ruth, Mazdak und Porphyrius, Berlin, 1953.

Amato, Eugenio and Ramelli, Ilaria, "Filosofia rhetoricans in Niceforo Cumno: 1'inedito trattato Sui corpi primi e semplici", Medioevo Greco 6 (2006), 1-40, 2.

Amerio, Maria Luisa, “Ancora sui nuovi frammenti di Appiano", Invigilata Lucernis 21 (1999), 35-42.

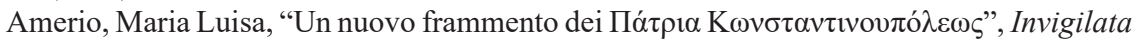
Lucernis 29 (2007), 7-13.

Anderson, Benjamin, "Classified Knowledge: The Epistemology of Statuary in the Parastaseis Syntomoi Chronikai”, BMGS 35(1) (2011), 1-19.

Angelov, Dimiter, "Byzantine Imperial Panegyric as Advice Literature", in: Rhetoric in Byzantium, ed. Elizabeth M. Jeffreys, Aldershot, 2003, 55-63.

Angelov, Dimiter, Imperial Ideology and Political thought in Byzantium (1204-1330), Cambridge-New York (NY), 2006.

Aubreton, Robert, "La tradition manuscrite des épigrammes de l'anthologie palatine", REA 70 (1968), 32-82.

Auwers, Jean-Marie and Guérard, Marie-Gabrielle, Procopii Gazaei Epitome in Canticum canticorum, Turnhout, 2011.

Baldwin, Barry, "Malchus of Philadelphia", DOP 31 (1977), 91-107.

Banchich, Peter Thomas, "Introduction: The Epitome of Histories", in: The History of Zonaras: From Alexander Severus through the Death of Theodosius the Great, edd. Peter Thomas Banchich and Eugene Lane, New York (NY), 2009, 1-19.

Bandini, Angelo Maria, Catalogus codicum Graecorum Bibliothecae Laurentianae II, Florentiae, 1768 [Leipzig 1961].

Baumstark, Anton, "Lucubrationes Syro-Graecae", Jahrbücher für classische Philologie, Suppl. 21 (1894), 353-524.

Barbour, Ruth, Greek Literary Hands A.D. 400-1600, Oxford, 1981.

Barnes, Timothy David, "The editions of Eusebius' Ecclesiastical History", GRBS 21 (1980), 191-201.

Batareikh, Elie (ed.), Chrysostomika, Rome, 1908, 978-1005.

Bazzani, Marina, "Theodore Metochites, a Byzantine Humanist", Byz 76 (2006), 32-52.

Beck, Hans-Georg, "Zur byzantinischen 'Mönchschronik", in: Speculum historiale. Geschichte im Spiegel von Geschichtsschreibung und Geschichtsdeutung (Festschrift für Johannes Spörl aus Anlass seines 60. Geburtstages), edd. Clemens Bauer, Laetitia Boehm, and Max Müller, Freiburg im Breisgau, 1965, 188-197.

Beck, Hans-Georg, "Christliche Mission und politische Propaganda im byzantinischen Reich", Settimane di studio del Centro Italiano di Studi sull'Alto Medioevo 14 (1967), 649-674.

Berger, Albrecht, Untersuchungen zu den Patria Konstantinupoleos (Poikila Byzantina 8), Bonn, 1988. 
Berger, Albrecht, Accounts of Medieval Constantinople: The Patria (Dumbarton Oaks Medieval Library 24), Cambridge (MA), 2013.

Berger, Friederike, Die Textgeschichte der Historia animalium des Aristoteles (Serta Graeca 21), Wiesbaden, 2005.

Bertini-Malgarini, Alessandra, “Alcuni detti di Diogene Cinico nel cod. Vat. gr. 96", in: Studi per Riccardo Ribuoli, ed. Franco Piperno, Roma, 1986, 17-26.

Bertrac, Pierre, "Le texte de la Bibliothèque historique", in: Diodore de Sicile. Bibliothèque historique. Tome I, Introduction générale. Livre I, Paris, 1993 [Paris, 2002], lxxvii-clxvi.

Bianchi, Ugo, "La doctrine zarathoustrienne des deux esprits", in: Selected Essays on Gnosticism, Dualism and Mysteriosophy, ed. Ugo Bianchi, Leiden, 1978, 361-389.

Bianconi, Daniele, "La biblioteca di Cora tra Massimo Planude e Niceforo Gregora, Una questione di mani”, Segno e Testo 3 (2005), 391-438.

Biedl, Artur, "Der Heidelberger Cod. Pal. Gr. 129 - Die Notizensammlung eines byzantinischen Gelehrten", Würzburger Jahrbücher für die Altertumswissenschaft 3 (1948), 100-106.

Biedl, Artur, Das grosse Exzerpt $\Phi$. Zur Textgeschichte des Laertios Diogenes (Studi e Testi 184), Città del Vaticano, 1955.

Blaudeu, Philippe, "Mémoire monophysite et besoins chalcédoniens. Quelques réflexions sur les vestiges de l'Histoire ecclésiastique de Jean Diacrinoménos", Adamantius 7 (2001), 76-97.

Blaudeu, Philippe, Alexandrie et Constantinople, 451-491: de l'histoire à la géoecclésiologie (Bibliothèque des écoles françaises d'Athènes et de Rome 327), Paris, 2006.

Bleckmann, Bruno, Die Reichskrise des III. Jahrhunderts in der spätantiken und byzantinischen Geschichtsschreibung. Untersuchungen zu den nachdionischen Quellen der Chronik des Johannes Zonaras [PhD thesis, Universität Köln], München, 1992.

Bleckmann, Bruno, "Bemerkungen zu den Annales des Nicomachus Flavianus", Historia 44 (1995), 83-99.

Bleckmann, Bruno, "Fragmente heidnischer Historiographie zum Wirken Julians", in: Jenseits der Grenzen: Beiträge zur spätantiken und frühmittelalterlichen Geschichtsschreibung, edd. Andreas Goltz, Hartmut Leppin, and Heinrich SchlangeSchöningen, Berlin, 2009, 61-78.

Bleckmann, Bruno, "Der salmasische Johannes Antiochenus: ein Versuch zur Bestimmung seines Profils für die Geschichte der Spätantike", in: Historiae Augustae: colloquium Genevense in honorem F. Paschoud septuagenarii. Les traditions historiographiques de l'Antiquité tardive: idéologie, propagande, fiction, réalité, edd. Lavinia Galli Milić and Nicole Hecquet-Noti, Bari, 2010, 51-62.

Bleckmann, Bruno, "Last Pagans, Source Criticism and Historiography of the Late Antiquity", Millennium 12 (2015), 103-116.

Blockley, Roger C., The Fragmentary Classicising Historians of the Later Roman Empire: Eunapius, Olympiodorus, Priscus, and Malchus, II, Liverpool, 1983.

Boissevain, Ursul Philip, De Excerptis Planudeis et Constantinianis ab Angelo Maio editis quae vulgo Cassio Dioni attribuuntur, Roterodamum, 1884.

Boissevain, Ursul Philip, "Über die dem Ioannes Antiochenus zugeschriebenen Excerpta Salmasiana”, Hermes 22 (1887), 161-178.

Boissevain, Ursul Philip, Dionis Cassii Cocceiani Historiarum romanarum quae supersunt, I, Lipsiae, 1895.

Boor, Carolus de, Nicephori archiepiscopi Constantinopolitani opuscula historica (Teubner), Leipzig, 1880. 


\section{Bibliography}

Boor, Carolus de, "Zu den Excerptsammlungen des Konstantin Porphyrogennetos", Hermes 19 (1884a), 123-148.

Boor, Carolus de, "Zur Kenntnis der Handschriften der griechischen Kirchenhistoriker. Codex Baroccianus 142”, Zeitschrift für Kirchengeschichte 6 (1884b), 478-494.

Boor, Carolus de, "Neue Fragmente des Papias, Hegessipus and Pierius in bisher unbekannten Excerpten aus der Kirchengeschichte des Philippus Sidetes", Texte und Untersuchungen 5(2), Lipsiae (1888), 167-184.

Boor, Carolus de, "Römische Kaisergeschichte in byzantinischer Fassung, III. Die salmasischen und treuschen Exzerpte", BZ 2 (1893), 195-211.

Boor, Carolus de, "Zu Johannes Antiochenus", Hermes 34 (1899), 298-304.

Boor, Carolus de, "Zweiter Bericht über eine Studienreise nach Italien zum Zwecke handschriftlicher Studien über byzantinische Chronisten", Sitzungsberichte der Königlich Preussischen Akademie der Wissenschaften zu Berlin 9 (1902), 146-164.

Boor, Carolus de, "Suidas und die Konstantinische Exzerptsammlung 1", BZ21 (1912), 381-430.

Boor, Carolus de, "Suidas und die Konstantinische Exzerptsammlung 2", BZ 23 (19141919), 1-127.

Booth, Phil, Crisis of Empire: Doctrine and Dissent at the End of Late Antiquity, Berkeley (CA), 2013.

Boyce, Mary, A History of Zoroastrianism, I, Leiden, 1975.

Boyce, Mary, A History of Zoroastrianism, II, Leiden, 1982.

Boyce, Mary and Grenet, Frantz, A History of Zoroastrianism, III, Leiden, 1991.

Brandt, Hartwin, "Zur historiographischen Konzeption des Isaurers Candidus", in: Griechische Profanhistoriker des fünften nachchristlichen Jahrhunderts, edd. Bruno Bleckmann and Timo Stickler, Stuttgart, 2014, 161-170.

Braund, David, Georgia in Antiquity: A History of Colchis and Transcaucasian Iberia 550 $B C-A D$ 562, Oxford, 1994.

Breccia, Gastone, "I trattati tecnici e l'enciclopedia di Costantino VII Porfirogenito: arte militare e agronomia", in: Voci dell'Oriente: Miniature e testi classici da Bisanzio alla Biblioteca Medicea Laurenziana, ed. Massimo Bernabò, Firenze, 2011, 133-142.

Bregman, Jay, Synesius of Cyrene: Philosopher-bishop, Berkeley (CA), 1982.

Brodka, Dariusz, "Eustathius von Epiphaneia und das Ende des Weströmischen Reiches", JÖB 57 (2006), 59-78.

Browning, Robert, "Notes on the 'Scriptor Incertus de Leone Armenio'”, Byz 35 (1965), 289-411.

Browning, Robert, History, Language and Literacy in the Byzantine World, Northampton, 1989.

Brubaker, Leslie and Haldon, John, Byzantium in the Iconoclast Era (ca. 680-850): The sources, Aldershot, 2001.

Brunt, Peter A., "On Historical Fragments and Epitomes”, CQ 30 (1980), 477-494.

Büchner, Karl, Somnium Scipionis, Wiesbaden, 1976.

Bühler, Winfried, Zenobii Athoi proverbia. Volumen primum, Prolegomena complexum, in quibus codices describuntur, Göttingen, 1987.

Burgess, Richard W., "The Dates and Editions of Eusebius' Chronici Canones and Historia Ecclesiastica”, Journal of Theological Studies 48 (1997), 471-504.

Burgess, Richard W., Studies in Eusebian and Post-Eusebian Chronography, Stuttgart, 1999.

Burgess, Richard W. and Kulikowski, Michael, Mosaics of time: The Latin chronicle traditions from the first century B.C. to the sixth century A.D. Volume One: A historical introduction to the chronicle genre from its origins to the High Middle Ages (Studies in the early Middle Ages 33), Turnhout, 2013. 
Burgess, Richard W. and Kulikowski, Michael, "The Historiographical Position of John Malalas. Genre in Late Antiquity and the Byzantine Middle Ages", in: Die Weltchronik des Johannes Malalas, edd. Mischa Meier, Christine Radtki, and Fabian Schulz, Stuttgart, 2016, 93-117.

Burgmann, Hans (ed.), Ecloga Basilicorum, Frankfurt am Main, 1988.

Burn, Andrew Robert, "Procopius and the Island of Ghosts", English Historical Review 70 (1955), 258-261.

Bury, John Bagnell (ed.), Edward Gibbon, The History of the Decline and Fall of the Roman Empire, IV, New York (NY), 1906a.

Bury, John Bagnell, "The Treatise De administrando imperio", BZ 15 (1906b), 517-577.

Bury, John Bagnell, "The Homeric and the Historic Kimmerians", Klio 6 (1907), 79-88.

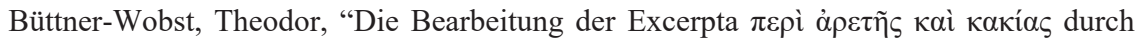
Salmasius”, BZ 14 (1905), 756-757.

Büttner-Wobst, Theodor, "Die Anlage der historischen Encyklopädie des Konstantinos Porphyrogennetos", BZ 15(1) (1906) 88-120.

Cameron, Alan, "Some prefects called Julian", Byz 47 (1977) 42-64.

Cameron, Alan, The Greek Anthology from Meleager to Planudes, Oxford, 1993.

Cameron, Alan, The Late Pagans of Rome, Oxford, 2011.

Cameron, Alan, "The Last Days of the Academy at Athens", in: Wandering Poets and Other Essays on Late Greek Literature and Philosophy, ed. Alan Cameron, Oxford, 2015, 205-245.

Cameron, Averil and Cameron, Alan, "Christianity and Tradition in the Historiography of the Late Empire", CQ 14(2) (1964), 316-328.

Cameron, Averil, "How Did the Merovingian Kings Wear Their Hair?" Revue belge de philologie et d'histoire 48 (1965), 1203-1216.

Cameron, Averil, "Agathias on the early Merovingians", Annali della Scuola Normale Superiore di Pisa, 2d ser., 37 (1968), 95-140.

Cameron, Averil, "Agathias on the Sassanians", DOP 23/24 (1969-1970), 67-183.

Cameron, Averil, Agathias, Oxford, 1970.

Cameron, Averil, "The Eastern Provinces in the Seventh Century A.D. Hellenism and the Emergence of Islam", in: Hellenismos. Quelques jalons pour une histoire de l'identité grecque, ed. Suzanne Said, Leiden, 1991, 287-313.

Cameron, Averil, "Disputations, Polemical Literature and the Formation of Opinion in the early Byzantine Period", in: Changing Cultures in Early Byzantium, ed. Averil Cameron, Aldershot, 1996a, 250-276.

Cameron, Averil,, Procopius and the Sixth Century, London, 1996b.

Cameron, Averil, "How to Read Heresiology", JMEMS 33(3) (2003), 471-492.

Canart, Paul, Catalogue des manuscripts grecs de l'Archivio di San Pietro (Studi e Testi 246), Cité du Vatican, 1966.

Canart, Paul and Peri, Vittorio, Sussidi bibliografici per i manoscritti greci della Biblioteca Vaticana, Città del Vaticano, 1970.

Canepa, Matthew P., The Two Eyes of the Earth. Art and Ritual of Kingship between Rome and Sasanian Iran, Berkeley (CA), 2009.

Cantore, Raffaella, Per la storia del testo di Erodoto: studi sulla famiglia romana, Bologna, 2013.

Carlini, Antonio, "La tradizione manoscritta del Pastor di Hermas e il problema dell'unità di composizione dell'opera", in: Festschrift zum 100-jährigen Bestehen der Papyrussammlung der Österreichischen Nationalbibliothek Papyrus Erzherzog Rainer, edd. Helene Loebensstein, Eve A. E. Reymond, Hermann Harrauer, Tito Orlandi, Antonio Carlini, and Danile Foraboschi, Wien, 1983, 95-112. 


\section{Bibliography}

Carolla, Pia, "Non deteriores. Copisti e filigrane di alcuni manoscriti degli Excerpta de Legationibus", Miscellanea Bibliothecae Apostolicae Vaticanae 15 (2008), 129-170.

Carolla, Pia, "John Malalas in the Excerpta Constantiniana de Insidiis (EI): A Philological and Literary Perspective", in: Die Weltchronik des Johannes Malalas: Autor, Werk, Überlieferung, edd. Mischa Meier, Christine Radtki, and Fabian Schulz, Stuttgart, 2016, 239-252.

Cassin, Matthieu, Debié, Muriel, and Perrin, Michel-Yves, "La question des éditions de l'histoire ecclésiastique et le livre X", in Eusèbe de Cesarée. Histoire ecclésiastique. Commentaire. Tome I: Etudes d'introduction, edd. Sébastien Morlet and Lorenzo Perrone, Paris, 2012, 185-207.

Cavallo, Guglielmo, "Alfabetismi e letture a Bisanzio", in: Lire et écrire à Byzance, ed. Brigitte Mondrain, Paris, 2006, 97-109,

Cavallo, Guglielmo and Odorico, Paolo, Lire à Byzance, Paris, 2006.

Cesa, Maria, "Etnografia e geografia nella visione storica di Procopio di Cesarea", Studi classici e orientali 32 (1982), 189-215.

Ceulemans, Reinhart and Auwers, Jeam-Mari, "Procopii Gazaei Epitome in Canticum Canticorum", Byzantion 82 (2012), 493-508.

Chadwick, Henry, "Ancient Anthologies and Florilegia, Pagan and Christian", in: Studies on Ancient Christianity (Variorum), Aldershot, 2006, XIX, 1-10.

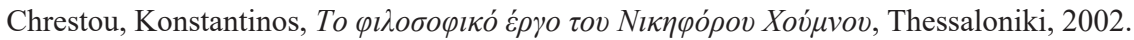

Christensen, Arthur, L'Iran sous les Sassanides, Copenhague, 1936.

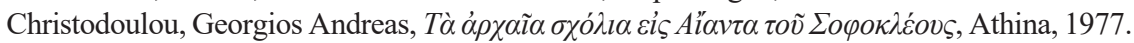

Cirillo, Salvatore, Codices Graeci manuscripti Regiae bibliothecae Borbonicae, II, Neapoli, 1832.

Cohen-Skalli, Aude, "Notice: Le text des fragments de la seconde pentade de la Bibliothèque Historique de Diodore", in: Bibliothèque historique. Fragments, I: Livres $V I-X$, ed. Aude Cohen-Skalli, Paris, 2012, vii-lxxvii.

Colonna, Aristide, "Sull'Argumentum dell'Aiace sofocleo", in: Studi di filologia classica in onore di Giusto Monaco, I, Palermo, 1991, 203-208.

Constantinides, Costas, Higher Education in Byzantium in the Thirteenth and Early Fourteenth Centuries (1204-ca. 1310), Nicosia, 1982.

Constantinides, Costas, "A marginal note on Britain and the Britons in an Athonite manuscript of Michael Glykas", in: Hypermachos: Studien zur Byzantinistik, Armenologie und Georgistik. Festschrift fur Werner Seibt zum 65. Geburtstag, edd. Christos Stavrakos, Alexandra-Kyriaki Wassiliou, and Mesrob K. Krikorian, Vienna, 2008, 15-23.

Cook, Brad L., "The Essential Philip of Macedon. A Byzantine Epitome of His Life", GRBS 45 (2005), 189-211.

Cramer, Anthony, Anecdota Graeca e codd. Manuscriptis Bibliothecae regiae Parisiensis, II, Oxonii, 1839.

Crisci, Edoardo, Marilena, "I più antichi codici miscellanei greci. Materiali per una riflessione", in: Il codice miscellaneo. Tipologie e funzioni. Atti del Convegno Internazionale - Cassino, 14-17 maggio 2003, edd. Edoardo Crisci and Oronzo Pecere (Segno e testo 2), Turnhout, 2004, 109-144.

Croke, Brian, "Uncovering Byzantium's historiographical audience", in: History as literature in Byzantium, ed. Ruth Macrides, Farnham, 2010, 25-53.

Crone, Patricia, "Kavad's Heresy and Mazdak's Revolt", Iran 29 (1991), 21-42.

Dagron, Gilbert, Constantinople imaginaire: études sur le recueil des patria, Paris, 1984. 
Dain, Alphonse, "L'encyclopédisme de Constantin Porphyrogénète", Lettres d'Humanité 12 (1953), 64-81.

Dain, Alphonse, "La transmission des textes littéraires classiques de Photius à Constantine Porphyrogénète", DOP 8 (1954), 33-47.

Dain, Alphonse and de Foucault, Jules Albert, “Les stratégistes byzantins”, TM 2 (1967), 317-392.

Daly, Loyd William, Contributions to a History of Alphabetization in Antiquity and the Middle Ages, Brussels, 1967.

Darrouzès, Jean, "Notes de littérature et de critique: I, Nicétas d'Heraclea ho tou Serron", REB 18 (1960), 179-184.

Debié, Muriel, "Syriac Historiography and Identity Formation", Church History and Religious Culture 89 (2009), 93-114.

De Groote, Marc, "The Soterios Project Revisited: Status quaestionis and the Future Edition", BZ 108 (2015), 63-78.

Delacenserie, Emerance, L'Histoire ecclésiastique de Socrate de Constantinople: banque de données et autorité historiographiques pour la création d'oeuvres originales au VIe $s$. (Théodore le Lecteur, Cassiodore, la première version arménienne) [ $\mathrm{PhD}$ thesis, Universiteit Gent], Gand, 2016.

Demoen, Kristoffel, "La poésie de la $\sigma 0 \lambda \lambda$ oүท́. Les paratextes métriques des manuscrits byzantins et le (vocabulaire du) recueil", in: Pour l'amour de Byzance: Hommage à Paolo Odorico, edd. Christian Gastgeber and Charis Messis, Francfort-sur-le-Main, 2013, 89-98.

De Stefani, Edoardo Luigi, “Excerptum Vaticanum De rebus mirabilibus”, Studi Italiani di Filologia Classica 11 (1903), 93-96.

De Stefani, Edoardo Luigi, "Gli excerpta della Historia animalium di Eliano", Studi Italiani di Filologia Classica 12 (1904), 145-180.

Detoraki, Marina, "Chronicon animae utile. La Chronique de Georges", in: Myriobiblos. Essays on Byzantine Literature and Culture, edd. Theodora Antonopoulou, Sofia Kotzabassi, and Marina Loukaki (Byzantinisches Archiv 29), Boston (MA)-Berlin, 2015, 103-130.

De Vore, David J., “Genre and Eusebius' Ecclesiastical History: Towards a Focused Debate", in: Eusebius of Cesarea: Tradition and Innovation, edd. Aaron Johnson and Jeremy Scott, Cambridge (MA), 2015, 19-49.

Devreesse, Robert, "Chaines exégétiques grecques", in: Supplément au dictionnaire de la Bible, I, edd. Louis Pirot, André Robert, Henri Cazelles, André Feuillet, and Jacques Briend, Paris, 1928, col. 1083-1234.

Diller, Aubrey, "Codices Planudei”, BZ 37 (1937), 295-301.

Diller, Aubrey, "The Tradition of Stephanus Byzantius", TAPhA 69 (1938), 333-348.

Diller, Aubrey, "Excerpts from Strabo and Stephanus in Byzantine Chronicles", TAPhA 81 (1950), 241-253.

Diller, Aubrey, "Pausanias in the Middle Ages", TAPhA 87 (1956), 84-97.

Diller, Aubrey, "The Manuscripts of Pausanias”, TAPhA 88 (1957), 169-188.

Diller, Aubrey, "A Greek Manuscript Strayed from the Vatican Library", Bodleian Library Record 7 (1962), 39-42.

Diller, Aubrey, Studies in Greek Manuscript Tradition, Amsterdam, 1983.

Dilts, Mervin R. "The Testimonia of Aelian's Varia Historia”, Manuscripta 15 (1971), $3-12$.

Dilts, Mervin R. Dilts, Claudius Aelianus. Varia Historia, Leipzig, 1974. 


\section{Bibliography}

Dimaio, Michael, "The Antiochene Connection: Zonaras, Ammianus Marcellinus, and John of Antioch on the Reigns of the Emperors Constantius II and Julia”, Byz 50 (1980), $158-185$.

Dimitrov, Dimitar Y., "Synesius of Cyrene and the Christian Neoplatonism: Patterns of Religious and Cultural Symbiosis", in: What Happened to the Ancient Library of Alexandria? edd. Mostafa El-Abbadi, Omnia Fathallah and Ismail Serageldin, Leiden, 2008, 149-170.

Dobesch, Gerhard, "Zu Virunum als Namen der Stadt auf dem Magdalensberg und zu einer Sage der kontinentalen Kelten”, Carinthia I 187 (1997), 107-128.

Dobschütz, Ernst, "Der Kammerherr Theophanes (Zu Konstantins des Purpurgeborenen Festpredigt auf die Translation des Christusbildes von Edessa)", BZ 10 (1901), 166-181.

Dorandi, Tiziano, Laertiana. Capitoli sulla tradizione manoscritta e sulla storia del testo delle Vite dei filosofi di Diogene Larzio (Beiträge zur Altertumskunde 264), Berlin-New York (NY), 2009.

Dorival, Gilles, Les chaînes exégétiques grecques sur les psaumes. Contribution à l'étude d'une forme littéraire, Louvain, 1986.

Dorival, Gilles, "Biblical Catenae: Between Philology and History", in: Commentaries, Catenae and Biblical Tradition, ed. Hugh Houghton (Texts and Studies 13), Piscataway (NJ), 2016, 90-106.

Downey, Glanville, A History of Antioch in Syria from Seleucus to the Arab Conquest, Princeton (NJ), 1974.

Dragon, Gilbert, Emperor and Priest: The Imperial Office in Byzantium, Cambridge, 2003.

Drijvers, Jan Willem, Helena Augusta. The Mother of Constantine the Great and the Legend of Her Finding of the True Cross, Leiden, 1992.

Drijvers, Jan Willem, "A Roman Image of the Barbarian Sasanians", in: Romans, Barbarians, and the Transformation of the Roman World. Cultural Interaction and the Creation of Identity in Late Antiquity, edd. Danuta Shanzer and Ralph W. Mathisen, Farnham, 2010, 67-76.

Drinkwater, John, The Alamanni and Rome 213-496 (Caracalla to Clovis), Oxford, 2007.

Drost-Abgarjan, Armenuhi, "Ein neuer Fund zur armenischen Version der EusebiosChronik", in: Julius Africanus und die christliche Weltchronistik, ed. Martin Wallraff (Texte und Untersuchungen zur Geschichte der altchristlichen Literatur 157), Berlin, 2006, 255-262.

Dubarle, André-Marie, "L'homélie de Grégoire le Référendaire pour la réception de l'image d'Édesse", REB 55 (1997), 5-51.

Ducellier, Alain, Chrétiens d'Orient et Islam au Moyen Âge VIIe - XVe siècle, Paris, 1996.

Duchesne-Guillemin, Jacques, Ohrmazd et Ahriman, Paris, 1953.

Duchesne-Guillemin, Jacques, “Ahriman”, Encyclopcedia Iranica, I/6-7 (1984), 670-673.

Dunbabin, Jean, Charles I of Anjou: Power, Kingship and State-making in Thirteenthcentury Europe, London, 1998.

Dusil, Stephan, Swedler, Gerald, and Schwitter, Rapahael (edd.), Exzerpieren-Kompilieren - Tradieren. Transformationen des Wissens zwischen Spätantike und Frühmittelalter, Berlin, 2017.

Dyck, Andrew R. (ed.), Epimerismi Homerici. Pars altera epimerismos continens qui

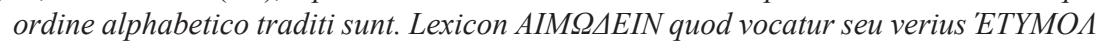

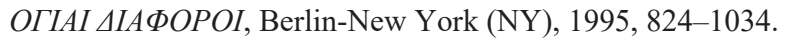




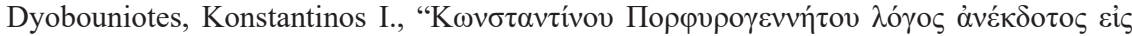

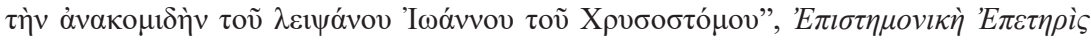

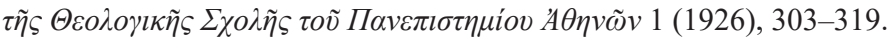

Ehrhard, Albert, "Zu den Sacra Parallela des Johannes Damascenus und dem Florilegium des Maximos", BZ 10 (1901), 394-415.

Eleutheri, Paolo, Storia della tradizione manoscritta di Museo, Pisa, 1981.

Eramo, Immacolata, “A Word from the General: Ambrosianus B 119 sup. and Protreptic Speeches in Byzantine Military Manuals", in: Anthologies of Historiographical Speeches from Antiquity to Early Modern Times, edd. Juan Carlos Iglesias-Zoido and Victoria Pineda, Leiden, 2017, 95-114.

Erbse, Hartmut, Theosophorum Graecorum fragmenta, Stutgardiae, 1995.

Featherstone, Jeffrey Michael, "The Logothete Chronicle in Vat. gr. 163", Orientalia Christiana 64(2) (1998), 419-434.

Featherstone, Jeffrey Michael, "Preliminary remarks on the Leipzig Manuscript of De Cerimoniis", BZ 95 (2002), 457-479.

Featherstone, Jeffrey Michael, "Further Remarks on the De Cerimoniis", BZ 97(1) (2004), $113-121$.

Featherstone, Jeffrey Michael, "Theophanes Continuatus VI and De Cerimoniis I,96", $B Z$ 104(1) (2011), 109-116.

Featherstone, Jeffrey Michael, "Theophanes Continuatus: A History for the Palace", in: $L a$ face cachée de la littérature byzantine. Le texte en tant que message immédiat. Actes du colloque international, Paris, 5-6-7 juin 2008, organisé par le centre d'études byzantines de l'EHESS sous la direction de Paolo Odorico (Dossiers byzantins 11), ed. Paolo Odorico, Paris, 2012, 123-135.

Featherstone, Jeffrey Michael, "Basileios Nothos as Compiler: The De Cerimoniis and Theophanes Continuatus", in: Textual Transmission in Byzantium: Between Textual Criticism and Quellenforschung, edd. Juan Signes Codoñer and Inmaculada Pérez Martin (Lectio 2), Turnhout, 2013, 353-372.

Featherstone, Jeffrey Michael, "Basil the Nothos as Compiler: The De Cerimoniis and Theophanes Continuatus", in: Textual Transmission in Byzantium: Between Textual Criticism and Quellenforschung, edd. Juan Signes Codoñer and Inmaculada Pérez Martin (Lectio 2), Turnhout, 2014, 353-372.

Ferroni, Lorenzo, "Compendia Planudea: un testimone inedito per la tradizione medievale indiretta del Pastore di Erma”, Reb.Publ.Litt. 26 (2003), 99-109.

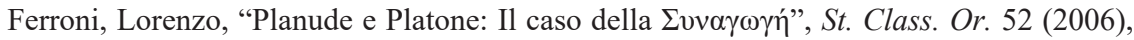
$275-302$.

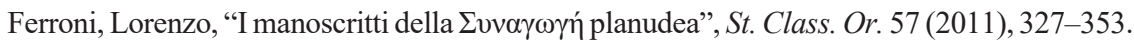

Flacelière, Robert, Plutarque, Vies, Paris, 1993.

Flusin, Bernard and Paramelle, Joseph, "La Vie métaphrastique de Pélagie BHG 1479", in: Pélagie la pénitente. Métamorphoses d'une légende, vol. 2. La survie dans les littératures européennes, ed. Pierre Petitmengin, Paris, 1984, 15-41.

Flusin, Bernard (ed.), "Constantin Porphyrogénète. Discours sur la translation des reliques de saint Grègoire de Nazianze (BHG 728)", REB 57 (1999), 5-97.

Flusin, Bernard, "L'empereur hagiographe, Remarques sur le rôle des premiers empereurs macédoniens dans le culte des saints", in: L'empereur hagiographe. Culte des saints et monarchie byzantine et post-byzantine. Actes des colloques internationaux «L'empereur hagiographe» (13-14 mars 2000) et «Reliques et miracles» (1-2 novembre 2000) tenus au New Europe College, ed. Petre Guran, Bucarest, 2001, 41-47. 


\section{Bibliography}

Flusin, Bernard, "Les Excerpta constantiniens: Logique d'une anti-histoire", in: Fragments d'historiens grecs: Autor de Denys d'Halicarnasse, Histoire d'un texte, ed. Sylvie Pittia, Rome, 2002, 537-559.

Flusin, Bernard, "Re-writing History: John Skylitzes' Synopsis Historion", in: John Skylitzes: A Synopsis of Byzantine History, 811-1057: Translation and Notes, ed. John Wortley, Cambridge, 2010, xii-xxxiii.

Foerster, Richtsteig (ed.), Libanii opera, I(2), Lipsiae, 1903.

Foerster, Richtsteig (ed.), Libanii opera, IX, Lipsiae, 1927.

Follieri, Henrica, Codices graeci Bibliothecae Vaticanae selecti temporum locorumque ordine digesti commentariis et transcriptionibus instructi, Città del Vaticano, 1969.

Formentin, Maria Rosa, Catalogus codicum Graecorum Bibliothecae Nationalis Neapolitanae, II, Roma, 1995.

Forster, Edward Seymour, De Mundo, Oxford, 1914.

Foss, Clive and Winfield, David, Byzantine Fortifications: An Introduction, Pretoria, 1986.

Freese, John Henry, The Library of Photius, New York (NY), 1920.

Fryde, Edmund, Greek Manuscripts in the Private Library of the Medici, 1469-1510, I, Aberystwyth, 1996.

Fryde, Edmund, The Early Palaeologan Renaissance (1261-c.1360), Leiden-Boston (MA)-Köln, 2000.

Frye, Richard Nelson, "BĀBAK”, Iranian Encyclopaidia III(3) (1988), 298-299.

Furrer-Pilliod, Christiane, Horoi kai hypographai. Collections alphabétiques de définitions profanes et sacrées, Vatican City, 2000.

Gaisford, Thomas, Poetae Minores Graeci, I, Lipsiae, 1823.

Gallavotti, Carlo, "Planudea VII", BollClass 8 (1987) 96-128.

Gamillscheg, Ernst and Harlfinger, Dieter, Repertorium der griechischen Kopisten 800 1600, 2. Teil: Handschriften aus Bibliotheken Frankreichs und Nachträge zu den Bibliotheken Großbritanniens, Wien, 1989.

Garzya, Antonio, Giangrande, Giuseppe, and Manfredini, Mario, Sulla tradizione manoscritta dei «Moralia» di Plutarco, Salerno, 1988.

Gelzer, Heinrich, Sextus Julius Africanus und die byzantinische Chronographie, I, New York (NY), 1880.

Gelzer, Heinrich, “Zu Africanus und Johannes Malalas”, BZ 3 (1894), 394-395.

Gentz, Günter and Aland, Kurt, "Die Quellen der Kirchengeschichte des Nicephorus und ihre Bedeutung fur die Konstituierung des Textes der älteren Kirchenhistoriker", ZNW 42 (1949), 104-141.

Gentz, Günter and Winkelmann, Friedhelm, Die Kirchengeschichte des Nicephorus Callistus Xanthopulus und ihre Quellen, Berlin, 1966.

Ghirshman, Roman and Ghirshman, Tania, Les Chionites-Hephtalites, Le Caire, 1948.

Giacone, Roberto, "Sul concetto di enciclopedia nel pensiero classico e medievale", Rivista di studi classici 21 (1973), 96-102.

Giannelli, Cyrus, "Vat. gr. 504", Rivista di Studi Bizantini e Neoellenici 5 (1939), 463.

Gottlieb, Gunther, "Die Nachrichten des Agathias aus Myrina über das Christentum der Franken und Alamannen", Jahrbuch des römisch-germanischen Zentralmuseums Mainz 16 (1969), 149-158.

Goukowsky, Paul, "Trois nouveaux extraits d'Appien”, in: Hellenica Symmicta, Histoire, linguistique, épigraphie, ed. Claude Brixhe, Nancy, 1995, 63-70.

Goukowsky, Paul, "Introduction", in: Diodore de Sicile, Bibliotheque Historique Fragments: Tome IV: Livres XXXIII-XL, ed. Paul Goukowsky, Paris, 2006, i-xxxiv. 
Goukowsky, Paul, "Quelques remarques sur le papyrus Hauniensis 6: 1'historien antique dans sa forge ou le degré zéro de l'écriture historique", in: Folia Graeca in honorem Edouard Will: Historica, edd. Paul Goukowsky and Christophe Feyel, Nancy, 2012, 155-192.

Goulet, Richard (ed.), Dictionnaire des philosophes antiques II, Paris, 1994.

Graux, Charles Henri, Essai sur les origines du fonds grec de l'Escurial: épisode de l'histoire de la renaissance des lettres en Espagne, Paris, 1880.

Greatrex, Geoffrey, “The Dates of Procopius' Works”, BMGS 18 (1994), 101-114.

Greatrex, Geoffrey, "Byzantium and the East in the Sixth Century", in: The Cambridge Companion to the Age of Justinian, ed. Michael Maas, New York (NY), 2005, 477-509.

Greatrex, Geoffrey, The Chronicle of Pseuso-Zachariah Rhetor: Church and War in Late Antiquity, Liverpool, 2011.

Greatrex, Geoffrey, "Perceptions of Procopius in recent scholarship", Histos 8 (2014a) 76-121.

Greatrex, Geoffrey, "Théodore le Lecteur et son épitomateur anonyme du VIIe siècle", in: Historiographie tardo-antique et transmission des savoirs, edd. Philippe Blaudeau and Peter Van Nuffelen, Berlin, 2014b, 121-142.

Greatrex, Geoffrey (ed.), Work on Procopius Outside the English-speaking World: A Survey, Newcastle upon Tyne, 2019.

Gregory, Timothy, A History of Byzantium, Oxford, 2005.

Grierson, Philip and Jenkins, Romilly James, “The Date of Constantine VII's Coronation”, Byzantion 32/1 (1962) 133-138.

Guscin, Mark (ed.), The Image of Edessa, Leiden, 2009.

Guy, Jean-Claude, Recherches sur la tradition grecque des Apophthegmata patrum, Bruxelles, 1962.

Hadot, Ilsetraut, "Simplicius or Pricianus? On the Author of the Commentary on Aristotle's De Anima", Mnemosyne 55(2) (2002), 159-199.

Hägg, Tomas, Photios als Vermittler antiker Literatur: Untersuchungen zur Technik des Referierens und Exzerpierens in der Bibliotheke, Stockholm, 1975.

Hagl, Wolfgang, Arcadius Apis Imperator: Synesios von Kyrene und sein Beitrag zum Herrscherideal der Spätantike, Stuttgart, 1997.

Haldon, John, Byzantium in the Seventh Century: The Transformation of a Culture, Cambridge, 1990.

Haldon, John, A Critical Commentary on the Taktika of Leo VI (Dumbarton Oaks Studies 44), Washington D.C., 2014.

Halkin, François, "Le règne de Constantin d'après la Chronique inédite du PseudoSyméon", Byz 29-30 (1959-1960), 7-27.

Hannick, Christian, "Enzyklopädie, Enzyklopädik", Lexikon des Mittelalters 3 (1986), 2031-2039.

Haupt, Herman, "Über die Herkunft der dem Dio Cassius beigelegten planudischen Excerpte", Hermes 14 (1879), 36-64 and 291-297.

Heiberg, Johan Ludvig (ed.), Paulus Aegineta, I-II, (Corpus medicorum Graecorum 9.19.2) Leipzig, 1921-1924.

Henning, Walter Bruno, Zoroaster. Politician or Witch-Doctor? London, 1951.

Hense, Otto, "Ioannes Stobeaus", RE 9(2) 1916, 2549-2586.

Herrenschmidt, Clarisse, "Le xwêtôdas ou mariage «incestueux» en Iran ancien", in: Épouser au plus proche, inceste, prohibitions et stratégies matrimoniales autour de la Méditerranée, ed. Pierre Bonte, Paris, 1994, 113-25.

Herzfeld, Ernst, Paikuli. Monument and Inscription of the Early History of the Sasanian Empire, I, Berlin, 1924. 
Heyden, Katharina, "Die christliche Geschichte des Philippos von Side, mit einem kommentierten Katalog der Fragmente", in: Julius Africanus und die Christliche Weltchronistik, ed. Martin Wallraff, Berlin, 2006, 209-243.

Hinz, Vinko, Nunc Phalaris Doctum Protulit Ecce Caput, (Beitrage Zur Altertumskunde 148), Munich, 2001.

Hock, Ronald and O'Neil, Edward, The Chreia and Ancient Rhetoric: Classroom Exercises, Atlanta (GA), 2002.

Hofeneder, Andreas, "Die Gründungslegende von Virunum", in: Akten des 5. deutschsprachigen Keltologensymposiums, Zürich, 7.-9. September 2009 (Keltische Forschungen. Allgemeine Buchreihe), edd. Karin Stüber, Thomas Zehnder, and Dieter Bachmann, Wien, 2010, 123-135.

Høgel, Christian, Symeon Metaphrastes: rewriting and canonization, Copenhagen, 2002.

Holmes, Catherine, "The rhetorical structures of John Skylitzes' Synopsis Historion”, in: Rhetoric in Byzantium, ed. Elizabeth Jeffreys, Aldershot, 2003, 187-199.

Holmes, Catherine, "Byzantine Political Culture and Compilation Literature in the Tenth and Eleventh Centuries: Some Preliminary Inquiries", DOP 64 (2010), 55-80.

Hose, Martin, "Das Gnomologion des Stobaios. Eine Landkarte des paganen Geistes", Hermes 133 (2005), 93-99.

Houghton, Hugh, The Latin New Testament. A Guide to Its History, Texts, and Manuscripts, Oxford, 2016.

Houghton, Hugh and Parker, David, "An Introduction to Greek New Testament Commentaries with a Prerliminary Checklist of New Testament Catena Manuscripts", in: Commentaries, Catenae and Biblical Tradition, ed. Hugh Houghton (Texts and Studies 13), Piscataway (NJ), 2016, 1-35.

Houghton, Hugh, Manafis, Panagiotis, and Myshrall, Amy, The Palimpsest Catena of Codex Zacynthius: Text and Translation (Texts and Studies 3), Piscataway (NJ), 2020.

Hovorum, Cyril, Will, Action and Freedom, Christological Controversies in the Seventh Century (Medieval Mediterranean: Peoples, Economies and Cultures, 400-1500), Leiden, 2008.

Howard-Johnston, James, "The De administrando imperio: A Re-examination of the Text and a Re-evaluation of Its Evidence about the Rus", in: Les centres proto-urbains russes entre Scandinavie, Byzance et Orient, edd. Michel Kazanskí, Anne Nercessian, and Constantin Zuckerman, Paris, 2000, 301-336.

Hunger, Herbert, Studien zur griechischen Paläographie, Wien, 1954.

Hunger, Herbert, Katalog der griechischen Handschriften der Österreichischen Nationalbibliothek, Wien, 1961.

Hunger, Herbert, Die profane hochsprachliche Literatur der Byzantiner, I-II, München, 1978. Hussey, Joan Mervyn, The Orthodox Church in the Byzantine Empire, Oxford, 1986.

Huxley, George Leonard, Anthemius of Tralles: A Study of Later Greek Geometry, Cambridge, 1959.

Iglesias-Zoido, Juan Carlos, and Victoria Pineda, Anthologies of Historiographical Speeches from Antiquity to Early Modern Times, Leiden, 2017.

Impellizeri, Salvatore, La letteratura bizantina da Costantino a Fozio, Firenze-SansoniMilano, 1975.

Irigoin, Jean, "Pour une étude des centres de copie byzantins", Scriptorium 13 (1959), 177-209. Irigoin, Jean, "Un écriture du Xe siècle: la minuscule bouletée", in: La paléographie grecque et byzantine, Paris 21-25 octobre 1974 (Colloques internationaux du Centre National de la Recherche Scientifique 559), edd. Jean Glénisson, Jacques Bompaire, and Jean Irigoin, Paris, 1977, 191-199. 
Irigoin, Jean and Flacelière, Robert, Plutarque. CEuvres Morales, I, Paris, 1987.

Istrin, Viktor Aleksandrovič, Xronika Georgija Amartola v drevnem slavjanorusskom perevode, II, Petrograd, 1922.

Jannin, Raymond, Constantinople byzantine: développement urbain et répertoire topographique, Paris, 1964.

Jeffreys, Elizabeth, Four Byzantine Novels, Liverpool, 2012.

Jenkins, Romilly James, "The Classical Background of the Scriptores Post Theophanem”, DOP 8 (1954), 11-30.

Jenkins, Romilly James, Constantine Porphyrogenitus, De Administrando Imperio, London, 1962.

Jenkins, Romilly James, "The Hellenistic Origins of Byzantine Literature", DOP 17 (1963), 37 and 39-52.

Johnson, Stephen, Later Roman Britain (Britain before the Conquest), London, 1980.

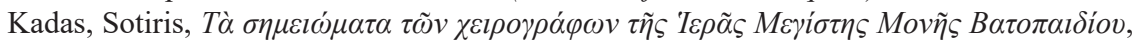
Hagion Oros, 2000.

Kaldellis, Anthony, “The Historical and Religious Views of Agathias. A Reinterpretation”, Byz 69 (1999), 206-252.

Kaldellis, Anthony, "Things Are Not What They Are: Agathias 'Mythistoricus' and the Last Laugh of Classical Culture", CQ 53(1) (2003), 295-300.

Kaldellis, Anthony, Procopius of Caesarea: Tyranny, History and Philosophy at the End of Antiquity, Philadelphia (PA), 2004.

Kaldelis, Anthony, "The Works and Days of Hesychios the Illustrius of Miletos", GRBS 45 (2005), 381-403.

Kaldellis, Anthony, in The Medieval Review 12.10 .30 (https://scholarworks.iu.edu/journa 1s/index.php/tmr/article/view/17693/23811).

Kaldellis, Anthony, "The Byzantine Role in the Making of the Corpus of Classical Greek Historiography: A Preliminary Investigation", Journal of Hellenic Studies 132 (2012), 71-85.

Kaldellis, Anthony, Ethnography after Antiquity. Foreign Lands and Peoples in Byzantine Literature, Philadelphia (PA), 2013.

Kaldellis, Anthony, "The Emergence of Literary Fiction in Byzantium and the Paradox of Plausibility", in: Medieval Greek Storytelling: Fictionality and Narrative in Byzantium (Mainzer Veröffentlichungen zur Byzantinistik 12), ed. Panagiotis Roilos, Wiesbaden, 2014, 115-130.

Kaldellis, Anthony, "The Manufacture of History in the Later Tenth and Eleven Centuries: Rhetorical Templates and Narrative Ontologies", in: Proceedings of the 23rd International Congress of Byzantine Studies, Belgrade, 2016, 293-306.

Kaltsogianni, Eleni, "The legacy of Aphthonios, Hermogenes and pseudo-Menander: Aspects of Byzantine Rhetoric under the Palaiologoi", in: A Companion to the Intellectual Life in the Palaiologan Period, ed. Sofia Kotzabassi (forthcoming), 1-63.

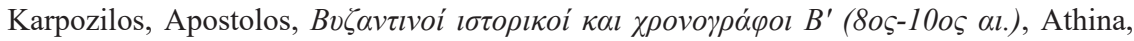
2002.

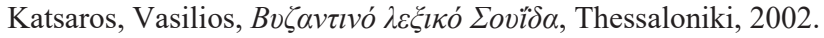

Kavrus-Hoffmann, Nadezhda, "Greek Manuscripts at Dumbarton Oaks: Codicological and Paleographic Description and Analysis", DOP 50 (1966), 289-312.

Kayser, Carl Ludwig (ed.), Flavii Philostrati Vitae Sophistarum, Heidelberg, 1838.

Kayser, Carl Ludwig (ed.), Flavii Philostrati Opera, I-II, Leipzig, 1871 [Hildesheim 1964].

Kazhdan, Alexander Petrovich and Wharton Epstein, Ann, Change in Byzantine Culture in the Eleventh and Twelfth Centuries, Berkeley-Los Angeles (CA), 1985. 


\section{Bibliography}

Kazhdan, Alexander Petrovich, "Encyclopedism", in: The Oxford Dictionary of Byzantium, I, ed. Alexander Petrovich Kazhdan, Oxford, 1991, 696-697.

Kazhdan, Alexander Petrovich, History of Byzantine Literature: 650-850, Athens, 1999.

Kazhdan, Alexander Petrovich and Angelidi, Christine, A History of Byzantine Literature, 850-100, Athens, 2006.

Kelly, Christopher, "Late Roman Bureaucracy: Going through the Files", in: Literacy and Power in the Ancient World, edd. Alan K. Bowman and Greg Woolf, Cambridge, 1994, 161-176.

Kennedy, George Alexander, Greek Rhetoric under Christian Emperors, Princeton (NJ), 1983.

Kidd, Douglas, Aratus Phaenomena, Cambridge, 1997.

Kindstrand, Jan Fredrik, "Florilegium e Basilio Magno ineditum", Eranos 83 (1985), 91-111.

Kindstrand, Jan Fredrik, "Claudius Aelianus und sein Werk", in: Rise and Decline of the Roman World (Aufstieg und Niedergang der Römischen Welt II. 34. 4), ed. Wolfgang Haase, Berlin-New York (NY), 1998, 2954-2996.

Klíma, Otakar, "Bahrām III”, in: Encyclopaedia Iranica, III(5) (2012), 514-522 (available online at http://www.iranicaonline.org/articles/bahram-03).

Koder, Johannes, Gemüse in Byzanz: Die Versorgung Konstantinopels mit Frischgemüse im Lichte der Geoponika, Wien, 1993.

Kopff, E. Christian “Thomas Magister and the Text of Sophocles' Antigone”, Transactions of the American Philological Association 106 (1976), 241-266.

Körtner, Ulrich Heinz Jürgen and Leutzsch, Martin, Papiasfragmente. Der Hirt des Hermas, Darmstadt, 1998.

Koutrava-Delivoria, Barbara, "La contribution de Constantin Porphyrogénète à la composition des Geoponica”, Byz 72 (2002), 365-380.

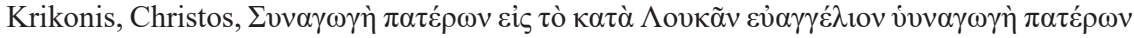

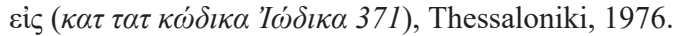

Kugeas, Socrates, “Analecta Planudea”, BZ 18 (1909), 106-146.

Kuiper, Franciscus Bernardus Jacobus, “Ahura Mazdā, 'Lord Wisdom'?”, Indo-Iranian Journal 18(1-2) (1976), 25-42.

Kurtz, Eduard, Die Sprichwörtersammlung des Maximus Planudes, Leipzig, 1886.

Laiou, Angeliki, Constantinople and the Latins. The Foreign Policy of Andronicus II, 1282-1328, Cambridge, 1972.

Laiou, Angeliki, "Some Observations on Alexios Philanthropenos and Maximos Planudes", BMGS 4 (1978), 89-99.

Lake, Kirsopp and Lake, Silva, Dated Greek Minuscule Manuscripts to the Year 1200, III, Boston (MA), 1934-1939.

Lamb, William, The Catena in Marcum: A Byzantine Anthology of Early Commentary on Mark (Texts and Editions for New Testament Study 6), Leiden-Boston (MA), 2012.

Lambros, Spyridon, Catalogue of the Greek Manuscripts on Mount Athos, II, Cambridge, 1900.

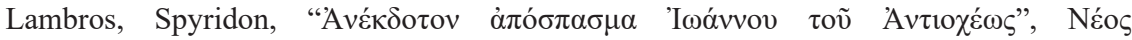

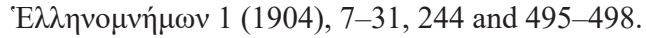

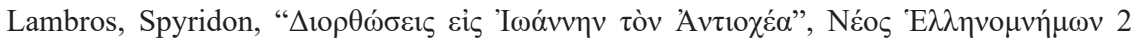
(1905), 240-241 and 503-506.

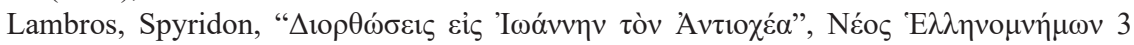
(1906), 124-126.

Lampsides, Odysseas, "Collectanea Planudea und die Chronike Synopsis von Konstantinos Manasses", BZ 77 (1984), 1-2. 
Langebec, Jacob (ed.), "Meginhardi Historia de Translatione S. Alexandri Wildeshusam", in: Scriptores Rerum Danicarum II, ed. Jacob Langebec, Hafniae, 1773, 38-49.

Latyshev, Vasiliǐ Vasil'evich, Pravoslavnyi Palestinskij Sbornik 59, Petrograd, 1910.

Laourdas, Vasilios, "The Codex Ambrosianus Graecus 81 and Photius”, BZ 44 (1951), $370-372$.

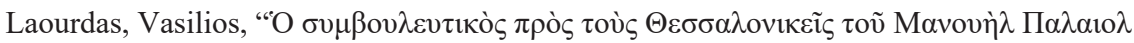
ófov”, Makedonika 3 (1955), 290-307.

Lauxtermann, Marc, "Byzantine Poetry and the Paradox of Basil II's Reign”, in: Byzantium in the Year 1000, ed. Paul Magdalino, Leiden, 2003a, 199-216.

Lauxtermann, Marc, Byzantine Poetry from Pisides to Geometres: Texts and Contexts (Wiener Byzantinischen Studien XXIV/I), Wien, 2003b.

Lauxtermann, Marc, "The Anthology of Cephalas", in: Byzantinische Sprachkunst, edd. Martin Hinterberger and Elisabeth Schiffer, Berlin, 2007, 194-208.

Lee, Doug, Information and Frontiers: Roman Foreign Relations in Late Antiquity, Cambridge, 1993.

Lefort, Jacques, "The Rural Economy, Seventh-Twelfth Centuries", in: The Economic History of Byzantium, I, ed. Angeliki Laiou, Washington D.C., 2008.

Lehmann, Yves, Aristoteles romanus: la réception de la science aristotélicienne dans l'Empire gréco-romain, Turnhout, 2013.

Lemerle, Paul, “L'Encyclopédisme à Byzance l'apogée de l'Empire, et particulièrement sous Constantin VII Porphyrogénète”, Cahiers d'Histoire Mondiale 9 (1965), 596-616.

Lemerle, Paul, Le Premier Humanisme Byzantine. Notes et remarques sur enseignement et culture à Byzance des origines au Xe siècle, Paris, 1971.

Leone, Pietro Luigi (ed.), Maximi Monachi Planudis Epistulae, Amsterdam, 1991.

Ljubarskij, Jakov, "Theophanes Continuatus und Genesios: Das Problem einer gemeinsamen Quelle", Byzantinoslavica 48 (1987), 12-27.

Ljubarskij, Jakov, "Quellenforschung and/or Literary Criticism: Narrative Structures in Byzantine Historical Writings", SO 73 (1998), 5-73.

Lounges, Telemachos, "Sur la date du De Thematibus", REB 31 (1973), 299-305.

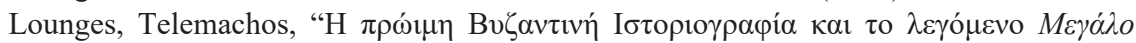

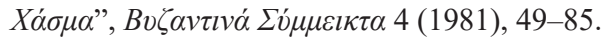

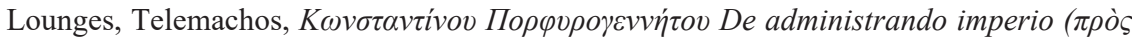

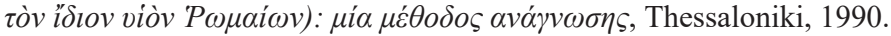

Lounges, Telemachos, Iustinianus Petrus Sabbatius: Society, Politics and Ideology in the 6th c. AD., Thessaloniki, 2005.

Louth, Andrew, Maximus the Confessor, London, 1996.

Louth, Andrew, St John Damascene: Tradition and Originality in Byzantine Theology, Oxford, 2002.

Louth, Andrew, "Photios as a Theologian", in: Byzantine Style, Religion and Civilization: In Honour of Sir Steven Runciman, ed. Elizabeth M. Jeffrey, New York (NY), 2006, 206-223.

Lozovsky, Natalia, "Roman Geography and Ethnography in the Carolingian Empire", Speculum 81 (2006), 325-364.

Luria, Solomon, "Entstellungen des Klassikertextes bei Stobaios", RhM 78 (1929), 81-104 and 225-248.

Maas, Michael, John Lydus and the Roman Past: Antiquarianism and Politics in the Age of Justinian, London, 1992.

Maas, Michael, "Delivered from Their Ancient Customs: Christianity and the Question of Cultural Change in Early Byzantine Ethnography", in: Conversion in Late Antiquity 


\section{Bibliography}

and the Early Middle Ages. Seeing and Believing, edd. Kenneth Mills and Anthony Grafton, Rochester, 2003, 152-188.

Maas, Michael, "Strabo and Procopius: Classical Geography for a Christian Empire", in: From Rome to Constantinople. Studies in Honour of Averil Cameron, edd. Hagit Amirav and Bas Ter Haar Romeny (Late Antique History and Religion 1), Leuven, 2007, 67-84.

Maas, Paul, Textual Criticism, trans. Barbara Flowers, Oxford, 1958.

Maass, Ernst, Commentariorum in Aratum reliquiae, Berolini, 1898.

Macrides, Ruth, "How the Byzantines Wrote History", in: Proceedings of the 23rd International Congress of Byzantine Studies, Belgrade, 2016, 257-265.

Macuch, Maria, "Inzest im vorislamischen Iran”, AMI 24 (1991), 141-154.

Magdalino, Paul, The Empire of Manuel I Komnenos, 1143-1180, Cambridge, 1993.

Magdalino, Paul, "The Non-Juridical Legislation of Leo VI", in: Acta Atheniensia ad Ius Byzantinum Spectantia, ed. Spyros Troianos, Athens-Komotini, 1997, 169-182.

Magdalino, Paul and Nelson, Robert, "Introduction", in: The Old Testament in Byzantium, edd. Paul Magdalino and Robert Nelson, Washington D.C., 2010, 1-38.

Magdalino, Paul, "Orthodoxy and History in Tenth Century Byzantine Encyclopedism", in: Encyclopedic trends in Byzantium? edd. Peter van Deun and Caroline Macé (OLA 212), Leuven-Paris-Walpole, 2011, 143-160.

Magdalino, Paul, "Byzantine Historical Writing, 900-1400", in: The Oxford History of Historical Writing, 2: 400-1400, edd. Sarah Foot and Chase F. Robinson, Oxford, 2012, 218-237.

Magdalino, Paul, "Byzantine Encyclopaedism of the Ninth and Tenth Centuries", in: Encyclopaedism from Antiquity to the Renaissance, edd. Jason König and Greg Woolf, New York (NY), 2013a, 219-231.

Magdalino, Paul, "Constantine VII and the Historical Geography of Empire", in: Imperial Geographies in Byzantine and Ottoman Space, edd. Sahar Bazzaz, Yota Batsaki, and Dimiter Angelov (Hellenic Studies Series 56), Washington D.C., 2013b, $23-42$.

Magdalino, Paul, "Knowledge in Authority and Authorized History: The Imperial Intellectual Programme of Leo VI and Constantine VII", in: Authority in Byzantium, ed. Pamela Armstrong, Farnham, 2013c, 187-209.

Mai, Angelo, Scriptorum veterum nova collectio e vaticanis codicibus, II, Romae, 1827.

Malherbe, Abraham J., The Cynic Epistles. A Study Edition (Sources for Biblical Study 12), Missoula, 1977.

Mallan, Christopher, “The Style, Method and Programme of Xiphilinus' Epitome of Cassius Dio's Roman History”, GRBS 53 (2013), 614-640.

Maltomini, Francesca, "Selezione e organizzazione della poesia epigrammatica fra IX e X secolo: la perduta antologia di Costantino Cefala e l'Antologia Palatina", in: Encyclopedic Trends in Byzantium? edd. Peter van Deun and Caroline Macé (OLA 212), Leuven-Paris-Walpole, 2011, 109-124.

Manafis, Panagiotis, "Political Margins. Geography and History in the Excerpta Anonymi", Byz 87 (2017a), 233-257.

Manafis, Panagiotis, "The Excerpta Anonymi and the Constantinian Excerpts", Byzantinoslavica 75 (2017b), 250-264.

Manafis, Panagiotis, "The Sources of Codex Zacynthius and their Treatment", in: Codex Zacynthius: Recovering Early Gospel Text and Commentary (Texts and Studies: Third Series), edd. Hugh Houghton and David Parker, Piscataway (NJ), 2020, 81-99. 
Manafis, Panagiotis, "History through an Excerpt Collection. The Case of the Excerpta Anonymi and the Patria of Constantinople", in: Les historiens fragmentaires de langue grecque à l'époque impériale et tardive, edd. Eugenio Amato, Pasqua de Cicco, Bertrand Lançon, and Tiphaine Moreau, Rennes (forthcoming).

Mango, Cyril and Ševčenko, Ihor, "Additional Note on the Tombs and Obits of the Byzantine Emperors”, DOP 16 (1962), 1 and 3-63.

Mango, Cyril, "Antique Statuary and the Byzantine Beholder”, DOP 17 (1963), 53-70.

Mango, Cyril, "Historical Introduction", in: Iconoclasm, edd. Anthony Bryer and Judith Herrin, Birmingham, 1977, 105-177.

Mango, Cyril, "Who Wrote the Chronicle of Theophanes?", Zbornik Radova Vizantološkog Instituta 18 (1978), 9-17.

Mango, Cyril, "The Tradition of Byzantine Chronography", Harvard Ukranian Studies 12/13 (1988-1989), 360-372.

Mango, Cyril, Nikephoros Patriarch of Constantinople: Short history (CFHB, $13=$ Dumbarton Oaks texts, 10). Washington D.C., 1990.

Mango, Cyril, "The Relics of St Euphemia and the Synaxarion of Constantinople", $B B G G$ 53 (1999), 79-87.

Maniaci, Marilena, "Il codice Greco 'non unitario'. Tipologie e terminologia”, in: Il codice miscellaneo. Tipologie e funzioni. Atti del Convegno Internazionale - Cassino 14-17 maggio 2003, edd. Edoardo Crisci and Oronzo Pecere (Segno e testo 2), Turnhout, 2004, 75-108.

Marava-Chatzinikolaou, Anna and Toufexi-Paschou, Christina, Catalogue of the Illuminated Byzantine Manuscripts of the National Library of Greece, 1 Manuscripts of New Testament texts, Athens, 1978.

Marcovich, Miroslav, Hippolytus. Refutatio omnium haeresium (PTS 25), Berlin, 1986.

Marcovich, Miroslav, Diogenis Laertii Vitae philosophorum, II: excerpta Byzantina et Indices, Stuttgart, 1999.

Marcotte, Didier, "Le Palatinus gr. 398 et les origines de la collection philosophique", in: The Libraries of the Neoplatonists, ed. Cristina D'Ancona, Leiden-Boston (MA), 2007, 167-175.

Mariev, Sergei, “Neues zur Johannischen Frage?” BZ 99 (2006), 535-549.

Mariev, Sergei (ed.), Ioannis Antiocheni Fragmenta quae supersunt omnia (CFHB 47), Berlin, 2008.

Mariev, Sergei, "Über das Verhältnis von Cod. Paris. gr. 1630 zu den Traditionen des Johannes Malalas und des Johannes von Antiochien", JÖB 59 (2009), 177-190.

Mariev, Sergei, "John of Antioch Reloaded: A Tutorial, 2016", in: Die Weltchronik des Johannes Malalas: Autor, Werk, Überlieferung, edd. Mischa Meier, Christine RadtkiJansen and Fabian Schulz, Stuttgart, 2016, 253-265.

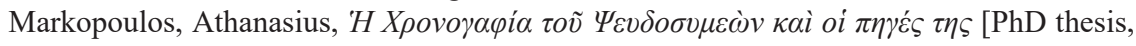
University of Ioannina], Ioannina, 1978.

Markopoulos, Athanasius, "Le témoignage du Vaticanus gr. 163 pour la période entre 945-963”, Symm 3 (1979), 83-119.

Markopoulos, Athanasius, "Sur les deux versions de la Chronographie de Symeon Logothète", BZ 76 (1983), 279-284.

Markopoulos, Athanasius, "Théodore Daphnopatès et la Continuation de Théophane", JÖB 35 (1985), 171-182.

Markopoulos, Athanasius, "Quelques remarques sur la famille des Génésioi aux IXe-Xe siècles”, Zbornik Radova Vizantološkog Instituta 24-25 (1986), 103-108. 


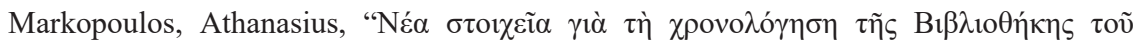

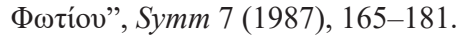

Markopoulos, Athanasius, "Constantine the Great in Macedonian Historiography, Models and Approaches", in: New Constantines: The Rhythm of Imperial Renewal in Byzantium, 4th -13th Centuries: Papers from the Twenty-Sixth Spring Symposium of Byzantine Studies, St Andrews, March 1992, ed. Paul Magdalino, Aldershot, 1994, 159-170.

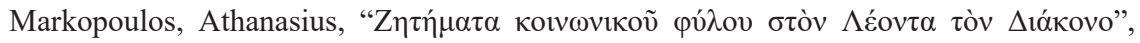

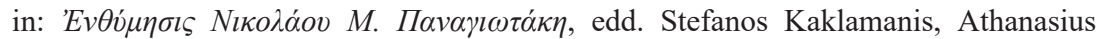
Markopoulos, and Giannis Mavromatis, Heraklion, 2000, 475-493.

Markopoulos, Athanasius, "Byzantine History Writing at the End of the First Millennium", in: Byzantium in the Year 1000, ed. Paul Magdalino, Leiden-Boston (MA), 2003, 189-197.

Markopoulos, Athanasius, "Roman Antiquarianism: Aspects of the Roman Past in the Middle Byzantine Period (9th-11 th centuries)", in: Proceedings of the 21 st International Congress of Byzantine Studies: London, 21-26 August, 2006, edd. Elizabeth Jeffreys and Fiona K. Haarer, Aldershot, 2006, 277-297.

Markopoulos, Athanasius, "Genesius: A Study", in: Realia Byzantina, edd. Sofia Kotzabassi and Giannis Mavromatis (Byzantinisches Archiv 22), Berlin-New York (NY), 2009, 137-150.

Markopoulos, Athanasius, "Teachers and Textbooks in Byzantium. Ninth to Eleventh Centuries", in: Networks of Learning: Perspectives on Scholars in Byzantine East and Latin West, c. 1000-1200, edd. Sita Steckel, Niels Gaul, and Michael Grünbart, Münster, 2014, 3-15.

Markopoulos, Athanasius, "Le public des textes historiographiques à l'époque macédonienne", Parekbolai 5 (2015), 53-74.

Martin, Jean (ed.), Scholia in Aratum vetera, Stutgardiae, 1974.

Martini, Emidio and Bassi, Domenico, Catalogus codicum Graecorum Bibliothecae Ambrosianae, Mediolanum, 1906 [Hildesheim 1978].

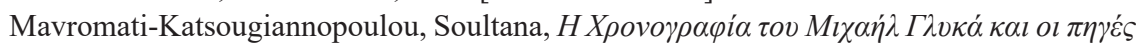

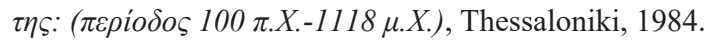

Mazal, Otto, Der Roman des Konstantinos Manasses: Überlieferung, Rekonstruktion, Textausg. der Fragmente, Wien, 1967.

Mazzucchi, Carlo Maria, "Dagli anni di Basilio Parakimomenos (cod. Ambr. B119 sup.)", Aevum 52 (1978), 267-316.

Mazzucchi, Carlo Maria, "Alcune vicende della tradizione di Cassio Dione in epoca bizantina”, Aevum 53 (1979), 94-139.

McCabe, Anne Elena, Byzantine Encyclopaedia of Horse Medicine: The Sources, Compilation, and Transmission of the Hippiatrica, Oxford, 2007.

McDonough, Scott, "Were the Sasanians Barbarians? Roman Writers on the Empire of the Persians", in: Romans, Barbarians, and the Transformation of the Roman World. Cultural Interaction and the Creation of Identity in Late Antiquity, edd. Danuta Shanzer and Ralph W. Mathisen, Farnham, 2010, 55-65.

Mecella, Laura, "Gli Excerpta Planudea, Pietro Patrizio e la tradizione storiografica occidentale", in: La storiografia tardoantica. Bilanci e prospettive, edd. Valerio Neri and Beatrice Girotti, Milano, 2016, 153-168.

Méhat, André, Étude sur les 'Stromates' de Clément d'Alexandrie, Paris, 1966.

Meier, Mischa, "Candidus: Um die Geschichte der Isaurer”, in: Griechische Profanhistoriker des fünften nachchristlichen Jahrhunderts, edd. Bruno Bleckmann and Timo Stickler, Stuttgart, 2014, 171-194. 
Menchelli, Mariella, "Un copista di Planude. Platone ed Elio Aristide in moderne e arcaizzanti di XIII secolo", Scripta 7 (2014), 193-204.

Mercati, Giovanni, De'cavalieri, Franchi, and Pietro, Pio, Codices Vaticani Graeci, Codices 1-329, Roma, 1923.

Mercati, Giovanni, Scritti d'Isidoro il Cardinale Ruteno e codici a lui appartenuti che si conservano nella Biblioteca Apostolica Vaticana (Studi e Testi 46), Rome, 1926.

Mergiali, Sophia, L'enseignement et les lettrés pendant l'époque des Paléologues (12611453), Athènes, 1996.

Metzler, Karin, Prokop von Gaza. Eclogarum in libros historicos Veteris Testamenti epitome. Teil 1: Der Genesiskommentar, Berlin-Boston, 2015.

Miller, Emmanuel Clément Bénigne, "Fragments inédits de Théodore le Lecteur et de Jean d'Egée”, Revue archéologique N.S. 26 (1873), 273-288 and 396-403.

Mioni, Elpidius, Bibliothecae Divi Marci Venetiarum codices Graeci manuscript, II, Roma, 1985.

Molin, Michel, "De l'intérêt des Excerpta historica iussu Imp. Constantini Porphyrogeniti pour la lecture de la dernière décade de Dion Cassius", Ktema 29 (2004), 209-213.

Mommsen, Christian Matthias Theodor, "Ueber die dem Cassius Dio beigelegten Theile der planudischen und der constantinischen Excerpte", Hermes 6 (1872), 82-91.

Mondrain, Brigitte, "La lecture du De administrando imperio à Byzance au cours des siècles", TM 14 (2002), 485-498.

Moore, John M., The Manuscript Tradition of Polybius, Cambridge, 1965.

Morgan, Terese, "Encyclopaedias of Virtue? Collections of Sayings and Stories about Wise Men in Greek", in: Encyclopaedism from Antiquity to the Renaissance, edd. Jason König and Greg Woolf, New York (NY), 2013, 108-128.

Müller, Karl Konrad, Eine griechische Schrift über Seekrieg, Wülrzburg, 1882.

Müller, Karl Wilhelm Ludwig, Die Fragmente der griechischen Historiker, IV, Paris, 1851.

Mullett, Margaret Elizabeth, "No Drama, No Poetry, No Fiction, No Readership, No Literature", in: A Companion to Bynantium, ed. Liz James, Chichester, 2010, 227-238.

Murphy, David J. "Hyphens in Greek Manuscripts", GRBS 36 (1995), 293-314.

Musso, Olimpio, "Sulla struttura del cod. Pal. Gr. 398 e deduzioni storico-letterarie", Prometheus 2 (1976), 1-10.

Mutschmann, Hermann (ed.), Sexti Empirici opera, I, Leipzig, 1912.

Nagel, Wolfram, Ninus und Semiramis in Sage und Geschichte: Iranische Staaten und Reiternomaden vor Darius, Berlin, 1982.

Nautin, Pierre, "La continuation de l'«Histoire ecclésiastique» d'Eusèbe par Gélase de Césarée", REB 50 (1992), 163-183.

Nautin, Pierre, "Théodore Lecteur et sa «réunion de différentes Histoires» de l'Église", REB 52 (1994), 213-243.

Nedungatt, George and Featherstone, Michael (edd.), The Council in Trullo Revisited (Kanonika 6), Roma, 1995.

Németh, Andreas, Imperial Systematization of the Past: Emperor Constantine VII and His Historical Excerpts [PhD thesis, Central European University], Budapest, 2010.

Németh, Andreas, "The Imperial Systematization of the Past in Constantinople: Constantine VII and His Historical Excerpts", in: Encyclopaedism from Antiquity to the Renaissance, edd. Jason König and Greg Woolf, New York (NY), 2013, 232-258.

Németh, Andreas, "Layers of Restorations: Vaticanus gr. 73 Transformed in the Tenth-. Fourteenth-, and Nineteenth centuries", Miscellanea Bibliothecae Apostolicae Vaticanae XXI (Studi e Testi 516), 2015, 281-330.

Németh, Andreas, "Excerpts versus Fragments: Deconstructions and Reconstructions of the Excerpta Constantiniana", in: Canonical Texts and Scholarly Practices: A Global 
Comparative Approach, edd. Anthony Grafton and Glenn W. Most, Cambridge, 2016, 253-274.

Németh, Andreas, "Compilation Methods of the Excerpta Constantiniana Revisited: From One Compilator to the Three-Stage Model of Teamwork", Byzantinoslavica 75 (2017), 265-290.

Németh, Andreas, The Excerpta Constantiniana and the Byzantine Appropriation of the Past, Cambridge, 2018.

Neusner, Jacob, "Rabbi and Magus in Third-Century Sasanian Babylonia", History of Religions 6(2) (1966), 169-178.

Neville, Leonora, "Why Did the Byzantines Write History?" In: Proceedings of the 23rd International Congress of Byzantine Studies, Belgrade, 2016, 265-276.

Nicol, Donald, "The Byzantine Reaction to the Second Council of Lyons 1274", Studies in Church History 7 (1971), 113-146.

Nicol, Donald, The Despotate of Epiros 1267-1479. A Contribution to the History of Greece in the Middle Ages, Cambridge, 1984.

Nicol, Donald, "Thessalonica as a Cultural Centre in the Fourteenth Century", in: Studies in Late Byzantine History and Prosopography, ed. Donald Nicol, London, 1986, 121-131.

Niece, Benedictus, Flavii Iosephi opera. Antiquitatum Iudaicarum Libri I-XX, Berolini, 1887-1890.

Niece, Benedictus, Flavii Iosephi opera, IV. Iosephi Vita, Berolini, 1890 [Berolini, 1955].

Niels, Gaul, Thomas Magistros und die spätbyzantinische Sophistik. Studien zum Humanismus urbaner Eliten in der frühen Palaiologenzeit, Wiesbade, 2011.

Nilsson, Ingela, "Discovering literariness in the Past: Literature vs. History in the Synopsis Chronike of Konstantinos Manasses", in: L'écriture de la memoire: la littérarité de l'historiographie. Hermeneia. Actes du troisiéme colloque international sur la littérature byzantine (Dossiers Byzantins 6), edd. Paolo Odorico, Panagiotis A. Agapitos, and Martin Hinterberger, Paris, 2006, 15-31.

Nilsson, Ingela, "Raconter Byzance: La littérature au XIIe siècle", Séminaires Byzantins 3, Paris (2014), 98-111.

Nock, Arthur Darby, Festugière, André Jean, and Ramelli, Ilaria (edd.), Corpus hermeticum, Milano, 2006.

Nollé, Johannes, Die Abwehr der wilden Schweine. Schwarzwildjagden im antiken Lykien, München, 2001.

Noret, Jacques, "Notes de ponctuation et d'accentuation byzantines; Notes of Byzantine Punctuation and Accentuation", Byzantion 65(1) (1995), 69-85.

Noret, Jacques, "L'accentuation de $\tau \varepsilon$ en grec byzantin", Byzantion 68(2) (1998), 516-518.

Nyström, Eva, Containing Multitudes: Codex Upsaliensis Graecus 8 in Perspective, Uppsala, 2009.

Ochoa, Jose, "La historia nueva de zosimo en los excerpta de legationibus", Myrtia 5 (1990), 77-92.

Odorico, Paolo, "La cultura della $\Sigma v \lambda \lambda o \gamma \eta$ : 1) Il cosiddetto enciclopedismo bizantino. 2) Le tavole del sapere di Giovanni Damasceno", BZ 83(1) (1990), 1-21.

Odorico, Paolo, "Un esempio di lunga durata della trasmissione del sapere: Cecaumeno, Sinadinos, l'Antichità, l'età moderna", in: Aspetti di letteratura gnomica nel mondo antico, 1, ed. Maria Serena Funghi, Firenze, 2003, 283-299.

Odorico, Paolo, "Gli gnomologi greci sacro-profani. Una presentazione", in: Aspetti di letteratura gnomica bel mondo antico, 2, ed. Maria Serena Funghi, Firenze, 2004, 61-96. 
Odorico, Paolo, "Parce que je suis ignorant", in: Imitatio-Aemulatio-Variatio. Akten des internationalen wissenschaftlichen Symposiums zur byzantinischen Sprache und Literatur (Wien, 22-25 Oktober 2008), edd. Andreas Rhoby and Elisabeth Schiffer, Wien, 2010, 209-216.

Odorico, Paolo, "Cadre d'exposition/cadre de pensée - la culture du recueil", in: Encyclopedic Trends in Byzantium? edd. Peter van Deun and Caroline Macé (OLA 212), Leuven-Paris-Walpole, 2011a, 89-107.

Odorico, Paolo, "Monuments de rêve. Représentation architecturale dans la littérature byzantine", in: Ekphrasis: La représentation des monuments dans les littératures byzantines et byzantino-slaves. Réalités et imaginaires, edd. Vladimír Vavřinek, Paolo Odorico, and Vlastimil Drbal, Byzantinoslavica 69(3) Supplementum, Prague, 2011b, 33-47.

Odorico, Paolo, "Dans le dossier des chroniqueurs. Le cas d'Eustathe d'Antioche", in: Textual Transmission in Byzantium: Between Textual Criticism and Quellenforschung, edd. Juan Signes Codoñer and Inmaculada Pérez Martin (Lectio 2), Turnhout, 2014a, 373-389.

Odorico, Paolo, "Du recueil à l'invention du texte: le cas des Parastaseis Syntomoi Chronikai", BZ 107(2) (2014b), 755-784.

Odorico, Paolo, "Du premier humanisme à l'encyclopédisme: une construction à revoir", in: Autour du Premier humanisme byzantin et des Cinq études sur le XIe siècle, quarante ans après Paul Lemerle, edd. Bernard Flusin and Jean-Claude Cheynet (Travaux et Mémoires 21/2), Paris, 2017, 23-42.

Oikonomidès, Nicolas, Les listes de préséance byzantines des IXe et Xe siècles, Paris, 1972.

O’Meara, Dan (ed.), Michaelis Pselli Philosophica minora, I-II, Leipzig, 1989.

Omont, Henri Auguste, Inventaire sommaire des manuscrits grecs de la Bibliothèque nationale, II, Paris, 1888 a.

Omont, Henri Auguste, Inventaire sommaire des manuscrits grecs de la Bibliothèque nationale, III, Paris, $1888 \mathrm{~b}$.

Omont, Henri Auguste, Fac-similes des mss. grecs datés de la Bibliothèque Nationale du IXe au XIVe siècle, Paris, 1891.

Omont, Henri Auguste, Inventaire sommaire des manuscrits grecs de la Bibliothèque nationale, $I V$, Paris, 1898.

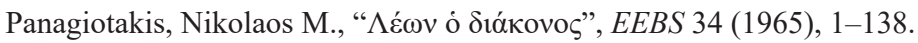

Panella, Theodora, "Resurrection appearances in the Pauline catenae", in: Commentaries, Catenae and Biblical Tradition (Texts and Studies 3.13), ed. Hugh Houghton, Piscataway (NJ), 2016, 117-140.

Papadogiannakis, Yiannis, "Encyclopedism in the Byzantine Byzantine Questionand-answer Literature: The Case of Pseudo-Kaisarios", in: Encyclopedic Trends in Byzantium? edd. Peter van Deun and Caroline Macé (OLA 212), Leuven-Paris-Walpole, 2011, 29-41.

Papaioannou, Stratis, Michael Psellos. Rhetoric and Authorship in Byzantium, Cambridge, 2013.

Parker, David and Birdsall, Neville, "The date of Codex Zacynthius ( $\Xi$ ): a new proposal”, Journal of Theological Studies 55(1) (2004), 117-131.

Parmentier-Morin, Edith, "Les fragments de Denys d'Halicarnasse attribués à Nicolas de Damas", in: Fragments d'historiens grecs, autour de Denys d'Halicarnasse, ed. Sylvie Pittia, Rome, 2002, 461-476. 
Parmentier-Morin, Edith and Barone, Francesca Prometea, Nicolas de Damas. Histoires. Recueil de coutumes. Vie d'Auguste. Autobiographie, Paris, 2011.

Paschalides, Symeon, "From Hagiography to Historiography: The Case of the Vita Ignatii (BHG 817) by Niketas David the Paphlagonian", in: Les Vies des saints à Byzance: Genre littéraire ou biographie historique? edd. Paolo Odorico and Panagiotis Agapitos (Dossiers byzantins 4), Paris, 2004, 161-173.

Paschoud, François, "Chronique d'historiographie tardive”, Antiquité Tardive 14 (2006), 325-344.

Patzig, Edwin, Johannes Antiochenus und Johannes Malalas. Jahresbericht der Thomasschule für das Schuljahr Ostern 1891 bis Ostern 1892, Leipzig 1892.

Patzig, Edwin, "Über einige Quellen des Zonaras", BZ 5 (1896), 24-53.

Patzig, Edwin, "Über einige Quellen des Zonaras”, BZ 6 (1897), 322-356.

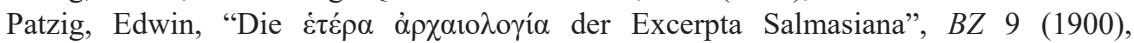
357-369.

Patzig, Edwin, “Die Abhängigkeit des Jo. Antiochenus von Jo. Malalas”, BZ 10 (1901), 40-53.

Payne Smith, Robert, The Third Part of the Ecclesiastical History of John, Bishop of Ephesus, Oxford, 1860.

Pérez Martin, Inmaculada, "Un esemplare della Retorica di Aristotele copiato da Massimo Planude e Giovanni Zaride", in: Byzantium. Identity, Image, Influence (Abstracts of Communications), ed. Karsten Fledelius, Copenhagen, 1996.

Pérez Martin, Inmaculada, “La escuela de Planudes: notas paleográficas a una publicación reciente sobre los escolios euripideos", BZ 90 (1997), 73-96.

Pertz, Georg Heinrich, Monumenta Germaniae Historica, Scriptores, II, Hannoverae, $1829,673-681$.

Piccione, Rosa Maria, "Scegliere, raccogliere e ordinare. Letteratura di raccolta e transmissione del sapere", Humanitas 58 (2003), 44-63.

Piccolomini, Enea, "Intorno ai Collectanea di Massimo Planude", Rivista di Filologia 2 (1874), 101-117 and 149-163.

Piccolomini, Enea, "Estratti inediti dai codici greci della biblioteca Mediceo-Laurenziana", Ann.Univ.Tosc. 16 (1879), 231-350.

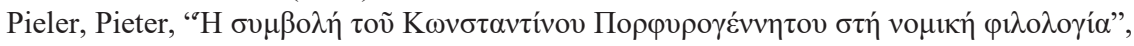
in: Constantine VII Porphyrogenitus and His Age, ed. Athanasius Markopoulos, Athens, 1989, 79-86.

Pittia, Sylvie, Fragments d'historiens grecs, autour de Denys d'Halicarnasse, Rome, 2002.

Polemis, Ioannis, Poems. Theodore Metochites (CCSG 83), Turnhout, 2017.

Pouderon, Bernard, "Le codex Parisinus graecus 1555 A et sa récension de l'Épitomè byzantin d'histoires ecclésiastiques", REB 56 (1998), 169-191.

Pouderon, Bernard, "Le témoignage du codex Baroccianus 142 sur Athénagore et les origines du didaskaleion d'Alexandrie", in: Science et vie intellectuelle à Alexandrie (Ier-IIIe siècle après J.-C.), ed. Gilbert Argoud (Mémoires 14), Saint-Etienne, 1994, $163-224$.

Power, Tristan, "Suetonius' Famous Courtesans", in: Suetonius the Biographer. Studies in Roman Lives, edd. Tristan Power and Roy K. Gibson, Oxford, 2014, 231-255.

Praet, Raf, "Re-anchoring Rome's Protection in Constantinople: The pignora imperii in Late Antiquity and Byzantium", Sacris Erudiri 55 (2016), 277-319.

Prandi, Luisa, "Tipologia e struttura dei lemmi di argomento greco nella Suda", in: Il lessico Suda e la memoria del passato a Bisanzio, ed. Giuseppe Zecchini, Bari, 1999, 9-28.

Pratsch, Thomas, "Untersuchungen zu De Thematibus Kaiser Konstantins VII", Поккi $\lambda \alpha$

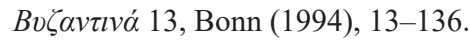




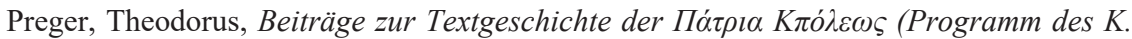
Maximilian Gymnasiums), München, 1895.

Radt, Stefan, Strabonis Geographika, I-IV, Göttingen, 2002-2011.

Rafiyenko, Dariya, "Towards the Compilation Principles of Excerpta historica Constantiniana", Byzantinoslavica 75 (2017), 291-324.

Rance, Philip, "The date of the military compendium of Syrianus Magister (Formerly the sixth-century anonymus Byzantinus)", BZ 100 (2007), 701-737.

Rapp, Claudia, "Byzantine Hagiographers as Antiquarians, Seventh to Tenth Centuries", Byzantinische Forschungen 21 (1995), 31-44.

Rawlinson, Henry, "Notes on Seistan", Journal of the Royal Geographical Society of London 43 (1873), 272-294.

Reidy, Joseph, "Eusebius of Emesa and the Continuatio Antiochiensis Eusebii", Journal of Ecclesiastical History 66 (2015), 471-487.

Reinsch, Diether Roderich, "Historia ancilla litterarum? Zum literarischen Geschmack in der Komnenenzeit: Das Beispiel der Synopsis Chronike des Konstantinos Manasses", in: Pour une 'nouvelle' histoire de la littérature byzantine: problèmes, méthodes, approches, propositions. Actes d'un colloque international philologique, Nicosie, mai 2000 (Dossiers Byzantins, 1), edd. Paolo Odorico and Panagiotis A. Agapitos, Paris, 2002, 81-94.

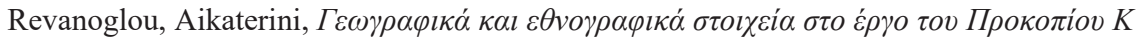

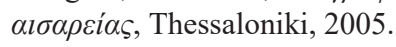

Rey, André-Louis, "Les erotapokriseis dans le monde byzantine: tradition manuscrite des textes anciens et production de nouveaux textes", in: Erotapokriseis: Early Christian Question and Answer Literature in Context, edd. Annelie Volgers and Claudio Zmaghi (Contributions to Biblical Exegesis and Theology 37), Leuven, 2004.

Richard, Marcel, "Les florilèges diphysites du Ve et du VIe siècle", in: Das Konzil von Chalkedon: Geschichte und Gegenwart, I, edd. Aloys Grillmeier and Heinrich Bacht, Würzburg, 1951.

Richard, Marcel, "Les premières chaînes sur le Psautier", Revue d'Histoire des Textes (1957), 87-98.

Richard, Marcel, "Florilèges spirituels grecs", Dictionnaire de Spiritualité 33-34 (1962), 475-512.

Richard, Marcel, "Aлò $\varphi \omega v \tilde{\eta} \varsigma^{\prime}$, in: Opera Minora, III, ed. Marcel Richard, Turnhout, 1977, 191-222.

Riedinger, Rudolf, Pseudo-Kaisarios Überlieferungsgeschichte und Verfasserfrage, München, 1969.

Ringrose, Kathryn M., The Perfect Servant: Eunuchs and the Social Construction of Gender in Byzantium, Chicago (Ill) and London, 2003.

Roberto, Umberto, "Sulla tradizione storiografica di Candido Isaurico", Mediterraneo antico 3 (2000), 685-727.

Roberto, Umberto, "Gli Excerpta Salmasiana di storia greca e orientale dello Ps. Giovanni di Antiochia e le Chronographiae di Giulio Africano", in: Selecta Colligere II, edd. Rosa Maria Piccione and Matthias Perkams, Alessandria, 2005a, 253-293.

Roberto, Umberto (ed.), Ioannis Antiocheni fragmenta ex Historia chronica (Texte und Untersuchungen zur Geschichte der altchristlichen Literatur 154), Berlin, $2005 \mathrm{~b}$.

Roberto, Umberto, "Byzantine Collections of Late Antique Authors: Some Remarks on the Excerpta historica Constantiniana", in: Die Kestoi des Julius Africanus und ihre Überlieferung, edd. Martin Wallraff and Laura Mecella, Berlin-New York (NY), 2009, 71-84. 


\section{Bibliography}

Roberto, Umberto, "L'interesse per Cassio Dione in Pietro Patrizio e nella burocrazia palatina dell'età di Giustiniano", in: Cassius Dion: nouvelles lectures, I, edd. Valérie Fromentin, Estelle Bertrand, Michèle Coltelloni-Trannoy, Michel Molin, and Gianpaolo Urso, Bordeaux, 2016, 51-67.

Robins, Robert Henry, The Byzantine Grammarians. Their Place in History, Berlin-New York (NY), 1993.

Ronconi, Filippo, "Per una tipologia del codice miscellaneo Greco in epoca mediobizantina", in: Il codice miscellaneo. Tipologie e funzioni. Atti del Convegno Internazionale - Cassino 14-17 maggio 2003, edd. Edoardo Crisci and Oronzo Pecere (Segno e testo 2), Turnhout, 2004, 145-182.

Ronconi, Filippo, I manoscritti greci miscellanei. Ricerche su esemplari dei secoli IX-XII (Testi, Studi, Strumenti 21), Spoleto, 2007.

Ronconi, Filippo, "La collection brisée. La face cachée de la collection philosophique: les milieux socioculturels", in: La face cachée de la littérature byzantine. Le texte en tant que message immédiat (Actes du colloque international, Paris, 5-6-7 juin 2008 organisé par le centre d'études byzantines de l'EHESS), ed. Paolo Odorico, Paris, 2012, 137-166.

Ronconi, Filippo, "Pour la datation de la Bibliothèque de Photius. La Myriobiblos, le Patriarche et Rome", in: Byzanz und das Abendland II. Studia Byzantino-Occidentalia, ed. Erika Juhász, Budapest, 2014, 135-153.

Rubin, Berthold, Prokopios von Kaisareia, Stuttgart, 1954.

Rudberg, Stig Y., "Morceaux choisis de Basile sélectionnés par Syméon Métaphraste", Eranos 62 (1964), 100-119.

Russell, James Robert, "Burial iii. In Zoroastrianism”, in: Encyclopaedia Iranica, IV(6), ed. Ehsan Yarshater, London-New York (NY), 1982, 561-563.

Rydén, Lennart, The Life of St. Andrew the Fool: Introduction, Testimonies and Nachleben Indices (Acta universitatis Upsaliensis. Studia byzantina Upsaliensia 4), I, Stockholm, 1995.

Säflund, Gösta, The Polyphemus and Scylla groups at Sperlonga, Stockholm, 1972.

Salsano, Alfredo, "Voce Enciclopedia", in: Enciclopedia Einaudi I, edd. Ruggiero Romano and Alfredo Salsano, Torino, 1977, 3-64.

Sauget, Joseph-Marie, Premières recherches sur l'origine et les caractéristiques des synaxaires melkites XIe-XVIIe siècles, Bruxelles, 1969.

Sautel, Jacques Hubert, "Sur un Épitomé des Antiquités romaines de Denys d'Halicarnasse: les Ambrosiani A 80 sup. et Q. 13 sup. Complément à l'édition du livre III", Revue d'Histoire des Textes 30 (2000), 71-92.

Sbordone, Francesco, Strabonis Geographica, I, Roma, 1963.

Schartau, Bjarne, The Impact of Thomas Magistros's Introductory Matter (Vita, hypotheseis) to the Euripidean Triad, Odense, 1973.

Schippmann, Klaus, "Fīrūz", in: Encyclopaedia Iranica, IX(6), 2012, 631-632 (available online at http://www.iranicaonline.org/articles/firuz-1).

Schmid, Ulrich and Sigismund, Marcus "Die Markierung von Zitaten in den Handschriften", in: Von der Septuaginta zum Neuen Testament, edd. Martin Karrer, Siegfried Kreuzer and Marcus Sigismund (ANTF 43), Berlin-New York (NY), 2010, 75-152.

Schminck, Andreas, Studien zu mittelbyzantinischen Rechtsbüchern, Frankfurt am Main, 1986.

Schreiner, Klaus, "Die Historikerhandschrift Vaticanus Graecus 977: ein Handexemplar zur Vorbereitung des konstantinischen Exzerptenwerkes?” JÖB 37 (1987), 1-30.

Schulte, Hendrich, Paralipomena Cycli. Epigramme aus der Sammlung des Agathias: Text, Übersetzung, Kommentar, Trier, 2006. 
Scott, Roger, "The Events of Every Year, Arranged without Confusion: Justinian and others in the Chronicle of Theophanes Confessor", in: L'écriture de la memoire: la littérarité de l'historiographie. Hermeneia. Actes du troisiéme colloque international sur la littérature byzantine (Dossiers Byzantins 6), edd. Paolo Odorico, Panagiotis A. Agapitos, and Martin Hinterberger, Paris, 2006, 49-65.

Scott, Roger, "Byzantine Chronicles", The Medieval Chronicle 6 (2009), 31-57.

Scott, Roger, "The Byzantines wrote Chronicles", in: Proceedings of the conference Chronicles as Literature at the Crossroad of Past and Present, Munich, April 29-30, 2016, ed. Sergei Mariev (forthcoming).

Serventi, Stefano, "Il Vaticanus gr. 167, testimone della Continuatio Theophanis, e I marginalia di un anonimo lettore bizantino", Aevum 75 (2001), 267-302.

Ševčenko, Ihor, Études sur la polémique entre Théodore Métochite et Nicéphore Choumnos, Bruxelles, 1962.

Ševčenko, Ihor, “Three Paradoxes of the Cyrillo-Methodian Mission”, Slavic Review 23(2) (1964), 220-236.

Ševčenko, Ihor, "Palaeologan Renaissance", in: Renaissances before the Renaissance. Cultural Revivals of Late Antiquity and the Middle Ages, ed. Warren Treadgold, Stanford (CA), 1984, 144-171.

Ševčenko, Ihor, "Religious Missions Seen from Byzantium", Harvard Ukrainian Studies 12/13 (1988-1989), 7-27.

Ševčenko, Ihor, "Re-reading Constantine Porhyrogenitus", in: Byzantine Diplomacy. (Papers from the Twenty-fourth Spring Symposium of Byzantine Studies, Cambridge, March 1990), edd. Jonathan Shepard and Simon Franklin, Aldershot, 1992a, 167-195.

Ševčenko, Ihor, "The Search for the Past in Byzantium around the Year 800", DOP 46 (1992b), 279-293.

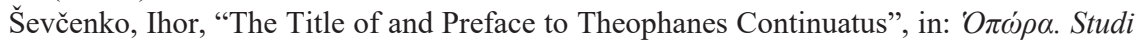
in onore di mgr. Paul Canart per il LXX compleanno. (Bolletino della Badia Greca di Gtottaferrata 52), edd. Santo Lucà and Lidia Perria, Grottaferrata, 1998, 77-93.

Shaked, Shaul, "Some Notes on Ahreman, the Evil Spirit, and His Creation", in: Studies in Mysticism and Religion, edd. Gershom Scholem, Efraim Elimelech Urbach, Raphael Jehudah Zwi Werblowsky, and Chaim Wirszubski, Jerusalem, 1967, 227-234.

Shepard, Jonathan, "Byzantium Expanding, 944-1012", in: The New Cambridge Medieval History: 3, ed. Timothy Reuter, Cambridge, 1999, 586-587.

Shepard, Jonathan, "The ruler as instructor, pastor and wise: Leo VI of Byzantium and Symeon of Bulgaria", in: Alfred the Great: Papers from the Eleventh-Centenary Conferences (Studies in Early Medieval Britain and Ireland), ed. Timothy Reuter, Aldershot, 2003, 339-360.

Shepard, Jonathan (ed.), The Cambridge History of the Byzantine Empire c. 500-1492, New York (NY), 2008.

Sickenberger, Joseph, Titus von Bostra. Studien zu dessen Lukashomilien (TU 2), Leipzig, 1901.

Sickenberger, Joseph, Die Lukaskatene des Niketas von Herakleia (TU 22.4), Leipzig, 1902.

Signes Codoñer, Juan, "Algunas consideraciones sobre la autoría del Theophanes Continuatus", Erytheia 10 (1989), 17-28.

Signes Codoñer, Juan, "Constantino Porfirogéneto y la fuente común de Genesio y Theophanes Continuatus I-IV”, BZ 86/87 (1993-1994), 319-341. 


\section{Bibliography}

Signes Codoñer, Juan and Santos, Francisco Javier Andrés (edd.), La Introducción al derecho (Eisagoge) del Patriarca Focio (Nueva Roma 28), Madrid, 2007.

Signes Codoñer, Juan, "Towards a Vocabulary for Rewriting in Byzantium", in: Textual Transmission in Byzantium: Between Textual Criticism and Quellenforschung (Lectio 2), edd. Juan Signes Codoñer and Inmaculada Pérez Martin, Turnhout, 2013, 61-90.

Signes Codoñer, Juan, "Theophanes at the Time of Leo VI", in: Studies in Theophanes (Travaux et Mémoires 19), edd. Marek Jankowiak and Federico Montinaro, Paris, 2015, 159-176.

Signes Codoñer, Juan, "Dates or Narrative? Looking for Structures in Middle Byzantine Historiography (9th to 11th Century)", in: Byzanz und das Abendland IV. Studia Byzantino-Occidentalia, ed. Erica Juhász, Budapest, 2016, 227-256.

Signes Codoñer, Juan, "The Author of Theophanes Continuatus I-IV and the Historical Excerpts of Constantine VII Porphyrogenitus", in: Investigatio Fontium II. Griechische und lateinische Quellen mit Erläuterungen, edd. Zoltán Farkas, László Horávth, and Tamás Mészáros, Budapest, 2017, 17-41.

Sode, Claudia, "Sammeln und Exzerpieren in der Zeit Konstantins VII. Porphyrogennetos. $\mathrm{Zu}$ den Fragmenten des Petros Patrikios im sogenannten Zeremonienbuch", in: Encyclopedic Trends in Byzantium? edd. Peter van Deun and Caroline Macé (OLA 212), Leuven-Paris-Walpole, 2011, 161-176.

Sotiriadis, Georgios, “Zur Kritik des Johannes von Antiocheia”, Jahrbücher für Classische Philologie Suppl. 16 (1888), 1-126.

Sotiroudis, Panagiotis, "Unedierte Verse aus dem Codex Vaticanus Graecus 96", JÖB 33 (1983), 249-254.

Sotiroudis, Panagiotis, Untersuchungen zum Geschichtswerk des Johannes von Antiocheia, Thessaloniki, 1989.

Speck, Paul, "Der zweite Theophanes: Eine These zur Chronographie des Theophanes", in: Freie Universität Berlin: Byzantinisch-neugriechische Seminar (Poikila Byzantina 13), edd. Thomas Pratsch, Claudia Sode, Paul Speck, and Sarolta Takàcs, Bonn, 1994, 431-483.

Stefec, Rudolf S., "Die Überlieferung der Deklamationen Polemons", Römische historische Mitteilungen 55 (2013), 99-154.

Stefec, Rudolf S., Flavii Philostrati Vitas sophistarum. Ad quas accedunt Polemonis Laodicensis Declamationes quae exstant duae, Oxonii, 2016.

Stenton, Frank Merry, Anglo-Saxon England, Oxford, 1967.

Stevens, Luke "The Origin of the de Boor Fragments Ascribed to Philip of Side", Journal of Early Christian Studies 26(4) (2018), 631-657.

Stevenson, Enrico, Codices manuscripti Palatini graeci Bibliothecae Vaticanae, Romae, 1885.

Stevenson, William Henry, "The Beginnings of Wessex”, English Historical Review 14 (1899), 32-46.

Sullivan, Dennis, Siegecraft: Two Tenth-century Instructional Manuals by Heron of Byzantium, Washington D.C., 2000.

Tannery, Paul (ed.), Diophanti Alexandrini Opera omnia: cum graecis commentariis, I-II, Lipsiae, 1895.

Tartaglia, Luigi, "Livelli stilistici in Costantino Porfirogenito", JÖB 32(3) (1982), 197-206.

Tartaglia, Luigi, "Meccanismi di compilazione nella Cronaca di Giorgio Cedreno", in: Bisanzio nell'età dei Macedoni. Forme della produzione letteraria e artistica, edd. Fabrizio Conca and Gianfranco Fiaccadori, Milano, 2007, 239-255.

Taxidis, Ilias, “Léon Bardalès: Sa vie et son œuvre”, Parekbolai 1 (2011), 97-113. 
Theodoridis, Christos, "Kritische Bemerkungen zum Lexikon des Suidas", Hermes 121 (1993), 184-195.

Thompson, Edward Arthur, "Procopius on Brittia and Britannia", CQ 30 (1980), 498-507. Thompson, Edward Arthur, Romans and Barbarians: The Decline of the Western Empire, Madison (WI), 1982.

Tinnefeld, Franz Hermann and Voordeckers, Edmond, Iohannis Cantacuzeni Refutationes Duae Prochori Cydonii et Disputatio cum Paulo Patriarcha Latino Epistulis Septem Tradita (CCSG 16), Turnhout, 1987.

Toynbee, Arnold, Constantine Porphyrogenitus and His World, New York (NY), 1973.

Treadgold, Warren, The Nature of the Bibliotheca of Photius, Washington D.C., 1983.

Treadgold, Warren, "The Macedonian Renaissance", in: Renaissances before the Renaissance: Cultural Revivals of Late Antiquity and the Middle Ages, ed. Warren Treadgold, Stanford (CA), 1984, 65-98.

Treadgold, Warren, A History of the Byzantine State and Society, Stanford (CA), 1997.

Treadgold, Warren, The Early Byzantine Historians, New York (NY), 2007.

Treadgold, Warren, The Middle Byzantine Historians, New York (NY), 2013.

Treu, Maximilian (ed.), Maximi Monachi Planudis Epistulae, Breslau, 1890.

Turyn, Alexander, Studies in the Manuscript Tradition of the Tragedies of Sophocles, Urbana, 1952.

Turyn, Alexander, Dated Greek Manuscripts of the Thirteenth and Fourteenth Centuries in the Libraries of Italy, I-II, Urbana, 1972.

van Deun, Peter and Macé, Caroline (edd.), Encyclopedic Trends in Byzantium? Proceedings of the International Conference Held in Leuven, 6-8 May 2009, Leuven, 2011.

van Dieten, Jan Louis, Zur Überlieferung und Veröffentlichung der Panoplia dogmatike des Niketas Choniates (Zetemata byzantina 3), Amsterdam, 1970.

van Nuffelen, Peter, "Gélase de Césarée, un compilateur du cinquième siècle", BZ 95 (2002), 621-640.

van Nuffelen, Peter, "John of Antioch, Inflated and Deflated. Or: How (not) to Collect Fragments of early Byzantine Historians", Byz 82 (2012), 437-450.

van Nuffelen, Peter, "Introduction: Historiography as a Cultural Practice", in: Historiographie tardo-antique et transmission des savoirs, edd. Philippe Blaudeau and Peter van Nuffelen, Berlin, 2015, 11-20.

van Nuffelen, Peter, "Malalas and the Chronographic Tradition", in: Die Weltchronik des Johannes Malalas - Quellenfragen, edd. Laura Carrara, Mischa Meier, and Christine Radtki-Jansen, Stuttgart, 2017, 261-272.

van Nuffelen, Peter, "Ecclesiastical Historiography", in: A Companion to Late Antique Literature, edd. Scott Mc Gill and Ed Watts, Malden, 2018, 161-175.

van Nuffelen, Peter and van Hoof, Lieve (edd.), Clavis Historicorum Antiquitatis Posterioris An Inventory of Late Antique Historiography (A.D. 300-800), Turnhout, 2020.

Vasiloudi, Maria, Vita Homeri Herodotea. Textgeschichte, Edition, Übersetzung, BerlinBoston (MA), 2013.

Vassis, Ioannis, Initia Carminum Byzantinorum (Supplementa Byzantina 8), Berlin-New York (NY), 2005.

Verheyden, Joseph, "The Shepherd of Hermas", in: Writings of the Apostolic Fathers, ed. Paul Foster, London, 2007, 63-71.

Verpeaux, Jean, Nicéphore Choumnos, Homme d'État et Humaniste Byzantin (ca 1250/1255-1327), Paris, 1958. 


\section{Bibliography}

Vitelli, Girolamo, "Frammenti della Archeologia di Giovanni Antiocheno nel cod. Paris. gr. 3026", Studi Italiani di Filologia Classica 3 (1895), 382-384.

von Falkenhausen, Vera, "Italy in Byzantine Literature of the Tenth Century", in: Constantine VII Porphyrogenitus and His Age, ed. Athanasius Markopoulos, Athens, 1989, 25-38.

Vryonis, Speros, The Decline of Medieval Hellenism in Asia Minor and the Process of Islamization from the Eleventh through the Fifteenth Century, Berkeley (CA)-London, 1971.

Wachsmuth, Curt, Studien zu den griechischen Florilegien, Berlin, 1882.

Wallies, Maximilianus (ed.), Ioannis Philoponi in Aristotelis analytica priora commentaria, Berlin, 1905.

Wallraff, Martin (ed.), Julius Africanus und die christliche Weltchronik, Berlin, 2006.

Walton, Francis R., “A Neglected Historical Text”, Historia 14 (1965), 236-251.

Ward, John, "Procopius Bello Gothicum II. 6.28 - The problem of contacts between Justinian I and Britain", Byz 38 (1968), 460-471.

Wäschke, Hermann, "Reihenfolge der Exzerpte Konstantins", Philologus 41 (1882), 270-283.

Wendel, Carl, "Planudea", BZ 40 (1940), 406-445.

Wendel, Carl, "Maximos Planudes", RE 40 (1950), 2202-2253.

Welsby, Derek Anthony, The Roman Military Defence of the British Province in Its Later Phases, Oxford, 1982.

West, Martin Litchfield, Textual Criticism and Editorial Technique Applicable to Greek and Latin Texts, Stuttgart, 1973.

West, Martin Litchfield (ed.), Carmina Anacreontea, Stuttgart, 1993.

Westerink, Leendert Gerrit, "Le Basilikos de Maxime Planude", Byzantinoslavica 27 (1966), 98-103.

Westerink, Leendert Gerrit, "Le Basilikos de Maxime Planude", Byzantinoslavica 28 (1967), 54-67.

Westerink, Leendert Gerrit, "Le Basilikos de Maxime Planude", Byzantinoslavica 29 (1968), 34-50.

Westermann, Anton, Biographoi. Vitarum scriptores graeci minores, Brunsvigae, 1845.

Whitby, Mary, "Procopius' Buildings Book I: A Panegyrical Perspective", Antiquité Tardive 8 (2000), 45-57.

Whitby, Michael, “The Chronicle Sources of Theophanes”, Byz 53 (1983), 312-345.

Whitby, Michael, "Greek Historical Writing after Procopius: Variety and Vitality", in: The Byzantine and Early Islamic Near East, Col. I: Problems in the Literary Source Material, edd. Averil Cameron and Lawrence I. Conrad (Studies in Late Antiquity and Early Islam 1), Princeton (NJ), 1992, 66-74.

Whittow, Mark, The Making of Orthodox Byzantium, 600-1025, Berkeley (CA), 1996.

Wiesehöfer, Joseph, "Kawad, Khusro I and the Mazdakites. A New Proposal”, in: Trésors d'Orient, edd. Philippe Gignoux, Christelle Jullien, and Florence Jullien, Paris, 2009, 391-409.

Wilson, Nigel Guy, "A Chapter in the History of Scholia", CQ 17/2 (1967), 244-256.

Wilson, Nigel Guy, "Scholarly Hands of the Middle Byzantine Period", in: La paléographie grecque et byzantine - Colloques internationaux du C.N.R.S, Paris, 21-25 octobre 1974, edd. Jean Glénnison, Jacques Bompaire, and Jean Irigoin, Paris, 1977, 221-239.

Wilson, Nigel Guy, "Planudes and Triclinius", GRBS 19 (1978), 389-395.

Wilson, Nigel Guy, Scholars of Byzantium, London, 1983 [London 1996].

Wilson, Nigel Guy, Photius. The Bibliotheca, London, 1994. 
Wolf, Gustavus, Porphyrii de Philosophia ex oraculis haurienda, Berolini, 1856.

Wolters, Paul, "De Constantini Cephalae anthologia", RhM 38 (1883), 97-119.

Wood, Ian, "The End of Roman Britain: Continental Evidence and Parallels", in: Gildas: New Approaches, edd. David Dumville and Michael Lapidge, Woodbridge, 1984, 1-25.

Wood, Philip, We Have No King But Christ: Christian Political Thought in Greater Syria on the Eve of the Arab Conquest (c.400-585), Oxford, 2010.

Wünsch, Richard (ed.), Ioannis Laurentii Lydi liber de mensibus, Lipsiae, 1898.

Zecchini, Giuseppe, "La storia Romana nella Suda", in: Il lessico Suda e la memoria del passato a Bisanzio, ed. Giuseppe Zecchini, Bari, 1999, 75-88. 


\section{Names and subject index}

Aeetes, Colchian nobleman 248

Aelian 113; De natura animalium 13, 189 , 192; Varia Historia 120, 182n15

Agapius, bishop of Caesarea 179

Agathias of Myrina 22, 75n171, 99,

217n16; Agathias excerpts 60, 110-113, 135, 140-146, 222, 229; Cycle 22n126, 115n50; Daphniaka 22n116, 115n50; on Franks 97n293, 97n295, 104n343, 135-140; Historiae 22n126, 107, 183, 225; in Leo the Deacon 75; on Persia 135-140

Agrippas II 171

Ahriman 245, 246

Alamanni 135, 138, 243

Alexander, Bishop of Jerusalem 178

Alexander, doctor 252

Aligern, Gothic military leader 138 , 141,243

Ammianus Marcellinus 130, 132; Res Gestae 98n303, 131, 172n125, 250

Anastasius, Byzantine Emperor 87, $111 \mathrm{n} 10$

Anastasius of Sinai 112; Quaestiones et responsiones 15

Anatolius, bishop of Laodicea 179

Anatolius, member of the senate 251

Andronicus II, Byzantine Emperor 186n52, 203-211, 229

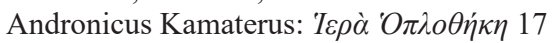
Angles 101, 104

Anonymus Post Dionem 57n62

Anthemius of Tralles, architect 135, 252

Anthologia Barberiana 21

Anthologia Palatina 11, 80n197

Antiochus: Pandecta scripturae sacra 14, $15 \mathrm{n} 74$

Apollodorus 9; Bibliotheca 83n213, 84

Apophthegmata Patrum 14
Appian of Alexandria: Historia Romana 46, 47-48, 55-56, 59, 61, 76-77, 224

Aratus Solensis: Phaenomena 52, 58, 186n55

Ardasher I, Persian King 246, 249

Arian: Bithyniaca 83

Aristarchus et Callithea 189, 192

Aristotle 189, 246, 247, 252; Historia animalium 189, 192; Meteorologica 252n9; Rhetorica 188

Athanasius of Alexandria 18n97, 24, $173 n 128$

Athenaeus: Deipnosophistae 189, 192

Attalus, martyr 178

Aulus Gellius: Noctes Atticae 13

Bactria 245

Bahram II, Persian King 250

Bahram III, Persian King 250

Basil I, Byzantine Emperor 21n114, 25, 85n220; Procheiros Nomos 21

Basil II, Byzantine Emperor 44n7, 67n102, 74

Basil of Caesarea 16, 24, 152, 182; Homiliae in hexaemeron $18 \mathrm{n} 97$

Basil the Nothos: Ambrosianus B 119 sup. 22, 83n211; DC 24n137; EC 24, 67n102, 81; Menologion 20n110; Theophanes Continuatus xixn4

Belisarius, Byzantine general 225, 253

Berenice, Agrippas II's sister 171

Boethus: Lexicon 7, 7n34

Bonifacius, Roman general 130, 134

Britons 101, 103, 104, 106

Brittia 50-51, 96, 100-101, 103-107, 137n128, 224

Candidus 249, 249n2, 251

Carthaginians 210 
Cassiodorus: HE 169, 169n116

Cassius Dio, Historiae Romanae 55n49, 68n105, 115; in Excerpta Anonymi 46, 50, 56-57, 59-61, 77-81, 106, 223-225; in Excerpta Planudea 191; in Excerpta Salmasiana 110, 114-116, 127, 129, $132,134,146,222,225$

catenae 4, 11, 14, 17-18, 20, 41n209, 53, 225, 228; Codex Zacynthius 16, 17n92, 29n154; on 1 Corinthians 4n21; Euthymius Zigabenus 16, 16n89; first Palestinian catena 5; on Luke 14n73, 16; on Mark 14n72, 16; Nicetas of Heraclea 6, 16n89; Procopius of Gaza 5, 14, 14n71; in Psalmos 148; Theophylact, bishop of Ohrid 16, 16n89; Titus of Bostra 14, 14n73; Victor of Antioch 14

Catherine of Courtenay, Latin Empress 210, 210n208

Cavadh I, Persian King 250, 251

Cedro, theologian 177

Cerinthus 177

Chosroes I, Persian King 143, 246, 247, 249

Chosroes II, Persian King 42n214

Chronicon paschale 143, 169, 170, 171, $172,216,217 \mathrm{n} 16$

Clement of Alexandria: Stromata 13, $13 n 65$

Cleopas 169

Codex Zacynthius see catenae

Colchians 135, 245, 248

Constantine V, Byzantine Emperor 91, 93, 93n269

Constantine Manasses, Breviarium Chronicum 2, 217; and Excerpta Planudea xxiv, 189, 192, 193, 194, 195, 198, 213, 222; and Excerpta Salmasiana $116,126,133$

Constantine Porphyrogenitus: $D A I$ xix, 1 , 24, 34n174, 37, 67, 70, 81, 99, 102, 104, 216; DC 10, 24, 24n137, 24n138, 37, 37n190, 57n62, 67, 83n211, 216; DT xix, 24, 67, 70, 81, 102, 216; Geoponica xix, xixn10, 7, 8, 35, 35n181, 37, 38, 38n193; Theophanes Continuatus xix, $1,25,41 \mathrm{n} 210,42 \mathrm{n} 212,67,81 \mathrm{n} 203$, $82,83 \mathrm{n} 213,218 \mathrm{n} 22$; Translation of the relics of the Image of Edessa 72, 72n152; Vita Basilii xixn4, 1, 1n1, 42n212, 82n204, 85n220, 100, 216n12

Constantinople: Artotyrianos 93, 93n273, 94n274; Augusteum 88; Forum 90n251, 93n268; Hippodrome 61, 63; Philadelphion 87, 87n229, 93; St Agathonikos, church 87, 88n236, 94n279; St Barbara, church 93, 94n274; St Mocius, church 87; Zeuxippus 88, $88 \mathrm{n} 240,89 \mathrm{n} 247$

Constantius I, Roman Emperor 180

Constantius II, Roman Emperor 57n62

Continuatio Antiochensis Eusebii 172, 172 n 128

Cosmas Indicopleustes: Topographia Christiana 99n306

Cotrigurs 253

Cumae 138, 141, 142, 243, 244

Demetrios Kydones $211 \mathrm{n} 212$

Demetrios Triklinios 204, 204n165, 204n166, 205n166, 205n167

Dexippus 130, 131; Skythika 130n103;

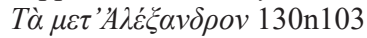

Dio Chrysostom 189, 192

Diocletian, Roman Emperor 130, 179, 180

Diodorus of Sicily, Bibliotheca historica: in EC 40n206, 68n110, 75n171; in Excerpta Anonymi 73, 73, 83n213; in Excerpta Hoescheliana 2n6, 218, 227; in Excerpta Planudea 212; in Excerpta Salmasiana 120, 131, 245; in Leo the Deacon 75

Diogenianus: Lexicon 6; Proverbia 182, $182 \mathrm{n} 14$

Dionysius, bishop of Alexandria 178, 179

Dionysius of Halicarnassus, Antiquitates Romanae: epitome 218, 227, 228; in EC 75n171, 76n177; in Excerpta Anonymi 83, 84; in Excerpta Planudea 193n115; in Leo the Deacon 75

Dioscorus, doctor 252

Doctrina Patrum 15, 20, 35n177

Domitian, Roman Emperor 56, 176

Drepana 171, 172, 172n125, 172, 173

Ebionites, heresy 177

Emmaus 169, 170, 171

encyclopaedism xviii, xviiin1, xviiin3, xix, $\mathrm{xx}, 20$

Ephalites see Ephthalitai

Ephthalitai 251

Eudokia, Byzantine Empress 63

Eunapius: historical fragments 130n103, 131; Vitae sophistarum 247

Eusebius of Caesarea: Chronicon 18n97, 118, 171, 172, 173, 217n16; Constantini 
imperatoris oratio ad coetum sanctorum 249; $H E$ xxiv, xxvn28, 29, 226; $H E$ excerpted in Epitome 155-161, 174, 175-180, 219, 221; HE in manuscripts of the Epitome 147-152, 163-164, 169, 171, 171n124, 173n130; Onomasticon 169, 169n113, 142; Supplementa ad quaestiones ad Marinum 169; Vita Constantini 172n125, 249

Eusebius of Emesa 173n128

Eustathius, abbot $14 \mathrm{n} 74$

Eustathius of Antioch 18n97

Eustathius of Epiphania 150n29

Eustathius of Thessaloniki: scholia on Homer 58

Euthymius Zigabenus 16, 16n89, 17n94;

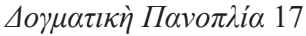

Eutropius, Breviarium: in EC 116; in Excerpta Salmasiana 129, 130, 131, 131, 132, 132; Paeanius' translation 192, 194, 196

Evaristus, bibliothecarius 16n85

Excerpta Anonymi: About the Sorcery of the Varni 96; On Cyrus 59, 72, 75, 75n173, 84, 108; On Remus and Romulus 59, 72, 75, 75n173, 84, 108; On the island of Brittia 96; On the river Istros 59, 72, 72n158, 84, 108

Excerpta Hoescheliana see Diodorus of Sicily

Flavius Aetius, Roman general 130, 134

Flavius Josephus 18n97; Antiquitates Judaicae 150n29, 151, 160, 175, 195, 195n123, 251; Vita 151, 160

Florilegia xx, 11, 11n54, 13, 13n69, 14-17, 18, 20, 21n112, 29n154, 42, 225

Franks: in Agathias 97n293, 97n295, 104n343, 135, 136, 138, 243, 244; in Excerpta Anonymi 101, 103, 104, 105; in Excerpta Salmasiana 135, 138, 243, 244; in Procopius 101, 101n324, 136n118, 137n128, 242; in Tactika $99 n 311,104 n 340$

Frisians 101

Gaius Suetonius Tranquillus 120, 120n82; De genere vestium 120, 120n82;

De regibus libri tres 120

Galla Placidia, regent to Valentinian III 130, 134

Gaul 101, 103

Gelasius of Caesarea 147, 150, 155, 160, 221; HE 147n2, 151, 152, 155n74, 156, 157, 159, 159, 160n93, 161
Gelasius of Cyzicus, $H E 9$

Genesius, Regum Libri Quattuor 42n212, $81,81 \mathrm{n} 203,82 \mathrm{n} 207,218 \mathrm{n} 22,221$; in Excerpta Anonymi 83, 83n212, 84, $84 \mathrm{n} 217$

George Akropolites 205n167

George Cedrenus, Compendium historiarum 19, 19n105, 19n107, 57n61, 217n16, 220n29; in Excerpta Planudea 191, 192, 193; in Excerpta Salmasiana 116, 116n56, 126, 133

George Karbones 205n177

George Pachymeres 204, 205n167, 205n169, 210n208, 244

George Syncellus, Ecloga chronographica 2, 2n7, 108n364, 216, 220; in Epitome 169, 170, 171, 171n123; in Excerpta Salmasiana 118, 130, 131

George the Monk 220, 226; Chronicon 2, 2n9, 3, 3n11, 18, 18n98, 40n206, $42 \mathrm{n} 212,126,216,217 \mathrm{n} 16$

Germanus of Constantinople 23, 87n231

Getae 83

Gnomologia xx, 14-15, 17, 20, 228

Gregory of Cyprus 205n 167

Gregory of Nazianzus 24, 72, 186n51, 187n65, 208

Gregory of Nyssa 5

Gregory Referendarios, homily on the translation of the Mandylion 71, 72n152

Hagia Sophia: in Excerpta Anonymi 88, 89, 91, 94, 95, 95n283; in Excerpta Salmasiana 135, 252

Haimodein Lexicon 22, 22n125, 23n128

Hegesippus 152, 169, 174, 219n24, 221

Helenopolis see Drepana

Helladius, Lexicon 6, 7

Hermas' Pastor 190, 190n99

Hermegisclus, King of the Varni 103, 104, 107

Herodotus, Historiae 21, 98, 113, 245, 252; on Cyrus 76; in Excerpta Anonymi $46,48,55,59,61,224$; in Leo the Deacon 75; on Medes 83n213; on River Istros 73, 73, 73n160, 73n161

Heruls 98, 105n353, 130n103, 137, $137 \mathrm{n} 128,140$

Hesychius of Alexandria, grammarian 246

Hesychius of Miletus 87; Onomatologos 23; Patria I 83, 91

Hippiatrica xix, 29n154, 37, 38

Hippolytus of Rome, Refutatio omnium haeresium 9 
Hormizd II, Persian King 250

Hormizd III, Persian King 251

Huns 97n293, 98n296, 138, 243, 251, 253

Illus, Byzantine general 250

Isaurians 248, 249

Isidore of Miletus, architect 252, 253

Isidore Ruthenus, scholar 186, 186n46

Isidore the Younger see Isidore of Miletus

Jerome: Chronicon 169, 170, 171, 172, 172, 172n127, 172n128; De Viris

Illustribus $173 \mathrm{n} 131$

John Chrysostom 21, 38, 206

John Diacrinomenus, $H E$ 147, 147n4; in

Epitome 155, 156, 159, 161, 163, 221;

in Hansen's edition 162; in manuscript tradition 149, 149n23, 150

John Lydus, De Magistratibus 57n61, 57n62, 138n132; De Magistratibus in Excerpta Anonymi 47, 57, 72, 72n159, 73, 73, 73n162; De Magistratibus in Excerpta Planudea 193, 193n112; De Mensibus 57, 57n61; De Mensibus in Excerpta Anonymi 47-48, 51, 55, 72-73; De Mensibus in Excerpta Planudea 190, 192; De Ostentis 32, 48, 57, 57n61, 220

John Malalas Chronographia 40n206, $83,114 \mathrm{n} 47,115,217,217 \mathrm{n} 16,217 \mathrm{n} 20$, 227; on earthquake of 557 251; in Excerpta Salmasiana 110, 114, 116; in Exc.Salm.II A 119, 119, 120, 128, 146, 222, 223, 225; on Exc.Salm.II B 133, 133n112, 134; on Hagia Sophia 253; on Hellenopolis 172n125; on Justinian 247; in Parisinus gr. 1630 120-127

John Moschus 14n67

John of Antioch, Historia chronica 219, 222, 223, 225, 227, 249, 249n2, 253; in Athonensis Iviron 812 196-203; in $E C$ 40n206, 68n110, 76, 147n6; in Excerpta Planudea xxiv, 188, 192, 192, 193, 193n112, 193n115, 194, 213; in Excerpta Salmasiana xxiii, 78n188, 110, 145, 146, 222; in Exc.Salm.I 117-118; in Exc.Salm.II 118-120; in Ecx.Salm. II B 130, 133n107, 134, 134n114; Johannische Frage 115-117; and John Lydus 57n61; manuscript tradition 111-115; in Parisinus gr. 1630 120, $120 \mathrm{n} 85,121$

John of Damascus 14n67, 23, 191n103, 218; Sacra parallela $15 \mathrm{n} 74,35$, $35 \mathrm{n} 177,36$
John of Ephesus HE 247

John Pediasimos 204, 205n167

John Scylitzes, Synopsis historiarum 2, 2n3, 19, 19n105, 216

John Stobaeus, Anthologium 14, 14n69, 20, 22n124, 24, 27, 34, 36, 37

John the Lybian 249

John Xiphilinus, Epitome of Cassius Dio 56n58, 219, 222, 223; in Athonensis Iviron 812 196, 196, 197, 198, 198n136; in Excerpta Anonymi 77; in Excerpta Planudea xxiv, 188, 189, 189n79, 192, 194, 195, 195, 202-203, 213

John Zarides 188

John Zonaras, Epitome historiarum 2, 2n4, 56n58, 216, 216n16; in Excerpta Salmasiana 133

Jordanes: Getica; 101n321; Romana 131

Julian the Apostate, Roman Emperor 86,87

Julius Africanus: Cesti 13, 13n65, 171n123; Chronographiae 115n49, 116, 116n61, 118, 120, 120n82, 222

Julius Nepos, Roman Emperor 250

Justin II, Byzantine Emperor 88

Justinian I, Byzantine Emperor 21n114; in Agathias 139, 222; in Excerpta Anonymi 85, 87-88, 89n244, 90, 95-99, 101-108; in Excerpta Salmasiana 245; in John Lydus 138n132; in John Malalas; 114n47; in John of Antioch 114n45; Justinianic Code 21; in Parastaseis 87-88, 89, 89n243, 94n277, 94n279; in Patria II 94, 94n278, 95n281; in Patria IV $95 \mathrm{n} 283$

Justinian II, Byzantine Emperor 89, 89n243, 90, 94, 95

Kavadh I Persian Emperor 251

Kranos, philosopher 63, 64

Kyrvos, philosopher 63

Lazi 142, 248

Leo I, Byzantine Emperor 94

Leo III, Byzantine Emperor 90, 90n249, 90n250, 91, 92, 93; Ekloge 21

Leo V, Byzantine Emperor 41

Leo VI, Byzantine Emperor xviii, xx, 21, 21n114, 24n138, 70n121, 82n204, 85n220; Basilica 21; Book of the Prefect 21; collection in Laurentianus Plut. 55.4 81n202; Tactika 21, 35, 37, 99, 99n311, $104 \mathrm{n} 340$

Leon the Mechanic 46, 49, 52, 58 
Leoquelle 132-134, 146, 225

Leo the Deacon 67n100, 74; Historia 67, 74, 74n167, 75

Licinius, Roman Emperor 130, 163

Lucca 244

Malchus 251, 251n3

Manuel Holobolos 205n167

Manuel Moschopoulos 204n166, 205n167

Martin, Byzantine general 245

Matthaios Kamariotes 112

Maurice, Byzantine Emperor 22n126;

Strategicon 137, 137n126, 137n127

Maxentius, Roman Emperor 163, 180

Maximin, Roman Emperor 180

Maximinus II Daia, Roman Emperor 163

Maximus Planudes: Basilikos 205-207; scriptorium 186-188

Maximus the Confessor 15, 15n77, 24

Meletius, bishop of Pontus 179

Menander Protector 22, 22n126, 137n126, $137 \mathrm{n} 130,139,217 \mathrm{n} 16$; in EC 251

Metrodorus, grammatikos 252

Michael VIII, Byzantine Emperor 113n37, 198n136, 203, 205n167

Michael IX, Byzantine Emperor 205, 206, 210, 210n208

Michael Glycas 106n354, 217n16

Michael Psellos: Chronographia 99n309, 216; encomium of Symeon Metaphrastes 26, 27, 30-31, 39-41, 61, 64

Michael Tarchaneiotes Glabas 211

Moors 97n293, 244

Narseh, Persian King 250

Narses, Byzantine general 138, 142, 243, 244, 250

Nicephorus II Phocas, Byzantine Emperor 81

Nicephorus, Patriarch 69n111, 217n16; Breviarium historicum 216; Chronographia brevis 108n364, 216

Nicephorus Callistus Xanthopulus 151, 152, 153, 153n60, 221; in Baroccianus gr. 142 153n62, 154, 154n70, 223

Nicephorus Gregoras 112

Nicetas, bishop of Heraclea see catenae

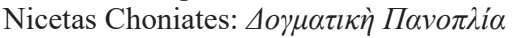
17, 19n94

Nicetas the Paphlagonian 42n212, 82n207

Nicolaus of Damascus 76, 76n174, 76n177, 81n201

Nicomedia 173, 179, 186, 187n60
Nicopolis 169, 170, 171

Nikephoros Chumnos 204, 204n163, 206n174, $211 \mathrm{n} 212$

Nikolaitans, heresy 177

Nonnus of Panopolis: Dionysiaca 83; Paraphrasis sancti evangelii Joannei 187

Norici 83

Ohrmazd, deity 246

Olympius, advocate 252

Onoguris 248

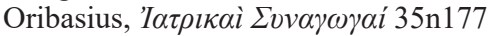

Paeanius, translation of Eutropius' Breviarium xxiv, 188, 192, 192, 194, 195, 195, 213, 222, 223; in Athonensis Iviron 812 196, 196, 197, 198

Palatine Anthologia 11n55, 21, 40n206

Palladius, Roman official 138, 139n133, 141,243

Palladius of Helenopolis, De gentibus Indiae et Bragmanibus 99n306

Papak, Persian prince 246

Papias, Bishop of Hierapolis 169, 169n112, 221

Paraphrases in Dionysium Periegetam 73, 73n164

Parysatis, Persian Queen 245, 249

Patria of Constantinople: Patria I see Hesychius of Miletus; Patria II 46, 46n21, 46n22, 53, 54, 54n42, 55n49, 77n182, 85, 91-95; Patria III 91, 93, 93n269; Patria IV 91, 95, 95n283

Pausanias, Graeciae descriptio 186n54, 188, 188n74, 188n75, 192

Pechenegs 99n309

Pelops, philosopher 63

Peroz I, Persian King 250, 251

Persian Royal Annals 120

Peter the Patrician 38, 207; Historia 78, 79, 80; On ceremony 63

Philip I, Latin Emperor of Constantinople 172

Philip of Side, Historia christiana 147n5, 221; in Hansen's edition 162; in manuscript tradition $152,155, \mathbf{1 5 9}$, 160-161

Philippicus, Byzantine Emperor 89, 89n243, 89n247, 89n248

Philostorgius, HE 99n306, 151, 154, 254n68, 173n131, 173n133

Phocas, Byzantine Emperor 42n214 
Photius 23n130, 158; Amphilochia 15n81, 23; on Appian 55, 56, 56n54; Bibliotheca 6-9, 23, 23n130, 24, 36, 36n185, 68n105, 99; on Candidus 251; on Diodorus of Sicily 227, 227n56; Lexicon 6n31, 22n125; on Malchus 251, $25 \ln 3$; in manuscripts 150,151 ; on Philostorgius 154, 154n69; on Sopater 3, 4n16, 36n185; on Stobaeus 14n69, $27,27 \mathrm{n} 150,34,34 \mathrm{n} 175,36-37$; on Theophanes of Byzantium 251, 251n6 Phrynichus the Arabian 6

Pierius, bishop of Alexandria 169, 179, 221

Plato 185,186 n53, 187, 189, 190, 190n100, 191, 192, 247

Plutarch 55, 245, 246; in Excerpta Planudea 184, 187n61, 208, 208n195; in Excerpta Salmasiana 119, 119, 121

Polybius, Historiae 4n23, 26n148, 218; as collection of excerpts 2n6, 226, 227, $227 \mathrm{n} 55$; in EC 66, 66n92, 81n201

Polychronius 23

Priscus of Panium 97n293, 98n303, 130, 134, 248

Procopius of Caesarea: De aedificiis 22n126, 105n353; De bellis in Excerpta Anonymi 96-98, 100, 101, 103-106, 224; De bellis in Excerpta Salmasiana 119, 119, 131, 134, 134n113, 136-138; Historia Arcana 22n126

Procopius of Gaza see catenae

Ps.-Apollodorus see Apollodorus

Ps.-Aristotle, De mundo 189, 189n82, 192

Ps.-Caesarius, Quaestiones et responsiones $15,73,73,112$

Ps.-Dionysius the Areopagite 14, 24, 152

Ps.-Eustathius of Antioch Commentary on the Hexaemeron 17, 18n97

Ps.-Neilos of Ankyra, Narrationes 99n306

Ps.-Symeon, Chronographia 18, 82, 216; in Cedrenus 19; in Excerpta Salmasiana 116, 116n56, 126, 127, 128; on Medes $83,83 \mathrm{n} 213$

Sandilch 253

Scholia in Dionysium Periegetam 49, 58,83

Scholia on Apollonius Rhodius 83

Semiramis, Assyrian Queen 245, 249

Sharpur I, Persian King 139, 144, 246, 249,250

Sharpur II, Persian King 246, 247, 250
Siderun 244, 249

Sigibert I, Frankish King 243

Socrates of Constantinople, HE 147n2, $156,160,172 \mathrm{n} 125$; in $E C 71$; in Epitome 152n57, 156, 165n11; in Theodorus Anagnosta 21, 155n74, 156

Sopater 3, 8, 9, 36n185, 158

Sophronius of Jerusalem 14n67

Sozomen, HE 151; in Epitome 152n57, 156, 165n111; in Parastaseis 88n239; in Theodorus Anagnosta 21, 155n74, 156, 169

Stephanus Byzantius 2n6, 83, 83n210; Ethnica 24n138, 83n212, 98n304, $25 \ln 4,252$

Strabo, Geographica 83, 83n213; in Excerpta Planudea 186n54, 188, 188n72, 192; in Excerpta Salmasiana 245

Suda 22; on Candidus 249n2; and EC 23, 23n128; and Excerpta Anonymi 46n21, 83n216; and Excerpta Planudea 194, 198-202; and Excerpta Salmasiana 120, 248, 251; on Hippiatrica 19n9; on Julius Africanus 171, 171n121; on Parastaseis 53; in Parisinus gr. 1630 120-127; on Peter the Patrician 57n62; on seven philosophers 247; on Suetonius 120n82

Symeon Logothetes, Chronicon 18n102, 82, 82n206, 216, 217, 217n16; in Excerpta Anonymi 81n197; in Excerpta Salmasiana 116, 116n56, 126, 127, 128, $132,133,133$; on the title 18,19 n 103

Symeon Metaphrastes 26, 27, 82n206, 251; collections of speeches 16 ; Menologion 20, 20n110; working method 30, 30n161, 33, 64

Synaxarion Ecclesiae Constantinopolitanae 16, 16n85, 17, 72 Synesius 190n91, 192; De insomniis 190, 192; De Providentia 190, 192; Dio, sive de suo ipsius instituto 190, 192; Encomium calvitii 190, 192

Tarasius, Patriarch 15, 41n210

Telephis, fortress 245

Theodore Daphnopates xixn4, 16; oration on the translation of the arm of St John Prodromos 71

Theodore Metochites 204, 204n163, 206n174

Theodore the Lector, the Byzantine 53

Theodoret of Cyrrhus, $H E$ 21, 23, 155n74, $156,165 \mathrm{n} 111,247$; HE in manuscript tradition 148, 149, 151, 152, 156 


\section{Names and subject index}

Theodorus Anagnosta 21, 21n112, 165n111, 177n141, 221; HE 147, 147n3; HE in Hansen's edition 162; HE in headings of the Epitome 153-157; HE in manuscript tradition 149-153, 156, 159, 161n97, 163; HT 161, 169; HT in Hansen's edition 162; HT in manuscript tradition 150-153, 155, 155n74, 156, $157,159,161 \mathrm{n} 97$

Theodosius I, Byzantine Emperor 84

Theodosius II, Byzantine Emperor 36, 67

Theon of Alexandria 46, 52, 52n25, 58

Theophanes Confessor, Chronographia 99, 216, 217n16, 218n22, 226, 253; in Cedrenus 19; in DAI 1, 24n138; in EC 102; in Epitome 172, 172, 172n127, 172n128, 173; prooemium 2, 2n7, 18, 18n101, 220, 220n38

Theophanes of Byzantium 251

Theophylact, archbishop of Ohrid see catenae

Theophylact Simocatta 22, 217n16; Historiae 22n126, 69n111, 243

Theosophia Tubingensis 191n104, 192

Theotecnus, bishop of Caesarea 179

Thomas Magistros 204, 204n165, 204n166, 205n166, 205n167

Thucydides, Historiae 75, 75n171, 247

Tiberius, Roman Emperor: in Epitome 175; in Excerpta Anonymi 78, 79n191, 79n192; in Excerpta Planudea 195

Tiberius II, Byzantine Emperor 150

Titus of Bostra see catenae

Tralles 252
Uranius, pseudo-philosopher 247

Utigurs 253

Valentinian III, Roman Emperor 119

Valentinus, theologian 177

Valerian, Roman Emperor 139, 144,249

Varni 50, 51, 96, 103, 104, 107, $107 \mathrm{n} 362$

Verina, Byzantine Empress 87, 87n232, 93, $94 \mathrm{n} 274$

Victor of Antioch see catenae

Vindanius Anatolius of Beirut 8

Virunum 83n214

Vita Andreae Apostoli 99n306

Vita Barlaam et Joasaph 99n306

Vita Luciani 173n130, 173n131, 173 n133

Vita sancti Andreae Sali 16

Vita Sancti Macarii Roman 99n306

Yazdegerd II, Persian King 251

Zabergan 253

Zeno, Byzantine Emperor 250

Zeno, rhetorician 135, 252

Zosimus, Historia Nova 217n16; in Excerpta Salmasiana 130, 130n103, 131, 131, 132, 133, 250

Zosimus of Ascalon, Lives of Demosthenes $111,111 \mathrm{n} 10,112$

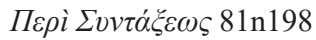

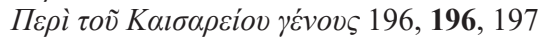




\section{Manuscripts index}

Athens, Ethniki Bibliothiki: Ms. 63 45n19; Ms. 174 45n19; Ms. 179 45n19; Ms. 2641 45; Ms. 2645 45n19

Brussels, Bibliothèque royale de Belgique: Bruxellensis 11031-16 10, 10n51

Cambridge, University Library: MS Additional 1732 182; MS Additional 10062 (Codex Zacynthius)

Escorial, Real Biblioteca: Scorialensis B.I.4 26, 26n148; Scorialensis $\Omega . I . i i$ 68, $68 \mathrm{n} 110$

Florence, Biblioteca Medicea Laurenziana: Laurentianus Conv. Soppr. 71 182; Laurentianus Plut. 32,16 186n51, 187, 191, 191n104, 208; Laurentianus Plut. 55,4 81, 83n211; Laurentianus Plut. 55,7 187n58; Laurentianus Plut. 56,11 188; Laurentianus Plut. 56,22 187n60; Laurentianus Plut. 59,1 187, 187n57; Laurentianus Plut. 59,30 181, 188-191, 192, 193, 194, 195, 223; Laurentianus Plut. 70.355

Heidelberg, Universitätsbibliothek: Palatinus gr. 23 11n56, 21; Palatinus gr. 129 114, 186; Palatinus gr. 398 22, $22 \mathrm{n} 123$

Jerusalem, Greek Patriarchal Library: Panaghiou Taphou 466 6; Timiou Stavrou 5545

Leipzig, Universitätsbibliothek: Lipsiensis Rep. I.17
Milan, Veneranda Biblioteca Ambrosiana: Ambrosianus 157 188; Ambrosianus B 119 sup. 83n211; Ambrosianus $C 126$ 187; Ambrosianus C 235182

Mount Athos: Athonensis Dionysiou 70 44; Athonensis Iviron 175 106n354; Athonensis Iviron 371 6, 6n30; Athonensis Iviron 812 192, 193n108, 196-201, 206, 223; Athonensis Koutloumousiou 10 4; Athonensis Vatopedinus 286 148, 148n8, 150-154, 158, 159, 161, 161n97, 162, 163; Athonensis Vatopedinus 530 53n30

Munich, Bayerische Staatsbibliothek: Monacensis gr. 3584

Naples, Biblioteca nazionale: Neapolitanus graecus 165 181, 182, 185, 192; Neapolitanus graecus 166 [II D 4] 114

Oxford, Bodleian Library: Auctarium E.2.12 45; Auctarium E.4.18 148, 149, 156, 159, 163, 171, 171n123, 174, 223; Baroccianus graecus 134 45; Baroccianus graecus 142 148, 148n8, 151, 153-154, 157n83, 157n84, 158-163, 171n123, 174, 221, 223; Baroccianus graecus 182 122; Baroccianus graecus 235 5, 5n28

Paris, Bibliothèque nationale de France: Parisinus graecus 139 45; Parisinus graecus 702 53n30; Parisinus graecus 854 24n136; Parisinus graecus 1156 148, 148n8; Parisinus graecus 1336 $17,53,53 \mathrm{n} 37,54,92,92 \mathrm{n} 261,92 \mathrm{n} 262$, 221; Parisinus graecus 1393 188, 188n73; Parisinus graecus 1409 181, 
184, 185n36, 189, 192; Parisinus graecus 1410 188; Parisinus graecus 1555a 147n6, 148n8, 149, 150, 150n30, 159, 159, 160, 162, 174; Parisinus graecus 1630 119, 120-127; Parisinus graecus 1666 68, 68n110; Parisinus graecus 1671 112; Parisinus graecus 1712 74n167, 82n205; Parisinus graecus 1763 110, 113, 114; Parisinus graecus 1808 190; Parisinus graecus 2009 24n136; Parisinus graecus 2550 26n148; Parisinus graecus 2667 187n59; Parisinus graecus 3026 114; Parisinus suppl. graecus 384 11n56; Parisinus suppl. graecus 607a 44-47, 49, 52, 52n28, 54-55, 59, 59n73, 61, 63, 67, 67n99, 74, 76, 92n262, 96, 108n364, 223; Parisinus suppl. graecus 1156 148, 148n8, 149, 150, 156, 159, 162, 163

Patmos, Monastery of Saint John the Theologian: Ioannu 58 53n30

Tours, Bibliothèque municipale de Tours: Turonensis 980 26, 26n147, 26n148, 68, 68n107, 69n114, 83n211

Vatican, Biblioteca Apostolica Vaticana: Arch. S. Petri B 58 45n20; Barberinianus gr. 310 22n122; Ottobonianus gr. 345 186, 186n44; Palatinus gr. 93 xxvn28, 110, 110n1, 112, 113, 114, 135, 247; Palatinus gr. 141 181, 183, 185, 186; Palatinus gr.
209 186, 186n44; Reginenses gr. 132 188, 188n70; Reginenses gr. 133 188, 188n70; Urbinatus gr. 20 44; Urbinatus gr. 82 205n168; Urbinatus gr. 102 226, 26n50, 227; Vaticanus graecus 73 68, 68n108, 83n211; Vaticanus graecus 96 xxvn28, 110, 111, 111n14, 112, 113, 114, 115, 117, 135, 247; Vaticanus graecus 152 96n285; Vaticanus graecus 156 130n103; Vaticanus graecus 167 19n4, 83n204; Vaticanus graecus 253 182; Vaticanus graecus 258 182; Vaticanus graecus 468 54, 54n43; Vaticanus graecus 759 6; Vaticanus graecus 914 185n38; Vaticanus graecus 951 181, 184, 185, 186, 191; Vaticanus graecus 977 22n126, 69n111; Vaticanus graecus 1065 24n136; Vaticanus graecus 1307 74n167; Vaticanus graecus 1340, 188; Vaticanus graecus 1605 37n188; Vaticanus graecus 1613 44; Vaticanus graecus 1950 182; Vaticanus graecus 236955

Venice, Biblioteca nazionale Marciana: Marcianus graecus 344 156n75, 157; Marcianus graecus 413 188; Marcianus graecus 481187

Vienna, Österreichische Nationalbibliothek: Vindobonensis phil. gr. 21182

Washington D.C., Dumbarton Oaks: MS 1 45n20; MS 3 45n20; MS 4 45n20 